DOE/PE-03871-01

\title{
MASTER
}

DR. 1163

\section{Distributed Energy Systems: A Review of Related Technologies}

November 1979

Prepared for:

U.S. Department of Energy

Assistant Secretary for Policy and Evaluation

Office of Advanced Technology and

$\mathrm{R}$ and D Policy 


\section{DISCLAIMER}

This report was prepared as an account of work sponsored by an agency of the United States Government. Neither the United States Government nor any agency Thereof, nor any of their employees, makes any warranty, express or implied, or assumes any legal liability or responsibility for the accuracy, completeness, or usefulness of any information, apparatus, product, or process disclosed, or represents that its use would not infringe privately owned rights. Reference herein to any specific commercial product, process, or service by trade name, trademark, manufacturer, or otherwise does not necessarily constitute or imply its endorsement, recommendation, or favoring by the United States Government or any agency thereof. The views and opinions of authors expressed herein do not necessarily state or reflect those of the United States Government or any agency thereof. 


\section{DISCLAIMER}

Portions of this document may be illegible in electronic image products. Images are produced from the best available original document. 


\section{NOTICE}

This report was prepared as an account of work sponsored by the United States Government. Neither the United States nor the United States Department of Energy, nor any of their employees, makes any warranty, express or implied, or assumes any legal liability or responsibility for the accuracy, completeness, or usefulness of any information, apparatus, product, or process disclosed, or represents that its use would not infringe privately owned rights. Reference herein to any specific commercial product, process, or service by trade name, mark, manufacturer, or otherwise, does not necessarily constitute or imply its endorsement, recommendation, or favoring by the United States Government or any agency thereof. The views and opinions of authors expressed herein do not necessarily state or reflect those of the United States Government or any agency thereof. 


\section{MAS TETC \\ Distributed Energy Systems: A Review of Related Technologies}

November 1979

Prepared by:

Arthur D. Little, Inc.

Cambridge, Massachusetts

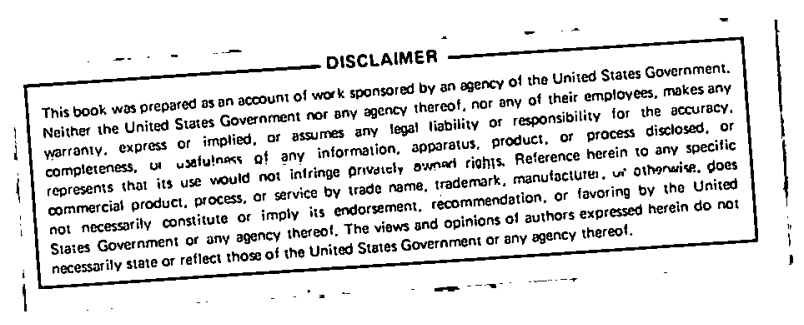

Prepared for:

U.S. Department of Energy

Assistant Secretary for Policy and Evaluation

Office of Advanced Technology and

$R$ and $D$ Policy

Washington, D.C. 20585

Contract No. EX-76-C-01-3871 
Avallable from:

National Technical Information Service (NTIS)

U.S. Department of Comerce

5285 Port Royal Road

Springfield, Virginia 22161

Price: Printed copy: \$76 27.40

Microfiche: $\$ 3.0050$ 


\section{PREFACE}

Recent widespread interest in the contribution that distributed energy systems (DES) may make to the nation's energy supply has prompted the preparation of this report. It is intended to act as a source of technical information on the technologies upon which DES are based. It attempts to present a balanced description of the present state of these technologies, expectations for their future growth and the problems that may be encountered. There is brief mention of the complex systems that may have to be created if DES are to provide reliable and predictable supplies of energy, or are to be connected to the central electrical power network. Estimates of equipment capital and operating costs are also provided.

The report was prepared under the direction of the office of Technical Program Evaluation and its successor, the office of Advanced Technology and $R$ and $D$ Policy, Assistant Secretary for Policy and Evaluation, U.S. Department of Energy. 
THIS PAGE

\section{WAS INTENTIONALLY LEFT BLANK}


1 DISTRIBUTED ENERGY SYSTEMS

1.1 Introduction

1.2 Distributed Energy Systems

1.3 The Structure of this Report

1.4 Summary of Technologies and Factors Affecting

1.5 Direct Costs

1.6 Indirect Costs and Credits

$1-22$

1.7 Conclusions

References

2 PHOTOVOLTAIC SYSTEMS

2.1 Introduction

2.2 Teehnieal Diseussion

2.3 Economico Diocuooion

2.4 Limitations

References

3 SOLAR-THERMAL SYSTEMS

3.1 Introduction

3.2 Technical Discussion

3-2

3.3 Economics Discussion

3.4 Limitations

$3-28$

References

4 SOLAR HEATING AND COOLING

4.1 Introduction

4.2 Technical Discussion

4.3 Economics Discussion

4.4 Limitations

References

5 RUN-OF-THE-RIVER HYDROELECTRIC POWER GENERATION

5.1 Introduction

5.2 Technical Discussion

5.3 Economics Discussion

5.4 Limitations

$5-1$

$5-7$

References

6 WIND POWER SYSTEMS

6.1 Introduction

6.2 Technical Discussion

6.3 Economics Discussion 
TABLE OF CONTENTS (continued)

CHAPTER

PAGE

7 SOURCES OF BIOMASS AND THEIR DIRECT CONVERSION TO ENERGY

7.1 Introduction

7-1

7.2 Blomass Resources

$7-1$

7.3 Technical Discussion

$7-11$

7.4 Economics Discussion

$7-19$

References

$7-25$

8 SOLID FUELS DERIVED FROM BIOMASS

8.1 Introduction

8.2 Technical Discussion

8-2

8.3 Economics Discussion

$8-5$

8.4 Limitations

8-8

References

$8-11$

9 ENERGY FROM BIOMASS VIA BIOCONVERSION PROCESSES

9.1 Introduction

9.2 Technical Discussion

$9-1$

9.3 Economics Discussion

$9-1$

9.4 Limitations

9-8

References

$9-11$

9-15

10 BIOMASS GASIFICATION AND LIQUIFACTION

10.1 Introduction

10-1

10.2 Technical Discusston

10-1

10.3 Economics Discussion

10-9

10.4 Limitations

$10-11$

References

10-13

11 FLUIDIZED-BED COMBUSTION

11.1 Introduction

11-1

11.2 Technical Discussion

11-3

11.3 Economics Discussion

11-11

11.4 Limitations

$11-14$

References

11-15

12 ON-SITE COMBUSTION TURBINE-POWERED ENERGY SYSTEMS

12.1 Introduction

12-1

12-2

12.2 Technical Discussion

12-16

12.3 Economics Discussion

12-18

12.4 Limitations

12-21 
TABLE OF CONTENTS (continued)

CHAPTER

PAGE

13 ON-SITE DIESEL-POWERED ENERGY SYSTEMS

13.1 Introduction

13-1

13.2 Technical Discussion

13-2

13.3 Economics Discusston

$13-7$

13.4 Limitations

13-10

References

$13-11$

14 STIRLING ENGINE-POWERED ENERGY SYSTEMS

14.1 Introduction

14-1

14.2 Technical Discussion

14-3

14.3 Special Attributes of Stirling Engines

$14-17$

14.4 Applications

$14-20$

14.5 Limitations

$14-24$

References

14-27

15 ORGANIC RANKINE CYCLE ENGINES

15.1 Introduction

15-1

15.2 Technical Discussion

$15-2$

15.3 Economics Discussion

15-10

15.4 Limitations

$15-12$

References

15-18

16 FUEL CELLS

16.1 Introduction

16-1

16.2 Technical Discussion

16-2

16.3 Economics Discussion

16-5

16.4 Limitations

16-9

16.5 Recent DevelupmenLs

$16-10$

References

$16-11$

17 HEAT PUMPS

17.1 Introduction

17-1

17.2 Technical Discussion

17-5

17.3 Economics Discussion (Residential Applications)

$17-24$

17.4 Limitations

$17-26$

References

$17-31$

18 COAL-BASED DOMESTIC HEATING

18.1 Introduction

18-1

18.2 Technical Discussion

18-2

18.3 Economics Discussion

$18-9$

18.4 Limitations

18-11

References

18-13 
TABLE OF CONTENTS (continued)

CHAPTER

PAGE

19 THERMAL ENERGY STORAGE

19.1 Introduction

19-1

19.2 Technical Discussion

19-2

19.3 Economics Discussion

$19-15$

19.4 Limitations

$19-18$

References

19-21

20 SECONDARY BATTERIES

20.1 Introduction

20-1

20.2 Technical Discussion

20-2

20.3 Economics Discussion

20-8

20.4 Limitations

20-13

References

20-15

21 HEAT TRANSPORT BY HEAT PIPES

21.1 Introduction

21-1

21.2 Technical Discussion

21-3

21.3 Limitations

21-14

References

21-19

22 INDUSTRIAL COGENERATION

22.1 Introduction

22-1

22.2 Technical Discussion

22-5

22.3 Factors Affecting the Use of Industrial Cogeneration

22-26

22.4 Future Prospects for Cogeneration

$22-29$

References

$22-33$

23 TOTAL ENERGY SYSTEMS

23.1 Introduction

23-1

23.2 Technical Discussion

23-3

23-3 Economics Discussion

23-16

23-4 Limitations

23-25

References

23-31 
CHAPTER 1

DISTRIBUTED ENERGY SYSTEMS

Section 1.1: Introduction

The modern industrialized society depends upon the widespread availability of inexpensive and reliable supplies of energy. The invention of the steam engine permitted the energy in coal to be converted to mechanical energy and was a major factor in the Industrial Revolution. It also made possible the generation of electricity on a large scale. As technology developed, the equipment for converting the energy in fossil fuels to more usable forms improved in efficiency and grew in size. As a consequence, the energy conversion industries became noted for their ability to produce energy reliably and at progressively lower unit cost. To meet the apparently ever-growing demands of their customers, they developed systems for the production and distribution of energy-rich fuels, such as coal, natural gas and oil, and for the centralized generation and distribution of electricity. As these power systems grew In power capacity and extent, they made obsolete, older, smaller, less efficient, and less reliable energy conversion plants.

Within the past decade, and particularly since 1973, the energy industries have become increasingly the targets of public criticism. The three areas of most common concern appear to be the rapid increase in energy prices, the environmental impact of large energy installations such as electric power plants, and the rellability of supply, particularly to urban areas. Critics accuse the industries of failing to operate in the nation's best interests by making inefficient use of non-renewable fossil and mineral fuels, and of being insensitive to the economic and environmental concerns of their customers. The plans offered by the critics generally advocate:

- reduction of demand, e.g., through changes in patterns of use and technical developments such as better thermal insulation of buildings;

1-1 $\quad 1.1-1.38$ 
- improvements in efficiency of use, e.g., by cogeneration of electricity and heat for domestic or industrial use;

- the greater use of energy conversion systems which take advantage of local energy sources and deliver energy matched to local needs;

- more extensive use of renewable energy sources, e.g., solar, wind, hydropower, and blomass.

The final category has been referred to as the "soft" energy path. The conventional use of non-renewable fossil and nuclear fuels, for comparison, is referred to as the "hard" energy path.

The term "distributed energy systems" (DES) 1s applied to those energy systems which use (largely, but not exclusively) local energy sources to meet local energy needs. They may vary in size from small solar systems designed to supplement the hot water needs of a singlefamily residence, to a cogeneration plant which uses, for example, wood wastes to provide electricity and process steam to a paper mill and the local community. The systems may be relatively simple, as in the case of the solar hot water heater, or complex, if electrical or thermal energy storage systems are Included; they may be isolated or they may be connected to the local electric utility either to receive power in times of shortage or to deliver it to the utility in times of surplus. The role that DES will play in the future cannot be clearly designated. It is likely to depend upon population density, local energy resources, and energy demands. DES can supplement the existing centralized power system or they may, as hypothesized in the Callfuruid study to be examined later, become a dominant component of the overall entergy supply system.

\section{Section 1.2: Distributed Energy Systems}

Many of the principal arguments in favor of the greater use of DES are to be found in the works of Schumacher, ${ }^{(1)}$ Lovins, $(2,3)$ and Commoner. ${ }^{(4) *}$ Lovins, for example, has presented his perception (Figure 1-1) of the United States' energy future if the present reliance upon centralized energy industries is continued. He offers for comparison

* References are 1isted at the end of each chapter. 


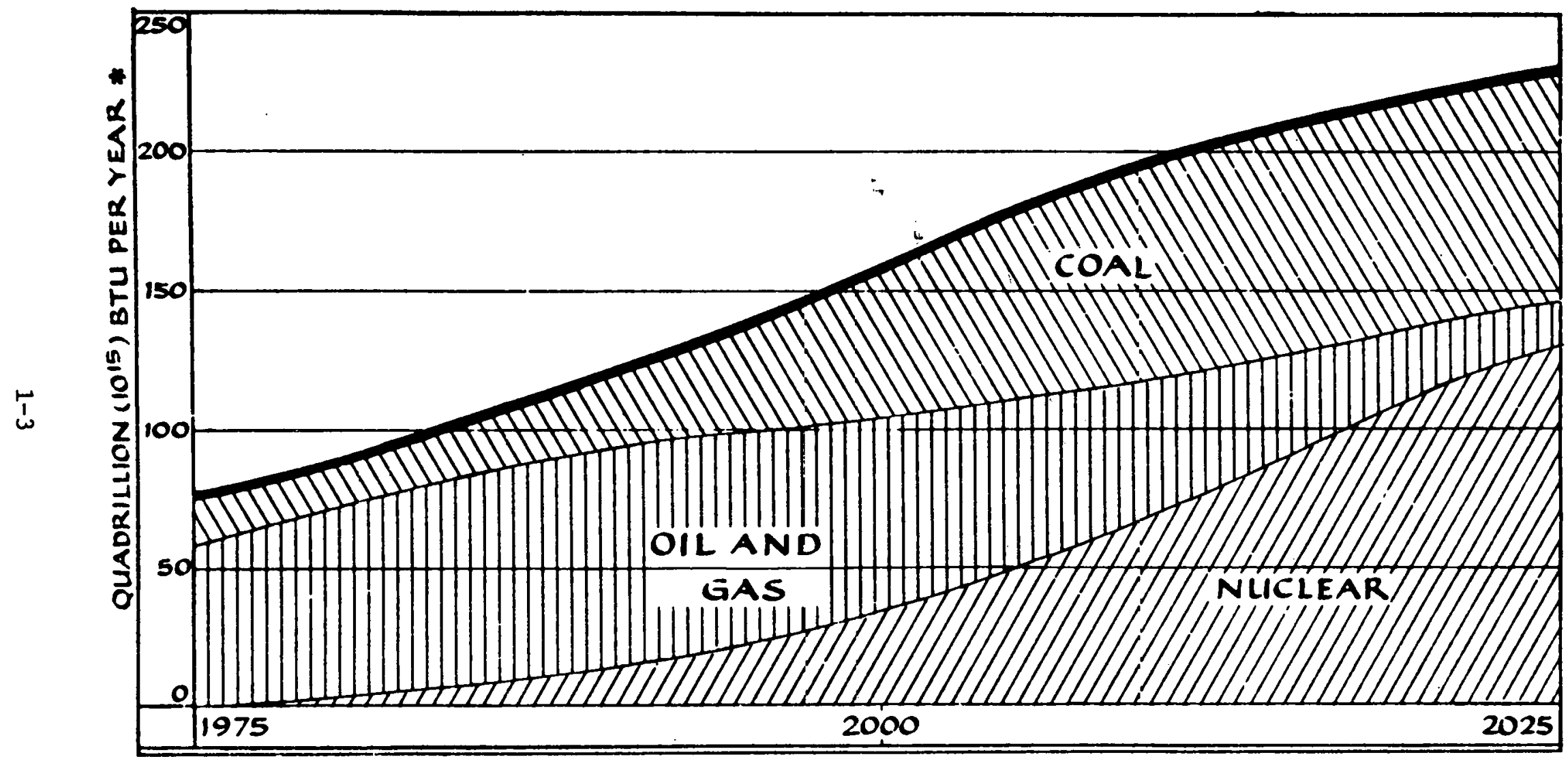

* or QUINTILLION (1018) JOULES PER YEAR

SOURCE:- From Reference 3, SOFT ENERGY PATHS, Copyright 1977, Friends of the Earth Internationa1. Reprinted with permission from Ballinger Publishing Company.

FIGURE 1-1 AN ILLUSTRATIVE SCHEMATIC FUTURE FOR U.S. GROSS PRIMARY ENERGY USE, BASED ON CENTRALIZED ENERGY SYSTEMS 
"an alternative illustrative future" (Figure 1-2) in which fossil and nuclear fuels are replaced by "soft" technologies by the year 2025 . Lovins' criticisms of the conventional or "centralized" approach (responsible for Figure 1-1) are based principally upon (a) environmental effects (large quantities of warm cooling water from central electric power plants, the operation of coal and uranium mines, and the increased concentration of carbon dioxide in the atmosphere from the combustion of fossil fuels); and (b) the combination of accelerating capital costs and long lead times which, he claims, will lead the electric utility industry to bankruptcy.

The alternative, $\vec{F}$ igure $1-2$, requires a massive reduction in demand to $30 \%$ of that predicted for 2025 in Figure 1-1. This is to be achleved, first, by "technical fixes," e.g., improved thermal insulation of buildings and more extensive use of cogeneration and, second, by "social changes," e.g., car pools, smaller cars, and mass transit stimulated by changes in prices, regulatory requirements, or "gentler inducements." The residual demand in Figure 1-2 is to be met by the widespread use of "soft" technologies which are characterized by their use of renewable energy sources, by diversity, by the use of "low" technology, and by their being matched in scale and in energy quality to their end-use.

The preceding approach to meeting future U.S. energy needs has received extensive criticism. Perry and streiter ${ }^{(5)}$ have questioned the validity of Lovins' economic analysis. They suggest that if the "technical fixes" prove to be as successful and as cost-effective as he claims, then they will stimulate increased demand and the hoped-for energy savings, based upon improved energy efficiency, will be less than expected. Yulish ${ }^{(6)}$ has edited a selection of 10 essays by economists, sociologists, and technologists with reputations and backgrounds in solar energy, nuclear engineering, physics, and chemical engineering. As a group, the writers take Lovins to task for technical Inaccuracies, particularly in his treatment of solar energy, for unrealistically low projections of future growth, for faulty economic analysis, and for ignoring the political and social implications of the widespread introduction of "soft" energy technologies.

The extent to which the energy needs of a highly developed 


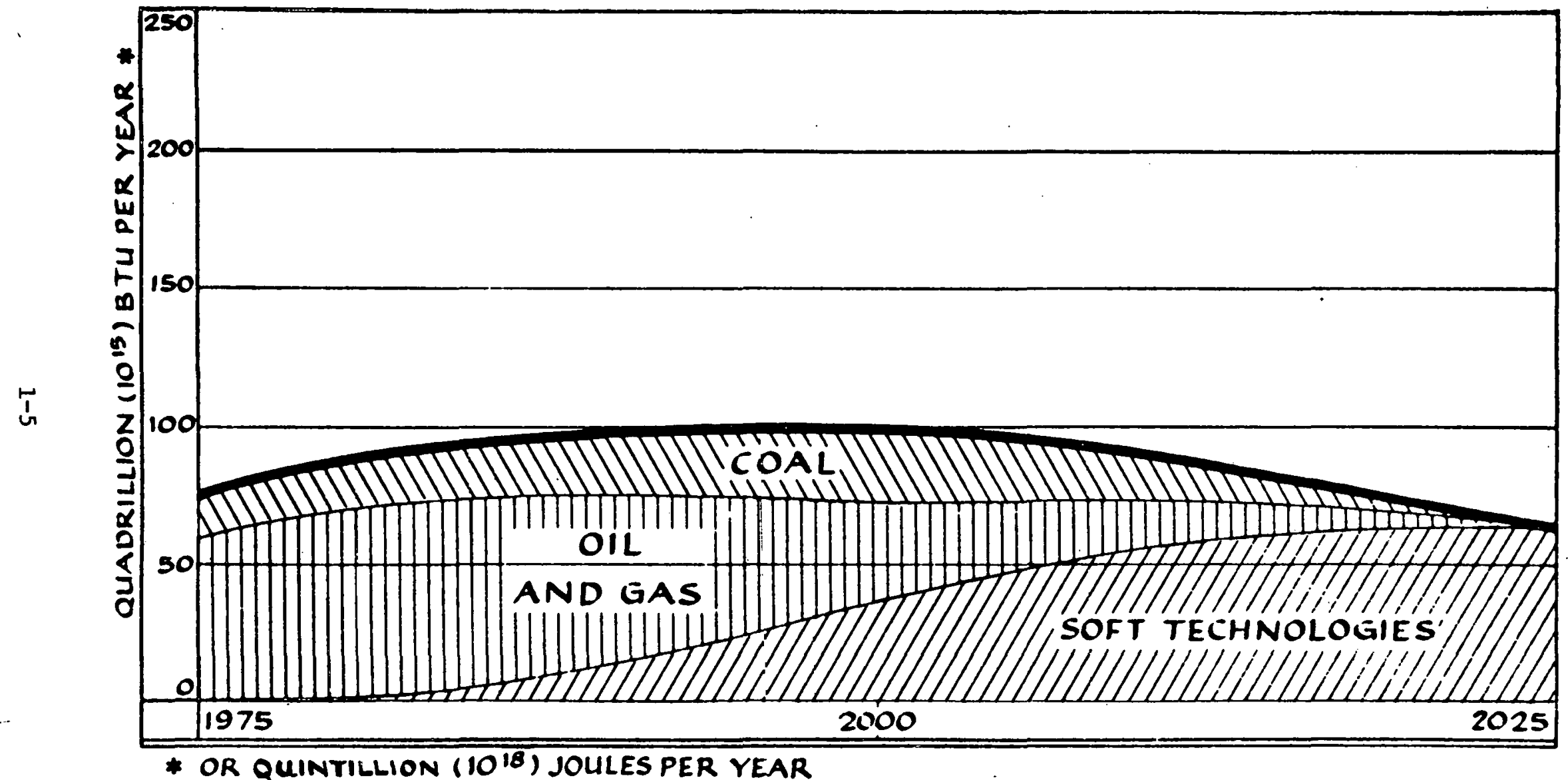

SOURCE: From Reference 3, SOFT ENERGY PATHS, Copyright 1977, Friends of the Earth International. Reprinted with permission from Ballinger Publishing Company.

FIGURE 1-2 AN ALTERNATE ILLUSTRATIVE FUTURE FOR U.S. GROSS PRIMARY ENERGY USE, BASED ON THE USE OF "SOFT" ENERGY TECHNOLOGIES 
modern society (the state of California in the year 2025) can be supplied by an energy system that is based substantially upon distributed and renewable energy sources is analyzed in the interim report "Distributed Energy Systems in California's Future." ${ }^{(7)}$ The results of the study are contalned in the two energy supply/demand balances for California - 2025 presented in Figures $1-3$ and 1-4. The former presents the "centralized case" and 1ts method of meeting a demand for 5.3 quads*; the latter presents the components of the "distributed case" in meeting a demand for 4.7 quads. The differences in approach are clear.

The distributed case implies the following: (a) the use of electric vehicles for urban transportation; (b) half of the available land that contains non-commercial forest, brush and grasslands (almost $17 \%$ of the total land area in California) as well as municipal and agricultural wastes will be required to produce 1 quad of energy from biomass; and (c) the generation of 0.7 quad of electricity from the wind w111 require "17,000 to 35,000 wind energy conversion devices with an average rated capacity of 3.5 megawatts . . Such a system would extend over about $6 \%$ of the land area, but would occupy only a small part of that area which could be used at the same time for farming or grazing." (7) In discussing the "centralized case," the report states: "If the same end-use requirements developed here were to be met by using conventional energy forms, the resource requirements and environmental Impacts would be substantial. If all energy were derived from coal (using electricity, synfuels, etc.), California in 2025 would require the mining of about 380 million tons per year, about $60 \%$ of the coal used by the entire United States today. If electricity produced from nuclear plants were used to meet all the electricity needs (except those met by hydropower), about twenty-two 1000-megawatt plants would be required which would replace 54 million tons of coal per year." $(7)$

The preceding paragraphs in this section suggest the following conclusions:

${ }^{\star} 1$ quad $=10^{15} \mathrm{Btu}$. 


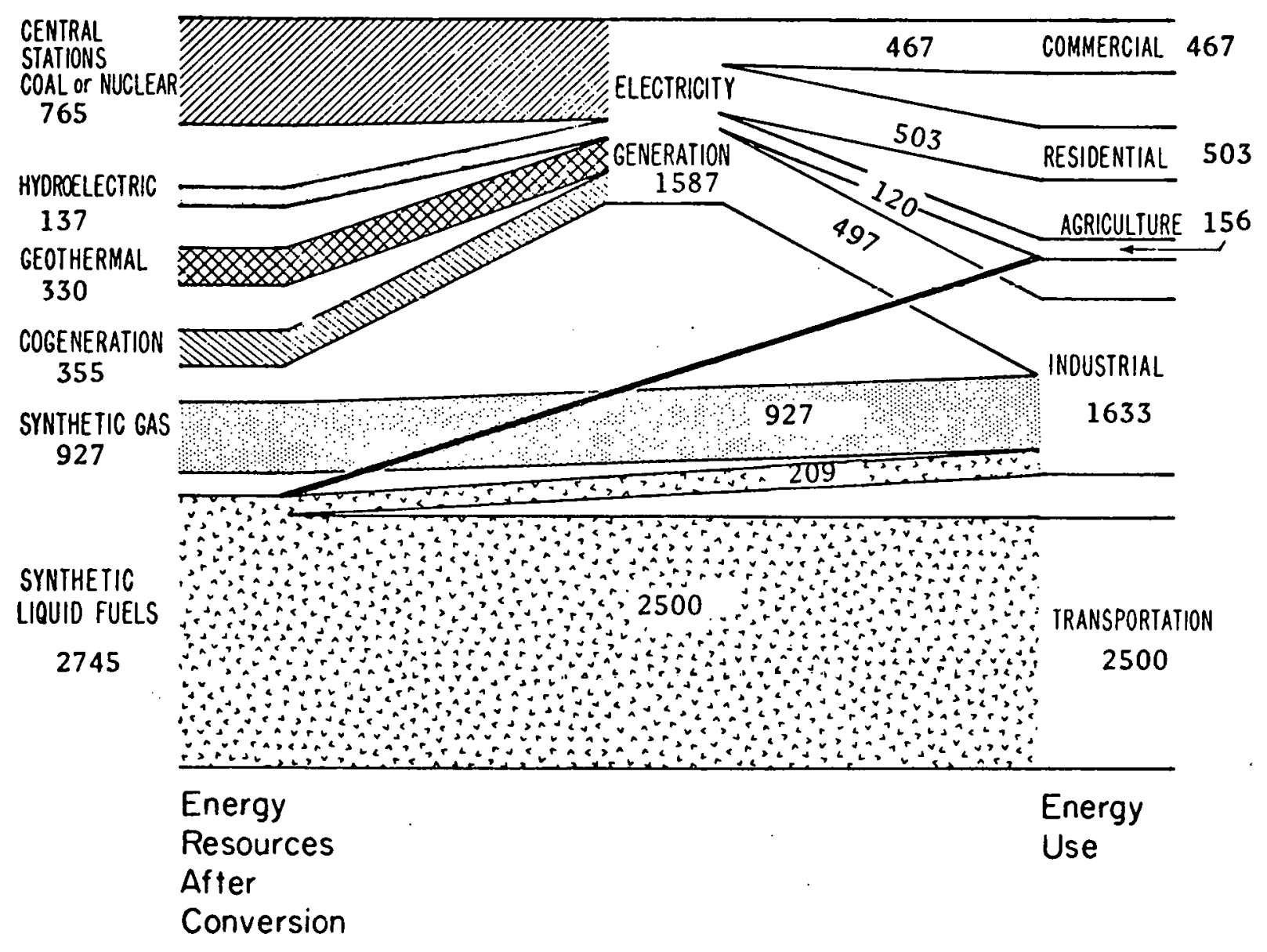

SOURCE: Reference 7.

FIGURE 1-3 ENERGY SUPPLY/DEMAND BALANCE FOR CALIFORNIA -- 2025 (Centralized Case; energy in units of $10^{12} \mathrm{Btu}$ ) 


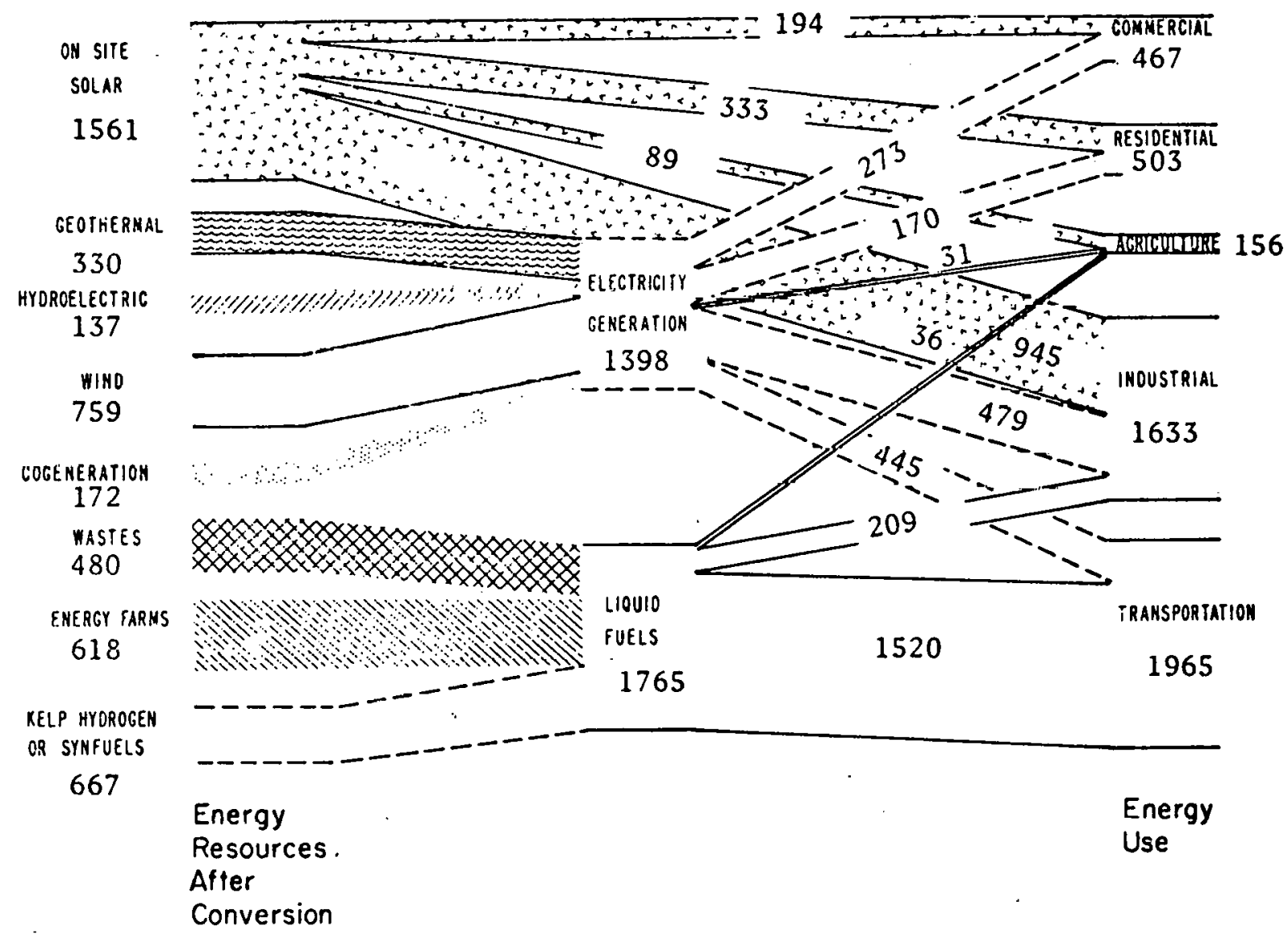

SOURCE: Reference 7.

FIGURE 1-4 ENERGY SUPPLY/DEMAND BALANCE FOR CALIFORNIA -- 2025

(Distributed Case; energy in units of $10^{12} \mathrm{Btu}$ ) 
- There are problems and deficiencies in the existing "centralized" energy industries, and there are alternative energy sources and technologies that may have been Insufficientiy exploited in the past;

- the proponents of DES may have overstated thetr energy and economic benefits; but the supporters of centralized systems have also been optimistic in estimating their costs and benefits;

- It is not at all clear that the large-scale use of biomass to produce 1iquid fuels, or solar energy to generate electricity, will not encounter problems and organizational structures similar to those of today's centralized power utflities;

- It is unlikely that the future energy systems in the United States will be all "hard" or all "soft"; it is much more likely that both classes of technology will be required, and ways must be found to ensure that the two complement one another;

- the social, institutional, and legal implications of the widespread use of DES are not understood and probably have been greatly understated, partfcularly in their impact upon the urban resident or the working farmer. As was pointed out by Perry and Strelter:

"Claims that new technologies are both economic and ready to be applied widely on a commerclal scale are common in the scientific and engineering community -- even when there is little or no basis for such claims. It is only necessary to cite a'few examples, . . to illustrate how carefully claims of the availability and economic competitiveness of a new technology must be evaluated. The evaluation must include not only an examination of the technical and economic status but, just as importantly, the nature of the environmental, political, institutional, legal, regulatory, and financlal barriers that must be overcome before the technology can be 
deployed widely enough to make an Important contribution to encrgy supply. Making such evaluations has been just as difficult for new "hard" technologies as it has been for "sort" ones."

In the report which follows we have attempted to begin this invest $1-$ gation of the technical, economic, institutional, and soctal implications of the large-scale use of distributed energy systems. We have started at the beginning by limiting our attention to those questions that may be described as necessary if not sufficient -- the technical feasibility and the readiness for commerctal deployment of those selected technologies which may be considered as future components of an energy supply system based upon distributed energy sources. We have not attempted to analyze the technical and social issues raised by the possible widespread use of DES, although we recognize that these questions may be of major importance in the future. Within the limits of avallable funding and time we have attempted to present a balanced description of the states of the different technologies, their costs and environmental effects, and how they may be used individually or in combination. We have also presented a guide to additional sources of information.

Section 1.3: The Structure of This Report

Chapters $2 \cdot$ through 23 are each devoted to an examination of a technology, or a combination of technologles, that is likely to find a place in future distributed energy systems. The objective is to provide the reader, who has some technical background but is not a spectalist, with enough scientiflc and engineering information to indicate the present state of technical development, where the problems are, and the probable direction of future improvements. Each chapter includes a discussion, or at least a brief mention, of related questions, e.g., environmental impacts, problems connected with energy storage or connection to the electric utility system, if desirable, and inst1tutional problems. An extensive list of references is provided.

\footnotetext{
* Such as interconnection, centralịed control, and energy storage.
} 
Information on costs, both present and expected, is presented in the manner that is conventional for each technology, but enough detail is provided so that the reader may reconstruct, from the base data provided, derived information, e.g., the expected costs of delivered energy. A summary sheet ${ }^{*}$ accompanies each chapter; it presents, in condensed form, the information on performance and costs contained in the chapter.

A comment upon the costs presented in the technology chapters is in order. As far as possible, the information on current costs reflects accurately the costs of manufactured equipment. In some cases, however, these may be subject to rapid change, and in others, installation costs represent a large and variable fraction of total system costs. In both cases, accuracy may be less than the published costs might suggest. Future costs present an even more difficult problem. When there is little consensus, even among experts, on future energy costs or rates of inflation, it is clearly unwise to regard predictions of future costs with anything less than skepticism. In the case of technologies that are still evolving or, having achieved technical success, are now approaching commercialization, it is hard to estimate future costs with any accuracy: (a) for systems that have yet to achieve technical maturity, there is an inevitable tendency to confuse future cost predictions with the desires or the objectives of the proponents; (b) for technologies ready for commercialization (in which case it is customary to assume unit costs will be reduced as production and the market grow), government intervention may be required to stimulate the creation of the market.

In the remainder of this chapter we review some of the problems that must be addressed 1.f there is to be a large-scale introduction of distributed energy systems. We also compare, on the basis of cost information presently available, the costs of energy produced by the various technologies. This analysis should be regarded principally $\bar{x}$

Cost data in the technology summary sheets are given in 1977 dollars. Average unit $O \& M$ costs include the costs of parts and labor for maintenance; they do not include "annual capitalization charges" and costs of fuel. 
as a means of comparing one technology with another -- on the basis of our present understanding of it -- not as an absolute prediction of future energy costs.

Section 1.4: Summary of Technologies and Factors Affecting Their Evaluation

The individual chapters which follow contain technicai descriptions of various distributed energy systems, along with estimates of important economic parameters. The purpose of this chapter is to discuss the factors which enter into a comparison of these technologies and the evaluation of their suitabllity for meeting part of our national energy requirements. The technologies may be classified as follows:

Group I. Those which produce energy from fuel that is essentially free and is received directly in usable form from the environment :

Photovoltaic conversion

Solar thermal generation of electricity

Solar heating and cooling

Run-of-the-river hydropower

Windmills

Group II. Those which produce energy from fuel that must be mined, grown, or otherwise prepared:

Biomass (1ncluding refuse material) -direct conversion by burning

Fluidized-bed combustion

Domestic burning of coal

Diesel engines

Organj.c Rankine cycle engines

Stirling engineo

Gas turbines

Fuel cells

Group III. Those which are not primary energy-producing devices, but rather are complementary to such devices:

Pyrolysis (fuel producing)

Fermentation (fuel producing) 
Solid fuels from biomass (fuel producing)

Heat pumps (electrically powered)

Batteries

Thermal storage

Heat pipes

Group IV. Combined systems:

Industrial cogeneration

Total energy systems

Table 1-1 contains a summary of the principal characteristics and applications of these technologies. It should be kept in mind that many of the electricity-producing technologies also admit the option of waste heat recovery, usually for water-heating or space-conditioning applications.

One of the advantages of decentralized and smaller scale technologies is that they may be better adapted to particular applications, especially with respect to the efficient use of energy. For example, despite various heat-recovery cycles, large central generation stations release substantial quantities of waste heat. Because these stations are usually sited some distance from the population centers they serve, and also because of various institutional factors, it is generally not possible to find uses for this waste heat. On the other hand, the waste heat produced by an on-site generation system is often easily recoverable for process or space-conditioning applications. Decentralized sources of energy can (and must) be designed and evaluated with site-specific characteristics in mind, among them being:

- balance between and extent of electrical and thermal requirements,

- daily and seasonal variations in energy requirements,

- local availability of renewable reșources, e.g., sunlight, wind, water power,

- projected fuel prices and vulnerability to sudden changes,

- capital availahility,

- environmental restrictions, 
- reliability requirements,

- personnel capab1lities, and

- local utilities (rates, gas pressure, etc.).

Even though there can be significant economies of scale associated with large central stations, the adaptability of distributed systems can more than make up for this fact in a number of specific circumstances. Fuel cost changes and technical improvements over the next 20 years are expected to increase the importance of some of these decentralized technologies.

While an advantage in their implementation, the site-specific dependency and numerous potential configurations of these technologies make it difficult to compare and evaluate them in general terms. Other phases of the Department of tinergỹ program wlll be able to do this for specific scenarios and case studies. Such work is outside the scope of the present report, the purpose here being to summarize the basic general data, so far as they are available, and to outline the factors which require detailed treatment in more specialized studies.

Factors which enter into an evaluation of this type include:

- direct costs (capital, fuel, operation and maintenance);

- Indirect costs and credits (heat recovery, transmission and distribution, rellabilicy, etc.); and

- matters which are difficult or impossible to measure in economic terms (institutional barriers, safety, regulatory patterns, environmental effects, etc.).

It is important to keep in mind further that evaluations of data may lead to different conclusions for persons or groups with different points of view. For example, the user of energy might simply compare the costs of various systems to the rates available from the utility. If a utility is trying to evaluate the effects of a significant level of implementation of decentralized power production, perhaps owned by the utility itself, it will also consider system-wide effects on transmission and distribution requirements, probably to a greater extent than would the individual user. These considerations will be reflected in various costs of power 


\begin{tabular}{|c|c|c|c|c|c|c|c|c|c|c|c|c|c|}
\hline \multirow[b]{2}{*}{ Technotogy } & \multirow[b]{2}{*}{$\begin{array}{c}\text { Inpert } \\
\text { (onpromary) }\end{array}$} & \multicolumn{3}{|c|}{ Ourput (primary) } & \multirow[b]{2}{*}{ Status' } & \multicolumn{6}{|c|}{ Prindipal Applicartions } & \multirow[b]{2}{*}{ Complementury Toctinologios } & \multirow[b]{2}{*}{ Commonts } \\
\hline & & $\begin{array}{l}\text { Shaft Power } \\
\text { or Ebectidty }\end{array}$ & rput (primary) & Fuol & & $\begin{array}{l}\text { Individual } \\
\text { Residencoses }\end{array}$ & 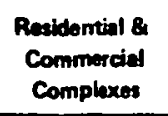 & Industrial & Utility & Irolened & Communities & & \\
\hline Phorovoltesic & sunlight & $100 \mathrm{~W}-1 \mathrm{MW}$ & & & pilot & $\checkmark$ & $\checkmark$ & $\checkmark$ & $\checkmark$ & $\checkmark$ & & barteries end/or back-up genereration & intermittency: daily, sesonal, westher \\
\hline Solur thermal & sunlight & $1 \mathrm{~kW} \cdot 150 \mathrm{MW}$ & & & pilot & & $\checkmark$ & $\checkmark$ & $\checkmark$ & $\checkmark$ & $\checkmark$ & $\begin{array}{l}\text { batteries or thermal storage and/or bock-up } \\
\text { generertion }\end{array}$ & 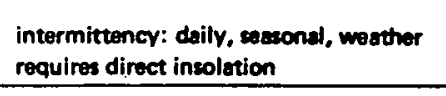 \\
\hline Solur heating//cooling & sunlight & & $\begin{array}{l}\text { water \& sposes } \\
\text { heating/cooling }\end{array}$ & & $\begin{array}{c}c \text { commercial } \\
\text { (ear }(y)\end{array}$ & $\checkmark$ & $\checkmark$ & $\checkmark$ & & $\checkmark$ & $\checkmark$ & thermal storage & $\begin{array}{l}\text { intermintency: deily, semonal mo } \\
\text { wother }\end{array}$ \\
\hline Rum-of-river hydro & water power & 50kW-500Mw & & & commercial & (2) & & $\checkmark$ & $\checkmark$ & & & small pondage & sessonal flucturations \\
\hline Windmills & wind & $100 \mathrm{~W}-2.0 \mathrm{MW}$ & & & pilot $^{3}$ & $\checkmark$ & $v$ & $\checkmark$ & $\bar{v}$ & $\checkmark$ & & batteries and/or back-up generation & wind varietions \\
\hline Biomess-direct combustion & cops, wastes & IMN-100MW & (4) & & $\begin{array}{c}c \infty m \text { mercial } \\
\text { (early) }\end{array}$ & & & $\checkmark$ & $\checkmark$ & $\checkmark$ & $\checkmark$ & $\begin{array}{l}\text { biomass production, collection, and } \\
\text { distribution }\end{array}$ & \\
\hline Pyrolyois & $\begin{array}{l}\text { municipal solid } \\
\text { wasto }\end{array}$ & & & $\begin{array}{l}\text { gess, oil } \\
\text { mothenoil }\end{array}$ & pilot & & & & & & $\checkmark$ & energy conversion device for fuel produced & \\
\hline Fermentertion & crops, wastes & & & $\begin{array}{l}\text { Methane } \\
\text { ethyl alcohol }\end{array}$ & developmental & & & $\checkmark$ & $\checkmark$ & & $v$ & energy connversslon devilue lus Iutl produced & \\
\hline Solld fuels from biomeass & municipal solid & & & $\begin{array}{l}\text { refuse derived } \\
\text { solid fuel }\end{array}$ & $\begin{array}{c}c \text { commercial } \\
\text { (early) }\end{array}$ & & & $\checkmark$ & $\checkmark$ & & $\checkmark$ & energy conversion device for fuel produced & . \\
\hline Fludidizod bood & $\infty 001^{3}$ & & & & large-scale testing & & & $\checkmark$ & $\checkmark$ & & $\checkmark$ & coal distribution and disposal & \\
\hline Domestic cosal & $\infty$ & & $\begin{array}{l}\text { water \& space } \\
\text { heating }\end{array}$ & & commercial & $\checkmark$ & & & & & & coal distribution and disposal & coal handling a serious problem \\
\hline Diesol enginess & $\begin{array}{l}\text { diesal fuel, } \\
\text { natural gas }\end{array}$ & $100 \mathrm{~kW}-1 \mathrm{MW}$ & & & 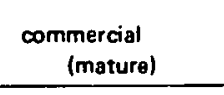 & (6) & $v$ & $\checkmark$ & $\checkmark$ & & $\checkmark$ & fuel supply & environmental effects moy be significant \\
\hline Orgenic Rankine engines & $\begin{array}{l}\text { low temperature } \\
\text { hoet }^{\prime}\end{array}$ & $2 k W-2 M W$ & & & developmental & & $\checkmark$ & $\checkmark$ & & & & $\begin{array}{l}\text { low temperanure hear source, such as } \\
\text { waste heat or solar system }\end{array}$ & promising in several combined cycles \\
\hline Hest pumps & electricity & & $\begin{array}{l}\text { water \& spsces } \\
\text { heating/cooling }\end{array}$ & & commercial & $\checkmark$ & $\checkmark$ & $\checkmark$ & & & & electricity supply & both heating end cooling \\
\hline Stirling engines & $\begin{array}{l}\text { high temporature } \\
\text { heat }\end{array}$ & $3 *$ W.500kW & & & developmental & & $\checkmark$ & $\checkmark$ & $\checkmark$ & $\checkmark$. & & high temper reture heat source & fual versatility \\
\hline Ges turtines & $\begin{array}{l}\text { distillotet fuvel } \\
\text { natural gass }\end{array}$ & $700 \mathrm{~kW}-25 \mathrm{MW}$ & & & $\begin{array}{c}\text { commercial } \\
\text { (mature) } \\
\end{array}$ & & $\checkmark$ & $\checkmark$ & $\checkmark$ & & $\checkmark$ & fuel supply & \\
\hline Fural colls & light hydrocarbons & $200 \mathrm{KW}-26 \mathrm{MW}$ & & & pilot & & $\checkmark$ & $\checkmark$ & $v$ & & $\checkmark$ & fuel supply & \\
\hline Botteries & electricity & storage & . & & pilot & $\checkmark$ & $\sqrt{ }$ & $\checkmark$ & $\checkmark$ & $\checkmark$ & $\checkmark$ & & \\
\hline Thermal norage & heat & & storage & & developmental ${ }^{9}$ & $\bar{v}$ & $\checkmark$ & $\checkmark$ & & & $\checkmark$ & & \\
\hline Hest pipes & hest & & transport & & commercial & & & & & & & & \\
\hline Industrial coneneration & $\begin{array}{l}\text { coal, residues, } \\
\text { oil, gas }\end{array}$ & $500 \mathrm{~kW}-400 \mathrm{MW}$ & steam & & commercial & & $v$ & $\checkmark$ & & & & & \\
\hline Toral energy vystems & $\begin{array}{l}\text { cosl, oil, gas, } \\
\text { sunlight }\end{array}$ & $500 \mathrm{~kW}-30 \mathrm{MW}$ & $\begin{array}{l}\text { water \& space } \\
\text { heating/cooling }\end{array}$ & & pilot & & $\nu$ & $\checkmark$ & $\checkmark$ & & $v$ & & \\
\hline $\begin{array}{l}\text { Notess: } \\
\text { 1. Status description may } \\
\text { 2. Very small units to sup } \\
\text { atthough they are far fr } \\
\text { 3. Windmills hove been av } \\
\text { 4. Primery snd supplemen } \\
\text { residenecos. The larger }\end{array}$ & 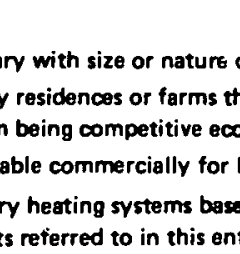 & $\begin{array}{l}\text { application. } \\
\text { th have appropriate } \\
\text { omically in most ca } \\
\text { nited applications it } \\
\text { lon wood are availal } \\
\text { y can also supply st }\end{array}$ & $\begin{array}{l}\text { r supplies are com } \\
\text { and are not expect } \\
\text { irrigation pumpin } \\
\text { commercially fors } \\
\text { for various uses, a }\end{array}$ & $\begin{array}{l}\text { rcially available, } \\
\text { to become so. } \\
\text { or many years. } \\
\text { Il units, such as } \\
\text { n atternative to or }\end{array}$ & $s$ & & $\begin{array}{l}\text { 5. Sluoge and } \\
\text { 6. Gererally or } \\
\text { 7. These engin } \\
\text { 8. Cosidderive } \\
\text { 9. Temperature }\end{array}$ & 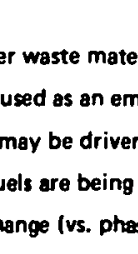 & $\begin{array}{l}\text { are impor } \\
\text { ncy back- } \\
\text { waste hea } \\
\text { stigated. } \\
\text { hange) sys }\end{array}$ & $\begin{array}{l}\text { long term pec } \\
\text { wer source } \\
\text { olar heat. } \\
\text { are commerc }\end{array}$ & $\begin{array}{l}\text { ibilities. } \\
\text { this applicationi. } \\
\text { Ily available as pa }\end{array}$ & sola: herting systems. & \\
\hline
\end{tabular}
PRINCIPAL CHARACTERISTICS AND APPLICATIONS OF DISTRIBUTED ENERGY TECHNOLOGIES 


\section{THIS PAGE \\ WAS INTENTIONALLY \\ LEFT BLANK}


generation and supply, and the results may be quite different from the utility rates themselves. When the government evaluates such systems, considerations such as dependence on foreign fuels, vulnerability to sabotage, effects on the economy, etc., may all become more prominent in the analysis.

\section{Section 1.5: Direct Costs}

The direct costs involved in the installation of energy-producing equipment include:

- capital costs of the plant,

- fuel costs, and

- maintenance and other operating costs.

In themselves, these do not constitute a sufficient basis for choosing between candidate technologies, but they do provide a starting point. Capital costs are generally given in terms of the peak power capacity of a unit (e.g., $\$ / \mathrm{kW}$ ), while the other costs are given in terms of energy produced (e.g., $\$ / \mathrm{kWh})$. By amortizing the capital cost over the expected lifetime of the plant and by considering the plant's expected energy output, the capital cost can also be represented on a dollar per unit energy basis. The sum of all these energy costs may be regarded as the life-cycle energy production cost of the technology. It gives one indication of the economic picture associated with a particular type of plant. (Obviously, variations in assumptions concerning cost of capital, inflation, fuel cost escalation, etc., may critically affect the relative values of this parameter for different technologies.) For plants with similar operating characteristics, size, and location within the electric utility network, a comparison of life-cycle costs can be very important in choosing among alternatives. This would be the case, for example, in comparing large coal-fired and nuclear generating stations. In the case of comparisons between technologies with highly different operating characteristics, however, this parameter is only one aspect of the picture. The reason for this is that different technologies can have vastly different effects on the overall energy system, and the indirect costs associated with 
these can be enormous. For example, that fraction of photovoltaic capacity which requires conventional generation back-up during periods of low insolation must bear the cost of the additional capacity. On the other hand, energy sources distributed so that they are close to the load do not entail the large transmission and distribution costs of central generators.

Further discussion of such system effects will be presented in the next section, but it is useful to begin here with a summary of the direct costs associated with the various technologies. Figure 1-5 summarizes typical data for various electricity-producing technologies. To lend some perspective, Table 1-2 gives a recent estimate of the average cost of delivered electricity to industrial users in certain major U.S. cities. The approximate annual costs for various home heating systems are shown in Table 1-3. Critical economic assumptions are listed in Table 1-4.

It must be emphasized again that the energy costs given in this section cannot simply be compared directly in order to evaluate the relative merits of different technologies. These data are only starting points, which require the further addition of various indirect costs and credits, as well as application and site-specific considerations, before being useful to the evaluative process. It must also be kept in mind that all of these calculations are based largely on cost projections, often for technologies in an active stage of development. Therefore, the tables should be interpreted in the sense: "If costs and parameters are such, then the energy costs will be as calculated." The data are not firm enough to regard the conclusion alone as a forecast. Furthermore, wide ranges of costs may be obtained, depending on site-specific conditions and trends in the economy. Certain observations can be made from some of these calculations, however. For example, even though solarthermal electric systems presently exhibit cost advantages over photovoltaic systems, the former depend primarily on mechanical components whose prices are not expected to decrease. On the other hand, projected solar cell developments with possibly dramatic cost savinge give this technology a competitive advantage in the long run. One also observes 


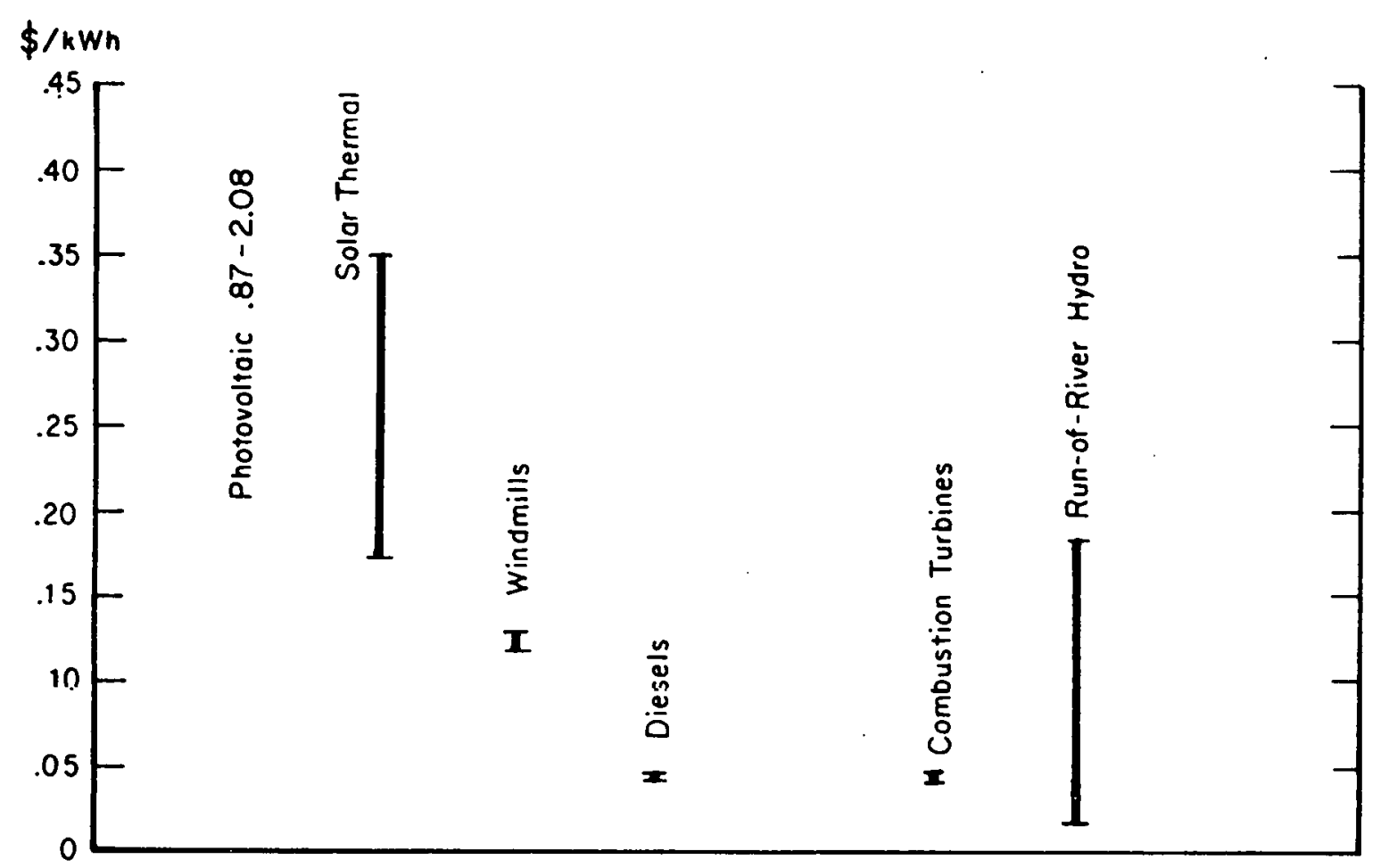

1978

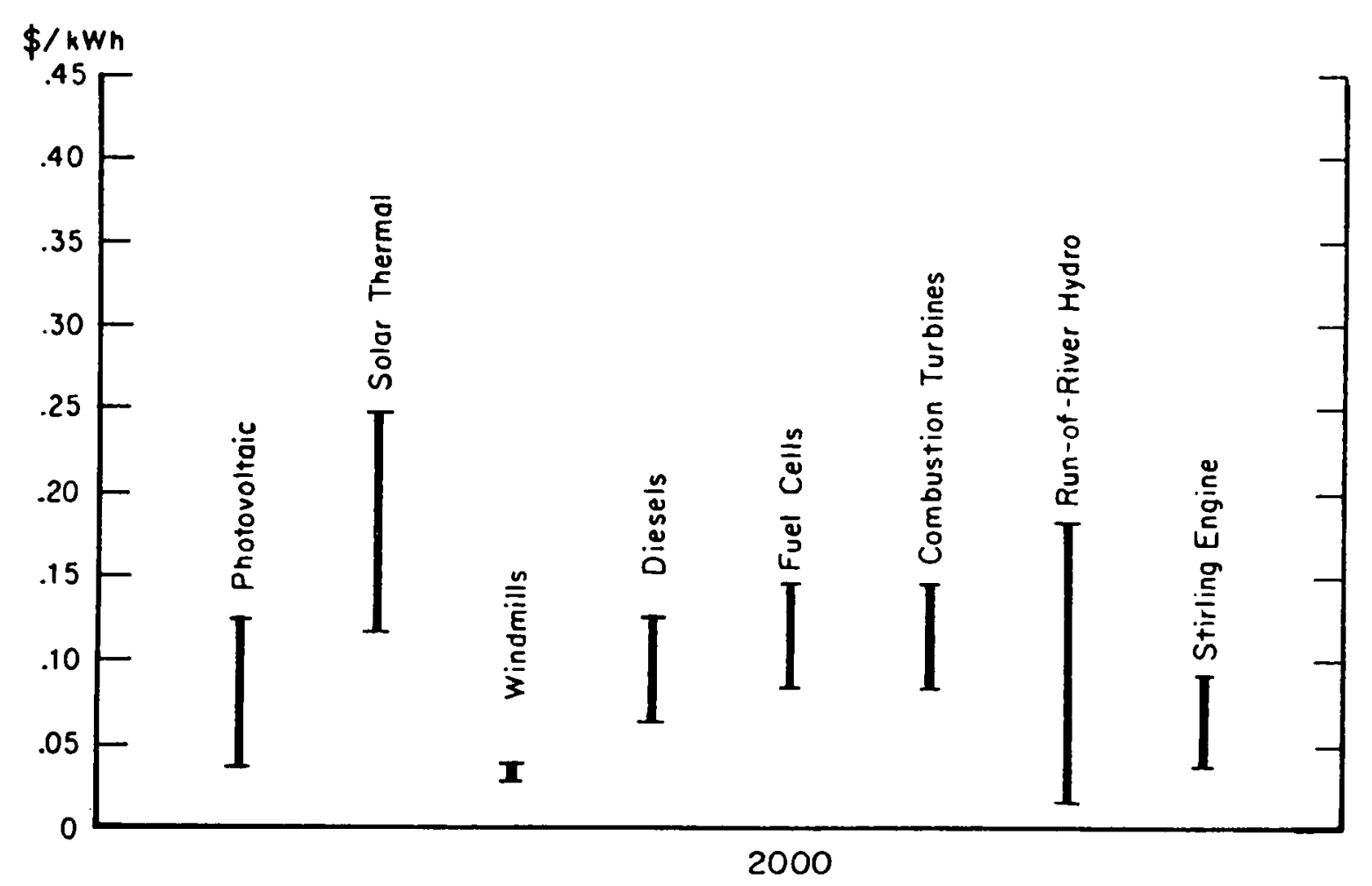

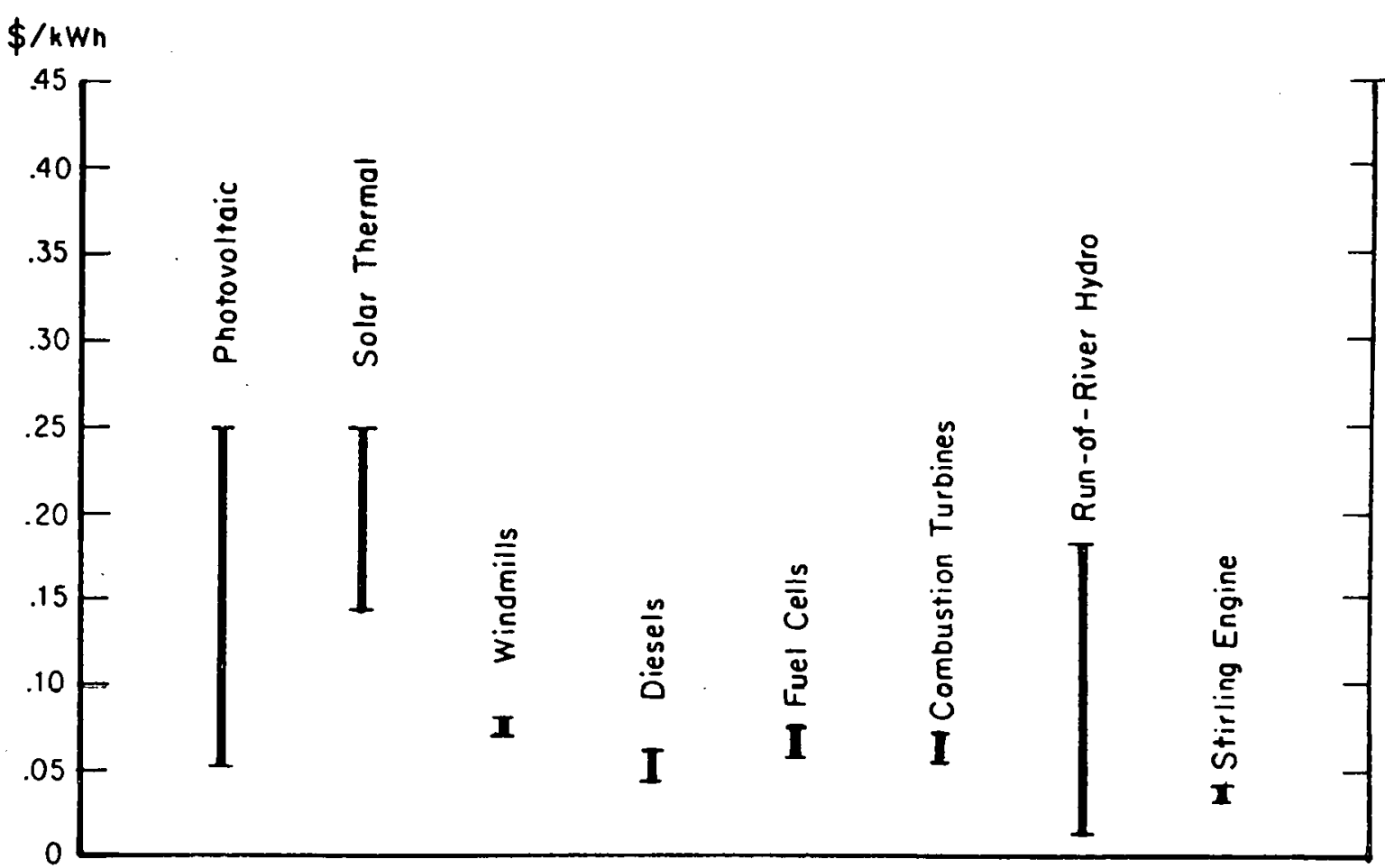

1985

All calculations are in constant 1978 dollars. Conversion from the 1977 basis of the individual chapters has been accomplished using an inflation rate of $7 \%$. For the purpose of this comparison, two factors have been standardized: a system operating life of 20 years, and annual malntenance cost equal to $5 \%$ of the capital cost. The cost of capital was assumed to be $6 \%$ because constant dollars were used. Capita1 costs are amortized over the 20 year life, and each system is assumed to have zero salvage value. Average operating efficiencies for combustion turbines and diesels werc taken to be $27 \%$ and $35 \%$, respectively.

Fuel cost escalation ranges (growth in terms of constant dollars) were assumed as follows: coal, 1-3\%; diesel fuel and naphtha, 3-6\%; natural gas, 3-6\%. Fuel costs used in these calculations were as follows in 1978 dollars: coal, $\$ 1.20 / 10^{6}$ Btu; diesel fuel, $\$ 2.90 / 10^{6} \mathrm{Btu}$; naphtha, $\$ 4.10 / 10^{6} \mathrm{Btu}$; natural gas, $\$ 1.90 / 10^{6} \mathrm{Btu}$. The prices of fuels vary widely because of sulfur content, transportation distance, and contractual duration; the fuel prices shown here represent typical mid-1978 values. For a range of fuel prices to utilities in the Unfted States, see any issue of Electrical Week. The widening cost ranges for certain technologies, such as Stirling engines, are due to increasing fuel cost uncertainties further into the future.

Note that most of the parameters and costs cited above may vary considerably depending on site, equipment and configuration, ownership, etc. and that fuel and maintenance costs used for this comparison are not necessarily the same as the costs used in each chapter.

FIGURE 1-5 LIFE CYCLE ELECTRICAL EFERGY PRODUCTION COSTS FOR VARIOUS TECHNOLOGIES 
THIS PAGE

\section{WAS INTENTIONALLY LEFT BLANK}


TABLE $\cdot 1-2$

REGIONAL DELIVERED ELECTRICITY COSTS TO INDUSTRIAL USERS (\$/kWh)

$\frac{\text { Atlanta }}{.028} \quad \frac{\text { Boston }}{.041} \quad \frac{\text { Chicago }}{.031} \quad \frac{\text { Los Angeles }}{.030} \quad \frac{\text { Portland (Ore.) }}{.017}$

Source: Reference 8 (1978 data).

TABLE $1-3$

APPROXIMATE ANNUAL ENERGY COSTS FOR DOMESTIC HEATING SYSTEMS

\begin{tabular}{lccc} 
Type & \multicolumn{1}{c}{$/ 10^{6} \mathrm{Btu}^{(1)}$} & $\frac{\$ / \mathrm{kWh}^{(2)}}{}$ & Annual Cost (3) \\
Oil & 6.42 & .022 & $\$ 963$ \\
Gas & 3.75 & .013 & 563 \\
Coa1 & 8.96 & .031 & 1344 \\
Solar & 19.26 & .066 & 2889 \\
Electric & 11.53 & .039 &. \\
Resistance & 9.94 & .034 & 1730 \\
Heat Pump & & & 1491
\end{tabular}

(1) A11 costs are in 1978 dollars. All systems are assumed to have a 25-year life. Capital costs and data in terms of $\$ / 10^{6}$ Btu are taken from individual chapters. Annual fixed cost (less maintenance) is installed cost divided by 25 ; i.e., homeowners are not expected to pay fixed charges based on interest over the life of the system. Annual malntenance cost was assumed to be $5 \%$ of the capital cost. System efficiencies were assumed as follows: electric resistance, $95 \%$; gas, $75 \%$; o $11,65 \%$; coa1, $55 \%$. The heat pump coefficient of performance was assumed to be 2.0 .

(2) Data in this column are based upon an exact conversion of 3413 Btu per kWh.

(3) A typical home heating requirement of $150 \times 10_{6}^{6}$ Btu per year was assumed. This column is simply column $1\left(\$ / 10^{6} \mathrm{Btu}\right)$ times 150 . 
ECONOMIC DEFINITIONS AND ASSUMPTIONS

\section{Cost of Capital}

Fixed Charge Rate

Operation and Maintenance Costs
The cost of capital is the weighted cost of money (capita1) to an organization, and is baced upon the yip1d (interest) paid on bonds, common stocks and preferred stocks. The cost of capital varies considerably depending on the type of organization. It is lowest for organizations which can secure federal or state government backing of securities and preferential tax treatment (such as electrical cooperatives and state power authorities), and highest for investor-owned organizations which do not have government-backed securities and preferential tax treatment accorded to investor income.

The fixed charge rate is a number, expressed in decimal or percentage form, which is used to determine the annual fixed costs associated with owning an investment (such as a powergenerating facility). A fixed charge rate includes the cost of capital, which is the dominant component, and provisions for amortization of investments, insurance, taxes, etc. The range of fixed charge rates primarily reflects differing costs of capital and tax treatment; fixed charge rates of $10 \%$ to $19 \%$ may be appropriate, depending on the type of organization, for equipment operating lifetimes on the order of 20 years. For short equipment lifetimes (e.g., 5 years), the fixed charge rate will be higher. . Annual fixed charges are determined by multiplying the capital cost of a facility times the fixed charge rate. The fixed charge rates used in each chapter reflect the probable type of investing organization.

Operation and maintenance costs, also known as $O \& M$ costs, are defined in this report to include all of the costs associated with operating and maintaining a facillty during a year, excluding fuel costs. O\&M costs include labor and materlals used to keep a facility in operation, plus incidental noncápital charges as appropriate. 
that fuel price escalation may make a number of alternative technologies competitive over the next 20 years.

Section 1.6: Indirect Costs and Credits

The following paragraphs discuss varlous credits and Indirect costs associated with distributed energy systems. Representative quantitative results determined in other studies are presented.

A. Heat Recovery

Moet of the electricily-generating technologies discussed in the previous section produce significant quantities of thermal energy. Recent increases in energy costs have caused considerable attention to be focused on the recovery of much of this energy. Modes of recovery include:

- high-pressure process steam

- space heating (direct or via heat pumps)

- heat-actuated air conditioning

- water heating

- bottoming cycles (such as an organic Rankine cycle) for additional electric generation.

These are in addition to certain heat-recovery functions which are standard parts of the basic equipment design (such as preheating of air for gas turbines). The ratios of recoverable thermal energy to the electric energy output, as well as the temperature, vary from one technology to another and are important factors in assessing specific applications. A monetary credit for the recovered heat can be determined by estimating the cost of producing an equivalent amount of heat by other methods. For rough calculations, the principal component of this credit is generally taken to be the fuel savings involved. (Capital costs of alternative heating equipment or of heat-recovery equipment are small by comparison when computed on a life-cycle basis.) If electricity is produced at $33 \%$ efficiency and if it is possible to recover half the waste heat, then for each $\mathrm{kWh}$ of electricity produced one obtains about 3,400 Btu. The cost of producing 3,400 Btu from an efficient. (85\%) boiler using 
fuel ofl at $\$ 2.70 / 10^{6} \mathrm{Btu}$ is $\$ .011$, and thus this credit can be applied to the electricity cost. This is just one example, based on experience with diesels and gas turbines, but heat-recovery credits are also possible for various potential applications of photovoltaic, solar thermal, biomass conversion, fluidized bed combustion, Stirling, and fuel cell systems. The chapters on cogeneration and total energy systems will give more detailed examples.

\section{B. Transmission and Distribution}

The calculation of transmission and distribution credits for distributed energy technologies is very problematic. Some of the work which has been done on this subject is summarized in the next paragraph.

There have been otudies by Rrnnkhaven National Laboratory and by the Bechtel Corporation, among others, concerning the cost of transmission and distribution equipment associated with new central generation capacity. Brookhaven estimates $\$ 75 / \mathrm{kW}$ for transmission and $\$ 140 / \mathrm{kW}$ for distribution, ${ }^{(9)}$ both in 1974 dollars. Bechtel estimates $\$ 69 / \mathrm{kW}$ for transmission and $\$ 420 / \mathrm{kW}$ for distribution, ${ }^{(10)}$ also in 1974 dollars. Obviously such estimates depend on many assumptions, such as user requirements, fraction of lines which are underground, etc. (Some of the ditferences are discussed by Lovins. (3)) However, these details are not important for our purposes. Lovins' approach is to add these figures to central station generating costs as part of the calculation of the cost of marglnal lncieases in delivered electrir power.

Other workers have computed, on the basis of certaln scenarios, the savings in transmission and distribution requirements that might accompany the Implementation of load-leveling batterles as a distributed energy technology. In particular, a study by one utility of the effect of battery installations at distribution substations as a substitute for a total of $500 \mathrm{MW}$ of peaking generators (5\% of total installed capacity) yielded credits of $\$ 61 / \mathrm{kW}$ and $\$ 3 / \mathrm{kW}$ for transmission and distribution savings. (11) This work has been reviewed to incorporate a revised economic basis and possible extrapolation to other situations, but this review has not resulted in substantial modifications to these particular credits. 
One reason why the treatment of these credits is problematic is that there are wide variations in possible configurations for distributed technologies. For systems incorporating a utility back-up, there would be little or no credit available for transmission or distribution. For systems without such a back-up, the resulting savings would vary greatly depending upon installation size, voltage requirements, location, and other factors. Even for an installation in a densely populated area, the introduction of utility power to an institution or complex may necessitate the construction of a separate substation. (For hospitals, sometimes two substations are required by law. (13), A fairly typlcal example is that of a suburban college which was already supplied by utility power and which wanted to extend power to a new sports complex containing an ice rink and tennis courts. To cover the peak load of $560 \mathrm{~kW}$, it would have been necessary to construct a separate substation at a cost of $\$ 45,000$, or roughly $25 \%$ of the capital cost of the independent diesel power supply that was eventually installed.

In a case such as the one just described, where the owner/user is not the electric utility, it is doubtful that incremental changes in the burden on the transmission system or on other sections of the distribution system would have any effect on a user's course of action. The user would generally calculate the life-cycle energy cost by taking this direct substation credit off the capital cost and then comparing the resulting energy cost with the rate offered by the utility. In the case cited, with credits for heat recovery and distribution, the energy cost came to about $\$ .04 / \mathrm{kWh}$, which compared favorably with the (rather high) rate of $\$ .06 / \mathrm{kWh}$ available from the utility.

This example introduces a second reason why a general discussion of transmission and distribution credit is problematic, namely, that the correct credit depends on one's point of view. The user will take a "local" point of view, seeing specific cost comparisons affecting him. This fact is important in estimating the commerclalization potential of many of these technologies. On the other hand, the ut1lity will take a broader point of view, positing a certain level of implementation of decentralized power supply (perhaps installed and owned by the utflity) 
and then calculating the resulting changes in system requirements and costs. At this level, as well as from the viewpolnt of governments, which may be concerned with state, regional, national energy requirements, the full credits for transmission and distribution may indeed be appropriate.

\section{Waste Disposal}

For power systems based in whole or in part on municlpal solid waste, credits may be assigned according to the alternative cost of waste disposal as well as the recovery of recyclable materials. These credits depend on specific circumstances.

\section{Capac1ty DLsplacement}

Solar and wind energy conversion systems have the inherent disadvantage of being dependent on fluctuating sources of energy. While such systems usually contain as an integral part some degree of storage, this is ordinarily sufflcient to cover relatively short periods of negligible input (such as the night-time when there is no solar radiation), but inadequate to cover several days of unfavorable weather conditions. Increasing storage to guarantee reliability at a level comparable to that generally provided by the utility industry is not a cost-effective alternative, except in rare circumstances. The provision of alternative onsite generators is a viable option for some cases. Nevertheless, the option generally considered to be of greatest applicability is a utility connection for back-up power. However, there are serious complications associated with this. It is most economical. for utilities to produce electricity at a steady level. If their load shows significant fluctuations, then enough generating capactty must be built up to cover the highest peaks, but much of this will stand idle during periods of low demand. Thus, the capital expense of the generating equipment must be distributed over a sma'ller energy output, resulting in a higher unit cost of electrical energy. The economics of the situation are such that to meet the steady (baseluad) part of the load, utilitles do best to anvest in capital-intensive generation equipment (e.g., nuclear, coal) whose assoclated fuel costs are relatively low. To meet cyclic and peak demands, 
it is better to use less expensive equipment (e.g., gas turbines), a1though they have higher fuel costs. Elaborate computer programs are used by utilities to determine the optimal mix of new equipment they should add in order to meet expected load increases. This represents a straightforward, albeit complicated, economic optimization problem whose inputs include the desired level of system rellability, the parameters associated with all the different kinds of equipment, the load forecast, and any special constraints relevant to the situation. It is possible to incorporate solar and wind systems into this scheme and to measure the changes in the conventional generation $\mathrm{mix}$ and capacity called for when they are included, although accurate and effictent ways of doing this are only now being developed. (Selected examples follow later in this section.)

Suppose one wants to determine the effect of a total of $100 \mathrm{MW}$ of photovoltaic capacity on a certain system. If the photovoltalc capacity had about the same availability and rellability as conventional equipment, then this 100-MW capacity would be equivalent to $100 \mathrm{MW}$ of conventional equipment for operating purposes, and nne could say that the capacity displacement credit of the photovoltalc systems is $100 \%$. If the photovoltaic capacity were "totally unrellable," then clearly it would not displace any required conventional capacity, and its credit would be $0 \%$. This does not mean that the system would be useless, but only that it requires a total back-up. Its value then would be measured simply in terms of the fuel that would be saved by the back-up system whenever the photovoltaic system was working. (This is called the "fuel saver mode" and represents the least favorable framework within which to evaluate the economic merits of such a system.)

If the photovoltalc capacity had some intermediate level of reliability, then a corresponding capaclty displacement credit could be calculated. This calculation would require the specification of parameters relating to the avallability. of the system, the time correspondence between system dally peak loads and array output, etc. In short, when the optimal generation planning program is run with $100 \mathrm{MW}$ of photovoltalc capacity as a constraint, the amount of conventional capacity will generally be reduced by some amount between 0 and $100 \mathrm{MW}$ over the case 
without the photovoltaic system. Th1s reduction (as a percentage of $100 \mathrm{IfW}$ ) would be the capacity credit. Although it is customary to speak of these credits in terms of power units, in fact the economic significance depends on what kind of unfts they are. It actually turns out that the proportions in the generation mix may be altered, so a comparison of the total costs of the plans must be made to estimate accurately the results in dollars.

Determinations of this type are spectfic to utility service areas, and recently a number of examples of this type have been run. The same kind of calculations are also possible for model utilities and other artiflclal scenarios. Since scenarlo and case studies do not fall within the scope of this phase of the DOE program, only some brief indication of past work will be mentioned. Naturally, the same princlples apply to all the solar technologies.

A study based on data and projections for the Salt River Project (Arizona) (15) calculated a capacity credit of $48 \mathrm{MW}(=48 \%)$ for $100 \mathrm{MW}$ of photovoltaic penetration, and a credit of $65 \mathrm{MW}(=16 \%)$ for $400 \mathrm{MW}$ of penetration. (These levels of penetration represented $1.5 \%$ and $6 \%$, respectively, of total installed capacity.) The point here is that increased dependence on the solar system introduces additional unreliability, which must be compensated for by a larger reserve margin.

A study of solar thermal systems ${ }^{(16)}$ indicated capacity credits anywhere from $8 \%$ to $92 \%$, depending on various system options: Effects on the generation $\mathrm{mix}$ were also given. In general, solar thermal plants would be expected to displace intermediate generation capacity in present real systems, although somc degree of baseload displacement would occur in systems where the generation mix was close to optimal.

Studies of capacity credits appropriate to wind energy conversion systems have concentrated on large wind farms located at carefully chosen and geographically separated sites. In one case, (17) capac1ty credits ranging from $16 \%$ to $29 \%$ were calculated, but the plant sizes made extrapolation to the smaller system scale of the present report impossible. (In particular, twelve 500-MW sites and four 1500-MW sites were the options treated.) The combination of wind untts with conven- 
tional or pumped hydro systems is one way to enhance reliability, but this would generally only be appropriate for rather large instailations.
A report
(19)
and a book
(20)
on solar space conditioning dis-

cuss the fact that these systems may even increase the utility's peak load, while certainly decreasing the load factor. As an example of how this can happen, the authors point out that equipment designed for solar use-(such as an absorption cooling system) can be much less efficient to run in the back-up mode than the conventional equipment that would have been installed otherwise (1.e., compression cycle refrigeration).

Utility customers who require back-up service to support intermittent capacity would generally be assessed an approximation of 1ts additional cost by means of a periodic demand charge, based on the difference between their peak and average demand levels.

Certain other technologies also exhibit some of the character1stics just discussed. These include the following:

- Hydropower. In many areas, rivers and streams run at their lowest levels during the summer (lower precipitation, high evaporation) and winter (water captured as ice). But most utilities have their peak demands during these periods. The result is that the contribution from hydropower services does not reduce by very much the total alternative capacity that must be built (although it may affect the desired generation $\mathrm{mix}$ ).

- Blomass. Certain biomass conversion schemes may have seasonally varying outputs due to fuel availability. When the power produced is primarily intended for and well matched to on-site requirements, then a large capacity credit may be associated with the system. This has been the case with past experience in the sugar industry, where crop wastes are burned to prodyfi, steam and electricity for process needs. (2I) (The processing season may be relatively short, e.g., 70 days in Louistana.) 


\section{E. Reliability and Reserve Margin}

Some discussion of reliability appeared in the previous section, but that was in connection with fluctuating sources of energy. There is, in fact, another aspect of rellability inherent in any configuration of distributed energy systems that feed power into a central network.

To illustrate the basic principle, we consider an extremely simple example. Suppose a constant load of $100 \mathrm{MW}$ is to be met by a utility, one of whose power supplies is a 100-MW central station with an outage rate ${ }^{*}$ of $10 \%$. If the reliability constraint on the system requires, that the load be met at least $99 \%$ of the time, then complete redundancy must be built in to cover most of the time that the central station is down. Another central station of $100 \mathrm{MW}$ with the same ava11ability factor would be sufficient, for at least one of the units would be available all but . $1 \times .1=.01=1 \%$ of the time. In this case, one refers to the extra $100 \mathrm{MW}$ as the "reserve margin." As a percentage of the $10 a d$, it is $100 \%$ in this case. Obviously, it is undesirable to have to maintain such a large reserve margin. For a given level of system reliability, a smaller reserve margin would mean lower capital requirements.

To see how this may come about, suppose that the 100-MW load were to be met by a utilfty having one-hundred 1-MW generacors feeding in power, as might be the case in a more distributed system, and suppose that each of these also has an outage rate of $10 \%$ and that these outages are independent of each other. (Thus, we are discussing effects of 'mechanical' rellability, rather than outages due to weather effects, which would generally be highly correlated for sun and wind machines.) From a probabilistic standpoint, it is quite unlikely that all 100 generators would be down simultaneously (prob $=(.1)^{100}=10^{-100}$ ); in fact, it is quite unlikely that the number that will be down at any time will differ very much from 10. Straightforward statistical calculations show that

* Outage time generally includes several categories, principally forced outages and scheduled maintenance. The distinction is not important for the present illustration. 
supplementing the system with 20 more similar 1-MW units will satisfy the overall reliability constraint. In this case then, a reserve margin of $20 \mathrm{MW}$ or $20 \%$ is sufficient. The source of the advantage here is that a large number of independent generators behave in aggregate much closer to the predicted statistical mean, and fewer large deviations need to be protected against. (This same factor implies that loss of load, during that small fraction of time when it does occur, may be expected to be much less in the case of a large number of independent generators.)

The factor illustrated here will play a role in the calculatiun of the optimal generation mix for a particular system. Obviously, the example given of a $100 \%$ reserve margin was exaggerated to make the point, but even an effect of a few percentage points on the size of the reserve margin would have significant economic implications for a utility. The technologies most likely to contribute to this effect are those which have high availability and which can provide power to the utility network from a number of decentralized locations. Prime candldates include fuel cells, run-of-river hydro-plants, gas turbines, and, in certain circumstances, industrial cogeneration plants (22) with surplus electricity.

\section{F. Utility Interface}

In previous sections, as well as in the individual technology chapters, reference has been made to several possible relationships between a decentralized energy source and the central utility network. It may be useful to summarize them here.

Independent Systems. A number of applications are viable without any connection to the utility. These range from isolated wind-powered irrigation systems to total energy systems at the community level. Almost all such applications need to incorporate some reserve capacity, which may be in the form of storage, alternative generators, or some combination. 
One-Way Systems. These are systems which can only 1mport power along their utility connection. Economic penalties Include the cost of installing the utility connection (which may include one or more substations) and a high demand charge. If the on-site generator or storage system produces direct current, then inversion equipment will be necessary for many applications. Selfcommutated inverters tend to be quite expensive (see Table 2-3), while line-commutated inverters may constitute a substantial reactive load for the utility. ${ }^{*}$ If storage is part of the on-site system, then 1 t may also be possible to use it in a load management mode, so as to lcesen the pnnr load factor effect on the utility. Another option presently being investigated by some utilities is the provision of such backup power on an interruptible basis, which would also lessen the capacity requirements on the utility.

Two-Way Systems. Systems in which energy can be exported from a decentralized energy source to the uttlity have additional problems, among them the following:

- Power may only be available when it is not very useful to the utility, such as during the night when operations at a cogenerating plant are at a lower level.

- Legal requirements concerning the price to be pald by the utility for this power may be disadvantageous economically. For example, simply running the electric meter in reverse (thereby using the standard customer rate) falls to account for the utility's cost of providing back-up capacity. In addition, this rate may be more than it costs the utility to generate off-peak power 1tself. Experiments involving such two-way systems have been begun by a number of utilities, (23) but they are expected to be slow to encourage this option.

* There are programs sponsored by DOE and EPRI to develop more efficient and economical self-commutated inverters. 
- Utilities want to be sure to have control over what enters their power lines, both for the safety of their workers and the security of their system (e.g., stability). While controls have been well tested on cogenerating industrial plants feeding the electrical network, a large number, of quite small systems (e.g.,' residential photovoltaic arrays) might be more difficult to deal with.

Distributed Utility Generators. Some distributed generators would actually be part of the utility system. For example, these might be fuel cells installed relatively close to the load or even on-site cogeneration plants owned and operated by the utility.

Section 1.7: Conclusions

All of the distributed energy technologies discussed in this report represent potentially viable options for contributing to the country's needs, although the residential burning of coal is not expected to show much additional promise. Even machines which have traditionally been wasteful of prime fuels (diesels, gas turbines) are expected to have an important role in our energy development, this because of increased emphasis on cogeneration and because of the potential for coal-derived fuels. The economics of various systems are very much in doubt because further technological development is necessary in order to evaluate them properly. For a recent economically oriented analysis of America's energy future, the reader is referred to the Ford Foundation Study, Energy: The Next Twenty Years. (24) Two other widely' publicized recent books, Energy in America's Future, The Choices Before Us ${ }^{(25)}$ (a study prepared for the Resources for the future National Energy Strategies Project) and Energy Future ${ }^{(26)}$ (Report of the Energy Project at the Harvard Business School), also deal with distributed energy systems within the larger context of long-term energy options. With previously cited references they present a spectrum of views and analytic approaches to the larger problem whose technologies are addressed in this report. For example, Stirling engines, which might 
compete directly with. Diesel engines, but have wider fuel options, have not even been built in the sizes envisioned. The development of much less expensive photovoltaic arrays awaits major technical improvements. Even the technology of windpower, which is relatively old, shows interesting new developments that are not well tested (e.g., vertical axis machines). And basic to the success of many of these technologies are hoped-for improvements in energy storage. 


\section{REFERENCES}

1. Schumacher, E.F. Small is Beautiful. New York: Harper and Row, 1973.

2. Lovins, A.B. "Energy Strategy: The Road Not Taken?" Foreign Affairs, October 1976. pp. $65 \mathrm{ff}$.

3. Lovins, A.B. Soft Energy Paths: Toward a Durable Peace. Cambridge, Massachusetts: Ballinger Publishing Company, 1977.

4. Commoner, B. The Poverty of Power. New York: Alfred A. Knopf, 1976.

5. Perry, H., et al. Multiple Paths for Ellergy Pollcy, A Uritique of Lovins' Energy Strategy. New York: National Economic Research Associates, 1977.

6. Yulish, C.B. Soft v.s. Hard Energy Paths: 10 Critical Essays on Amory Lovins' "Energy Strategy: The Road Not Taken?". New York: Charles Yulish Associates, 1977.

7. Craig, P., et al. Distributed Energy Systems in California's Future. Interim Report. Prepared under Contract No. W-7405-ENG-48 by Lawrence Berkeley Laboratory/Lawrence Livermore Laboratory for U.S. Department of Energy, March 1978. NTIS Report No. HCP P7405-01/02.

8. "How Energy Costs Vary." Business Week, April 10, 1978. p. 44H.

9. Beller, M. Sourcebook for Energy Assessment. Prepared by Brookhaven National Laboratory. December 1975. NTIS Report No. BNL-50483.

10. Carasso, M., et al. The Energy Supply Planning Model. Reports prepared by Bechtel Corporation tor National Science Foundation, August 1975. NTIS Report Nos. PB245 382 and PB245 383.

11. Public Service Electric and Gas Company. Economic Assessment of the Utilization of Lead Acid Batteries in Electric Utility Systems. Report to Energy Research and Development Administration, November 1977. NTIS Report No. HCP/T2857-1.

12. METREK Division of MITRE Corporation. Lead Acid Battery: An Evaluation of Commercialization Strategies. Report to Energy Research and Development Administration, November 1977. NTIS Report No. MTR -7592 .

13. New England Memorial Hospital, Stoneham, Massachusetts. Private correspondence with the Plant Supervisor, 1978.

14. Cummins Engine Company, Inc., Dedham, Massachusetts. Cogeneration Feasibility Study for Babson College, Wellesley, Massachusetts, 1976. 


\section{REFERENCES (continued)}

15. Chowaniec, C.R., et al. "A Reliability Assessment Technique for Generating Systems with Photovoltaic Power Plants." Energy Development IV. IEEE Power Engineering Soclety, 1978. pp. $137 \mathrm{ff}$. Publication 78TH0050-5-PWR.

16. Ballance, J.W., et al. "Integration of Solar Generation into Electric Utility Systems." Energy Development IV. IEEE Power Engineering Society, 1978. pp. $6 \mathrm{ff}$. Publication 78TH0050-5-PWR.

17. General Electric Company. Wind Energy Mission Analysis. Report to Energy Research and Development Administration, February 1977. NTIS Report No. C00/2578-1/2.

18. Todd, C.J., et al. Cost Effect1ve Electric Power Generation from the Wind. Bureau of Reclamation, Denver, Colorado, 1977. NTIS Report No. PB273 582.

19. Feldman, S.L., et al. "The Effect of Solar Buildings on Peak Load." Electrical World 191(6): 150, March 15, 1978.

20. Feldman, S.L., et a1. The Economics of Solar Energy: The Public Ueility Interface. (In preparation).

21. Lipinsky, E.S. "Fuels from Sugarcane and Corn." Energy' Development IV. IEEE Power Engineering Society, 1978. pp. 39 ff. Pub11cation 78TH0050-5-PWR

22. Solt, S.M. "Cogeneration Becoming More Attractive." Electrical World 191(6): 119, March 15, 1978.

23. Yamagiwa, A., et al. "Experimental Evaluation of a Solar/WindPowered Space Heating and Hot Water Heating System in the Pactfic Northwest." Proceedings of the Twelfth Intersociety Energy Conversion Engineering Conference, Washington, D.C., August 28 September 2, 1977. pp. $1243 \mathrm{ff}$.

24. Landsberg, J.J., et a1. Energy: The Next Twenty Years. Cambridge, Massachusetts: Ballinger Publishing Company, 1979.

25. Schurr, S.H., et al. Energy in America's Future, The Chotces Before Us. Baltimore, Maryland: The Johns Hopkins University Press, 1979.

26. Stobaugh, R. and Yergin, D., eds. Energy Future. New York, New York: Random House, 1979. 


\section{SUPPLEMENTARY BIBLIOGRAPHY}

1. General Electric Company. Requirements Assessment of Photovoltalc Power Plants in Electric Utility Systems. Prepared for Electric Power Research Institute, June 1978. EPRI Report No. EPRI ER-685-SY.

2. Pittman, P.F. Conceptual Design and Systems Analysis of Photovolta1c Power Systems. Prepared by Westinghouse Electric Corporation for U.S. Department of Energy, April 1977. NTIS Report No. AL0-2744-13.

3. Southern California Edison Co. Integration of Solar Thermal Power Plants Into Electric Utility Systems. Vols. 1 and 2. Prepared for U.S. Energy Research and Development Administration, September 1976. NTIS Report Nos. TID $27627 / 1$ and TID 27627/2.

4. Aerospace Corporation. Penetration Analysis and Margin Requirements Associated with Large-Scale Utilization of Solar Power Plants. Prepared for Electric Power Research Institute, August 1976. EPRI Report No. EPRI ER-198. (NTIS Report No. PB 257 546).

5. Aerospace Corporation. SHACOB: Requirements Definition and Impact Analysis. Prepared for Electric Power Research Institute, June 1978. EPRI Report No. EPRI ER-808.

6. Nathanson, D., et al. "Solar Heating and Cooling: An Electric Utility Perspective." Energy Technology 5: Challenge to Technology, Proceedings of the 5 th Energy Technology Conference, Washington, D.C., February 27 - March 1, 1978. Washington, D.C.: Government Institutes, Inc., April 1978.

7. Nathanson, D., et al. "Preferred Residentlal Solar Heating and Cooling Systems Compatible with Electric Utility Operation." Proceedings of the 1977 Meeting of the International Solar Energy Society. Parkville, Victorla, Australia, June 1977.

8. Marsh, W.D. "Utility Applications of Wind Power Plants." Energy Technology 5: Challenge to Technology, Proceedings of the 5th Energy Technology Conference, Washington, D.C., February 27 - March 1, 1978. Washington, D.C.: Government Institutes, Inc., April 1978. pp. 83 ff.

9. Feldman, S.L. et al. Public Utility and Solar Energy Interface: An Assessment of Policy Options. Flnal Report. Prepared by Clark University and Total Environmental Action, Inc. for U.S. Energy Research and Development Administration, December 1976. NTIS Report No. DSE/ 2523-2. 


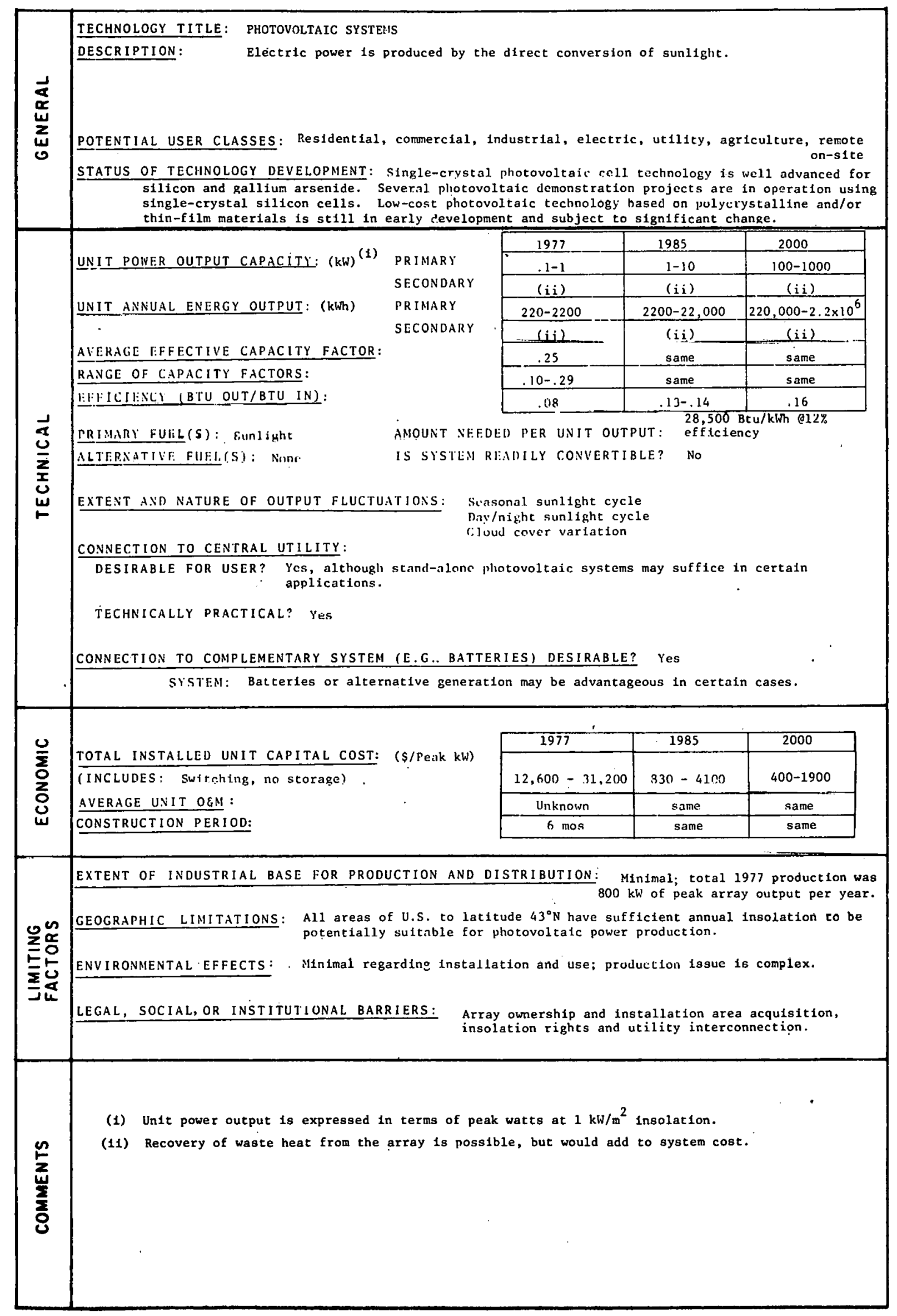


CHAPTER 2

PHOTOVOLTAIC SYSTEMS

Section 2.1: Introduction

A photovoltaic converter produces direct current electrical power from sunlight by a physical process which does not require the use of a heat engine. The electrical power available is directly proportional to the total solar flux intercepted by the photovoltalc array and is, therefore, proportional to the land surface occupied by the 11ght-collecting elements of the array. All presently envisioned photovoltaic array designs are modular in concept, with the basic array elements quite small, i.e., a few $\mathrm{cm}^{2}$ to a few $\mathrm{m}^{2}$. In general, the photovoltaic array must be Interfaced with its load via a power conditioner, and other elements of the photovoltaic distributed energy system (PV-DES) may include a utility tie line and energy storage, e.g., batterles.

Because the technology of photovoltaic devices and systems is st11l rapidly evolving, predictions of the future design, performance, energy and dollar cost cannot be made with certainty. However, it does appear that the PV-DES w11l offer considerable flexibility in application and may be of value to a wide range of industrial, agricultural, commercial, and residential power consumers.

\section{Section 2.2: Technical Discussion}

A. The Photovoltaic Converter

Photovoltaic converters are semiconductor devices in which electrical energy is produced from photons of light by a two-step process: $(1,2)$

1. The photon is absorbed by the semiconductor and its energy utilized in the production of an electronhole pair.

2. The electrical charges are separated at a potential barrier within or at the surface of the semiconductor and made avallable for work in an external load. 
Although the quantum process of electron-hole pair production is nearly $100 \%$ efficient for photons of energy greater than the semiconductor bandgap energy, there is considerable energy loss because only that portion of the photon energy equal to the semiconductor bandgap energy is potentlally recoverable. Photons with energy less than the bandgap energy do not produce charge pairs, and photons with energy in excess of bandgap energy have their surplus energy converted into heat. For a given spectral distribution of solar irradiance, there is an optimum converter bandgap. Figure 2-1, which is patterned after the presentation of Prince, (3) shows the theoretical efficlency, $n$, vs. bandgap curve for Air Mass Zero (AMn) i.1.umination; that is, the insolation available outside the atmosphere. The bandyap jositions of varioue candidate photnunltaic semiconductors are noted.

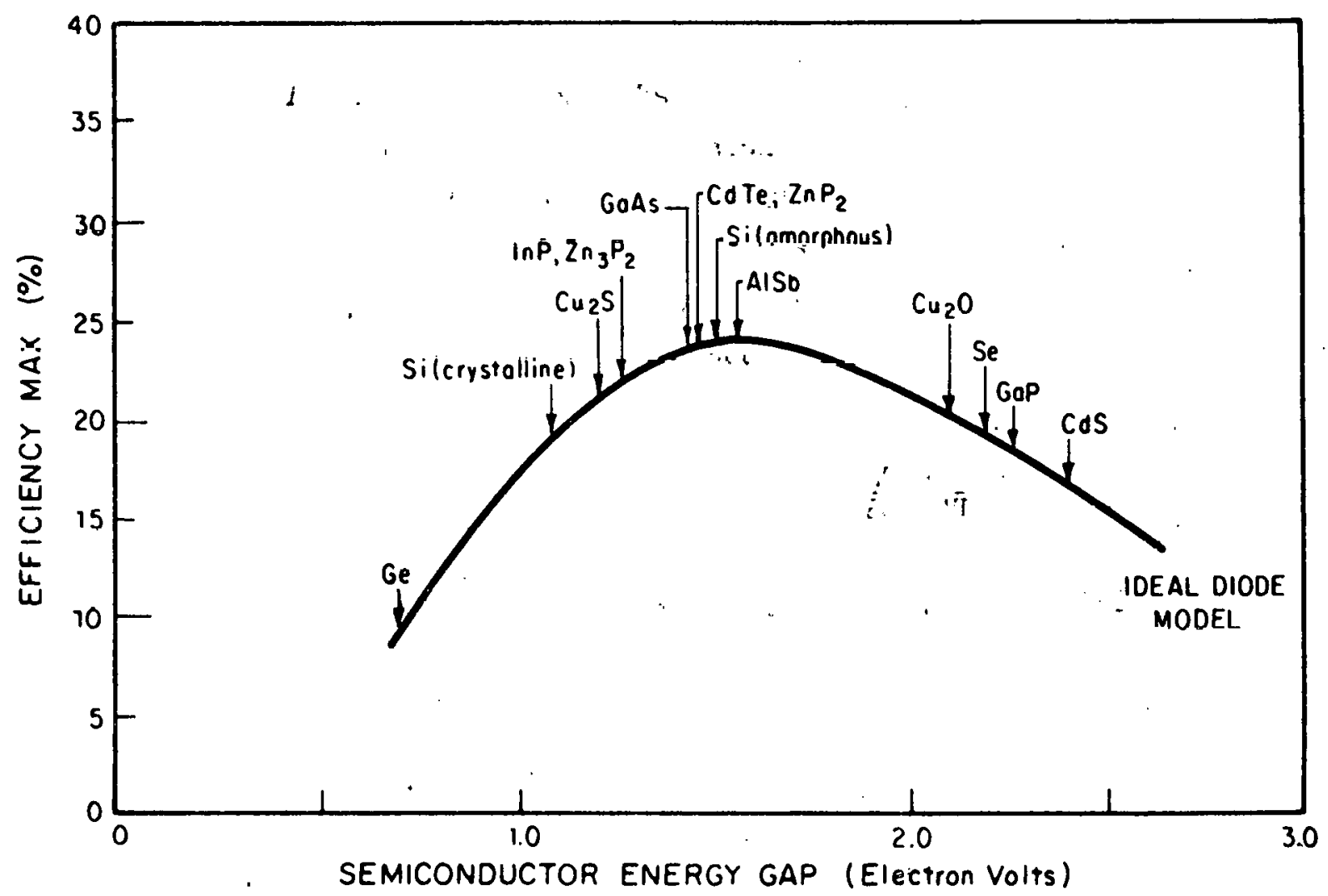

SOURCF: Adapted from Reforence 3.

FIGURF. 2-1 THEORETICAL EFFICIENCY OF PHOTOVOLTAIC MATERIALS 
The efficiencies presented in Figure 2-1 are based upon $100 \%$ efficient electron-hole pair production and charge collection for all photons of energy greater than the bandgap energy and ideal diode behavior of the semiconductor junction. Losses due to shunt and series resistance in the photovoltaic cell are also neglected. Nevertheless, efficiencies within a few percent of the theoretical values have been demonstrated for singlecrystal silicon ( $\mathrm{Si}$ ) and gallium arsenide (GaAs) photovoltaic cells.

Although photovoltaic semiconductors may be utilized in novel ways, such as for thermophotovoltaic conversion ${ }^{(4)}$ or in edge-illuminated (5) or multiple-junction, graded-bandgap devices, ${ }^{(6)}$ the most 1ikely technology for the 1977-2000 period is the single-potential barrier cell utilizing illumination normal to the junction.

Table 2-1 summarizes the range of array efficiencies likely to be achieved in the 1985-2000 time period for those photovoltaic materials now receiving the greatest attention. Air Mass One (AM1) illumination, i.e., clear day, sun directly overhead, and no concentration of the sun11ght, is assumed. The references 1dentifled provide a technical review of the candidate materials of "The array efficiencies are Arthur D. Little, Inc., estimates and allow for optical 1osses. within the array which may range from as little as $2 \%$ for a planar array to as high as $20 \%$ for a concentrating array employing supplemental protective covers.

TABLE 2-1

THE THEORETICAL AND PROJECTED ARRAY EFFICIENCIES OF SELECTED PHOTOVOLTAIC MATERIALS

Theoretical

Material

Silicon-crystalline Silicon-amorphous Gallium arsenide Cadmium sulfide
Efficiency (\%)

22

$15(1)$

24

17
Array

Efficiency (\%) Reference

10-14

$7-11$

$12-16$

7-11
7

8

9

10

(1) The difference between this efficiency and that shown in Figure 2-1 is the result of excessive losses because of the amorphous structure.

Single-crystal silicon has been the preferred photovoltaic material for more than a decade. Its theory, technology, and application are well developed, and a high degree of confidence exists that the projected 
array efficlency of $10-14 \%$ given in Table 2-1 will be realized.

The major thrust of present single-crystal, silicon-solar-cell development is to reduce material preparation cost. Several novel crystal-growing methods are being developed. The objective is to grow ready-to-use material in strip form so that the conventional process of sawing and polishing wafers from bulk single-crystal material can be replaced.

Cast polycrystalline silicon is also being investigated,

and though this material has the same theoretical efficiency as singlecrystal silicon, the presence of grain boundaries gives rise to additional losses and a lower realizable efflciency. Moet Intereating of the castIng techniques are those which produce sheet material of 50-100 $\mu \mathrm{m}$, a thickness which provides essentially total optical absorption of the AMl spectrum in a ready-to-use substrate. However, for good current collection efficiency, such material must have grains which extend completely through the sheet and are several sheet thicknesses in diameter. So far, such material is not being reliably produced and post-casting treatments are being Investigated to improve grain size, including laser and electron-beam-pulse melting followed by rapid recrystallization.

Another approach to a thin-film silicon photovoltaic cell involves the use of hydrogenated amorphous silicon. I'his material is prepared by establishing a glow discharge in silane, $\mathrm{SiH}_{4}$, and recombining the atomic components of the dissociated gas on a substrate placed near the discharge. If substrate temperature is controlled, a specific amount of hydrogen can be incorporated into the amorphous film. The result is a reduction in the amorphous silicon defect density and an adjustment in the bandgap energy. Material prepared by the discharge method has a very high optical absorption coefficient for photons of energy in excess of the bandgap value, and only 1- $\mu \mathrm{m}$-thick films are needed to provide nearly complete photon absorption. In addition, the higher bandgap energy of amorphous silicon promises less efficiency decline with increased operating temperature than occurs with crystalline silicon. To date, however, the highest efficiency demonstrated in an amorphous silicon photovoltaic device at AMl 1llumination is less than $6 \%$ ( ${ }^{(8)}$ With some confidence, an efficiency of $7-8 \%$ can be projected, but additional, fundamental discovery will be required to reach the 
$11 \%$ array efficiency cited in Table 2-1.

Gallium arsenide, GaAs, is a nearly ideal photovoltaic material in terms of its excellent energy bandgap match, 1.43 electron volts, to AMl sunlight and its high optical absorption coefficient above the threshold wavelength. Devices of about $23 \%^{(9)}$ conversion efficiency at AMl have been produced, and the ability of this material to work at a higher temperature than silicon or cadmium sulfide-copper sulfide (CdS- $\mathrm{Cu}_{2} \mathrm{~S}$ ) has favored its application in high-concentration systems. As with crystalline silicon, GaAs photovoltaic devices are well understood and the projected array efficiency of $12-16 \%$ given in Table 2-1 is well supported.

Thin-film polycrystalline GaAs films have been grown by vapor deposition on a variety of substrates, but the performance of $p-n$ junction photovoltaic devices using this material has been compromised by excessive grain-boundary diffusion of the dopants used for junction formation. Schottky barrier polycrystalline GaAs cells have been made with an efficiency of about $5 \%$.

The CdS- $\mathrm{Cu}_{2} \mathrm{~S}$ system has been widely studied since its photovoltaic properties were discovered in 1954 . The interest in this system has been sustained by the promise of at least two low-cost manufacturing technologies suited to very large-scale production and by the hope that further research would overcome the early problems of modest efficiency, 5-6\% for typical production cells, and poor life except under carefully controlled environmental conditions. To date an efficlency of $9.15 \%(12)$ has been achieved in the laboratory for CdS-Cu $2 S$ photovoltaic cells, and a projection to $10 \%$ device efficiency for this material is well founded. The higher efficiency required to yield an array value of $11 \%$ is based on the cited development of the [CdZn]S-Cu${ }_{2} S$ ce11, where the incorporation of the zinc is intended to give a better electron affinity and lattice match across the junction. However, preliminary experimental results with this system have indicated difficult development ahead, and the array efficiency may be limited to the middle of the profected range. 
For a long life and reliable operation, all photovoltaic cells require some form of protective covering. Aside from protection against dirt and moisture, the active region of the cells must be kept free from contact with various atmospheric pollutants which can migrate through the semiconductor and deteriorate performance. Some solar cells such as CdS- $\mathrm{Cu}_{2}$ S are particularly dependent on a glass-face $\bar{d}$, hermetic enclosure for a useful life, but, even for silicon and gallium arsenide, it is not clear that anything less than this type of completely hermetic encapsulation will provide the 10- to 20-year cell life desired.

\section{B. System Options}

Figure 2-2 shows a generalized diagram of a solar photovoltalc power plant, including provisions for a utility tie line over which power may be extracted or transmitted, depending on the requirements of the local load and the local photovoltaic power generation. Individual installations, particularly in the $10-\mathrm{kW}$ peak to $100-\mathrm{kW}$ peak range, are likely to be less complex than the system shown and may contain as little as a solar cell panel, the DC switchgear, and a DC load. Addition of the $\mathrm{DC} / \mathrm{AC}$ inverter to this basic system would permit AC loads to be serviced. The addition of batteries and the charging regulator would increase the power plant utilizalion factor. The further addition of the $\mathrm{AC}$ switchgear and the $\mathrm{AC} / \mathrm{DC}$ converter would permit the utility tieline connection, and, finally, concentrators and/or cell heat exchangers could be added for cost or performance reasons.

The first major component of the system is the photovoltalc array itself, which may be a directly illuminated flat panel, or it may incorporate a concentrator. Unlike the solar thermal converter, there is relatively little direct performance benefit to operating photovoltaic materials at very high intensity levels, ${ }^{(13)}$ and the princlpal reasons for considering concentration in a photovoltaic system are economic. At present, the per-unit-area cost of reflectors (or refractive lenses) is 5-15 times lower than the unit-area cost of crystalline silicon photovoltaic 


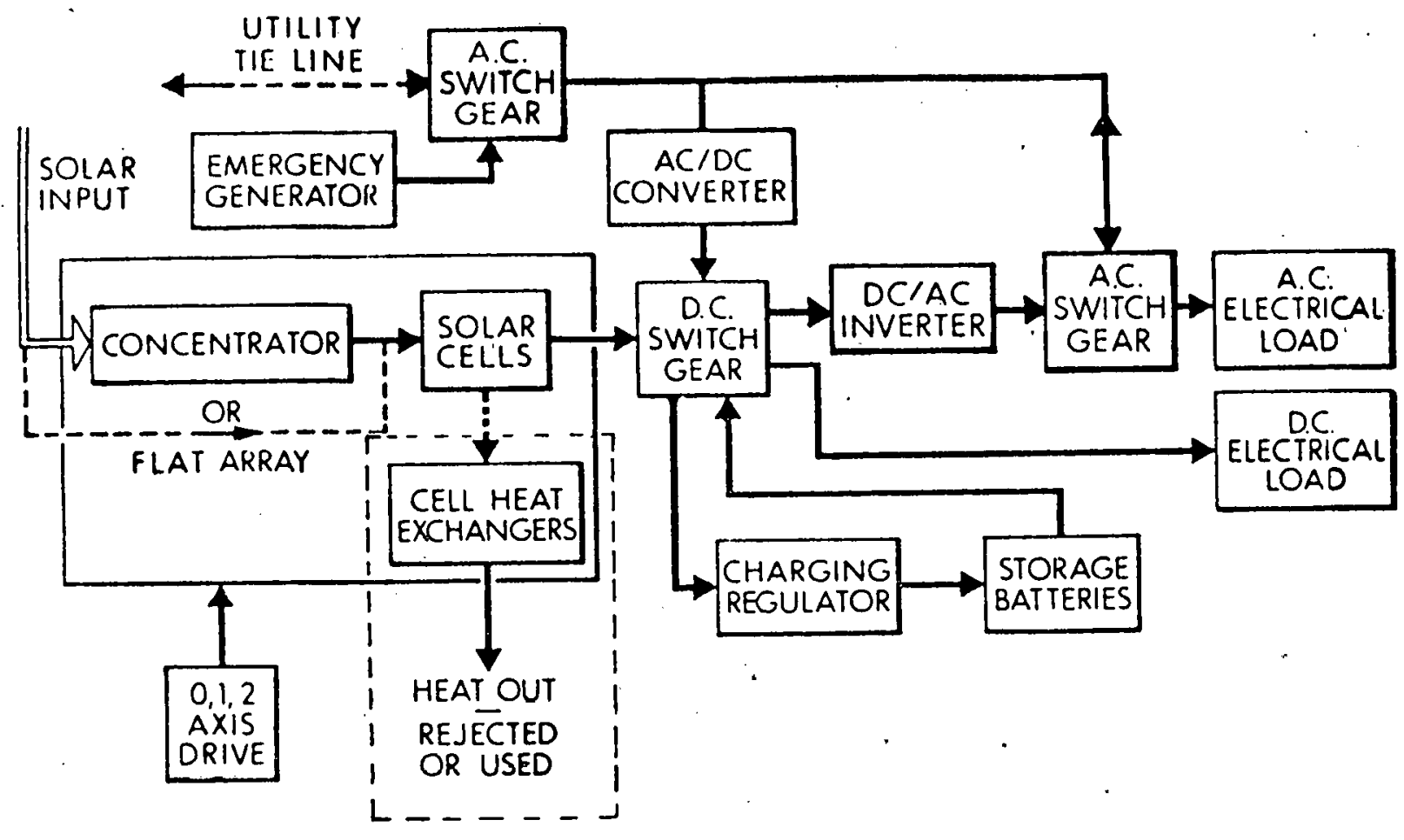

SOURCE: Reference 14.

FIGURE 2-2 SOLAR PHOTOVOLTAIC POWER PLANT SCHEMATIC. 
cells. Therefore, the cost of a photovoltalc panel can be greatly reduced if expensive photovoltaic cell area is replaced by relatively inexpensive reflector (or lens) area capable of concentrating solar radiation. Clearly this advantage of concentration will be diminished as the cost of photovoltaic cells is reduced and will vanish entirely when cell cost becomes roughly equivalent to that of reflectors on a per-square-foot basis.

An additional reason for considering concentration is that it may make feasible the use of very high efficiency (20-40\%) photovoltalc cells, which may be extremely expensive on a unit-area basis, and/or which may be fabricated from material of limited availability. Some of the mult1ple-junction III-V* compound photovoltair cells now in development might fall into this category. The use of such high-efflciency material could dramatically reduce the collecting aperture for a given system-power level, and thereby provide a more attractive system option from both environmental and cost viewpoints.

Concentrators applicable to photovoltaic arrays range from simple flat reflectors to refractive Fresnel lenses and Cassegrain optical systems. (See Chapter 3 for more detall on concentrating optics.) The type of concentrator selected will be largely dependent upon the level of concentration desired. The flat-plate or passive reflector will provide concentration ratios up to $2 \mathrm{X}$. Compound parabolic concentrators are best suited for concentration ratios in the $2 \mathrm{X}-10 \mathrm{X}$ range. Linear concentrators, such as parabolic troughs, are appropriate for concentration ratios in the $10 \mathrm{X}-40 \mathrm{X}$ range. For concentration levels greater than $40 \mathrm{X}$, point-focus systems are being developed.

The use of concentrators and the resultant increase in solar cell Irradiance requires careful thermal design to limit the solar-cell operating temperature. Liquid cooling is generally used above $2 \mathrm{x}$, and there may be an opportunity to apply the warm water to local heating needs. With silicon cells, the maximum water temperature would be 1 imited to about $50^{\circ} \mathrm{C}$. With a higher bandgap material such as GaAs, the water temperature could be allowed to rise to $85-90^{\circ} \mathrm{C}$.

*These are compounds formed from elements of the third and fifth columns in the periodic table. 
The second essential component of the photovoltalc system, the DC switchgear, has two functions. First, it must allow selection of load alternatives, e.g., storage, load usage, or transmission via utillty tie line; and second, it must optimize the power transfer from the array to the load by continually adjusting the array interconnections so that an impedance match is maintained. In view of the variations in 11lumination intensity over the array, and from one location on the array to another under scattered clouds, the DC switching function is extremely important in achleving good array performance.

DC-to-AC inversion will be required for most local loads, since the majority of electrical equipment now in use has been designed for AC operation.

The AC switchgear will function primarily to direct power from or to the utility tie line, if one is used, to balance the AC load requirements against the power which is locally produced.

The contribution of energy storage to the operational value of PV power systems has been considered in several studies, $(15,16,17)$ and the economic benefit of such storage has been found to be very sensitive to the rate structure and power sell-back opportunities associated with the local utility grid. Battery life is also an important consideration. Without time-of-day pricing, no sell-back of excess PV power, and a 10-year battery 1ife, the value of storage was found to be less than $\$ 20 / \mathrm{kWh}$ (1977 dollars). (15) A time-of-day rate variation of $3: 1$, a sell-back ratio of 0.5 , and an assumed battery life of 20 years were found to justify storage costs in the range of $\$ 100-\$ 150 / \mathrm{kWh}(1979$ dollars). (17)

The optimum size of the PV array for a given user is also strongly influenced by the availability of storage.

Figure 2-3, which has been taken from the General Electric study, (15) shows the effect of array size and energy storage (in this example, battery storage) on the PV displacement of central station power for three selective locations. It is readily evident that the addition of moderate amounts of such storage, about six hours of peak 


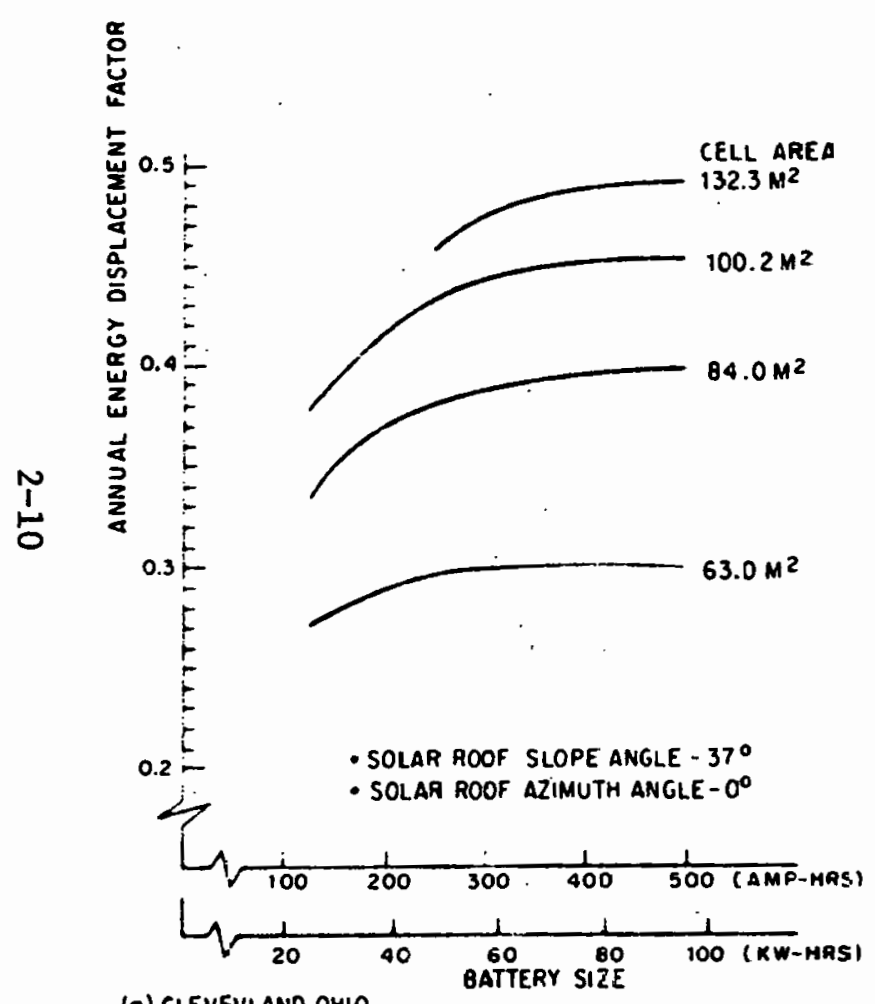

(a) CLEVEVLANO,OHIO

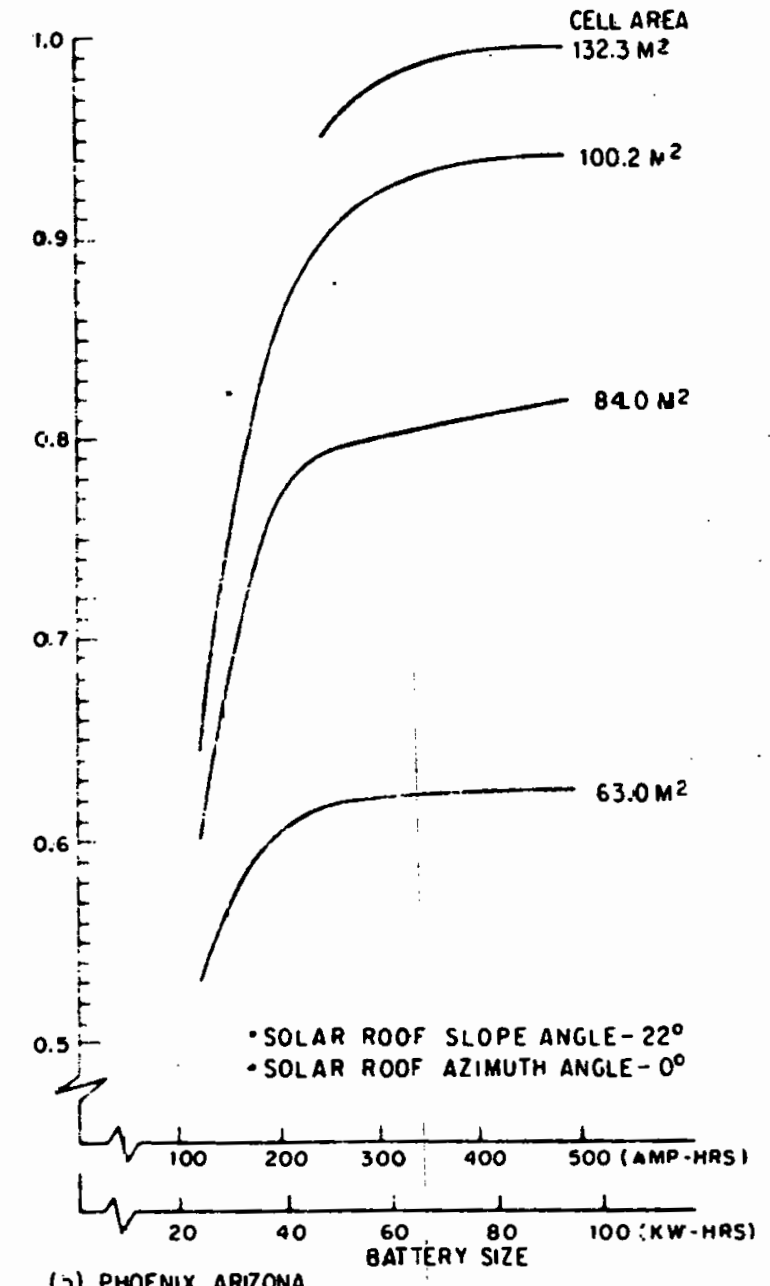

(j) PMOENIX, ARIZONA

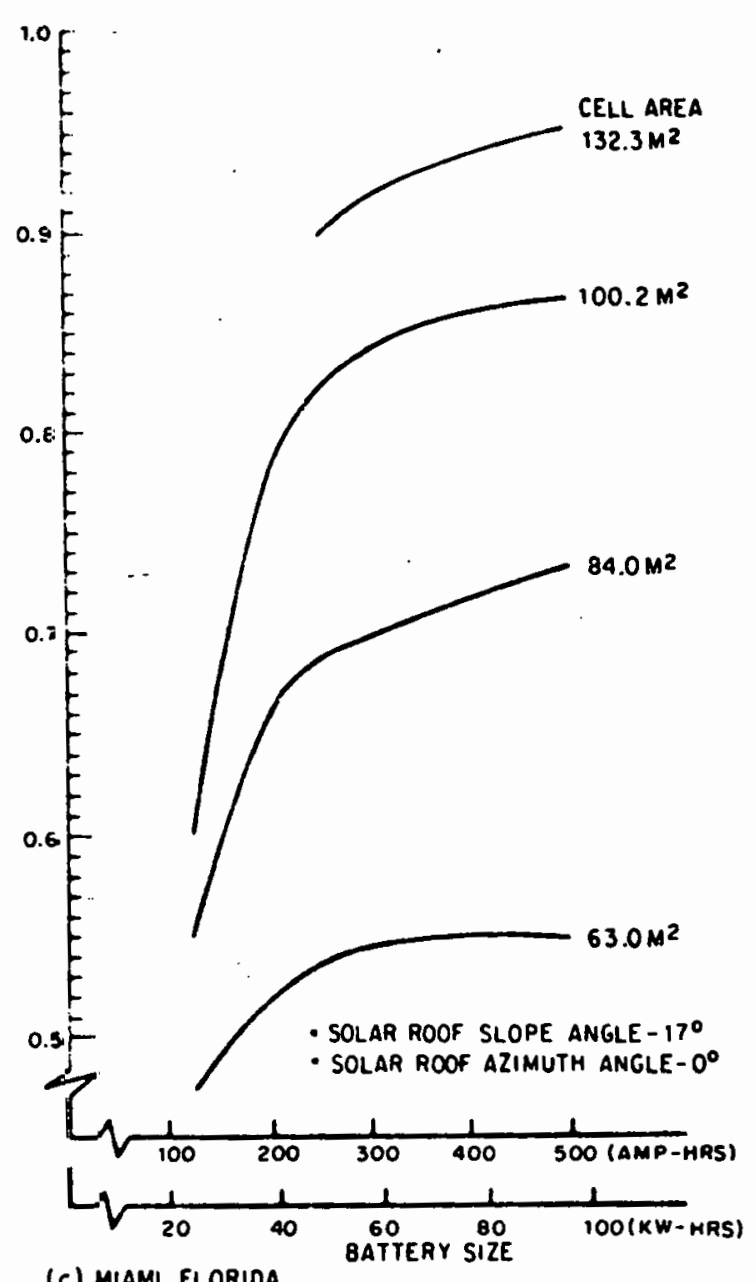

(c) MIAMI, FLORIOA

SOURCE: Reference 15.

FIGURE 2-3 PERFORMANCE SENSITIVITY TO ARRAY AND BATTERY SIZE 
array output, would provide significant additional displacement of central station power. Where storage is economically justifiable (based on the consideration given above), its use increases the optimum size of the PV array.

Section 2.3: Economics Discussion

A. The Photovoltalc Array

Because the technology of photovoltaic material and array production is still rapidly evolving, the ultimate costs of manufacture are difficult to project. The driving force for the present broad-range cost reduction effort in photovoltaics is the DOE Photovoltaic Conversion Program. (18)

National Photovoltalc Program Plan (February 3, 1978) and include photovoltalc array price targets of $\$ 2000 /$ peak $\mathrm{kW}$ by 1982 , $\$ 500 /$ peak $\mathrm{kW}$ by 1986, and \$100-300/peak kW by 1990. These targets are given in 1975 dollars. All subsequent costs will be given in 1977 dollars, where one 1975 düllar $=1.121977$ dúllars.

Of the several estimates of future PV array prices $(19,20,21)$ : for those photovoltaic materials identified in Table 2-1, the more optimistic involve extremely large extrapolations from present manufacturing costs and require fundamental technical and manufacturing advances in order to be realized. Table 2-2 11lustrates the range of PV price estimates which must be considered at this time. The upper price limft is set by assuming that single-crystal silicon remains the dominant PV material and that only modest production efficlency gains and the use of concentrators are employed to reduce prices. The lower price 1imit, on the other hand, could be realized by a breakthrough in thin-f1lm cells, In which case, the simple planar array would be favored. For comparison, the DOE price targets are also given in Table 2-2, expressed now in terms of 1977 dollars. These targets are seen to be close to the most optimistic price projections. 
TABLE 2-2

PHOTOVOLTAIC ARRAY PRICE PROJECTIONS (1) IN 1977 (S/Peak kW)

$$
1977 \quad \underline{1982} \quad \underline{1985} \quad \underline{1986} \quad \underline{1990} \quad \underline{2000}
$$

\begin{tabular}{|c|c|c|c|}
\hline Upper & 20,000 & 3,000 & 1,000 \\
\hline Lower & 12,000 & 500 & 100 \\
\hline
\end{tabular}

DOE Targets ..... $\quad 2,240 \quad 560 \quad 112-336$

(1) Note that no allowance has been included for space cost or supporting structure. SOURCE: References 18, 19, 20, 21, and Arthur D. Little, Inc.

B. Balance of the Photovoltaic System

Unlike the technology of the photovoltalc array, the technology. required for switching and conditioning the power produced by the array 18 well established, and prices may be estimated accurately from aval1able production components. Table 2-3 provides a summary of such costs. The price ranges indicated depend principally on the scale of the installation with the lower figure appropriate to equipment of $100 \mathrm{~kW}$ and larger, and the higher figure applicable to equipment of $10 \mathrm{~kW}$ or small-. er. For these estimates, it 18 assumed that:

- the local load 1s primarily for AC power;

- a utilfy tie line is avallable to supply power in excess of the photovoltalc capab111ty; and

- a good power factor 1s presented to the utility tie lines.

Increased production volume 18 projected to reduce the above prices by about $20 \%$ for the year 2000 . Table 2-4 provides a summary of the capital cost projections for the PV-DES without storage. The addItion of storage equal to $81 x$ hours of peak array output would add $\$ 500-$ $\$ 800 / \mathrm{kW}$ to the estimates, thus improving energy avallablilty at higher cost and lower overall system efficiency. 
TABLE 2-3

POWER CONDITIONING AND SWITCHING COSTS 1977 (\$/Peak kW) DC Array Switching (1)

AC Switching (2) $100-150$

$\mathrm{DC} / \mathrm{AC}$ Inversion

- Line Commutated $(3)$

- Self-Commutated ${ }^{(4)}$

$30-50$

$100-200$

$200-500$

(1) To optimize power transfer to load

(2) Utility/local load/PV power interface.

(3) Residential units under $10 \mathrm{~kW}$.

(4) Required for stand-alone systems or where utility tie line cannot supply switching current.

SOURCE: Arthur D. Little, Inc., estimates based upon discussions with manufacturers, June 1978 .

TABLE 2-4

PV-DES CAPITAL COST PROJECTION IN 1977 \$/PEAK $\mathrm{kW}$

Land (1)

$1977 \quad \underline{1985} \quad \underline{2000}$.

$\begin{array}{lrrrrr}\text { Support Structure } & (1) & 100- & 200 & 100-200 & 100-200 \\ \text { Photovoltaic Array } & (2) & 12,000-30,000 & 500-3,000 & 100-1,000 \\ \text { Power Conditioning } & 500-1,000 & \frac{230-900}{830-4,100} & \frac{200-400-1,900}{12,600-31,200} & \end{array}$

(1) No separate land acquisition cost is allocated since arrays will most likely be integrated with the exterfor of the buildings they serve. The support structure cost figure is an estimate of the supplemental cost of such buildings or the cost to modify existing ones.

(2) Cost of the photovoltaic array in $\$ / \mathrm{m}^{2}=n I \times$ cost in $\$ / \mathrm{kW}$, where $n=$ array efficiency, and $I=$ peak solar irradiance in $\mathrm{kW} / \mathrm{m}^{2}$.

SOURCE: Arthur D. Little, Inc., estimates. 
Section 2.4: Limitations

Other than economics, the principal non-institutional 1imitations on the application of the PV-DES are :

- the availability of sunlight,

- the availability of photovoltaic material,

- the energy requirements of production,

- the life expectancy and reliability of the photovoltaic array, and

- the environmental impact of the production of PV-DES components, their installation, and their use.

As previously noted, the flat-plate array is likely to be the most prevalent form of photovoltaic energy collector, and a number of analyses have been made $(22,23,24)$ of the solar radiation incident on a tilted surface. Such analyses are based upon National Weather Service horizontal insolation measurements $(25,26)$ and upon models of the direct and diffuse solar radiation. These data have been complled, rehabilitated, and coordinated with surface meteorological observations by the National Oceanic and Atmospheric Administration. (27)

Neville ${ }^{(28)}$ has computed the solar energy which is potentially available at selected sites within the Unfted States for flat-plate collectors, 1.e., planar photovoltaic arrays, of both tracking and nontracking designs. His results, summarized in Table 2-5, show that local weather conditions are even more important than latitude in determining solar energy availability. In some parts of the continental United States, the solar energy available for fixed-position, flatplate arrays is double that available in other regions, for examplé, the clear weather areas of the Southwest versus Seattle or Boston. However, up to latitudes of $43^{\circ}$ at least, the energy availability is $60-70 \%$ of the Southwest levels. Thus the PV-DES may not be at a great disadvantage in the more northerly areas of the country.

Figure 2-4 illustrates the impact of current material avallability on the potential for power generation in that 1 thows the peak power generating capability which would be realized if the total annual 
TABLE $2-5$

POTENTIAL SOLAR ENERGY FOR SELECTED CITIES - ANNUAL TOTAL

(in units of $\mathrm{kWh} / \mathrm{m}^{2}$ )

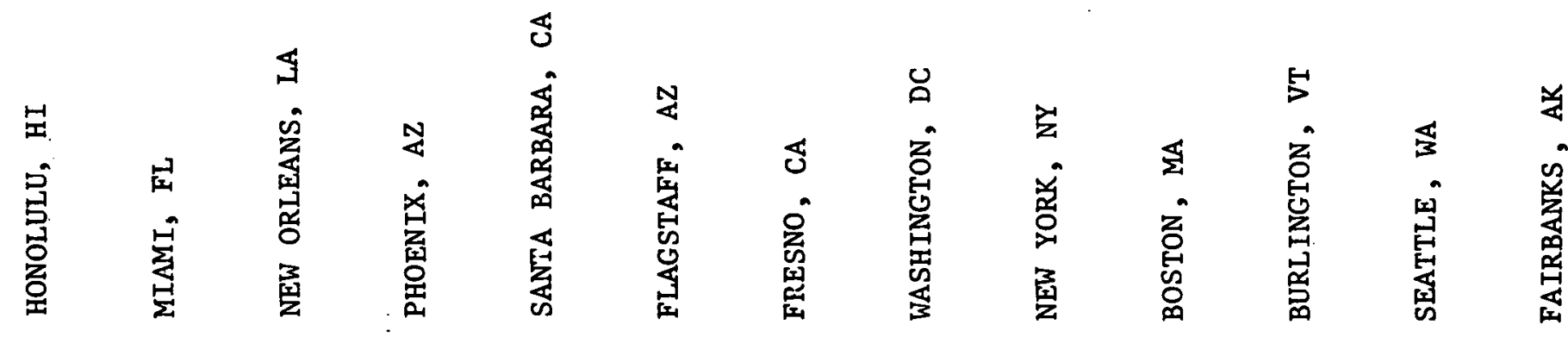

North

$21^{\circ} 18^{\prime} 25^{\circ} 47^{\prime} 29^{\circ} 51^{\prime} 32^{\circ} 27^{\prime}$

$34^{\circ} 25^{\prime} 35^{\circ} 12^{\prime}$

$36^{\circ} 44^{\prime} 38^{\circ} 54^{\prime} 40^{\circ} 45^{\prime} 42^{\circ} 4^{\prime}$

$44^{\circ} 18^{\prime} 47^{\circ} 37^{\prime} 64^{\circ} 48^{\prime}$

$\stackrel{N}{\sim}$

\begin{tabular}{lllllllllllrrrr}
\hline $\mathrm{E}_{\mathrm{TP}}(1)$ & 3195 & 3177 & 3037 & 3004 & 2966 & 2957 & 2915 & 2862 & 2832 & 2795 & 2748 & 2678 & 2210 \\
$\mathrm{E}_{\mathrm{TPW}}$ & 2085 & 2076 & 1817 & 2580 & 2163 & 2541 & 2401 & 1688 & 1721 & 1629 & 1370 & 1272 & 1073 \\
$\mathrm{E}_{\mathrm{HOR}}$ & 1307 & 1235 & 1078 & 1476 & 1184 & $1-98$ & 1334 & 907 & 1003 & 849 & 716 & 634 & 423 \\
$\mathrm{E}_{1.0}$ & 1532 & 1425 & 1276 & 1785 & 1450 & 1459 & 1627 & 1153 & 1119 & 1058 & 900 & 812 & 720 \\
$\mathrm{E}_{20}$ & 1713 & 1852 & 1466 & 2050 & 1700 & 1675 & 1898 & 1311 & 1311 & 1236 & 1044 & 952 & 720 \\
$\mathrm{E}_{\text {WT-10 }}$ & 1987 & 1953 & 1701 & 2369 & 1935 & 1930 & 2203 & 1517 & 1511 & 1420 & 1194 & 1097 & 787 \\
\hline
\end{tabular}

(1) Here, $\mathrm{E}_{\mathrm{TP}}$ is the maximum amount of solar energy available; $\mathrm{E}_{\mathrm{TPW}}$ is the energy available to an ideal tracking collector after correction for weather; $\mathrm{E}_{\mathrm{HOR}}$ is the energy which a horizontal collector will provide; $E_{10}$ that of a flat-plate collector inclined $10^{\circ}$ to the horizontal and facing south; $E_{20}$ inclined $20^{\circ}$ facing south; and $E_{W T-10}$ the energy sipplied by a collector inclined $10^{\circ}$ facing south but with east-west tracking.

SOURCE: Reference 28. 


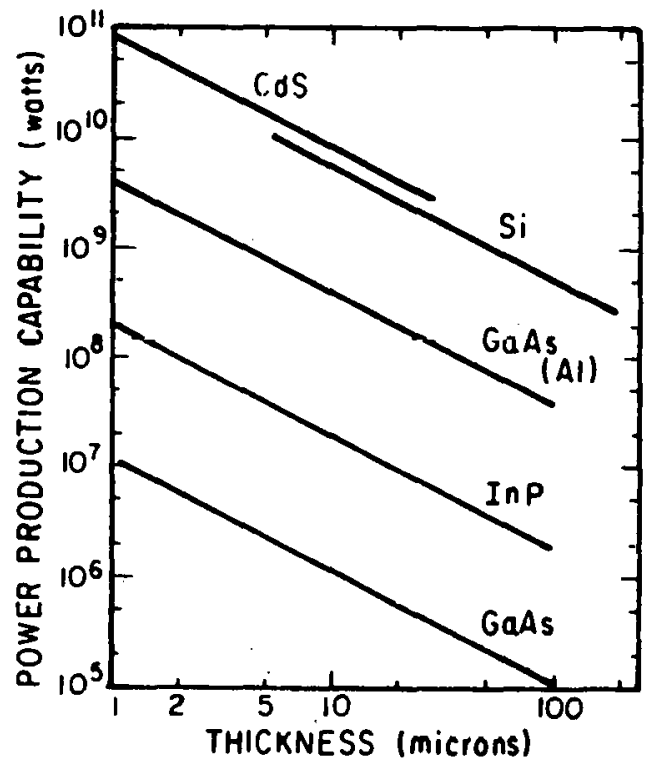

SOURCE : Réferencè 29.

FIGURE 2-4 PEAK POWER PRODUCTION CAPABILITY OF SEVERAL MATERIALS USING PRESENT PRODUCTION RATE IN THE U.S. $10 \%$ EFFICIENCY, $100 \mathrm{MW} / \mathrm{cm}^{2}$ INSOLATION, NO CONCENTRATION

United States production of $\mathrm{Cd}, \mathrm{Ga}$, In and semiconductor grade $\mathrm{S1}$ were dedicated to photovoltaic use in planar, non-concentrating arrays at $10 \%$ efficiency. The curve labelled GaAs(A1), rather than the lower GaAs curve, would apply if the gallium present in aluminum ore were recovered rather than discarded as waste.

Further considerations on material abundance $(29,30)$ show that of the elements contained in the candidate semiconductors, only silicon, zinc, copper, tin, sulfur, phosphorus, and oxygen place no limits on photovoltaic cell production due to their availability. Cadmium, antimony, and gallium are intermediate in availability, and their large-scale use, 1.e., annual production of new peak capacity greater than $10^{9}$ We, could cause supply dislocations, while indium and tellurium are so scarce that they can be considered only for very material-conserving systems, 1.e., those operating at high concentration ratios.

The energy costs of photovoltaic cell manufacture have been estimated for selected production processes $(31,32)$ primarily involving singlecrystal silicon, but it is very difficult to assess the relevance of such 
estimates to the production methods which will ultimately be applied in large-scale manufacture. Clearly, the energy consumption required to produce photovoltaic arrays will become increasingly important as production quantities rise since this energy requirement will be in competition with other energy needs in a period of escalating energy cost and declining availability from fossil fuel sources.

The life expectancy of photovoltaic arrays will depend upon the choice of photovoltaic materials, the cell design, the method and materials used for encapsulation, and the operating temperature. Gandel et a1. (31) have estimated that silicon and gallium arsenide photovoltalc cells will have a life expectancy of about 10 years and cadmium sulfide cells will have a life expectancy of about 5 years. The basis for these.. estimates was not detailed and their applicability to future production. cells is uncertain. Reliable life expectancy data will be available only when photovoltaic cells of production design have been subjected to longterm testing under actual field conditions.

The environmental impact of the PV-DES may also be largely assoclated with the manufacturing process. The actual deployment of the arrays themselves should have little impact on the local environment, particularly if they are mounted on existing structures or future buildIngs which satisfy other local needs. However, the manufacture of the arrays will require substantial mining of selected materials and subsequent chemical and electronic processing. These processes and their. energy requirements may indeed have substantial environmental consequences. 


\section{REFERENCES}

1. Rappaport, P., et al. "The Photovoltaic Effect." Photoelectronic Materials and Devices. Edited by S. Larach. New York: D. Van Nostrand Company, Inc., 1965. pp. $239 \mathrm{ff}$.

2. Landsberg P.T. "An Introduction to the Theory of Photovoltaic Cells." Solid State Electronics 18(12):1043, December 1975.

3. Prince, M.B. "Silicon Solar Energy Converters." Journal of Applied Physics 26(5):534, May 1955 .

4. Swanson, R.M., et al. Silicon Photovoltaic Cells in Thermophotovoltaic Conversion. Prepared by Stanford Electronics Laboratories for Electric Power Research Institute, February 1977. EPRI Report No: EPRI-ER-478.

5. Sodba, M.S., et a1. "Performance of Diffused Vertical Multijunction Solar Cell." Solar Energy 18(3):265, 1976.

6. Varian Associates, 611 Hansen Way, Palo Alto, California 94303. Private communications. 1977.

7. Wolf, M. "A New Look at Silicon Solar Cel1 Performance." Energy Conversion. New York: Pergamon Press, 1971. Vol. II. pp. $63 \mathrm{ff}$.

8. Carlson, D.E., et a1. "Amorphous Silicon Solar Ce11s." Applied Physics Letters 28(11):671, June 1, 1976.

9. Hovel, H.J. "Solar Cells." Semiconductors and Semimetals. Edited by R.K. Willardson and Alfred C. Beer. New York: Academic Press, 1975. Vol. II. pp. $71 \mathrm{ff}$.

10. Rothwarf, A. Theoret 1cal Prospects of the CdS-Cu ${ }_{2} \mathrm{~S}$ Solar Cell. Pre pared by Delaware University, Institute of Energy Conversion for National Science Foundation, March 1976. NTIS Report No. PB 252409.

11. Lindmayer, J. "Semi-crystalline Silicon Solar Cells." Twelfth IEEE Photovoltaic Spectalists' Conference, Baton Rouge, Louislana, November 15-18, 1976. Paper 2.3.

12. Meakin, J.D. "Cadmium Sulfide-Copper Sulfide Heterojunction Cell Research." Photovoltaics Advanced Materlals Review Meeting Proceedings, October 1978. Sponsored by Solar Energy Research Institute, Golden, Colorado. pp. $291 \mathrm{ff}$.

13. Dean, R.H., et al. "Silicon Solar Cells for Highly Concentrated Sunlight." RCA Review 36(2):324, June 1975.

14. Pope, M.D. "Solar Photovoltafc Field Tests and Applications Program." Proceedings of the ERDA Semiannual Solar Photovoltaic Program Review Meeting, Orono, Malne, August 3, 1976. Sponsored by Maine University for Energy Research and Development Administration. pp. 588 ff. NTIS Report No. CONF-760837-P2. 


\section{REFERENCES (continued)}

15. Kirpich, A. Conceptual Design and Systems Analysis of Photovoltaic Systems. 3 volumes. Prepared by General Electric Company for Energy Research and Development Administration, March 1977. NTIS Report No. ALO/3686-14 (V.1-3).

16. Clark, R., Sandia Laboratories. "Storage for Photovoltaics." Photovoltaic Advanced Research and Development Annual Review Meeting Proceedings, Denver, Colorado, September 17-19, 1979. Sponsored by Solar Energy Research Institute, Golden, Colorado. To be published December 1979.

17. Pittman, P.F. Conceptual Design and Systems Analysis of Photovoltaic Power Systems. Final Report. Volume 1: Executive Summary. Prepared by Westinghouse Electric Corporation for Energy Research and Development Administration, April 1977. NTIS Report No. ALO-2744-13 (V.1).

18. U.S. Department of Energy. National Photovoltaic Program Plan. February 3, 1978. NTIS Report No. DOE/ET-0035(78).

19. Office of Technology Assessment. Application of Solar Technology to Today's Energy Needs. Washington, D.C., June 1978. Vol. I, Chapt. X. pp. 393-394, $405 \mathrm{ff}$.

20. Moore, R.M. "Cost Predictions for Photovoltaic Energy Sources." Solar Energy 18(3):225, 1976.

21. RCA Corporation, 30 Rockefeller Plaza, New York, New York 10020. Private communications. 1977.

22. Liu, B.Y., et a1. "Daily Insolation of Surfaces Tilted toward the Equator." ASHRAE Transactions. 68:526, 1962

23. Norris, D.J. "Solar Radiation on Inclined Surfaces." Solar Energy $10(2): 72,1966$.

24. Klein, S.A. "Calculation of Monthly Average Insolation on Tilted Surfaces." Solar Energy 19(4):325, 1977.

25. Baldwin, J.L. Climates of the United States. Prepared by U.S. Department of Commerce, National Oceanic and Atmospheric Adminfstration. Washington, D.C.: Government Printing Office, 1973. GPO Document No. C55.202:c61.

26. National Climatic Center. Local Climatoligical Data; National Summary. Asheville, North Carolina: Environmental Data and Information Service, National Oceanic and Atmospheric Administration, published monthly and annually. Superintendent of Documents Classification No. C55.287/2.

27. National Oceanic and Atmospheric Administration. Hourly Solar Radiation - Surface Meteorological Observations, SOLMET, Vol. 1 , Users Manual. Washington, D.C.: U.S. Department of Commerce, December 1977. 


\section{REFERENCES (continued)}

28. Neville, R.C. "Solar Energy and the Residence - Some System Aspects." Solar Energy 19(5):539, 1977.

29. Hovel, H.J. "Solar Cells." Semiconductors and Semfmetals. Edited by R.K. Willardson and Alfred C. Beer. New York: Academic Press, 1975. Vol. II. pp. 217-222.

30. Arthur D. Little, Inc. Evaluation of Solar Cells for Potential Space Satellite Power Applications. Prepared for National Aeronautics and Space Administration, June 1977. NASA Report No. 77-30612/ 4GA. pp. $11 \mathrm{ff}$.

31. Gande1, M.G., et al. Assessment of Large-Scale Photovolta1c Materials Production. Prepared by Lockheed Missiles and Space Company, July 1976. Report No. LMSC-HKEC-D496940. Avallable from Defense Ducuilieitation Center, Cameron Stac1on, Alexandrla, Vlrglula 22314.

32. Duncan, C.S., et al. Low Cost Silicon Solar Array Project. Large Area Silicon Sheet Task: Silicon Web Process Development. Report prepared by Westinghouse Research and Development Center for Jet Propulsion Laboratory under contract with the National Aeronautics and Space Administration, 1977. NTIS Report No. N78-23563/7GA. 


\section{CHAPTER 3}

\section{SOLAR THERMAL POWER SYSTEMS}

\section{Section 3.1: Introduction}

In a solar thermal power system, solar energy is converted to heat by a collector system (usually using some degree of solar concentration); this heat is then used to operate a heat engine. The shaft output of the heat engine can be used to drive any form of rotary electric or mechanical equipment such as electric generators, water pumps, or the compressors of cooling systems.

Solar thermal power systems are being developed both for smallscale (1-25 kW) on-site applications $(1,2,3)$ (irrigation pumping, a1r conditioning) and for large central systems that produce electric power for the utility grid. $(4,5,6)$ This size flexibility could make solar thermal power systems well suited for distributed energy system applications.

Many approaches to solar thermal power are being investigated. These include 10 - to medium-temperature $\left(200-500^{\circ} \mathrm{F}\right)$ systems which can utilize low levels of solar concentration, and high-temperature systems $\left(600-1800^{\circ} \mathrm{F}\right)$ which require higher levels of solar concentration. Several of the system options are listed below:

Low Levels of Solar Concentration (1X-10X):

- Flat-plate collector with Rankine cycle engine,

- Compound parabolic concentrator (CPC) with Rankine cycle engine, and

- Flat-plate collector using planar reflector with Rankine cycle engine.

Medium Levels of Solar Concentration (10X-40X):

- Parabolic trough with Rankine cycle engine,

- Linear-slat concentrator with Rankine cycle. engine, and

- Linear Fresnel lens with Rankine cycle engine. 
High Levels of Solar Concentration $(50 \mathrm{X}-2000 \mathrm{X}) \mathrm{:}^{*}$

- Parabolic dish with open Brayton cycle engine,

- Parabolic dish with Stirling engine, **

- "Power Tower" system with steam turbine, and

- "Power Tower" system with open Brayton cycle engine.

The economic performance of solar thermal power systems is most influenced by the cost and thermal performance of the solar collector subsystem used to convert solar energy into heat.

It should be noted that all of the collectors using medium or high levels of concentration require highly collimated solar radiation (referred to as direct) for their operation. As indicated in the "Limitations" discussion of Section 3.4, in most parts of the country. a rather high percentage of the incident solar radiation is scattered by moisture, dust, etc. This radiation, referred to as diffuse, is not utilizable by concentrating systems. In New England, about $40 \%$ of the total radiation incident on a south-facing surface tilted at the latitude angle through the year is diffuse, while in the desert areas of the Southwest only $20-25 \%$ of the annual radiation is diffuse. Consequent1y, the performance of medium- and high-level concentrators will vary greatly depending on location.

Several of these collector subsystems appropriate for thermal power applications are discussed in the following sections.

\section{Section 3.2: Technical Discussion}

\section{A. Low Level Concentrators}

Flat-plate collectors of advanced design have been used as heat sources for operating organic Rankine cycle engines ${ }^{* *}$ at low temperature levels $\left(175-250^{\circ} \mathrm{F}\right) .(1)$ At these low operating temperature levels, the efficiency of the engines is so low that large areas of collectors are required for a specified power output. It is, therefore, doubtful that

\footnotetext{
*HIgher levels of concentration are possible, but this range is generally considered attainable with current technology. 
solar power units using flat-plate collectors will find wide use, with the possible exception of specialized remote power applications where system simplicity is of paramount importance.

Organic Rankine cycle engines, however, can be operated efficiently with relatively moderate heat-input temperatures of $250-$ $600^{\circ} \mathrm{F}$. which can be achieved with low levels (2X-10X) of solar concentration. The most advanced of the options available for low-level focussing (which do not require continuous tracking) is the compound parabolic concentrator (CPC) shown in Figure 3-1. This collector arrangement is in an advanced development stage at the Argonne National Laboratory, and several industrial firms have license agreements, which will probably lead to its near-term commerclal availability.

The external appearance of this collector is similar to that of a conventional flat-plate collector. The outer glass or plastic cover plate protects the reflective surfaces from dirt and moisture, helping to ensure stable performance characteristics. Because of its optics, the $\mathrm{CPC}$ can utilize solar radiation over a wide acceptance angle (the magnitude depending on concentration ratio). Consequently, the collector need not track the sun on a daily basis and can utilize some of the diffuse radiation. * (See Section 3.4.A for discussion of insolation limitations.) This makes the use of CPC collectors appropriate in a wide range of climatic conditions, and could result in their widespread use within distributed energy systems.

The average annual efficiency of several CPC collector options is shown in Figure 3-2, along with that of a parabolic trough design: As indicated, low-level concentrators can achieve annual efficiency levels of $40-55 \%$ at temperatures of $300-550^{\circ} \mathrm{F}$, which are consistent with the operation of Rankine cycle engine systems.

\section{B. Medium Leve1 Concentrators}

Three types of medium-level concentrators either in use or in an advanced stage of development are:

\footnotetext{
* Typical1y, 20-35\% for concentration ratios between 3 and 5 .
} 


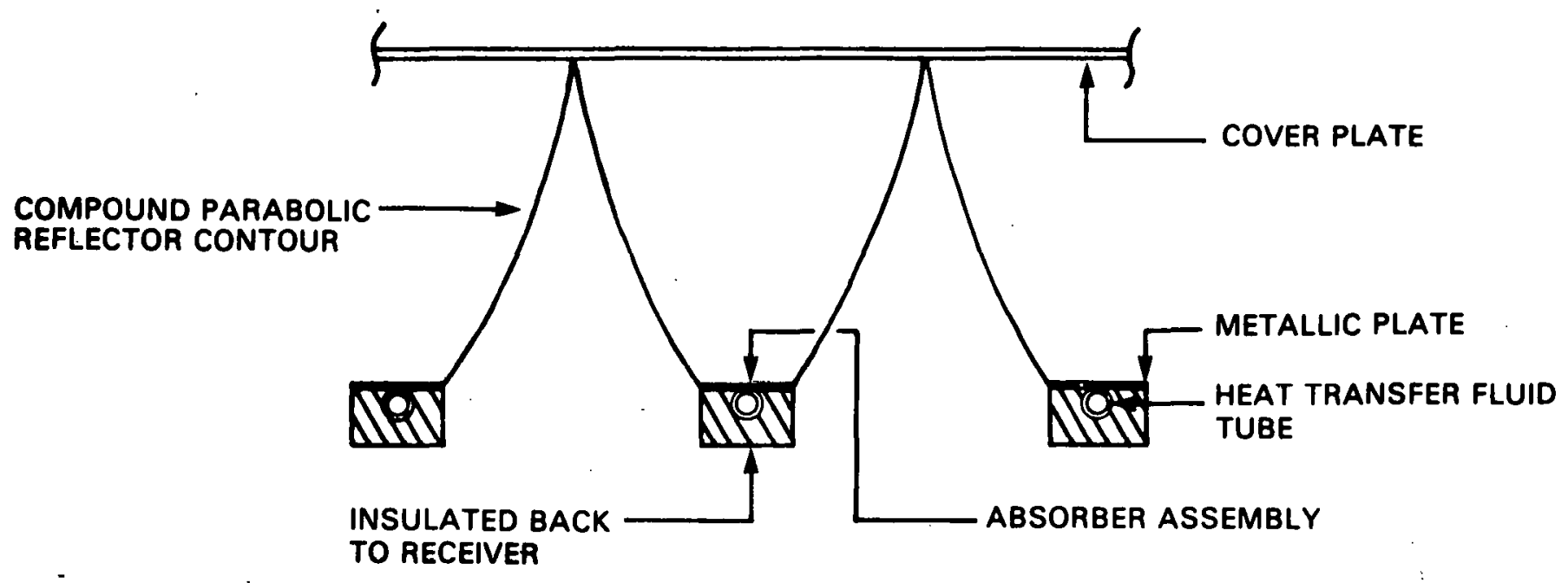

a) Using conventional flat-plate absorber

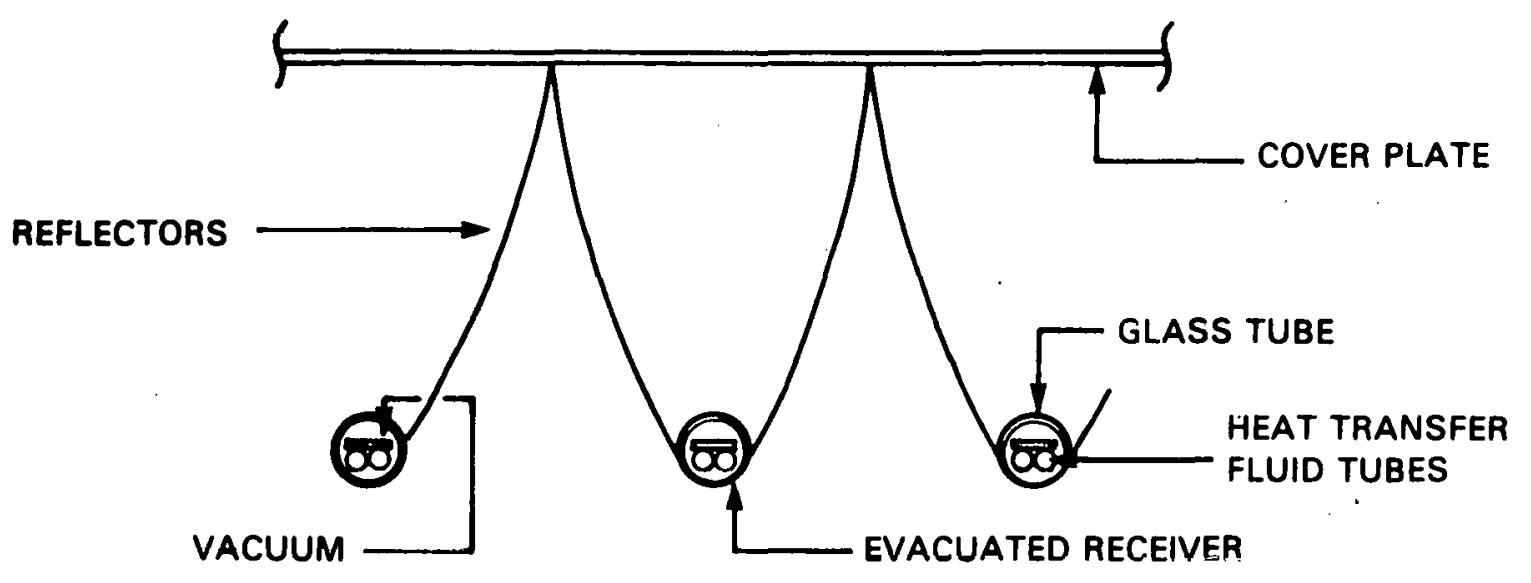

b) Using evacuated glass tube receivers

\section{Characteristics:}

- Accepts radiation over a wide half angle $\left(13.6^{\circ}\right.$ for a $3 X$ concentrator) which increases efficiency and minimizes number of tilt adjustments.

- Reflectors are protected by the cover plate which improves efficiency and reliability.

- No tracking required which simplifies installation and operation.

SOURCE: Arthur D. Little, Inc.

FIGURE 3-1 CHARACTERISTICS OF COMPOUND PARABOLIC CONCENTRATOR COLLECTOR 


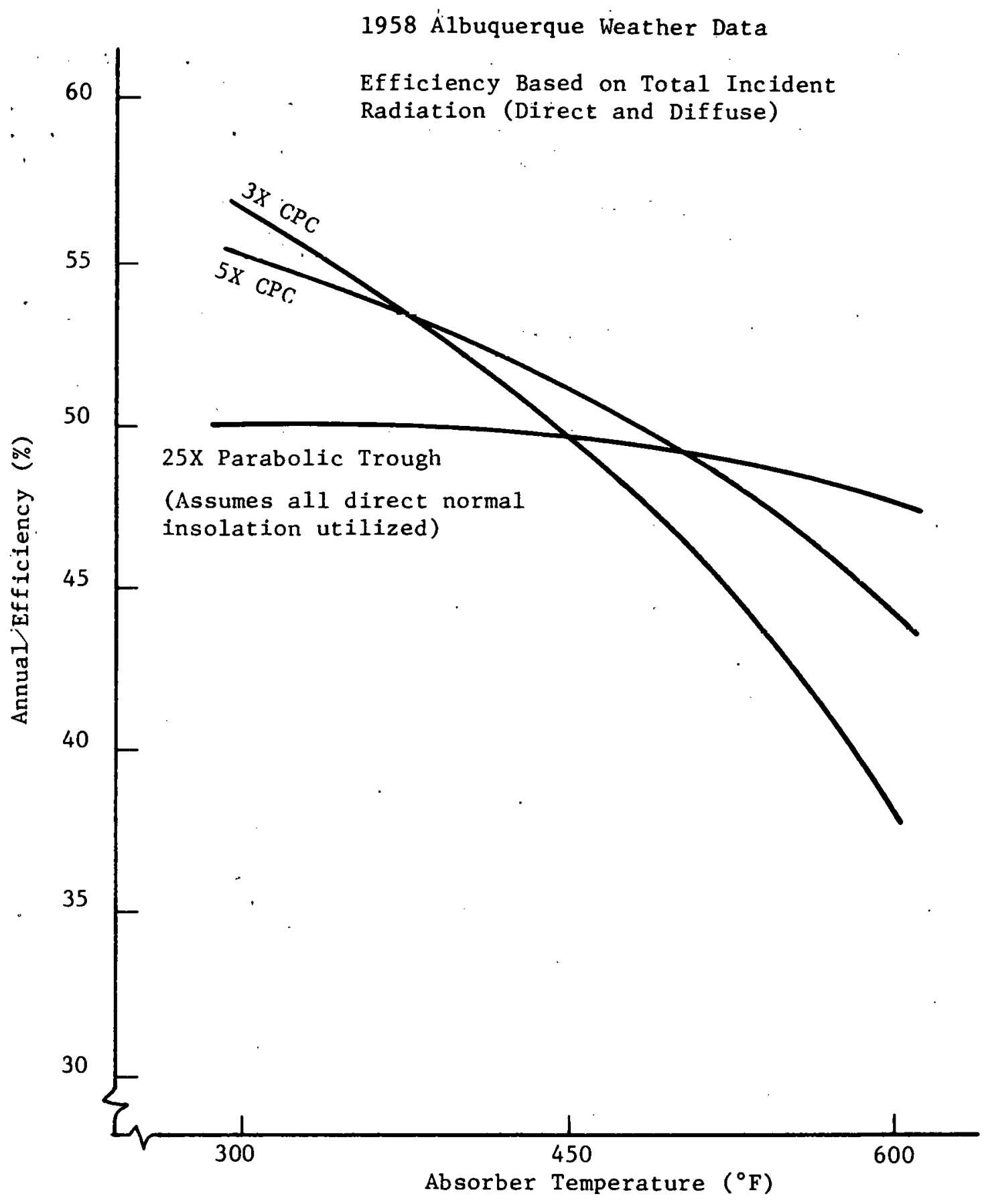

SOURCE: Reference 7.

FIGURE 3-2 ANNUAL COLLECTOR PERFORMANCE

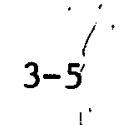


- Parabolic troughs,

- Segmented mirrors, and

- Fresnel lenses.

In a parabolic trough collector, shown in Figure 3-3, the cross section of the reflector perpendicular to the major axis of the collector is a constant parabola which focusses the solar energy on a line. The linear receiver is rigidly located at the focus of this parabola. Several types of receivers are being used, depending on the operating temperature levels under consideration. Evacuated tube receivers, such as those shown in Figure 3-1b, are often considered for use in solar power applications, where there is an incentive to operate at elevated temperature levels.

The geometric concentration ratios for parabolic trough concentrators are typically in the $20 \mathrm{X}-40 \mathrm{X}$ range. The major losses from the more sophisticated collector designs (in general, those using a special or evacuated receiver configuration) tend to be optical and not thermai in nature. Optical losses include the following:

- Surface Quality: For engineering surfaces capable of operation under severe'climatic conditions, specular reflectivities range from 0.7 to 0.9 . The higher end of this range requires the use of silvered glass which is difficult to form in the shape of a parabolic trough. The use of silvered glass is, however, consistent with several of the segmented mirror configurations.

- Geometric Errors: Precise surface contours (0.1-0.25 degree error tolerance) are required to direct all the reflected light to the receiver assembly. In practice, there will usually be surface contour errors which result in $5-10 \%$ of the reflected light being misdirected.

- Dust Factor: ' Under many realistic operating conditions there will be thin layers of dirt or dust on the reflector surface and these will reduce reflectivity. 


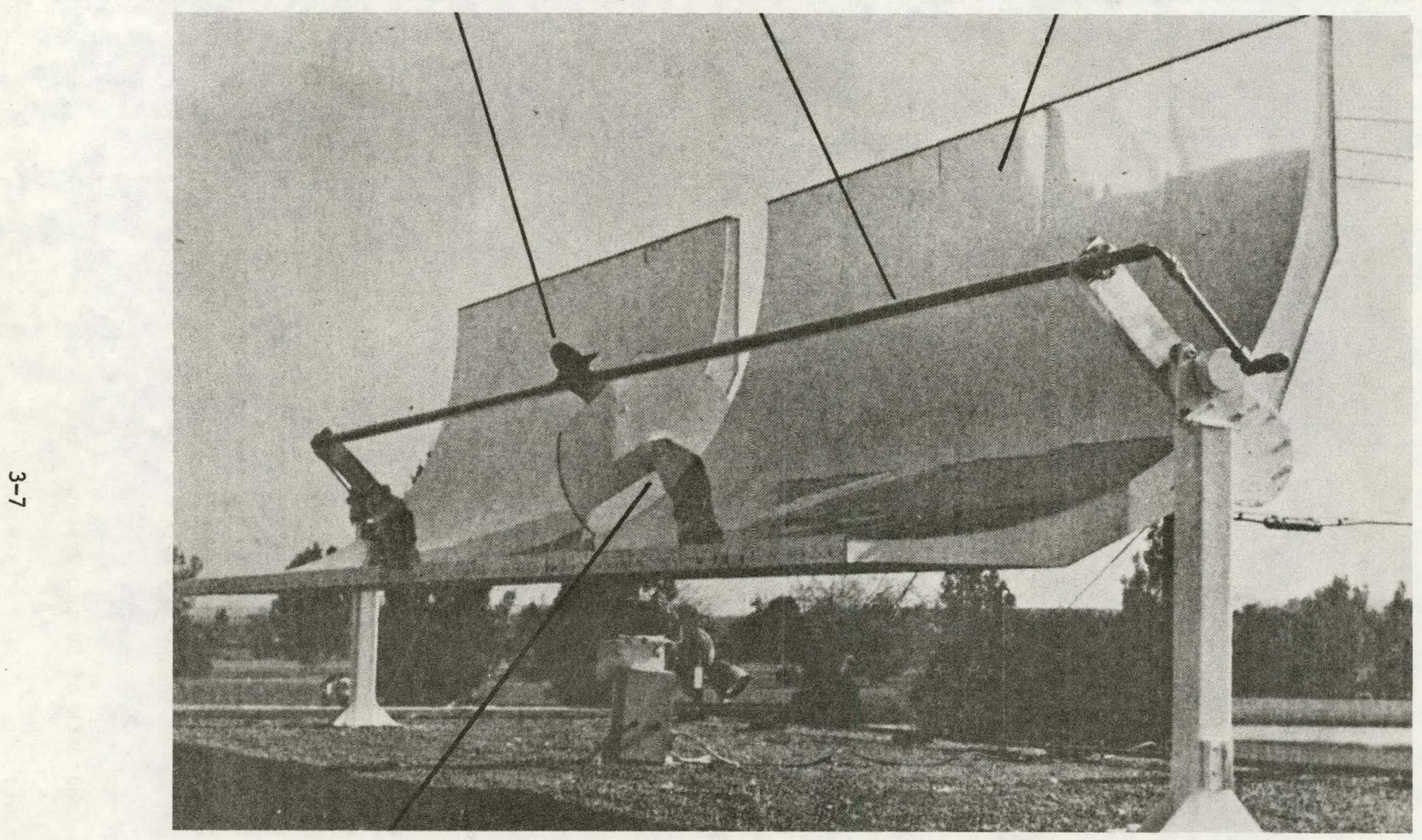

MOTOR DRIVE

SOURCE: Acirex Aerotherm, 485 Clyde Avenue, Mountain View, California 94042.

FIGURE 3-3 PARABOLIC TROUGH COLLECTOR 
Such layers of dust can easily reduce the amount

of reflected 1 ight by $5 \%$, even if the reflector

is cleaned frequently.

There will also be optical losses associated with transmitting the concentrated sunlight into or onto the receiver. These take the form of transmission losses through glass tubes (with evacuated tube receivers) and non-ideal absorption into the absorber plate. The projected annual efficiency (energy collected annually divided by the total annual insolation incident on the collector) of a typical $25 \mathrm{x}$ parabulic Liough concentrator for the Albuquerque area is shown in Figure 3-2. Even at noon on a clear day, the optical losses referred to above reduce the efficiency of the collector by about $30 \%$, even at low temperature levels.

A segmented mirror-type concentrating collector is comprised of a receiver assembly and a series of parallel mirrors that reflect the incident energy onto the receiver in much the same fashicn as the parabolic trough collectors. Two configurations that are in advanced stages of development are illustrated in Figures 3-4 and 3-5. In the first (SLATS $^{\circledR *}$ ), the receiver is affixed to the basic frame of the assembly and the mirrors are rotated about their major axis to direct the light into the stationary receiver. $(8,9)$ In the second concept, Fixed-Mirror Solar Collector (FMSC), the mirrors are fixed in place and the receiver swings overhead to account for the dafly apparent movement of the sun. (10)

One motivation for such designs is to reduce the amount of equipment necessary to provide tracking, since it requires a smaller, simpler mechanism to move several small mirrors, or one pipe, than it does to move a comparatively large, rigid trough and receiver assembly. In addition, making the mirror segments to the required tolerance should be less complex than making a large surface to corresponding specifications. Repairs to the reflector surface are also simplified, since only the damaged slat(s) need be replaced. For the rotating-slat design, protection for the reflective surfaces is provided by downward rotation during night, cloudy, or no-demand periods.

* Registered trademark of Suntec Systems, Inc. 


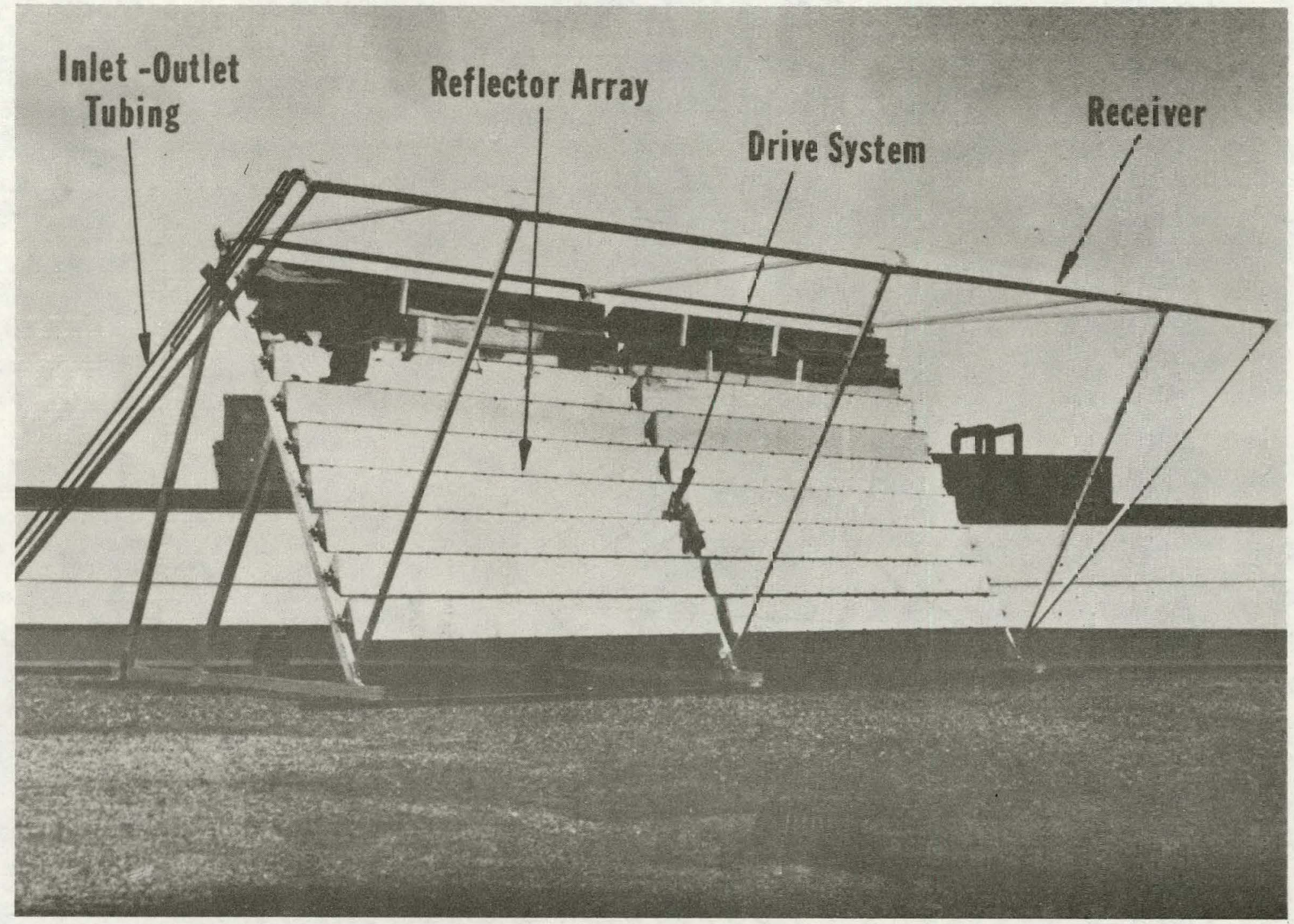

SOURCE: Reference 8.

FIGURE 3-4 SLATS $^{\circledR}$ COLLECTOR CONFIGURATION 


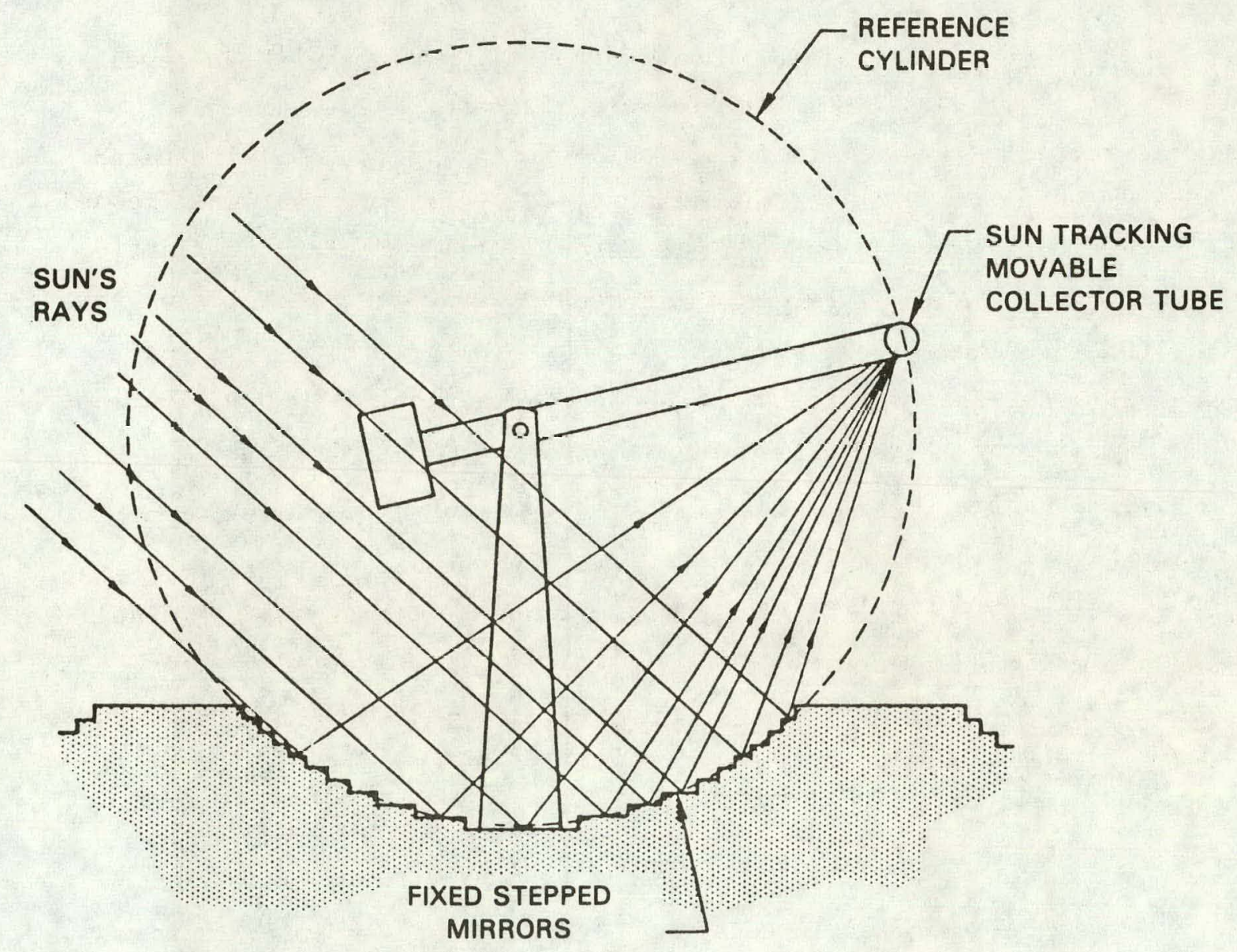

SOURCE: Reference 9.

FIGURE 3-5 FIXED-MIRROR SOLAR COLLECTOR (FMSC) CONFIGURATION 
All segmented mirror-type configurations are medium-level concentrators. Therefore, the comments on the optical and thermal losses associated with the parabolic trough designs apply here also.

A Fresnel concentrator can be of either medium- or high-level design. $(9,11)$ The distinguishing feature of these devices is that light is refracted and not reflected onto the receiver. As illustrated in Figure 3-6, light energy is incident on the top surface of the Fresnel lens. This energy passes through the material (either glass or plastic) and is refracted by small ridges or grooves on the underside of the lens which, though shown flat in the figure, can be either flat or curved. A curved Fresnel concentrator has a shorter focal length than a flat lens system, but is correspondingly more difficult to manufacture.

Tracking requirements are similar to those of reflector-type concentrators for equal levels of solar concentration. Durability of plastic lenses and the difficulty of manufacturing linear glass Fresnel lenses are major challenges which have limited the use of these lens systems. In addition, the difficulty in maintaining clean surfaces under actual use (the grooves tend to become clogged with dust) is of real concern.

\section{High Level Concentrators}

As previously mentioned, practical medium-level concentrators can achieve concentration ratios of about 20X-40X. High-1evel concentrators with similar tracking and geometrical accuracies can achieve concentration ratios of $400 \mathrm{X}$ to $2000 \mathrm{X}$. However, this higher concentration ratio capability requires two-axis tracking which makes the design and operation of high-level concentrating systems more complicated than those of medium-level concentrators.

Two basic approaches to high concentration systems are being investigated:

- Central receiver, and

- Distributed collector configuration. 

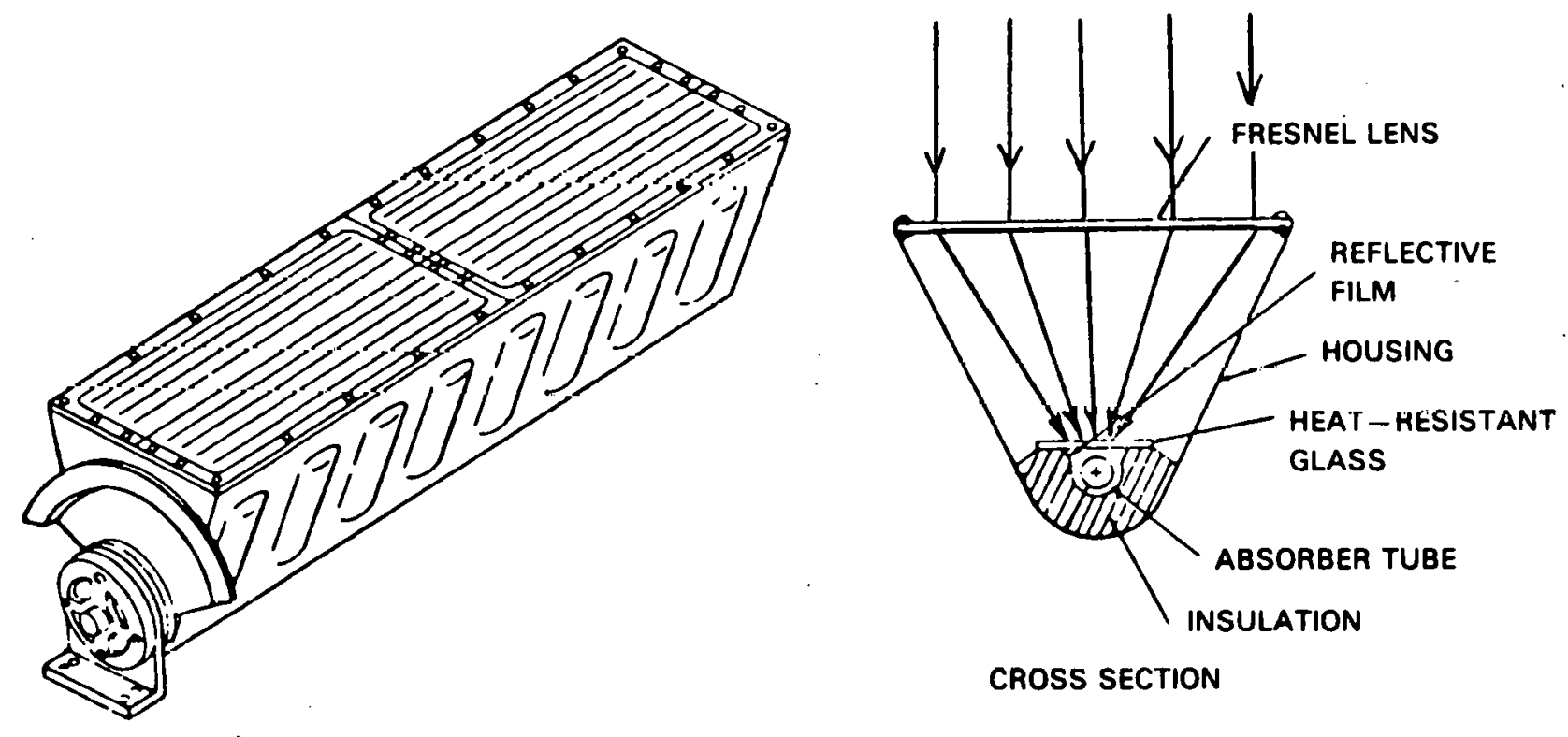

SOURCE: Reference 11.

FIGURE 3-6 MEDIUM-LEVEL FRESNEL LENS CONCENTRATOR 
A central receiver system (also known as the "power tower" concept) utilizes a large number of individually guided mirrors (heliostats) placed in an array at the base of a tall tower, as shown in Figure 3-7. The incident solar energy is reflected from the mirrors to a receiver mounted on top of the tower, where it is absorbed by a heat-transfer medium (usua11y steam). The steam so generated can be used to operate conventional steam turbine generator equipment. $(4,5)$

The major cost component in such a system is expected to be the heliostats, which require precise two-axis tracking, highly reflective and geometrically precise surface contours, and structural rigidity to withstand high wind loads. Several of the heliostat concepts under development are shown in Figure 3-8.

The primary advantage of the "power tower" concept is that the solar energy from a large area is collected in a central location, which greatly reduces the requirements for piping heat-transfer medium over large distances in comparison with those for systems using a distributed collector array (troughs, etc.). Also, because of the high levels of solar concentration involved $(1000 \mathrm{X}-2000 \mathrm{X})$, it is possible to attain temperatures in the $900-1200^{\circ} \mathrm{F}$ range, which allows efficient operation of conventional steam power equipment.

The "power tower" system is most often considered for use at high power levels (100 megawatts and higher) in arid, high-insolation regions, with a high percentage of direct radiation. However, the DOE is now studying the use of a mini-power tower for individual irrigation pumping systems at the 150-kW power level which might be applicable for distributed energy systems in some remote geographical regions. (12)

Another approach to high-level concentration, which is well adapted to distributed energy system applications, is the use of parabolic dish concentrators. $(13,14)$ One such system is shown in Figure 3-9. In this system the concentrated solar energy is used to operate an open Brayton cycle engine, thereby eliminating the need for a heat-rejection system as required by Rankine cycle engines. Brayton cycle engines (which require temperature levels in excess of $1200^{\circ} \mathrm{F}$ for efficient operation) 


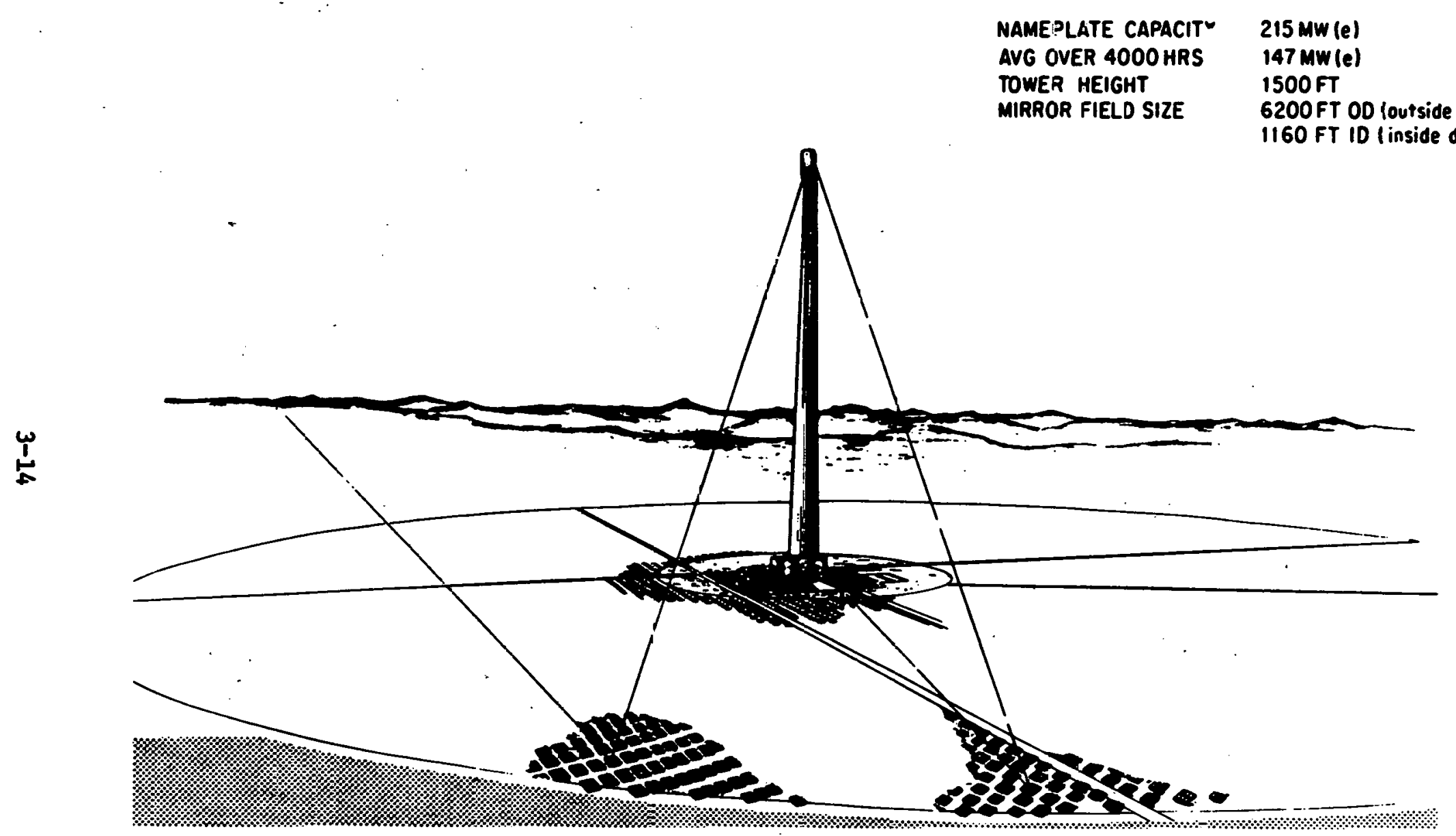

SOLRCE: Reference 5.

FIGURE 3-7 CENTRAL RECEIVER CONCEPT 

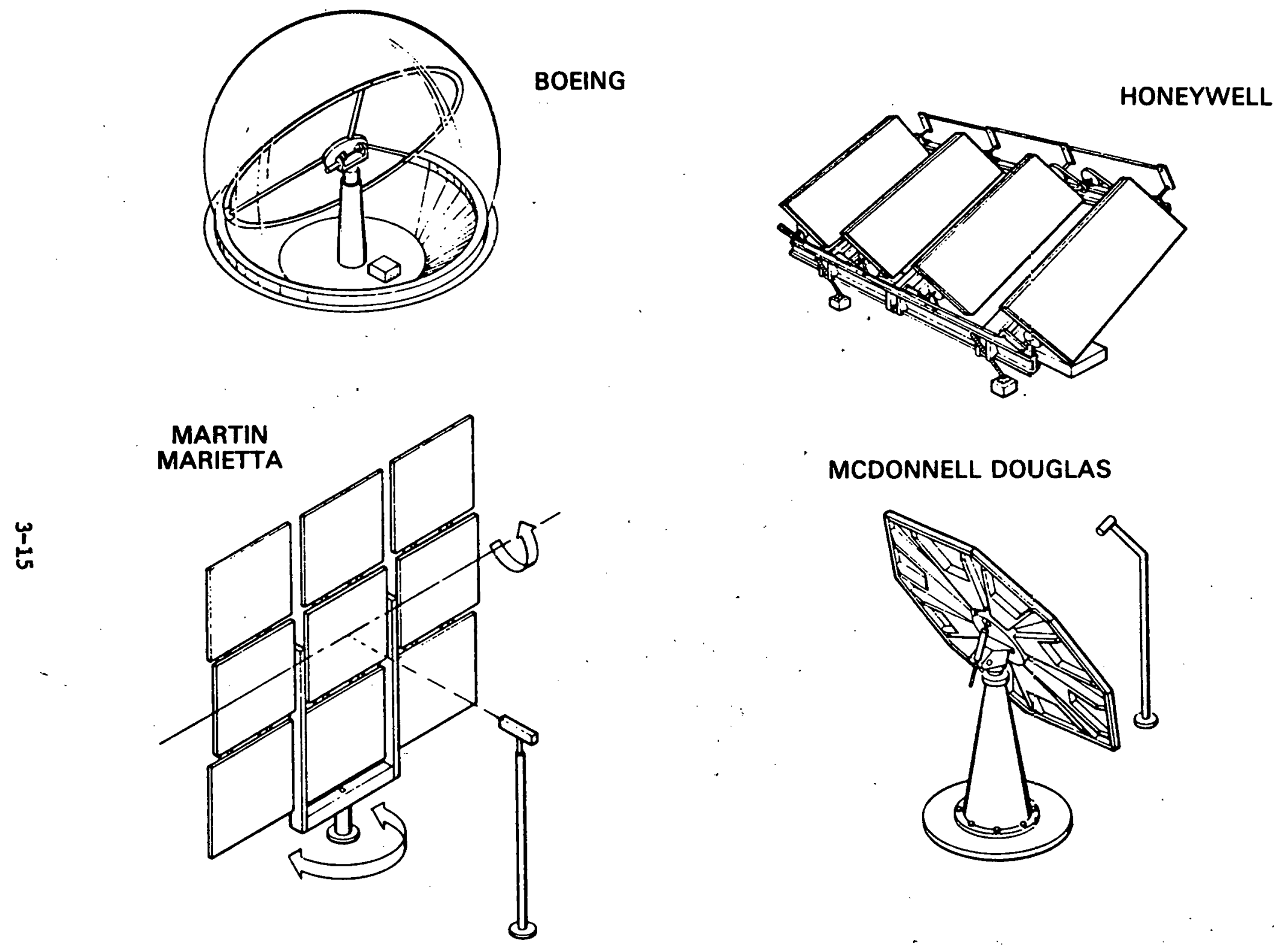

\section{MCDONNELL DOUGLAS}

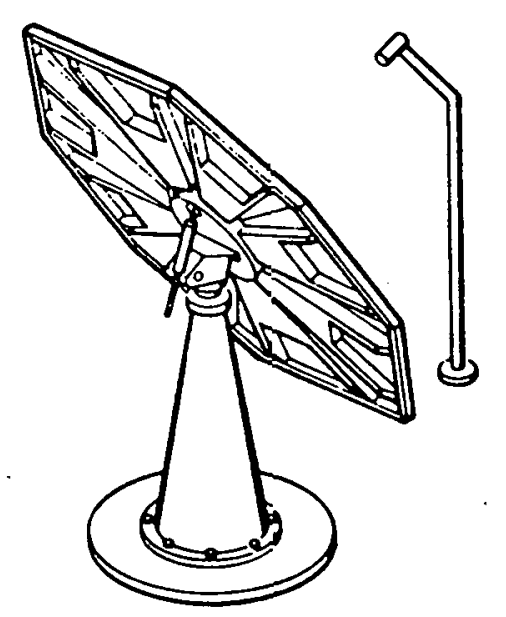

SOURCE: Reference 9.

FIGURE 3-8 HELIOSTAT CONFIGURATIONS 


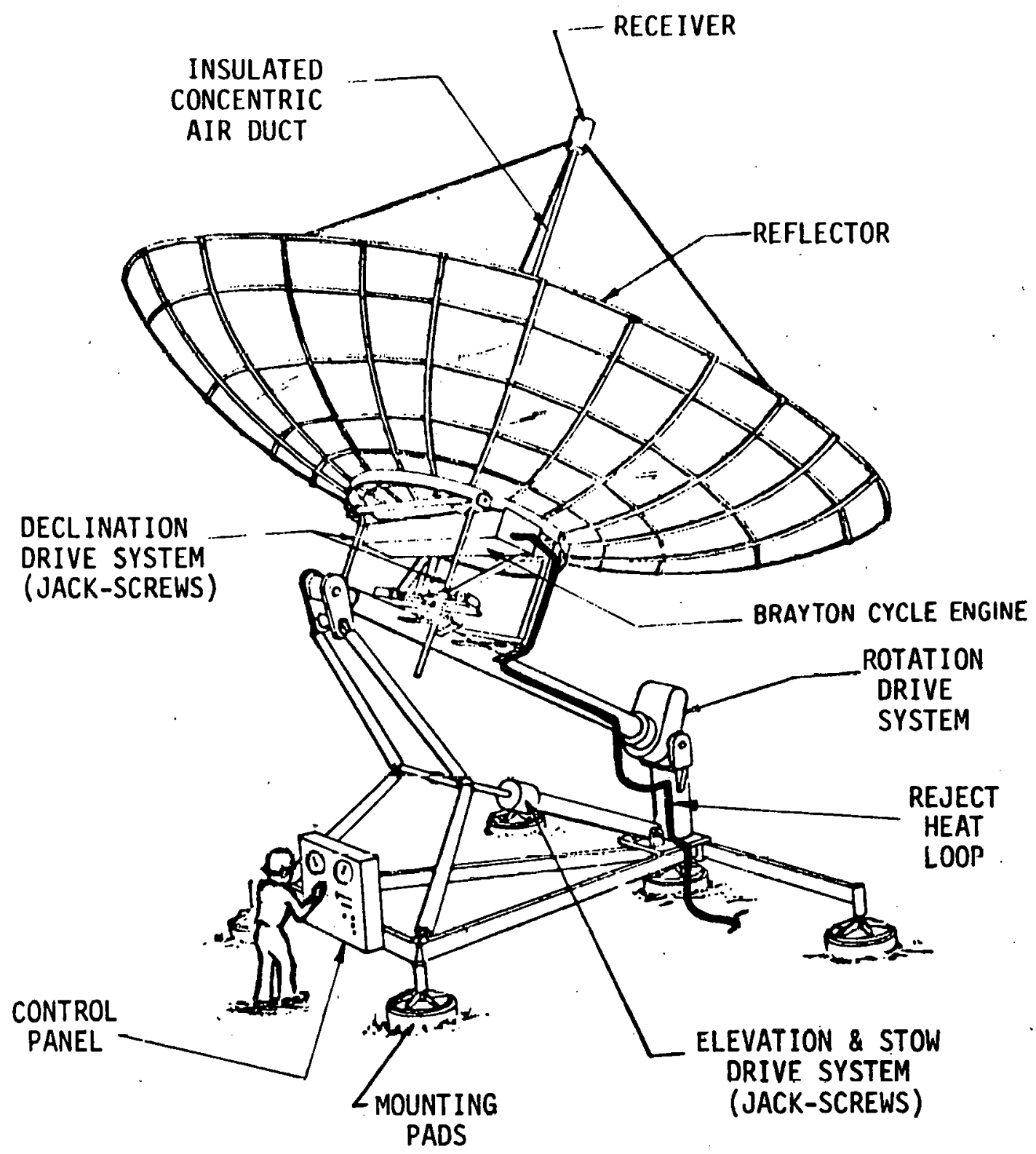

SOURCE: Reference 14.

FIGURE 3-9 CONCEPTUAL DESIGN FOR 10-kW PARABOLIC DISH/BRAYTON CYCLE ENGINE SYSTEM 
are also being considered for use in conjunction with the "power tower" point concentrator system previously described.

Advantages of parabolic dishes include their ability to generate very high temperature levels (Figure 3-10) and their flatter output curve during the day (as compared to that of medium-level concentrators) as a result of following the sun with a two-axis tracking system.

\section{System Performance}

There is a wide range in the projected thermal/economic performance levels of the various collector/heat engine solar power options being investigated. In general, when operating in arid regions, the higher concentration systems (such as the "power tower") are projected to have more favorable performance characteristics than lower level concentrating systems, primarily because of their ability to operate at higher temperatures and, thereby, higher efficlency levels. On the other hand, these highconcentration systems may entail a higher degree of risk because of uncertainties in the nature of solar radiation (discussed in Section 3.4) and the requirement to maintain precise two-axis tracking under severe environmental conditions.

The systems for which there is the most operational experience at this time are those using parabolic trough collectors and organic Rankine cycle engines. Several such systems have been installed in the United States, and their performance characteristics are currently belng evaluated. The performance of this system, which is well adapted for use in distributed energy systems, should be similar to that of other Iinear concentrator/engine options that are under consideration (for example, segmented mirror systems with steam Rankine cycle engines). Therefore, this system configuration is considered below to illustrate the general performance characteristics of distributed solar thermal power systems in this size range. 


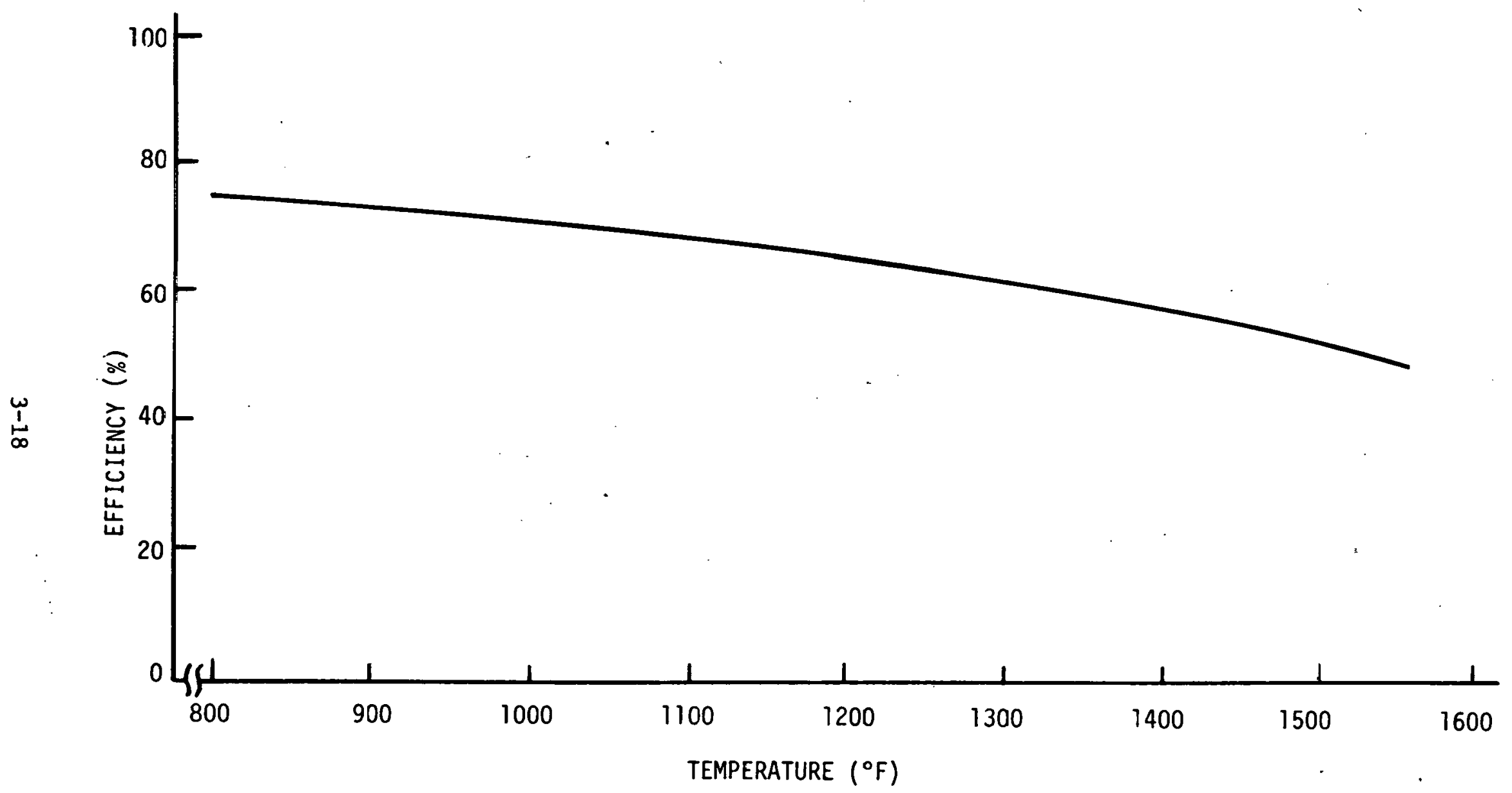

SOURCE: Reference 14.

FIGURE 3-10 VARIATION GF PARABOLIC DISH COLLECTOR EFFICIENCY WITH TEMPERATURE 
The annual thermal performance of the parabolic trough collectors In these systems is similar to that shown in Figure 3-2. The efficiency characteristics of the organic Rankine cycle engines which can be used to convert solar energy into mechanical power are discussed in Chapter 15.

The collector efficiency and engine efficiency characteristics can be used to determine an overall system efficiency defined as:

$$
n_{s}=n_{c} \times n_{e}
$$

where:

$$
\begin{aligned}
& \eta_{s}=\text { system efficiency, } \\
& \eta_{c}=\text { collector efficiency, and } \\
& \eta_{e}=\text { engine efficiency. }
\end{aligned}
$$

The resultant system efficiency is presented in Figure 3-11. As indicated, for this (and any other collector-engine combination), there 18 an operating temperature which maximizes system efficiency and, therefore, minimizes collector array area requirements for any specified output. For the design considered, the system efficiency under average solar flux conditions is about $14 \%$ and occurs at an operating temperature of about $600^{\circ} \mathrm{F}$. However, the efficiency vs. temperature curve is fairly flat, and there may be practical advantages for operating the system at as low a temperature as possible, consistent with acceptable efficiency levels. Such practical considerations include the ability to use a hot water thermal storage system (1imited by operating pressures) and choice of materials of construction, pumps, valves, etc. System operation in clear-day, noon flux conditions will result in a higher system efficiency than those shown in Figure 3-11.

\section{E. Energy Availability and Storage}

If no storage is used, most of the output from a solar thermal power unit will be produced during a relatively short period of 5-6 hours during the middle of the day. Consequently, without storage, solar thermal power units can be used only to supplement conventional power sources or to handle loads that can be satisfied on a discretionary basis (for example, irrigation water pumping). Without the use of energy storage, $1 \mathrm{~kW}$ of 


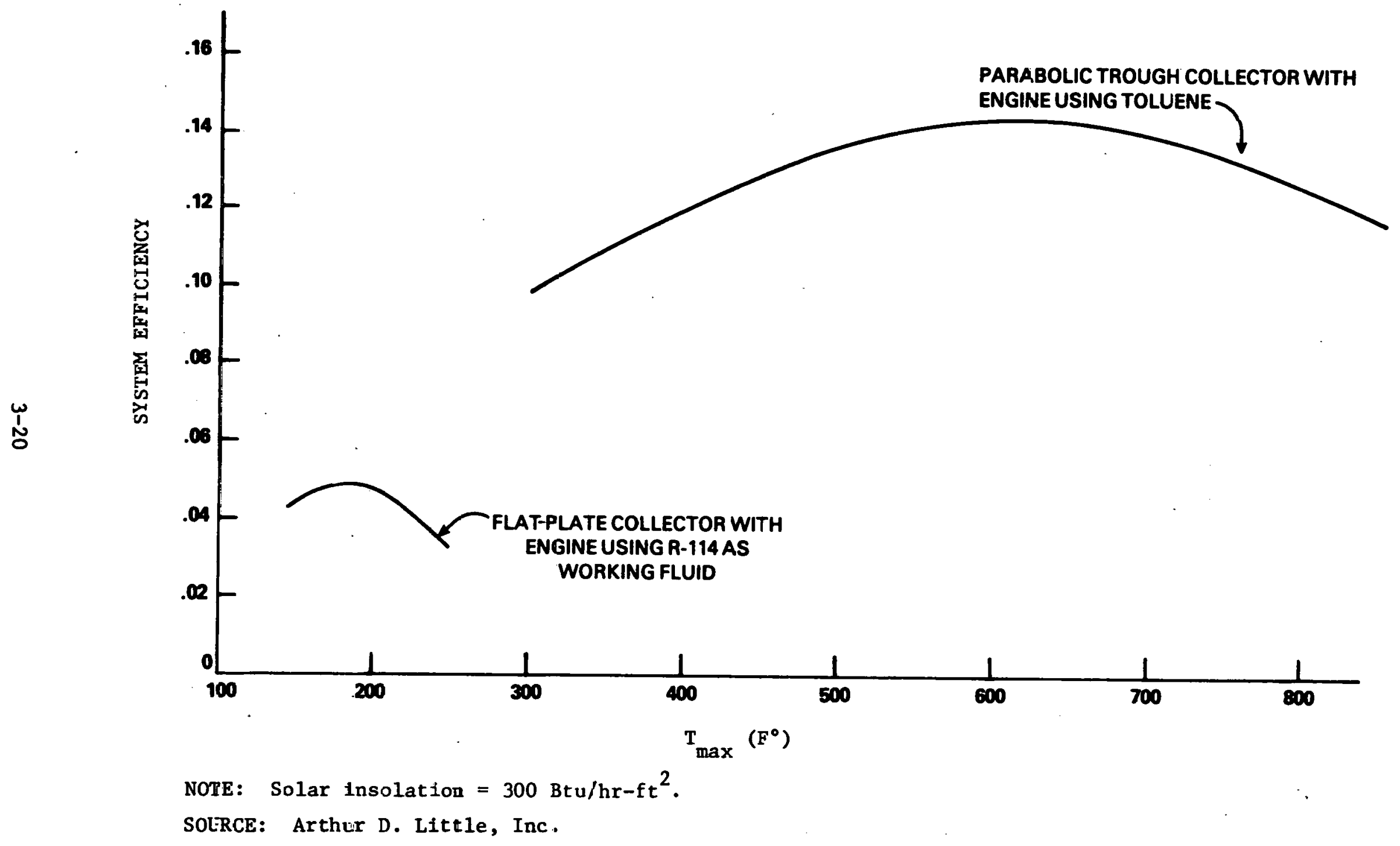

FIGURE 3-11 OVERALL SYSTEM EFFICIENZY 
capacity will generate about 5-8 kWh of electric energy. In fairly sunny areas such as Alburquerque, N.M., the annual capacity factor* of a zero storage system would be roughly $12-16 \%$. This should be considered when comparing the cost of solar thermal power systems with conventional systems which can operate at rated capacity on demand (24 hours per day, as available).

For many applications, energy storage will be required for practical system operation. For solar thermal power systems, thermal storage is generally utilized; this allows operation of the heat engine during periods of luw (or zero) insolation and provides a buffer to prevent unnecessary thermal cycling of equipment. For low-temperature systems (up to about $300^{\circ} \mathrm{F}$ ), water can be used as the storage medium. For temperatures up to about $750^{\circ} \mathrm{F}$, heat-transfer oils can be used for energy storage, while at higher temperatures various heat-of-fusion salts have been constdered. (9) Practical higher-temperature, energy storage systems are still in the developmental stage. $(15,16)$

The output of a solar thermal power system is mechantcal energy in the form, of shaft power. This form of output is highly flexible and can be used as appropriate to drive electrical generators, the compressors of cooling systems, or water pumps. The applications which are receiving primary attention for use with solar thermal power units are discussed below.

Irrigation Water Pumping:

Water pumping is a particularly favorable application for solar thermal power systems, since the water being pumped can be used for cooling the condenser of the heat engine, the water can be pumped primarily when the sun is shining, thereby eliminating or reducing the need for thermal storage, and water pumping is often required in rural areas where

\footnotetext{
* Annual capacity factors for system operation without storage in more cloudy regtons, such as New England, would be about 9-12\%.
} 
conventional energy costs are high. Consequently, irrigation water pumping Is the most advanced of the solar thermal power applications. Several dozen small. (1-25 kW) water pumps using flat-plate collectors and organic Rankine cycle engines have been installed by Sofretes (a division of Renault Moteurs International of France) in rural areas of Africa and Mexiço. $(3,17)$

A 25-kW system was installed under DOE sponsorship in

the Estancia Valley of New Mexico using parabolic trough collectors and an organic Rankine cycle engine. A 150-kW system of similar design was Installed in Gila Bend, Arizona, as part of a program sponsored by the. Northwest Mutual Life Insurance Company. (18)

\section{Alr Conditioning:}

The output of a solar thermal power unit can be directly coupled to the compressor of a vapor compression cooling system. Solar air conditioning has the potential advantage that the heaviest air conditioning loads often occur during periods of high solar flux.

Several solar air conditioning systems using solar collector/ organic Rankine cycle engine combinations to drive vapor compression cycles have been demonstrated. $(2,19)$ These systems are primarily in the 2-25 ton range (requiring approximately 2-25 hp of solar drive engine capacity) and have utilized both flat-plate and linear concentrator collector systems.

\section{Electric Power Generation:}

Any solar thermal power unit can be used to generate electric. power, which replaces or supplements that provided by the utility. This application is often complicated by the requirement for precise speed control and switch gear to ensure a proper interface between the solar power system and the utility. To date, solar thermal electric power systems have not been extensively demonstrated. However, the primary thrust . of the DOE program and, in particular, the "power tower" program is to generate electricity to be fed into the electric grid. Furthermore, 
the Jet Propulsion Laboratory has initlated a program to develop smaller (1-5 MW) solar thermal electric power systems for use within a distributed energy system context. (20)

Total Energy System:

The heat engine of a solar thermal power system rejects most $(60-85 \%)$ of its input energy as heat at relatively low temperature levels $\left(80-200^{\circ} \mathrm{F}\right)$. This lower temperature reject heat can be used for space heating or for process/domestic hot water preheating. For this reason, there has been an active program at the Sandia Laboratories for over four years to develop solar thermal power systems for use within a total energy system context. $(21,22)$

Solar total energy systems are particularly well suited for use within a distributed energy system since the energy-conversion devices (both electrical and thermal) can be placed close to the buildings being served.

\section{Section 3.3: Economics Discussion}

'lhere has been very liüited experience with colar thermal pnwer systems because they are in the experimental stage. Thus, there is a wide variation in cost projections, making it difficult to establish even a rough guide with regard to the cost and economic performance of the power system options.

The system option for which costs are best formulated is the example system discussed in Section 3.2, 1.e., a parabolic trough/organic Rankine cycle engine. It is expected that these costs will be simflar

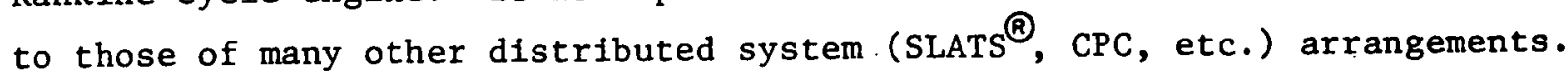
Such systems are being considered for small power units (typlcally 3-500 kW) which might be used in remote regions for pumping and power-generating functions. Such applications are often serviced by engine-driven pumps and generators.

Table 3-1 indicates the present and projected costs of a range of solar concentrator options. The costs indicated for larger quantities were rough estimates at the time of the survey (1976) and generally not. based on time-proven designs (because they are subject to change as dictated by experience). However, these figures indicate that a concentrator 
TABLE 3-1

STATUS OF SOLAR CONCENTRATOR SYSTEMS

\begin{tabular}{|c|c|c|c|c|c|}
\hline TYPE & COMPANY & $\begin{array}{c}\text { CONCENTRATION } \\
\text { RATIO } \\
\end{array}$ & $\begin{array}{l}\text { PRESENT WHOLESALE } \\
\text { PRICE }\left(\$ / \mathrm{ft}^{2}\right) \\
\end{array}$ & $\begin{array}{r}\text { MASS PROD. } \\
\text { PRICE }\left(\$ / f t^{2}\right) \\
\end{array}$ & $\begin{array}{r}\text { CURRENT } \\
\text { STATUS } \\
\end{array}$ \\
\hline CPC & Steelcraft, Inc. & - & $\begin{array}{c}25 \\
\text { (excluding rack) }\end{array}$ & $\begin{array}{c}15-20 \\
\text { (excluding rack) }\end{array}$ & $\begin{array}{l}\text { commercial } \\
\text { production }\end{array}$ \\
\hline Parabollc trough & $\begin{array}{l}\text { Alberquerque- } \\
\text { Western, Inc. }\end{array}$ & 20 & $\begin{array}{c}4.50-4.75 \\
\text { (plus tracker) }\end{array}$ & $\begin{array}{l}\text { developing } \\
\text { advanced design }\end{array}$ & $\begin{array}{l}\text { commercial } \\
\text { production }\end{array}$ \\
\hline Parabollc trough & Beam Englneering & - & 22 or less & "much less" & $\begin{array}{l}\text { commerclal } \\
\text { production }\end{array}$ \\
\hline Parabolic trough & $\begin{array}{l}\text { Acurex Corp. } \\
6^{\prime} \text { wide } \\
4^{\prime} \text { wide }\end{array}$ & $\begin{array}{r}58 \\
-\end{array}$ & $\begin{array}{l}15-22 \\
13-20\end{array}$ & $\begin{array}{c}\text { less } \\
8\end{array}$ & $\begin{array}{l}\text { commerclal } \\
\text { production }\end{array}$ \\
\hline Parabolic trough & Solartec Corp. & - & $9-16$ & about same & $\begin{array}{l}\text { commercial } \\
\text { production }\end{array}$ \\
\hline $\begin{array}{l}\text { lixed trough; } \\
\text { tracking recelver }\end{array}$ & AAI & 8 & - & $8-9$ & R\&D \\
\hline $\begin{array}{l}\text { Fixed stepped trough; } \\
\text { tracking recelver }\end{array}$ & General Atomic Co. & 60 & - & $\begin{array}{c}6 \\
\text { (1nstalled) }\end{array}$ & R\&D \\
\hline $\begin{array}{l}\text { Fixed stepped trough; } \\
\text { tracking receiver }\end{array}$ & Sclentific Atlanta & - & $14-15$ & abọut same & $\begin{array}{l}\text { commerctal } \\
\text { production }\end{array}$ \\
\hline Linear helfostat & Itek & - & - & 10 & R\&D \\
\hline Linear hellostat & Schedah1 & 40 & $20-25$ & $4-10$ & $\begin{array}{r}\text { prototype } \\
\text { testing }\end{array}$ \\
\hline Linear Fresnel lens & Nor thrup, Inc. & 10 & $12-17$ & $\begin{array}{c}8 \\
\text { (1nstalled) }\end{array}$ & $\begin{array}{l}\text { commercial } \\
\text { production }\end{array}$ \\
\hline Parabolic dish & $\begin{array}{l}\text { ANSALDO/ } \\
\text { Messerschmidt }\end{array}$ & - & 165 & 1 e.s8 & ready for order \\
\hline Parabolic dish & JPL & 1000 & - & 11 & R\&D \\
\hline Parabolic trough & Sunpower Systems & - & 12 & about same & $\begin{array}{l}\text { comercial } \\
\text { production }\end{array}$ \\
\hline $\begin{array}{l}\text { Multiple parabolic } \\
\text { dishes w/solar cella }\end{array}$ & Varian & 1000 & $\begin{array}{c}60-90 \\
(w / 0 \text { cells })\end{array}$ & very low & R\&D \\
\hline $\begin{array}{l}\text { Multiple parabolic } \\
\text { dishes w/solar celle }\end{array}$ & MIT & $300-500$ & - & $?$ & R\&D \\
\hline $\begin{array}{l}\text { Fixed dish; tracking } \\
\text { recelver }\end{array}$ & E-Systems, Inc. & - & - & $\begin{array}{c}3-5 \\
\text { (installed) }\end{array}$ & R\&D \\
\hline $\begin{array}{l}\text { liult1ple Fresnel } \\
\text { lens w/solar cells }\end{array}$ & Sand La Labs & $50-100$ & $\left(w / 0 c^{21}\right.$ & $(w / 0 \operatorname{cells})$ & prototype \\
\hline Parabollc trough & Polyeolax & 25 & $\mathrm{NA}^{*}$ & NA & NA \\
\hline
\end{tabular}


cost of approximately $\$ 8 / \mathrm{ft}^{2}$ to $\$ 12 / \mathrm{ft}^{2}$ may be attainable in production quantities. (9) The resultant system cost on an installed basis is estimated in Figure 3-12. As indicated, installed system cost would approach $\$ 2000 /$ peak $\mathrm{kW}$ (without storage), based on the assumptions indicated. The installation costs are significant and probably the most difficult to estimate, because of variations in labor costs, site preparation, etc.

The useful output of a solar thermal power system is measured in $\mathrm{kWh}$ per year. For the example system this would be approximately $1750 \mathrm{kWh}$ per year per peak $\mathrm{kW}$ of installed capacity when operated in a favorable climatic region such as Albuquerque, New Mexico.

The cost of electrical energy from a solar power unit is a function of many variables, including:

- initial cost,

- operation and maintenance costs,

- interest rates,

- depreciation (useful life), and

- capacity factor.

The curves of Figure 3-13 assume operation in a high solar flux area, the installed system cost shown in Figure 3-12, annual fixed charges of $12 \%$, and annual operating and maintenance costs of $5 \%$ of the installed system cost. (23) Curves are provided for two assumptions re-garding the time duration of the load:

\section{Case A: Year-round operation}

This case assumes that the power unit is used on a year-round basis. Such applications could include electric power generation and desalination.

Case B: Periodic operation

This case assumes that the system is used only half the year. 


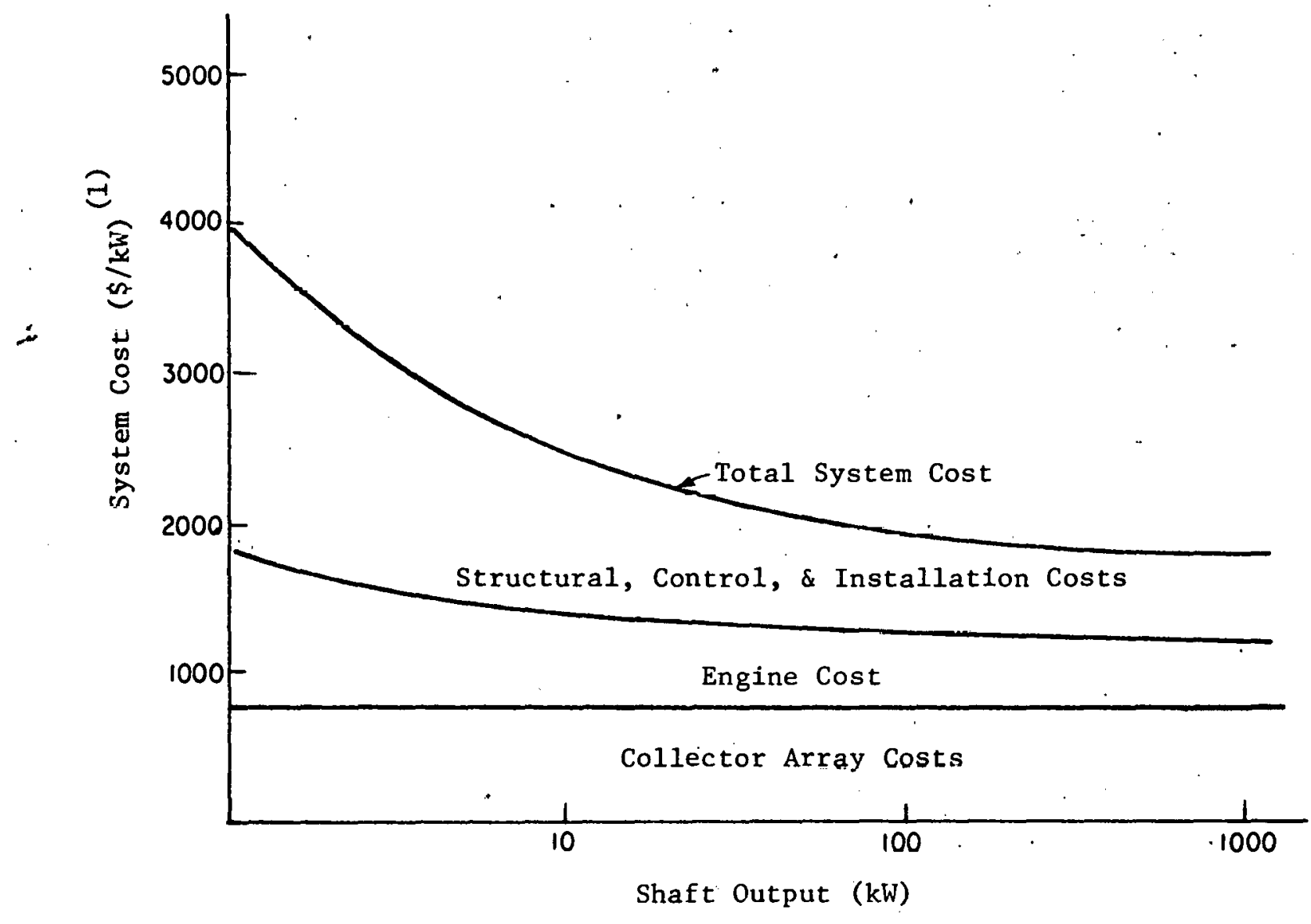

(1) Refers to peak kllowatt, no storage included.

SOURCE: Reference 23.

FIGURE 3-12 COST OF INSTALLED SOLAR THERMAL POWER SYSTEM (Parabolic Trough/Organic Rankine Cycle Engine) 


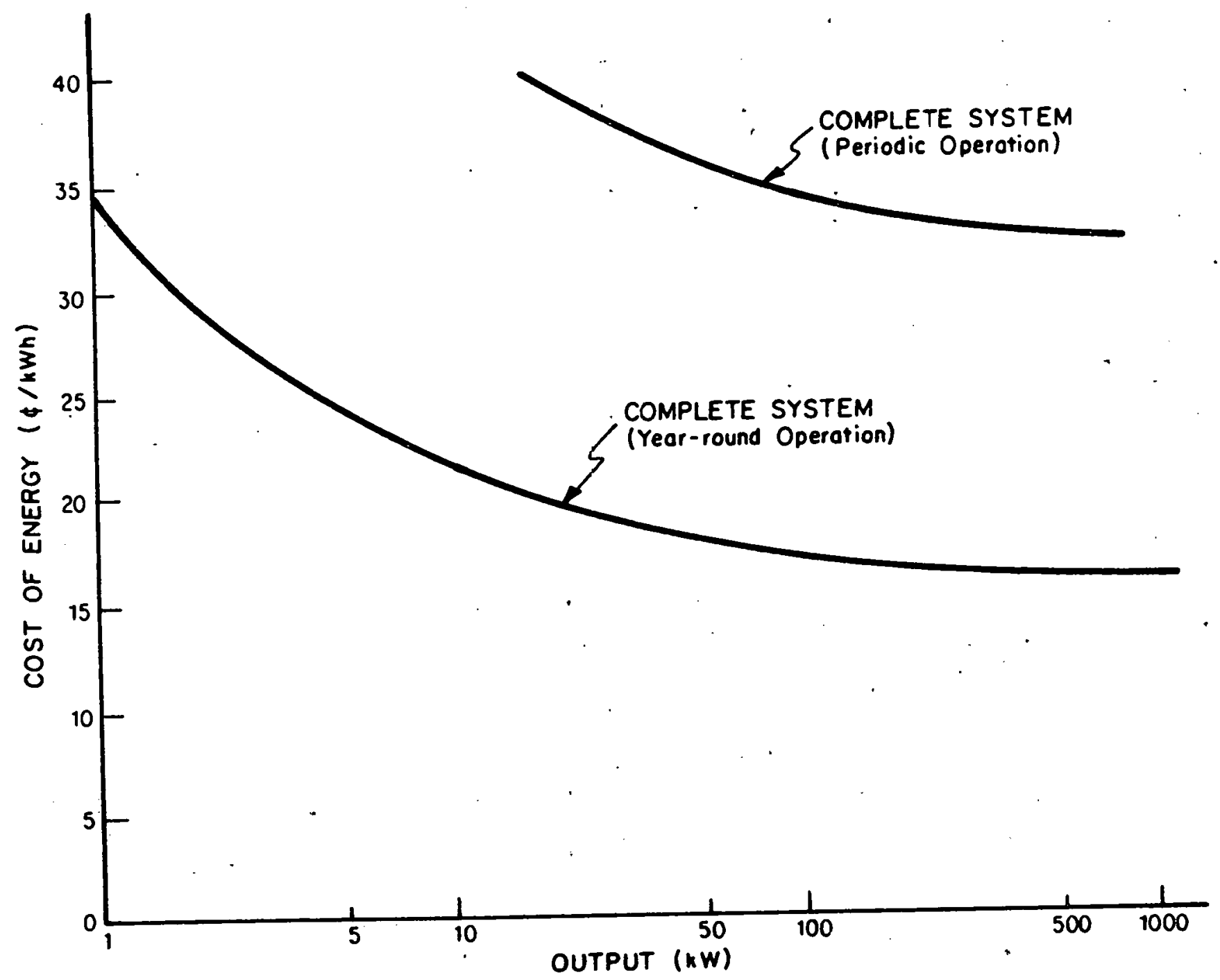

SOURCE: Rieference 23.

FIGURE 3-13 COST OF ELECTRICAL ENERGY (Parabolic Trough/Organic Rankine Cycle Engine) 
This may be the case for many air conditioning and irrigation pumping applications.

The cost of power produced by the system is in the $16-34 \mathrm{c} / \mathrm{kWh}$ range for systems with year-round operation. This cost of power is still much higher than that from large central utilities, but may approach that from small Diesel and gas turbine power units if anticlpated increases in fuel costs occur.

Power costs from large (150-MW) central receiver power systems are projected to be in the $8-15 \mathrm{c} / \mathrm{kWh}$ range. (24) These relatively low power-cost projections reflect, in part, the large size of these power units and the assumption of large-scale production of key subsystems. They assume solar avallability typical of Albuquerque, New Mexico (approximately $0.7 \times 10^{6} \mathrm{Btu} / \mathrm{ft}^{2} / \mathrm{yr}$ total) and installed hellostat costs in the $\$ 8-\$ 10 / \mathrm{ft}^{2}$ range. These low hellostat costs are estlmated to require minimum production levels of 50,000 hellostats per year (sufficient for a total capacity of $250 \mathrm{MW})$. Because of technical performance and cost uncertainties associated with these systems, there is still considerable disagreement whether the overall economic performance goals for this type of system will be achieved.

Section 3.4: Limitations

\section{A. General Constderattons}

Solar thermal power generation w1ll probably require some degree of flux concentration to be practical, because of the elevated temperatures required for efficlent operation of most heat engines. With the exception of the CPC design, this implies some form of concentrating optics which accept only highly collimated solar radiation. Since, in many areas, a significant portion of the insolation is diffuse (measurements in Phoenix Indicate that $20-25 \%$ of its total annual insolation is diffuse), (25) systems which can utilize only this direct insolation will be at a disadvantage. To make matters worse, a portion of that insolation classified as direct (originating from within 5.5 degrees of the sun) is also 
unusable to these systems since they are unable to focus energy from outside the angle subtended by the solar disk ( 0.5 degree).

The above considerations could limit the applicability of higher concentration systems to arid portions of the country, where there is less solar scattering by dust, clouds, haze, pollution, etc.

\section{B. Equipment Availability}

There are a number of companies offering solar collectors which utllize some degree of cuncentialiun dild which could be used in powcr systems. Four of the firms which have supplied concentrating collectors for various demonstration projects are listed in Table 3-2, along with specifications for their equipment. The collector systems indicated have usually been provided on a demonstration basis and, therefore, the supply of these collectors is not as assured as for the flat-plate variety. The CPC collector, which is in advanced development, is not at this time commercially available, although it is expected to be available in the near term (one-three years).

While both the parabolic dish and power tower are being experimentally investigated, neither is available on a commercial basis. The major emphasis being given the "power tower" program indicates, however, that heliostats could become cormercially available in the near term (five years) if the test programs now being initiated are successful.

The availability of the heat engines which might be used in solar thermal power systems is discussed separately in their respective chapters.

\section{Safety}

Aside from the safety considerations associated with the engine (outlined in chapters devoted to each engine), these systems should not encounter safety problems other than those attributable to any system using high-temperature, heat-transfer fluids (oil, high-pressure water, etc.). Care should be taken to avoid spills, burns, etc. 
TABLE 3-2

\section{MANUFACTURERS OF CONCENTRATING SOLAR COLLECTORS}

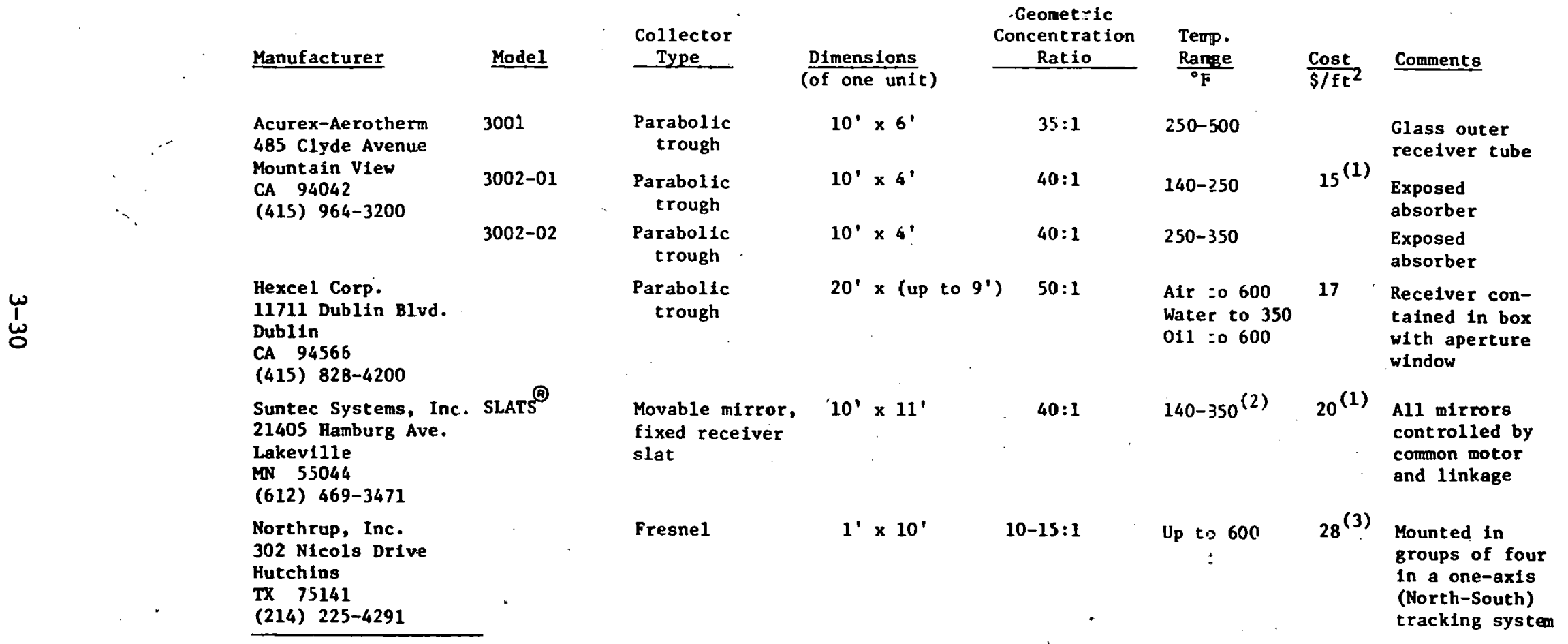

(1) Based on $5,000 \mathrm{ft}^{2}$ to $10,000 \mathrm{ft}^{2}$.

(2) Higher-temperature system under development.

(3) Includes track1ng mechan1sm and controls, insulated manifolding, frame, and expansion joints.

SOURCE: Based on data compiled by Arthur D. Little, Inc. 


\section{Environmental Concerns}

Distributed solar thermal energy systems are expected to be environmentally quite benign. There will be no burned fuel residue or hazardous waste material to dispose of, as with more conventional energy systems, although each engine type may have environmental considerations associated with its use, e.g., with its working fluid.

If a cooling tower is used, the plume could perhaps have a very minor effect on local climate, and the tower itself could adversely affect the view of the landscape. Care would have to be taken to avold large temperature rises and working-fluid leaks into a local body of water, should this method of direct condenser cooling be selected. However, by the very nature of a distributed energy system, the cooling loads will be comparatively small. Such small-scale systems are not expected to have a serious impact on local ecosystems.

Even a small 10-MW (peak) power plant will require about 80 acres of land for Installation. Therefore, one environmentally related issue which could significantly impact the use of solar thermal power units is land availability. In regions of the country where there are large areas of arid land, the land availability issue may not be a significant economic or environmental barrier. In other parts of the country, however, the environmental impact of a solar thermal power plant could be significant since the installation of significant capacities of solar thermal power generating capacity may require utilization of tracts of what is now farm, forest, or grassland.

\section{E. Output}

The basic output of all the solar thermal power systems is shaft power which can be used to drive generators, pumps, or compressors. This provides a great deal of flexibility in the use of solar thermal power systems and facilitates integration with the utility (since synchronous alternating power can be produced directly). 


\section{THIS PAGE LEFT BLANK}




\section{REFERENCES}

1. Blancardi, F., et al. "Design and Operation of a Solar-Powered Turbocompressor Air Conditioning and Heating System." 10th Intersociety Energy Conversion Engineering Conference, Newark, Delaware, August 17-22, 1975. pp. $186 \mathrm{ff}$.

2. Prigmore, D., et al. "A Prototype Solar Powered Rankine Cycle System Providing Residential Air Conditioning and Electricity." 9th Intersociety Energy Conversion Englneering Conference, San Francisco, California, August 26-30, 1974. pp. 326 ff.

3. Girardier, J.P., et al. "Les Moteurs Solaires et L'Habitat pour Les Zones Arides-Realisations Actuelles et Perspectives." Conference on the Sun in the Service of Mankind, Parts, France, July 2-6, 1973.

4. Sandia Laboratories. Highlights Report Solar Thermal Conversion Program Central Power Projects. Report prepared for Energy Research and Development Administration, March 1977. NTIS Report No. SAND77-8011.

5. Powe11, J.C. Dynamic Conversion of Solar Generated Heat to Electricity. Vo1. II, Executive Summary. Prepared by Honeywell, Inc. for National Aeronautics and Space Administration, August 1974. NASA Report No. N75-16079.

6. Grosskreutz, J., et a1. "Solar Thermal Conversion to Electricity Utillzing a Central Recelver, Open Cycle Gas Turbine Design." 12 th Intersociety Energy Conversion Engineering Conference, Washington, D.C., August 28 - September 2, 1977. pp. 1209 ff.

7. Arthur D. Little, Inc. Conceptual Deslgn and Analysis of a Compound Parabolic Concentrator Collector Array. Final Report. Prepared for Argonne National Laboratory, August 1977. NTIS Report No. ANL-K-773855-1.

8. Suntec Systems, Inc., Lakeville, Minnesota. Product 1iterature. May 1977.

9. Office of Technology Assessment. Application of Solar Technology to Today's Energy Needs. Vo1. II. Washington, D.C. June 1977.

10. Aerospace Corporation. Technical Summary of Distributed Collector Concepts. Prepared under Contract No. F(04-3)1101 for U.S. Energy Research and Development Administration, 1976. NTIS Report No. ATR-76 (7523-07)-1(II).

11. Northrup, Inc., Hutchins, Texas. Product literature. November 1976.

12. Alvis, R.L., et al. Solar Irrigation Program Plan. Second Revision. Sandia Laboratories, May 1978. NTIS Report No. SAND78-0308. 
13. Gupta, B., et al. Technical Feasibility Study of Modular Dish Solar Electric Systems. Prepared under Contract No. NAS3-19740 by Honeywell, Inc. for U.S. Energy Research and Development Administration, March 1976. NTIS Report lio. ERDA/iNASA/19740-76/1.

14. Arthur D. Little, Inc. Phase I Report - Preliminary Design of a $10 \mathrm{KW}$ Solar Heated Open Brayton-Cycle Engine. Prepared for Civil Engineering Laboratory, Naval Construction Battalion Center, Port Hueneme, California, 1977.

15. Comstock and Wescott, Inc., Cambridge, Massachusetts. Product literature and personal communications. May 1977.

16. Bramlette, T.T. et al. Survey of High Temperature Thermal Energy Storage. Report prepared by Sandia Laboratories, March 1976. NTIS Report No. SAND75-8063.

17. Sofretes (Renault Moteurs International), L. Boursdidiere, France. Product 1iterature. May, 1976.

18. Alexander, G., et al. Final Report on the Modification and 1978 Operation of the Gila-Bend Solar-Powered Irrigation Pumping System. Prepared by Sandia Laboratories, March 1979. NTIS Report No. SAND79-7009.

19. Eckard, S. "Test Results for a Rankine Engine Powered Vapor Compression Air-Conditioner for 366K Heat Source." 11th Intersociety Energy Conversion Engineering Conference, State Line, Nevada, September 12-17, 1976. pp. $1169 \mathrm{ff}$.

20. Jet Propulsion Laboratory. Executive Summary Point Focusing Distributed Receiver Technology Project. Report prepared for Department of Energy, 1978. Pasadena, California, Jet Propulsion Laboratory Report No. 5104-26.

21. Sandia Laboratories. Proceedings of the Solar Total Energy Symposium. Sponsored by U.S. Energy Research and Development Administration, Albuquerque, New Mex1co, January 1977. NTIS Report No. SAND77-0029.

22. Petterson, B., Jr. Solar Total Energy Test Facility Project. Sem1annual Report - October 1976 - March 1977. Report prepared by Sandia Laboratories, August 1977. NTIS Report No. SAND77-0738.

23. Arthur D. Little, Inc. Phase I Report - Solar Assessment Study in Support of the International Ekistics Program. Report prepared for the Argonne National Laboratory, Argonne, Illino1s, 1977.

24. Sandia Laboratories. Recommendations for the Conceptual Design of the Barstow, California Solar Central Receiver Pilot Plant Executive Summary. October, 1977. NTIS Report No. SAND77-8035. 


\section{REFERENCES (continued)}

25. Information from Desert Sunshine Exposure Tests, Inc., Phoenix, Arizona, September 1976.

26. Gruther, D., et al. "Results from Circumsolar Radiation Measurements." Sharing the Sun! Solar Technology in the Seventies. A joint conference of the American Section of the International Solar Energy Society and the Solar Energy Society of Canada, Inc., Winnipeg, Canada, August 15-20, 1976. Vol. I. pp. $363 \mathrm{ff}$. 
SUPPLEMENTARY BIBLIOGRAPHY

1. Sandia Laboratories. Solar Total Energy Program Semi-Annual Report, April 1975 - September 1975. Apri1 1976. NTIS Report No. SAND76-0078.

2. Selcuk, M. A Preliminary Technical and Economic Assessment of Solar Thermal Power Plants Using Line Concentrators. Jet Propulsion Laboratory, July 1975. NTIS Report No. EM342-302.

3. Univers1ty of Minnesota and Honeywe11, Inc. Research Applied to Solar Thermal Power Systems. Report prepared for National Science Foundation, January 1974. NTIS Report No. NSF/RANN/SE/GI-34871/PR/73/4.

4. Jarvinen, R. "Solar-Heated Air Turbine Generating Systems." 10th Intersociety Energy Conversion Engineering Conference, Newark, Delaware, August 17-22, 1975. pp. $583 \mathrm{ff}$.

5. Backus, C. "Fixed Mirror Solar Concentration for Electrical. Ceneration." 10th Intersociety Energy Converstion Engineering Conference, Newark, Delaware, August 17-22, 1975. pp. $601 \mathrm{ff}$.

6. Wen, L., et al. "Comparative Performance of Solar Thermal Power Generation Concepts." 11th Intersociety Energy Conversion Engineering Conference, State Line, Nevada, September 12-17, 1976. pp. $1206 \mathrm{ff}$.

7. Caputo, R., et al. "Solar Thermal Electric Power Plants: Their Performance Characteristics and Total Social Costs." 11th Intersociety Energy Conversion Engineering Conference, State Line Nevada, September $12-17,1976$. pp. $1216 \mathrm{ff}$.

8. The Aerospace Corporation. Highlights of the Solar Total Energy Systems, Distributed Collector Systems, and Research and Development Projects Semiannual Review, Atlanta, Georgia, January 26-27, 1976. Sponsored by the Energy Research and Development Administration under Contract No. E(04-3)-iloi. E1 Segundo, California, March 26, 1976. Aerospace Report No. ATR-76(7523-11)-5.

9. Sandia Laboratorles. Solar Total Energy Program Semiannual Report, October 1975 - March 1976. June 1976. NTIS Report No. SAND76-0205.

10. McCulloch, W.H. et al. Small Solar Thermal Power Systems Profects Semtannual Report, October 1977 - March 1978. Report prepared by Sandla Laboratories, February 1979. NTIS Report No. SAND78-0951.

11. Sandia Laboratories. An Introductory Comparison of Brayton and Rankine Power Cycles for Central Solar Power Generation. July 1978. NTIS Report No. SAND78-8010.

12. Jet Propulsion Laboratory. Thermal Power Systems Applications Project, Annual Technical Report. Vol. 1. Pasadena, California: California Institute of Technology, Jet Propulsion Laboratory, January 1979. 


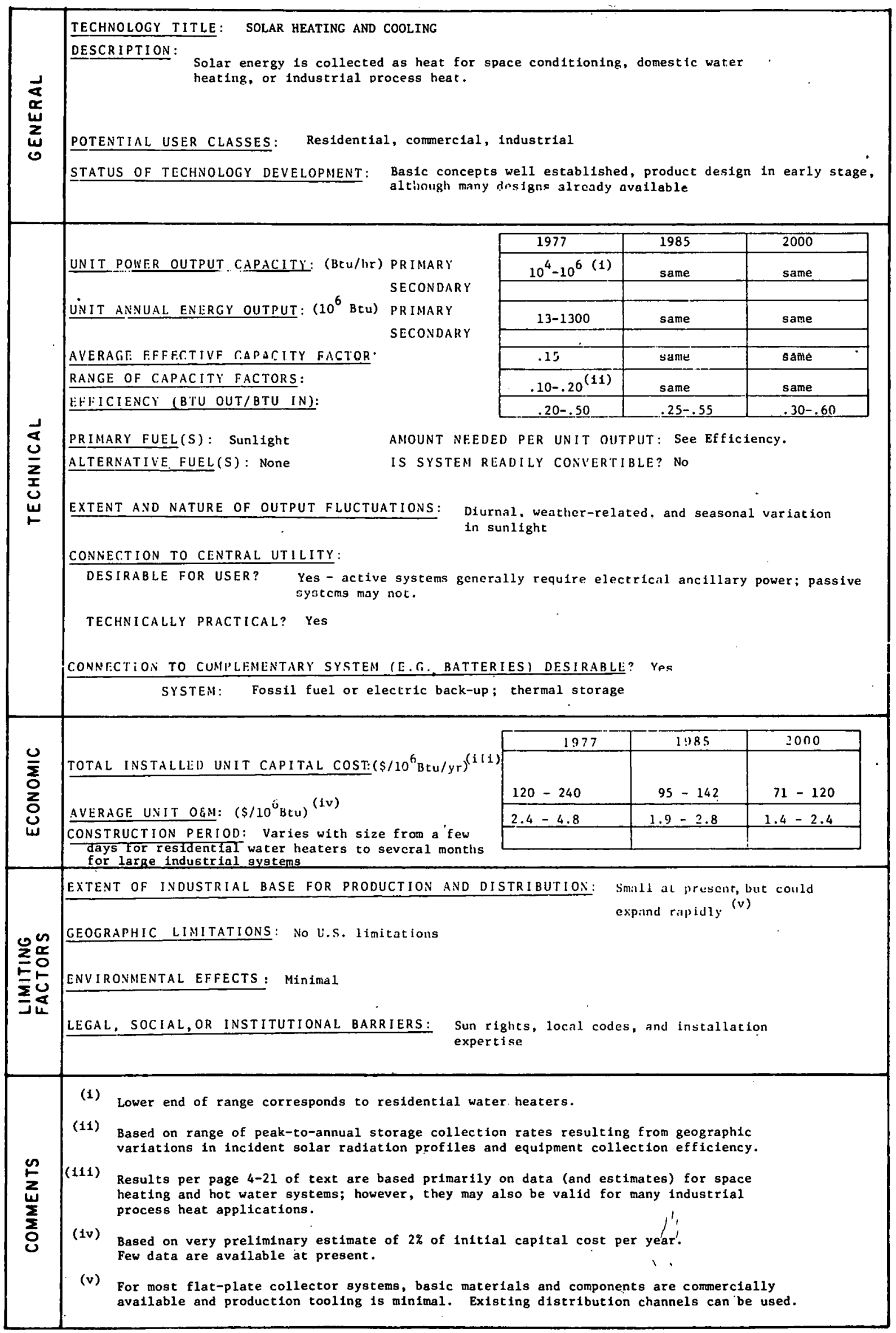


CHAPTER 4

SOLAR HEATING AND COOLING

\section{Section 4.1: Introduction}

Solar heating and cooling systems use heat collected from the sun's radiation for space conditioning or domestic water heating. The equipment elements include: solar collectors, thermal storage devices, heat-actuated air conditioners (for solar cooling), and the necessary controls and ancillary. equipment. Since it is generally agreed that, at least in the near future, solar heating and cooling will tend to supplement rather than supplant conventional systems, the interfaces with conventional equipment and utility-supplied back-up energy are critical. As with all systems involving solar collection, the collected energy will be proportional to the collector area (and efficlency). Present system sizes range from the order of $50 \mathrm{ft}^{2}$ for small domestic water heaters to more than $5,000 \mathrm{ft}^{2}$ for large commercial space heating and/or cooling systems.

Solar heating and cooling constitutes an infant but rapidly expanding industry. As recently as the end of 1974, the Unfted States had only 62 solar houses, ${ }^{(1)}$ and now they number in the thousands. The solar heating and cooling industry is projected to have an annual sales volume of $\$ 1.5$ to $\$ 2.5$ billion by $1990--$ with the cumulative. installed capacity equivalent to a savings in national energy use of 0.3 to $0.5 \%$ (2) Recent projections of the Domestic Policy Review and Council on Environmental Quality indicate solar heating and cooling

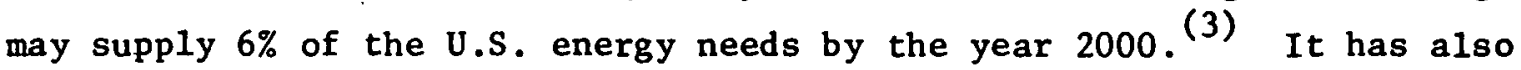
been estimated that, by 2020 , solar heating and cooling might supply from $5-10 \%$ of the national energy use. (4)

Section 4.2: Technical Discussion

\section{A. Solar Collectors}

Solar collectors are devices which, by virtue of geometry or surface properties, absorb solar energy as heat and impart this energy 
to a heat-transfer fluid circulated through the collector. The thermal design of collectors involves maximizing the amount of heat absorbed and, at the same time, minimizing the various heat losses. Since the heat losses from the collector will increase with collection temperature, the efficiency of a solar collector (the ratio of heat energy collected to solar energy incident) will decrease with increasing collection temperature.

Flat-plate (or non-concentrating) collectors in which the absorber surface is essentially planar are more applicable to low and moderate temperatures and function successfully for diffuse as well as direct radiation. Very-low-temperature designs (e.g., swimming pool heaters) consist merely of a black metal or plastic absorber sheet through which liquid is circulated. However, in most collectors for space conditioning, the absorber is insulated on the back side and covered on the sunlit side by one or more glazings which are transparent to solar radiation but inhibit convective and radiative losses. A basic collector might employ one or two glass or plastic panes above a flat black absorber. Improvements to this design which, can result in increased performance at additional cost and complexity include:

- selective surface coatings on the absorber which are highly absorbent to solar energy but have a low infrared emittance;

- improved pane transmittance by means such as surface etching (to reduce reflection loss) or reduction of absorption within the pane itself (e.g., the use of low iron glass); and

- minfmizing convective transfer between the absorber and cover pane by means of transparent honeycomb cells.

The evacuated tubular design is an advanced collector concept capable of moderate- to high-temperature operation without substantial concentration. This device consists of a selective black absorber located within an evacuated cylindrical tube so that radiation and 
conduction losses are greatly reduced. The evacuated tubular collector, like the flat-plate collector, collects diffuse as well as direct oun11 ght.

The concentration of solar energy increases collection efficiency by reducing the absorber area relative to the aperture (collection) area* High-temperature collection is enhanced by an increased concentration ratio, but this incurs the expense of greater precision of construction and more sophisticated requirements for sun tracking. A valiety of designs exist. Many of the designs involve focussing optics that bring the sun's rays to a single point or line focus. On the other hand, non-imaging designs have been proposed which act as light funnels, concentrating the radiation in a smaller area, but without the precision required for focussing and with a greater tolerance in terms of sun tracking. The methods of tracking vary widely, including designs where either the absorber, the complete reflector, or segments of the reflector move. Typlcal designs discussed in more detall in Chapter 3 include:

- Cylindrical collectors, which result in a line focus. High-concentration parabolic cylinders aligned with axes in the north-south direction can achieve high temperature at the expense of continuous, although rotation only, tracking. Lower concentrating troughs aligned in the east-west position--in approximately the direction of the apparent path of the sun--may require only periodic, seasonal adjustments.

- The compound parabolic reflector ${ }^{(5)}$ is an example of a non-1maging concentrator which, for a given concentration ratio, may be more tolerant of off-axis radiation than focussing designs.

- The Fresnel lens concentrator, which accomplishes concentration with a Fresnel lens instead of a reflector mirror.

* Th1s permits the economical use of the more sophlsticated collection technology. 
- The Solar Linear Array Thermal Systems (SLATS) ${ }^{\circledR}$ collector utilizes a series of slat-like mirror segments which are moved slightly during the course of the day to track the sun. (7)

The concentrating designs, and particularly the more highly concentrating versions, are not effective in collecting diffuse radiation; and, therefore, the applicability of these collectors may be limited to regions with a large amount of direct insolation. Also, because higher temperature performance generally entails some penalties in terms of cost and system complexity, these designs are more likely to find application in commercial installations requiring air conditinning or industrlal process heat applications, rather than residentlal hot water or space heat applications.

Figure 4-1 illustrates the performance of three typical collectors -- a two-pane, flat-plate collector; a vacuum-insulated tubular collector; and a concentrating collector of the SLATS variety.

This plot, which is the common way of expressing the performance of flat-plate collectors, shows efflciency (the ratio of collected to Incident solar energy) as a function of the parameter $\frac{\Delta T}{I}$, where $\Delta T$ is the temperature difference between the fluid entering the collector and the ambient air surrounding the collector, and $I$ is the solar radiation incident on the collector per unit area. (In the case of concentrating collectors, which collect only direct radiation, the efficiency and the parameter $\frac{\Delta T}{I}$ should be based on the direct component of total insolation.)

For low-temperature applications, such as solar water heating, the temperature difference between collector and ambient may typically be in the range of $50^{\circ} \mathrm{F}$. Therefore, for an average incident radiation of $250 \mathrm{Btu} / \mathrm{hr}-\mathrm{ft}{ }^{2}$, the parameter $\frac{\Delta \mathrm{T}}{\mathrm{I}}$ would be about 0.2 . In this range, the higher-temperature designs generally do not have a sufficient performance advantage over flat-plate collectors to justify their increased cost and system sophistication -- particularly for small, residential systems. Note that we would expect the collection efficiency to be higher with the 


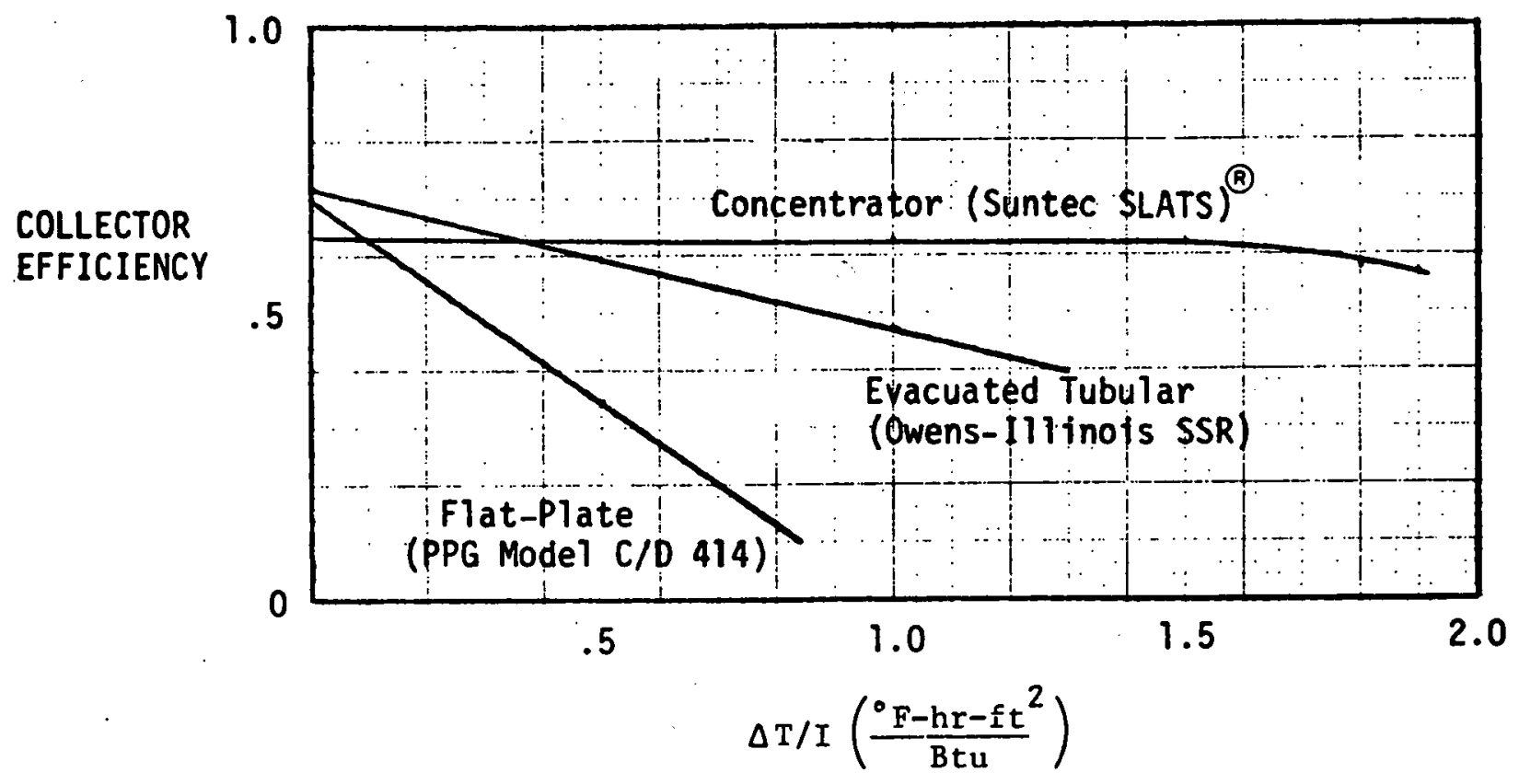

$\frac{\Delta T}{I}=\frac{\text { Inlet Fluid Temperature - Ambient Air Temperature }}{\text { Incident Radiation }}$

SOURCE: Manufacturer's data per Reference 8 .

FIGURE 4-1 COLLECTOR PERFORMANCE DATA 
evacuated tubular collector -- particularly under cloudy conditions, which lead to higher values of $\frac{\Delta T}{I}$. On the other hand, a concentrator, while having some advantages in performance under clear sky conditions, would not function as well in cloudy weather, where a large portion of the radiation would be diffuse.

For higher-temperature applications, such as afr conditioning and many industrial process heat applications, where the parameter $\frac{\Delta T}{I}$ may be in excess of 0.4 , the higher-temperature designs generally have a clear advantage over flat-plate collectors.

Solar collectors may employ either liquld or air as the heat-transfer fluid. Liquid heat-transfer fluids tend to result in more effective heat transfer and minimum puinglng power at the expense of requiring provisions to avold freezing, overheating, or corrosion. Air has advantages in reliability and potential for storage stratification, offset to some extent by reduced heat transfer, higher fluid circulation power, and larger duct sizes. For space heat applications, the reasons for choosing between air and liquid may be quite specific to the application and the designer's preference. In concentrating collectors, or where heat-actuated cooling is required, air is unlikely to be effective because of its limited heat-transfer capabilities.

\section{B. Therma1 Storagc}

Thermal storage must function tn accept the solar heat when available from the collector and supply it to the system load elements as needed. Functionally, it must have both the desired storage capacity and heat-transfer capability. Most existing systems utilize storage with capacity sufficient for diurnal variations in solar flux -- or, at most, a few cloudy days. An alternative approach is to use long-term storage, designed to cope with several cloudy days, ${ }^{(9)}$ or even to level seasonal variations in solar radiation and load. Long-term storage designed to use summer sun for winter has been technically demonstrated in early solar work at MIT and by others, although the large storage sizes required have been considered uneconomical to date. ${ }^{(10)}$ The Annual Cycle Energy 
Storage (ACES) concept is a variation of long-term storage which uses the storage of ice for summer cooling and its production by means of a heat pump for winter heating.

The vast majority of present-day solar storage systems utilize materials with high specific heats -- such as water or rocks. However, developments continue on phase-change materials which would result in markedly reduced storage volume and weights. In some instances, where substantial interior temperature swings can be tolerated, the mass of the building can be used effectively for thermal storage.

For low-temperature thermal storage (below $200^{\circ} \mathrm{F}$ ), water has the advantage of high specific heat and good heat-transfer characteristics and has been the material of choice for low-temperature systems involving liquid collectors. The most common containment for water storage has been steel tanks ranging in size from residential solar water heater tanks of as few as 50 gallons to tanks of several thousand gallons for large systems. Other design approaches have included concrete, fiberglass-reinforced plastic, and plastic or rubber-1ined wooden containers.

Where air collectors are used, rock storage consisting of beds of approximately 1-in. pebbles is generally used. Rock storage is commonly contained in insulated concrete or wooden bins. This type of storage results in larger stratification, permitting the air sent out to the collectors to be nearly room temperature.

Change-of-phase or latent heat materials have the advantage of h1gh storage capacity. The use of these materials requires the resolution of many technical problems, such as incongruent melting and settiing in salt hydrates, a tendency to supercooling, volume expansion on melting, and corrosiveness. Although work continues in this area and it appears to show promise, no change-of-phase heat storage systems have yet been taken to the manufacturing stage other than for small temperaturestabilizing containers. Change-of-phase materials would be particularly attractive for cold storage, since the operating temperature range of materials used for cold storage for air conditioning must necessarily be small -- on the order of $10^{\circ} \mathrm{F}$. 
Table 4-1 illustrates the relative performance of rocks, water, and a phase-change material for a temperature swing of $20^{\circ} \mathrm{F}$. The sensible heat content (per unit weight or volume) of rocks or water corresponding. to a temperature change of $20^{\circ} \mathrm{F}$ is small compared to that of a material experiencing a phase change. Thus the weights and volumes required to store the same amount of heat are considerably larger than those for the phase-change material. For larger temperature swings, the sensible heat content of rocks and water would be increased and the advantage of the phase-change material would be less pronounced. Additional discussion on thermal storage for solar and other applications is presented in Chapter 19.

\section{TABLE $4-1$}

RELATIVE WEIGHTS AND VOLUMES OF THERMAL STORAGE MATERIALS FOR $20^{\circ} \mathrm{F}$ TEMPERATURE SWING AND EOUAL HEAT STORAGE

\section{Relative Weight Relative Volume}

Typical Phase-Change Materlal

$$
1.0
$$

Water

5.0

Rocks

25.0

17.0

SOURCE: Reference i3.

\section{Heat-Actuated Cooling}

Heat-actuated cooling (i.e., a cooling system whose power is derived from a thermal energy source) could be used for air conditioning or for a variety of industrial processes involving refrigeration and/or dehumidification. Several heat-actuated refrigeration cycles exist, including the absorption cycle, Rankine cycle, and desiccant cycle.

Absorption machines represent a well-developed technology for air conditioning. Several manufacturers (Carrier, York, Trane) presently market units of 100-ton capactty or greater. Arkla Industries also has equipment down to three tons, including units specifically designed for solar cooling. (14) The 11thium-bromide absorption machines can operate at 
relatively low inlet temperatures $\left(200^{\circ} \mathrm{F}\right.$ ) and have the advantage of a very close approach to ideal Carnot cycle performance. However, they do require a cooling tower, which is a disadvantage, at least for residential applications.

The Rankine cycle, or other heat-engine-driven cycles, has the capability of shaft-power production, electric drive in the auxiliary mode, and (with some penalty in performance) air cooling. For a given temperature level, the coefficient of performance (COP) is not likely to be superfor to that of the lithium-bromide water-absorption machines. However, as development of advanced concentrating collectors progresses, Rankine and other heat engine cycles operating at higher temperatures are expected to have more potential.

Desiccant drying systems use materials, desiccants, or sorbents, which can attract and remove water from an afr stream. The materials commonly used remove water by reversible reactions and, therefore, can be regenerated with heat. Some systems involve partial rehumidification with "overdrying" to achieve cooling as well as dehumidification. Some types can operate at relatively low temperatures (i.e., $160^{\circ} \mathrm{F}$ or less).

Liquid absorbents, such as triethylene glycol, have been used in commercial systems for dehumidification of inlet ventilation air for space conditioning applications and other process uses. Commercial liquid absorbent systems are manufactured by Niagara Blower, Midland Ross, and others. An experimental solar hot-air-driven liquid absorption machine was operated successfully by Loff in the early 1950's. (15) A variation of this design was planned for the Citicorp building, but was not implemented. (16)

Concepts involving solid desiccants have been studied experimenta11y. (17) The Institute of Gas. Technology is designing a solid desiccant device for residential use, with a probable size. range of 3 to 10 tons of cooling. (18) 


\section{System Design}

\section{Solar Hot Water Heating}

Solar hot water systems can be used for domestic hot water in a variety of building types and for process hot water in industrial applications. In many applications, solar water heating can be relatively cost-effective, since the reasonably low operating temperatures and seasonally steady-load profiles promote high collection efficiency, and the displaced energy is frequently high-cost electric resistance heat.

As shown in Figure 4-2, a solar water heater will consist of a solar collector, a heat-storage tank, and a heat-transfer loop with the necessary ancillary equipment and controls. This configuration, as pictured, is typical of the pumped-loop, remote-storage design most common In the United States. This basic solar hot water heater concept 1s applicable to a range of bullding types and process applications and can utilize a variety of different types of solar collectors and heattransfer loops (including different types of heat-exchanger and freezeprevention methods), and interface with different types of auxiliary energy. Thermosiphon loops and combined storage/collector units are also design options which, to date, have been used most extensively overseas.

The solar water heater system can be designed either as a preheater with dedicated solar storage or integrated with the auxiliary in such a way that a single tank is used for both solar storage and auxiliary heat addition. The preheater version, with 1 ts independent solar storage (frequently equal to daily water consumption), can be readily interfaced with any type of auxiliary water heater. In the integrated tank version which is currently available only with electric auxiliary, the solar heat input is normally supplied near the bottom of the tank and the electric heater element located at approximately midhelght, such that the bottom of the tank serves as solar storage and the top as the auxiliary water heater. Both types are in common use, with the integrated type belng favored for compactness (and 


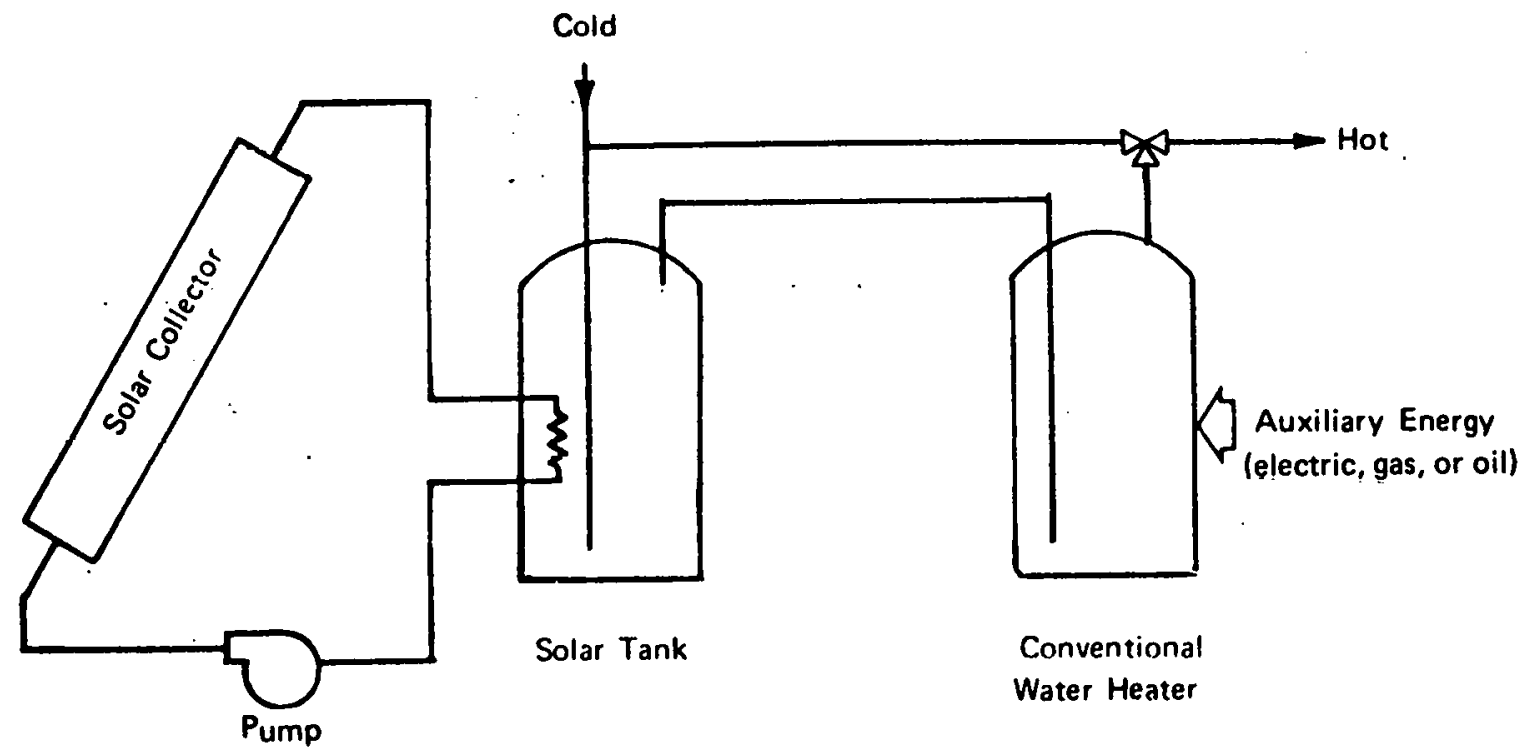

a. Preheater Version

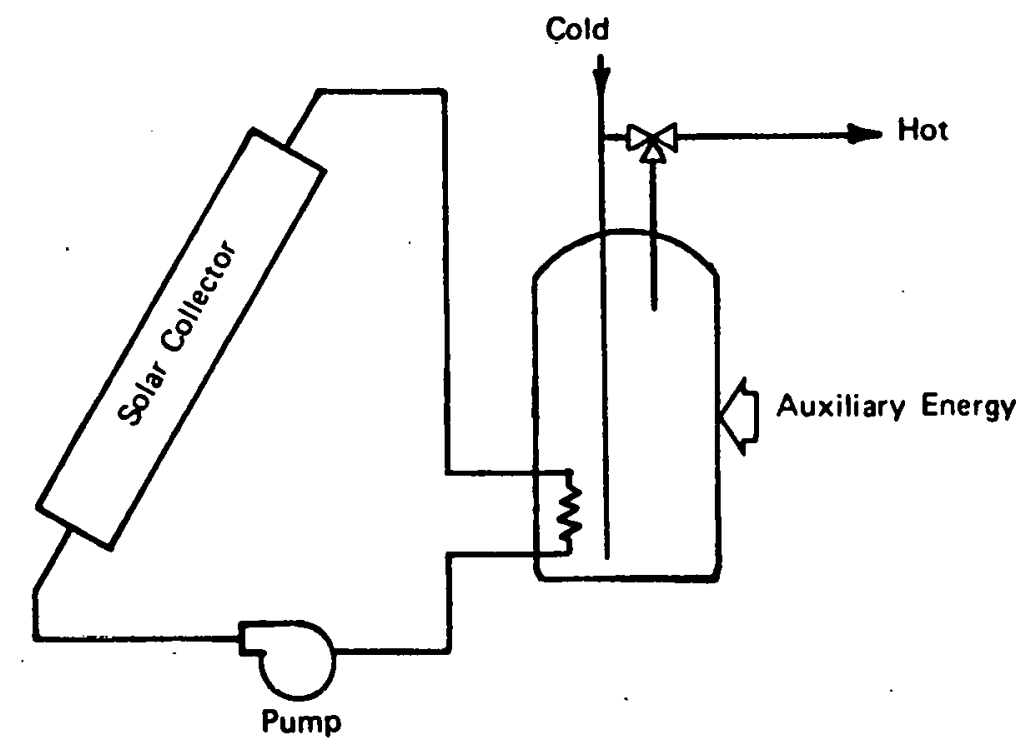

b. Integrated Tank Version

FIGURE 4-2 SCHEMATIC OF SOLAR WATER HEATING SYSTEMS 
lower equipment cost) and the preheater having advantages of easy interfacing with all auxiliaries, as well as providing extra large storage where water consumption is very high.

Solar water heaters are generally designed to supply from 40-70\% of hot water load on an annual basis. The economic optimum size, which varies with climatic conditions, is normally a balance between having the system large enough to achieve a reasonably 'low cost per unit area -- yet not close enough to $100 \%$ solar to substantially reduce overall efficiency because the system has excess capacity in summer months.

\section{Solar Space Heat and Hnt Water}

Although there may be certain space-heating-only opportunities, especially when building mass can be used for thermal storage, in most instances solar space heating is combined with a hot water system. Figure 4-3 shows a space heat and hot water, system with heat pump and resistance heat auxiliary. In this system, the thermal storage, heated by the solar collector, serves both to preheat water and to provide space heating. Auxiliary heat, shown here in the form of an electric heat pump and resistance elements, supplies the domestic water and space heating requirements when the tempexature of thermal storage is not adequate.

For the sake of generality, the heat pump is shown schematically In a multi-mode configuration, having the dual capability of either supplying auxiliary heat in parallel with the solar system as an airto-air heat pump, or operating in series with the solar tank as a liquid source "solar-assisted" heat pump. The merits of series vs. parallel operation have received considerable attention. The series liquidsource heat pump will tend to have a higher coefficient of performance (COP) * than the parallel air-source heat pump, since its source temperature is . generally higher. (Low source temperatures not only reduce COP, but even

* The COP of an electric heat pump is the dimensionless ratio of heat output to electric power input. 


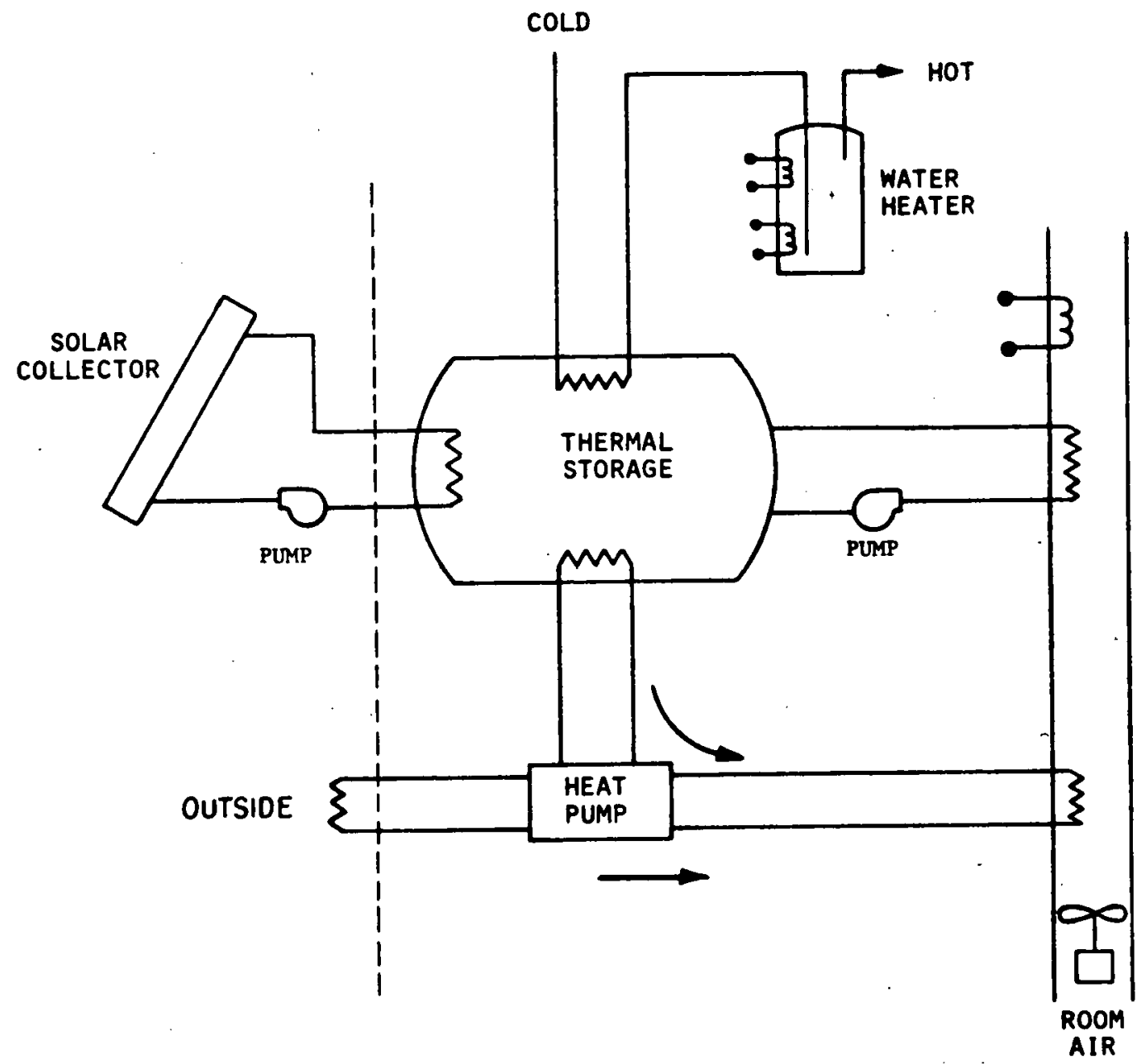

FIGURE 4-3 SCHEMATIC OF SPACE HEAT AND HOT WATER SYSTEM WITH. HEAT PUMP AND RESISTANCE HEAT AUXILIARY 
more importantly, as discussed in Chapter 17, lead to reduced capacity with the resulting need for supplemental resistance heat.) On the other hand, the parallel air-source heat pump operates a smaller fraction of time than the series liquid-source heat pump since, in the parallel mode, solar is allowed to supply heat directly -- and under favorable conditions might supply the total heating load. Most current investigators seem to agree that, in terms of energy consumption, there is no significant difference, although the parallel mode may have a small advantage. $(19,20)$

In general concept, this system is applicable to a wide range of building types and auxiliary energy sources, since the heat pump can be replaced by fossil fuel heat. The capacity factor of systems involving space hearing tends to be lower than hot-water-only systems because of the seasonal variation in load. In northern areas where the seasonally variable space heating load is much larger than the seasonally steady hot water load, it is particularly difficult to achieve both high solar fractions and high capacity factors (without employing very large long-term seasonal storage). However, in terms of overall economics, this can sometimes be offset by the larger space heating systems that have lower costs per unit area because of economies of scale.

3. Combined Cooling, Space Heat, and Hot Water

Figure 4-4 shuws schemarically a combined space cooling and heating and hot water system. This system involves the addition of a heatactuated air conditioner to the hot water supply from the solar tank and is otherwise conceptually the same as the space heating system. The addition of cooling tends to level annual load profiles, but the higher temperatures required for the heat-actuated cooling machines efther result in low collector efficiency or may require more efficient, more expensive collectors. Also, the performance of systems involving solar cooling tends to be penalized by the relatively low COP of heat-actuated equipment relative to that of electric vapor-compression devices. 


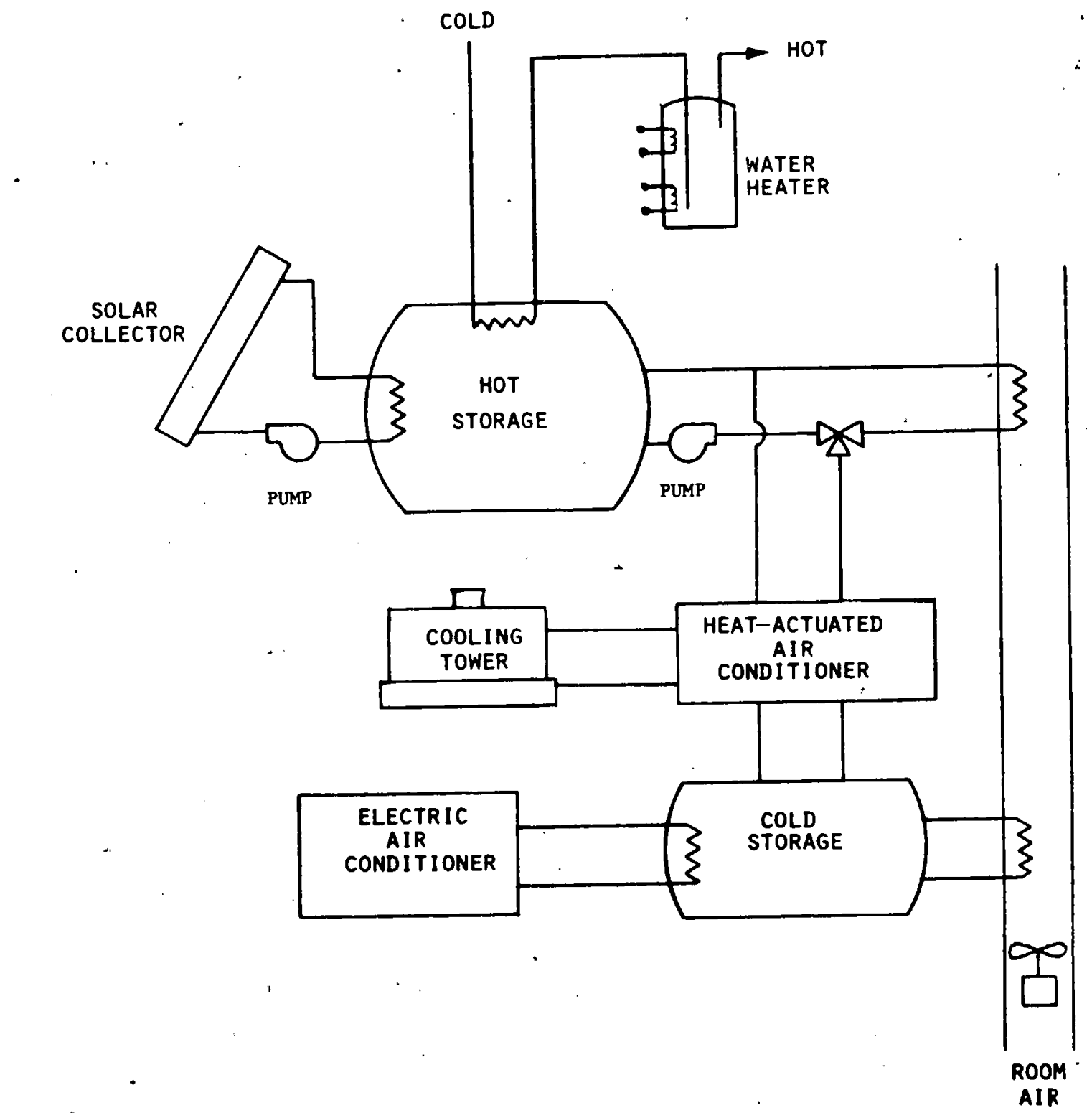

FIGURE 4-4 SCHEMATIC OF COMBINED SPACE COOLING AND HEATING SYSTEM WITH HOT WATER SUPPLY, USING HOT AND COLD STORAGE 


\section{Electric Load Management Aspects}

While solar systems reduce the amount of auxillary energy needed, they do not necessarily reduce the power capacity that a utility must maintain to supply the bullding. Therefore, it may be desirable to the utility. (and to the consumer in terms of reduced energy costs) to Incorporate load management into the solar system. One load management approach is to use on-site thermal storage, particularly since the solar system already has storage equipment which might be utllized and/or expanded for this purpose. The Electric Power Research Institute is conducting an extensive, experimental study of solar and/ or load management techniques involving thermal storage (in the context of reducing energy consumption and diurnal peak lenand) in 10 allelectric residences in Albuquerque, New Mexico, and on Long Island, New

York. (21) Long-term storage may also be appropriate, particularly where the major concern is seasonal, rather than diurnal, peaks. As an alternative to thermal storage, the building's peak demand requirements might be reduced by on-site storage of another energy form -- such as the use of an oil-fired back-up furnace.

\section{Passive Systems}

Although more difficult to categorize than the active systems discussed above, there are a number of passive methods of using solar eneigy for building heating and cooling which, in some instances, are more cost-effective than active systems. $(22,23)$ Although not initially receiving the attention (and Government funding) given to active systems, interest 1n passive systems is increasing. A recent DOE research and development project summary lists more than 30 passive solar projects.

Although no complete definition of passive heating and cooling systems has yet evolved, it is generally accepted that in these systems thermal energy flows by natural means such as radiation, conduction, and convection, and any non-renewable energy used to control this process is very small in comparison with the prime energy flows. $(25,26)$. This definition precludes the type of pumps or blowers 
characteristic of the fluid movement in active systems but does not rule out use of sma11 quantities of non-renewable energy for movement of insulation or changes in damper position. A general characteristic of passive systems is that room temperature control is not likely to be as precise as in mechanically controlled conventional, or active solar, systems. The use of building elements for collection and thermal storage, rather than detached collectors and storage tanks, both allows opportunities for improvements in efficiency and economics and results in building temperatures being more responsive to diurnal variations in solar gain and heat loss as well as to extensive cloudy periods. Whether or not the resulting temperature stability is adequate depends on both the skill of the passive solar designer and the attitude of the building occupants.

The simplest type of passive solar system is the direct gain system, using large south-facing windows for solar collection with the building mass providing thermal storage. Some involve dual-purpose collection/storage walls, such as the Trombe wall in systems designed by Centre National de 1a Recherche Scientifique ${ }^{(27)}$ and the drumwall design of S. Baer of Zomeworks Corporation. (28) The use of a greenhouse outside a thermal storage wall combines the two approaches discussed above. The Hay-Skytherm system ${ }^{(29)}$ is an example of a roof pond with movable insulation which collects heat in the winter and rejects heat in the summer. Thermal siphon systems for hot water heating and space heating are also classed definitionally as passive systems, although in terms of the hardware involved (1.e., the solar collector panels), they have a great similarity to active systems. MIT Solar Building 5, which represents a rather sophisticated approach to temperature control in a direct-gain system, uses light-weight celling tiles (containing a phase change material) which are charged with sunlight reflected from louvers in south-facing windows. $(30,31)$

Passive systems have traditionally been difficult to quantify because of both the diversity of types and the lack of design and operational data. Although, in general, passive systems are still not 
as well defined as active systems, recent work has served both to Improve understanding of this approach and indicate its promise. Results of operating passive systems have shown that these systems are capable of supplying substantial portions of building energy, even in relatively poor climates -- in part, because of their relatively low operating temperatures. (25) Recent results from HUD programs indicate that the two passive systems measured achieved substantially higher collection efficiency than the active systems measured. (32) Analytical methods are being developed which will be valuable in the analysis of the design of passive systems. The preliminary results indicate that these systems would be expected to have a performance comparable to that of active systems.

\section{Industrial Process Heat}

Industrial process heat accounts for about $25 \%$ of all U.S. energy usage -- or approximately equal to that used for heating and cooling of buildings -- with about one-third at temperatures of $350^{\circ} \mathrm{F}$ or less. (34) The posstble solar applications range from relatively low-temperature water or air heating for washing or agricultural drying, to high-temperature steam and hot air heating for use in distillation and high-temperature drying. At the lower end of the temperature spectrum, flat-plate collectors may be adequate, whereas, for the higher temperature applications, various concentrating systems will be required.

Although temperature levels and collector design requirements may vary widely from one application to another, industrial process heat installations generally have the common features of large size, permitting economies of scale, and relatively steady load, leading to good equipment utilization and high annual collection efficlencies. The large size of the installations may permit sophistications of design and control and rigorous maintenance procedures which might not be practical in smaller installations, such as those more commonly used for space heating and cooling.

Because of the large investment required, solar heating for 
industrial processes has proceeded somewhat more slowly, and the examples are fewer than those for heating and cooling of bulldings. However, in recent years, the number of industrial process heat applications has increased, either with private or public funding. Examples include systems for drying agricultural products and lumber, heating or preheating process water, pasteurizing beer, curing concrete, and drying fabrics. $(35,36)$

\section{Energy Conservation}

Although by definition it is somewhat independent of solar heating and cooling, energy conservation should always be considered in the design of solar heating and cooling systems. In passive systems, the two are likely to be very closely related, as in the case of large windows which must have adequate multiple glazing and/or curtains or other methods of movable insulation to keep heat loss to a tolerable leve1. Even with active systems where energy conservation methods may be physically distinct from the solar system, it is extremely important that energy conservation be implemented to the point where Incremental lupluveiments in energy conscrvation would have life cycle rnsts comparable to those of the solar system.

\section{Section 4.3: Economics Discussion}

There are many economic indices for judging solar systems. One convenient and graphic parameter which allows the cost of solar heat to be compared with that of heat produced by other energy forms :is the. solar heat cost formulation originally used in the pioneering economic work of Löf and Tybout. (37) As shown below, solar heat cost can also be readily related to payback. Solar heat cost (SHC) can be written as:

$$
\operatorname{SHC}=\frac{(C / A) R}{\bar{n} Q_{1} / A}
$$

where:

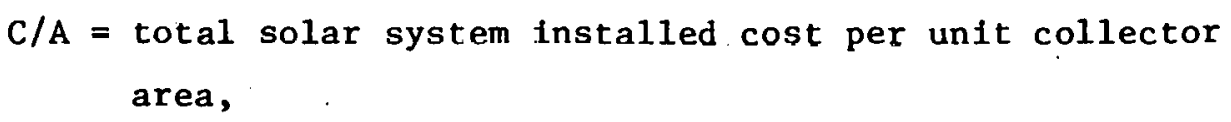

The benefit of the solar system is the cost of conventional fuel not used--the "fuel saver" mode of operation. 


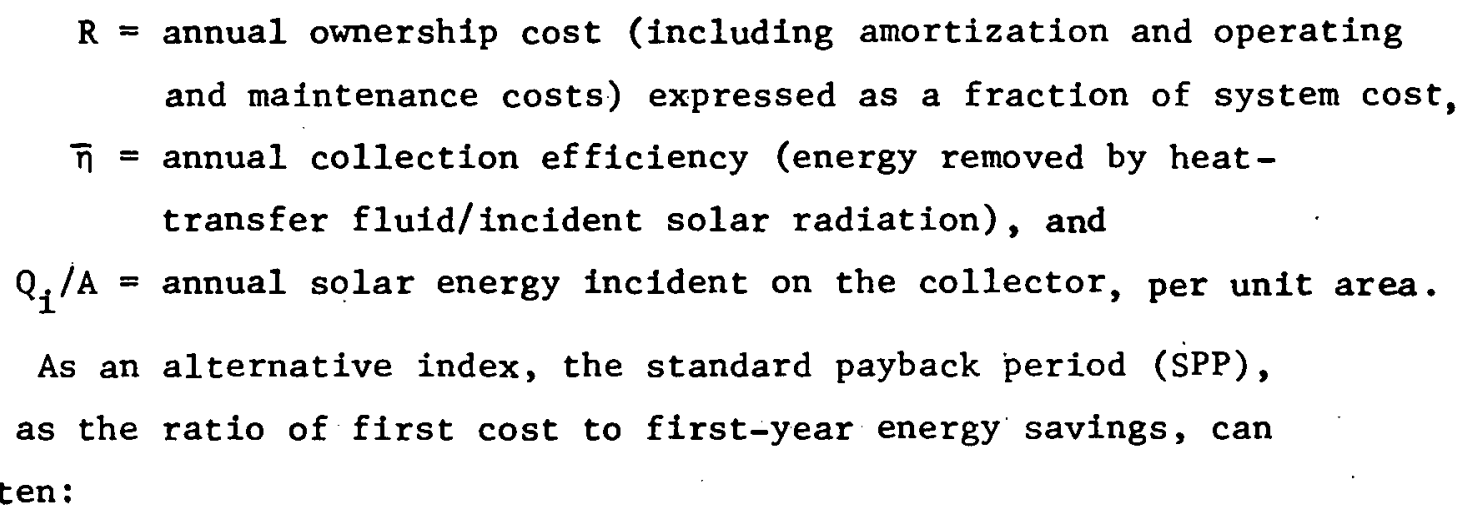

$$
S P P=\frac{C / A}{\bar{n} Q_{1} / A(V / Q)}=\frac{S H C}{R(V / Q)}
$$

where:
$V / Q=$ cost, per unit heat quantlty, of heat delivered from conventional fuels.

Data and estimates on system costs vary widely. Solar water heaters installed in the New England Electric experiment averaged about $\$ 2,000$ for systems which incorporated normally $50 \mathrm{ft}^{2}$ of collector, for an average cost of $\$ 40 / \mathrm{ft}^{2}$. (38) The installed costs of residential water heaters in Florida in early 1977 averaged about $\$ 30 / \mathrm{ft}^{2}$ for new construction and $\$ 35 / \mathrm{ft}^{2}$ for retrofit. (39) A variety of systems installed on commercial buildings ranged from $\$ 15-50 / \mathrm{ft}^{2} \cdot{ }^{(40)}$ A detailed study by MITRE presents costs for various generic solar system types in terms of both fixed costs (largely nonsolar-related) and area-dependent costs (subdivided into ultimate mass production costs and costs subject to experience) for both residential and commercial buildings. (41)

Typical results from the MITRE work ${ }^{(41)}$ indicate the 1977 cost of a $50 \mathrm{ft}^{2}$ water heater is about $\$ 31 / \mathrm{ft}{ }^{2}$, with an expected ultimate cost of $\$ 23 / \mathrm{ft}^{2}$. A recent DOE analysis uses current installed costs of $\$ 25-40 / \mathrm{ft}^{2}$ for space heat and hot water systems--with reduction to \$15-20/ft ${ }^{2}$ foreseen. (42) As the basis of a 1977 analysis of market development, ${ }^{(2)}$ system cost ranges were estimated as $\$ 25-50 / \mathrm{ft}^{2}$ for 1977, $\$ 20-30 / \mathrm{ft}^{2}$ for 1985 , and $\$ 15-25 / \mathrm{ft}^{2}$ for $1990-$ all in constant (1977) dollars. These ranges, which appear in reasonable agreement with other sources, were used in the estimation of solar heat costs. 
It should be pointed out that these estimates represent costs prior to application of tax credits. The ranges given are intended to be averages of the general spectrum of sizes, equipment types, installation requirements, etc. The cost savings with time arise from projected improvements in distribution, installation techniques, and product design.

Collection efficiency is dependent on collector and system. design. Flat-plate systems optimally sized for water heating, and for some space heating applications, can achieve an annual effictency of about $35 \%$. (2) However, systems designed to supply large fractions of space heating -- or to provide high temperature for solar cooling -- can have significantly lower annual efficiency. Likewise, somewhat higher annual efficiencies may be achieved with advanced collectors. However, it is felt that the annual efficiency of $35 \%$ is a reasonable average to be used In conjunction with the system costs discussed previously.

Annual incident radiation will vary from about $750,000 \mathrm{Btu} / \mathrm{ft}^{2}$ in the Southwest to about $500,000 \mathrm{Btu} / \mathrm{ft}^{2}$ in the Northeast. As a nationwide average, we used $600,000 \mathrm{Btu} / \mathrm{ft}^{2}$.

Annual ownership cost is defined as the overali annual rate, expressed as a percentage of system capital costs, which covers interest, depreciation, taxes, and operating and maintenance costs. We used a value of $10 \%$-- corresponding to a 20 -year mortgage at $8.5 \%$. We further. assumed that $0 \& M$ costs are offset by the positive effects of tax benefits.

On the basis of the foregoing costs and assumptions, we arrived at the solar space heating costs shown In Table 4-2.

TABLE 4-2

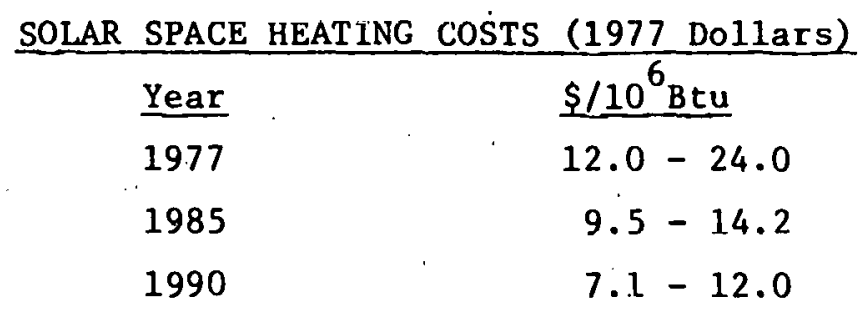

SOURCE: Arthur D. Little, Inc., estimates, based on a $10 \%$ annual ownership cost, and other assumptions stated in the text. 
The above solar space heating costs can be compared directly with the cost of heat delivered from conventional energy. A 1976 survey of typical locations presents the cost of heat delivered from ofl and gas (at $60 \%$ combustion efficiency) at $\$ 4-6 / 10^{6} \mathrm{Btu}$ and $\$ 2-5 / 10^{6} \mathrm{Btu}$, respectively, and (omitting Seattle, Washington) the cost of electric heating from resistance and heat pump at $\$ 8-15 / 10^{6} \mathrm{Btu}$ and $\$ 4-7 / 10^{6} \mathrm{Btu}$, respectively. (43) A 1977 tabulation of conventional energy prices by state leads to similar results. (44) Note that the solar costs ( $\$ / 10^{6}$ Btu) divided by the annual ownership costs $(10 \% / y r)$ result in the total installed capital costs $\left(\$ / 10^{6} \mathrm{Btu} / \mathrm{yr}\right)$ presented on the technology summary sheet.

Table 4-3 compares the cost of solar heat with heat delivered by other conventional energy sources for the 1977 time period, and presents the range of standard payback periods achieved by solar when it displaces conventional energy sources. Note that the standard payback period is an Index defined simply as the ratio of first cost of the solar equipment to the first-year energy savings--and, as shown previously (Section 4.3), is equal to the solar heat cost divided by the product of the unit cost of heat delivered from conventional fuels and the annual ownership cost. (When the solar heat cost equals the cost of heat delivered from conventional fuels, the standard payback period equals the reciprocal of the cost of ownership--or, in this case, 10 years.)

TABLE 4-3

1977 DELIVERED HEAT COSTS AND ACHIEVABLE PAYBACK PERIOD

\begin{tabular}{lcc}
\hline $\begin{array}{l}\text { Energy } \\
\text { Source }\end{array}$ & $\begin{array}{c}\text { Cost of } \\
\text { Ielivered Heat } \\
(\$ / 106 \text { Btu })\end{array}$ & $\begin{array}{c}\text { Standaxd } \\
\text { Payback Period } \\
\text { (Years) }\end{array}$ \\
\cline { 2 - 4 } Solar & $12-24$ & -- \\
Electric Resistance & $8-15$ & $8-30$ \\
Electric Heat Pump & $4-7$ & $17-60$ \\
O11 & $4-6$ & $20-60$ \\
Gas & $2-5$ & $24-120$
\end{tabular}

(1) This is the payback period for a solar system which displaces the identified alternative energy source.

SOURCE: Arthur D. Little, Inc., estimates per Table 4-2 and other assumptions stated above. 
The comparison shows solar heat to be competitive with resistance heating in areas of high electric costs, although not yet with fossil fuels or heat pumps. In the time period from 1985 to 1990, solar heat costs will become increasingly competitive with electric heating and, perhaps, fossil fuels, depending on the cost escalation of these fuels relative to that of solar equipment.

The economic analysis presented above deals with rather simple indices of solar heat costs and simple payback and does not at tempt to deal explicitly with all the elements which may go into making financtal decistons on solar. However, it is valuable to recognize the impact of some of these factors, particularly operating and maintenance expenses and Government incentives, such as tax credits.

Data on operating and maintenance (O\&M) expenses for solar heating and cooling systems are in a very preliminary state. MITRE estimates Indicate annual $O \& M$ of the order of $1 \%$ of initial capital cost per year. Ward, et al. (45) indicate costs of $1 \%$ a year, for maintenance only, for alr systems. Calculations of operating costs for solar hot water heaters indicate pump electrical input is equivalent to about $0.5 \%$ of inftial capital cost per year. As a preliminary estimate, $2 \%$ of initial cost per year, as is noted in the summary sheet at the beginning of this chapter, appears reasonable. The economic analysis above did not deal with O\&M cost explicitly, or with other issues such as tax credits and escalation in energy savings. The solar heat costs presented assume $0 \& M$ is one of the factors leading to an annual ownership cost of $10 \%$. In the payback calculations, the first-year energy savings are based solely on the cost of the conventional (electrical or fossil) energy displaced by solar energy. (If the $2 \%$ O\&M had been included as a penalty against the first-year energy savings, the payback period would be 12.5 years rather than 10.)

The inclusion of tax credits can substantially reduce first cost and make a large impact on solar financing. At this writing, the federal tax credit is $30 \%$ on the first $\$ 2,000$ of system cost and $20 \%$ on the next $\$ 8,000$. Additionally, many states offer tax credits, which may be taken in addition to the federal credit. For a $\$ 2,000$ solar hot water heater, the federal tax credit alone makes a reduction of $30 \%$ in the solar heat costs and standard payback. Arguments can be made that, with this tax credit and by appropriately financing the solar system, 
It is possible for the consumer to maintain a net positive cumulative cash flow for a solar hot water heater, even when displacing a reasonably low-cost energy form, such as natural gas ${ }^{(46)}$ at present energy costs.

The economic outlook for an active system Involving direct solar cooling appears less satisfactory in the reasonably near term than for hot water and (optimally sized) space heat and hot water systems, because heat-actuated machinery requires high collection temperatures and tends to have a low coefficient of performance relative to electric air conditioning. For instance, at design point, the inlet water temperature for a 3-ton 1ithium bromide absorption machine is $1.95^{\circ} \mathrm{F}$, and the system's thermal coefficient of performance (COP) is 0.72 . (14) This relatively low thermal COP puts solar cooling at a disadvantage when competing against electric air conditioning where the electric COP (cooling achieved per unit electrical input) may be three to four times higher. Also; at least for residential applications, the first cost of heat-actuated cooling equipment is very high.

The economics of passive systems are more difficult to quantify and will vary widely with the system type. It is likely that some types of direct-heat-gain passive systems, which may primarily involve substituting double-glazed windows for what might otherwise have heen an opaque south wall, can be cost-effective and may result in better economies than active space heat systems. Early data from solar demonstration projects indicate very low system costs for a passive system consisting of plastic glazing retrofitted to an existing warehouse waj.1. (47)

Industrial process heat applications may permit sophistication in solar system design and maintenance procedures which would be impractical for most heat and cooling appilications -- as well as opportunities to achieve some economies of scale with very large systems. On the other hand, these solar systems must meet industrial economic criteria which can be different, and possibly more severe, than for residentlal applications. It has been estimated that because fossil fuel is currently a tax-deductible expense to industry, and because industry needs a high

\footnotetext{
* Thermal cooling achieved per unit of solar heat input.
} 
rate of return on capital, allowable system costs may have to be much lower than for residential equipment -- therefore, significant tax incentives may be required to achieve economic viability. (34) Lastly, the public relations aspects of solar systems and the possibility of loss of normal energy supplies may have a very important impact on what otherwise would be purely financial decisions.

Section 4.4: Limitations

Other than the major element of economic competitiveness discussed previously, the major obstacles for widespread implementation of solar heating and cooling systems include:

- geographic variation in sunlight,

- siting constraints, and

- institutional problems.

The geographic varlation in sunlight, discussed in more detall in Chapter 2, results in areas in the Northeast having only slightly more than half the solar radiation enjoyed in sections of the Southwest. At present, this is somewhat counterbalanced by the fact that the price of competing fuels is likewise higher in the Northeast; however, in the future, there may be a trend toward equalization of energy prices. In addition, certain systems employing concentrating collectors which might be quite effective in the Southwest would suffer a great performance penalty in the Northeast where much more of the total radiation is diffuse rather than direct.

Siting constraints may preclude the application of solar systems to many bufldings. These constraints include blockage by adjacent trees and/or buildings and a building/roof orientation which is inappropriate or difflcult for collector mounting. These problems are particularly acute in retrofit situations where there is no opportunity to adjust the siting of the bullding to be compatible with solar energy utilization.

Also, if the collector were to be ground-mounted or placed in a very conspicuous and awkward location on the roof, there could be 
esthetic problems. There are even situations where reflections caused by the collector may be considered an annoyance to neighboring residents. Lastly, the subject of vandalism must always be kept in mind, although, to date, experience has been that this has been a very minor problem, even with ground-mounted collectors. (38)

Depending on how the industry matures, institutional problems may impede the growth of solar heating and cooling. In early programs, such as the New England Electric Solar Water Heater Experimental Program, the lack of personnel skilled in installation, troubleshooting, and maintenance has resulted in high installation costs and unsatisfactory operation. $(38,48)$ Also, there w111 be a period of time required for standards and warranty arrangements to develop which will both protect the consumer and not be unduly restrictive in terms of solar system design. 


\section{REFERENCES}

1. Shurcliffe, W.A. Solar Heated Buildings - A Brief Survey. Twelfth edition. Available from W.A. Shurcliffe, 19 Appleton Street, Cambridge, Massachusetts. March 3, 1976.

2. Arthur D. Little, Inc: Solar Heating and Cooling of Buildings . (SHACOB) Commercialization Report. Part B - Analysis of Market Development, Vol II: Technical Report. Final Report prepared under Contract No. CR-05-70066-00 to Federal Energy Administration, 1977.

3. "Solar Advocates Allies of 011 Execs; U.S. 20\% Solar by Year 2000: Harvard." Solar Energy Intelligence Report, January 29, 1979. pp. $43 \mathrm{ff}$.

4. Stanford Research Institute. Solar Energy in America's Future. Report to Energy Research and Development Administration, March 1977. NTIS Report No. DSE/115-2.

5. Winston, R. "Principles of Solar Concentrators of a Novel Design." Solar Energy 16(2):89, 1974 .

6. Pendleton, R.L. "Evaluating a Solar Energy Concentrator." ASHRAE Journa1 18 (11):47, November 1976.

7. Davidson, J.H., et al. "The Solar Linear Array Thermal System." Solar Age, February 1978. pp. 12 ff.

8. Manufacturers' Product Literature.

(a) PPG Solar Systems Data Sheet 3, Form G-752. Avallable from PPG Solar System Sales, One Gateway Center, Pittsburgh, Pennsylvania 15222.

(b) The Owens-Illinois SUNPAK Shaped Reflector. Brochure No. 6-4380-24-10M, 1976. Available from Richard E. Ford, Owens-Illinois, Inc., P.0. Box 1035, Toledo, Ohio 43666 .

(c) SLATs ${ }^{\circledR}$ - A New Concept in Solar Collectors. May, 1977. Avallable from George Kannapel, Suntec Systems, 2101 Wooddale Drive, St. Paul, Minnesota 55119.

9. Hyman, M. Jr. " $100 \%$ Solar Space for New England." ASHRAE Journal $18(1): 66$, January 1976.

10. Anderson, B. Solar Energy: Fundamentals in Building Design. New York: McGraw-H111 Book Company, 1977. pp. 230-234. 


\section{REFERENCES (continued)}

11. Moyers, J.C., et a1. "The Annual Cycle Energy System Concept and Application." Proceedings of the International Conference on Energy Use Management, Tucson, Arizona; October 24-28, 1977. New York: Pergamon Press, 1978.

12. Plckering, E.E. "Residential Hot Water Solar Energy Storage." Proceedings of the Workshop on Solar Energy Storage Subsystems for the Heating and Cooling of Bulldings, Charlottesville, Virginia, April 16-18, 1975. American Society of Heating, Refrigerating, and Air Conditioning Engineers, Inc., 1975. NTIS Report No. NSF/RA/N-75/041.

13. Telkes, M. "Thermal Storage for Solar Heating and Cooling." Proceedings of the Workshop on Solar Energy Storage Subsystems for the Heating and Cooling of Buildings, Charlottesville, Virginia, April 16-18, 1975. American Society of Heating, Refrigerating, and Air Conditioning Englneers, Inc., 1975. NTIS Report No. NSF/RA/N-75/041.

14. Arkla Industries, Evansville, Indiana. Product 11terature.

(a) Solatre 36--3 Ton Absorption Chiller for Solar Air Conditioning. Form No. SA-41030, November 1976.

(b) Solaire 300--25 Ton Absorption Chiller for Solar Air Conditioning. Form No. SA-41041, October 1978.

(c) Arkla Solaire Puts the Sun in One Neat Package. Form No. Ss-11210, January 1978.

15. Löf, G.O.G. "Cooling with Solar Energy." World Symposium on Applied Solar Energy, Phoenix, Arizona, November 1955. Pp. $171 \mathrm{ff}$.

16. National Sclence Foundation. "NSF Grant Funds for Study of Solar Energy System Atop New York Skyscraper." News Release, February 1975.

17. Lunde, P.J. Solar Powered Destccant Alr Conditioning System, Final Report, June 1, 1974 - December 31, 1974. Prepared by The Center for Environment and Man, Inc. for National Science Foundation, Apr11 1, 1975. NTIS Report No. CEM-4171-526.

18. Rush, W. "Solar Desiccant Systems." Workshop Proceedings on Solar Cooling for Buildings, Los Angeles, California, February 6-8, 1974. Document No. NSF-RA-N-74-063. NTIS Report No. PB 239419.

19. Freeman, T.L., et a1. "Computer Modeling of Heat Pumps and the Simulation of Solar-Heat Pump Systems." American Soclety of Mechanical Engineers Winter Meeting, Houston, Texas, November 30 - December 4, 1975. ASME Paper 75-WA-So1-3. 


\section{REFERENCES (continued)}

20. Marvin, W.C., et al. "Optimum Combination of Solar Energy and the Heat Pump for Residential Heating." Sharing the Sun! Solar Technology in the Seventies. A joint conference of the American Section of the International Solar Energy Society and the Solar Energy Society of Canada, Inc., Winnipeg, Canada, August 15-20, 1976. Vo1. 3. pp. 321-323.

21. Arthur D. Little, Inc. System Definition Study: Solar Heating and Cooling Residential Project. Summary Report Prepared for Electric Power Research Institute, July 1977. Report No. EPRI ER-467-SY.

22. Stromberg, R.P. Passive Solar Bulldings: A Compilation of Data and Results. Prepared by Sandia Laboratorles, August 1977. NTIS Report No. SAND77-1204

23. Keller, M.H., ed. Passive Solar Heating and Cooling. Proceedings of a conference and workshop, coordinated by Los Alamos Scientific Laboratory, Albuquerque, New Mexico, May 18-19, 1976. NTIS Report No. LA-6637-C.

24. U.S. Department of Energy. Solar Heating and Cooling Research and Development Project Summaries. May 1978. NTIS Report No. DOE/CS-0010.

25. Balconb, D.J. "Summary of the Passive Solar Heating and Cooling Conference." Passive Solar Heating and Cooling. Proceedings of a conference and workshop coordinated by Los Alamos Scientific Laboratory, Albuquerque, New Mexico, May 18-19, 1976. NTIS Report No. LA-6637-C.

26. Yellot, J. "Passive Solar Heating and Cooling Systems." ASHRAE Journal 20(1):60, January 1978.

27. Trombe, F., et al. "Concrete Walls to Collect and Hold Heat." Solar Age, August 1977. pp. $13 \mathrm{ff}$.

28. Baer, S. "The Drum Wa11." Proceedings of the Solar Heating and Cooling for Buildings Workshop, Part I: Technical Sessions. Sponsored by the National Sclence Foundation, Washington, D.C., March 21-22, 1973. NTIS Report No. PB 223536.

29. Hay, H.R. "Evaluation of Proved Natural Radiation Flux Heating and Cooling." Proceedings of the Solar Heating and Cooling for Buildings Workshop, Part I: Technical Sessions. Sponsored by the National Science Foundation, Washington, D.C., March 21-22, 1973. NTIS Report No. PB 223536.

30. Johnson, T.E. "Lightweight Thermal Storage for Solar Heated Bulldings." Solar Energy 19(6):19, 1977.

31. Mahone, D. "Three Solutions for Persistent Passive Problems." Solar Age, September 1978. pp. $21 \mathrm{ff}$. 
REFERENCES (continued)

32. Freeborne, W. "Performance of HUD Residential Solar System." Preconference Proceedings - Solar Heating and Cooling Systems Operational Results, Colorado Springs, Colorado, November 28 - December 1, 1978. Washington, D.C.: U.S. Department of Energy, 1978.

33. Balcomb, J.D. "Simulation Analyses of Passive Solar Heated BuIlding Prellminary Results." Solar Energy 19(3):277, 1977.

34. Dickinson, W.C. "Solar Energy for Industrial Process Heat." Solar Age, August 1977. pp. $29 \mathrm{ff}$.

35. "Solar Supplements Industry Needs." Solar Engineering, August 1978. pp. $25 \mathrm{ff}$.

36. "Industrial Process Heat-Creative Opportunities in Solar Design." Solar Age, March 1979. pp. $1.9 \mathrm{ff}$.

37. Lobf, G.O.G., et al. "Solar House Heating." Natural Resources Journa1 $10(2): 268$, Apri1 1970 .

38. Arthur D. Little, Inc. Inter1m Report on New England Electric Residential Solar Water Heating Experiment. Westborough, Massachusetts: New England Electric (System), Inc., May 1977.

39. F1orida Solar Energy Center. New and Retrofit Solar Hot Water Installation in Florida, January through June, 1977. Prepared for U.S. Department of Energy, April 1978. NTIS Report No. HCP/15663-01.

40. Intertechnology Corporation. Intertechnology Corporation Report of Solar Energy Systems Installation Costs for Selected Commercial, Buildings. Prepared for U.S. Energy Research and Development Administration, December 1976. NTIS Report No. C00/2688-76-13.

41. MITRE Corporation. System Description and Engineering Costs of Solar Related Technologies, Vol. II: Solar Heating and Coollng of. Buildings (SHACOB). Prepared for U.S. Energy Research and Development Administration, June 1977. NTIS Report No. MTR-7485-VOL-2.

42. Bezdek, R.H. An Analysts of the Current Economic Feasibllity of Solar Water and Space Heating. U.S. Department of Energy, January 1978. NTIS Report No. DOE/CS-0023.

43. U.S. Energy Research and Development Administration. An Economic Analysis of Solar Water and Space Heating. Prepared by Division of Solar Energy of ERDA, November 1976. NTIS Report No. DSE-2322-1.

44. Roach, F. Prospects for Solar Energy: The Impact of the National Energy Plan. Los Alamos Scientific Laboratory, December 1977. NTIS Report No. LA 7064-MS. 


\section{REFERENCES (continued)}

45. Ward, J.C., et a1. "Maintenance Costs of Solar Air Heating Systems." Proceedings 1977 Annual Meeting of the American Section of the International Solar Energy Society. Cape Canaveral, Florida: Florida Solar Energy Center, 1977. pp. 10-2 ff.

46. Butt, S.H. "The Fallacy of Cutback." Solar Energy Industries Association Newsletter, 4(16), December 1978.

47. King, T.A., et a1. "Cost Data Collection from Solar Demonstration Projects." Preconference Proceedings - Solar Heating and Cooling Systems Operational Results, Colorado Springs, Colorado, November 28 - December 1, 1978. Washington D.C.: U.S. Department of Energy, 1978.

48. Sullivan, C.N. "Installation: A Key to Successful Solar Program." Solar Age, September 1977. 


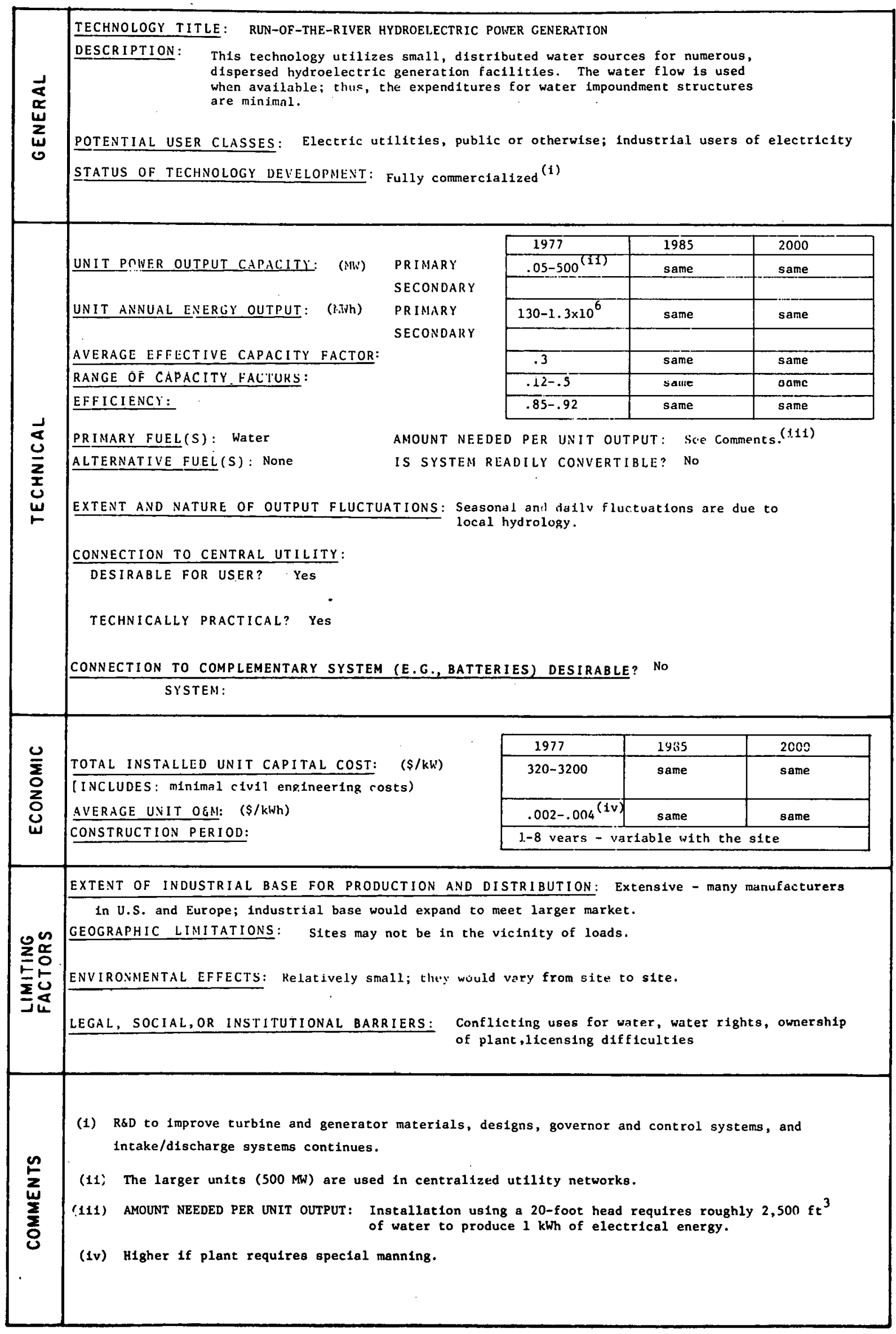


CHAPTER 5

RUN-OF-THE-RIVER HYDROELECTRIC POWER GENERATION

\section{Section 5.1: Introduction}

During the past 40 years, many small ${ }^{*}$ hydro power plants were abandoned in favor of large, centralized, fosstl-fueled and large, hydro-electric power plants. The economic rationale (high costs for operating personnel and low availability) for abandoning the low-head, essentially "run-of-the-river" hydro plants was correct when the decisions were made. However, subsequent changes in the technology and the relative economics of small hydro power plants now prompt a re-examination of the issue.

\section{Section 5.2: Technical Discussion}

A. Turbine Types

The two general classes of water turbines and their appropriate subclasses are:

1. Reaction turbines

a. Francis turbine

b. Propeliler turbines

i. Nagler turbine (fixed propeller blades)

ii. Kaplan turbine (variable pitch propeller)

2. Impulse turbines

The parameters of a specific project determine the most appropriate type of turbine. Table 5-1 outlines the usual limits on the operating head. The Francis turbine (Figure 5-1) is a modern version of the old water wheel of Colonial times. It is also called a pressure turbine; this term reflects the pressure change across the turbine runner.*

\footnotetext{
* Up to $5 \mathrm{MW}$.

**

The turbine runner is the revolving part of the turbine and is made up of a number of blades or buckets attached to a hub.
} 
TABLE 5-1

GENERAL ARRANGEMENTS OF TURBINE INSTALLATIONS

AND USUAL HEAD LIMITS EMPLOYED

\begin{tabular}{|c|c|c|c|c|}
\hline Type & Sotting & Construction & $\begin{array}{l}\text { Number } \\
\text { of } \\
\text { runners }\end{array}$ & $\begin{array}{l}\text { Usual bead } \\
\text { limits for } \\
\text { direct- } \\
\text { connected } \\
\text { units, ft }\end{array}$ \\
\hline \multirow{5}{*}{$\begin{array}{l}\text { Reaction turbines, } \\
\text { S-to } 1.300 \text {-ft bead: }\end{array}$} & \multirow[b]{2}{*}{$\begin{array}{l}\text { Open flume, } \\
5 \cdot 10 \text { 40-1t } \\
\text { head. }\end{array}$} & Vertical. $\ldots \ldots \ldots \ldots \ldots \ldots \ldots \ldots$ & $\mathbf{1}$ & $5-40$ \\
\hline & & 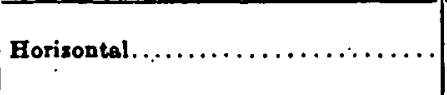 & $\begin{array}{l}1 \\
2 \\
4\end{array}$ & $\begin{array}{l}12-40 \\
16-40 \\
16-30\end{array}$ \\
\hline & \multirow{3}{*}{$\begin{array}{l}\text { Encased } \\
\text { is-to } 1.300- \\
\text { it hesd. }\end{array}$} & Plate steel $\left\{\begin{array}{l}\text { vertical } \ldots \ldots \ldots \ldots \ldots \\
\text { horisontal } \ldots \ldots \ldots \ldots \ldots \\
\text { borisontal } \ldots \ldots \ldots \ldots\end{array}\right\}$ & $\begin{array}{l}1 \\
1 \\
2\end{array}$ & $\begin{array}{l}40-300 \\
30-100 \\
30-100\end{array}$ \\
\hline & & $\begin{array}{l}\text { Concrete, vertical. } \ldots \ldots \ldots \ldots \ldots \ldots \ldots \\
\text { Concrete epiral, vertical. } \ldots \ldots \ldots \ldots \ldots\end{array}$ & 1 & $\begin{array}{l}15-50 \\
15-90\end{array}$ \\
\hline & & 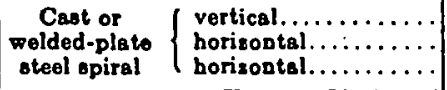 & $\begin{array}{l}1 \\
1 \\
2\end{array}$ & $\begin{array}{l}75-1.300 \\
50-600 \\
50-500\end{array}$ \\
\hline \multirow{2}{*}{$\begin{array}{l}\text { Impulse wheele, } \\
\text { s00-to } 5,500-1 t \text { hesd } \\
\vdots\end{array}$} & \multirow{2}{*}{ Encased } & 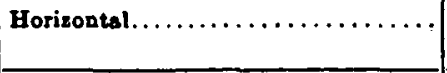 & 1 & $\begin{array}{l}500-5.500 \\
500-1.500\end{array}$ \\
\hline & & Vertical . . . . . . . . . . . . . & $\mathbf{1}$ & $500-5,500$ \\
\hline
\end{tabular}

SOURCE: Reference 1.

This pressure/potential energy is converted to mechanical energy by turning the runner. The direction of water flow at the turbine entrance is perpendicular to the rotor's axis of rotation; water flow at the turbine exit is parallel to the rotor's axis.

In the propeller turbines, the direction flow is almost parallel to the runner's axis of rotation (axial or vertical shaft turbines). The runners resemble a ship's propeller, or its inverse, and are much simpler than those of the Francis turbine. The pitch of the propeller blades of the Kaplan turbine varies automatically during operation in order to keep the speed of the turbine constant, despite variations in the operating conditions, so that the turbine will always operate at maximum efficiency.

A recent variation of the Kaplan turbine design is the tubular-type turbine (Figure 5-2). This was developed to simplify the water flow passages and thereby reduce the required amount of anclllary construction work at the hydro generation plant. The most recent development in tubular turbines is the bulb unit (Figure 5-3) 


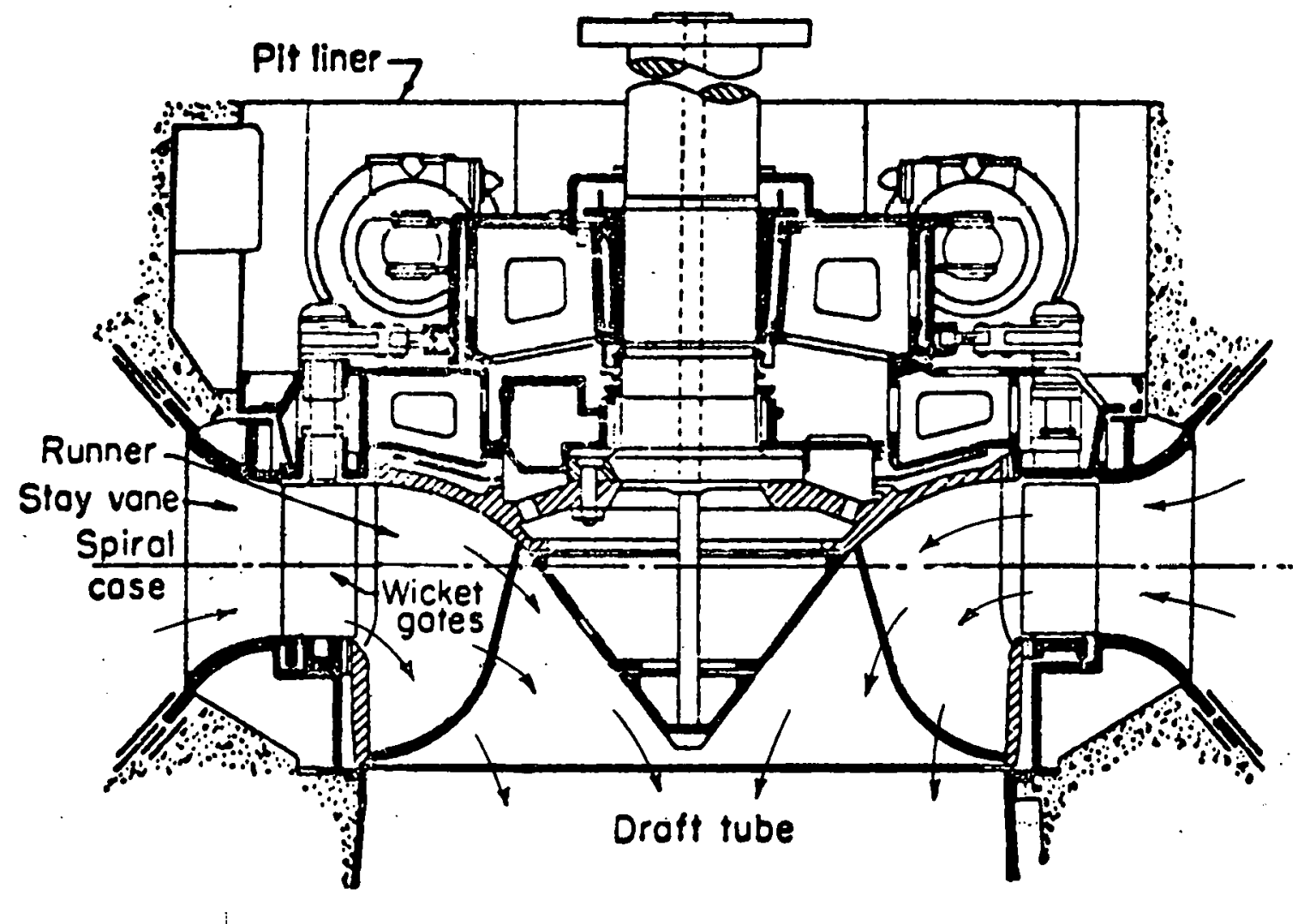

SOURCE: Reference 1.

FIGURE 5-1 MEDIUM-HEAD FRANCIS TURBINE 


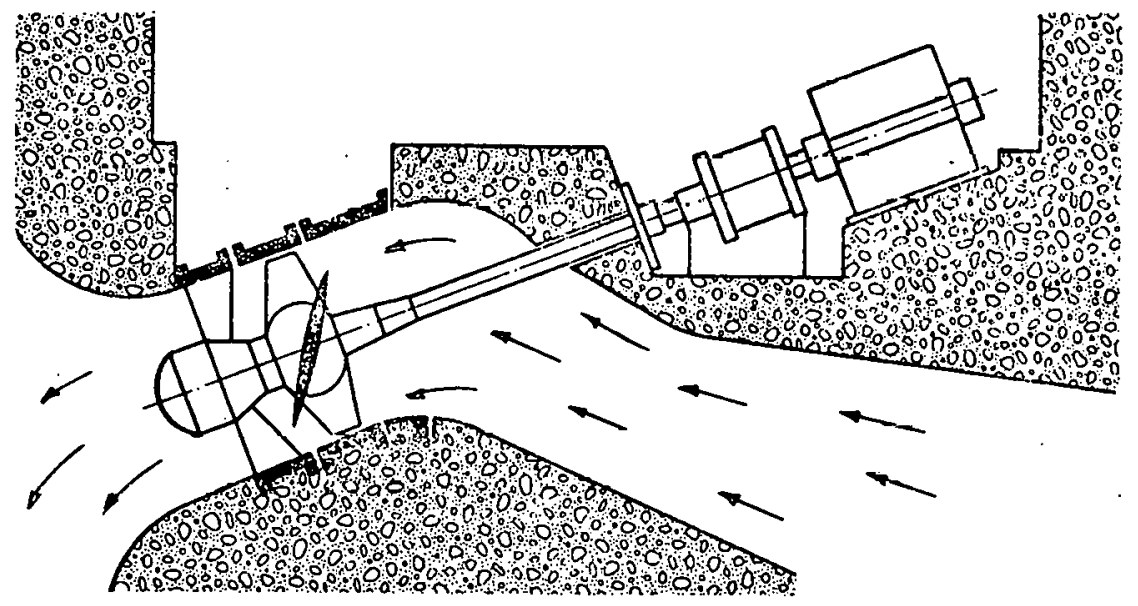

SOURCE: Reference 2.

1

FIGURE 5-2 TUBULAR TURBINE WITH THE SYNCHRONOUS GENERATOR OUTSIDE THE WATER STREAM 


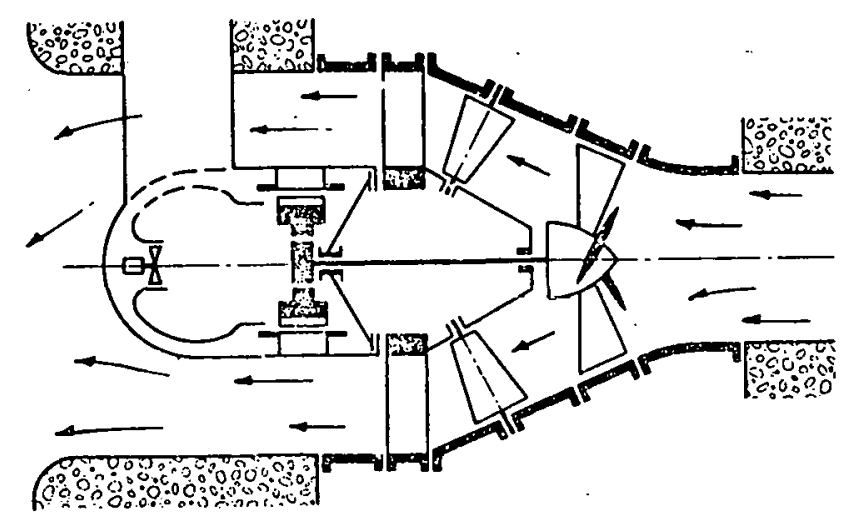

SOURCE: Reference 2 .

FIGURE 5-3 TUBULAR TURBINE WITH WATER FLOW AROUND THE SYNCHRONOUS GENERATOR (BULB TURBINE)

in which the generator is completely encased in a bulb in the middle of a flow conduit. The disadvantage is the difficulty associated with maintenance.

The impulse turbine is usually found at sites where high heads (> $500 \mathrm{ft}$ ) are avallable. The pressure/potential energy of the water is converted to kinetic energy in a nozzle or guide vanes. The resulting high-velocity stream of water is then directed on to the runner; there is no pressure change across the turbine. An example of this type of unit is shown in Figure 5-4.

The availability of hydro turbines to take advantage of our available hydro resources does not appear to be a problem. Until recently, there was only one major U.S. manufacturer (James Leffel \& Co.) of extremely small hydro turbines (<1 NW), ${ }^{(4)}$ although several U.S. companies claim they can manufacture the larger units. The bulb turbine, now commercially available in Europe, could become available from U.S. manufacturers rather quickly. when the market develops. Significant competition presently exit.s between U.S. and foreign manufacturers. The hydro turbine represents a mature technology; changes in this technology will probably be evolutionary in form rather than revolutionary and encouraged by the continuing competition. 


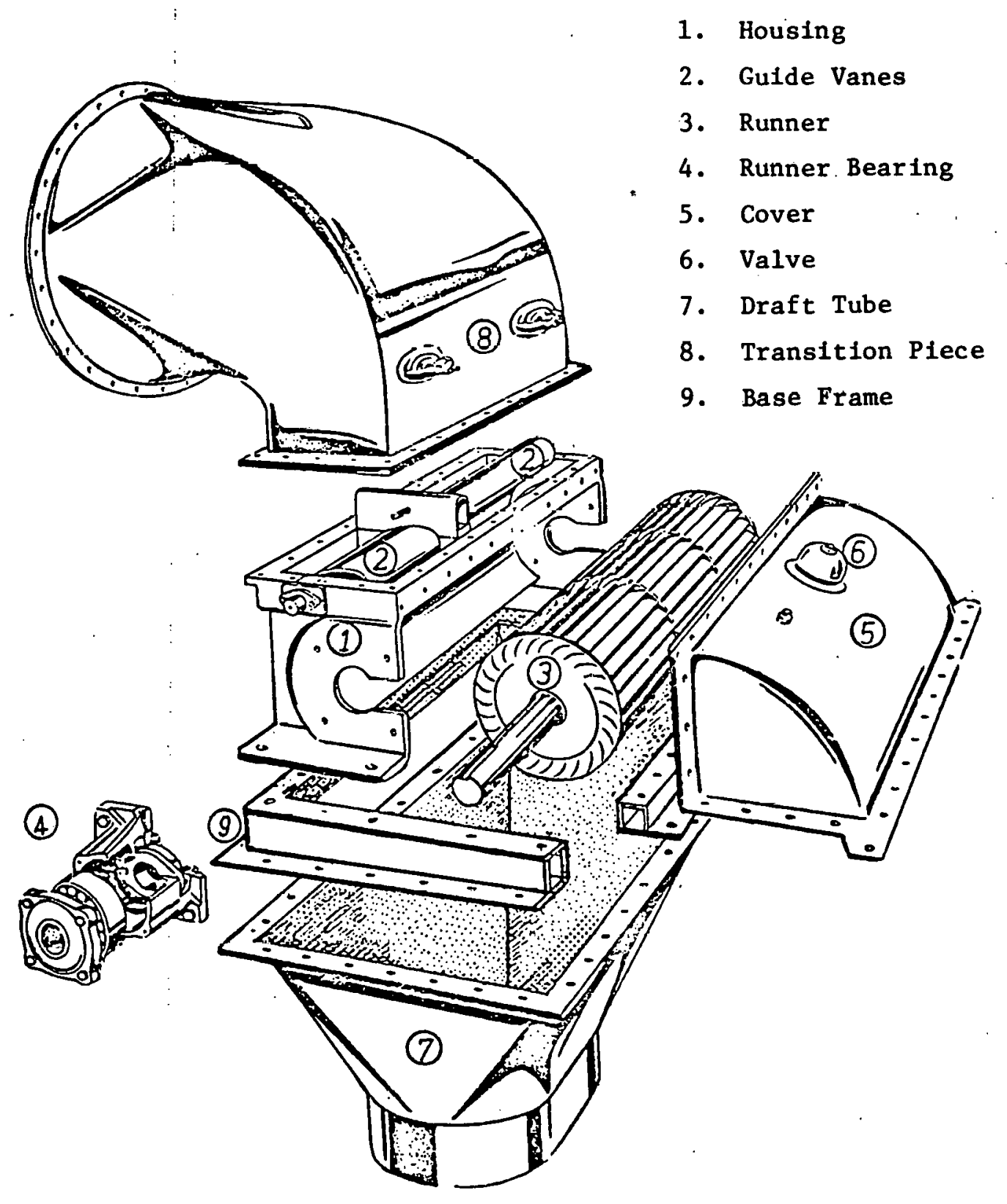

SOURCE: Reference 3.

FIGURE 5-4 AN OSSBERGER TURBINE ASSEMBLY

(AN EXAMPLE OF AN IMPULSE TURBINE) 


\section{B. Power Potential at a Specific Site}

All turbines require that water be channeled to them, under pressure, In large pipes or penstocks, from a source some height above the turbine. The maximum water flow rate and pressure determine the maximum (not the average) amount of electric power that can be generated at the site. The water flow rate is defined by the characteristics of the site, 1.e., the amount of local rainfall, drainage area, the soil type in the drainage basin, etc. The pressure avallable at any particular site, however, can be changed by increasing the hydraulic head available:behind a dam installed at the site either by increasing the height of the dam or by placing the powerhouse downstream and lower than the base of the dam. Figure 5-5 shows how the power available at a site varies with the water flow rate and the hydraulic head.

Some hydro sites may not require the construction of new dams since some hydro power (mechanical and electrical) plants have been abandoned during the past 40 years. While the turbines were usually removed from the sites when the plants were decommissioned, the civil works, i.e., the dams, penstocks, etc., remain and, if in good condition, might be reclaimed. In addition, many large-scale hydro plants and dams constructed for other purposes do not exploit the total hydro power resources available at their sites; it is possible that additional power generating equipment could be installed at these dams at minimal cost. However, since many of these dams are very old and may require extensive rehabilitation, each site must be evaluated individually.

\section{Section 5.3: Economics Discussion :}

A. Capital Cost of Run-of-the-River Hydrogeneration

The head and water flow rate at a site will both tend to define the capital cost of the hydro power unit at the site. If the head is low, the amount of water which must flow through the turbine in order to generate a $\mathrm{kWh}$ of electric energy must be high. The equipment necessary to process these large water flows is larger and more costly 


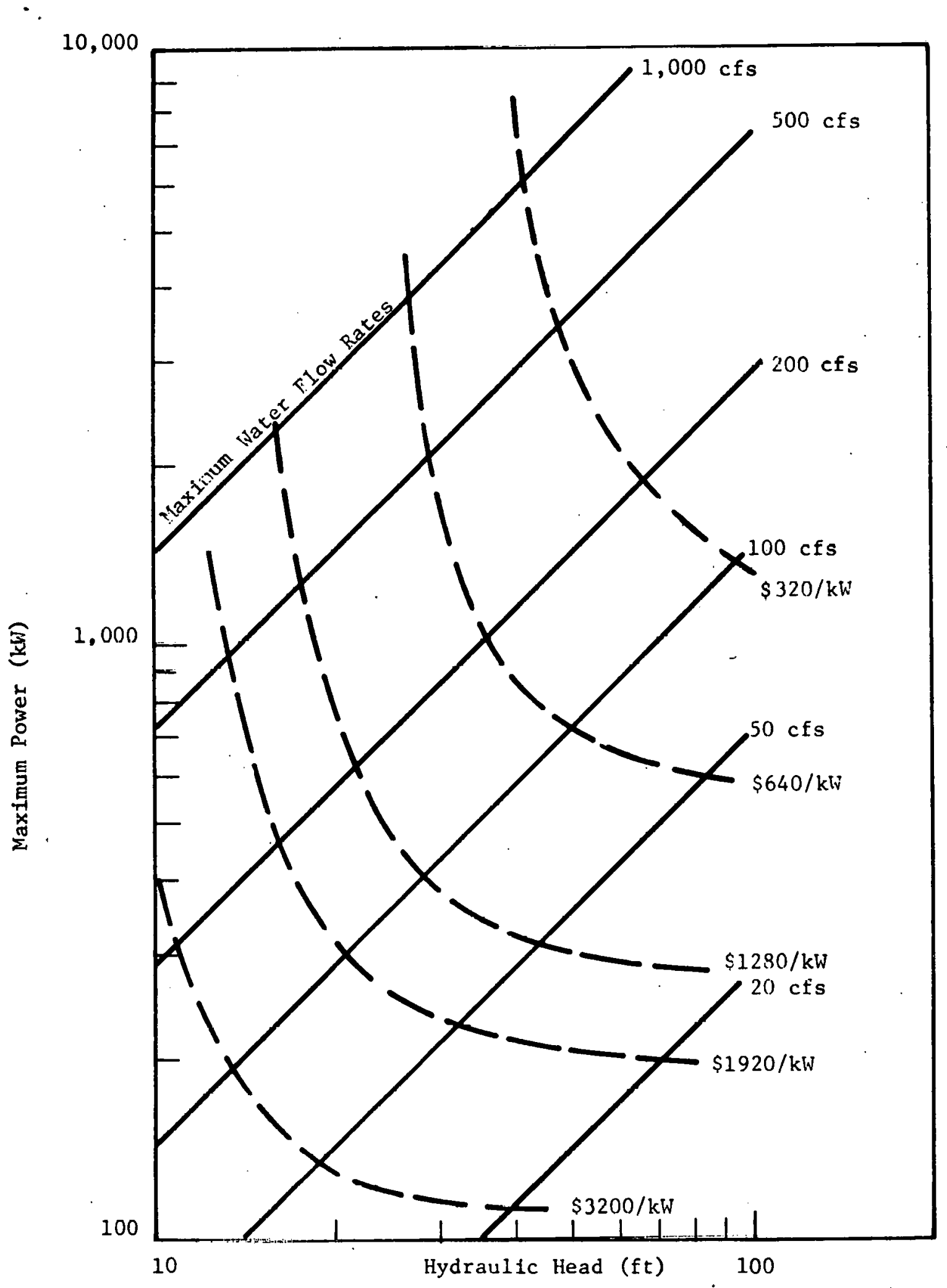

SOURCE: References 3 and 5.

FIGURE 5-5 POWER AVAILABLE FROM A HYDROGENERATOR AND UNIT COST AS A FUNCTION OF THE HYDRAULIC HEAD AND WATER FLOW RATE. (The efficiency is assumed to be a constant. Costs include turbogenerators, control systems and minimal civil works.) 
than the equipment needed to process smaller water flows. In general, for the same generated power, the higher the head, the lower the capital cost of the design capacity power plant.

One estimate ${ }^{(5)}$ (generally confirmed by References 3 and 4 ) of the variation of the capital cost ${ }^{*}$ of run-of-the-river hydro plants with head and water flow rates has been plotted as constant-cost contours in Figure 5-5 (dashed lines). These contours demonstrate the previously mentioned increase in the unit cost with the maximum water flow rate, given the same electrical output. They also show the economies of scale that result from installing large amounts of capacity at a single site. Because of the strong dependence of the cost of the needed civil works on site, these costs should be used only to indicate the approximate cost of run-of-the-river hydrogeneration.

To minimize the capital costs of the plant by using the economies of scale, the number of generating units should be kept to a minimum. However, other considerations, such as flexibility of operation, higher-efficiency operation during times of low power demand, and the minimum loss of capacity during shutdown for repair or maintenance, might indicate the use of multiple units where one unit would be feasible in terms of physical stze. For example, Figure 5-6 presents data on the variation of the hydro plant efficiency with power output when the plant has multiple units. Figure 5-7 shows how the same effect can be obtained in an impulse turbine with a segmented runner.

Most of the investigators of run-of-the-river hydrogeneration have limited themselves to a consideration of low-head installations ( $<50 \mathrm{ft}$ ) as one way of reducing the size and cost of the associated civil works. However, natural high-head sites do exist and could be very useful in a distributed energy system. The equipment (impulse turbines) needed to use these heads is available in the appropriate sizes (100 kW - $10 \mathrm{MW})$. The cost contours in Figure 5-5 for the high-head systems were derived with the assumptions that the head occurs naturally and that only a minimal amount of civil works is required.

* Cost includes the cost of turbines, generators, control systems, and minimal civil works (e.g., earth-moving, construction of dams, etc.). 


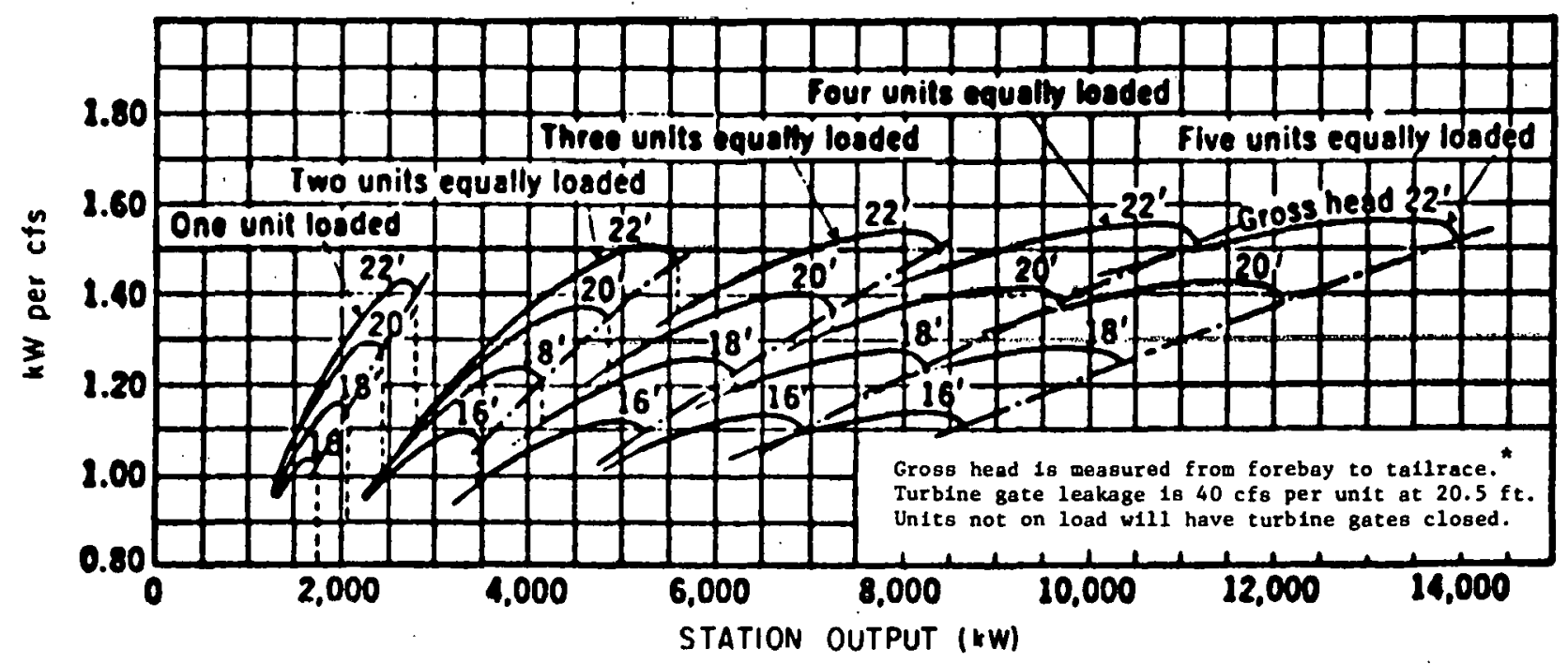

*

* The forebay is the water súpply area before the entrance to the penstock. The tailrace is the channel into which the water from the turbine is discharged. The gross head is the difference in height between the two.

SOURCE: Reference 6.

FIGURE 5-6 PERFORMANCE CURVES FOR A LOW-HEAD HYDROELECTRIC POWER PLANT 


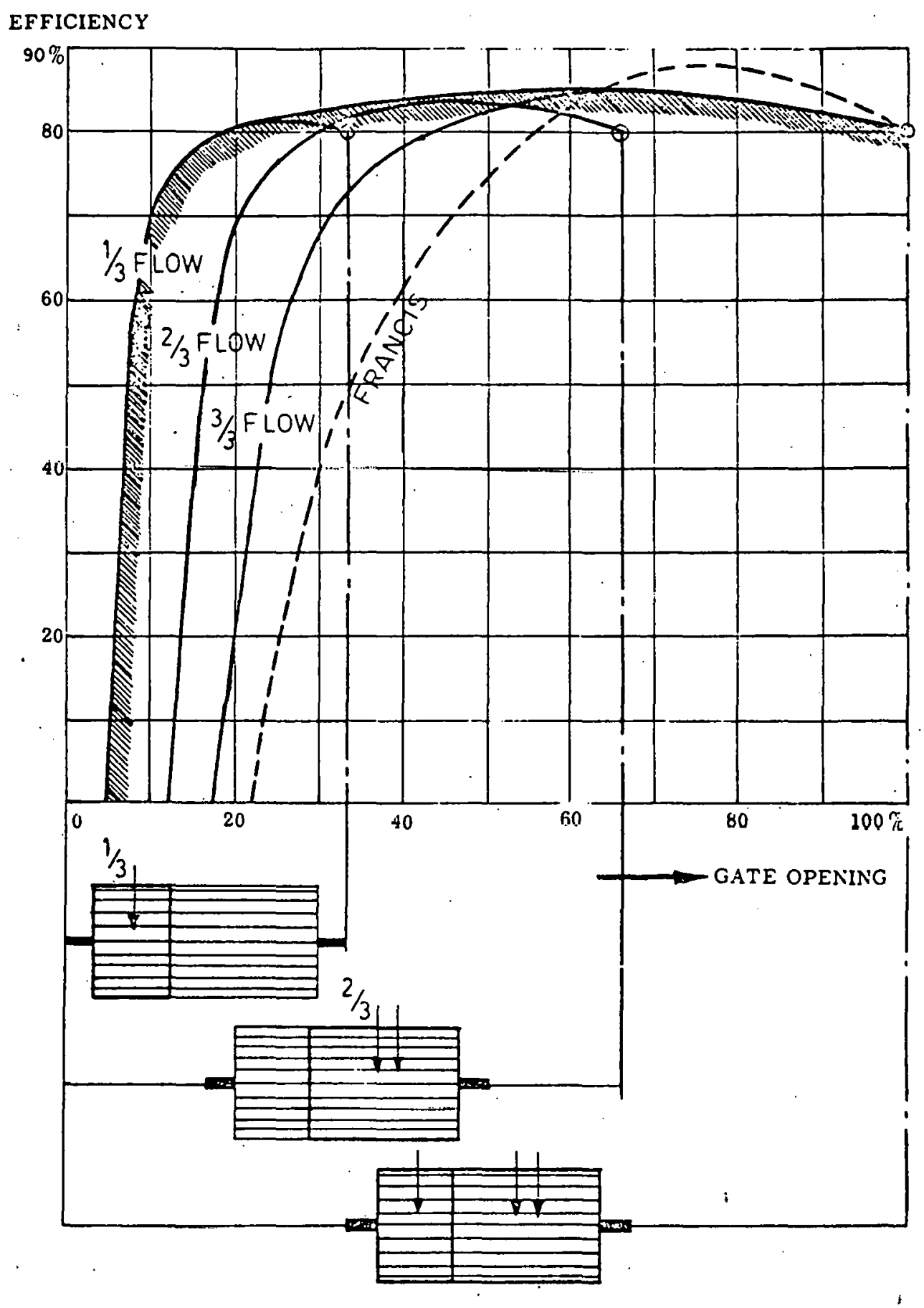

SOURCE: Reference 3 .

FIGURE 5-7 EFFICIENCY AS A FUNCTION OF THE GATE OPENING: OSSBERGER (IMPULSE) TURBINE WITH A SPLIT RUNNER AND THE FRANCIS TURBINE 


\section{B. Operation and Maintenance Requirements and Costs}

Discussions with the maintenance personnel of two utilities (7)

Indicated that small, low-speed hydrogenerators can operate for years with only a relatively small amount of scheduled maintenance. For example, the four run-of-the-river units on the Deerfield River in Massachusetts were all installed before 1910 and have operated, essentially without trouble, for more than 67 years. Therefore, an estimate of $0 \& M$ costs of $\$ 0.002$ to $\$ 0.004 / \mathrm{kWh}$ is generally accepted unless special manning requirements justify a higher figure. (7)

The cost of operating the plants is often cited as one of the reasons why so many small run-of-the-river hydruytuerators were shut down in the 1940 's. Before the equipment became available to control the hydro plants remotely, it was necessary to have plant operators on-site 24 hours a day to take full advantage of the available wacer. 'lhus, It cost aboul the same amount to operate smaller plants as to run larger plants. When the cost of fuels for the fossil plant was low, the total cost per $\mathrm{kWh}$ of operating the large fossil-fueled plant (including fuel) could be comparable to the total cost per $\mathrm{kWh}$ of running the small hydro plant; however, the plants were usually retired only when they required major rehabilitation. With remote control systems, one operator can control several hvdro plants from a single location. The cost of operating a small. station is no longer the predominant factor determining the economic desirability of small hydro power units.

\section{Section 5.4: Limitations}

Statistics compiled by the Federal Power Commission (8) Indicate that as of January 1, 1976, sites capable of providing a total additional 113.7 GWe of hydroelectric power at an average capacity factor of 0.4 had been Identified. Excluding Alaska, the data show 80.4 GWe at an average capacity factor of 0.33 . These sums do not include the sites along waterways in protected wilderness areas or parkland. However, the cost of developing each of these sites and the limitations on the energy avallability at each site:affect the development potential of this resource. Unfortunately, the water flow at any site is not constant throughout the year. Thus, the energy availability at a site bears little 
relationship to the peak power avallability, which is the reason for the relatively low capacity factor.

The FPC report ${ }^{(8)}$ contains a list of hydroelectric sites in which individuals have shown interest at some time in the past. It provides information on the peak power available at each site, the total amount of energy available at each site in an average year, the available proposed head, and the corresponding amount of storage capacity (pondage) at each site. It does not describe how the volume of water flow varies during the year.

The capacity available from run-of-the-river hydroelectric plants will vary throughout the year. Typically, water flow rates reach a maximum during the spring run-off and a minimum either during the heat of summer or when the surface water is frozen into position and cannot run off. Unfortunately, the times of peak demand for electrical energy occur during the summer (air conditioning load) or the winter (lighting and heating load). The run-of-the-river plant might be unavailable to the utility because of low-water conditions during the utility's peak demand season. If the electric utility cannot rely on the hydrogeneration capacity during the period of peak demand, additional foss1l-fueled capacity would be required to meet the peak demand. This consideration would reduce the value of the run-of-the-river power plants to the utility.

If the hydro plant is owned by a non-utility, the local utilities' problems may be exacerbated. The private owner reaps all the benefits of low-cost power when the water flow is avallable but must turn to the utility for back-up power when the water flow is unavailable. The utility gets little or none of the benefits of the hydro plant but may stili need to Install fossil-fueled capacity to meet the power demand of the hydro plant owner during the season of minimum water flow. If this season coincides with the utility's peak demand season, the cost impact on the utility, and indirectly on the other customers of the utility, could be significant.

One method of dealing with seasonal variations of the water flow to the run-of-the-river plants is to control the river. The water flow to the four units on the Deerfield River in Massachusetts is controlled by 
a single dam upstream. The cost of the dam and associated reservolr can be split between all four hydro units. By operating the hydro units to meet the daily peak during all seasons, the utility can maximize its fuel (o11 or gas) savings throughout the year. Because all of the previously mentioned dams on the Deerfield River and the upstream reservoir are owned by the same corporation, the question of cost allocation was not important. It is, however, possible to allocate upstream reservoir costs to the different owners of several downstream plants.

The undeveloped or abandoned hydro power sites listed in the FPC survey (8) for New York State as having no pondage are shown in figure 5-8 according to their hydraulic head and potential rated power. The wide variation of these two parameters from site to site clearly shows why any general statements about these resources can be misleading. The cost contuurs of Figure $5-5$ have also been replotted in Figure 5-8. It should be noted that a few of the sites 1isted by the FPC for New York State can be eliminated because their capital costs are very high. It should also be noted that many of the low-head sites were developed and then abandoned. (The plans and blueprints of these sites are probably still available.)

The U.S. Army Corps of Engineers ${ }^{(9)}$ estimates that the national hydro power potential at existing small dams (head $<100 \mathrm{ft}$, power $<5 \mathrm{MW}$ ) is 26.6 million $\mathrm{kW}$ with a potential energy yield of $85 \times 10^{9} \mathrm{kWh} / \mathrm{yr}$. The Corps' methodology (dictated by the short time avallable for the Corps' study) ylelded estimates only, and the actual potential may be somewhat less.

One of the postulated advantages of distributed energy systems is the location of the energy source close to the energy demand, resulting in a reduction in transmission costs and losses, and an increased flexlbility in the system's operations. Unfortunately, there is no guarantee that hydro sites, run-of-the-river or otherwise, will be available in the vicinity of the load. Therefore, geographic distribution and proximity to load centers will be critical factors in assessing the potential of increased run-of-the-river hydrogeneration and the associated costs. 


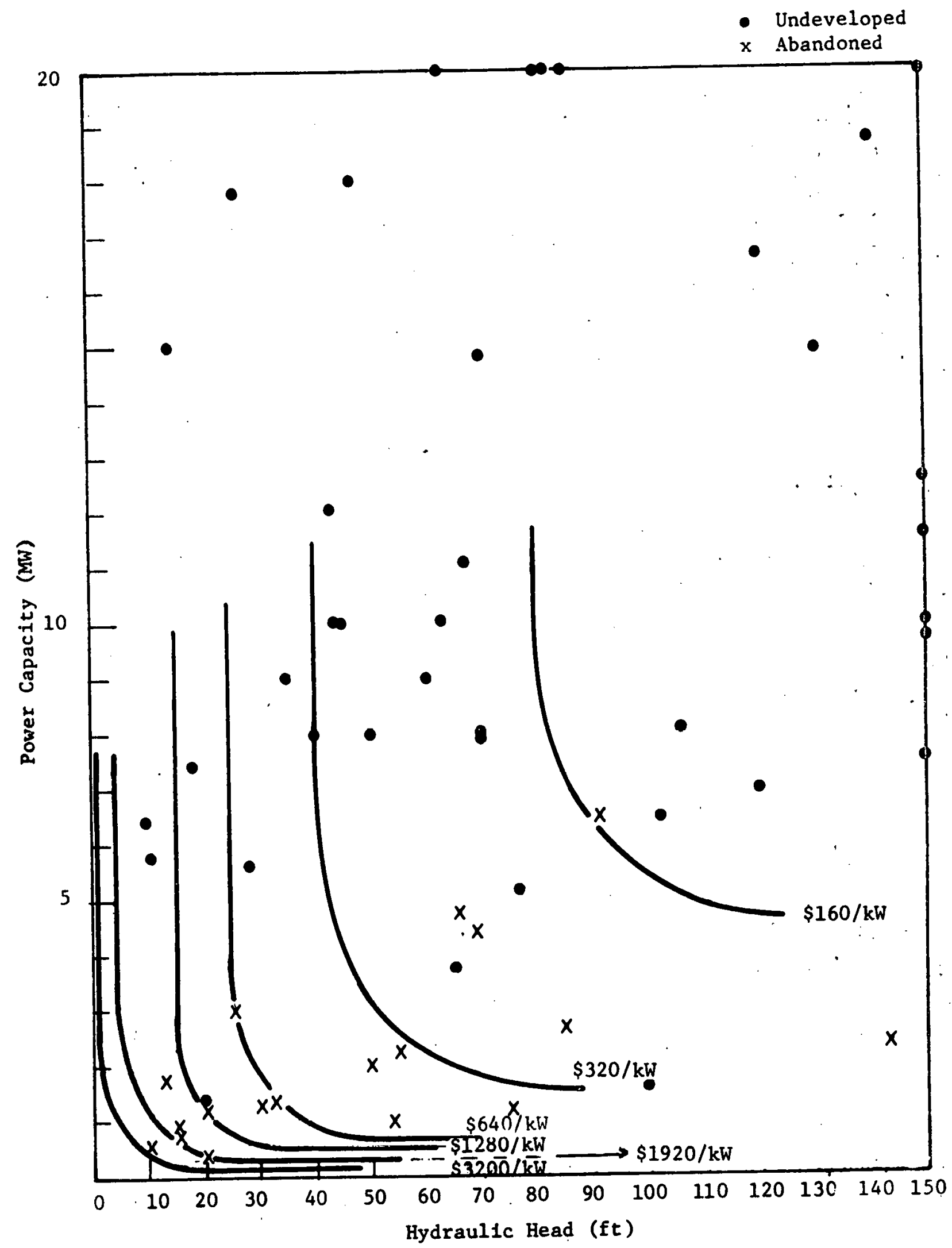

SOURCE: References 4 and 8 .

FIGURE 5-8 UNDEVELOPED AND ABANDONED HYDROELECTRIC SITES IN NEW YORK STATE 
Detailed studies of particular geographic areas have been Inftiated recently, as, for example, in New England and New York. (10) Whatever the geographic distribution of the small hydrogeneration sites, the chances are that these sites will be located on the distribution network (69 $\mathrm{kV}$ or less) rather than on the transmission network. Thus, they w11l probably be used to meet the needs of the customers located off the local distribution feeders rather than those of customers located on the other side of the utility's service area.

The utilization of hydro power at particular sites may be inconsistent with other important water uses. For example, removing large amounts of water from a river for irrigation during the dry season at a point upstream from a hydroelectric power plant will reduce the dependable stream capacity of the plant during that perfod of time, Water rights, 1.jke mineral rights, are bought and sold independently of the land. The water at potential hydro power sites may now be owned by institutions which may expect to use the water for purposes which will eliminate the powergenerating potential at the downstream sites. The mutipurpose aspects of river basin development are recognized in the Federal Power Act, which requires the Federal Power Commission ${ }^{*}$ to evaluate a water resources plan prior to licensing. (11)

The environmental aspects of hydro power developments vary significantly from site to site. The construction of new dams can result in erosion, dust, and other discharges that may contribute to downstream siltation and pollution. Following construction, the physical and chemical characterIstics of the water may be changed from that which previously existed; dissolved oxygen levels may decline. Dams act as barriers to the flow of heavier-than-water chemicals, organisms, and silt. Thus, the presence of a dam may have a major impact on the local site ecology and on related recreational opportunities. The installation of new generating equipment at existing dams avoids most of the impacts associated with construction of a new dam, whereas the construction of a large number of new small dams might attract significant opposition. However, these environmental

\footnotetext{
* Now the Federal Energy Regulatory Commission (FERC).
} 
Impacts may be less than the impact of alternative fossil fueled power plants; each installation must be evaluated independently.

The issue of small dam safety is also relevant to a discussion of run-of-the-river hydro power. In particular, one must consider the safety of animals and people in the water near a normally functioning facility, as well as the safety of downstream installations should the dam fail. With respect to the former, there exist standard design procedures for minimizing hazards around the water passages. (12) With respect to the latter, design criteria generally call for construction sufficient to withstand the largest flood that can reasonably be expected to occur at the site. (12) However, a review of the nation's dams by the Army Corps of Engineers (13) indicated that approximately 20,000 of the 49,329 dams of the nation are so located that fallure of the dam or misoperation of the discharge facilities could result in loss of human life and appreciable property damage, and that dam safety programs in most jurisdictions are efther nonexistent or inadequate to protect the public from hazards created by dams. Run-of-the-river facilities are relatively safe because the pondage for these dams is smal1; however, in view of the findings of the Corps, this 1ssue warrants close study. 
THIS PAGE

\section{WAS INTENTIONALLY LEFT BLANK}




\section{REFERENCES}

1. Rheingans, W.J. "Hydraulic Turbines." Standard Handbook for Mechanical Engineers. 7th ed. Edited by T. Baumelster. New York: McGraw-Hill. pp. 9-183 ff.

2. Brown-Boveri, North Brunswick, New Jersey. Product literature on synchronous machines for water power generation. August, 1977.

3. E.W.E. Stapenhorst, Inc., Montreal, Quebec. Product 1iterature on synchronous machines for water power generation. August, 1977.

4. National Academy of Sclences. Energy for Rural Development. Washington, D.C., 1976.

5. O'Brien, E. "Small Hydro Plants for the Northeast." Electrical World 188 (4)::61, August 15, 1977.

6. Stelnberg, M.J., et al. Economic Loading of Power Plants and Electrical Systems. New York: John Wiley and Sons, 1943.

7. New England Power Company, Westborough, Massachusetts and Wisconsin Public Service Corporation, Green Bay, Wisconsin. Private communication.: August 1977.

8. Federal Power Commission. Hydroelectric Power Resources of the United States. Washington, D.C., 1976.

9. McDonald, R.J. Estimate of National Hydroelectric Power Potential at Existing Dams: Washington; D.C.: U.S. Army Corps of Engineers, July 1977.

10. "New York Launches Study of Hydroelectric Capacity." Electrical Week, September 12, 1977. p.5.

11. Federal Power: Commission. The 1970 National Power Survey. Washington, D.C., 1971.

12. U.S. Department of the Interfor. Design of Sma11 Dams. Washington, D.C., 1973.

13. U.S. Army Corps of Engineers. National Program of Inspection of Dams. Washington, D.C., May 1975. 


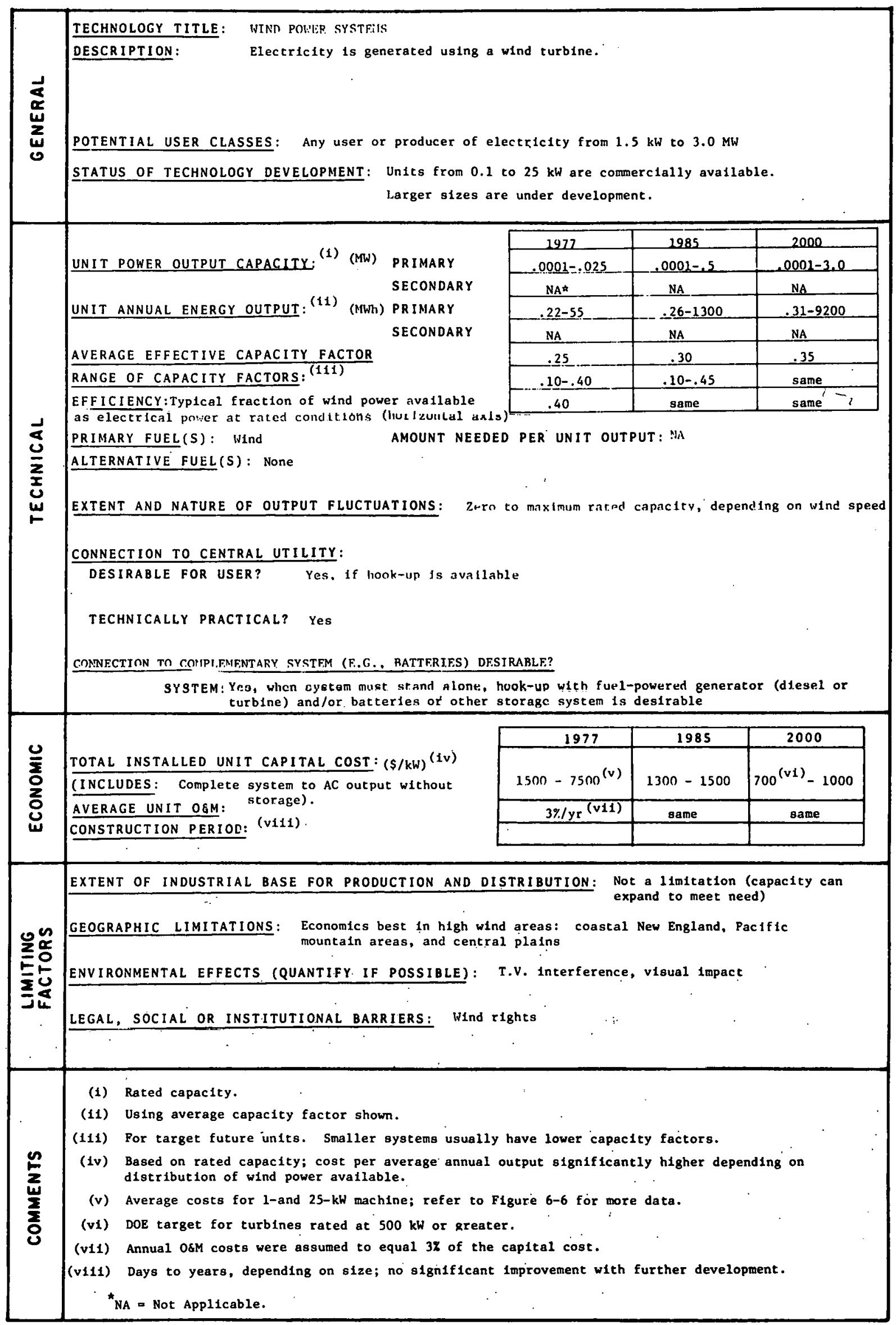


CHAPTER 6

\section{WIND POWER SYSTENS}

\section{Section 6.1: Introduction}

There is a great deal of experience in the use of wind power plants for generating electricity or mechanical pumping power. * Systems range from do-it-yourself installations $(2,3)$ to utility-sized applications. (4) Systems are in use today and are being installed in remote areas where power from the central utility system is not available or too expensive, or where operation of engine-generators is impractical. $(5,6)$ Most of the commercially available wind generators have maximum outputs in the 0.1 - to 15-kW range. (7) The upper end of this size range may be applicable to residential on-site power units in the United States. $(8,9)$ The present worldwide market for small wind generators is estimated to be only about $\$ 3$ to $\$ 6$ million, but 1 it is expected to grow substantially as the cost of conventional energy sources increases and the technical/ economic performance of wind turbine systems is improved.

There are several DOE-supported programs underway to develop larger wind power units with output capacities in the $100-$ to $3000^{-} \mathrm{kW}$ range. $(10,11)$ These units, several of which are in the preliminary testing stage, would be applicable to on-site applications, serving multiple residential units, commercial buildings, and stmall industrial operations.

\section{Section 6.2: Technical Discussion}

A. Types of Wind Turbines

Wind generators are generally classified as being horizontal- or vertical-axis types. Within these categories a large number of different designs have been developed. Figure 6-1 shows some of the configurations.

* Reference 1 has an excellent discussion of the history and operation of wind power systems. 


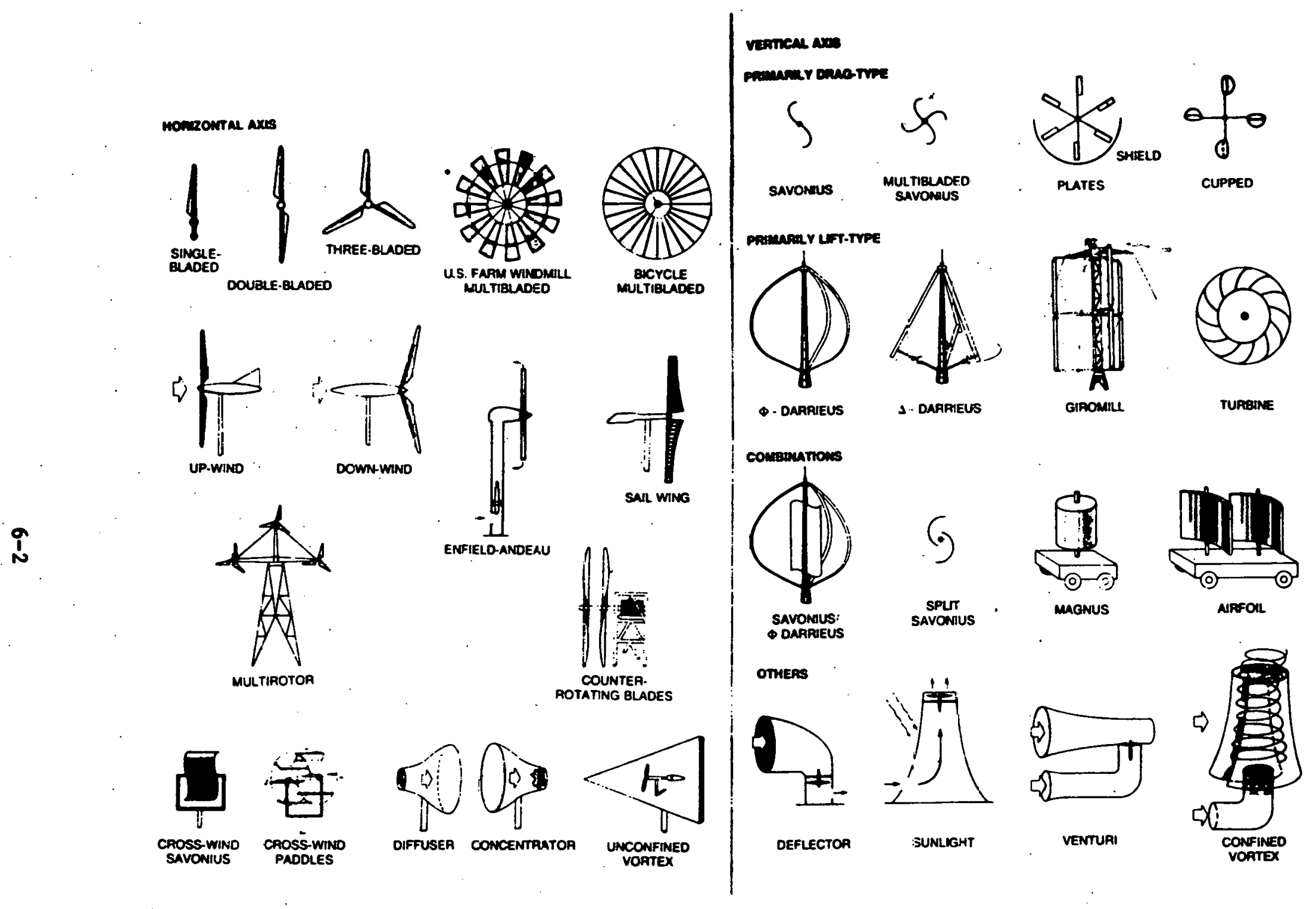

SOURCE: Reference 1.

FIGURE 6-1 WIND MACHINE CONFIGURATIONS 
Most units currently in use are horizontal-axis wind turbines with either two or three blades. Figure 6-2 shows one such machine. The design of the blades is similar to that of an airplane propeller (in fact, wind turbine blades have often been made by companies which make propellers for small airplanes). Sophisticated aerodynamic shapes result in wind turbines that have coefficients of performance which are approximately $80 \%$ of the theoretical maximum. It is doubtful, therefore, that significant improvements can be made in the aerodynamic efficiency of these machines which would, in turn, lead to reductions in size for a given output. Wind turbine/generators of this type with blade diameters up to 25 feet are commercially available from a number of companies cited below.

The most common vertical axis wind generators utilize Darrieus Rotor or Savonius S-Shape Rotor configurations. Darrieus Rotor machines have higher coefficients of performance and better wind speed/output characteristics than Savonius Rotor machines and are, therefore, probably better suited for larger-scale applications. Several firms ${ }^{*}$ now offer vertical axis wind generators of the Darrieus Rotor type with outputs ranging up to $37 \mathrm{~kW}$. A schematic of one of these machines is shown in Figure 6-3.

The principal advantages of vertical axis wind generators are: since they can accept wind from any direction, the machine design is simpler than that of the horizontal axis machines which must face into the wind; since the position of the electric generator is fixed relative to the ground, complicated linkages and slip rings are not required; since the generator can be mounted on the ground rather than on a tower, access to the generator equipment is improved. These advantages must be balanced against the efficiency levels of approximately $75 \%$ of those having horizontal-axis equipment, ${ }^{(1)}$ as well as the fact that most designs are not self-starting.

The following discussion concentrates on horizontal-axis wind turturbines, since this is the main type being used for electrical power production at this time. Although the vertical-axis machines may have a competitive advantage in smaller sizes, the basic economics of wind power generation

* See Table 6-1 for sample firms; also see Reference 12 for general listing of firms in the wind energy fleld. 


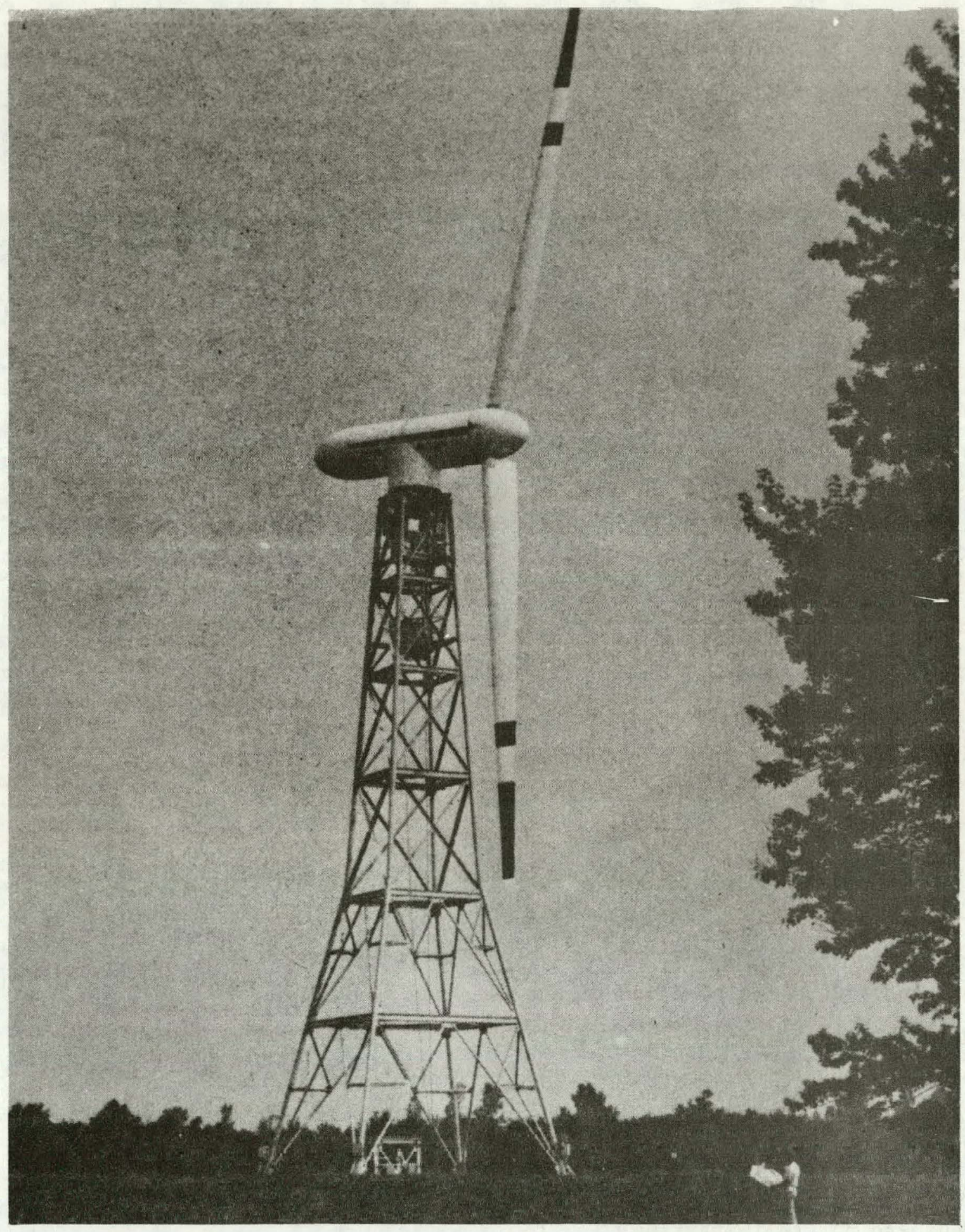

SOURCE: Reference 13.

FIGURE 6-2 DOE/NASA $100 \mathrm{~kW}$ MOD-0 WIND TURBINE 
TABLE 6-1

COSTS OF WIND GENERATOR SYSTEMS

PARTIAL LIST OF COMMERCIALLY AVAILABLE WIND MACHINES

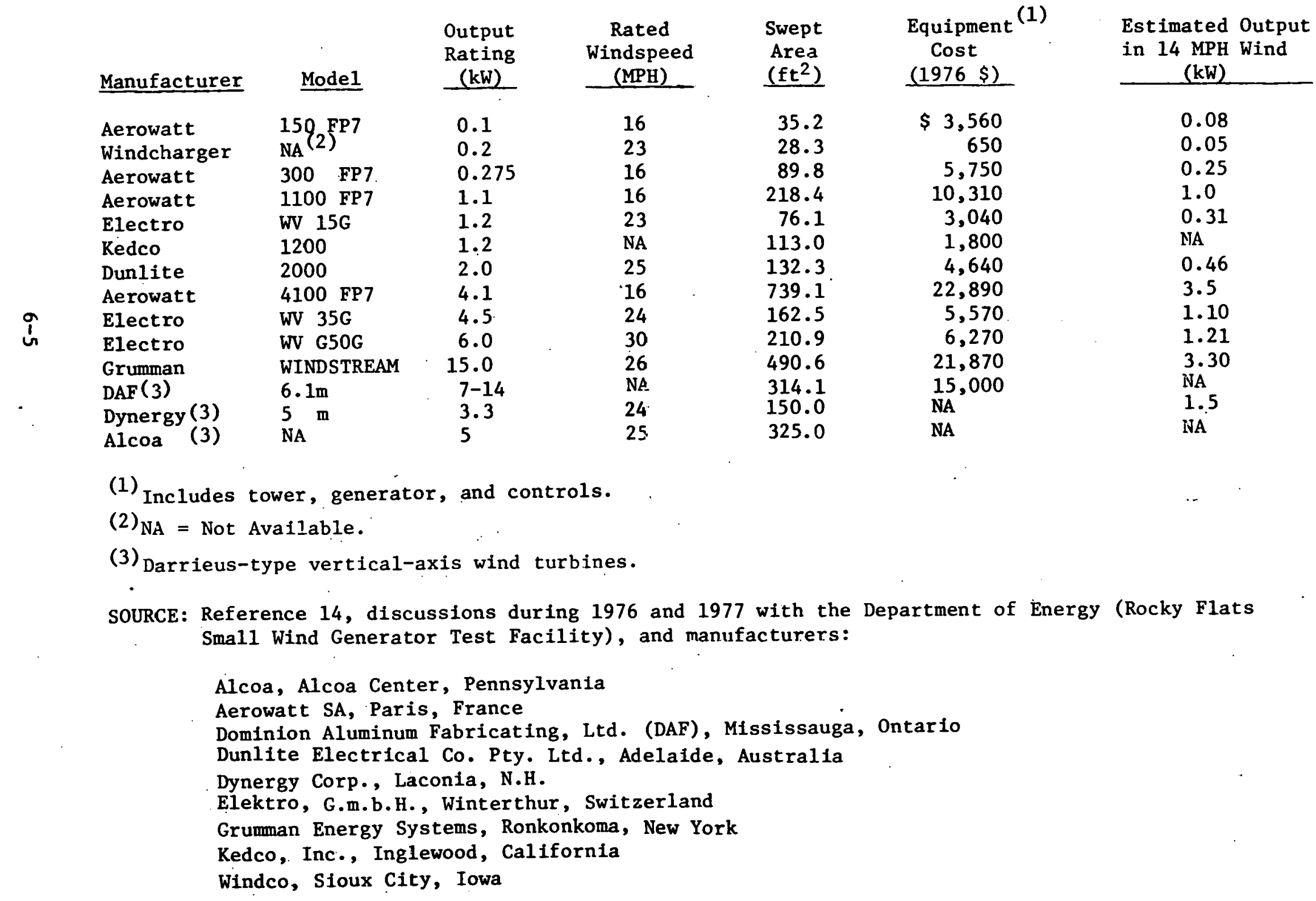




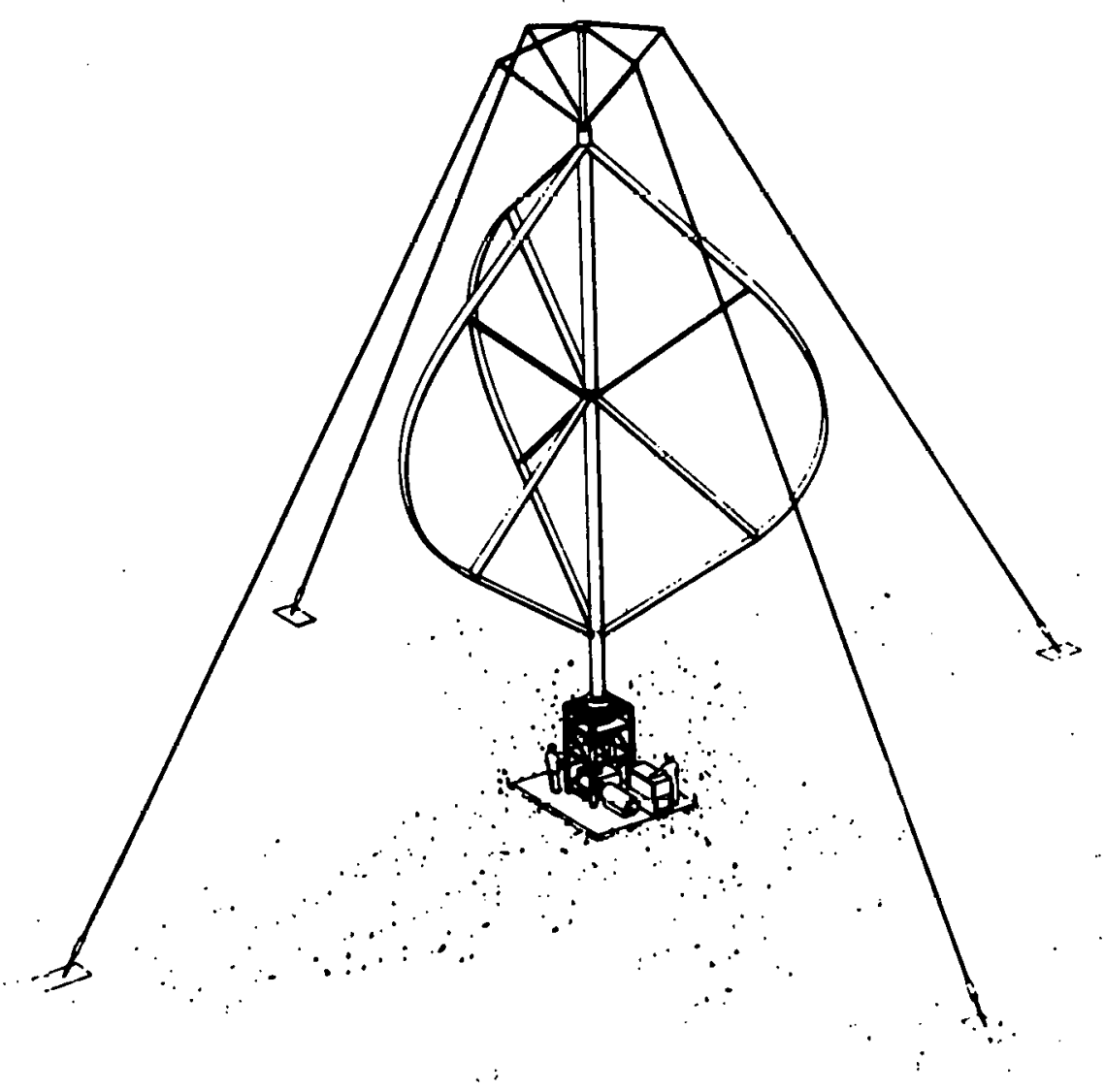

SOURCE: Reference 15 .

FIGURE 6-3 VERTICAL-AXIS WIND TURBINE

$$
\text { 6-6 }
$$


discussed below should apply to both cases.

\section{B. System Description}

Several different system configurations have been proposed for on-site generation of electrical power. In one, the wind turbine would stand alone, isolated from any electric utility. Batteries or backup generating capacity would be provided. In another, the wind turbine would be backed up by the utility so that power would automatically be drawn from the utility whenever the demand exceeded on-site supply. Excess capacity would be wasted or stored in batteries or as heat in water. In a third configuration, the wind turbine system would be backed up by the utility; excess capacity would be passed to the utility, and no on-site storage would be used. One study ${ }^{(16)}$ indicated that this last mode of operation would be most economical.

A schematic of a typical small isolated wind turbine generator with on-site storage is shown in Figure 6-4. The system shown consists of several major components:

- A wind turbine sub-assembly which includes the blades, hub mechanism with overspeed controls, generator, and turntable to allow the turbine to rotate into the wind.

- A tower to support the wind turbine sub-assembly at the proper height for the length of the blades and the variation in wind velocity with height above ground and local obstructions.

- A battery pack (with appropriate charging circuits) to store excess output for use as determined by load profiles.

- An inverter system to convert the dc output of the wind turbine generator and the battery pack into ac power, consistent with the distribution system and appliance loads.

- An auxiliary englne to drive the ac generator if the battery pack is exhausted and Insufficient electricity is available from the wind turbine. 


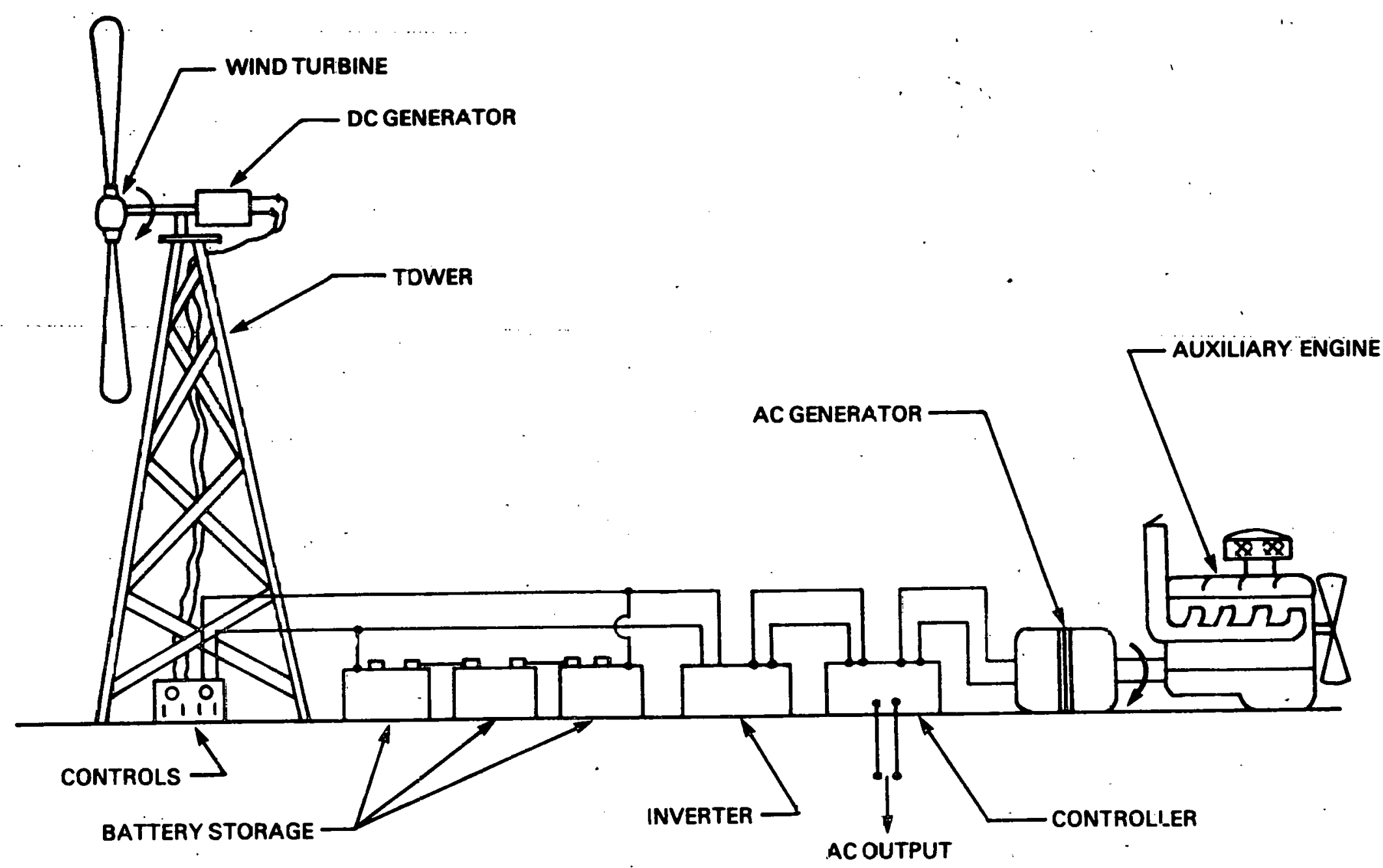

SOURCE: Arthur D. Little, Inc.

FIGURE 6-4 SCHEMATIC OF AN ISOLATED WIND POWER SYSTEM 
The schematic shown is for commerclally avaflable wind power units which generate dc power, in order to eliminate the need to operate at a precisely controlled constant speed for ac power generation. For these systems, an inverter would be used to convert dc output to ac power for use with conventional appliances. The larger wind turbine systems under development operate at constant speed (by proper control of blade angle) so that a synchronous ac generator can be driven directly.

\section{Operational Characteristics}

specd,

The power of the wind is proportional to the cube of the windavailable, as discussed in the following paragraphs. The strong sensitivity of wind power to wind speed implies that a small variation in wind speed can significantly affect the power output of a wind turbine. As a result, the viability of wind turbine systems can be highly variable with location. Consequently, locations only a few miles apart can have significantly different potentials for wind power utilization, depending on factors such as tree cover, bodies of water, and local topography. " These general data on wind velocities do not necessar1ly correlate with the actual distribution at a site and site-specific measurements should be made.

The actual output curve (power vs, wind speed) of a wind turbine typically consists of three pieces:

(1) the output is zero below a "cut-in" wind speed $V_{\text {in }}$ (In the region of 6 to $9 \mathrm{mph}$ );

(2) the output increases with wind speed to the speed $V_{r}$ at which the turbine delivers its rated power, $P_{r}$; and

(3) above a wind speed $v_{m}$, (which is at or slightly greater than $v_{r}$,) the output of the machine is held constant at $P_{m}$ by control of the pitch of the blades to prevent excessive tip speeds in high winds. At a speed $V_{\text {out }}$ the machine is closed down and the blade is feathered for self-protection. (1)

The design curve for a modern, recently installed large wind turbine is presented in Figure 6-5. ${ }^{(20)}$ The data points indicate that the actual

${ }^{\star}$ References 17,18 , and 19 discuss siting considerations and wind distribution throughout the Untted States. 


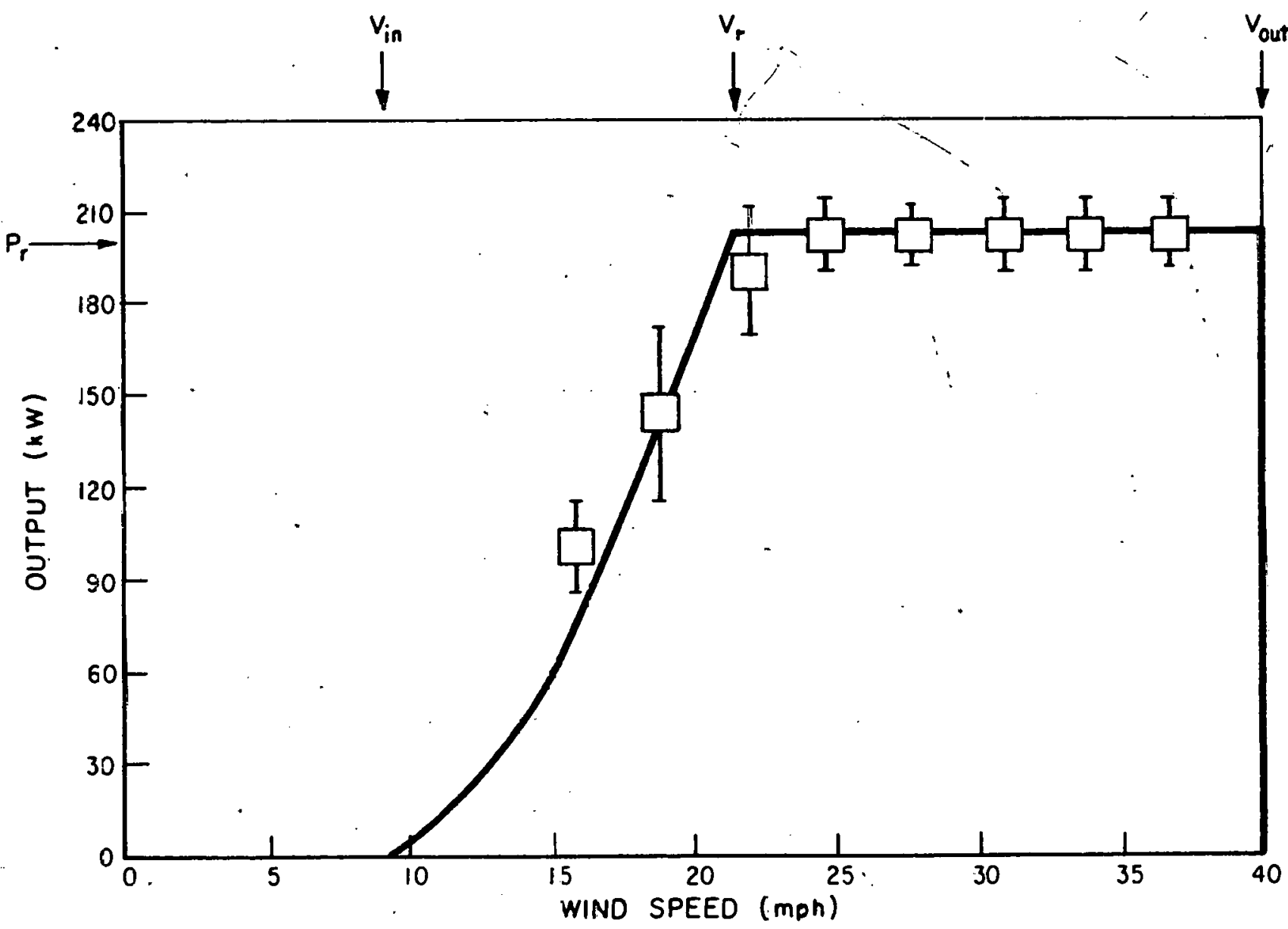

The joxes show actual recorded power outputs, and the 1 ines Indicate \pm 1 standard deviation. SOURCE: Reference 20 .

FIGURE 6-5 THEORETICAL OUTPUT POWER FOR CLAYTON, NM, WIND MACHINE (MOD-OA) AT VARIOUS WIND SPEEDS 
performance of the machine was close to expectations.

The output power of a turbine is less than the power theoret 1cally present in the wind stream. Their ratio is commonly referred to as the power coefficient, $C_{P}$. Aerodynamic analysis ${ }^{(11)}$ predicts an "ideal" maximum for $C_{p}$ for propeller windmills of approximately $60 \%$. Typically observed maximum values of $C_{P}$ are lower and depend upon the type of machine, ${ }^{(21)}$ e.g., $47 \%$ for two-blade types, $35 \%$ for Darrieus rotor machines, and $30 \%$ for Savonius rotor machines.

The variation of the: power output, $P$, of an actual machine with windspeed between $V_{\text {in }}$ and $V_{r}$ can be calculated only with difficulty, even with full and accurate knowledge of the aerodynamis and control characteristics of the machine. Alternatively, it may be conventent to assume for $P$ (see, for example, Justus ${ }^{(21)}$ ) a cubic polynomial relationship in $V$, in which the coefficients are determined by matching at $V_{\text {in }}$ and $v_{r}$ or $v_{m}$. The design output curve in Figure 6-5 follows the equation:

$$
P=0.0226 \mathrm{~V}^{3}+0.538 \mathrm{~V}-21.3
$$

for $V_{1 n} \leq V \leq V_{r}$ within less than $5 \%$ of $P$.

Wind turbine generators are usually rated at their maximum output capability which occurs typically at wind speeds in the 20-30 mph range for commercially available equipment. Even in areas of favorable wind regimes, average wind speeds are rarely over 12-16 mph near ground level. In these areas, the average output of wind turbines is only $1 / 8$ to $1 / 3$ of the rated output, which indicates that the rated output 18 usually a poor indicator of actual output performance. INASA designs for large capacity systems reach rated outputs at lower wind velocities. This leads to higher capacity factors than those of the commercial units currently available. Depending on site location, DOE expects to have capacity factors which range from $25-40 \%$ for 500 to $3000-\mathrm{kW}$ untts.

In addition to the factors which reduce the conversion efficiency c1ted above, there are further losses in the conversion of shaft power to electricity. Generators typically have an efficiency of $95 \%$. When a dc generator is used, an inverter must be employed to produce ac. 
Typical full-1oad efficiencles range from $85 \%$ for $15-\mathrm{kW}$ untts to $93 \%$ for 100-kW units and up. At partial load conditions, this efficlency is reduced. For a horizontal-axis machine, combining these efflciencies ylelds an insțantaneous conversion rate, ac output divided by avallable wind power, of approximately 0.4 . This must be further reduced by the capacity factor discussed above to obtain the actual annual output.

One of the major difficulties in utllizing wind turbine systems is matching the demand for power with the availability of wind. Because of the wide variations in available wind power discussed above, it would be necessary to incorporate a substantlal energy storage system if the wind system were to be the only source of power. In most cases, the economics of substituting an on-site wind turbine system for power from a central utility withnit a provioion for backup by the utility are not advantageous. Several different approaches to this problem, currently used or being considered, are discussed briefly in the following paragraphs.

Very large wind turbine systems of the type being developed by NASA for DOE which are used to generate power within a central powcr system could be used in situations where an existing hydroelectric capability exists nearby. (23) In this case, wind power would be used to displace hydropower whenever sufficlent wind velocity was avallable. When the wind velocity dropped below a certain point, hydro would pick up the load. The savings in this case would be in the form of the dammed water which would nnt be used to generale power when wind was avallable.

In a central power system, the total capacity added by a wind turbine system cannor be used to replace base load-generating capacity because of the random avallability of wind power. The primary advantage comes from the displacement of higher cost fuels for peaking equipment with wind energy.

Larger systems without a connection to the central power system ut1lize other forms of backup. A system currently being installed on Cuttyhunk Island in Massachusetts uses a diesel-powered system to provide energy when the wind velocity is too low. $(23,24)$ This diesel system 1s already providing power on the 1sland, and the wind power system will simply be added to reduce operating cost when the wind velocity is 
sufficlent to generate power. The diesel system will automatically start up when the output from the wind turbine system drops below a minimum value. Similar systems with diesel backup have been installed in other remote areas.

D. Energy Storage

Lead-acid batteries may be included in a wind turbine system to provide short-term storage capability. These battery systems are sized to store a fraction of the energy generated for use in meeting peak demands during the typical dally cycle. However, they do not store sufficlent energy to supply the system over a prolonged period of low wind avallabllity. These systems generally rely on the use of energy from the utility system for backup. If batteries are employed, it is Important to account for losses within the storage subsystem. (25)

A number of other storage systems have been proposed for use with wind power systems. $(1,5)$ These include:

- hydrogen storage systems in which hydrogen is generated by electrolysis of water and stored to provide heat or to power fuel cells whei energy is required;

- thermal storage in which mechanical work is converted to heat or in which electrical energy is stored as heat for use in space heating;

- flywheel storage in which electrical or mechanical energy is used to drive flywheels which subsequently produce electricity on demand;

- compressed air storage in which the mechanical or electrical energy generated by the wind system is used to compress air, which is pumped underground; and

- the use of wind power to generate nitrogen fertilizer which can be stored as generated and used when required. (26) 
These systems are all in the conceptual or early experimentai stage at this point and estimates of the storage costs associated with them are not we11 defined.

\section{E. Equipment Availability}

There are about two dozen companies now making wind turbine generators in the United States, Europe, and Australia. These units were developed primarily to generate power in remote areas where the cost of operating engine-generators or extending the utility grid was prohibitive. The characteristics of some commercially availablc wind Luıblue generators are shown in Table 6-1.*

\section{Section 6.3: Economics Discussion}

\section{A. Cost of Wind Turbine Systems}

Figure 6-6 shows how the installed cost of complete wind generators varies with system capacity. Typical commercially avallable units are in the 1-25 kW range and have installed costs of $\$ 1500-\$ 3000$ per $\mathrm{kW}$ based on maximum output capacity. ${ }^{* *(14)}$ Cost estimates of systems in the $1000-\mathrm{kW}$ size range were taken from a number of reports as analyzed by JBF. (27) Table 6-2 summarizes their data. The cost shown in Figure 6-6 as "DOE goal" is the cost which DOE projects for large units (500-1500 kW) once they are fully developed and in production. (23) The larger size units may be applicable for some on-site applications involving apartments, commerçial builinings, and industrial plants.

Representative breakdowns of costs for several wind power systems are summarized in Table 6-3. As indicated, the wind turbine (blades, hul, generator, and controls) comprises the major system cost. The relative costs of components are similar to those for other wind turbine generators in this capacity range.

\footnotetext{
* See Reference 27 for other companies and addresses. **

Based on average wind speeds, the cost/kW can be significantly higher and varies depending on the wind conditions at each individual site.
} 


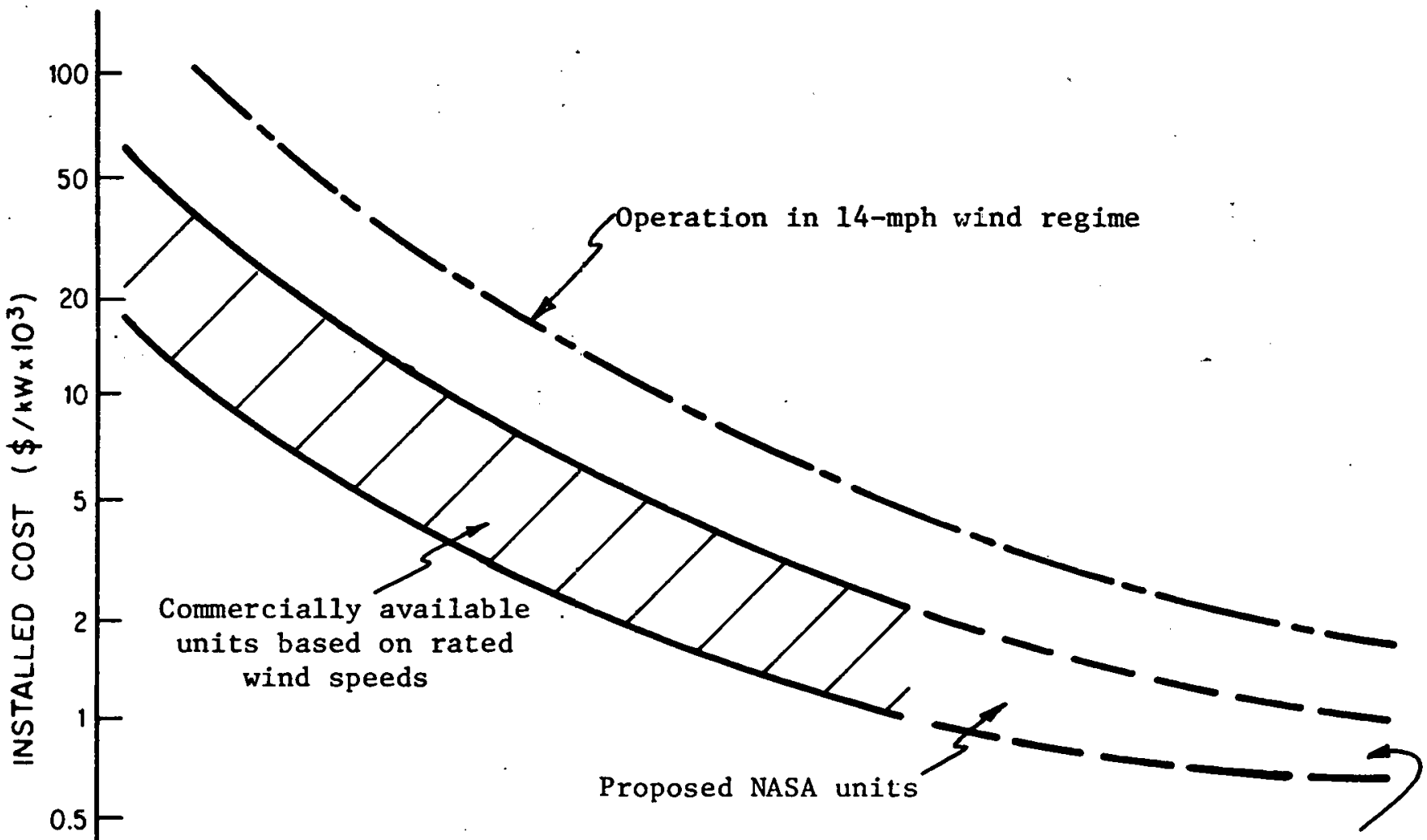

DOE goal for $500-1500 \mathrm{~kW}$ wind turbines

NOTE: - Estimated costs in 1977 dollars, but all units are not commercially available 0.2 - Larger NASA desizns reach rated output at lower wind velocities than smaller commercial units.

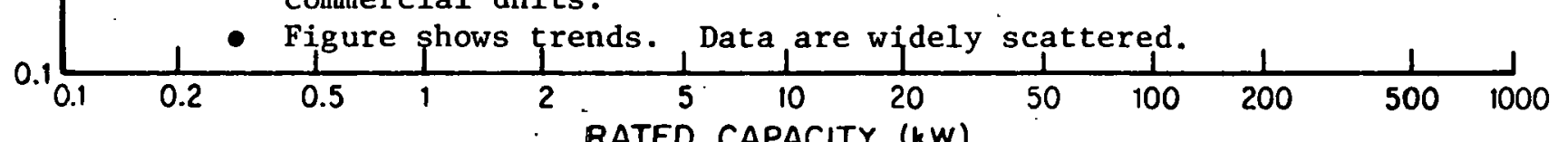

SOURCE: Arthur D. Little, Inc.

FIGURE 6-:6 COST OF WIND GENERATORS 
TABLE 6-2

INSTALLED CAPITAL AND ENERGY COST ESTIMATES FOR 1 MEGAWATT WIND TURBINE SYSTEMS PURCHASED IN 100-UNIT LOTS

\begin{tabular}{|c|c|c|c|}
\hline $\begin{array}{l}\text { Study } \\
\text { Source } \\
\end{array}$ & $\begin{array}{c}\text { Capital } \\
\text { Cost } \\
(1977 \mathrm{~s} / \mathrm{kW}) \\
\end{array}$ & $\begin{array}{c}\text { Capacity } \\
\text { Factor } \\
(\%) \\
\end{array}$ & $\begin{array}{c}\text { Energy } \\
\text { Cost }(\mathrm{c}) \\
(1977 \mathrm{mills} / \mathrm{kWh}) \\
\end{array}$ \\
\hline Lockheed $(28)$ & 1211 & 53.7 & $38.4^{(d)}$ \\
\hline G.E. (29) & 504 & 38.0 & 28.0 \\
\hline $\operatorname{Kaman}(30)$ & 652 & 43.0 & 32.0 \\
\hline Aerospace ${ }^{(31)}$ & 588 & 40.0 & 31.0 \\
\hline Honeywe 11 (32) & 739 & 43.0 & 36.3 \\
\hline SWRI (33) & 842 & 59.0 & 30.1 \\
\hline G.E. ${ }^{(34)}$ & 793 & 38.0 & $44.0^{(\mathrm{d})}$ \\
\hline
\end{tabular}

(a) In Reference 27, the JBF Study, data from previous studies were analyzed. The reference numbers of these studies (28-34) are shown in parentheses.

(b) Costs taken from Reference 27, Table B4, and escalated at $8 \%$ for two years to represent 1977 costs of all equipment, Installation, and site preparation.

(c) Energy cost (EC) calculated by Reference 27 as follows:

$$
\mathrm{EC}=\frac{\mathrm{C}_{e}(\$ / \mathrm{kW}) \times \mathrm{FCR}(\%) \times 10^{3}}{8760(\mathrm{hrs}) \times \mathrm{CF}(\%)},
$$

where $C_{c}=$ capital cost of system,

FCR $=$ fixed charge rate $=18.5 \%$, which includes a $3 \%$ component due to O\&M costs, and

CF = capacity factor.

(d) These energy costs were calculated using the equation in note (c), but have been normalized by JBF(27) to account for variations in the (the vertical wind speed profile coefficient) assumed in the Lockheed (28) and General Electric Studies. $(29,34)$ 
TABLE 6-3

\section{COST SUMMARY FOR THREE SIZES OF WIND TURBINES} (in 1977. $S / \mathrm{kW}$ in $18-m p h$ Wind) (I)

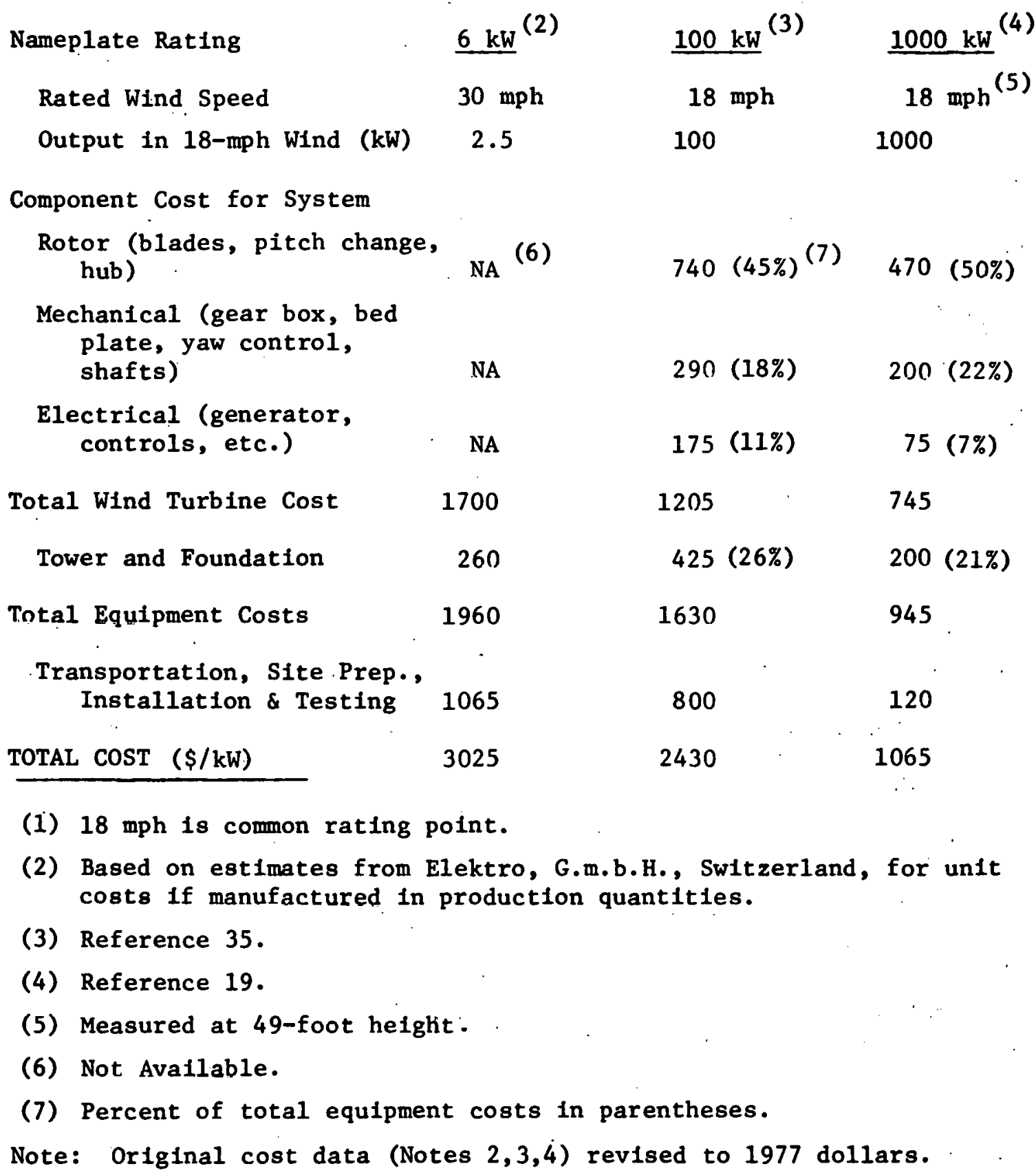




\section{B. Future Cost Reductions}

Several of the commerclally avallable wind turbine generators are technically sophisticated, and their performance approaches the best obtainable. It is, therefore, doubtful that large cost reductions can be expected in the smaller units as a result of improvements in performance. However, based on experfence with similar products, increased production would probably have cost benefits on the order of $20-50 \%$, and simplified design and/or reduced material requirements may also decrease costs.

The unit costs projected for the larger units are seen to be less than half those of the smaller units (FIgure 6-6) due, in part, to economies of scale associated with the major components such as generators, blades, and cowers. These lower costs represent goals at this time and are not as firm as the costs indicated for smaller units. which are commercially available.

\section{Wind Turbine Energy Costs}

The costs associated with owning and operating a wind power system include:

- Annual capital charges including interest on the initial cost and taxes,

- O\&M costs, consisting of normal maintenance and periodic repalrs of broken or faulty components.

Few relfable data are available on factors such as O\&M costs, forced outage rates, etc. Routine maintenance includes tasks such as lubrication, replacing worn generator brushes, checking wiring and fasteners, etc. In estimating costs, a value of $3 \%$ of capital costs per year has been used as a representative number for these types of operations. (22)

Figure 6-7 shows estimates of future wind energy costs reported by NASA ${ }^{(36)}$ for three sizes of wind turbines :

- MOD-OA has a rated power output of $200 \mathrm{~kW}$ at a wind speed of $20 \mathrm{mph}$. This model is regarded as "first- 


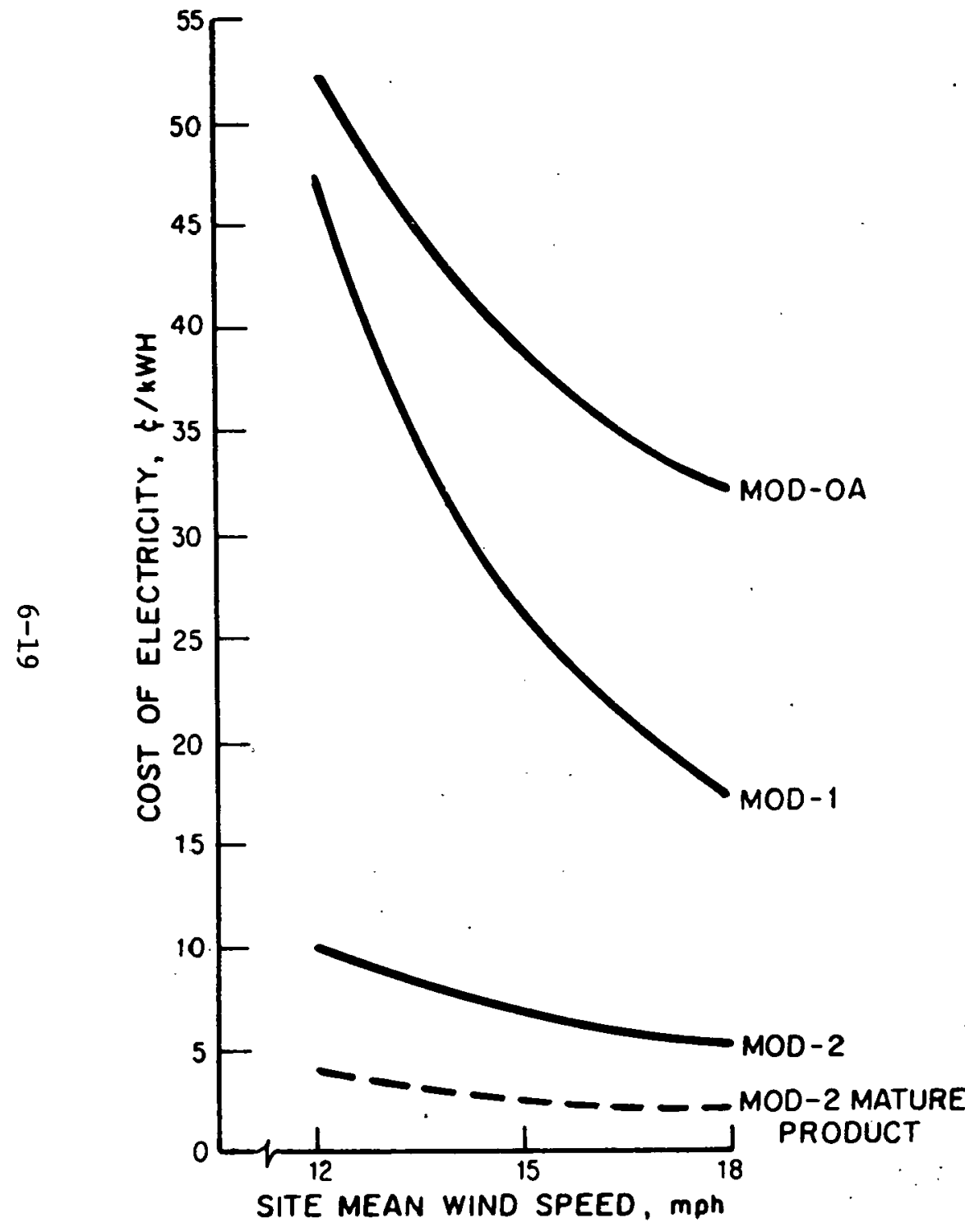

NOTES:

A) $\mathrm{COE}=\frac{\mathrm{ACC}+(\mathrm{O} \& \mathrm{M})}{\mathrm{AEO}}$

where $\operatorname{COE}=$ Cost of Electricity $(\$ / \mathrm{kWh})$,

ACC = Annual Capital Charges (Capital cost $x .18$ ) (Note B),

O\&M = Capital C ost $\mathrm{x} .03$, and

AEO = Annual Energy Output (Figure 6-9).

B) Installed Capita1 Cost (1977\$)

\begin{tabular}{|c|c|c|}
\hline Mode1 & Total & Per $\mathrm{kW}$ \\
\hline $\mathrm{OA}$ & $\$ 1.6 \times 10^{6}$ & $\$ 8000$ \\
\hline MOD-1 & $4.8 \times 10^{6}$ & 2400 \\
\hline MOD-2 & $2.8 \times 10^{6}$ & 1100 \\
\hline MOD-2 & $1.4 \times 10^{6}$ & 560 \\
\hline
\end{tabular}

SOURCE: Reference 36 .

FIGURE 6-7 ESTIMATED COST OF ELECTRICITY VS. SITE MEAN WIND SPEED FOR MOD-OA, MOD-1, MOD-2, AND MOD-2 (MATURE PRODUCT) WIND TURBINES. The assumptions involved in preparing the estimates are listed in the Notes. 
generation-technology"; its power output curve is presented in Figure 6-5.

- MOD-1 is a larger first-generation-technology machine with a rated output of $2000 \mathrm{~kW}$ at $22 \mathrm{mph}$. The first example of this type was undergoing acceptance tests in ear1y 1979.

- MOD-2 is a second-generation-technology machine designed to be "cost competitive, safe, reliable . . for utflity applications at moderate wind sites."

It has a rated output of $2500 \mathrm{~kW}$ at $18 \mathrm{mph}$. MOD-2 machines are scheduled to begin operations in 1980.

The power output curves of these three machines are presented in Figure 6-8. With a knowledge of the distribution of wind speeds at a typical site and the output characteristics of the turbine, the annual energy outputs can be calculated. They are presented in Figure 6-9 as a function of mean wind speed for an assumed machine availability of $90 \%$. The resulting energy costs are presented in Figure 6-7 for MOD-OA, MOD-1, and two generations of MOD-2 turbines. The "mature" version of the MOD-2 machine assumes significant capital cost reductions as a result of experience and large-scale manufacture.

The data presented in Figure 6-7 clearly indicate that the cost of energy increases rapidly with decreasing, average wind speed. They emphasize the importance of operating wind turbine generators only in areas having favorable wind regimes -- probably where the mean wind speed is 15 or greater.

\section{Section 6.4: Limitations}

\section{A. Introduetion}

As indicated above, the major factor which will linit the widespread implementation of on-site wind turbine generators will be their cost when compared to conventional power sources. Institutional and 


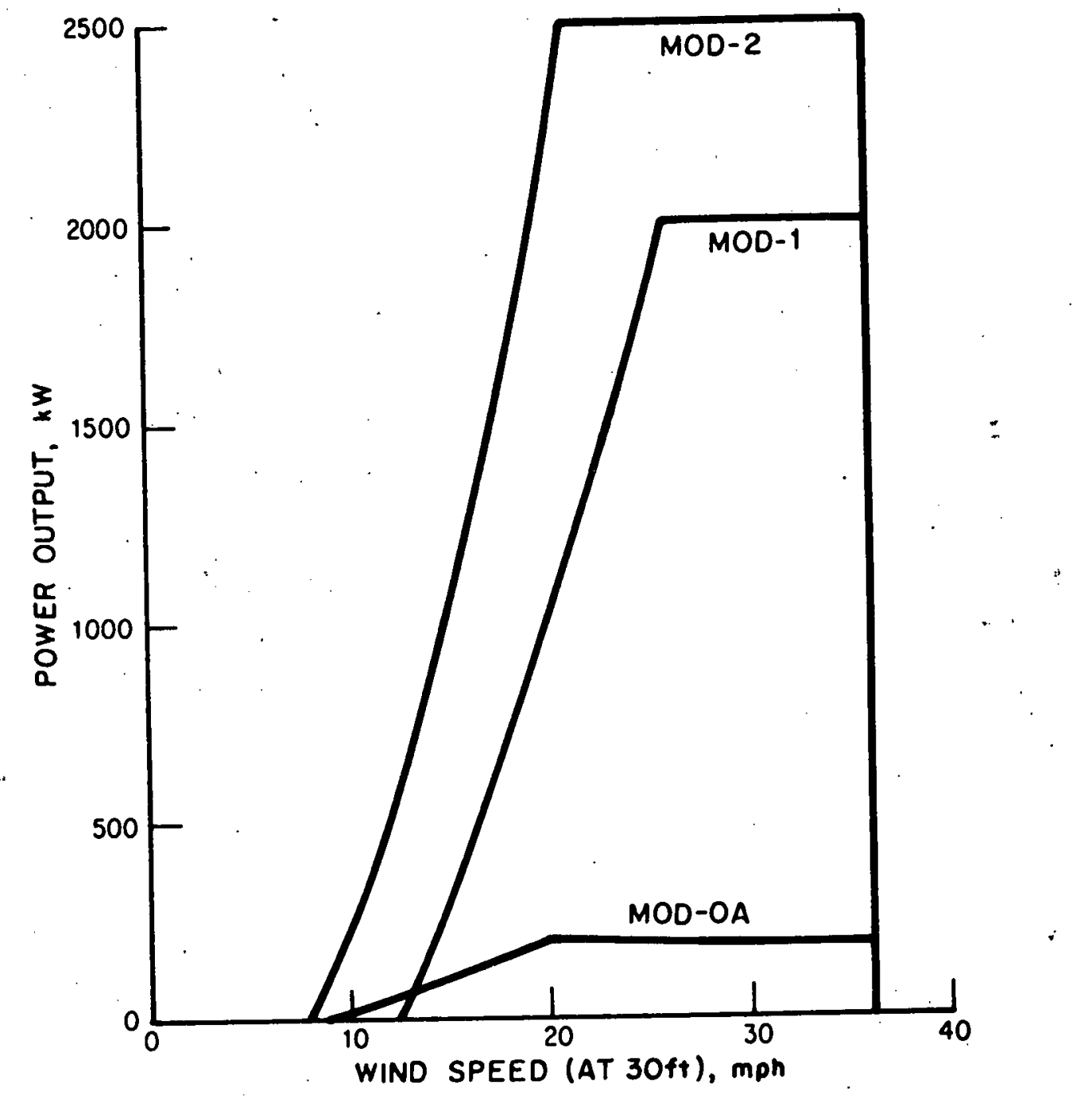

SOURCE: Reference 36 .

FIGURE 6-8. POWER OUTPUT AS A FUNCTION OF WIND SPEED

FOR THREE WIND TURBINES 


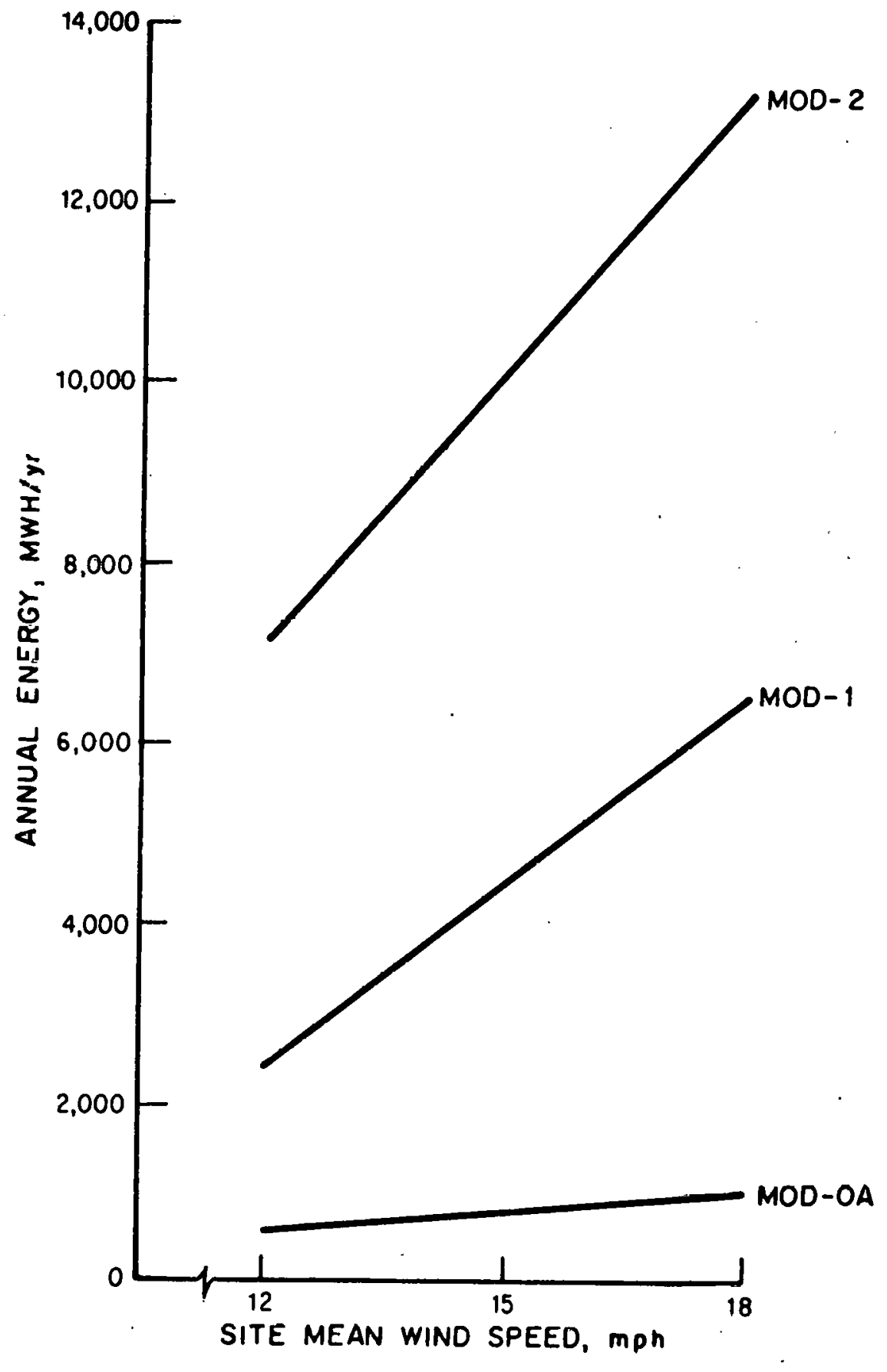

SOURCE: Reference 36.

FIGURE 6-9 ANNUAL ENERGY OUTPUT VS. SITE MEAN WIND SPEED FOR THREE WIND TURBINES, AT AN ASSUMED MACHINE AVAILABILITY OF $90 \%$ 
industrial barriers may be associated with such issues as the ability to provide a sufficient number of skilled technicians for system installations, integration with central utility systems, and component production Iimitations. Other serious barriers to the widespread implementation of wind turbines for on-site use will probably be those associated with:

- availability of 1and and "wind rights,"

- interference with television reception due to blade motion,

- geographic limitations, and

- negative visual impacts resulting from the height of the wind turbine installations.

B. Detailed Discussion

1. Geographic Limitations

As mentioned in the technical discussion, the actual power output of a wind turbine generator is extremely sensitive to wind speed. In order for a system to be economically attractive, a high annual average wind power is required. Although local conditions may cause anomalies in the data, it is possible to identify areas where wind turbines are most likely to be effective. Figure 6-10 shows a map of the United States on which average wind power is plotted. From this map, it can be seen that Northeast and Pacific coastal areas and the central plains represent the most likely sites. However, even in these regions variations from one year to another can be as large as $40 \%$. (5) Therefore, system designs must include provision for extended periods of low wind availability. In addition, wind turbines generate wakes which limit how closely the units can be spaced. (12) Thus, for large groupings of turbines, a significant land area may be required. The question of wind rights can arise if the wind system to a turbine is blocked by a neighboring turbine or building.

\section{Aesthetics}

In order to make reasoned judgments on the visual impact of 


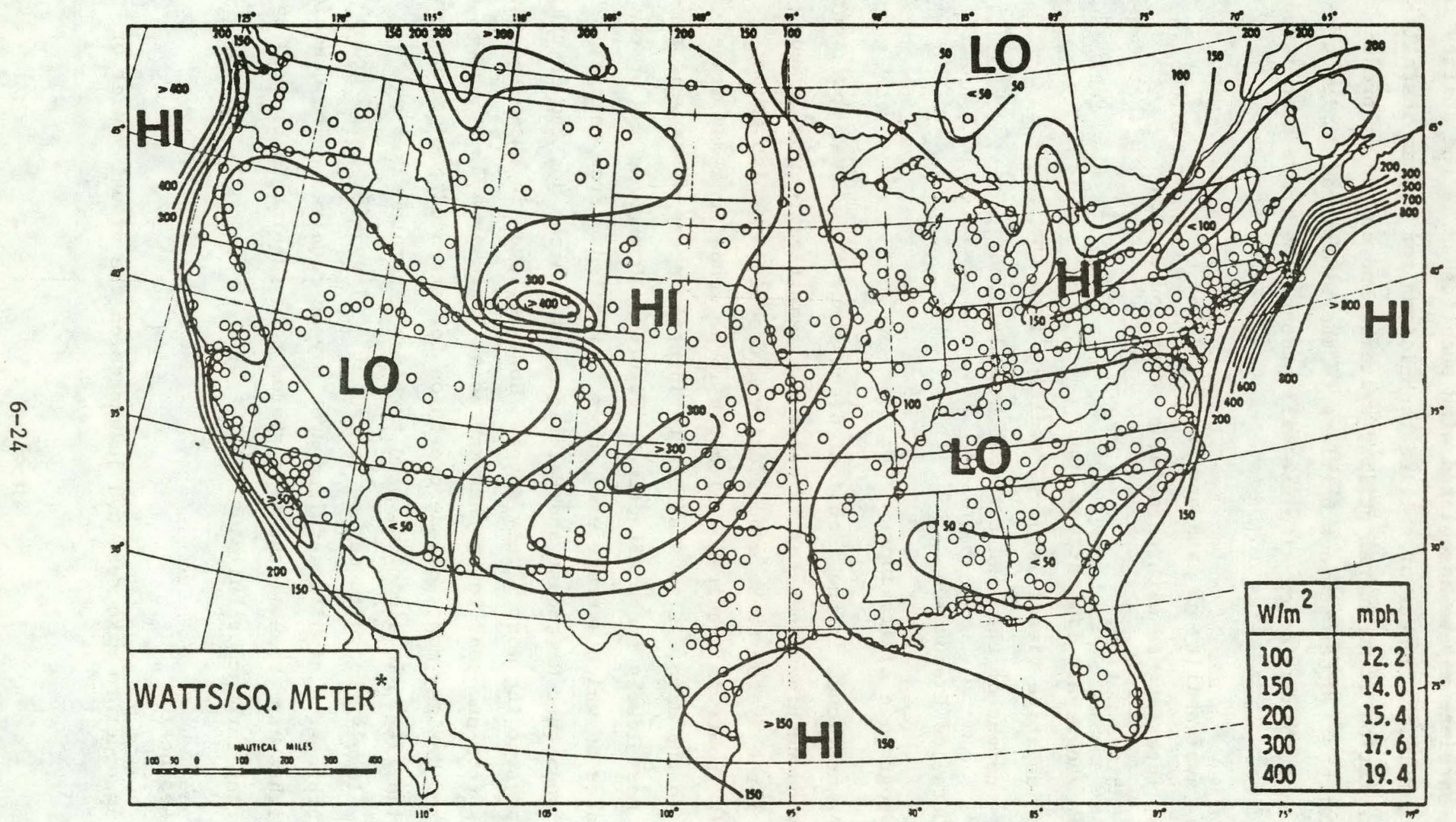

*Perpendicular to wind, 33 feet ahove surface. 0 indicates location measurement made. SOURCE: Reference 37 .

FIGURE 6-10 AVAILABLE WIND POWER - ANNUAL AVERAGE 
on-site wind turbine power plants, it is important to consider the sizes of the units that would be used in typical residential and commercial applications. As previously indicated, the size of a unit required to produce a given power output is very sensitive to the average wind speed. Therefore, the size of the system (blade diameter, tower height, etc.) required for any given application will depend on the typical wind velocities prevalent in the location under consideration. Table 6-4 presents estimates for the size of wind turbine power plants that would be used for three potential applications. The following wind regimes are shown:

- Strong Wind Regime ( $16 \mathrm{mph}$ ) - This would correspond to these areas of the country with particularly high average wind conditions such as parts of the Great Plains and coastal areas of New England.

- Average Wind Regime ( $12 \mathrm{mph}$ ) - Corresponds to areas with fairly average wind conditions such as the Middle Atlantic states and parts of the Rocky Mountain area.

- Low Wind Regime ( $9 \mathrm{mph}$ ) - Corresponds to areas with below average wind speed conditions such as parts of the West Coast and the Southwest.

In an area of "average" wind conditions, a single-family house would require a tower approximately 35 feet high and a turbine blade diameter of 19 feet to satisfy a major portion of the electrical power requirements. Small apartment houses would require a tower about 80 feet high with wind turbine blades 100 feet in diameter if a single wind turbine generator were used, and a typical commercial building would require a tower over 100 feet high to support a turbine with a blade diameter of 150 feet. Clearly; there are serious questions whether it would be acceptable to the public to use a multiplicity of wind turbines of these sizes in residential and commercial areas. 
TABLE 6-4

BLADE DIAMETER (FEET) ${ }^{(1)}$ FOR ON-SITE APPLICATIONS

WITH DIFFERENT AVERAGE WIND SPEEDS

High Wind
\begin{tabular}{l} 
(16 mph) \\
\hline
\end{tabular} $\quad \begin{aligned} & \text { Average Wind } \\
& (12 \mathrm{mph})\end{aligned} \quad \begin{array}{r}\text { Low Wind } \\
(9 \mathrm{mph})\end{array}$

Residence (16 kWh/day)

12

19

26

Apartment House

(480 kWh / lay)

62

101

1,40

Commercial Bullding

(1300 kWh/day)

92

150

212

(1) Wind turbine sizing assumes $20 \%$ electrical losses in power conditioning and storage battery subsystems, and $40 \%$ of power used without passing through storage system.

SOURCE: Arthur D. Little, Inc. 


\section{Electrical Interference}

The motion of metal wind turbine blades may cause interference problems for television receivers. This is particularly true for the larger turbines which might service groups of houses, apartments, or commercial properties. For these larger units, the range of the interference problem could severely limit the placement of wind turbine systems. $(38,39)$ 
THIS PAGE

4

\section{WAS INTENTIONALLY \\ LEFT BLANK}




\section{REFERENCES}

1. Mitre Corporation. Wind Machines. Report prepared for the National Science Foundation, October 1975. Report No. NSF-RA-N-75-051.

2. Park, J. "Operational Experience with Smal1 Wind Units, Vo1. II." Proceedings of the Eleventh Intersociety Energy Conversion Engineering Conference, State Line, Nevada, September 12-16, 1976. pp. 1795 ff.

3. Page, J.K., et a1. "The New Alchemy: How to Survive in Your Spare Time." Smithsonian Magazine 5(11):82, 1975.

4. Malver, F., et al. "The Application of Wind Power Systems to the Minnesota Power and Light Company." Sharing the Sun! Solar Technology in the Seventies. A joint conference of the American Section of the International Solar Energy Society and the Solar Energy Society of Canada, Inc., Winnipeg, Canada, August 15-20, 1976. pp. 289 ff.

5. Merriam, M.F. "Wind Energy for Human Needs." Technology Review $79: 29$, January 1977.

6. Higgin, R., et a1. "Preliminary Assessment of the Potential for Medium and Large Capacity Wind Generators Used as Fuel Savers for AC Diesel Based Power Systems in Ontario." Sharing the Sun: Solar Technology in the Seventies. A joint conference of the American Section of the International Solar Energy Society and the Solar Energy Suclety of Canada, Inc., Winnipeg, Canada, August 15-20, 1976. pp. $180 \mathrm{ff}$.

7. Product information from the following companies:

a. ENERTECH CORPORATION

P.0. Box 420

Norwich, Vermont 05055

b. GRUMMAN ENERGY SYSTEMS

4175 Veterans Memorial Highway

Ronkonkoma, New York 11779

c. REDE CORPORATION

P.0. Box 212

Providence, Rhode Island 02901

d. BOSTON WIND, INC.

2 Mason Court

Charlestown, Massachusetts 02129

e. THE HELLER-ALLER COMPANY

22920 North Bellwood Drive

Southfield, Michigan 48034

f. AUTOMATIC POWER

P.O. Box 18738

Houston, Texas 77023 
REFERENCES (continued)

8. Yamagiwa, A. "Experimental Evaluation of a Solar/Wind Powered Space Heating and Hot Water Heating System in the Pacific Northwest." Proceedings of the Twelfth Intersociety Energy Conversion Engineering Conference, Washington, D.C., August 28 - September 2, 1977. pp. $1243 \mathrm{ff}$.

9. Quinn, B. "The Consumer's Cost of Electricity from Windmills." Proceedings of the Eleventh Intersoclety Energy Conversion EngineerIng Conference, State Line, Nevada, September 12-16, 1976. pp. 1745 ff.

10. Hirschfeld, F. "Wind Power." Mechanical Engineering 99:20, 1977.

11. Puthoff, R., et al. Status Report of $100 \mathrm{~kW}$ Experimental Wind Turbine Generator Project. National Aeronautics and Space Administration, 1975. NASA Technical Memorandum No. NASA TM X-71758.

12. American Wind Energy Association. An Index of Manufacturers, Researchers, and Distributors Currently Involved in Lhe Development of Wind Energy Conversion Systems. Prepared under Contract No. E-(29-2)-3533 for U.S. Department of Energy, February 1978.

13. Obermier, T. An Economic Evaluation of Small Scale Wind Powered Electric Generation Systems. American Society of Mechanical Engineers, 1976. Paper No. 76-WA/ENER-1.

14. Kaza, K.R.V., et al. Evaluation of Mostas Computer Code for Predicting Dynamic Loads in Two-Bladed Wind Turbines. Washington, D.C.: U.S. Department of Energy, 1979.

15. Sandia Laboratories. Sandia Vertical-Axis Wind Turbine Program, Technical Quarterly Report, October - December 1975. April 1976. NTIS Report No. EAND76-0036.

16. General Electric Space Division. Applied Research nn Finergy Storage and Conversion for Photovoltaic and Wind Energy Systems. January 1978, NTIS Report No. HCP/T-22221-01/1.

17. Sandia Laboratories. Wind Power Climatology. December 1974. NTIS Report No. SAND74-0435.

18. Radice, F.C. "Siting of Wind Driven Apparatus." Proceedings of the Eleventh Intersociety Energy Conversion Engineering Conference, State Line, Nevada, September 12-16, 1976. pp. $1736 \mathrm{ff}$.

19. Lockheed-California Company, Burbank, California. Wind Energy Mission Analysis. Prepared under Contract No. EY-76-C-03-1075 for Energy Research and Development Administration, April 1976. 


\section{REFERENCES (continued)}

20. Reddock, T.W., et al. "No I1l Winds for New Mexico Utility." IEEE Spectrum 16(3):57, 1979.

21. Justus, C.G. Winds and Wind System Performance. PhIladelphia, Pennsylvania: Franklin Institute Press, 1978.

22. Metz, W.D. "Wind Energy: Large and Small Systems Competing." Science $197: 971,1977$.

23. Bechtel Corporation. Energy Storage and Power Conditioning Aspects of Photovoltaic Solar Power Systems. Prepared under Contract No. F(11-1) - 2748 for Energy Research and Development Administration, netoher 1.975.

24. "Island Eyes Wind Energy Proposal." Boston Herald American, September 4, 1977. pp. A3.

25. Dubey, M. "Conversion and Storage of Wind Energy as Nitrogenous Fertilizer." Proceedings of the Twelfth Intersociety Energy Conversion Engineering Conference, Washington, D.C., August 28 September 2, 1977 . pp. $525 \mathrm{ff}$.

26. Federal Energy Administration. Wind Energy Conversion Systems Manufactur1ng and Sales Activity 1975 and 1976. April 1977. NTIS Report No. FEA/B-77/121. pp. $265 \mathrm{ff}$.

27. JBF Scientific Corporation. Summary of Current Cost Estimates of Large Wind Energy Systems. Report prepared for Energy Research and Development Administration, February 1977. NTIS Report No. DSE/2521-1.

28. Lockheed-California Company, Burbank, California. Wind Energy Mission Analysis. Prepared under Contract No. EY-76-C-03-1075 for Energy Research and Development Administration, April 1976.

29. General Electric Corporation. Design Study of Wind Turbines $50 \mathrm{~kW}$ to $3000 \mathrm{~kW}$ for Electric Utillty Application. Vol. II Analysis and Design. Report prepared for National Aeronautics and Space Administration, December 1976. NTIS Report No. ERDA/NASA/9403-76/2.

30. Kaman Aerospace Corporation. Design Study of Wind Turbines $50 \mathrm{~kW}$ to $3000 \mathrm{~kW}$ for Electric Utility Applications - Analysis and Design. Report prepared for National Aeronautics and Space Administration, February 1976. NTIS Report No. DOE/NASA-9404-76/2.

31. The Aerospace Corporation. Wind Power for the California Aqueduct. E1 Segundo, California, March 1976.

32. Honeywe11, Inc. The Application of Wind Power Systems to the Service Area of the Minnesota Power and Light Company, Executive Summary. October 1976 - March 1977. Quarterly Report No. 3. Minneapol1s, Minnesota, 1977. 


\section{REFERENCES (continued)}

33. Ligon, C. et a1. Operational Cost and Technical Study of Large Windpower Systems Integrated with an Existing Electric Utility. Prepared by Southwestern Public Service Company, April 1976. NTIS Report No. COO-2621-2.

34. General Electric Corporation. 'Wind Energy Mission Analysis. Prepared under Contract No. EY-76-C-02-2578 for Energy Research and Development Administration, October 1976.

35. Böer, K.W., ed. Sharing the Sun! Solar Technology in the Seventies. A joint conference of the American Section of the Internatinnal 3olar Energy Society and the Solar Energy Society of Canada, Inc., Winnipeg, Canada, August 15-20, 1976.

36. Robbins, W.H., et al. "Large Horizontal Axis Wind Turbine Development." Wind Energy Tnnovative Systems Conferience, Colorado Springs, Colorado, May 23-25, 1979. NASA Technical Menúrandum No. NASA TM-79174.

37. Blackwell, B.F., et al. Wind Energy -- A Revitalized Pursuit. Sandia Laboratories, 1975. NTIS Report No. SAND75-0166.

38. Sengupta, D.L., et al. Electromagnet1c Interference by Wind Turbine Generators. Final Report prepared under Contract No. EY-76-S-02-2846. A001 for the U.S. Department of Energy, March 1978.

39. Senior, T.B.A., et al. Wind Turbine Generator Siting and TV Reception Handbook. Prepared by University of Michigan under Contract No. EY-76-S-02-2846A001 for the U.S. Department of Energy, January 1978. University of Michigan Technical Report No. 014438-1-T. 


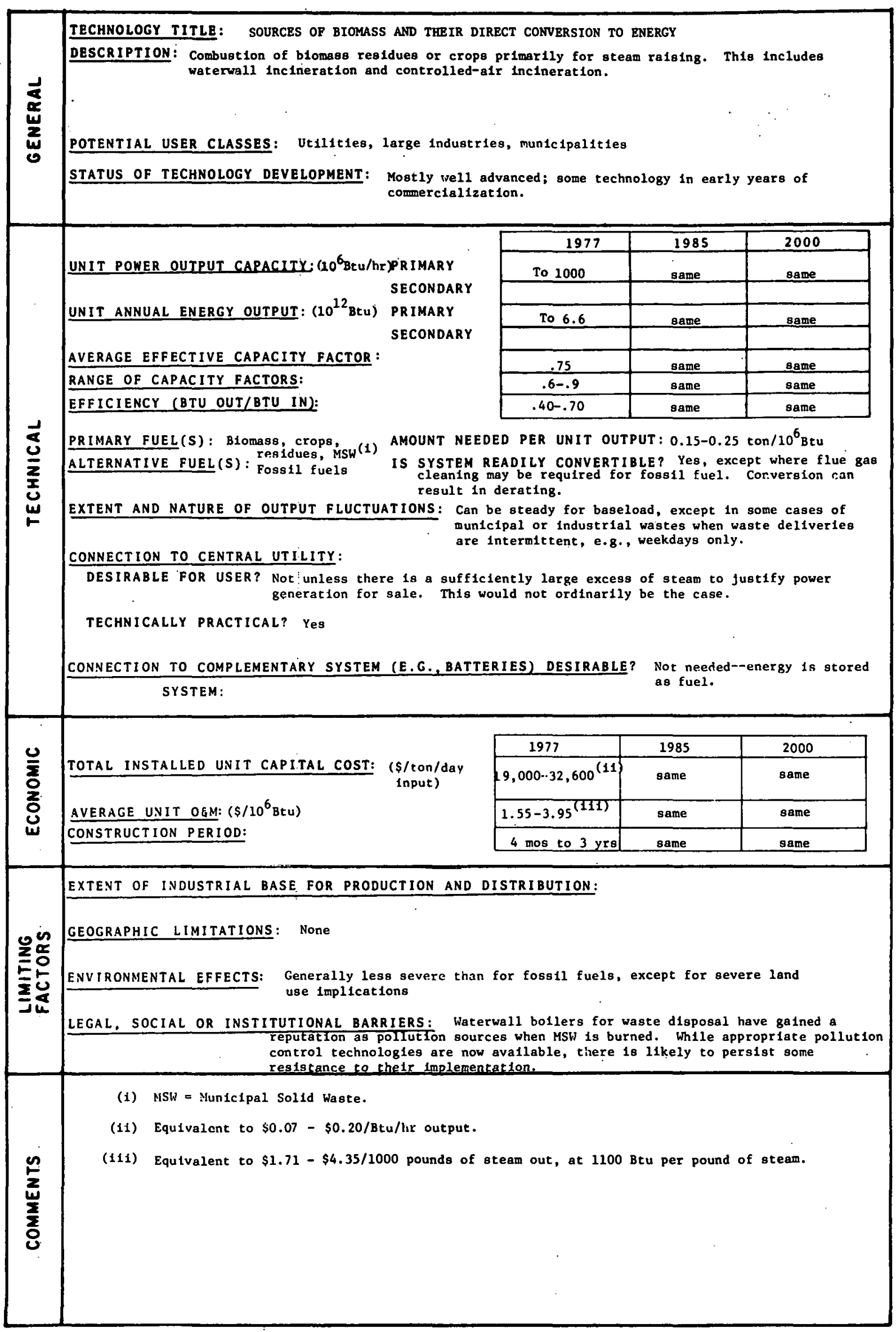


CHAPTER 7

SOURCES OF BIOMASS AND THEIR DIRECT CONVERSION TO ENERGY

\section{Section 7.1: Introduction}

The sources of biomass that are presently of the greatest interest as new sources of energy are as follows:

- Blomass Farms

- Land

- Water

- Cellulosic Residues

- Crop (agricultural)

- Wood (forestry)

- MSW (municipal solid wastes)

- Other Blological Residues

- Manure

- Sewage sludge.

Biomass farms (plantations) would grow terrestrial crops, such as timber, forage grass, and sugar cane, or aquatic crops, such as water hyacinth and algae to be converted to other energy forms by combustion, fermentation, gasification, or iqquefaction. The gasification product could be used to produce ammonia, an important chemical intermediate, and thereby displace the large fossil energy requirement in conventional plants.

Cellulosic residues, such as crop residues, wood residues (primartly those presently left in the forests), and $\mathrm{MSW}^{*}$ (primarily the combustible organic fraction) could also be converted to energy by similar techniques.

\section{Section 7.2: Biomass Resources}

Numerous studies have been conducted to investigate the possibility of growing annual crops such as corn, (1) sorghum, (2) kenaf, (3) or *unicipal Sol1d Waste. 
sunflowers, (3) or perennial crops such as sugarcane, (2) Sudan grass, (3) or wood $^{(4)}$ as energy sources. The crop offering the highest yleld per acre per year, sugarcane ( 20 tons dry biomass/acre/year), also requires large quantities of water, fertilizer, and other energy expenditures, including those for harvesting, to promote maximum yleld. Ylelds from hardwoods -- such as eucalyptus, cottonwoods, anit red alder -- and warm season grasses -- such as perennial sorghums and Bermuda grasses -are much lower (8-10 tons dry blomass/acre/year), but the water and fertilization requirements also are much lower. $(3,5)$

Limiting factors in the utilization of agricultural residues as an energy source are the competing demands for use of these materials as silage for livestock (influenced by grain prices) and the need for these residues for field mulch and soil t1lth. In addition, the seasonality of agricultural waste production and its susceptibility to blological degradation also are drawbacks to the utilization of agricultural wastes.

A large percentage of the wood residue generated at pulp and paper mills, sawmills, and plywood plants is already belng utilized as fuel or converted to wood products. The residues generated in the forest logging operations represent a source that could be more efficiently utilized in some cases, but new developments, such as whole-tree chipping to utilize more of the wood for paper pulp production, could eventually lead to a reduction in the availability of this residue.

Most of the fuel value of MSW is due to 1 ts paper content. The heat value of this paper fraction may be recovered either directly from MSW by thermal or blological processes, or by first separating the paper fraction and then converting it to fuel. Essentially all of the waste paper (95\%, Arthur D. Little, Inc., estimate) recycled to papermaking is segregated at the point of generation of waste and does not appear in MSW. Depending on waste-paper-market conditions, which tend to fluctuate widely, some of this paper might also be avallable for use as fuel or as an energy source.

The total quantity of 11vestock manure generated annually is about 1.9 billion wet tons ${ }^{(6)}$ which is equivalent to about 350 million dry tons. 
The vast majority of this falls on open pasture land; only about 26 million dry tons. (7) specifically are collected and returned to the so11. Depending on the economics, a major portion of this might also be made avallable for energy production, and much of the residue could be recycled to the land for its nutrient value.

Sewage sludge 1s, for the most part, an ineffectively used source of energy. Most of this sludge is anaerobically or aerobically digested; but in the digestion systems used today, a major portion of the fuel energy created is required for heating the digestors. An estimated 5.6 million tons of sewage sludge were generated in 1974 . As more munfclpalities are required to increase their treatment of sewage, this figure can be expected to increase. Sewage sludge, like MSW and unlike manure and agricultural wastes, is generated in more highly populated areas closer to the energy demand market.

\section{A. Fuel Farms: Land}

Table 7-1 summarizes the current ylelds and nutrient requirements for selected possible energy crops at various U.S. locations. The table shows the ranges of yield -- from about 5 dry tons per acre for some hardwoods to more than 20 dry tons per acre for sugarcane in Hawa1i. To sustain these yields in most locations requires about 10 $1 \mathrm{~b}$ of nitrogen (as N), 0-5 lb of phosphorus (as $\mathrm{P}_{2} \mathrm{O}_{5}$ ), and 0-20 1b of potassium (as $\mathrm{K}_{2} 0$ ) per dry ton of blomass yleld. Water requirements vary from moderate levels for hardwoods, which can be supplied by natural rainfall in many locations, to very high levels, requiring significant Irrigation, in most U.S. areas.

The land area which would be required to support the energy needs of a small electric power plant (100 MW, operating at an annual average output of $60 \mathrm{MW}$ ) 1s about 50 square miles for Populas and 17 square miles for sugarcane (Texas).*

* Assumes a power ${ }_{6} \mathrm{plant}$ heat rate of $10,500 \mathrm{Btu} / \mathrm{kWh}$, and an energy content of $17 \times 10^{6} \mathrm{Btu} /$ ton for wood and $15 \times 10^{6} \mathrm{Btu} /$ ton for sugarcane. 
TABLE 7-1

YIELD AND RESOURCE REQUIREMENTS OF POTENTLAL ENERGY CROPS

\begin{tabular}{|c|c|c|c|c|c|c|c|}
\hline \multirow[b]{2}{*}{ Species } & \multirow[b]{2}{*}{ Location } & \multirow{2}{*}{ 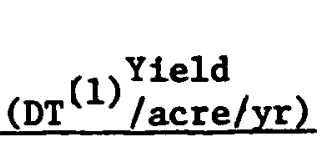 } & \multicolumn{3}{|c|}{$\begin{array}{c}\text { Fert1lizer } \\
\text { (1b/acre) }\end{array}$} & \multirow{2}{*}{$\begin{array}{c}\text { Water } \\
(\text { acre-ft/yr) }\end{array}$} & \multirow[b]{2}{*}{ Ref. No. } \\
\hline & & & $\mathbf{N}$ & $\mathrm{P}_{2} \mathrm{O}_{5}$ & $\mathrm{~K}_{2} \mathrm{O}$ & & \\
\hline \multirow[t]{5}{*}{ Sugarcane } & Florida & 10.9 & 0 & $10-15$ & 180 & 10 & (2) \\
\hline & Loulsiana & 7.5 & $80-140$ & 40 & 80 & 8 & (2) \\
\hline & Texas & 11.7 & 0 & $0-40$ & 0 & 12 & (2) \\
\hline & Hawail & $\begin{array}{l}15.8 \\
20.0\end{array}$ & $\begin{array}{r}300-400 \\
180\end{array}$ & $\begin{array}{r}45-55 \\
75\end{array}$ & $\begin{array}{r}200 \\
180\end{array}$ & $\begin{array}{l}16 \\
14.7\end{array}$ & $\begin{array}{l}(2) \\
(8)\end{array}$ \\
\hline & Puerto Rico & 10.2 & $120-150$ & $0-168$ & $0-224$ & 10 & (2) \\
\hline Sugar beet & Continental U.S. & 3.7 & $20-150$ & $50-150$ & $100-300$ & $10-13$ & (2) \\
\hline Sweet Sorghum & Southeastern U.S. & $6-8$ & 40 & 40 & $30-40$ & $5-14$ & (2) \\
\hline Corn & Continental U.S. & $4-5$ & $120-140$ & $40-70$ & $20-80$ & $1.5-2$ & (2) \\
\hline American Sycamore & Continental U.S. & 6 & 69 & 13 & 71 & 3.5 & $(10,11)$ \\
\hline Eucalyptus & Continental U.S. & 5 & 58 & 11 & 60 & 3.5 & $(10,11)$ \\
\hline Populas & Continental U.S. & $9-10$ & $104-112$ & $20-22$ & $107-112$ & 3.5 & $(10,11)$ \\
\hline Red Alder & Continental U.S. & 9 & 104 & 20 & 107 & 3.5 & $(10,11)$ \\
\hline
\end{tabular}

(1) DT = dry tons. 
These estimates give support to earlier work of Povich, (8) who est 1mated that a 100-MW power plant would require a 32-square mile Hawailan sugarcane plantation when operated at full capacity (19 square miles ( $60 \mathrm{MW}$ ); and of Stanford Research Institute (SRI), (9) which estimated that a large, 1000-MW power plant would require a 245-square mile area of high-yield land. SRI further estimated that a total of 5 acre-feet of water per acre per year would be required.

Table 7-2 summarizes the recent production levels of crops which are candidates for blomass energy plantations. The table includes the possible future production rates if sufficient effort were directed to biomass energy projects. Affecting the ability to achieve these production levels are factors such as:

- urgency of the U.S. energy needs;

- quality of land cultivated -- much land not now used for agriculture is of poorer quality than that already being produced;

- rainfall -- since most energy plantation concepts w111 require some irrigaition, the avallability of water will be quite important; and

- need to recycle nutrients -- very large-scale energy farming will demand significant quantities of nutrients, especlally phosphate and potasslum, relative to present production levels and in-ground resources.

Battelle (2) estimated that in 1976 the cost of producing sugarcane in the United States ranged from \$18-32/ton of combustible organics $\left(\$ 1.20-\$ 2.13 / 10^{6} \mathrm{Btu}\right)$. This assumption is probably reasonable for 1977 also. Further, Battelle has speculated that in a critical need situation, the cost of sugarcane biomass production in 1985 and 2000 can be reduced to $\$ 15-28 /$ ton $\left(\$ .99-\$ 1.30 / 10^{6} \mathrm{Btu}\right)$ and $\$ 13-19 /$ ton $(\$ .85-\$ 1.27)$ $\left.10^{6} \mathrm{Btu}\right)$, respectively, through close spacing of crops. These costs are in 1977 dollars, updated by 6\% from 1976 dollars.

MITRE ${ }^{(10)}$ estimates that silvicultural biomass production costs of $\$ 0.99-\$ 1.57 / 10^{6}$ Btu w111 be feasible in the future at 10 spectfic sites 
TABLE 7-2

CURRENT AND FOTENTIAL FUTURE PRODUCTION OF BIOMASS ENERGY

\begin{tabular}{|c|c|c|c|c|c|c|c|c|}
\hline \multirow[b]{2}{*}{ Crops } & \multirow[b]{2}{*}{ Year (s) } & \multicolumn{3}{|c|}{ Recent Historical } & \multicolumn{3}{|c|}{ Possible -2000} & \multirow[b]{2}{*}{ Ref. No. } \\
\hline & & $\begin{array}{c}\text { Yleld } \\
\text { (DT/acre) }\end{array}$ & $\begin{array}{l}\text { Land Area } \\
\left(10^{6} \text { acres }\right)\end{array}$ & $\begin{array}{l}\text { Production } \\
\left(10^{\mathrm{DT} / \mathrm{yr}}\right)\end{array}$ & $\begin{array}{l}\text { Yield } \\
\text { (IT/acre) }\end{array}$ & $\begin{array}{l}\text { Land Area } \\
\left(10^{6} \text { acres }\right)\end{array}$ & $\begin{array}{l}\text { Production } \\
\left(10^{6} \mathrm{DT} / \mathrm{yr}\right)\end{array}$ & \\
\hline Sugarcane & 1975 & 12.9 & 0.77 & 10.0 & $8-25$ & 3.4 & 4B.7-73.4 & 2 \\
\hline Sweet Sorghum & $\begin{array}{r}\text { (avg 1973- } \\
1975)\end{array}$ & $6-8$ & 0.01 & 0.07 & $6-10$ & 1.8 & 15 & 2 \\
\hline Sugar beets & 1975 & 19.3 & 1.52 & 29.3 & * & 3.0 & * & 2 \\
\hline Corn & $\begin{array}{r}(\operatorname{avg} 1973- \\
1975)\end{array}$ & 0.85 & 60.7 & 51.7 & $6-7$ & 100 & $600-700$ & 1 \\
\hline Forest Products & 1976 & 0.90 & 500 & 450 & -- & -- & -- & 18 \\
\hline Biomass Farms & -- & - & -- & -- & $5-20$ & $270-325 * *$ & $410-488$ & 10 \\
\hline
\end{tabular}

\footnotetext{
${ }^{\star}$ Sugar beet production levels are expected to be guided by the demand for food sugar. Any production increases would displace other sugar sources which might be diverted to energy production. Increased land dedicated to sugar beets would be diverted from other crops, not noncrop land.

${ }^{\star \star *}$ Assumes $10 \%$ of land available for silvicultural biomass farms.
} 
In the Unfted States. The costs at these sites range from $\$ 1.28-\$ 2.62 /$ $10^{6}$ Btu (updated by $6 \%$ from 1976 to 1977 ).

Irrigation can contribute significantly to the cost of crops with high water demand, such as sugarcane. Using MITRE's figures (11) of \$100-670/acre for installation and \$20-50/acre/year for operation and maintenance, we estimate the total cost of irrigation to be $\$ 30-150 /$ acre/year, depending on the system employed. If the crop yield is 30 dry tons/acre at $15 \times 10^{6} \mathrm{Btu} / \mathrm{dry}$ ton, the irrigation system cost amounts to about $\$ 0.07-\$ 0.33 / 10^{6} \mathrm{Btu}$ plus the cost of water.

\section{B. Fue1 Farms: Water}

Ryther ${ }^{(12)}$ has pointed out that seaweed can be cultivated in U.S. waters with appreciable ylelds -- from 15-28 dry tons/acre/year in temperate Massachusetts to $57 \mathrm{dry}$ tons/acre/year in subtropical Florida. Dynatech $^{(13)}$ has indicated that, as producers of organic matter, aquatic plants have several advantages over terrestrial plants:

- withnut the need to attach themselves to the earth, the aquatic plants devote more of their photosynthate to blomass than to elaborate structural tissue;

- water is not a limitation;

- $\mathrm{CO}_{2}$ is not as growth-limiting, particularly in the ocean; and

- microscopic algae, In particular, are well suited to the absorption of sunlight and diffusion of nutrients because of their small size and simple shape.

On the other hand, nutrient limitations are an important factor. In the open ocean, nitrogen and phosphorus are the most severely limited nutrients in terms of limitations on plant growth; in coastal waters their concentrations are somewhat higher. (13) other nutrients such as carbon, hydrogen, oxygen, chlorine, sodium, potassium, calcium, magnesium, and sulfur are ordinarily present in ample quantitles in the ocean. Trace elements and certain organic substances (vitamins) are also required. 
Dynatech $^{(13)}$ concludes that the design of an aquatic biomass culture system involves the maximization of two major parameters: nutrient avallability and sunlight. When limiting nutrients are provided in sufficient quantity, the problem of optimum design becomes one of optimal use of incident sunlight. This can be controlled by both the culture depth and the rate of removal (harvesting) of material from the culture.

To date, no satisfactory cost-effective approach has been found for removing unicellular algae from the culture volume, although several methods - including centrifugation, flocculation, flotation, sedimentation, and filtration--have been tried. (13) Larger plants can, however, be harvested relatively easily.

Cso International, Inc., prepared a cost analysis for a 100square-mile microalgae biomass system. (14) Assuming an annual average biomass growth rate of 20 tons/acre/year, CSO estimated that the capital cost of this farm would be $\$ 222.2$ million, with no allowance for the cost of land. The operating cost (excluding depreciation and other capital related charges) would be an additional $\$ 18$ million per year. If capital charges are added at $15 \%$, the algae cost would be in excess of $\$ 40 /$ ton or about $\$ 2.70 / 10^{6}$ Btu.

\section{Cellulosic Residues: Crop (Agricultural) and Wood}

Approximately 75\% (237 million dry tons) of the 322 million dry tons of crop residue is returned to the soll. (7) of the balance, 61 million tons are fed to 1 ivestock directly, 13 million tons are sold as fodder, 9 million tons used as fuel, and only 2 million tons wasted. About $48 \%$ of this residue is from small grains and grasses and $35 \%$ is from grain, corn, and sorghums, which have an average energy content of about $14 \times 10^{6} \mathrm{Btu} /$ ton

The use of crop (agricultural) residues as a fuel energy source would withdraw the material from use as fleld mulch and soil tilth, which could in many cases have an adverse effect on subsequent growth 
of crops. (3) Crop residues presently being used for 11vestock feed might also be used as a fuel source, but would require replacement by other animal feeds (e.g., grain). Seasonal avallability, transportation cost, the possible adverse effect on cropland, and drying/storage requirements would all detract from the potential of this material as an energy source. The use of a mobile pyrolytic converter would reduce transportation cost and allow nutrients to be returned to the so11, but the fuel or energy produced would then have to be ut1lized locally or transpurted to where it could be used,

The cost of recovering logging residues and transporting them to the mill in conjunction with the regular harvest is estimated by SRI ${ }^{(15)}$ to be about $\$ 1.20-\$ 4.00 / 10^{6} \mathrm{Btu}(1977$ dollars). The estimated total volume of this harvesting residue in the logging area amounted to about 88 million dry tons in 1976, containing an average heating value of about $15 \times 10^{6} \mathrm{Btu} / \mathrm{ton}$. The unused wood and bark residues generated at the mill this same year were about $19 \mathrm{million}$ dry tons. (16)

\section{Municipal Solid Waste (MSW)}

The average quantity of MSW generated in the United States in the mid-1970's has been estimated at about 134 million tons per year. (17) The average composition of this waste in 1973 was estimated to be as follows:

$\begin{array}{lrlr}\text { Paper } & 39.6 \% & \text { Textiles } & 1.6 \% \\ \text { Glass } & 10.3 & \text { Wood } & 3.6 \\ \text { Metals } & 9.9 & \text { Food } & 13.3 \\ \text { Plastics } & 4.1 & \text { Yard Waste } & 14.1 \\ \text { Rubber \& Leather } & 2.7 & \text { Miscellaneous } & 1.5\end{array}$

The heating value of MSW is presently 4500-5000 Btu/lb and is expected to increase because the percentage of paper and plastic in MSW is increasing. 
The generation of MSW is concentrated in areas of high population, where there is also the greatest market for energy as well as a welldeveloped transportation system. It is common practice to transfer MSW from packer (collection) trucks into transfer vehicles when collection is remote from the disposal site. Arthur D. Little, Inc., estimates of typical costs for operation of the transfer station, transportation, and final disposal are as follows:

$$
\begin{array}{ll}
\text { Transfer Station } & (600-1400 \text { tons/day mapacity) } \$ 0.60 \$ 1.00 / \text { Lit } \\
\text { Hauling Cost } & \$ 1.60 / \text { ton for } 10 \mathrm{miles} \text {, one way } \\
& \$ 4.80 / \text { ton for } 50 \mathrm{miles,} \text { one way } \\
& \$ 5.00-20.00 / \text { ton for landfill or incineration. } \\
\text { Disposal Cost } & \\
\text { Another potential source of energy. (that is related to MSW) is }
\end{array}
$$
waste paper. A competing use for waste paper (segregated at the source of waste generation from MSW) is recycle to papermaking. The value of waste paper recycled to papermaking in 1976 was as follows:

\begin{tabular}{lrr}
\multicolumn{1}{c}{ Grade } & Price $(\$ /$ ton $)$ & Equivalent $\$ / 10$ \\
Corrugated Containers & $20-40$ & $1.33-2.67$ \\
Newsprint & $15-25$ & $1.00-1.67$ \\
Mixed & $5-15$ & $0.33-1.00$
\end{tabular}

Under market conditions similar to $1976^{\prime}$ s, the separated waste paper could be an economical energy source.

\section{E. Manure}

Obviously, the states where most of the an 1 mal manure is generated are in agricultural areas (e.g., Iowa, Illino1s, California, Oregon, Kansas, etc.). It is not surprising, therefore, that 26 million of the collectable 30 million dry tons are applied to the so11. (7) The cost of applying the manure to the soll varies from $\$ 1.50$ to $\$ 4 /$ ton of dry manure. This manure, which contains 5800-7700 Btu/1b (dry), (7) can also be used as feed for energy (methane) generation, but its agricultural value would have to be replaced by. other fertilizers and by returning the nutrient-rich, digested residue to the soll. 
F. Scwage Sludge

An estimated 5.6 million tons of sewage sludge were generated in 1974 in wastewater treatment facilities serving a population of 155 million. (6) Approximately $30 \%$ of municipal wastewater sludge is incinerated, with almost the entire remainder being anaerobically or aerobically digested prior to land application or ocean disposal. Following installation of full secondary treatment facilities in all municipalities, we estimate that the generation of municipal sewage sludge would nearly double. The additional sludge generated could be processed for energy recovery in more efficiently designed conversion systems.

\section{Section 7.3: Technical Discussion}

\section{A. - Combustion of Biomass Crops and Residues}

Biomass can be burned to produce steam or thermal energy for process, power generation, or heating use. In the past, the ash content of solid fossil fuels and the potential for char and slag formation have rendered them too dirty for many direct heating purposes." As a result, most of the technology practiced to date has been limited to the steamraising options. Today, with the increasing need for high energy conversion efficlency and with the increased attention to cleaner, renewable biomass fuels, the ability to utilize solid fuels in direct-fired applications (such as fluidized bed combustors) is improving.

MITRE $^{(10)}$ has summarized the range of biomass fuel combustion techniques. These include:

- fluidized bed combustion,

- charcoal/oil slurry firing,

- stoker firing, and

- suspension firing (analogous to pulverized coal firing).

The first two techniques are st1ll under development by the Department of Energy and are not commonly practiced on a commercial scale in the United States. Chapter 11 discusses the technology and economics of fluidized-bed combustion. While that discussion emphasizes coal applications,

* Examples of direct-fired wood waste applications are described in References 19 and 20. 
fluidized beds may be used also for biomass combustion. An inherent advantage of using biomass in a fluldized bed -- as in any combustor -is the relatively low sulfur content of the fuel. For the most part, the technology being developed to capture sulfur evolved from coal in a dolomite bed will not be required for biomass. Therefore fluidized beds should be able to be commercialized for biomass systems somewhat sooner and less expensively than for fossil fuel systems.

Stoker and suspension firing are commonly practiced solid-fuel combustion alternatives. The choice between the two is an economic one, depending most 1mportantly on the capacity of the furnace in question, but also on the specific fuel. Suspension firing requires a more severe pretreatment involving size reduction of the fuel to less than 100 microns, and sometimes drying to facilitate the necessary grinding. In larger furnaces (usually in the range of $50-200 \times 10^{6} \mathrm{Btu} / \mathrm{hr}$ ), this more severe treatment can be justified on the basis of its favorable economy of scale and its slightly improved combustion efficiency relative to the simple grinding and sizing (approximately $1 / 4 \mathrm{ln}$. ) required for stoker firing.

By far the most common device for recovery of the heat of combustion of a solid fuel is the steam boller. Depending on the conditions of temperature and pressure of the steam, it may be used for its thermal value and/or motive power to drive process equipment or an electric generator.

Conventional steam generation is a very old technology which has been modified and updated over the years to reduce investment requirements, improve efficiency, extend operating 1 ife, adapt to different fuels, and more recently, to minimize alr pollution. The boiler type, firing method, and specific design requirements depend critically on fuel properties and burning capacity. Ideally, the boller would be designed to burn a specific blomass fuel rather than be adapted at a later date. Usually, conversion from gas or ofl to solid-fuel firing involves derating the boiler to permit sufficient residence time for combustion of the solid particles. 
When coupled with the additional need for fuel storage and pretreatment, this option 1s often uneconomical. In short, boller fuels, whether blomass-derived or otherwise, are not readily substitutable as fuels for a particular boiler.

Municipal solid waste differs from most other terrestrial biomass sources in that it is a non-homogeneous mixture containing significant quantities of metals, glass, and dirt in addition to the primarily cellulosic combustible fraction. On the other hand, it is usually drier than harvested biomass. The non-homogeneity of MSW often requires that prior to combustion it be processed for the removal of recyclables and contaminants, which can corrode, erode, or foul heat-transfer equipment. (This is often the case whether the MSW is to be converted directly to thermal energy or to a solid, liquid, or gaseous fuel. Chapter 8 discusses conceptually some of the process steps which are often employed in MSW preprocessing.)

One of the major areas of Improvement in combustion/boiler technology has been the degree of integration of the furnace and the heat exchanger components (economizer, boiler superheater, etc.) Into a single unit. Today, nearly all large water-tube steam generators employ so-called waterwall construction, which minimizes the cost of the equipment by:

- eliminating the need for refractory lining to keep the steel shell cool -- water cooling accomplishes this;

- permitting shop fabrication in more cases (up to large sizes) because very little refractory must be applied in the fleld; and

- recovering energy in the furnace wall area.

The sales of industrial (no steam reheat) water-tube boilers in the United States in 1977 are presented in Table 7-3. They are arranged by fuel to lllustrate the extent to which biomass fuels have found widespread application.

These bollers are generally supplied by large manufacturers such as Babcock and Wilcox, Combustion Engineering, Foster Wheeler, Riley Company, and Zurn Industries, and by many other smaller companies. Some manufacturers 
TABLE 7-3

INDUSTRIAL WATER TUBE BOILER SALES IN THE UNITED STATES, 1977

\section{Fue1}

Wood

Bagasse

Black Liquor

Municipal Waste

Industrial Waste ${ }^{(1)}$

Fossil, a11
Units Sold

28

6

4

2

4

428
Capacity Sold

(1b steam/hr)

$$
\begin{array}{r}
2,700,000 \\
800,000 \\
1,300,000 \\
140,000 \\
1,800,000
\end{array}
$$

$33,960,000$

(1) Probably mostly non-biomass.

SOURCE: "Stationary Water-tube Boiler Sales, 1977"

Alierican Bullei Manufálusers Assucialión, Allington, VA. 1978.

produce all the system components (boilers, stokers or pulverizers, and burners, etc.); others purchase them from independent firms or even their competitors. Some firms specialize in burning certain fuels (e.g., The Bigelow Company, whose specialty is bagasse).

The city of Burlington, VT; is contemplating the installation of a 50-MW wood-fired power plant. Feasibility studies currently under way are concentrating on assessing the availability of wood at economic prices in the quantities required. (21) The city is presently burning a mixture of $75 \%$ wood chips and $25 \%$ oil to generate up to $9 \mathrm{MW}$ in a boiler originally designed for coal firing. (22)

Boiler units of the water-tube design for municipal wastes are referred to as waterwall incinerators. This technology has been practiced most widely in Europe. $(23,24)$ In the United States, waterwall inc1neracors are available using any of three proprietary grate designs from wheelabratorFrye, UOP, and Nashville Thermal Transfer Corp.; the Wheelabrator and UOP designs are based on the technology of Von Roll and Martin, respectively, which were developed in Europe. Non-proprietary systems are also offered by numerous architect-engineers. In either case the major'components are generally supplied by the same manufacturers. Current applications of these technologies in the United States are shown in Table 7-4. 
TABLE $7-4$

CURRENT APPLICATIONS OF WATERWALL INCINERATORS IN THE UNITED STATES.

\begin{tabular}{|c|c|c|c|c|}
\hline Location & Operator & Technology & $\begin{array}{c}\text { Capacity } \\
\text { (tons MSW/day) }\end{array}$ & Operational \\
\hline $\begin{array}{l}\text { Saugus, } \\
\text { MA }\end{array}$ & RESCO & $\begin{array}{l}\text { Wheelabrator- } \\
\text { Frye }\end{array}$ & 1200 & 1975 \\
\hline $\begin{array}{l}\text { Chicago, } \\
\text { IL }\end{array}$ & $\begin{array}{l}\text { Chicago } \\
\text { (Northwest) }\end{array}$ & UOP & 1800 & 1971 \\
\hline $\begin{array}{l}\text { Nashville, } \\
\text { TN }\end{array}$ & Tennessee & $\begin{array}{c}\text { Nashville Thermal } \\
\text { Transfer Corp. }\end{array}$ & 720 & 1974 \\
\hline $\begin{array}{l}\text { Harrisburg, } \\
\text { PA }\end{array}$ & Harrisburg & -- & 720 & 1972 \\
\hline
\end{tabular}

For these systems, the estimated average MSW-to-steam efficlency is about $67 \%,{ }^{(18)}$ wh1ch compares with about $80 \%( \pm 10 \%)$ for many moderately sized industrial coal-fired bollers.

Another combustion device which has been applied on a small. scale, mainly to solid waste materials, has become known as a modular controlled-air incinerator, or starved-air incinerator. It is shown schematically in Figure 7-1. $(26,27,28)$ since the primary chamber is deficlent in oxygen, it acts as a pyrolyzer and vaporizes the volatile components of the feed. The gases leaving the primary chamber contain large amounts of soot, hydrocarbons, and other combustibles which are completely burned in the secondary chamber by maintaining temperatures above $1400^{\circ} \mathrm{F}$ by operation of the auxiliary fuel burner. A thermocouple at the exit of the secondary chamber switches the burner on when the gas temperature at the exit falls below a preset temperature. At a high temperature setting, the burner is shut off, thereby conserving fossil fuel.

If the unit is designed for batch operations, ash is removed manually by opening a door at the end of the primary chamber; if the unit is designed for continuous operation, ash is removed by a continuous ash removal system at the end of the primary chamber. 


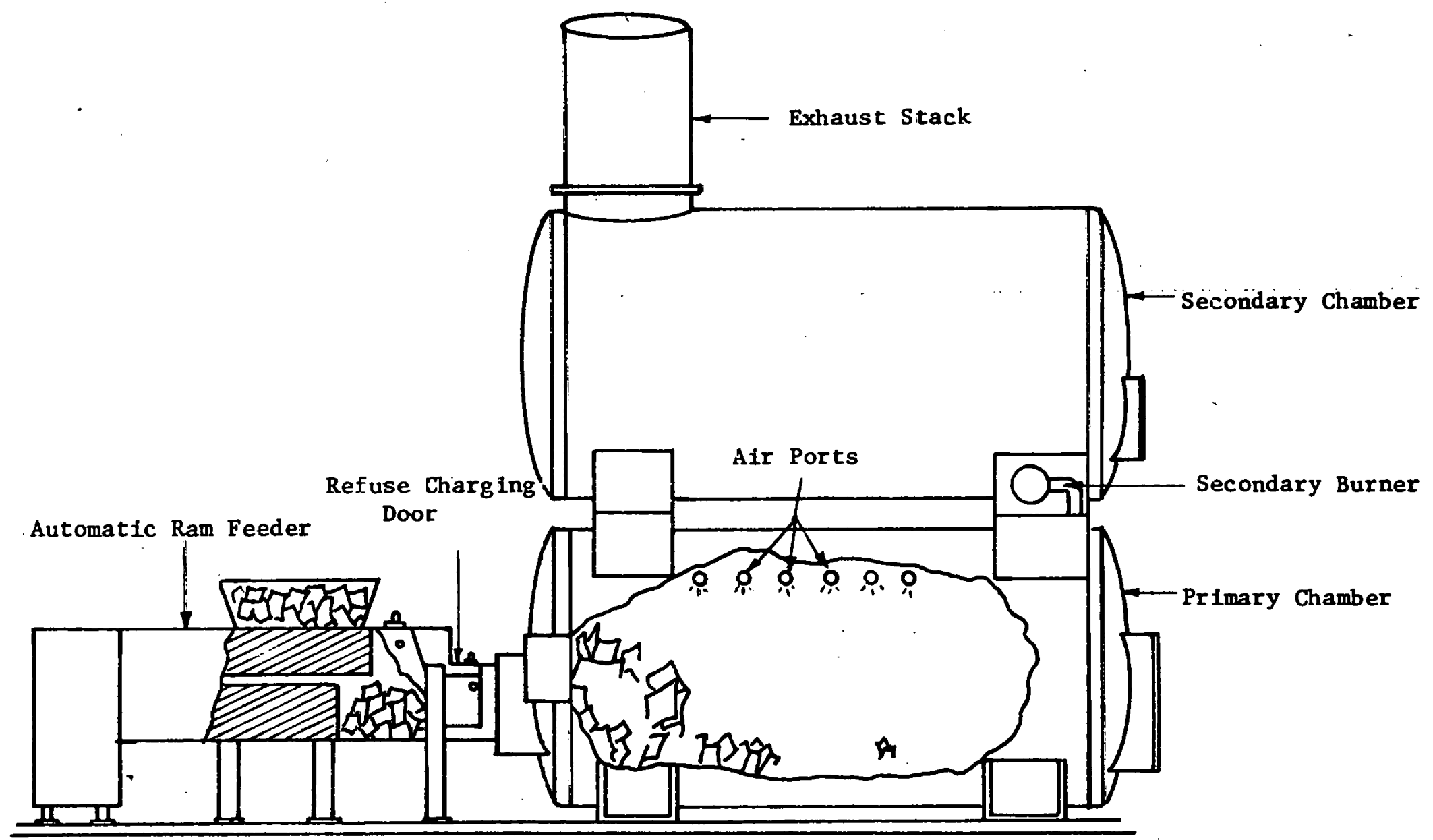

SOURCE: Arthur D. Little, Inc.

FIGURE 7-1 REPRESENTATION OF A CONTROLLED-AIR INCINERATOR 
For steam recovery, elther a waste-heat bofler can be mounted on the secondary chamber preceding the stack of the modular incinerator, or the hot flue gases can be ducted to a separate waste-heat boller. If there are several modular incinerators in a plant, ducting the hot gases to a separate waste-heat boller may have some advantage in that the operation of the steam system would be simplified. Boller feedwater treatment equipment and pumps are also required if steam 18 to be generated.

A typical overall fuel energy balance for the incinerator system at steady state is presented in Table 7-5. In calculating this balance, it has been assumed ${ }^{(20)}$ that the total fuel energy input to the incinerator is $10.6 \times 10^{6} \mathrm{Btu} /$ ton of feed, $9.5 \times 10^{6} \mathrm{Btu}$ in burning the feed, and $1.1 \times 10^{6} \mathrm{Btu}$ in burning 8 gallons of o11. The product steam ( $57001 \mathrm{~b} /$ ton of incoming MSW) contains $6.1 \times 10^{6} \mathrm{Btu}$; energy $1088 \mathrm{~s}$ Include $1.0 \times 10^{6} \mathrm{Btu}$ in the plant and $3.5 \times 10^{6} \mathrm{Btu}$ in the stack gases. The net energy recovered $186.1 \times 10^{6} \mathrm{Btu}$ less the purchased energy of $1.6 \times 10^{6} \mathrm{Btu}$, or $4.5 \times 10^{6} \mathrm{Btu}$, which $1 \mathrm{~s}$ equivalent to $42 \%$ of the total waste plus oll energy fed. Both the quantity and quality of the steam produced would change, depending upon assumptions made concerning the composition of the MSW, the auxillary fuel consumed, the operation of the unit, and the design of the boiler. Therefore, the figures shown are only for purposes of 1llustration.

The controlled-air incinerator has been specifically designed to minimize the entrainment of particulates in the flue gases and thus to avold the need for air pollution control equipment. Design constraints caused by this emission control requirement limit the size of modular incinerators to 25 to 50 tons/day of waste feed capacity. Units of capacities on the order of $100 \mathrm{lb} / \mathrm{hr}$ of waste are generally avallable from the same manufacturers. Many of these small units have found application in commercial establishments (e.g., restaurants) and Institutional buildings (hospitals). However, because of current economics, most installations do not include the steam recovery option. 
TABLE 7-5

ENERGY BAIANCE FOR CONTROLLED AIR INCINERATION WITH HEAT RECOVERY

Basis: One ton MSW Burned

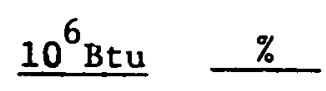

Energy Input to Incinerator

Municipal Solld Waste

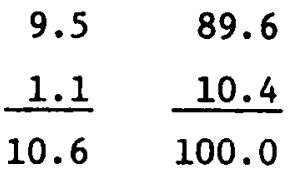

Energy Output from Incinerator

Steam Pipeline

$0.4 \quad 3.8$

Dissipated at Stack

3.533 .0

Other Losses (resldue, etc.)

$\frac{0.6}{4.5} \quad \frac{5.7}{42.5}$

Total Heat Losses

$\frac{6.1}{10.6} \quad \frac{57.5}{100.0}$

Energy Sold as Steam

Total Heat Out

$10.6 \quad 100.0$

Net Energy Recovered

Energy Sold as Steam

$6.1 \quad 57.5$

Less Purchased Energy Consumed:

\begin{tabular}{lllr} 
& Fuel Oil to Ineinerator & 1.1 & 10.4 \\
Electricity for Auxiliaries & 0.3 & 2.7 \\
Net Energy Recovered & Gasoline for Loader & 0.2 & 1.9 \\
\hline & 4.5 & 42.5
\end{tabular}

SOURCE: Arthur D. Llttle, Inc., calculations based on 1977 manufacturers' data, Including Consumat Systems, Inc., Richmond, VA., Environmental Control Products, Inc., Charlotte, NC., and Kelley Company, M11waukee, WI. 
An analog of this technology is finding increasing popularity as a domestic heat device. $(29,30,31,32)$. The so-called air-tight wood stove operates on the starved-air princlple, usually with two stages of combustion and an extended path for the combustion gases to maximize the opportunity for heat recovery in the building. Because of the relative simplicity of burning wood logs on a grate, wood stoves do not require the sophisticated controls of the large-scale incinerators and can operate essentially unattended. They are available in a wide varlety of designs from many $U, S$, and foreign manufacturers. Since the stoves are ordinarily located in the living area, aesthetics are a consideration in the design.

The major advantage of air-tight stoves is that they avoid the loss of large, uncontrolled quantities of warm room air by admitting only that air actually required for combustion, plus a nominal excess to ensure complete burning. The principal disadvantage is that for most conventionally designed homes, a wood stove is not capable of acting as a central heating system.

\section{Section 7.4: Economics Discussion}

\section{A. Biomass}

The estimated costs of producing and/or recovering various forms of biomass have been discussed above in conjunction with the technical discussions. In summary, it is projected that by $1985-2000$ some biomass forms, such as sugarcane and hardwoods, can be produced at costs competitive with coal's. Other forms, such as microalgae, may be produced at higher cost but in a form that may be converted to substitute natural gas at an overall cost competitive with that of synthetic natural gas (SNG) from coal. Of course, such profections assume reasonable advances in the current state of technology to achieve economically sound yields and recoveries. 
A detalled cost estimate for a 55-MW wood-fired power plant for electricity production was developed by MITRE ${ }^{(33)}$ in 1976 . The capital cost totaled $\$ 55 \mathrm{million}$, or $\$ 1000 / \mathrm{kW}$. Annual operation and maintenance costs of $\$ 3.6 \mathrm{mflilion}$ were estimated, exclusive of capital charges or fuel costs. The technology is quite similar to that practiced in the pulp and paper industry; direct cost comparisons are not possible because of the many specific requirements of integration in a pulp and paper plant, including cogeneration of electrictity, extraction of steam at various pressure levels, and combustion of special wastes such as black liquor.

\section{B. Municipal Snlid Waste}

Table 7-6 summarizes the estimated economics of waterwall incineration. The capital investment for a plant to process and convert 1000 tons/day of MSW is estimated to be $\$ 30.8$ million in 1976 dollars, or $\$ 30,800 /$ daily ton (equivalent to about. $\$ 32.6 \mathrm{million}$ in 1977 dollars, or $\$ 32,600 /$ ton/day). The estimated annual costs in 1977 , including capital charges of $10 \%$ and $18 \%$ as computed by Alich, et al., (34) are, respectively, $\$ 20.13$ and $\$ 28.03 /$ ton of $M S W$, or $\$ 3.36$ and $\$ 4.68 / 10001 \mathrm{~b}$ of steam. Any credits for dumping (tipping) fees or sale of scrap metals would lower the overall costs.

A similar economic analysis for modular-controlled air incinerators is presented in Table 7-7. The capilal Investment was estimated to be $\$ 19,000 /$ ton/day of MSW capactty in 1977; this includes no feed preparation or scrap recovery, as none is required for the incinerator. Because of the relatively small size of the units and labor intensity, they are assumed to be operational only 5 days per week. Debt amort1zation is $8 \%$ for 20 years, which is comparable to the $10 \%$ capital charge rate used in the waterwall system example. The disposal cost, Including no credit for tipping fees, is estimated on this basis to be $\$ 20.17 /$ ton -- equivalent to about $\$ 3.53 / 1000 \mathrm{lb}$ of steam sold.*

* Assumes 5710 Ib steam/ton of MSW. 


\section{TABLE $7-6$}

ESTIMATED ANNUAL OPERATING COST OF A

WATERWALL INCINERATOR

(1000-ton/day Plant)

\begin{tabular}{|c|c|c|c|}
\hline & $\$ 000 / y r$ & $\begin{array}{l}\$ / \text { ton } \\
\text { of MSW } \\
\end{array}$ & $\begin{array}{l}\$ / 10001 b \\
\text { Steam }(1)\end{array}$ \\
\hline Capital Investment (1977 dollars) & 32,600 & & \\
\hline \multicolumn{4}{|l|}{ Annual Operating \& Maintenance Costs } \\
\hline Operating Labor & 1,121 & 3.40 & 0.57 \\
\hline Maintenance Labor and Materials & 1,195 & 3.62 & 0.60 \\
\hline Purchased Utilities & 462 & 1.40 & 0.23 \\
\hline Miscellaneous & 308 & 0.93 & 0.16 \\
\hline Restdue Disposal & 297 & 0.90 & 0.15 \\
\hline TOTAL & 3,383 & 10.25 & 1.71 \\
\hline \multicolumn{4}{|l|}{ Annual Capital Charges (ACC) } \\
\hline $10 \%$ & 3,260 & 9.88 & 1.65 \\
\hline $18 \%$ & 5,868 & 17.78 & 2.97 \\
\hline \multicolumn{4}{|l|}{ Total Revenue Required ${ }^{(2)}$} \\
\hline $10 \%$ ACC & 6,643 & 20.13 & 3.36 \\
\hline $18 \%$ ACC & 9,251 & 28.03 & 4.68 \\
\hline \multicolumn{4}{|l|}{ Credits } \\
\hline Ferrous Metals & 533 & 1.68 & 0.27 \\
\hline \multicolumn{4}{|l|}{$\begin{array}{l}\text { Tota1 Revenue Required. from Sale } \\
\text { of Steam (excluding dumping fee) }\end{array}$} \\
\hline $10 \%$ ACC & 6,110 & 18.45 & 3.09 \\
\hline $18 \%$ ACC & 8,718 & 26.35 & 4.41 \\
\hline
\end{tabular}

(1) Assumes about $1100 \mathrm{Btu} / 1 \mathrm{~b}$ of steam at $67 \%$ efficiency from MSW to steam.

(2) "Total Revenue Required" is the annual cost of plant operation which must be reimbursed from plant income.

SOURCE: Stanford Research Institute, (34) updated to 1977 dollars by Arthur D. Little, Inc. 


\section{MODULAR-CONTROLLED AIR INCINERATOR WITH STEAM RECOVERY}

Fixed Capital Investment ( $\$ 000)$
Daily Plant Capacity (tons/day)
Investment ( $\$ /$ ton/day).

Annual Operating Costs

Variable Costs

Fuel 011

Power

Residue

Supplies

Semi-Varlable Cost

Operating Labor - 3 shifts, 7 men each e $\$ 5.00 / \mathrm{hr}$

Labor Overhead - $20 \%$ of Operating Labor

Adminfstration - $35 \%$ of Operating Labor

Maintenance

$$
\text { - 3\% of Fixed Capital }
$$$$
\text { Investment }
$$

\section{Fixed Costs}

$\begin{array}{ll}\text { Amortization } & -20 \text { years @ } 8 \% \\ \text { Insurance } & -1 \% \text { of Fixed Capital } \\ & \text { Investment }\end{array}$

Total Revenue Required from Sale of Steam (excluding dumping fee)

$$
1,393
$$

73.0

19,000

$\begin{array}{r}\$ / \text { ton } \\ \$ 000 / y r \quad \text { of MSW } \\ \hline\end{array}$

$\$ / 10001 \mathrm{~b}$

steam

\begin{tabular}{lll}
56.0 & 2.80 & 0.48 \\
10.0 & 0.50 & 0.09 \\
22.6 & 1.13 & 0.20 \\
$\underline{4.0}$ & $\underline{0.20}$ & $\underline{0.04}$ \\
\hline 92.6 & 4.63 & 0.81
\end{tabular}

231.0

11.51

2.04

46.2

2.30

0.41

80.9

4.03

0.72

$\frac{41.8}{399.9}$

2.09

$\underline{0.37}$

399.9

19.93

3.54

142.1

7.10

1.25

$\frac{13.9}{156.0}$

0.70

$\underline{0.12}$

156.0

7.80

1.37

648.5

32.36

5.72

SOURCE: Arthur D. Little, Inc., estimates, based on 1977 manufacturers' data, including Consumat Systems, Inc., Richmond, VA., Environmental Central Products, Inc., Charlotte, NC., and Kelley Company, Milwaukee, WI. 


\section{Resources}

The relatively low avallability of biomass and MSW resources in required quantities near energy-consuming (populated) areas may be a significant factor in deferring the broad commercialization of an energy-from-biomass industry. Farming itself is also an energy-intensive industry, but much of the energy required is in a form other than solid biomass (e.g., nitrogen fertilizers and liquid fuels for heavy, farm equipment). Thus, the direct use of biomass as a generic energy source on farms is $1.1 \mathrm{mited}$.

In the case of dedicated biomass plantations, the limitations of other natural resources, e.g., water and phosphorus, may be crictital.

Stanford Research Institute has performed a comprehensive study of biomass systems for the Department of Energy. (35) From more than 1100 candidates, 15 were selected for detailed study on the basis of technical feasibility and were subjected to further analysis by an economic model. Based on expected market penetration, four systems indicated the greatest near-term commercialization potential:

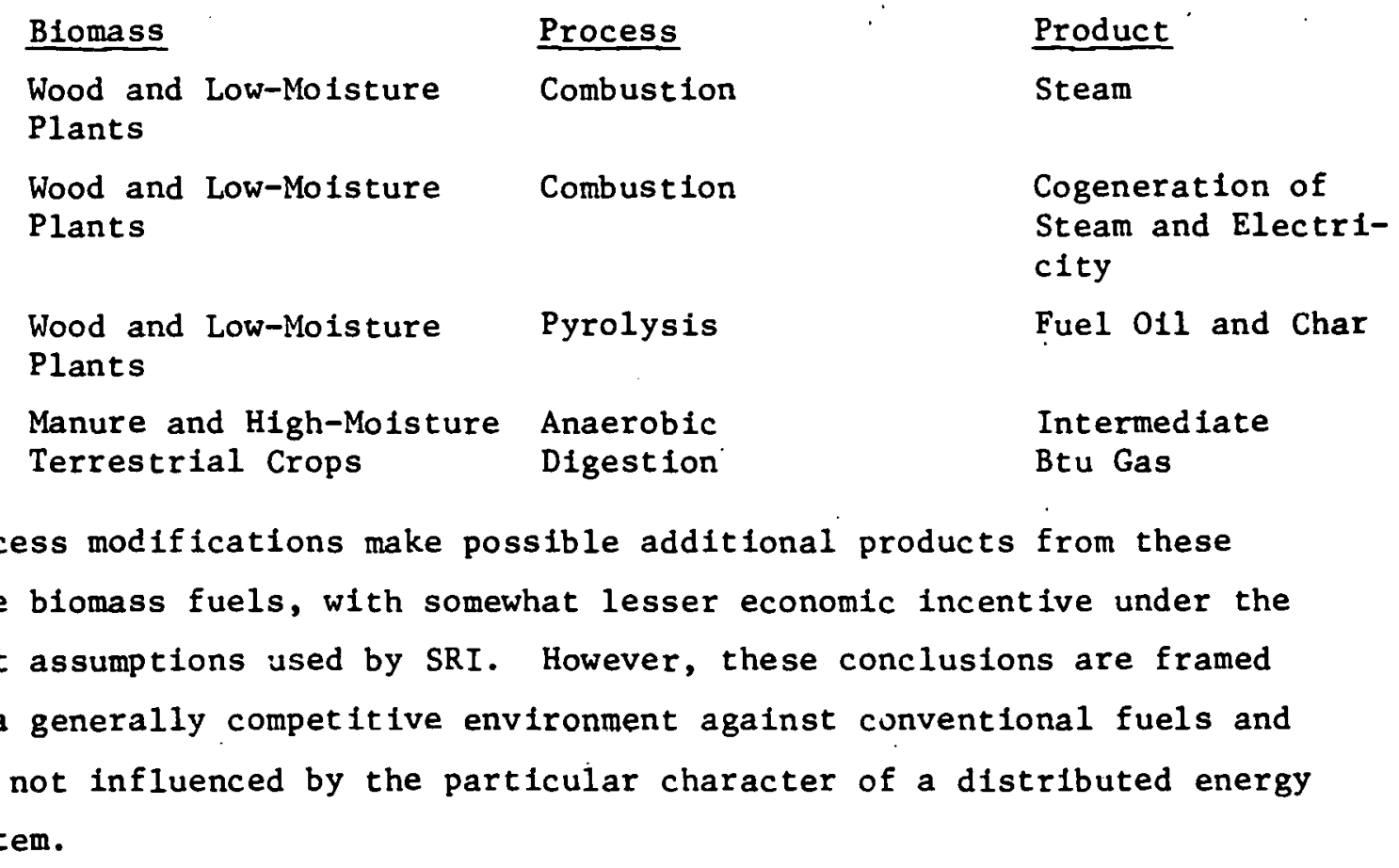


THIS PAGE

\section{WAS INTENTIONALLY LEFT BLANK}


1. Lipinsky, E.S., et al. Systems Study of Fuels from Sugarcane, Sweet Sorghum, and Sugar Beets, Vol. IV: Corn Agriculture, Task 77. Final Report. Prepared by Battelle Columbus Laboratorles for U.S. Energy Research and Development Administration, March 31, 1977. pp. 203 ff. NTIS Report No. BMI-1957A(v.4).

2. Lipinsky, E.S., et al. Systems Study of Fuels from Sugarcane, Sweet Sorghum, and Sugar Beets, Vol. II: Agrlcultural Considerations, Task 77. Final Report. Prepared by Battelle Columbus Laboratorles for U.S. Energy Research and Development Administration, March 31, 1977. NTIS Report No. BMI-1957(v. 2).

3. Jewe11, W.J. "Energy, Agriculture and Waste Management." Proceedings of the 1975 Cornell Agricultural Waste Management Conference, Ithaca, N.Y., 1975.

4. Inman, R.E., et al. S1lvicultural Biomass Farms, Vol. I: Summary Report. Prepared by MITRE Corporation for Energy Research and Development Administration, May 1977. pp. 62 ff. NTIS Report No. MTR $7347(\mathrm{v} .1)$.

5. Burwe11, C.C. "Solar Blomass Energy: An Overview of U.S. Potent1al." Science $199(4333): 1041$, March 10, 1978.

6. Prior, L.A. Land Avallability, Crop Production and Fert1lizer Requirements in the U.S. Washington, D.C.: Environmental Protection Agency, October 1975. EPA Report No. EPA/530/SW-166.

7. Allch, J.A., Jr., et al. An Evaluation of the Use of Agricultural Residues as an Energy Feedstock. Volumes 1 and 2. Report prepared by Stanford Research Institute for National Sclence Foundation, July 1976. NTIS Report Nos. PB 260763 and PB 260764.

8. Povich, M.J. "Fuel Farming." Chemtech 6(7):434, July 1976.

9. Alich, J.A., Jr., et al. Effective Utilization of Solar Energy to Produce Clean Fuel. Report prepared by Stanford Research Institute for National Science Foundation, June 1974. NTIS Report No. PB 233 956.

10. Inman, R.E., et al. Silvicultural Biomass Farms, Vol. IV: SiteSpecific Production Studies and Cost Analyses. Report prepared by MITRE Corporation for Energy Research and Development Administration, May 1977. NTIS Report No. MTR $7347(v .4)$.

11. Howlett, K., et al. S1lvicultural Blomass Farms, Vol. II: The Blomass Potential of Short Rotation Farms: Report prepared by MITRE Corporation for Energy Research and Development Administration, May 1977. NTIS Report No. MTR $7347(v .2)$. 


\section{REFERENCES (cont inued)}

12. Ryther, J.H., et al. "Cultivation of Seaweeds for Hydrocollo1ds, Waste Treatment, and Blomass for Energy Conversion." Preprint. Proceedings of the IX International Seaweed Symposium, Santa Barbara, California, August 1977.

13. Wilson, E.H., et al. Spectal Topical Report on Sources and Systems for Aquatic Blomass as an Energy Resource. Report prepared by Dynatech Corporation for the U.S. Department of Energy, October 21, 1977. Dynatech Report No. 1679. pp. 206 ff.

14. CSo International, Inc. Cost Analys1s of Microalgae Biomass Systems, Final Report: Design Assumptions and Englneerling Plans for 100Square Mile System. Report prepared for the U.S. Department of Energy, April 1978. pp. 98 ff. NTIS Report No. HCP/T1605-01.

15. Alich, J.A., ct al. An Evaluation of the Use of Agricultura1. Residucs as an Encrgy Foedstock - A Ton Site Suryey, Vn1. 2: St.11y Area Analysis. Report prepared by Stanford Research Institute for Energy Research and Development Administration, July 1977. pp. 404 ff. NTIS Report No. TID-27904/2.

16. E11is, T.H. "The Role of Wood Residues in the National Energy P1cture." Proceedings of the Forest Products Research Society Meeting on Wood Residue as an Energy Source, Denver, Colorado, September 3-5, 1975 .

17. Hansen, P. Residential Paper Recovery: A Mun1c1pal Implementation Guide. Prepared by U.S. Environmental Protection Agency in cooperation with National Center for Resource Recovery, Inc., 1975. NTIS Report No. PB 259454.

18. Resource Planning Associates. Waste Flow Characteristics and Resource Recovery. Prepared for Energy Research and Development Administration, October 1976. NTIS Report No. TID-27633.

19. Deardorff, D. "Direci Combustion Systems." Proceedings of the Forest Products Research Soclety Meeting on Wood Residue as an Encrgy Source, Denver, Colorado, September 3-5, 1975.

20. Jasper, M.T., et al. "Suspension Burning of Green Bark to DirectFired High-Temperature Kilns for Southern Pine Lumber." Proceedings of the Forest Products Research Soclety Meeting on Wood Res1due as an Energy Source, Denver, Colorado, September 3-5, 1975.

21. Cronin, T., Public Relations Department, Burlington Electric Company, Burlington, Vermont. Personal communications. July 1979. 
22. Bentley, G.K. New England Rural Energy Sources - Wood, Smal1-Scale Hydro, Direct Solar and Wind - An Assessment of Near-Term PotentiaT:Washington, D.C.: Energy Task Force of the New England Congressional Caucus, February 1979.

23. Resource Planning Associates, Inc. European Waste-to-Energy Systems: Case Study of Koersor, Denmark. Prepared for the Energy Research and Development Administration, June 1977. NTIS Report No. CONS/2103-3.

24. Resource Planning Associates, Inc. European Waste-to-Energy Systems, An Overview. Prepared for the Energy Research and Development Administration, June 1977. NTIS Report No. CONS/2103-6.

25. County Sanitation Districts of Los Angeles County. Report on Status of Technology in the Recovery of Resources from Solid Wastes. Los Angeles, Calffornia, January 1976.

26. Arthur D. Little, Inc. Opportunities for Regional Solld Waste Management. Report to the Regional Solid Waste Committee, Auburn, Maine, April 1975.

27. Arthur D. Little, Inc. Opportunities for Regional Solid Waste Management. Report to Minuteman Regional Refuse D1sposal Planning Board, Bedford, Massachusetts, April 1975.

28. Arthur D. Little, Inc. An Analysis of Selected Solld Waste Disposal Alternatives for the Town of Acton. Prepared for the Town of Acton, Massachusetts, May 1975.

29. Self, C.R. Wood Heating Handbook. Blue Ridge Summit, Pennsylvania: TAB Books, 1977 .

30. Irving, D. The Complete Book of Woodburning Stoves. New York: Drake Publishers, Inc., 1978.

31. Daniels, M.E. Fireplaces and Wood Stoves. New York: Bobbs-Merri11, 1977.

32. Harrington, G. The Wood-Burning Stove Book. New York: MacMillan Publishing Company Inc., 1977.

33. Bliss, C., et al. Silvicultural Blomass Farms, Vol. V: Conversion Processes and Costs. Report prepared by MITRE Corporation for Energy Research and Development Administration, May 1977. NTIS Report. No. MTR 7347 (v.5). 


\section{REFERENCES (continued)}

34. Al1ch, J.A., et al. Program Defintition for Fuels from Biomass. Prepared by Stanford Research Institute for the State of California Energy Resources Conservation and Development Program, 1976. SRI Project 5527.

35. SRI International. Mission Analysis for the Federal Fuels from Blomass Program, Vol. I: Summary and Concluslons. Report prepared for the U.S. Department of Energy, December 1978. 


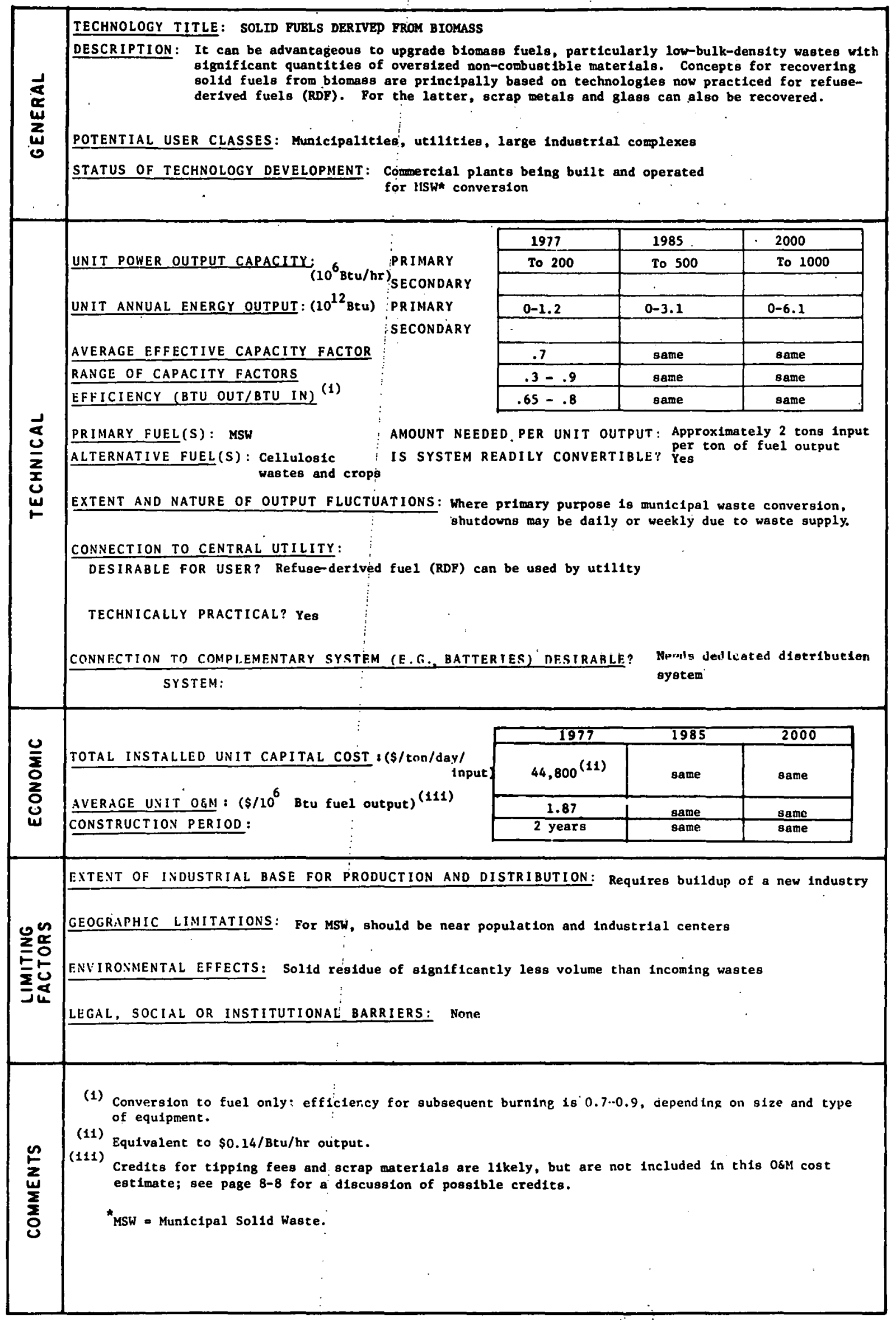


CHAPTER 8

SOLID FUELS DERIVED FROM BIOMASS

Section 8.1: Introduction

Most of the activity devoted to recovering the energy values of biomass materials in the form of combustible solid fuels has been limtted to wood residues and municipal solid waste (MSW).

Generally, pulp and paper plants and sawmills are located close to the source of raw material and are relatively remote from major population centers. As a result, where energy recovery is feastble, most wood wastes generated by these plants are burned by the plant operators to produce steam for electric power generation and process needs, rather than being transported significant distances to be burned by other energy consumers. In some cases, wood pellets or synthetic fireplace logs are produced, if there is an excess of wood wastes near an approprlate market.

MSW, on the other hand, is generated over wider areas in industrial and population centers where energy needs are large and diverse. Many commerclal firms and municipalities have proposed resource recovery systems as an alternative to direct incineration and landfill. The purpose of resource recovery is the sale and recycle of values contained in the MSW in order to offset, at least partially, the costs of collecting the waste and disposing of its residue. Among the recoverable resources are:

- energy-producing materials or fuels,

- ferrous metals,

- nonferrous metals, principally aluminum, and

- glass.

Solid fuels can be produced in shredded, powdered, or fibrous form, using wet or dry processing. Most solld fuels are processed by shredding in one or two stages, magnetic separation for ferrous metal recovery, and one or more classification steps to remove non-combustibles. Drying may be included. 
Powdered fuel is produced by a proprietary dry process (Combustion Equipment Associates, Inc.'s Eco-Fuel ${ }^{\circledR}$-II process). (1) In this process. a finely divided, high-bulk-density, dry, low-ash.fuel is produced. Ferrous metals are recovered, and processing for recovery of other materials can be added.

Fibrous fuel is produced by Black-Clawson ${ }^{(2)}$ in Its proprietary wet process based on wood pulping technology. This process was originally developed to recover fibers from MSW, but because of the 1imited markets for the low-quality, low-value flbers, Black-Clawson now plans to market the fibers as a fuel. This process also recovers the ferrous and nonferrous metals and glass.

Solid-fuel systems are offered by a number of system suppliers and architect-engineers. Most dry systems make use of similar equipment that has been well proven in other industries, although its use in processing MSW is new.

Since most commercial biomass-based solid fuels are derived from municipal solid waste, the technology discussion emphasizes this source. The technology can be adapted to accept other biomass forms where appropriate, including both agricultural products grown specifically for their energy values and residues from agricultural production for other purposes.

\section{Section 8.2: Technical Discussion}

A. Terrestrial Biomass Crops and Residues

The conversion of biomass products and residues has not been widely considered. The technology for size reduction of the terrestrial biomass materials is readily transferrable from that developed for the MSW resource recovery plants.described below. The basic difference lies in collection and preprocessing of the materials. Agricultural restdues are generally more dispersed than MSW which is usually concentrated in urban areas. Agricultural commodities and residues are generally more homogenous 
than MSW, which requires several preprocessing steps, such as the recovery and removal of recyclable metals and glass. Overall thermal efficlency, however, would probably be somewhat lower than that for MSW because of the lower molsture content and lesser need for drying the latter.

\section{B. MSW}

A refuse recovery factlity is designed to produce a number of products of sufficient quality to be sold as acceptable items of comerce. Equipment to produce quality byproducts, e.g., ferrous metals, is not directly relevant to a discussion of recovery of energy values, but noted to the extent that the equipment is required to "purify" the solid fuel to a reasonable quality (low ash content). Figure 8-1 shows the schematic process flow diagram for a conceptual resource recovery facility. (3)

In this flowsheet, MSW is fed to a first-stage hamermill. The underflow from the hammermill is fed onto a conveyor which passes under a magnetic separator. The ferrous scrap which is removed is low grade because it is contaminated with organics. Further processing can clean this scrap and enhance its value.

The shredded material is discharged from the conveyor belt into a trommel (or screen) which removes a fraction of the glass and dirt. The discharge from the trommel enters a second hammermill where the size of the shredded material is further reduced. From the second hammermill the material passes into a second trommel to remove additional glass and dirt. The glass and dirt removed from the two tromels would contain about $50 \%$ organics, would be of no value without further processing, and would be suitable only for disposition in a sanitary landf111. The shredded material from the second trommel passes into an air classifier. The light fraction from the air classifier is discharged into a surge bin and fed to a pellet mill from which the pellets are discharged to a fuel storage area. Thts is the clean fuel portion of the MSW. 


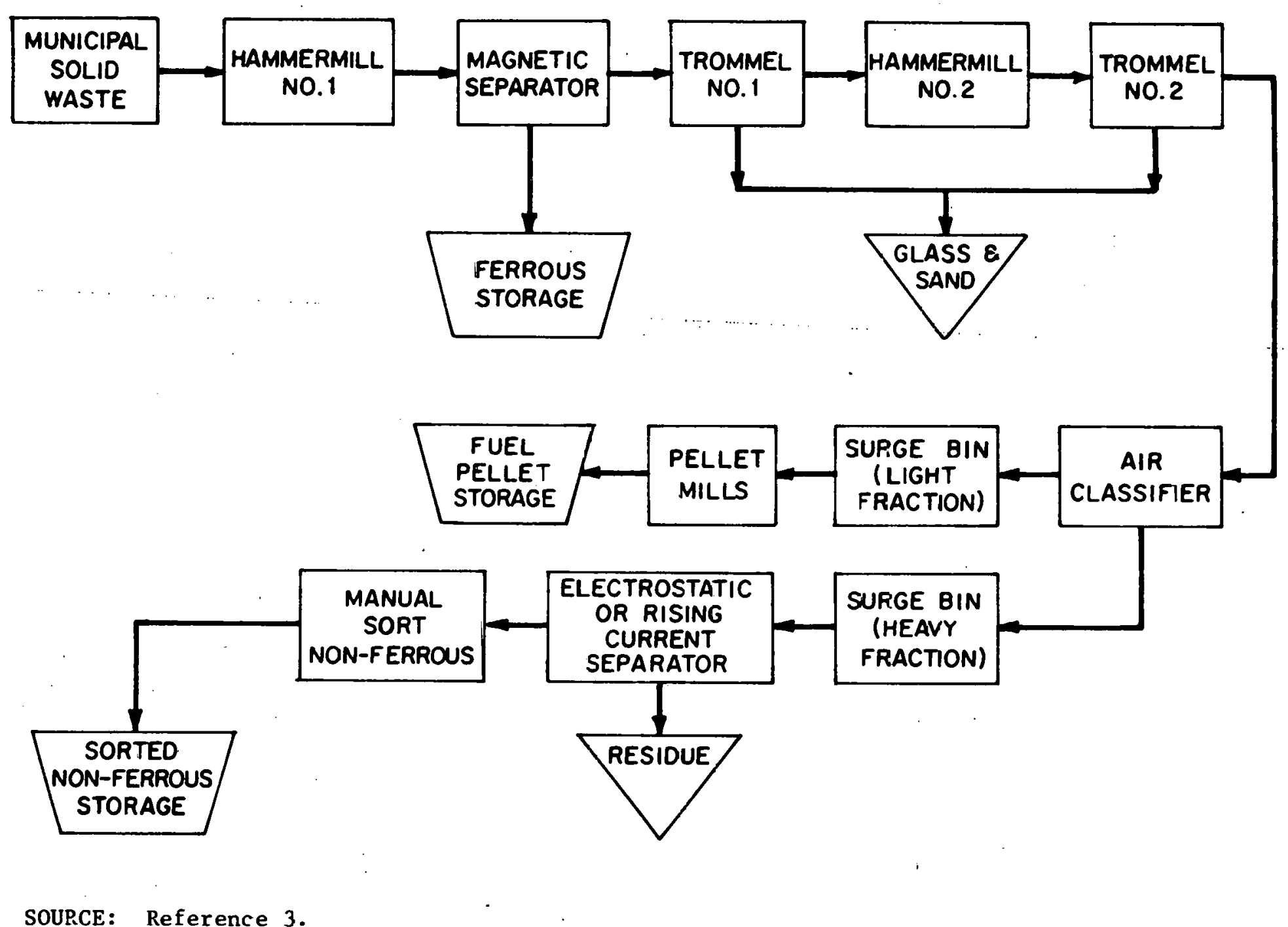

FIGURE 8-1 RESOURCE RECOVERY SCHEMATIC FLOה DIAGRAM 
The heavy fraction from the air classifier is fed to a device which separates the salable non-ferrous metals from the other heavy disposable high-molsture residues. The estimated solid-fuel product yleld of the process is $7.2 \times 10^{6} \mathrm{Btu} / \mathrm{ton}$ of $\mathrm{MSW},{ }^{(3)}$ equivalent to. about an $80 \%$ energy yleld on the basis of MSW at $4500 \mathrm{Btu} / \mathrm{lb}$.

The pellet mills in the process are a proprletary application of Systems Resource Recovery (SRR). (3) They could be omitted and the shredded organic fraction sold directly for its energy value; the energy yield would be slightly improved. The drawback of this approach would be the relatively low bulk density of the product which would add to the costs of storage and transportation.

An alternative approach is the proprietary development of Combustion Equipment Assoclates and Arthur D. Little, Inc., (2) which produces a dry powder of high bulk density known as Eco-Fuel ${ }^{\circledR}-$ II. The CEA/ADL process uses an elevated temperature ball mill to reduce the particle size of the product to a powdered state. A chemical addition step precedes the ball mill to embrittle the cellulosic material and minimize the electrical energy requirements of the ball mill.

Table 8-1 summarizes the properties of solid fuels dertved from refuse. Table 8-2 shows the components of energy recovery from use in the Eco-Fuel ${ }^{\circledR}$-II process. In all, a net recovery of $83 \%$ of that energy available in the feed MSW is estimated as net recoverable solld fuel.

The CEA/ADL process is being commercialized. One plant that w111 process 25. tons of MSW is now operating at East Bridgewater, Massachusetts. Another that will process 100 tons per hour is in shakedown at Bridgeport, Connecticut, and started up in mid-1978. Other plants are planned for Newark, New Jersey, and New York C1ty.

\section{Section 8.3: Economics Discussion}

Malcolm Pirnie, Inc., has estimated the cost of converting 1200 tons per day of municipal solid waste to a powdered fuel. (4) Including the cost of recovering both ferrous and aluminum scrap materials as 
TABLE 8-1

\section{PROPERTIES OF REFUSE-DERIVED FUELS}

Eco-Fue $1^{(9)}$-II

Combustibles \% by weight Ash . $\%$ by weight Molsture $\%$ by welght
88.6

9.4

2.0

100.0
Shredded Fuels. Dried (1) Undried

$$
77.0
$$$$
50-60
$$

13.0 20

10.0 20-30

100.0
100.0

Higher Heating Value (Btu/lb)

$$
7,800
$$

0.0006

30-35

Indefinite .

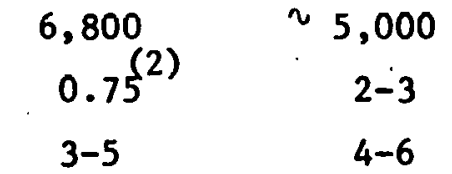

Indefinite

Average Particle Size (inches)

Bulk Density (1bs/ft $\mathrm{t}^{3}$ )

Storage Life

(1) Dried shredded fuel permits additional ash removal which is included.

(2) Two-stage shredding.

SOURCE:". Arthur D. Little, Inc., analysis of products from pllot scale and commerclal equipment. 


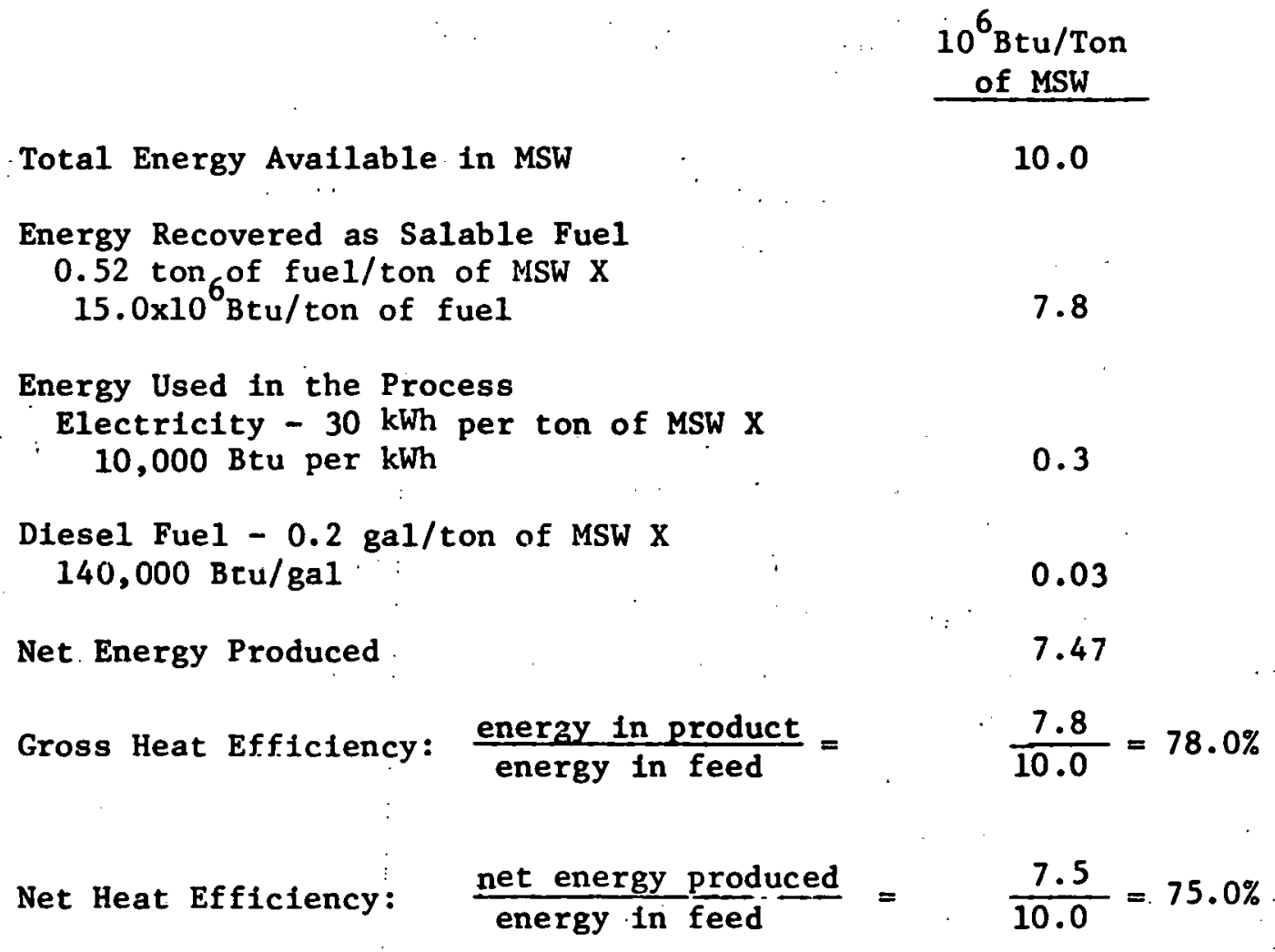

SOURCE: Reference 2 . 
byproducts, a plant of this type was estimated to require a capital Investment in 1977 of $\$ 53.8 \mathrm{million}$. This is equivalent to $\$ 44,800 / \mathrm{ton} / \mathrm{day}$ of MSW input, or $\$ 0.14 / \mathrm{Btu} / \mathrm{hr}$ of output assuming an energy content of $10 \times 10^{6}$ $\mathrm{Btu} /$ ton of MSW and a net energy efficlency to powdered fuel of $75 \%$ (Table $8-2)$.

The total estimated annual O\&M costs including all labor and overhead, maintenance, insurance, a management fee, and other associated costs are $\$ 6.4$ million, equivalent to $\$ 28.10 /$ ton of fuel output or $\$ 1.87 /$ $10^{6} \mathrm{Btu}$ of fuel output. Credits for byproduct metals reduce the net cost of operating the resource recovery facility to $\$ 26.40 /$ ton (or $\$ 1.76 / 10^{6} \mathrm{Btu}$ ) of fuel output. (4) These costs would be further offset if a disposal (or tipping) fee vere charged for the incoming NSW consistent with the cost of alternative disposal methods in the area which are usually in the range $\$ 5-20 /$ ton of MSW, equivalent to $\$ 0.68-2.70 / 10^{6} \mathrm{Btu}$ of solit fuel output.

Depending on the nature of the MSW feed, it 1s expected that the cost of producing shredded MSW is lower than that of Eco-Fue ${ }^{\circledR}-$ II or refuse-derived pellets because of the differences in capital costs. However, the ultimate chotce among the three forms of solid fuel must be made on the basis of a trade-off between product quality (principally bulk density as it relates to storage and transportation), product value, and plant costs.

\section{Section 8.4: Limitations}

The principal limitation on the wide-scale implementation of solid-fuels-from-waste technologies is cost. If inexpensive options are available for waste disposal, such as a local low-cost landfill, It may be difficult to justify a resource recovery facility on economic grounds, unless the entire system and related costs are carefully examined for a true comparison.

Another potential Iimitation, which is a function of the MSW composition, is the degree to which impurities in the solid fuel would foul the combustion and boiler equipment or pollute the air. The ash 
contained in the refuse-derived fuel would create excessive fly ash emissions if the equipment were not able to process impurities.

Chlorides present in plastics can contribute to air emissions and may be a source of corrosion of boiler tubes. Further specles, such as sodium, may lower the fusion temperature of the ash and contribute to fouling of boller tubes.

To date, operating experience with these fuels has been limfted and the technology cannot be considered fully commercial. Detalled operating data can alter the above estimates and potentially slow the development of future large-scale plants.

A final limitation is that of the avallability of MSW in quantities and continuity sufficient to represent a significant energy source. (A discussion of MSW availability is presented in Chapter 7.) MSW itself represents a steady product of urban areas, but other lowmolsture terrestrial biomass products, or byproducts, are avallable only seasona11y or must be collected from extensive areas. The resultant transportation and storage costs may represent a decisive factor in the economics of such a system. 
THIS PAGE

\section{WAS INTENTIONALLY LEFT BLANK}


REFERENCES

1. Chemical Profiles. New York: Schnell Publishing Company, Inc., 1977.

2. Beningson, R.M., et al. "Production of Eco-Fue1 ${ }^{\circledR}$ II from Municipal Waste, CEA/ADL Process." American Institute of Chemical Engineers 80th National Meeting, Boston, Massachusetts, September 7-10, 1975.

3. Systems Resource Recovery. Report to Southern M1d-Coast Regional Planning Commission. Long Beach, California, September 1974.

4. Malcolm Pirnie, Inc. Resource Recovery and Solid Waste Management Program. Summary Report for Westchester County, New York, Department of Public Works, December 1977.

5. Arthur D. Little, Inc. Opportunities for Reglonal Solid Waste Management. Report to Minuteman Regional Refuse Disposal Planning Board, Bedford, Massachusett8, April 1975. 


\section{SUPPLEMENTARY BIBLIOGRAPHY}

1. Franklin, M. A. "The Preparation of Fuels and Feedstocks from Municipal Solid Waste." Proceedings of a Workshop Held at New Orleans, Loulstana on February 8-10, 1977. Sponsored by the Municipal Environmental Research Laboratory, Cincinnati, Ohio, December 1977. NTIS Order No. PB 279077.

2. Weinstein, N. J. Municipal-Scale Thermal Processing of Solid Wastes. Report prepared by RECON Systems, Inc. for the Environmental Protection Agency, 1977. NTIS Report No. PB 263396.

3. Wilson, E., et al. Engineering and Economic Analysis of Waste to Energy Systems; Final Report, April 1975 - June 1977. Report prepared by Ralph M. Parsons Company for the Industrial Environmental Research Laboratory, Cincinnati, Ohio, May 1978. NTIS Report No. PB 285797.

4. County Sanitation Districts of Los Angeles County, California. Status of Technology in the Recovery of Resources from Solid Wastes. Los Angeles, January 1976.

5. Resource Planning Assoclates, Inc. Waste Flow Characteristics and Resource Recovery. Report prepared for Energy Research and Development Administration, October 1976. NTIS Report No. TID 27633.

6. Drobny, N. L. et al. Recovery and Utilization of Municipal Solid Waste: A Summary of Avallable Cost and Performance Characteristics of Unit Processes and Systems. Report prepared by Columbus Laboratories of Battelle Memorial Institute for the Environmental Protection Agency, 1971. NTIS Report No. PB 204922. 


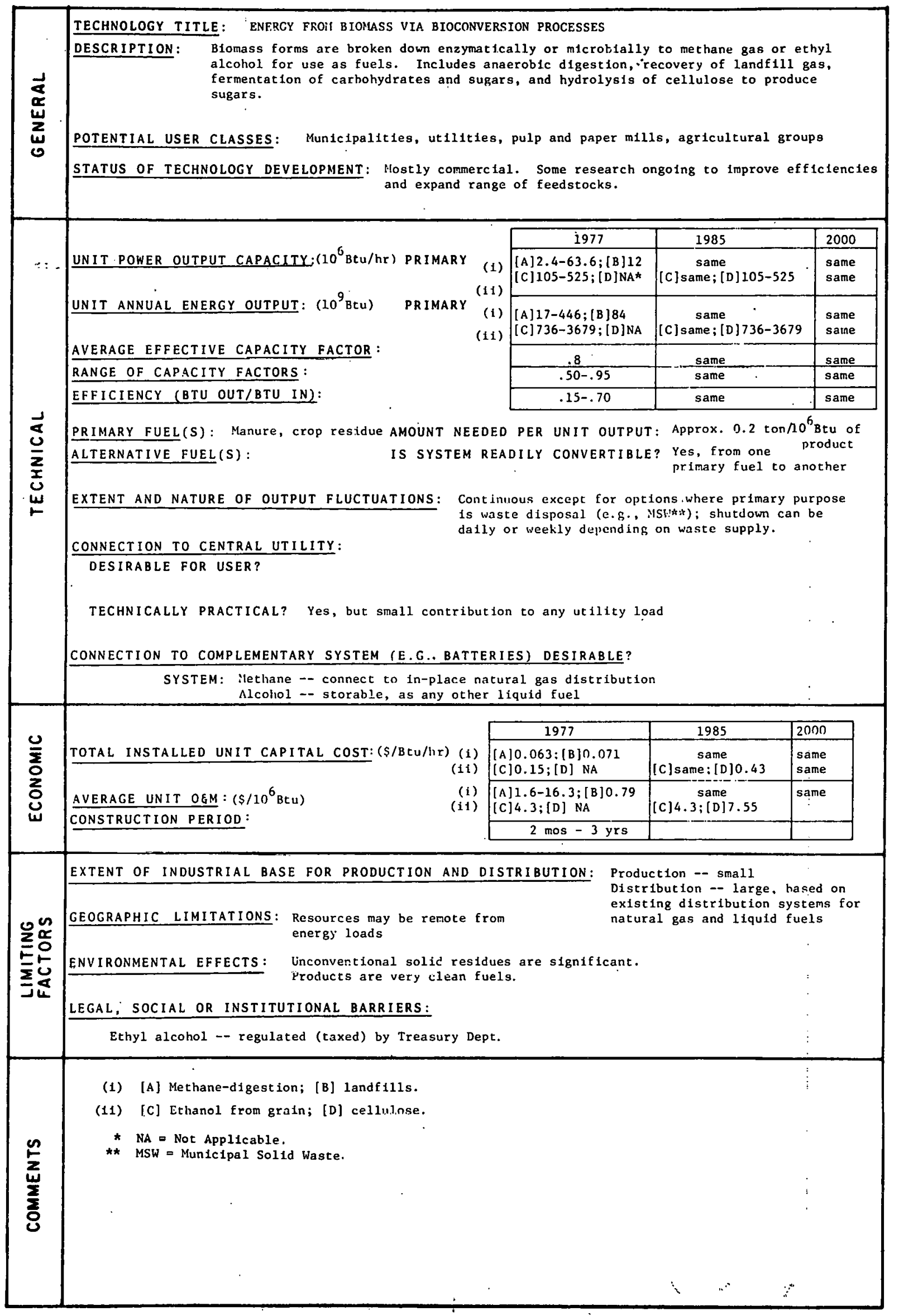


CHAPTER 9

ENERGY FROM BIOMASS VIA BIOCONVERSION PROCESSES

\section{Section 9.1: Introduction}

Fermentation is a general term referring to a group of processes whereby microbial activity under controlled conditions is used to transform organic material into desired end products. In the context of DES, the desired end products are substances that can be used as fuels for the purpose of generating electrical or motive power, or for space or domestic hot-water heating.

Biomass raw materials generally considered sultable for blological conversion into fuels include agricultural and maricultural crops, crop wood and feedlot residues, sewage sludge, and municipal solid waste. The most suitable fuel (In terms of ease of production and already established fuel markets) that can be produced from these materials by fermentation is methane gas.

Generally, only biomass having a high sugar or starch content can be converted directly into ethyl alcohol by anaerobic fermentation. In this specific type of fermentation process, yeast cells feed upon the biomass and convert the sugars or hydrolyzed starches into ethyl alcohol by means of a series of complex biochemical reactions. Because the biomass must have a high sugar or starch content, the primary feedstock for the production of ethyl alcohol has traditionally been edible crops (such as grains, sugar cane molasses, sugar beet molasses, and. fruits) rather than crop or wood residues.

Section 9.2: Technical Discussion

A. Methane

1. Anaerobic Digestion of Animal Residues and Aquatic Biomass Anaerobic digestion is an attractive process for converting biomass residues into fuel because it is a relatively simple and well understood process that can accept a wide variety of organic waste materials. 
Briefly, anaerobic digestion is the decomposition of organic materials by micro-organisms, in the absence of oxygen, to carbon dioxide and methane. The decomposition occurs in two steps: (1) the breakdown of the organic matter to organic acids (mainiy acetic acid) by one type of micro-organism, and (2) the conversion of these acids to methane and carbon dioxide by another type of micro-organism. The second step usually proceeds more slowly than the first. (1) The overall reaction is assumed to be: ${ }^{(1)}$

$\mathrm{C}_{m} \mathrm{H}_{\mathrm{a}} \mathrm{O}_{\mathrm{b}}+\left[\mathrm{m}-\frac{\mathrm{a}}{4}-\frac{\mathrm{b}}{2}\right] \mathrm{H}_{2} \mathrm{O} \rightarrow\left[\frac{\mathrm{m}}{2}-\frac{\mathrm{a}}{8}+\frac{\mathrm{b}}{4}\right] \mathrm{CO}_{2}+\left[\frac{\mathrm{m}}{2}+\frac{\mathrm{a}}{8}-\frac{\mathrm{b}}{4}\right] \mathrm{CH}_{4}$

Most biomass has a high cellulose content. The anaerobic digestion of cellulose $\left(\mathrm{C}_{6} \mathrm{H}_{10} \mathrm{O}_{5}\right)_{n}$ would produce carbon dioxide and methane in equal volumetric proportion. The complete digestion of 1 pound of cellulose would yleld 14.1 cublc feet of dry gas* at $60^{\circ} \mathrm{F}$, which would have a heating value of $505 \mathrm{Btu} / \mathrm{ft}^{3}$. (1)

Gas generation is often calculated on the basis of the volatile solids content of the feed which is quantified as the weight of solids that is lost from a sample when it is heated to and held at $600^{\circ} \mathrm{C}$. The volatile solids are that fraction which is generally amenable to attack by micro-organisms. One pound of volatile solids having the general chemical composition of $\mathrm{C}_{6} \mathrm{H}_{8.9}{ }^{0} 4.1$ will theoretically require 9.212 pounds of water and will provide 0.875 pound of carbon dioxide and 0.337 pound of methane.

In practice, the degree of conversion is much less than $100 \%$ and the gas composition will vary somewhat. The degree of conversion usually ranges from $25-70 \%$ (equivalent to gas production rates of 3.5 to $9.9 \mathrm{ft}^{3} /$ pound of biomass). $(2,3)$ In addition to the specific nature of the feed, factors that influence the degree of conversion include temperature, degree of mixing, residence time, $\mathrm{pH}$, solid concentrations, and the amount of nutrients and toxic materials.

Usually, the gas composition w111 range from 40-60\% methane by volume, with carbon dioxide being the other major component. The prin-

* Contalning approximately $50 \%$ methane. 
cipal impurity present in small concentration is hydrogen sulfide, which 1s formed from the small amount of sulfur contained in most biomass wastes. Hydrogen sulfide is of concern because of its ability to polson. catalysts (or fuel cell electrolytes) and its corrosive action on many metallic surfaces.

The digestion process is relatively simple in terms of physical equipment -- a digester, which is an appropriately sized agitated tank, to which water and biomass are added; dewatering and/or drying equipment, to reduce the mass and volume of the digested residue prior to disposal; and often gas cleaning and storage factlities. $(3,4,5)$

The anaerobic digestion of biomass materials has been studied by a number of researchers. $(2,6,7,8,9)$ Presently, there is a considerable amount of variation in the reported values of gas production by type of materlal. Most 11kely these differences are caused by inconsistency in the basis for reporting results. Factors which importantIy influence the degree of conversion are temperature, residence time, agitation, and the volatile solids content of the biomass waste. Data on these parameters are not always completely documented, making correlations between references difficult. However, sufficient data are available for the preparation of preliminary designs and cost estimates for digestion systems.

\section{a. Temperature}

Temperature has a strong influence on both the rate of gas production and the degree of conversion of biomass to gas. $(6,7,8$,$) As an$ example, with a given retention time, say 20 days, an anaerobic digester operating at a temperature of about $130^{\circ} \mathrm{F}$ will produce gas at a rate which is generaliy three times that of a digester operated at $60^{\circ} \mathrm{F}$. (6) The relationship between temperature and rate of gas generation is somewhat different in different temperature regimes. $(1,10)$ Mesophillic microorganisms are most active at temperatures below $110^{\circ} \mathrm{F}$ and have a maximum activity at about $94^{\circ} \mathrm{F}$. Above $110^{\circ} \mathrm{F}$ thermophillic microorganisms are most active and have a maximum activity at about $135^{\circ} \mathrm{F}$. The gas production rate falls off quite rapidly when the temperature exceeds $135^{\circ} \mathrm{F} .{ }^{(6)}$ 
b. Retention Time

Retention time also has a large influence on the degree of conversion. $(6,7)$ At lower temperatures, digestion is still proceeding at a significant rate after 20 days, and many systems have been built which provide more than 50 days' residence time. At elevated temperature, digestion is nearly complete in 20 days. The optimum residence time for a particular system would be determined by balancing the value and avallabllity of the blomass waste and cost of the digester.

c. Degree of Agitation

The degree of agitation also has a large influence on the degree of conversion at all temperatures. Systems have been operated with continuous agitation, $(6,7,9)$ intermittent agitation, $(9)$ and no agitation. $(2,4,5)$ Continuous agitation can double the degree of conversion relative to no agitation. The disadvantage is that the agitation consumes power and will increase operating costs. Agitation can be provided by mechanical mixers or by gas recirculation using a compressor and a suitable static mixing device.

\section{d. Solids Concentration}

The solids concentration of the slurry being digested is also important. Since the nonvolatile solids are essentlally inert materials which do not influence the digestion reactions, the solid concentration is usually expressed in terms of the volatile solids, which for manure and crop residues are generally about $70 \%$ and $90 \%$, respectively. $(2,5,11,12)$

$$
\text { e. } \mathrm{pH}
$$

The preferred $\mathrm{pH}$ range for digestion is in the range of 6.6 to $7.6 .(1,2)$ Normally, if no control is provided, the $\mathrm{pH}$ falls (becomes acidic) because $\mathrm{CO}_{2}$ forms bicarbonate by reaction with the hydroxyl Ion. (3) Alkaline materials, such as limestone, lime, or soda ash, can be used to control the $\mathrm{pH}$ by neutralizing or buffering this tendency. This condition, which favors the reaction and/or dissolution of $\mathrm{CO}_{2}$, tends to increase the concentration of methane in the gas-phase product. 


\section{f. Nutrients}

The micro-organisms require nitrogen, phosphorus, and some trace elements for optimum activity. $(1,2,3,5)$ Generally, animal wastes contain most of these nutrients. Plant wastes may not contain all of them. Nutrients, particularly nitrogen, may have to be added for opt1mum activity.

\section{g. Toxic Materials}

A number of toxic substances must be excluded from the process because they destroy the micro-organisms. $(1,2,3)$ Among these are oxygen, high concentrations of salts, ammonia, sulfides, and toxic organics, and low concentrations of the soluble heavy metal lons, such as copper, nickel, zinc, and hexavalent chromium.

\section{Methane from Landfills}

Solid-waste disposal sites are a potential source of energy in the form of a methane-containing gas stream which can be captured via strategically located wells within the site. Three ongoing projects in California are typical of such operations. $(13,14,15)$ The chemistry of the decomposition of blomass materials is the same as that described above in Section 9.2A.1. The princlpal difference between the two techniques is that the environmental conditions of the landfill are not practically controllable. Therefore, ylelds, production rates, and other parameters of interest cannot be controlled or optimized.

A landfill gas-recovery facillty would typlcally include several wells, a piping system to carry the collected gas to a gas purification system, and the purification system. The depth of the wells and rate of gas removal are limited by the allowable rate of air infiltration since infiltration dilutes the product gas and lowers its value.

The purification system is conventional and uses sorbents for removal of $\mathrm{CO}_{2}$ and water from the raw gas. (13) A compressor is usually required to withdraw the gas throught the wells, into the treatment system, and eventually into a gas distribution network or to a captive user.- At City of Industry, California, it is anticipated that about $400 \mathrm{ft}^{3} / \mathrm{min}$ 
of landfill gas ( $50 \%$ methane) can be sustained for up to 15 years.

This $1 \mathrm{~s}$ equivalent to about $12 \times 10^{6} \mathrm{Btu} / \mathrm{hr}$. For comparison, the output from Mountain View, California, is projected at about $11 \times 10^{6} \mathrm{Btu} / \mathrm{hr}$. (13)

B. Ethyl Alcoho1 - Fermentation of Blomass Crops and Residues

The basic reaction in the production of ethyl alcohol by fermentation is the conversion of sugars to ethyl alcohol by the microblal activity of yeast. Alcohol-tolerant yeast strains of Saccharomyces cerevisiae are usually used. They convert hexose sugars, such as glucose, fructose, sucrose, mannose, and galactose, to ethyl alcohol and carbon dloxide, theoretically yielding $51 \%$ and $49 \%$ by weight, respectlvely, as expressed by the equation: $(16)$

$$
\mathrm{C}_{6} \mathrm{H}_{12} \mathrm{O}_{6} \rightarrow 2 \mathrm{C}_{2} \mathrm{H}_{5} \mathrm{OH}+2 \mathrm{CO}_{2} \text {. }
$$

Organic materials, such as molasses, that contain fermentable sugars can be fermented directly, merely by mixing with water, adding yeast and nutrients, and adjusting environmental conditions such as $\mathrm{pH}$ and temperature. After alcohol accumulates to a sufficlent concentration, the fermented mash is distilled. (16)

When ethyl alcohol is produced from grain, an additional step 1s required because none of the commerclal yeasts is capable of fermenting starch directly. The grain must first be milled, mixed with water, and then cooked to hydrate and gelatinize the starch into a mash. Malt or mold enzyme preparations are added to enzymatically convert the mash into fermentable sugars. The resultant liquor is fermented into alcohol using yeast. The unconverted materials, referred to as distillers' dried grains, are a proteln-rich byproduct, readily marketed as an anfmal feed.

While the production of ethyl alcohol from sugar- and starchcontaining food crops dates back many centurles, ethyl alcohol production from biomass residues involves relatively new technology and is still the subject of research. The main problem is the conversion of the biomass into sugars that can be fermented by yeast. The cellulose in many plants is difficult to break down because of its crystalline nature and because 
in many plants (particularly trees) it is bound into a matrix of lignin, a substance particularly resistant to microblal degradation. A number of processes are avallable for the degradation of cellulosic materials. into sugars. These are briefly described in the following paragraphs. Acid Hydrolysis. It has been known for many years ${ }^{(17)}$ that sulfuric acid can hydrolyze cellulose to glucose when the mixture is heated to about $130^{\circ} \mathrm{C}$ under pressure. The solution must be neutralized to allow the growth of yeast when inoculated. The process has drawbacks, including: extensive pretreatment (size reduction and heating) of the biomass material; high acid costs; the need for corrosion-resistant, pressurized equipment; and the pollution problems associated with the disposal of moderately concentrated salt solutions from the neutralization step. Convesse, et al. (18) have noted that a promising area for improvement of the process would be the development of a plug flow reactor. The improvements would be realized in terms of higher sugar ylelds and greater heat conservation.

Enzymatic Saccharification. It is generally recognized by researchers in this area that the conversion of cellulosic material into sugars by enzymatic action is a more promising process because of its efficiency at low concentrations under mild conditions of temperature and $\mathrm{pH}$. A conceptual enzymatic saccharification process is that of Wilke. (19) The cellulose material is first pulverized, heated and sterilized, and cooled. It is then fed to a series of three mixerfilters where it countercurrently contacts the product sugar solution to recover about $95 \%$ of the enzyme. The solids and recovered enzyme then pass to the five-stage agitated digester where they are held for 40 hours at $45^{\circ} \mathrm{C}$ at a solid/liquid ratio of $1 / 20$. The sugar concentrates to a level of about $4 \%$ under these conditions. The makeup enzyme is produced in a biosynthesis system consisting of a growth fermentor and several induction fermentors where the fungus Trichoderma viride ${ }^{(20)}$ and a medium consisting of product sugars, protein, and minerals is employed. Spent solids from the hydrolyzer system are utilized in a boiler to produce the necessary process heat for both the hydrolization and the subsequent alcohol fermentation plant. 
To apply the above described hydrolysis technologies to the organic fraction of MSW, one would preprocess the MSW for the removal of inorganic materials which may be recyclable. The purpose would be to maximize operational control of the hydrolysis process, to minimize the size of the equipment, and to retain the inorganics in a relatively dry state. The chemistry of the technology would be unchanged. In fact, some of the technology as described above has been developed using newsprint as the cellulose source.

Ethyl alcohol from biomass is enjoying substantial growth as a fuel, particularly in automotive use. $(21,22,23)$ Gasohol, a mixture of $10 \%$ ethyl alcohol in gasoline, can be burned in internal combustion engines with no changes to the carburetor or other engine components and with no substantial change in mileage performance. There is, however, modest octane benefit when ethyl alcohol is added to most gasoline blends and gasohol is often able to compete as a premium fuel. Most of the ethyl alcohol belng produced for gasohol comes from corn processed in cunventional plants originally designed to produce beverage-grade alcohol.

The Archer-Daniels-Midland Company, currently the nation's largest producer of ethyl alcohol for fuel use, has its Decatur, Illinols, plant operating near its nameplate capacity of 75,000 gallons per day or $2 / \times 10^{6} \mathrm{gal} / \mathrm{yr}$. (23) While it is feasthle to run a plant to produce small quantities of ethyl alcohol, most ventures being considered fall in the range of $10-50 \times 10^{6} \mathrm{gal} / \mathrm{yr} .(2,2,23)$

\section{Section 9.3: Economics Discussion}

\section{A. Methane}

Many peripheral factors affect the economics of producing energy In the form of methane by anaerobic digestion, such as the preparation of the biomass feed, cleaning of the gas generated (particularly if it is to be pumped into a pipeline or used in fuel cells), disposal of the digested residues, and treatment of the organically contaminated supernatant, if necessary. The extent of gas storage requirements also affects the overall cost Importantly. 
Dynatech $^{(12)}$ has estimated (Table 9-1) the cost of methane production from manure in 1977 and has evaluated the sensitivity of the results from several viewpoints. The baseline design was a 10,000-head (cattle) feedlot using an environmental feedlot design and a continuously stirred tank reactor (CSTR) digester. An environmental feedlot employs a grate beneath the animals to factlitate the frequent removal of manure from the feedlot, which minimizes the loss of volatile material from the manure and maximizes methane yield. The estimated capital investment for the manure recovery and methane $\left(98,600,000 \mathrm{ft}^{3} / \mathrm{yr}\right.$, approximately $98,600 \times 10^{6} \mathrm{Btu} / \mathrm{yr}$ ) production system was $\$ 694,000$ (about $\$ 0.063 / \mathrm{Btu} / \mathrm{hr}$ of output), excluding engineering fee and contingency.

TABLE 9-1

1977 COST OF METHANE PRODUCTION FROM MANURE

Feedlot Size, Head No. of CSTR Methane Production Annual Gas

\begin{tabular}{|c|c|c|c|c|c|}
\hline \multirow[t]{2}{*}{$\begin{array}{l}\text { Feedlot } \\
\text { Size, Head }\end{array}$} & \multirow[t]{2}{*}{ Type } & \multirow[t]{2}{*}{$\begin{array}{l}\text { No. of CSTR } \\
\text { Reactors } \\
\end{array}$} & \multicolumn{2}{|c|}{ Cost $(\$ / M c f)^{(1)}$} & (Mcf) \\
\hline & & & O\&M & Tota1 & \\
\hline 10,000 & Environmental & One & 3.75 & 5.17 & 98.6 \\
\hline 10,000 & DArt & One & 16.26 & 22.45 & 20.9 \\
\hline 10,000 & Concrete & One & 10.07 & 13.15 & 31.6 \\
\hline 30,000 & Environmental & One & 2.26 & 3.17 & 278.4 \\
\hline 60,000 & Environmental & One & 1.81 & 2.54 & 556.9 \\
\hline 100,000 & Environmental & One & 1.62 & 2.24 & 928.1 \\
\hline 10,000 & Environmental & Optimum & 3.52 & 4.93 & 107.9 \\
\hline
\end{tabular}
Reactors Cost $(\$ / M c f)(1)$ Production

(1) $\$ /$ Mcf is approximately equal to $\$ / 10^{6}$ Btu for methane. SOURCE: Reference 12 .

The estimated cost of methane from the Mountain View, Cal1fornia, landf 111 is $\$ 2.79 / 10^{6} \mathrm{Btu}$ of which $\$ 0.79 / 10^{6} \mathrm{Btu}$ is for operation and maintenance. The capital investment for a system to recover $97,650 \times 10^{6}$ $\mathrm{Btu} / \mathrm{yr}$ would be $\$ 788,000$ (about $\$ 0.071 / \mathrm{Btu} / \mathrm{hr}$ ). (13)

For comparison, in 1977 natural gas was selling between $\$ 1.07$ and $\$ 2.98 / \mathrm{ft}^{3}$ in the continental United States. (24) 


\section{B. Ethyl Alcohol}

Development Planning and Research Associates estimated

the cost of producing ethanol via conventional fermentation in 1977.

A grain-based plant to produce 20 million gallons of ethanol per year (approximately as large as any plant module operating in the United States) would cost about $\$ 31.3 \mathrm{million}(\$ 1.56 / \mathrm{gal} / \mathrm{yr}$ or $\$ 0.15 / \mathrm{Btu} / \mathrm{hr}$ capltal investment). If grain (corn) were charged at $\$ 2.50 /$ bushel and byproduct distillers' dried grains were credited at $\$ 110 /$ ton, the cost of ethanol production would be $\$ 1.35 / \mathrm{gal}\left(\$ 16.00 / 10^{6} \mathrm{Btu}\right)$, including $0 \& \mathrm{M}$ at $\$ 0.363 / \mathrm{gal}(\$ 4.30 /$ $\left.10^{6} \mathrm{Btu}\right)$. This compares with a maximum selling price of $\$ 1.15 / \mathrm{gal}$ of industrial ethanol ( $95 \%$ proof) In 1977 , most of which was derived from ethylene.

Gince 1978, acveral etates have waived all or a portion of their gasoline taxes for gasohol. (22) The Federal Government has also begun subsidizing gasohol by waiving its $4 \mathrm{c} /$ gallon excise tax which amounts to $\$ 0.40 /$ gallon of ethyl alcohol.

Wilke (19) estimated the cost of producing sugars from blomass via the advanced enzymatic saccharification process described earlier. Eight hundred and eighty-five tons/day of cellulosic biomass (newsprint) would be converted to 238 tons/day of sugars in a $4 \%$ solution. The estimated fixed capital investment is $\$ 23.4$ million and the overall production cost is $\$ 0.052 / 1 b$ of sugars. A similar plant (including acid pretreatment to increase sugar production) to convert wheat straw to a like quantity of sugars would cost about $\$ 30$ million to construct and the cost of sugars would be about $\$ 0.047 / 1 \mathrm{~b}$.

W11ke (19) further estimated the cost of converting these sugars to ethanol (about $6.9 \times 10^{6} \mathrm{gal} / \mathrm{yr}$ or $585 \times 10^{9} \mathrm{Btu} / \mathrm{yr}$ ) by fermentation by Saccharomyces cerevisiae. The plant, comprising sugar concentration, fermentation, distillation, and yeast recovery, would cost about $\$ 5.4$ m111ion. When sugars are charged at $\$ 0.052 / 1 \mathrm{~b}$ (as above), the cost of $95 \%$ ethanol is estimated to be $\$ 1.05 / g a l$. The overall capital investment for the ethanol-from-cellulose process totals $\$ 28.8$ million $(\$ 0.43 /$ $\mathrm{Btu} / \mathrm{hr}$ of ethanol). Of the total production cost of $\$ 1.05 / \mathrm{gal}$ ( $\$ 12.43$ / $\left.10^{6} \mathrm{Btu}\right)$, feedstock MSW was charged at zero value; O\&M amounts to $\$ 0.64 /$ gal $\left(\$ 7.55 / 10^{6}\right.$ Btu). 
Section 9.4: Limitations

Methane from anaerobic digestion and from landfills can make a contribution to local energy needs where there may be sufficient resources available. However, the total contribution to the national energy requirements would be severely constrained by the availability of resources. For example, if $20 \%$ of all cattle manure (132 million head total population) were converted to methane at $9.28 \times 10^{6} \mathrm{ft}^{3}$ per 1000 head, approximately 0.24 quad of energy would be produced. (12) Similarly, If methane could be produced from landfills at the rate projected for City of Industry, California $\left(3 \times 10^{9} \mathrm{ft}^{3}\right.$ from $3.5 \mathrm{million}$ tons of solid waste over 19 years ${ }^{(14)}$ ), the entire estimated U.S. solid waste resource of 134 million tons (Chapter 7) would be capable of producing only about 0.11 quad. It should also be recognized that an important consideration in the recovery of methane from landfills is of ten the protection of surrounding areas from subsurface migration of explosive gas.

Crop residues, wood residues, inedible plants, and many other types of cellulosic biomass usually have low alternative value relative to the value of their contained energy. Thus, in producing energy from these materials, there would generally be few competing non-fuel alternative uses for the raw material. When considering the production of methane or ethyl alcohol from crop wastes, one should recognize that the seasonal avallability of feedstock for the digestion process creates both economic penalties and technological difficulties caused by irregular capacity utilization. Generally, the limitations of feedstock availability would be consistent with those discussed in Chapter 7. Furthermore, regardless of the type of blomass used in the digestion process, in most cases a significant amount of digested residue or sludge is produced, thus requiring some solld waste disposal. However, disposal of these materials on agricultural land can often have the benefit of restoring nutrient and/or soll-conditioning value.

Enzymatic conversion of cellulose is not yet a we11-developed technology. In addition, the primary use of ethyl alcohol today, when produced by fermentation, is for alcoholic beverages, which renders its 
value far greater than that of its energy content. Cost estimates for enzymatic processes should be viewed with a degree of caution. The economics can vary greatly with the type of biomass used, and unforeseen technical problems might significantly increase the production costs. As in the case of methane generation from biomass, maintaining a steady supply of biomass material could be a problem with regard to operating and crop storage costs and maintaining optimum plant throughput.

An extremely important competing factor is that enzymatic conversions are also belng used for the production of single-cell proteins, which have considerable value as an animal feed. Thus, a concerted attempt to expand both concepts commercially could present some serious growth limitations. With these limitations in $\mathrm{mlnd}$, it is difficult to envision ethyl alcohol produced by fermentation being used to any significant extent as a competitive liquid fuel in the United States.

Ethyl alcohol produced from grain and molasses (i.e., biomass sources) is usually not competitive with ethyl alcohol produced synthetically from ethylene (see Economics Discussion). In 1977 only about $6 \%$ of all industrial ethyl alcohol production in the United States was via fermentation. (26) Thus, significant technical advances appear necessary before ethyl alcohol can become an economical energy form.

Use of ethyl alcohol from renewables has the potential benefit of Improving farm prices and the general health of U.S. agriculture. However, food prices -- most corn is used for beef production -- hiay be significantly impacted. As an example, if $5 \%$ of the U.S. consumption of gasoline were displaced by ethyl alcohol, about 5.8 billion gallons would be required. (22) A yield of 2.6 gallons of alcohol per bushel of corn would require about 2.2 billion bushels of feedstock. This compares with a $1976 \mathrm{U} . \mathrm{S}$. crop of 5.7 billion bushels, ${ }^{(27)}$ but this alcohol can also be produced from other blomass sources of starches and sugars.

Ethyl alcohol which is intended or otherwise suitable for human consumption is regulated by the U.S. Treasury Department's Bureau of Alcohol, Tobacco, and Firearms (ATF). Ethyl alcohol which is produced for industrial or fuel use must be rendered unfit for human con- 
sumption (denatured) by use of a small quantity of any of a number of denaturants, such as one part gasoline in one hundred parts of alcohol.

Methane and alcohol fuels discussed in this chapter are generally considered relatively clean fuels for most applications. For the most: part they are at least as environmentally acceptable as the fuels they would displace.

There is considerable controversy as to whether fuel-grade ethyl alcohul requires a grcater energy input for production than can be obtained by burning it as fuel. $(29,30)$ The net energy loss depends in large part on the methodology used in the energy analysis. (30) Future technological developments should result in improved energy balance. 
THIS PAGE

\section{WAS INTENTIONALLY \\ LEFT BLANK}




\section{REFERENCES}

1. Pohland, F.G., ed. Anaerobic Biological Treatment Processes. Washington, D.C.: American Chemical Society, 1971. (Advances in Chemistry Series $\#_{105)}$.

2. Alich, J.A., et al. An Evaluation of the Use of Agricu1tural Residue as an Energy Feedstock. Vol. I. Prepared by Stanford Research Institute for National Science Foundation, July 1976. NTIS Report No. PB 260763.

3. Ad Hoc Panel of the Advisory Committee on Technology Innovation. Methane Generation from Human, Animal, and Agricultural Wastes. Washington, D.C.: National Academy of Sciencee, 1977.

4. Prasad, C.R., et al. Economic and Political Weekly 9:1347, 1974.

5. Singh, R.B. "The Bio-Gas Plant; Generating Methane from Organic Waste." Compost Science 13(1):20, 1972.

6. Pfeffer, J.T. "Temperature Effects on Anaerobic Fermentation of Domestic Refuse." Biotechnology and Bioengineering 16:771, 1974.

7. Pfeffer, J.T., et al. "Energy from Refuse by Bioconversion, Fermentation and Residue Disposal Processes." Resource Recovery and Conservation $1: 295,1976$.

8. Trevelyan, W.E. "Renewable Fuels, Ethanol Produced by Fermentation." Tropical Science $17(1): 1,1975$.

9. Clausen, E.C., et al. "Converting Crops into Methane.". Chemical Engineering Progress 73(1):71, January 1977.

10. Jewe11, W.J., et al. Anaerobic Fermentation of Agricultural Residue: Potential for Improvement and Implementation. Final Report. Prepared by Cornel1 UnIvers1ty for the U.S. Department of Energy, February 1978. pp. $427 \mathrm{ff}$. NTIS Report No. HCP/T2981-07.

11. Lank, R. "Cattle, Swine and Chicken Manure Challenges Waste Disposal Methods." Water and Sewage Works $117(4): 134,1970$.

12. Ashare, E., et al. Fuel Gas Production from Animal Residue. Prepared by Dynatech.R/D Company, 1977. pp. 202 ff. NTIS Report No. C0O/2991-10.

13. James, S.C., et al. "Methane Production, Recovery, and Ut1lization from Landfills." Symposium on Energy from Biomass and Wastes, Institute of Gas Technology, Washington, D.C., August 14-18, 1978. pp. $317 \mathrm{ff}$. 
14. Stearns, R.P., et al. "Recovery and Utilization of Methane Gas from a Sanitary Landfill - City of Industry, California." Sympostum on Energy from Biomass and Wastes, Institute of Gas Technology, Washington, D.C., August 14-18, 1978. pp. $325 \mathrm{ff}$.

15. Rice, F.C. "Commercial Production of Pipeline Quality Gas at Palos Verdes Landfill." Symposium on Energy from Biomass and Wastes, Institute of Gas Technology, Washington, D.C., August 14-18, 1978. pp. 345 ff.

16. Peppler, H.J. Microblal Technology. New York: Reinhold Publishing Corporation, 1967 .

17. Kressman, F.W. The Manufacture of Ethyl Alcohol from Wood Waste. Washington, D.C.: U.S. Department of Agriculture, 1922: Bullet in 410.

18. Convesse, A.0., et al. Acid Hydrolysis of Cellulose in Refuse to Sugar and Its Fermentation to Alcohol. Hanover, New Hampshire: Thayer School of Engineering, Dartmouth College, June 1973.

19. Wilke, C.R. "Production of Sugars and Ethanol Based on the Enzymatic Hydrolysis of Cellulose." Fuels from Biomass Symposium, University of Illinots at Urbana-Champa1gn, Apr11 18-19, 1977.

20. Spano, L.A., et al. Enzymatic Hydrolysis of Cellulosic Wastes to Glucose. Natick, Massachusetts: U.S. Army, Nat1ck Development Center, September 1975.

21. Anderson, Earl V. "Gasohol: Energy Mountain or Moleh111?" Chem1cal and Engineering News 56:8, July 31, 1978.

22. "U.S. Presses Drive for Use of Gasohol." 0il \& Gas Journal 77:54, July 2, 1979.

23. Levy, R. "How Far Can Casohol Go?" Dun's Review 114:44, July 1979.

24. Winton, J.M. "Plant Sites 1979." Chemical Week 123(18):41, November 1, 1978.

25. Development Planning and Research Associates, Inc. Gasohol, Economic Feasibility Study. Lincoln, Nebraska: Energy Research and Development Center, University of Nebraska, July 1978.

26. Chemical Profiles. New York: Schnell Publishing Company, Inc., 1977.

27. Lipinsky, E.S., et al. Systems Study of Fuels from Sugarcane, Sweet Sorghum, Sugar Beets and Corn, Vol. IV: Corn Agriculture, Task 77. Final Report. Prepared by Battelle Columbus Laboratories for Energy Research and Development Administration, March 31, 1977. NTIS Report No. BMI-1957A (V.4). 


\section{REFERENCES (cont1nued)}

28. Department of the Treasury, Bureau of Alcohol, Tobacco and Firearms. Ethyl Alcohol for Fuel Use. Washington, D.C., September 1978. Information brochure. No. ATF $P$ 500.1.

29. Weisz, P.B. et al. "High-Grade Fuels from Blomass Farming:

Potentials and Constraints." Science 206(4414):24. October 5, 1979.

30. Chambers, R.S. et al. "Gasohol: Does It or Doesn't It Produce Positive Net Energy?" Sclence 206(4414):789. October 5, 1979.

31. "Lowering the Cost of Alcohol." Sclence 206(4414):41. October 5, 1979. 
CHAPTER 10

BIOMASS GASIFICATION AND LIQUEFACTION

Section 10.1: Introduction

Blomass may be converted to liquids and/or gases by pyrolysis, which is the breakdown of organic materials by the application of heat. Strictly speaking, pyrolysis takes,place in the absence of molecular oxygen. However, since the reaction of oxygen with a portion of the solid fuel is a conventent and commonly used method of supplying the necessary heat for pyrolysis, the term is also used in a less strict sense to mean the gasification or 1iquefaction of biomass materials in a controlled but deficient amount of oxygen.

Depending on the severity of the pyrolysis treatment, the products will be one or more of the following:

- hydrocarbon gaece,

- carbon monoxide,

- carbon dioxide,

- hydrogen,

- water,

- oil,

- ash, and

- char.

Generally, when the desired product is a fuel gas, the principal output is a gaseous mixture of somewhat controllable portions of the first five constituents. These can be converted, usually catalytically, to other fuels such as methanol or methane, or utilized directly for their energy value.

Section 10.2: Technical Discussion

A. Terrestrial Biomass Crops and Residues

There are numerous pyrolysis processes under development to produce gaseous fuels and one that produces a liquid fuel from cellulosic 
materials. (3) While many of these processes have been developed prtmartly to convert municipal wastes, they are also applicable to cellulosic materials of any type.

One process which has been researched is a mobile alr-blown pyrolysis converter for agricultural wastes. The system proposed by the Georgia Institute of Technology Engineering Experiment Station would be capable of converting up to 200 tons/day of wastes in the fteld Into about 45 tons of a char-oil mixture. (4) The chief advantage of such a system is potential savings in transportation costs of the agricultural waste to a central processing facility.

In principle, the prucess (munted on two large flacbed crallers) would pyrolyze wet cellulosic feedstock in a manner analogous to the vertical shaft concept of Purox (described below) using air as the oxidant. The major research and development need is to gain knowledge of the product fuel properties so that the use of an available or specifically designed combustor can be assessed.

A partial listing of additional biomass gasifier manufacturers in the United States is shown in Table 10-1. A more comprehensive directory of air gasifiers for blomass can be found in Reference 5, which also summarizes the proven status of air-gasifier technology. A good track record based on the development of necessary equipment along with the sales and service network remains to be demonstrated. Presentation of generalized costs is not warranted in this report because economic viability requires a unique set of clrcumstances. (5) often the economics are published only for such unique circumstances, e.g., low prices for feedstocks and other process requirements, and low capitalrelated costs (interest and profit) as is the case for the data presented on page 8-2 of Reference 5 .

\section{B. Municipal Solld Waste (MSW)}

The systems developed by Monsanto (Tandgard) and Torrax (a subsidiary of Carborundum Environmental Systems) produce a low heatingvalue gas that.is burned on-stte to generate steam in a waste-heat boller. 


\section{PARTIAL LIST OF BIOMASS GASIFIER MANUFACTURERS IN THE UNITED STATES}

\begin{tabular}{|c|c|c|c|}
\hline Manufacturer & Type & $\underline{\text { Status }}^{(1)}$ & $\begin{array}{l}\text { Input } \\
\left(10^{6} \mathrm{Btu} / \mathrm{hr}\right)\end{array}$ \\
\hline Applied Engineering, Orangeburg, SC & Updraft & $\mathbf{n}$ & 8 \\
\hline Biomass Fuel Conversion, Yuba City, CA & Downdraft & $\mathrm{D}$ & 14 \\
\hline Century Research, Gardena, CA & Updraft & $\mathrm{C}$ & 85 \\
\hline Davis Gasifier, U. of Calif., CA & Downdraft & $\mathrm{D}$ & 14 \\
\hline “DeKalb Agricultural Research, DeKalb, IL & Updraft. & I & 1.7 \\
\hline Forest Fuels, Keene, NH & Updraft & $\mathrm{C}$ & $1-12$ \\
\hline Foster-Wheeler, Livingston, NJ & Updraft & II & 50 \\
\hline Halcyon, E. Andover, NH & Updraft & $\mathrm{C}$ & 8 \\
\hline Pioneer Hi-Bred Inst., Johnston, IA & Updraft & {[} & 7 \\
\hline Woodex Corp., Eugene, OR & Updraft & C & 10 \\
\hline
\end{tabular}

(1) Status of project: C, Commercial -- at least one unit in field

$D$, Demonstration, Testing

(2) Fuel Consumption in tons/hr is approximately $10^{6} \mathrm{Btu} / \mathrm{hr} \div 16 \times 10^{6} \mathrm{Btu} / \mathrm{dry}$ ton.

SOURCE: Reference 6 . 
The process developed by Unton Carbide Corporation produces a medium heating value gas that can be shipped via pipeline to commercial and ut1lity users. A process that produces a fuel oil has been developed by Occidental Research Corporation, a subsidiary of Occidental Petroleum Company.

The following subsections describe these processes in some detail. Where they are to be used for converting terrestrial biomass crops and residues, the need, if any, to remove tramp components (i.e., larger than 1/4-inch metals, glass, and other non-biomass materials) is, of course, obviated with an inherent reduction in cost. However, efficiencies of conversion of the organic fractions of the feeds should vary only slightly depending most importantly on the moisture content of the reactor feed.

1. Monsanto Landgard System

In this process, $(7,8,9)$ wastes are shredded, conveyed to a storage silo, and subsequently fed to a rotary kiln where the material is gasified. The kiln is fired with the small quantity of ofl which is produced within the process. The burner is arranged to provide a countercurrent flow of gases and solids, thus exposing the wastes to progressively higher temperatures as they pass through the kiln. The finished residue is exposed to the highest temperature of $1800^{\circ} \mathrm{F}$ just before it is discharged from the kiln and quenched in a water-filled tank. The residue Includes ash and char and, in the case of MSW, glassy aggregate and metal scrap.

Gases leaving the pyrolysis reactor at a temperature of $1200^{\circ} \mathrm{F}$ have a low heating value $\left(120 \mathrm{Btu} / \mathrm{ft}^{3}\right)$, making off-site transportation uneconomical. Therefore, these gases are immediately mixed with air and burned in an afterburner to liberate the heat of combustion. The combustion gases then pass through the waste heat boilers where steam is generated for distribution. About 4800 pounds of steam are recovered from 1 ton of municipal solid waste (MSW). (7)

Monsanto started up a 1000-ton/day demonstration plant in Balt1more in 1975, but this plant has been troubled by its inability to meet 
particulate emission standards.

Monsanto has since withdrawn from the project, and the system has been shut down for the installation of an electrostatic precipitator to control the emissions. $(10,11)$

\section{Torrax System}

The Torrax system, $(7,8,9)$ which was developed by the Carborundum Company and is marketed by ANDCO, is a high-temperature slagging pyrolysis system which, like the Landgard system, reduces cellulose to a low heatingvalue fuel gas. In this process the feed is charged as received (without shredding) into a gasifier, a vertical shaft furnace designed so that the descending refuse and the ascending high-temperature gases become a countercurrent heat exchanger. As the solid descends, three distinct. process changes occur: (1) drying, where moisture is driven off;

(2) pyrolysis due to the heat transfer from the ascending hot gases to the solid mass; and (3) combustion in the hearth where some of the carbonaceous char is oxidized to carbon dioxide in the presence of preheated air.

In the Torrax system, approximately 160 pounds of this char per ton of feed processed need not be oxidized; it becomes a byproduct. About $15 \%$ of the gross product gas is recycled for preheating the processed air which is supplied to the gasifier hearth. The remaining $85 \%$ of the product gas, which has a heating value of $100 \mathrm{Btu} / \mathrm{ft}^{3}$ is injected into an afterburner or secondary combustion chamber where it is burned to completion. The heat which is thus released is then directed to a waste heat boiler where $i t$ is recovered as steam. About 45,000 $\mathrm{ft}^{3}$ of gas are available for each ton processed. Thus, in the Torrax. process, 1 ton of MSW yields about 4.5 million Btu.

The principles of the Torrax process were originally proven in a 75-ton/day pilot plant operated intermittently since 1971. This plant, which is located in Erie County, New York, has processed a mixture of municipal solid waste and dried sewage sludge. A 200-ton/day prototype plant is now undergoing startup in Luxembourg, and at least two other plants are scheduled to be built in Europe in the near future. (7) 


\section{Union Carbide Purox System}

The Purox system $(7,8,9,12,13)$ developed by Union Carbide Corporation employs a slagging pyrolysis process that uses oxygen in place of air. The process produces a clean fuel gas and a fused ash. The key element of this system is a vertical shaft furnace. Shredded b1omass is fed into the top of the furnace reactor through a piston airlock system, while oxygen is injected into the bottom of the furnace. The solid material falls through varying temperatures zones on its downward passage through the vertical reactor. Char forms as the solids devolatilize at the top of the reactor. The char is then reacted with oxygen in a lower section to produce a temperature of about $3000^{\circ} \mathrm{F}$. The rising hot gases then provide the necessary lieat for treating the incoming material in the upper portion of the reactor. When solid waste is fed to the gasifier, metals, glass, and other non-combustibles are transformed into a molten slag by the high temperatures generated in the lower portion of the reactor.

Gases leaving the reactor contain $30 \%$ to $40 \%$ moisture. Ihis 18 removed in a clean-up step along with ash, tars, and other condensible 1iquids. The heating value of the resulting gas is approximately 300 Btu/cublc foot. The gas is compressed to 35 psig for delivery to the customer. Each ton of processed solld waste ylelds abuul 22,000 cubic feet of gas. Thus, this process generates about $6.8 \mathrm{milli}$ ion Btu/ton of input waste.

Following an evaluation of the process in a pllot plant, Union Carbide constructed a 200-ton/day facility in 1974 in South Charlestown, West Virginia, which demonstrated the feasibility of the concept. It has subsequently been shown that it is feasible to co-dispose of sewage sludge and MSW in the Purox systems. Union Carbide's plans to market the system are presently uncertain, most likely because of the rapidly escalating estimated costs of the process.

4. Occidental Flash Pyrolysis System This system, $(7,8,9,12)$ in contrast to the pyrolysis systems discussed above, provides for a front-end separation that permits the 
recovery of a full spectrum of secondary materials from MSW. The Occidental process for municipal solid waste utilizes two stages of shredding, air classification, magnetic separation, drying, and screening to produce shredded refuse-derived fuel (RDF) for the pyrolyzer feedstock.

The shredded RDF, which represents about $60 \%$ of the input waste, or other clean biomass fuel, is fed into a vertical stainlesssteel reactor, along with hot residue consisting of ash and/or char that is a by-product from the pyrolysis reaction. The hot char provides the energy needed to pyrolyze the organics. The material present in the reactor consists of a mixture of char, ash, and the pyrolysis gases. If the gases are cooled rapidly before they can completely react, a portion of the gas is condensed into an oll-like liquid fuel. Both the remaining gas and the char are reused within the system.

The fuel product is a viscous, highly oxygenated combustible IIquid which may pose storage, corrosion, and handling problems. The average heating value of the pyrolytic "ofl" is about 10,500 Btu/pound, compared with $18,000 \mathrm{Btu} /$ pound for typical No. 6 fuel oil. The Occidental process ylelds about 0.24 ton of ofl per input ton of waste, or about 0.4 ton per ton of solid materlal fed to the pyrolyzer. Thus, the liquid pyrolysis system ylelds slightly more than $0.5 \mathrm{million}$ Btu/million Btu input.

The first prototype:plant, a 200-ton/day facility, has been built by San Diego County with the financial assistance of a demonstration grant from the U.S. Environmental Protection Agency and a subsidy from Occidental Petroleum. The system was run "sporadically from. December, 1977 to last March (1978)."(14) Except for a brief run, the operation has been suspended since that time because of "operating failures and rising costs."(14)

\section{Conversion of Gasifier Products to Methane (Substitute Natural Gas) or Methanol}

Gasifier products are generally rich in carbon monoxide, hydrogen, and methane. These gases can be converted by appropriate catalytic processes to either methane or methanol as described briefly below. 


\section{Shift Conversion}

Shift conversion, or the water-gas reaction, Involves the reaction of carbon monoxide to produce hydrogen:

$$
\mathrm{CO}+\mathrm{H}_{2} \mathrm{O} \rightarrow \mathrm{CO}_{2}+\mathrm{H}_{2} \text {. }
$$

The reaction is generally employed to adjust the ratio of hydrogen to carbon monoxide in a gas mixture, usually for the purpose of a downstream synthesis step such as for the production of methane-rich gas or methanol. The process is widely practiced and the technology of the fixed-bed catalytic system is well known. $(15,16)$

\section{Methanation}

Methanation involves the reaction of carbon monoxide (or carbon dioxide) and hydrogen to produce a gas containing more than $90 \%$ (dry basis) methane by:

$$
\mathrm{CO}+3 \mathrm{H}_{2} \rightarrow \mathrm{CH}_{4}+\mathrm{H}_{2} \mathrm{O} \text {. }
$$

Unt11 recently, these processes have been developmental, with the primary emphasis belng to produce substitute natural gas from coalderived gas streams. Most work on the fixed-bed catalytic approaches undertaken by the various developers has centered on the removal of heat from the highly exothermic reaction under controlled conditions. This generally involves recycling a portion of the product gas to the feed and/or staging of several reactors in series. Several developers are now offering their systems commercially.

\section{Methanol Synthesis}

Methanol has been synthesized chemically for many years to produce a product for chemical use. It is now being more widely considered as a fuel mainly for utility and transportation uses. (17) The methanol is usually synthesized by the reaction of hydrogen and carbon monoxide (or carbon dioxide) in a fixed-bed catalytic reactor (Imperial Chemical Industries, Ltd., process):

$$
\mathrm{CO}+2 \mathrm{H}_{2}+\mathrm{CH}_{3} \mathrm{OH} \text {. }
$$


Chem Systems, Inc., is developing a process which, if successful, will produce methanol in a lower-cost, 1iquid-phase catalytic reactor.

Section 10.3: Economics Discussion

Reported costs for plants to convert municipal solid waste via pyrolysis are tabulated comparatively in Table 10-2. The capital investments are for the flxed plant only and do not include items such as land, startup cost, construction loan interest, etc. It is noteworthy that the estimated capltal costs vary widely among references. They are highest (In 1977 dollars) for the most recent references. Byproducts, where recovered, are credited to the operating cost, but the energy value of the product fuel is not credited. All MSW is delivered at the plant gate and a credit for applicable tipping (disposal) fee, which can range from $\$ 5$ to $\$ 20$ per ton, is not included.

In assessing the operating costs per unit capacity, one must remember that the capital charges are included only to the extent of debt retirement. There are no provisions for land, other capital needs, or business risk. Further, the products are of limited utility unless (1) used in the immediate locality of the plant because of high transportation costs of gaseous fuels and steam, or (2) upgraded, e.g., hydrogenation of the Occidental pyrolysis oil, or methanation of the Purox gas. The costs of such upgrading can vary so widely as a function of the fuel properties, that $1 t$ is not worthwhile to estimate ranges. Moreover, the needs for pollution control equipment are not completely defined, and these needs can contribute substantially to the cost of implementing the technologies.

In applying these technologies to other biomass fuel sources, It is possible -- even likely -- that the plant requirements and costs will drop somewhat because of the relative homogeneity and absence of tramp materials in these fuels. However, the costs associated with obtaining alternative waste materfals or growing blomass fuels must be factored into the analysis. 
TABLE $10-2$

\section{COSTS OF PYROLYSIS OF MSW}

\begin{tabular}{|c|c|c|c|c|c|c|}
\hline \multirow[t]{2}{*}{ Process } & \multirow[t]{2}{*}{$\begin{array}{c}\text { Capacity } \\
\text { (Ton/Day MSW) }\end{array}$} & \multirow[t]{2}{*}{$\begin{array}{c}\text { Capital Cost } \\
(1) \\
(1977 \text { \$/Ton/Day MSW) }\end{array}$} & \multicolumn{3}{|c|}{$\begin{array}{l}\text { Efficiency } \\
\text { Operating Cost } \\
\text { MSW To Fuel (\%) }\end{array}$} & \multirow[t]{2}{*}{ Reference } \\
\hline & & & $\begin{array}{l}\text { \$/Ton } \\
\text { MSW } \\
\end{array}$ & $\begin{array}{l}\$ / 10^{5} \text { Btu } \\
\text { Product }\end{array}$ & & \\
\hline $\begin{array}{l}\text { Monsanto- } \\
\text { Landgard }\end{array}$ & $500-1000$ & 16,400 & 6.12 & $1.30^{(4)}$ & NA & 9 \\
\hline Torrax & 300 & 21,300 & $\mathrm{NA}^{(5)}$ & NA & $40-60$ to steam & 9 \\
\hline Purox & $\begin{array}{l}500-1000 \\
200-1000 \\
1000\end{array}$ & $\begin{array}{l}51,300-76,900 \\
15,200 \\
32,100\end{array}$ & $\begin{array}{l}\text { NA } \\
5.39 \\
17.35\end{array}$ & $\begin{array}{c}\text { NA } \\
N A \\
2.45\end{array}$ & $\begin{array}{l}\text { NA } \\
\text { NA } \\
66\end{array}$ & $\begin{array}{r}3 \\
9 \\
12\end{array}$ \\
\hline $\begin{array}{l}\text { Occidental } \\
\text { Research }\end{array}$ & $\begin{array}{l}1000-1500 \\
150-2000\end{array}$ & $\begin{array}{r}64,500-82,500 \\
9,900\end{array}$ & $\begin{array}{l}\text { NA } \\
4.87\end{array}$ & $\begin{array}{c}\text { NA } \\
0.97\end{array}$ & $\begin{array}{r}\text { NA } \\
\sim 50\end{array}$ & $\begin{array}{l}3 \\
9\end{array}$ \\
\hline & $\begin{array}{l}1000 \\
1000-1500\end{array}$ & $\begin{array}{l}28,400 \\
50,6010-66,000\end{array}$ & $\begin{array}{c}10.58 \\
\text { NA }\end{array}$ & $\begin{array}{c}2.5 \mathrm{C} \\
\mathrm{MA}\end{array}$ & $\begin{array}{l}46 \\
\text { NA }\end{array}$ & $\begin{array}{r}12 \\
3\end{array}$ \\
\hline
\end{tabular}

(1) Capital costs updated from reference using the Chemical Enginee-ing Plant Cost Index.

(2) Operating costs updated from reference at $6 \%$ per year.

(3) Assumes $10 \times 10^{6} \mathrm{Btu} / \mathrm{ton}$ of raw MSW and the conversion effictency shown.

(4) Assumes $50 \%$ efficiency as a basis for comparison on $1 \mathrm{y}$.

(5) NA = Not Available. 


\section{Section 10.4: Limitations}

In addition to any economic constraints or competitive factors which may defer implementation of pyrolysis options, the finiteness of the resource base (discussed in Chapter 7) is a limiting factor.

The technology is presently in a very early stage of pilot plant testing and demonstration. A few small-scale gasifiers are operating successfully in the field, but most of the activity remains at the pilot plant level. Larger-scale MSW converters have suffered technical setbacks and are not progressing into commercialization at the rate originally hoped. 


\section{THIS PAGE}

\section{WAS INTENTIONALLY \\ LEFT BLANK}




\section{REFERENCES}

1. Morrison, R.T., et al. Organic Chemistry. 2nd edition. Boston, Massachusetts: Allyn and Bacon, Inc., 1966.

2. Lamb, T.J. "Fundamentals of Pyrolysis." Preprint. International Symposium on Energy Recovery from Refuse, 1975. Avallable from the author c/o Arthur D. Little, Inc., Acorn Park, Cambridge, Massachusetts.

3. Bechtel Corporation. Edison Coordinated Joint Regional Solid Waste Energy Recovery Project. San Francisco, California, Apr11 1977.

4. Milton, E., et al. Engineering and Economic Analysis of Waste to Energy Systems. Prepared by Ralph M. Parsons Co. for Environmental Protection Agency, May 1978. NTIS Report No. PB 285797.

5. Solar Energy Research Institute. Retrofit '79. Proceedings of a Workshop on Air Gasification, Seattle, Washington, February 2, 1979.

6. Reed, T.B., et al. "Technology and Economics of Close-Coupled Gas1fiers for Retrofitting Gas/011 Combustion Units to Biomass Feedstock." React '78. The Biomass Energy Institute, Inc. Winnipeg, Manitoba, Canada, October 3-4, 1978 .

7. Stanford Research Institute. Program Definttion for Fuels from Biomass. Prepared for the California Energy Resources Conservation and Development Commission, Sacramento, California, 1976.

8. Snyder, N.W. "Pyrolysis of Municipal Solid Waste to Fuels and Chem1cals." AIChE Symposium Series 73(162):150, 1977.

9. Midwest Research Institute. Resource Recovery, Catalogue of Processes. Washington, D.C.: Council on Environmental Quality, February 1973.

10. St. Clair, C.W. "Resource Recover Update." Pollution Engineering 10(9):44, September 1978.

11. Haslbeck, J.L., et al. Source Imission..Tests at the Fialtimore Demonstration Pyrolysis Facility. Prepared by TRW, Environmental Engineering Division for the Environmental Protection Agency, December 1978. NTIS Report No. BP 292113.

12. Bechtel Corporation. Fuels from Municipal Refuse for Ut1lities, Technology Assessment. Prepared for Electric Power Research Institute, Pa1o Alto, California, March 1975.

13. Mathematics Sclences Northwest, Inc. Feasibility Study: Conversion of Solid Waste to Methanol or Ammonia. Seattle, Washington: City of Seattle, Department of Lighting, September 6, 1974. 


\section{REFERENCES (continued)}

14. "Pyrolysis Failure." Engineering News Record 201:18, July 27, 1978.

15. Battelle Pacific Northwest Laboratories. The Gasification of Coal. A Battelle Energy Program report. Richland, Washtngton, July 1974. pp. $1 \mathrm{ft}$.

16. Arthur D. Little, Inc. Assessment of Fuels for Power Generation by Electric Utility Fuel Cells. Prepared for Electric Power Research Institute, October 1975. EPRI Report No. EPRI 318.

17. Hagen, D.L. Methano1: Its Synthesis, Use as a Fue1, Economics, and Hazards. Thesis prepared for University of Minnesota, December 1976. NTIS Report No. NP-21727.

18. Chem Systems, Inc. L1quid Phaoc Synthesis of Mellanol. Incerlm Report. Prepared for Electric Power Reocarch Instilute, May 1978. EPRI Report No. EPRI AF-693. 


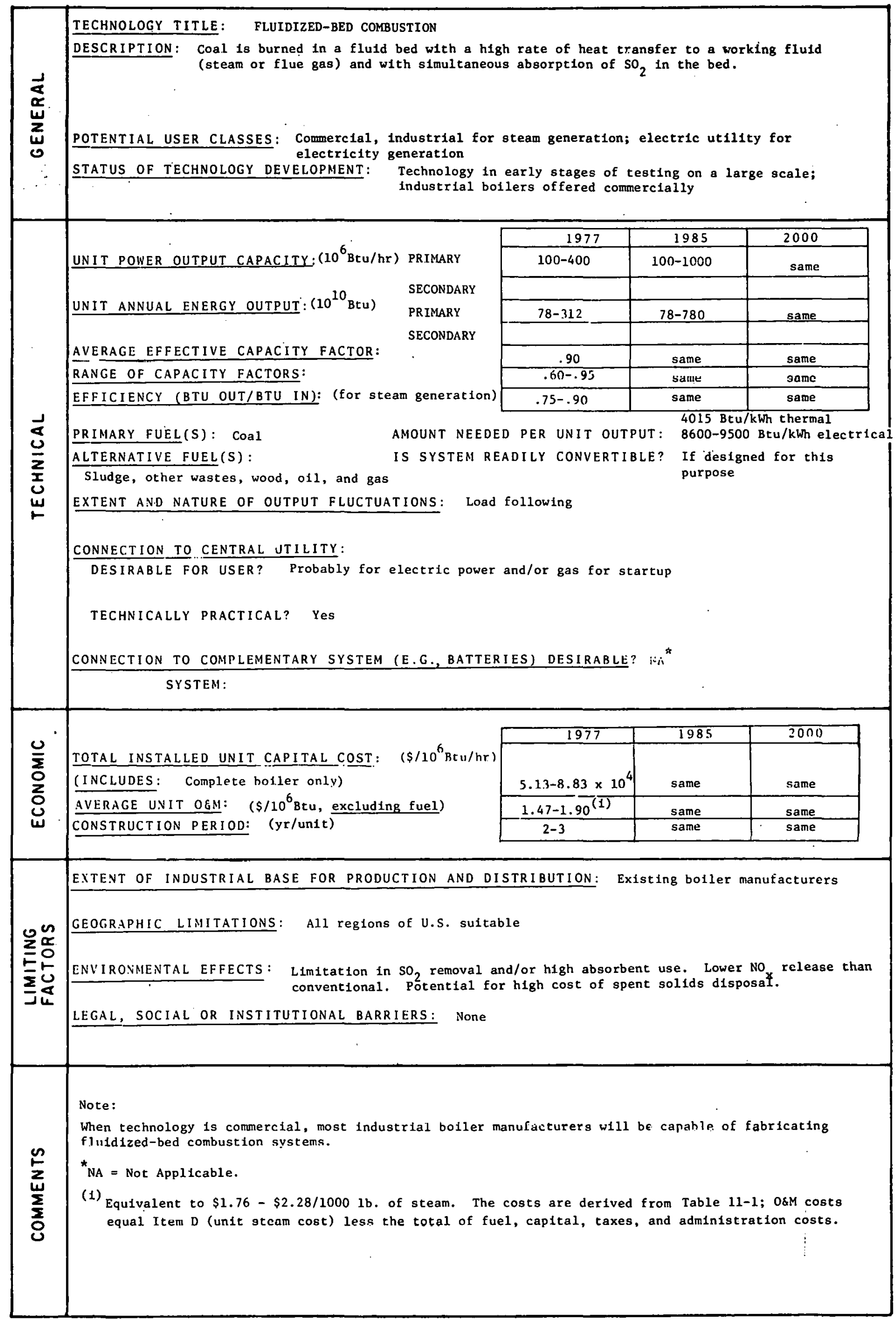


CHAPTER 11

\section{FLUIDIZED-BED COMBUSTION}

Section 11.1: Introduction

When a stream of gas (or 1iquid) is passed upward through a bed of particles at.an increasing rate, a stage is reached when the weight of the particles is overcome by the force exerted by the fluid flowing upward. At this stage the system resembles a violently boiling liquid and the bed of particles is considered to be fluidized. This state of fluidization is. stable over a wide range of gas (or liquid) fluidizing velocities, and the fluidized or fluid bed is characterized by a high degree of particle mixing, excellent mass transfer between the fluidizing gas (or liquid) and the particles, and excellent heat transfer between the gas (or liquid), the particles, the sidewalls and immersed heat-transfer surfaces.

The fluidized-bed combustion of coal involves the combustion of coarse (1/4-in.) particles of coal at atmospheric or elevated pressures in a fluidized bed of dolomite or limestone and coal ash at temperatures of $1500-1750^{\circ} \mathrm{F}$. This operating temperature is below the ash-softening point. The $\mathrm{SO}_{2}$ generated during combustion is absorbed by the limestone ("sorbent"), and spent sorbent and coal ash are removed from the bed. The low operating temperature reduces $\mathrm{NO}_{x}$ formation and also reduces the volatilization of alkal1 salts (such as sodium and potassium sulfate) in the fuel. To maintain the bed temperature at the desired level, the heat generated by the combustion is removed from the bed by immersing cooling tubes carrying a working fluid such as water, steam, or air in the bed. Alternatively, bed temperature can be maintained by supplying a substantial quantity of excess air to the bed to carry away the heat. Heat in the gases leaving the fluidized bed can also be transferred to the working fluid.

In contrast, the conventional combustion of coal involves the combustion of very small particles (74 microns) of pulverized coal entrained in the combustion air. Only the smaller botler sizes can economically burn coarse coal on a moving grate. The conventional system operates at h1gh temperatures -- typically $1800-2200^{\circ} \mathrm{F}$ in boller furnaces where the mineral matter In the coal is removed as dry ash, or up to 
$2700^{\circ} \mathrm{F}$ in boiler furnaces where the mineral matter is removed as a molten slag. The $\mathrm{SO}_{2}$ generated during combustion has to be removed by fluegas desulfurization (scrubbing) techniques. Because of higher operating temperatures, $\mathrm{NO}_{\mathbf{x}}$ formation is difficult to control, but is achleved by controlling combustion air. The heat generated by coal combustion is transferred to the working fluld -- steam/water -- In different sections of the boller, e.g., superheater, reheater, preheater, convection secrlons, economizer, water-wail sections and the air preheater.

Fluidized-bed combustion of coal can be used for generating Industrial process heat and electricity on a variety of thermodynamic cycles. Generally, these cycles fall into two broad categories: cycles based on a single working fluid--air, combustion products, or steam--and cycles based on two working fluids--steam and combustion products. The cycles are labelled open or closed depending on whether the working fluid is used just once or whether 1 t is recycled. Examples are: simple open cycle (heat is transferred to combustion products and excess air in a pressurized fluid bed; electricity is generated in a gas turbine); closed cycle (heat is transferred to steam or gas in the cooling tubes immersed in the bed; electricity is generated in a steam/gas turbine); and combined cycle (in pressurized fluid-bed combustion, the flue gases are expanded in a gas turbine while heat from the gas turbine exhaust and from the fluidized bed is transferred into a steam cycle).

Fluidized-bed bollers are in the early stage of large-scale testing and demonstration in the United States. Because of this, predictions of efficiency and cost cannot be made with certainty. Even with an accelerated testing program, fluidized-bed bollers are not expected to be in widespread commercial use unt11 1985 or $1990^{(1)}$ and might be delayed even

. longer. However, a few manufacturers of industrial-scale fluidized-bed boilers are offering these boilers "commercially," 1.e., under guarantees or warranties similar to those for conventional bollers. Under such warrantles, the seller of the boller does not assume any contingent liability and is not liable for any loss of production should such a loss 
result from non-performance of the fluldized-bed boiler. Thus it is not surprising that few, if any, such boilers have been ordered at this time except for further testing and demonstration.

In the long run, it appears that simpler fluidized-bed boiler systems may be better suited than conventional bollers with scrubbers for small- to medium-scale applications where they potentially offer a relatively compact and simple system for the generation of steam, and perhaps lower cost. However, costs of coal distribution and handling will have a major effect on the economics of these smaller systems. For large power-generating systems, these systems offer, at best, modest improvements in power generation efficiency or in cost over conventional systems. (2) In this area, the more complex pressurized fluid-bed botlers and combined cycles appear to be more promising in terms of efficiency, but their success is contingent on the availability of a combination of high-temperature particulate removal techniques and improved reliability of gas turbine technology.

W1th respect to larger systems, a TVA report ${ }^{(2)}$ concludes: "When uncertainties are included, the estimated cost of electricity for the three alternatives [conventional boller with flue gas desulfurization, atmospheric fluidized bed combustion, and pressurfzed fluidized-bed combustion] is so close that all are considered to be within the competitive range for further considerations." In contrast to flue gas scrubbing, which produces a wet sludge, fluidized-bed coal combustion produces a dry granulir waste. Future solid waste regulations will change the cost of disposal of wet and dry wastes and may affect the ranking. However, if this waste is considered to contain hazardous pollutants, it is likely that both types of wastes will require similar disposal strategles and Involve simflar disposal costs.

\section{Section 11.2: Technical D1scussion}

\section{A. Advantages}

Combustion of coal in fluidized beds has been under investigation for about 20-25 years. The aim of many of the earlier processes was to utilize high-ash coal fines (very small coal particles -- typically minus 
28 mesh -- not acceptable for grate burning) without incurring the high costs of grinding for pulverized coal firing. (3) The aim of the processes of current interest is to utilize the supertor heat and mass transfer properties of the fluidized bed in order to burn coal while absorbing $\mathrm{SO}_{2}$ in the combustor.

The expected advantages of fluidized-bed combustion are the following:

1. The $\mathrm{SO}_{\mathrm{x}}$ emissions are reduced by adding limestone or dolomite to the bed; $\mathrm{NO}_{\mathbf{x}}$ emissions are reduced because of lower combustion temperatures.

2. Costs are lowered, because a wider range of fuels can be used. These include high-ash, low-rank coals, sludge from secondary treatment of sewage, wood wastes and other biomass materials, and wastes from sulfite pulping of wood.

3. Capital costs would be lower than for conventiona]. bollers with scrubbing because of higher heat-transfer coefficients and the resulting compactness of size. In addition, it is expected that fluidized-bed boilers with a capacity up to $250,000 \mathrm{lb} / \mathrm{hr}$ of steam could be shopfabricated and shipped by rail. (1)

4. The combustor operates at high efficiency at lower combustion temperatures. Therefore, there is less volatilization and melting of minor components such as alkali metal compounds. This results in less emission of trace inorganic species and reduced fouling of heattransfer surfaces.

5. Grinding costs are lower since a fluidized bed requires coarser coal than conventional pulverized coal firing.

However, as described later in this section, all aspects of fluidized-bed combustion are undergoing intensive study. In light of data accumulated so far, it appears that while the advantages mentioned above can probably be realized, some tradeoffs are necessary in order to achieve these advantages. These tradeoffs occur in the following areas: 
1. Range of operating temperatures: High temperatures are preferred for rapid and complete combustion, but lower temperatures are necessary for $\mathrm{SO}_{2}$ absorption and to prevent slagging or melting of coal ash constituents. The usual approach has been to operate below the $\mathrm{CaSO}_{4}$ decomposition temperature $\left(1800^{\circ} \mathrm{F}\right)$ and to maximize carbon utilization by recirculating fine particles from the primary reactor, or to provide a second-stage reactor for burning up the carbon associated with particles that have been elutriated from the bed. For larger-scale boilers, efficient utilization of carbon is important. For smaller boilers, the loss of some unburned carbon to the solid-waste streams is less important. While some fluidized-bed combustors have operated under agglomerating ash conditions (e.g., the Igni-fluid boller ${ }^{(4)}$ ), most of the current designs incorporate $\mathrm{SO}_{2}$ absorption in the bed and avoid ash agglomeration. These considerations result in operating temperatures in the range of $1500-1750^{\circ} \mathrm{F}$. This temperature limits the thermodynamic efficlency of power generation cycles based on fluldized beds to about the same level as that obtained in modern conventional systems.

On the other hand, $\mathrm{NO}_{\mathrm{x}}$ emissions are not a problem. Limited data obtained with pressurized fluid beds indicate that No ${ }_{x}$ emissions are about $0.21 \mathrm{~b} / 10^{6} \mathrm{Btu}$ compared to the New Source Performance Standards of $0.71 \mathrm{~b} / 10^{6} \mathrm{Btu}$. (5) More data are needed to confirm these low levels of $\mathrm{NO}_{x}$ emissions and the effect of high excess air.

2. $\mathrm{SO}_{\mathrm{x}}$ removal: ${ }^{(5)} \mathrm{SO}_{\mathrm{x}}$ is removed by formation of $\mathrm{CaSO}_{4}$ by reaction with limestone or dolomite in an oxidizing environment. The bed temperature has to be below the decomposition temperature of $\mathrm{CaSO}_{4}$. It has been found that dolomite is more efficient (from the stoichiometric viewpoint) than ilmestone as an absorbent, but that in both cases about two to three times the stoichiometric amount of calctum oxide 
is required. Pressurized fluid beds are somewhat more efficient, and typical efficlencles are more than $90 \%$ sulfur capture for dolomite at stoichiometric ratios around 2 . When IImestone is used, the sulfur capture efficiency is lower and varies with the type of limestone. In atmospheric fluid beds, tests were conducted to determine limestone addition to give $\mathrm{SO}_{2}$ emissions of $1.2 \mathrm{lb}$ $30,10^{6} \mathrm{Bcu}$. lihe results indicate that calcium/sulfur ratios of 2.5 to 4.4 or more are required. (6) It has been found that the addition of salt ( $\mathrm{NaCl}$ ) decreases 1imestone requirements, presumably by opening of pores, but may lead to some agglomeration within the bed and possibly to superheater tube corrosion. The long-term effect of salt on fouling and corrosion in the fluidized-bed combustor is not known. In general, these high calclum/sulfur ratios result in an increase in operating costs when the absorbent is used on a once-through basis. Because of this, regenerative systems which remove $\mathrm{SO}_{2}$ from $\mathrm{CaSO}_{4} \mathrm{via}$ thermal decomposition or other chemical reactions are also being studied. Such regenerative systems are more complex, requiring a multiplicity of fluidized-bed reactors, and consequently involve higher capital costs, Regeneration will increase the efficiency of sorbent utilization but lower fuel efficiency. A simple schematic of a fluidized-bed combustor without regeneration is given in Figure 11-1. (1)

3. Erosion and corrosion: There appear to be relatively few data on the performance of boiler tubes in an abrasive environment such as a fluidized bed. However, this is not considered to be an area of major concern at the present time as the operating units do not show signs of 

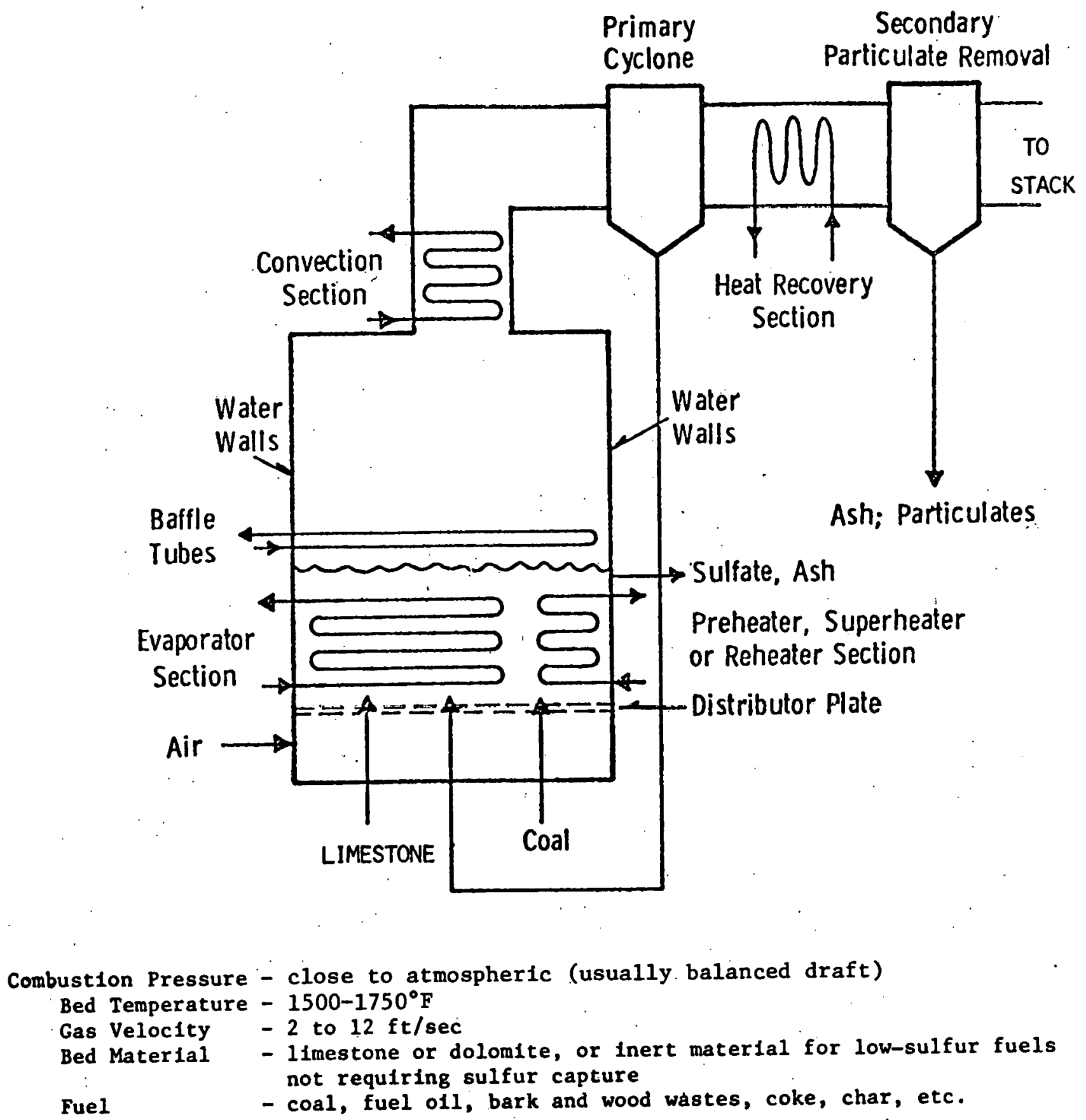

SOURCE: Reference 1.

FIGURF 11-1 SCHEMATIC DIAGRAM OF ATMOSPHERIC PRESSURE FLUIDIZEDBED COMBUSTION BOILER 
material loss.. Corrosion of superheater tubes is an uncertainty, even though it is believed that conventional superheater tube materials will be adequate. EPRI-sponsored work shows significant corrosion in the vicinity of coal injection points.

4. Selection of bed material: The physical integrity of the - bed material (limestone or dolomite) is important. Bed material which disintegrates into smaller particles under the thermal and mechanical shocks is unsuitable. The degree to which different deposits of limestone and dolomite comply with these requirements and the efficiency of $\mathrm{SO}_{2}$ absorption are not well known. Data on the behavior of different limestones are being compiled. (7)

5. Adaptability to different fuels: While a variety of fuels can be burned in a fluidized bed (e.g., sewage sludge, black liquor from sulfite pulping of wood, low-rank coals, sulfide minerals, and so on), a fluidized bed designed for one fuel will require considerable modification in fuel handling/fuel injection equipment to switch to another fuel. Coal injectors are a big technical problem area. Other materials such as sewage oludge and pulping wastes are usually injected as a slurry through nozzles.

Comprehensive descriptions of the various developmental programs are available. $(5,8)$ We present below a description of some of the major avenues of research.

\section{B. Atmospheric Pressure Systems}

These systems are attractive for industrial-scale boilers (about 300,000 1b/hr steam) and can be built in utility-scale units. Typical conditions for atmospheric pressure systems, based on Reference 9, and Arthur D. Little, Inc., estimates, are: 


$\begin{array}{ll}\text { Particle Size } & 1 / 4 \mathrm{fn} . \\ \text { Bed Depth } & 2-8 \mathrm{ft} \\ \text { Superficial Velocity* } & 2-12 \mathrm{ft} / \mathrm{sec} \\ \text { Bed Temperature } & 1400-1700^{\circ} \mathrm{F} \\ \text { Excess Air } & 10-50 \%\end{array}$

The major program in this area is the 30-MW module constructed by Pope, Evans and Robbins at Rivesville, West Virginia, under DOE funding. In this plant, steam is generated via water tubes immersed in the bed. In addition, the unit has water-tube walls, a convection economizer, . and a separate carbon burn-up cell.

Other programs $(8,1 n)$ in thls arca include a series of projects on industrial applications of fluld-bed technology for producing saturated steam, superheated steam, high-temperature air, and process heat in this country (e.g., Alliance, Ohio) and abroad (espectally in the U.K.), a component test and integration unit at Morgantown Energy Research Center, and a turbine technology unit (external combustor for gas turbine) at Oak Ridge National Laboratory. Additional work is in progress on plant conversions and on the utilization of anthracite waste.

\section{Pressurized Systems}

Pressurized systems appear to utilize the dolomite sorbent more effectively than the atmospheric pressure systems. (11) A critical problem area in the pressurized system is the need for cleaning particulates from the combustion gases at high temperatures in order to prevent buildup on or the corrosion/erosion of the gas turbine blades.** Typlcal conditions, based on Reference 11, and Arthur D. Little, Inc., estimates, are:

$\begin{array}{ll}\text { Particle Size } & 1 / 4 \mathrm{fn} . \\ \text { Bed Depth } & 6-15 \mathrm{ft} \\ \text { Superficial Velocity } & 2-10 \mathrm{ft} / \mathrm{sec}\end{array}$

* Superficial velocity is defined as the volumetric flow of the fluidlzing gas at operating conditions divided by the cross-sectional area of the bed.

** When the fluldized bed gasses power a gas turbine. 


$\begin{array}{ll}\text { Bed Temperature } & 1500-1800^{\circ} \mathrm{F} \\ \text { Excess Air } & 10-300 \% \\ \text { Pressure } & 100-200 \mathrm{ps} 1\end{array}$

Research on these systems is being conducted by Westinghouse, General Electric, British Coal Utilization Research Association (BCURA), Combustion Systems Ltd., Exxon, Argonne National Laboralury, Oak Kidge National Laboratory, Combustion Power, Curtiss-Wright and others.

\section{Contro1}

The ability of a combustor to alter combuotion rates in response to changing loads (e.g., turndown) is important in most applications. The fluidized bed boller can adapt to changing loads in a variety of ways, depending on the type of fluidized-bed combuslur in question and the degree of change required.

The heat transfer to the colls immersed in the bed can be varled by varying the bed temperature. This approach is likely to achieve a turndown of only about $60-65 \%$ of ful1 load in pressurtzed systems. (12). For larger load variations, the fluldized bed can be compartmentalized so that successive compartments can be shut off. Alternatively, since the heat-transfer coefficient to the tubes immersed in the bed is greater than that to the tubes in the freeboard, change can be achleved by : altering the height of the bed by adding or removing solids from the bed. In additinn, it hao been suggested that compressed air storage can.be used so that during periods of peak demand, the stored air s.an be uecd for fluldization and all of the gas turbine's ${ }^{*}$ output used for power generation. (12)

\section{E. Startup}

Any fluidized-bed installation requires an auxiliary fuel (oil, natural gas, or perhaps pulverized coal) for heating the bed material to the operating temperature before coal injection can begin. Similarly, an auxiliary power source is required to drive the fluidizing air fan.

\footnotetext{
* Driven by the combustion gasses of the fluidịed bed.
} 
Section 11.3: Economics Discussion

A fluidized-bed combustor, whether used in industrial-scale or utility-scale boilers, produces steam of a certain quality and is able to reduce emissions to the environment by the use of a sorbent for $\mathrm{SO}_{2}$ control and by selecting suitable operating conditions for NO $x$ control. In terms of system performance, electric power plants. based on atmospheric pressure combustors are projected to have heat rates of about $9500 \mathrm{Btu} / \mathrm{kWh}$ and steam conditions of $2400 \mathrm{psi} / 1000^{\circ} \mathrm{F} / 1000^{\circ} \mathrm{F}$, (steam pressure/superheater. temperature/reheater temperature). The pressurized system at low excess air is projected to have heat rates of $8600 \mathrm{Btu} / \mathrm{kWh}$, while the high-excess-air combustor offers a heat rate of about $9100 \mathrm{Btu} / \mathrm{kWh}$. Modern conventional plants meeting environmental standards have heat rates around $9100 \mathrm{Btu} / \mathrm{kWh} .{ }^{(13)}$ Thus, fluidized-bed boilers compete directly against modern conventional boilers with their associated stack-gas scrubbing system.

Economic comparisons between these two systems are difficult because the different technologies involved represent different levels of technological development and therefore of technical risk. Conventional boflers represent a mature technology and the potential for technical improvement is low. While accurate estimates for conventional systems are avallable, these estimates are often tailored and optimized for a specific type of coal. Costs can vary significantly as coal type and other site-specific factors are varied. (14) Stack gas scrubbing and other environmental control technologies are still on a learning curve and fall in an intermediate category where the costs of certain systems are known fairly accurately, but where a significant potential for improvement and for cost reduction exists. Fluidized-bed bollers represent a higher level of risk at present because long-term operating data are still unavailable. Only these data can answer questions about reliability, maintenance costs, applicability to different coal types, etc., which have an important bearing on the relative economic performance of this technology. 
Economic comparisons currently avallable between conventional and fluidized-bed technology typically show capital cost savings with fluidized-bed technology to be in the range of $10-20 \%$ and operating cost savings to be in the range of $5-15 \% .(2,12)$ Table $11-1$ presents estlmates prepared by the Exxon Research and Engineering Company for EPA/FEA/ERDA for industrial size boilers. The original estimates were in 1975 dollars. These have been updated to 1977 dollars using a uniform inflation factor of 1.12. (This factor corresponds to the changes in the Marshall \& Stevens equipment cost index over this period and is equivalent to an inflation rate of $5.1 \%$ per year.) In these estimates, an attempt was made by Exxon R\&E to discount for technical risk by increasing capltal investment by a "process development allowance." However, this allowance is relatively small (20\% for the unproven parts of the fluldized-bed system) and might not be adequate: While analogles are hazardous, it is instructive to recall that early estimates of the costs of flue gas desulfurization typically were less than the actual costs of successful systems by a factor of 2 .

Table 11-1 indicates that, on an industrial boiler scale, a fluidized-bed boiler will require 20-30\% less capital investment and have a 15-20\% lower operating cost. However, in our opinion, this difference cannot be considered significant at this time. In analyzing the components of the operating cost, it can be seen that the major impact is due to the difference in capital investment. Of lesser impor= tance is the difference in labor costs between the two systems. It is not clear why a conventional proven system will require more labor than a somewhat similar unproven system. 
TABLE 11-1

COMPARISON OF A FLUIDIZED-BED-BOILER VS. A CONVENTIONAL BOILER WITH FLUE GAS DESULFURIZATION

A. Basis: Independent Industrial boller plant; 1977 dollars; high-sulfur. ( $3.5 \%$ S) coal; capacity factor, $90 \%$.

$\begin{array}{lll}\text { Steam Rate (1000 1b/hr) } & \begin{array}{c}\text { Fluidized-Bed } \\ \text { Combustion }\end{array} & \begin{array}{c}\text { Conventional } \\ \text { with Scrubber }\end{array} \\ \text { Annual Steam Prod: }(106 \mathrm{~b} / \text { year }) & \frac{100}{78.4} 3,15 \frac{400}{3.6} & 78 \frac{100}{8.4} 3,15 \frac{400}{3.6}\end{array}$

B. Capital Investment: $\left(\$ \times 10^{6}\right)$

Fuel Handling

Boiler and Stack

Environmental and Whaste Disposal

Total Investment

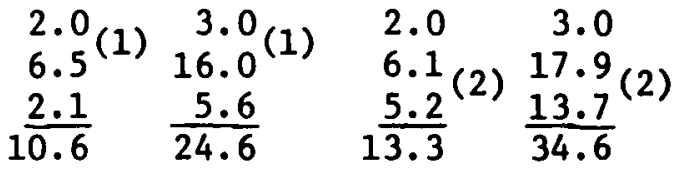

C. Operating Cost (c/1000 lb of Steam, Excluding Fuel Cost)

Labor

$\begin{array}{rrrr}63 & 20 & 85 & 27 \\ 50 & 41 & 37 & 29 \\ 28 & 28 & 34 & 38 \\ 40 & 24 & 50 & 33 \\ 20 & 20 & 25 & 25 \\ \frac{67}{268} & \frac{67}{200} & \frac{67}{298} & \frac{67}{219} \\ \frac{188}{456} & \underline{109} & \underline{236} & \underline{154} \\ \underline{141} & \underline{141} & \underline{141} & \underline{141} \\ 597 & 450 & 675 & 514\end{array}$

(1) Fluidized-bed boiler investments include a 20\% "process development" allowance.

(2) Scrubber investments include a 10\% "process development" allowance.

(3) "Normal" capital charge for industrial plants of $20 \%$ has been reduced by $6 \%$ inflation to convert to a constant dollar basis.

(4) Steam @ $1200 \mathrm{Btu} / 1 \mathrm{~b}$.

NOTE: Data escalated to 1977 dollars using a factor of 1.12 by Arthur D. Little, Inc.

SOURCE: Reference 1. 


\section{Section 11.4: Limitations}

The principal limitations on the use of fluidized-bed combustors on the industrial boiler scale include:

- environmental regulations, and

- cost and reliability of fluidized bed boilers.

The Clean Air Act Amendments of 1977 require the use of Best Avallable Control Technology for the permanent control of emissions of air pollutants to the atmosphere. At the current state of knowledge, fluidized beds are relatively inefficient in their use of sorbent, and this inefficiency appears to increase as the degree of sulfur dioxide removal is increased. While the efficiency of the sorbent can be increased by adding sodium chloride, the side effects of these additions have not been fully evaluated. Thus, it appears that any New Source Performance Standard which requires a high degree of $\mathrm{SO}_{2}$ capture would tend to decrease the cost advantages of this technology.

The extensive large-scale pilot plant and demonstration program will be able to answer the questions that will ultimately define the costs of this technology vis-à-vis conventional bollers with flue-gas desulfurization. These questions are related to corrosion, erosion, materials of construction, startup and shutdown problems, maintenance requirements, carbon utilization efficiency, sorbent efficiency, turndown, etcc. As noted earlier, while fluidized-bed combustion is a relatively flexible technology, the tradeoffs required involve additional equipment whose ramifications are not always included in the available cost estimates. For example, while there are various strategies available for achieving system turndown, it is not clear that the incremental cost for achieving a degree of control comparable to conventional systems has been included in the current cost estimates.

In the near term, fluidized-bed bollers are likely to be installed for the generation of process steam in Industrial applications. As noted earlier, fluldized-bed bollers of approximately $250,000 \mathrm{lb} / \mathrm{hr}$ of steam can be shop-fabricated and shipped by rall, resulting in significantly lower cost than a conventional boller of this size which would require field fabrication/assembly. 


\section{REFERENCES}

1. Farmer, M.H., et al. Application of Fluidized Bed Technology to Industrial Boilers. Report prepared by Exxon Research and EngineerIng Company for the Environmental Protection Agency, the Federal Energy Administration and the Energy Research and Development Administration, January 1977. NTIS Report No. EPA 600/7-77-011.

2. Reese, J.T. Utility Boiler Design/Cost Comparison: Fluidized Bed Combustion versus Flue Gas Desulfurization. Prepared by Tennessee Valley Authority for Environmental Protection. Agency, November 1977. NTIS Report No. EPA 600/7-77-126.

3. Skinner, D.F. The Fluldized Combustion of Coal. London: Mills and Boon, Ltd., 1971.

4. Squires, A.M. "Clean Power from Coal." Sclence 169(3949):821, August 28, 1970.

5. MITRE Corporation. Proceedings of the Fifth International Conference on Fluidized Bed Combustion, coordinated by the METREK Division, Washington, D.C., December 12-14, 1977. Vol. II. pp. $594-624,544-558,875-890$.

6. "Fossil Fuel and Advanced Systems Division R\&D Report." EPRI Journal, May 1977. pp. 39 ff.

7. Vogel, G.J., et al. Supportive Studies in Fluldized Bed Combustion, Annual Report July 1976 - June 1977. Report prepared by Argonne National Laboratory, 1977. NTIS Report No. ANL/CEN/FE-77-3.

8. Energy Research and Development Administration. Fossil Energy Program Report, July 1975 - October 1976. September 1977. NTIS Report No. ERDA-77-70. pp.70 ff.

9. MITRE Corporation. Proceedings of the Fifth International Conference on Fluidized Bed Combustion, coordinated by the METREK Division, Washington, D.C., December 12-14, 1977. Vol. II. pp. 157-374.

10. MITRE Corporation. Proceedings of the Fifth International Conference on Fluidized Bed Combustion, coordinated by the METREK Division, Washington, D.C., December 12-14, 1977. Vo1. I. pp. 31-99.

11. MITRE Corporation. Proceedings of the Fifth International Conference on Fluidized Bed Combustion, coordinated by the METREK Division, Washington, D.C., December 12-14, 1977. Vo1. II. pp. 385-458. 


\section{REFERENCES (cont1nued)}

12. Locke, H.B., et al. "Fluldized Beds: Clean Heat and Power Cycles Using Fluidized Combustion." Chemical Engineer, November 1975. pp. $667 \mathrm{ff}$.

13. Keairns, D.L. "Fluidized Bed Combustion." Proceedings of the Third Annual Conference on Coal Gasification and Liquefaction, University of Pittsburgh, Pittsburgh, Pennsylvania, August 1976.

14. Bechtel Corporation. Coal Fired Power Plant Capita1 Cost Estimates. Report to the Electric Power Research Institute, January 1977. 
CHAPTER 12

\section{ON-SITE COMBUSTION TURBINE-POWERED ENERGY SYSTEMS}

\section{Section 12.1: Introduction}

A. Development of the Technology

The principles of present combustion turbines* were first established by Dr. F. Stalze in 1872 and the first turbine in the United States was built at Cornell University in 1902. (1) The development of the technology, however, was delayed for several decades by the lack of knowledge in the fleld of aerodynamics and the unavallability of materials to withstand turbine inlet temperatures necessary for adequate overall cycle efficlencles.

Major technological breakthroughs in the fleld were pioneered in the 1930-1940 decade by Brown-Boveri, Sulzer Brothers, and Escher Wyss in Switzerland and by Air Commodore Frank Whittle in England. (2). In the United States, the Navy Department began serious investigations into the feasibility of using combustion turbines for aviation and marine propulsion in 1938. Today there are about 85 manufacturers of combustion turbines in the United States, England, Switzerland, France, Germany, the USSR, and Japan with a preponderance being in the United States and England. (3)

The Department of Energy is currently sponsoring a series of development and product-improvement research projects directed toward the clean burning of residual oils and coal-derived fuels in combustion turbines. Among the participant team leaders are Westinghouse/General Motors, General Electric, Curtiss-Wright, and United Technologies. (4)

*Commonly known as gas turbine; referred to here as combustion turbine to emphasize that the untt is capable of burning gaseous or 1iquid fuels. 


\section{B. General Characteristics}

Combustion turbines are relatively small and lightweight; hence they require only modest space and foundation. They do not require any cooling water and are therefore suitable for installation in arid climates. Combustion turbines can be controlled remotely and run unattended, and they permit rapid startup and loading.

\section{Applications}

Smaller combustion turbines are predominantiy used for military and commercial aviation and their discussion is beyond the scope of the present report. The oll and gas industries are major users of landbased combustion eurbines for powering compressors in gas pipeline transmission, compressor and pump drives in refineries and oil-well pressurization, as well as for electric power generation on offshore gas and oil platforms. The electric utility industry is another major user of combustion turbines for power generation, particularly as peak load and emergency backup units.

In total energy system applications, the combustion turbine drives an electric generator, and the exhaust heat is recovered in a waste-heat recovery boller for on-site application. Potential markets for this mode of operation include industrlal complexes, shopping centers, commercial facilities, and city districts.

\section{Section 12.2: Technical Discussion}

A. The Thermodynamic Cycle

Operation of a combustion turbine is based on the Brayton cycle. The simple combustion turbine consists of a compressor, a.combustion chamber, and a turbine. Figure $12-1$ is a schematic representation of these components. The compressor takes in the ambient air and pressurizes 1t. The pressurized air enters the combustion chamber where the fuel is injected. The combustion process heats the pressurized air which is allowed to expand in a turbine to a lower pressure, producing work. The air is then discharged at a lower temperature. The efficiency of the 


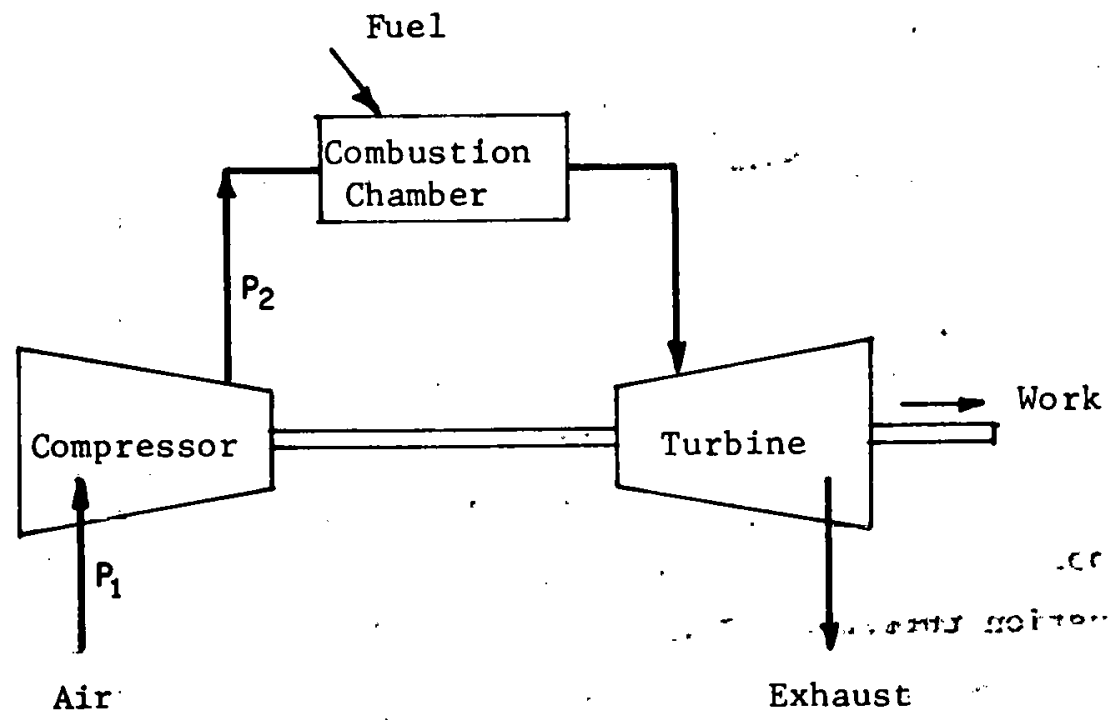

FIGURE 12-1 SCHEMATIC OF AN OPEN-CYCLE COMBUSTION TURBINE

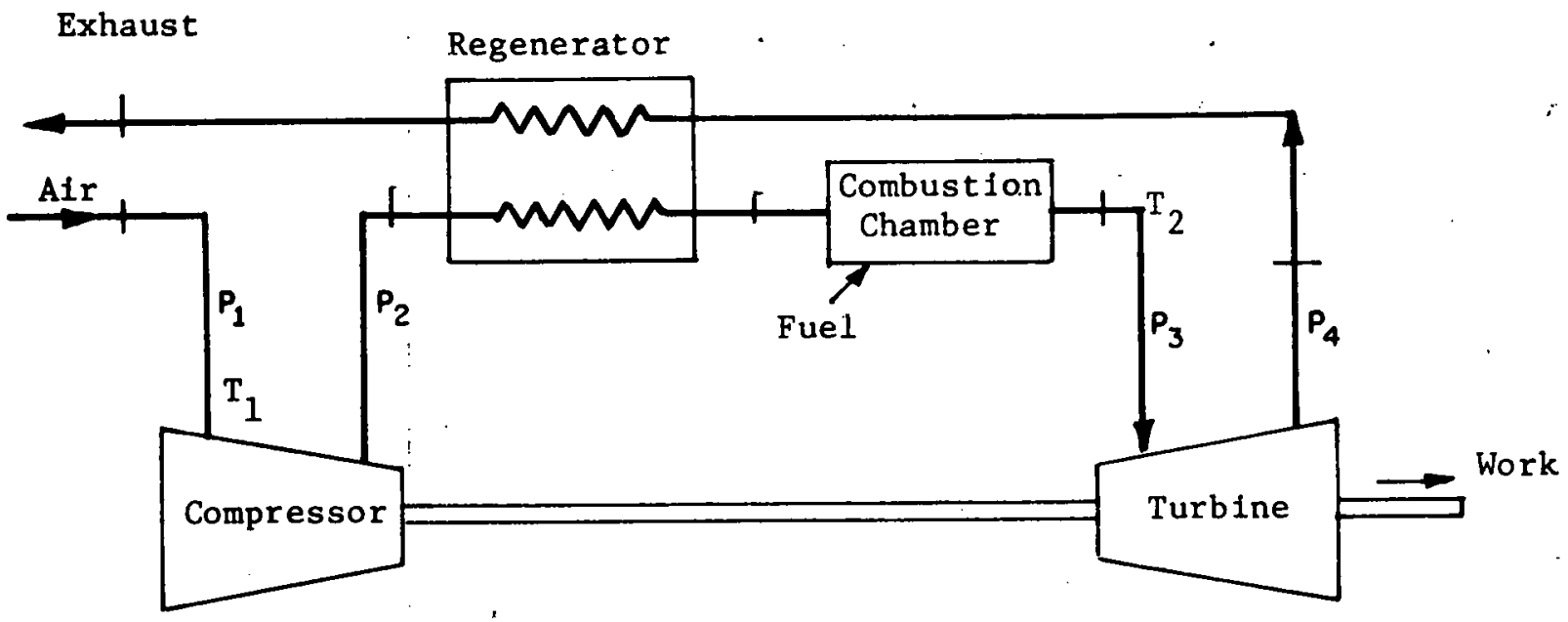

FIGURE 12-2 SCHEMATIC OF AN OPEN-CYCLE COMBUSTION TURBINE WITH REGENERATOR 
Brayton cycle is a function of the ratio of the compressor's output pressure to its input pressure $\left(P_{2} / P_{1}\right.$ in Figure 12-1) and the ratio of the turbine inlet temperature to the amblent air temperature. It is possible to Increase the efficlency of the cycle by utilizing the heat of the exhaust of the turbine to increase the temperature of the pressurized air entering the combustion chamber; this is done by installing a counterflow heat exchanger called a regenerator.

Figure 12-2 1llustrates a regenerative cycle. The influence of the compressor's pressure ratio on the Ideal Brayton and regenerative cycles $^{*}$ is shown in Figure 12-3. (5) The reason for the negative effect of the pressure ratio on the regenerative cycle is that, In contrast to the Brayton cycle, the efficlency depends not only on the compressor's pressure ratio but also on the ratio of minimum temperature, $T_{1}$, at the compressor's intake to the maximum temperature, $\mathrm{T}_{2}$, at the combustion chamber's outlet. (6)

We must also note that the efficiencies given in Figure 12-3 are for the 1deal cycles with 1deal (i.e., no losses) turbines and compressors. Actual combustion turbines have efficiencles much lower than the $40 \%$ to $50 \%$ shown in Figure 12-3. One reason for the low efficiency ... of the combustion turbines (ideal or actual) is the large amount of work required by the compressor. For example, in an Ideal combustion turbine, the compressor might require $40 \%$ of the turbine work; if the same pressure and temperature conditions are applied to an actual combustion turbine, the compressor work is as much as $60 \%$ of the turbine output and only $40 \%$ is delivered as net work.

The turbine inlet temperature is also an important factor in the efficiency of a combustion turbine. Figure 12-4 11lustrates the actual efficlency of a combustion turbine for various turbine inlet temperatures as a function of the pressure ratio. The structural integrity of blade material sets the upper limit on the turbine inlet temperature. In general, the thermal efficlency of combustion turbines built today falls somewhere in the range of $20-33 \%$. (3)

*Figure 12-3 Indicates the Ideal (maximum possible) efficiencies obtainable. By comparing the ideal cycle efficiencies with the actual cycle efficiencies, the reader can judge the improvements to actual (non-1deal) system efficlencles that may result from component development. 


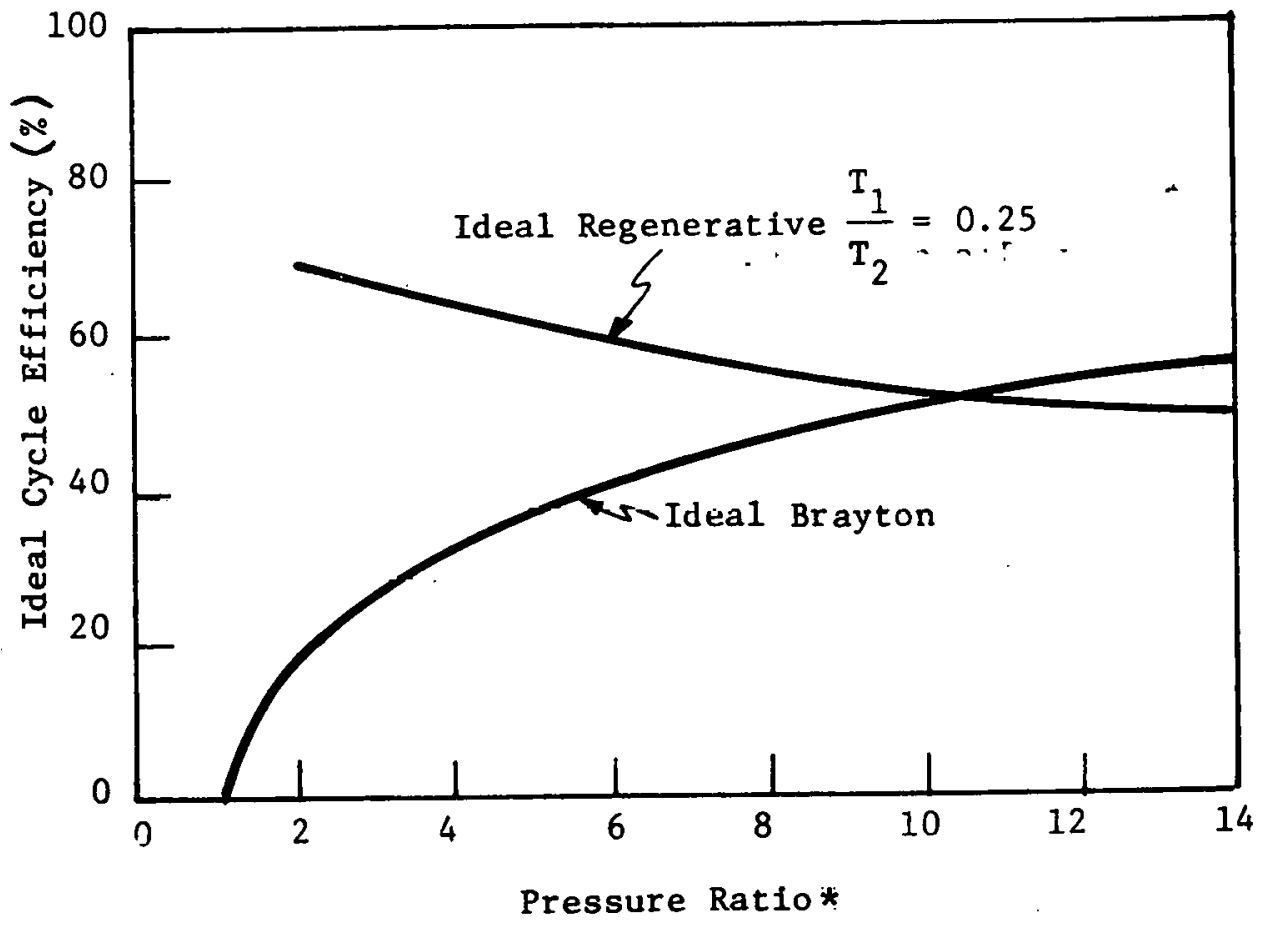

* Pressure ratio refers to $\frac{P_{2}}{P_{1}}$ in Figure 12-2.

SOURCE: Reference 5.

FIGURE 12-3 CYCLE EFFICIENCY AS A FUNCTION OF PRESSURE FOR THE IDEAL BRAYTON AND REGENERATIVE CYCLES 


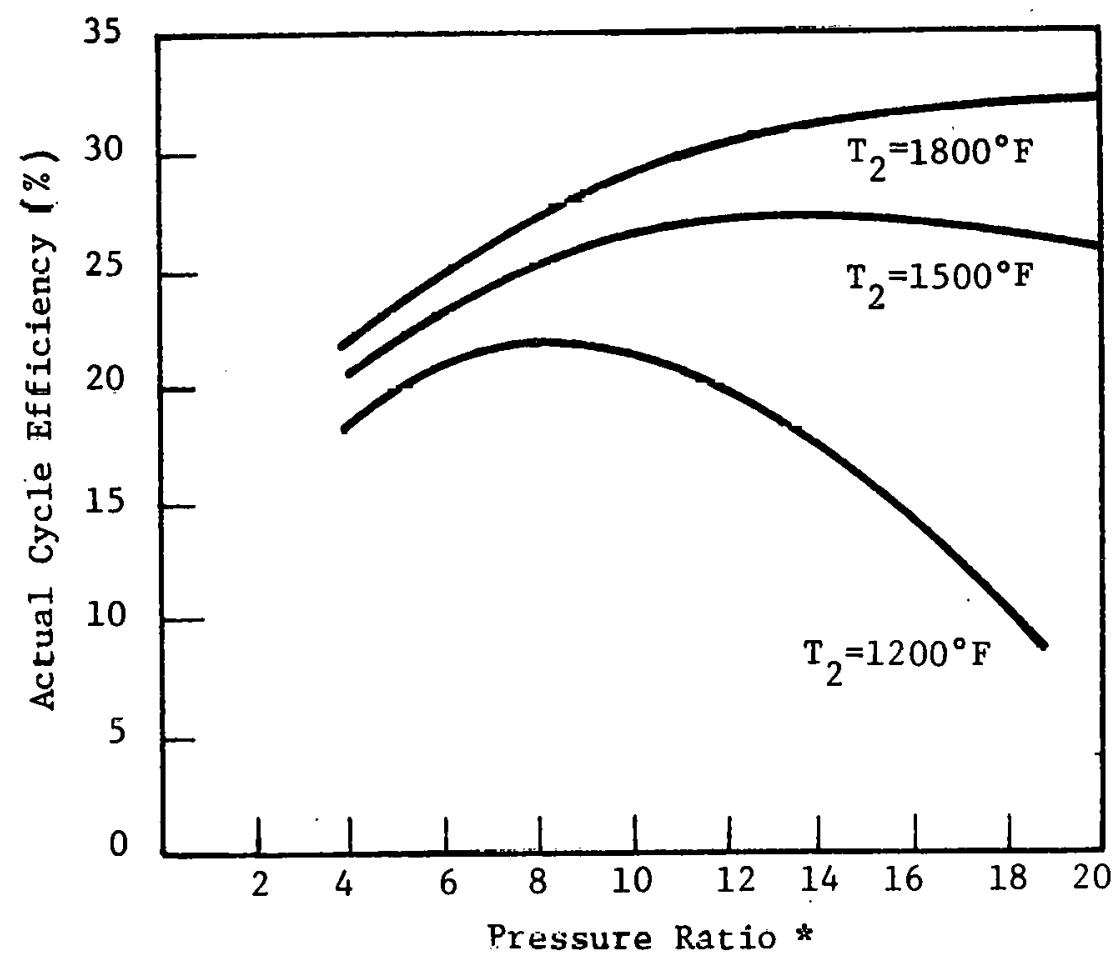

* Pressure ratio refers to $\frac{\mathrm{P}_{2}}{\mathrm{P}_{1}}$ in Figure 12-2.

SOURCE: Reference 3.

FIGURE 12-4 EFFECTS OF PRESSURE RATIO ON THERMAL EFFICIENCY FOR A SIMPLE GAS-TURBINE CYCLE AT VARIOUS TURBINE INLET TEMPERATURES $\left(\mathrm{T}_{2}\right)$ 


\section{B. Components}

Major components of a combustion turbine consist of the compressor, the combustion chamber, and the turbine.

The primary requirement of a combustion turbine compressor is that it handle a large volume of air at the highest possible efficiency. Multi-stage axial flow compressors are used in all the larger combustion turbines. Centrifugal compressors, which are simpler and more rugged than axial flow compressors, have lower efficiencies and are not readily adaptable to multi-staging. Compression ratios of the compressors used in land-based combustion turbine installations vary from $6: 1$ to $12: 1$, depending upon the size and design of the unit.

The combustion chamber has the function of bringing the gas to the desired uniform temperature with minimum impurities and minimum loss of pressure. In open-cycle combustion turbines, fuel is introduced into the combustion chamber under pressure and is mixed with the combustion air (primary air) at an air-fuel ratin of $50: 1$ to $70: 1$. (7) The gases of combustion are cooled by mixing them with the balance of the air (cooling or secondary air) which flows between the inner and the outer shells of the combustion chamber. The degree of cooling of the combustion gases is determined by the permissible maximum temperature that the blades of the first stage of the turbine can be exposed to. The mixing of cool air and hot combustion gases further complicates the design of the combustion chamber since it must produce a uniform turbine inlet temperature. Figure 12-5 shows a diagram of a combustion chamber.

The basic design and operating characteristics of the turbines used in combustion turbines are similar, in principle, to those for turbines used in steam plants; however, the blade materials used in the combustion turbine have to be able to withstand corrosion and erosion due to products of combustion. Figure 12-6 shows a sketch of the major components of a gas turbine assembly. 


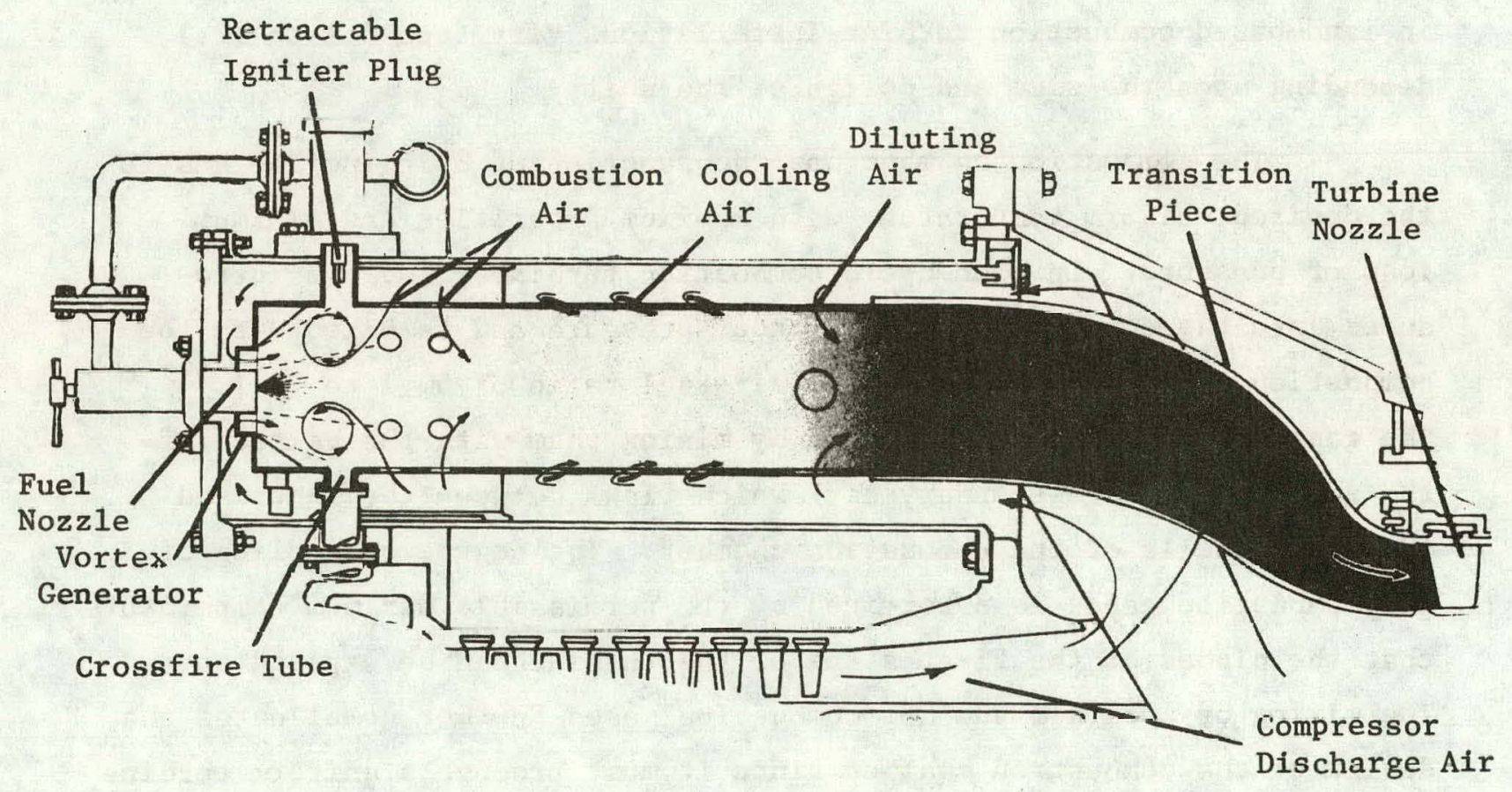

SOURCE: Reference 8 .

FIGURE 12-5 REVERSE-FLOW COMBUSTION CHAMBER FOR GENERAL ELECTRIC SERIES 5001 GAS TURBINES 


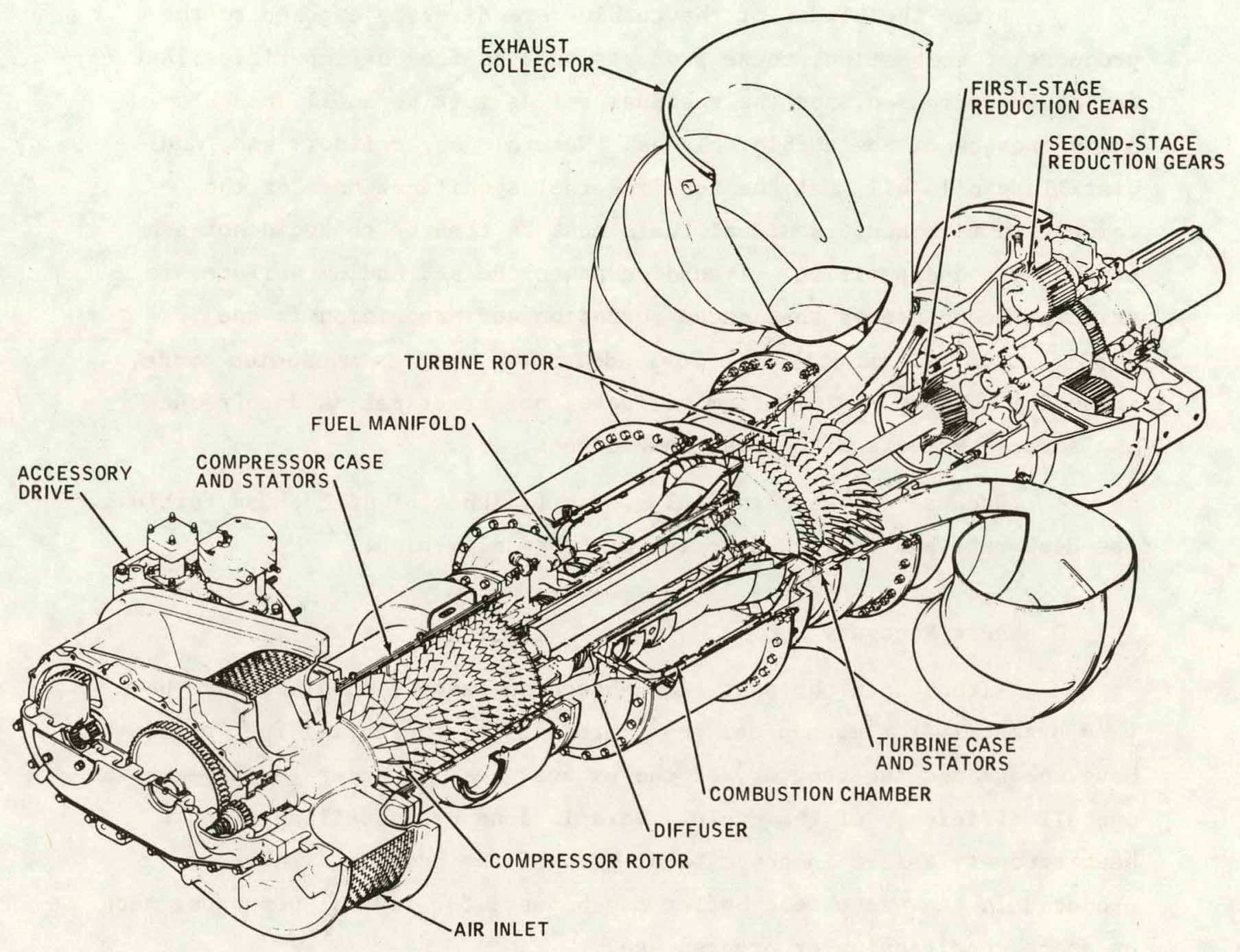

SOURCE: Reference 9.

FIGURE 12-6 SKETCH OF A 900- $\mathrm{kW}$ GAS TIRBINE 
C. Fuels

Since the blades of the turbine are directly exposed to the products of combustion, these products must be free of impurities that can cause corrosion, and the residual solids must be small enough to avoid erosion of the turbine blades. Natural gas, refinery gas, and distillate oils all meet the required fuel specifications for the combustion turbines. Residual fuels must be treated to avoid hot-ash corrosion and deposition. (Vanadium pentoxide and sodium sulfate are principal condensates that cause corrosion and deposition in the $1250^{\circ} \mathrm{F}$ to $1500^{\circ} \mathrm{F}$ range.) ${ }^{(10)}$ Fuel additives, such as magnesium oxide, magnesium sulfate and aluminum silicate, are sometimes used to reduce the adverse effects of combustion products.

Because of the relatively low efficiency of combustion turbines, the heat rate and fuel consumption are generally high.

\section{Heat Recovery}

Although in the past, land-based combustion turbines have been used primarily for mechanical power production, increasing fuel prices have encouraged the recovery of the exhaust heat in order to increase the overall efficiency of the cycle. This is done by installing a waste heat recovery boiler in the exhaust path of the turbine. The steam produced in the waste heat boiler may be used for several purposes, such as space conditioning or process use.

\section{E. Output Power Range}

Today combustion turbines are manufactured anywhere in the range of $35 \mathrm{~kW}$ to $85 \mathrm{MW}$ ( $^{(1,12)}$ This range includes small emergency power units as well as large utility installations. For on-site power applications, the output power range varies from 700 to $25,000 \mathrm{~kW}$. It should be noted here that the power output of a particular unit increases with the increase of the ambient pressure (decreasing elevation above sea level), 
and decreases as the ambient temperature rises; this is due to the inherent characteristics of the thermodynamic cycle (Brayton cycle) of the combustion turbine. Manufacturers typically specify the output power and heat rate of their units at standard pressure and temperature, with zero inlet and exhaust pressure losses, and supply charts and graphs for temperature, altitude, and inlet and exhaust pressure loss corrections. Figure 12-7 shows the altitude correction factor for the Model GS -4000 (3000-kW) gas turbine (manufactured by the Solar Division of International Harvester). Figures 12-8 and 12-9 show the effect of ambient temperature on total power nit.put of the same unit for gaseous and 1iquid fuels. (9)

The size of the units for a particular on-site power generation application depends primarily on the total electric load of the system, and for a cogeneration scheme, the thermal requirements of the site may determine the size of the unit. For reasons of reliability as well as routine (maintenance, overhaul) and forced outages, it is recommended that the total load be distributed over several units in order to have reserve capacity.

Heat rates for combustion turbines are considerably higher than those for diesel engines. In general, the heat rate of combustion turbines is somewhere in the range of $10,000 \mathrm{Btu} / \mathrm{kWh}$ ( $33 \%$ efficiency) to 17,000 $\mathrm{Btu} / \mathrm{kWh}(20 \%$ effictency). $(11,13)$ One manufacturer has built an exceptionally efficient combustion turbine with a heat rate of $8553 \mathrm{Btu} / \mathrm{kWh}(40 \%$ efficiency). The principal design characteristics of this unit include extraordinarily good component efficiency and attention to their aerodynamic details, high pressure ratio (12:1), and efficient cooling of the turbine blades, which allows turbine inlet temperatures as high as $2100^{\circ} \mathrm{F}$, while maintaining a metal temperature (blade temperature) of $1525^{\circ} \mathrm{F}$ ( ${ }^{(14)}$

The heat value of fuels used for combustion turbines is in the range of 18,000 to $20,000 \mathrm{Btu} / 1 \mathrm{~b}$ for 1iquid fuels (corresponding to $142,200 \mathrm{Btu} / \mathrm{gal}$ to $158,000 \mathrm{Btu} / \mathrm{gal}$, assuming an average specific gravity of $7.09 \mathrm{lb} / \mathrm{gal}$ ), and in the range of 800 to $1000 \mathrm{Btu} / \mathrm{scf}$ (standard cubic foot) for gas. Therefore, the liquid fuel consumption of an engine with $20 \%$ efficiency $(17,000 \mathrm{Btu} / \mathrm{kWh})$ and with $18,000 \mathrm{Btu} / 1 \mathrm{~b}$ fuel 
Altitude (1000's feet above sea level)

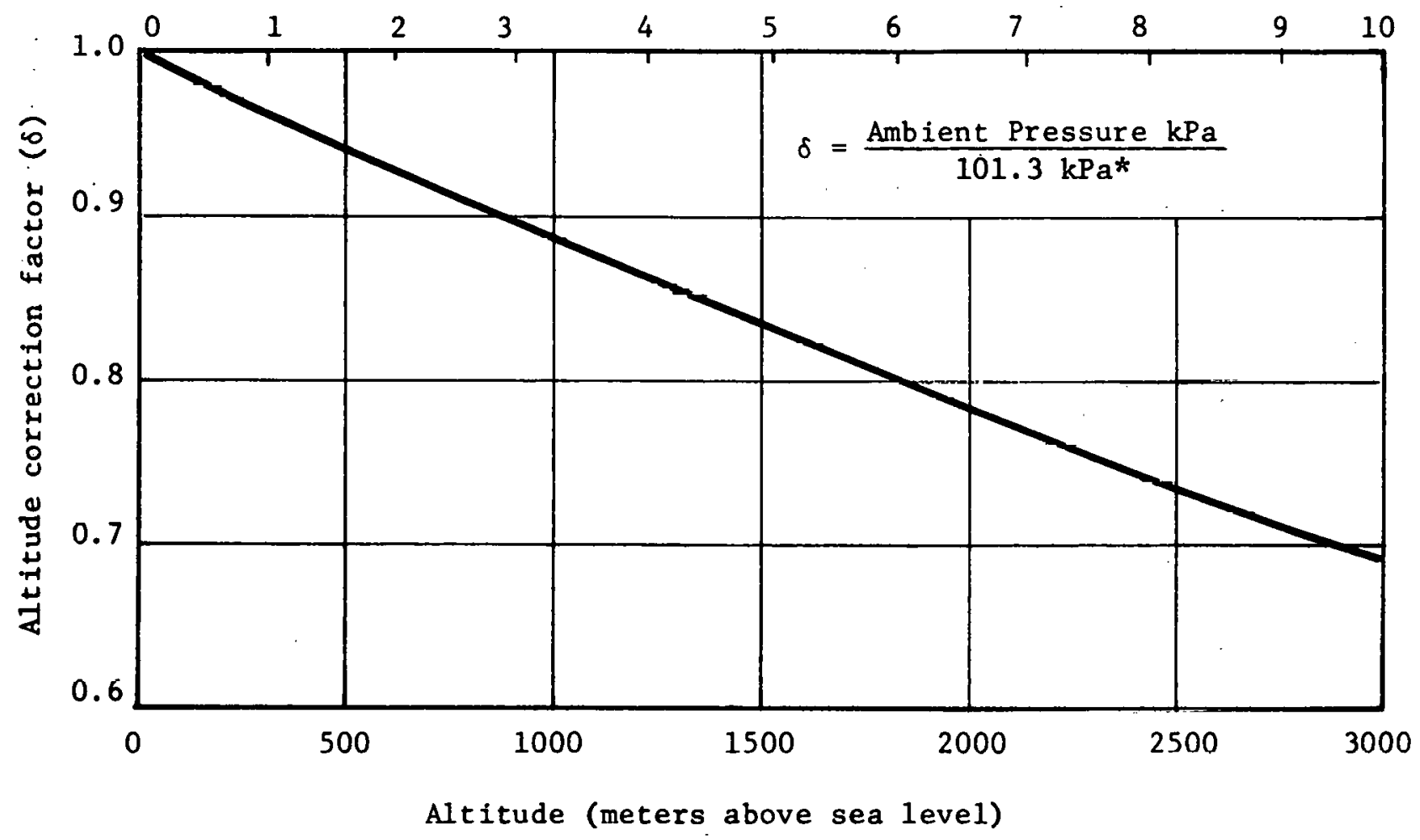

${ }^{*} 101.3 \mathrm{kPa}=14.7 \mathrm{pgla}=$ atmospherlc pressure at sea level. ** Avallable power output at a given altitude is equal to the rated power output at sea level multiplied by the value of $\delta$ for that altitude.

SOURCE: Reference 9.

FIGURE 12-7 ALTITUDE CORRECTION ${ }^{* *}$ FOR OUTPUT POWER (International Harvester-Solar's Model GS-4000, 3000-kW Rated) 


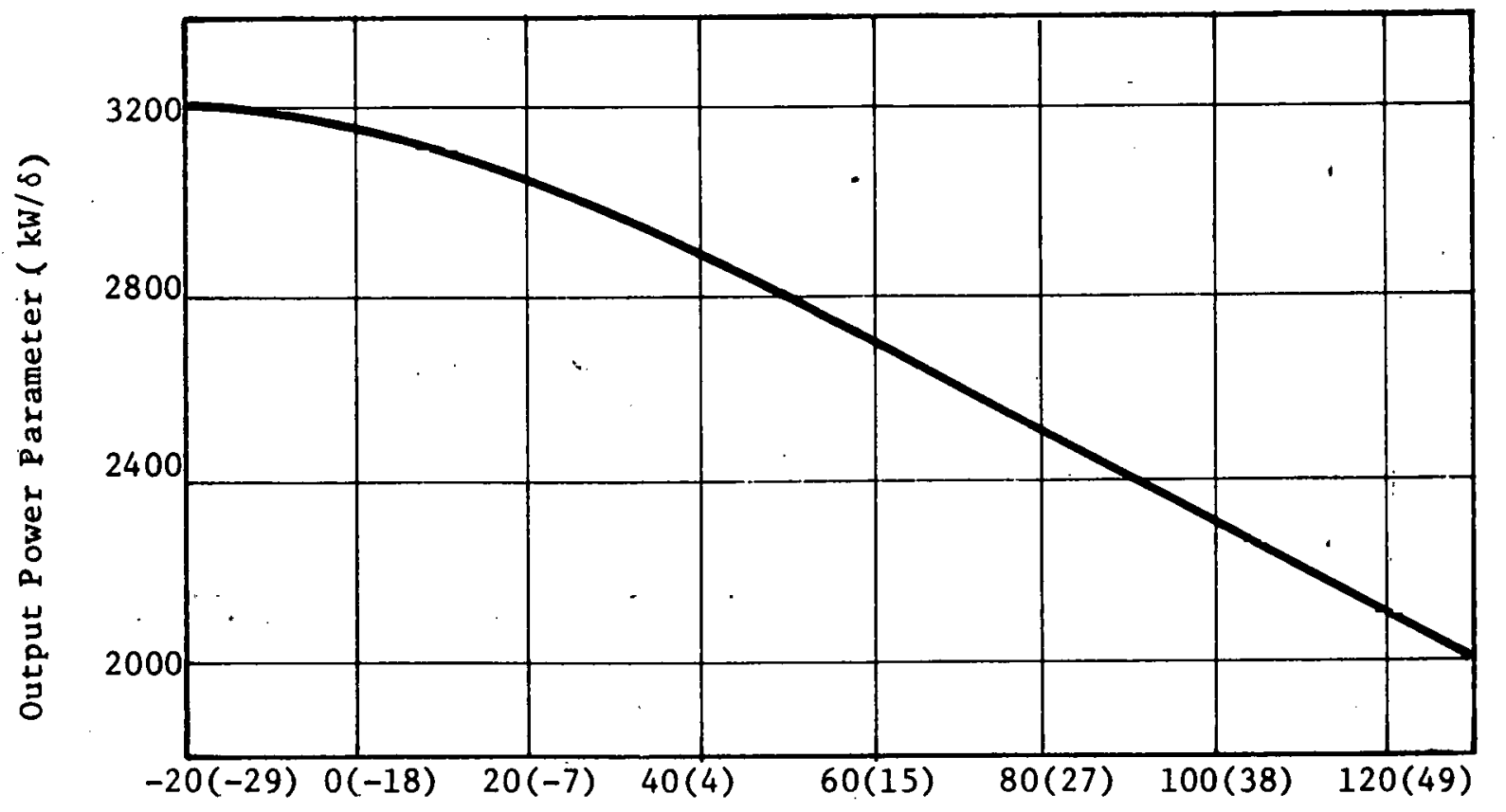

Typical Inlet Air Temperature $\left[{ }^{\circ} \mathrm{F}\left({ }^{\circ} \mathrm{C}\right)\right]$

SOURCE: Reference 9.;

FIGURE 12-8 TYPICAL MAXIMUM OUTPUT POWER VARIATION AS A FUNCTION OF INLET AIR TEMPERATURE FOR UNITS BURNING NATURAL GAS (Solar GS-4000, 3000-kW Rated) 


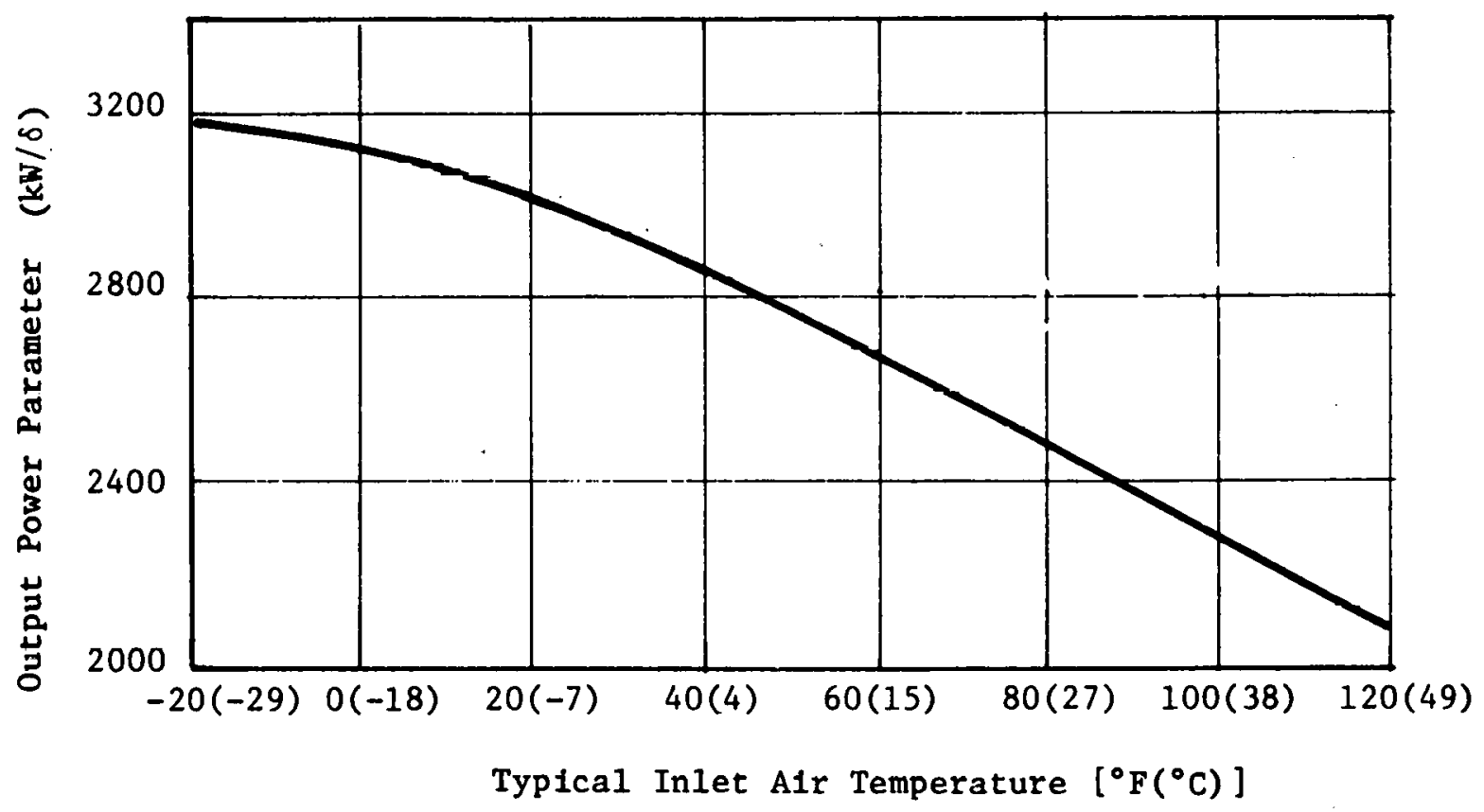

SOURCE: Reference 9.

FIGURE 12-9 TYPICAL MAXIMUM OUTPUT POWER VARIATION AS A FUNCTION OF INLET AIR TEMPERATURE FOR UNITS BURNING LIQUID FUEL (Solar GS-4000, 3000-kW Rated) 
Is about $0.12 \mathrm{gal} / \mathrm{kWh}$, and an engine using $20,000 \mathrm{Btu} / 1 \mathrm{~b}(158,000 \mathrm{Btu} /$ gal) fuel and which is $33 \%$ efficient $(10,000 \mathrm{Btu} / \mathrm{kWh})$ consumes about $0.063 \mathrm{gal} / \mathrm{kWh}$ of fuel. If the combustion turbine uses natural gas with a heat value of $800 \mathrm{Btu} / \mathrm{scf}$ and is on $1 \mathrm{y} 20 \%$ efficlent, it consumes $21 \mathrm{scf} /$ $\mathrm{kWh}$; for an efficiency of $33 \%$ and gas with a heat value of $1,100 \mathrm{Btu} / \mathrm{scf}$, the consumption $1 \mathrm{~s} 7.8 \mathrm{scf} / \mathrm{kWh}$.

It is important to note that part-load operation of a combustion turbine causes a considerable heat rate, and hence fuel consumption, penalty. On one occasion, ${ }^{(15)}$ a $6445-\mathrm{hp}(4834-\mathrm{kW})$ gas turbine was operated at below 50\% maximum rated output and required a $20 \%$ increase in specific fuel consumption; ${ }^{*}$ this test represents the best part-load operation achieved to date.

It is possible to improve the overall fuel utilization in a combustion turbine through the recovery of the exhaust waste heat. Waste heat recovery reduces the mechanical power output of the combustion turbine, and the size of the waste heat recovery boller 1s determined by the electric generation efficiency; overall fuel utilization, and the cost of the heat recovery equipment. Also, in units fired with liquid fuels containing sulfur compound, the exhaust temperature must be kept above the sulfur compound's dewpoint temperature to avoid the formation of deposits on surfaces; such a limitation generally does not exist with units f1red with natural gas. Heat recovery can result in $50-70 \%$ fuel utilization rates. In a particular total energy project ${ }^{(13)}$ (electric generation/district heating), an overall fuel utilization as high as $81 \%$ and a power generation of $24 \%$ were achleved, meaning that it was possible to recover as much as $75 \%$ of the discharged exhaust heat. Without heat recovery, an electric generation efficiency of $33 \%$ was recorded.

${ }^{*}$ lb of fuel/hp-hr. 


\section{Section 12.3: Economics Discussion}

\section{A. Market Opportunities}

The principal application of land-based combustion turbines is for electrical generation or mechanical power production (continuous or standby). The oil and gas industries as well as the utility industry are major users of larger (10-MW and higher) combustion turbines. For on-site total energy applications, the feasibility of installing combustion turbines depends on:

- availability of power from a utility;

- peak and average electrical load of the site;

- peak and average thermal load of the site;

- dally load profile and overall load factor of the on-site plant;

- relationship of the capital, fuel, and operating cost of on-site-generated energy to the cost , of purchased power; and

- comparative assessment of: (a) conventional boilers for heat generation and purchasing electric power from a utility, (b) steamcondensing cycle for electric and thermal energy generation, and (c) diesels with waste heat recovery.

The plant load factor is an important consideration in combustion turbine installations since the specific fuel consumption increases rapidly with part-load operation. Potential users include:

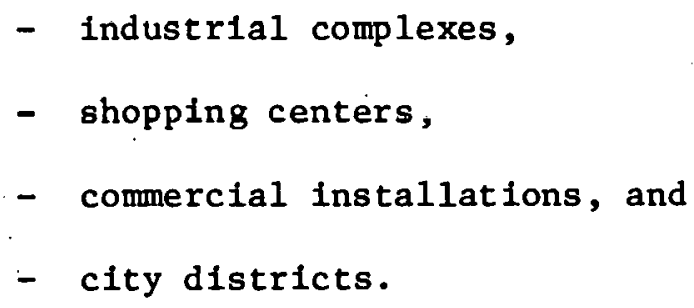

* Load factor is the ratio of the average hourly demand to the maximum hourly demand during the same perlod. 


\section{B. Costs}

Costs associated with combustion turbine installations include capital and installation costs, fuel cost, maintenance costs, and other operating costs. Capital costs of combustion turbines (compressor, turbine, generator), range from $\$ 100 / \mathrm{kW}$ to $\$ 225 / \mathrm{kW},(16,17,18)$ depending on the manufacturer and the accessory equipment required (e.g., sound-attenuating enclosure, weather-proof enclosure, filtration for sand, dust, and salt). Installation costs range from $\$ 40 / \mathrm{kW}$ to $\$ 65 / \mathrm{kW}$, depending on the size of the machine, geographic location, and necessary site preparations. Therefore, the cost of installed combustion turbines without heat recovery ranges from $\$ 140 / \mathrm{kW}$ to $\$ 290 / \mathrm{kW},(16,17,18)$ with $\$ 240 / \mathrm{kW}$ being the cost of a typical installed unit. The addition of heat recovery equipment will increase the Installed cost by $\$ 75 / \mathrm{kW}$ to $\$ 125 / \mathrm{kW}$, depending on the equipment. Hence the cost of combustion turbines with heat recovery is in the range of $\$ 215 / \mathrm{kW}$ to $\$ 415 / \mathrm{kW}$, and $\$ 340 / \mathrm{kW}$. is the cost of a typical installation with heat recovery. $(16,19)$ since the unit prices vary with efficiency, accessories, and machine design, it is difficult to general1ze about unit prices $(\$ / \mathrm{kW})$. However, unit prices genera11y decrease with increasing machine capacity.

In Section 12.2-E, the fuel consumption rate was estimated to be from $0.063 \mathrm{gal} / \mathrm{kWh}$ to $0.120 \mathrm{gal} / \mathrm{kWh}$ for 1 iquid-fuel-fired units and from $7.8 \mathrm{scf} / \mathrm{kWh}$ to $21 \mathrm{scf} / \mathrm{kWh}$ for gas-fired units. The price of fuels varles greatly according to geographic location and depends also on the Btu content. For the purposes of this chapter, assuming fuel prices of $\$ 0.50 / \mathrm{ga} 1$ for liquid fuel and $\$ 3.00 /$ Mcf (million $\mathrm{ft}^{3}$ ) for gas, fuel consumption costs will be $\$ 0.032 / \mathrm{kWh}$ to $\$ 0.060 / \mathrm{kWh}$ for unfts using distillate fuels, and $\$ 0.023 / \mathrm{kWh}$ to $\$ 0.063 / \mathrm{kWh}$ for units using natural gas.

On the average, a combustion turbine on continuous duty requires major overhaul after every 20,000 hours of operation. Units on standby that go through frequent startups and shutdowns may require overhaul more frequently'. A unit can have several overhauls during its lifetime. Therefore, it can have an operating lifetime of 80,000-100,000 hours. The cost of operation and maintenance of combustion turbines (excluding fuel cost and salaries for a full-time operator, but including labor and parts 
for routine maintenance and pertodic overhaul) is estimated to be about $\$ 0.002 / \mathrm{kWh}$ to $0.004 / \mathrm{kWh}$. (16) Therefore, the total operating cost (fuel, operation, maintenance) is in the range of $\$ 0.025 / \mathrm{kWh}$ to $\$ 0.067 / \mathrm{kWh}$ for combustion turbines burning natural gas or distillate fuels. It is not possible at this time to estimate the operation and maintenance costs for combustion turbines burning coal-derived fuels, but it is certian that they will be higher.

\section{Section 12.4: Limitations}

Factors limiting the application of combustion turbine total energy systems include economic disincentives of declining electric block rates (set by the utilities and regulatory agencles for large consumers) and environmental considerations (nolse and alr pollutions).

The declining utility block rate system discourages customers with large electric demand from generating their own electricity. Several load management programs (to reduce peak electricity demand) are under way around the country, and the trend is toward different rate systems, in particular to time-of-day rate schedules. However, it is not clear to what extent these would be applied to large industrial and commercial users, and it remains to be seen how future electric rate systems will affect the cost-benefit analysis of on-site cogeneration. From the environmental viewpoint, areas of concern are the nolse level of combustion turbines and their effect on local air quality. In general, gas turbines are designed to achieve a sound level of approximately $90 \mathrm{~dB}(\mathrm{~A})^{*}$ just outside the enclosure, in accordance with the near-field noise standards; ${ }^{(20)}$ this results in a far-field (about $400 \mathrm{ft}$ ) noise level of around 50-55 dB(A). In order to reduce the noise level to about $45 \mathrm{~dB}(\mathrm{~A})$ (the noise level for a quiet street) requires additional buildings and barriers.

Present design of combustion turbines requires burning of clean fuels (natural gas or distillate fuels); as a result, the emissions generally conform with the provisions of the Clean Air Act. There is, however, considerable research and development under way to produce coa1-

\footnotetext{
${ }^{\star} \mathrm{dB}(\mathrm{A})=$ frequency-weighted decibel scale for industrial purposes.
} 
derived fuels as a substitute for imported oil. The extent to which coal-derived fuels can be "cleaned up" is yet to be determined. The emissions from such fuels may result in particulate, sulfur compound, and $\mathrm{NO}_{\mathrm{x}}$ discharges above the levels set by the Environmental Protection Agency or by state and local regulatory agencies, and hence limit the use of such fuels in combustion turbines for on-site energy systems. 
THIS PAGE

WAS INTENTIONALLY

LEFT BLANK

12. 20 


\section{REFERENCES}

1. Gill, P.W., et a1. Fundamentals of Internal Combustion Englnes. Annapolis, Maryland: The U.S. Naval Institute, 1964. p. 16.1.

2. G111, P.W., et al. Fundamentals of Internal Combustion Engines. Annapolis, Maryland: The U.S. Naval Institute, 1964, p. 16.3.

3. Morrisson, R. "Gas Turbines." Standard Handbook for Mechanica1 Engineers. 7 th ed. Edited by T. Baumeister. New York: McGrawH111, 1967. p. 9-150.

4. "Gas Turbine Development Program for the Next Decade." Gas Turbine Internationa1, $17(5): 2.4$, September - October 1976.

5. Van Wylen, G.J., et a1. Fundamentals of Classical Thermodynamics. New York: John Wiley and Sons, Inc., 1965. p. 303.

6. Van Wylen, G.J., et al. Fundamentals of Classical Thermodynamics. New York: John Wiley and Sons, Inc., 1965. p. 308.

7. Morrisson, R. "Gas Turbines." Standard Handbook for Mechanical Engineers. 7th ed. Edited by T. Baumeister. New York: McGrawHi11, 1,967, p. $9-153$.

8. General F.lectric Co., Schenectady, New York. Product 1iterature, Series 5001 gas turbines. 1976.

9. International Harvester, Solar Division. "Gas Turbine Generator Sets." Handbook for Architects and Consulting Engineers. San Diego, California, 1976.

10. Morrisson, R. "Gas Turbines." Standard Handbook for Mechanical Engineers. 7th ed. Edited by T. Baumeister. New York: McGrawHi11, 1967. p. 9-155.

11. "Stand-by Gas Turbine Specification." Turbomachinery International, January-February 1978. pp. 32 ff.

12. General Electric Company, Wellesley, Massachusetts. Private correspondence. March 1978.

13. Schmoch, O.R. Land Gas Turbines 10-80 MW. London: Diesel Engineers and Users Association, 1973. Publication 355.

14. Detroit Diesel Allison, Box 894, Dept. U-5, Indianapolis, Indiana 46206. Private correspondence. March 1978. See also Reference 11, p. 34.

15. "Mode1 570 Rates 6445 hp with 8473 Btu Heat Rate." Gas Turbine World 7(3):58, March 1977. 
16. General Electric Company, Wellesley, Massachusetts; Curtiss-Wright Corporation, Wood Ridge, New Jersey; Avco-Lycoming Division, Stratford, Connecticut; Solar Division of International Harvester, Boston, Massachusetts. Private correspondence. March 1978.

17. "Competitive Bids and Orders." Gas Turbine World 7(7):5, July 1977.

18. "Competitive BIds and Orders." Gas Turbine World 8(1):5, January 1978.

19. "3-5 MW Plant to Pay for Itself in Three to Four Years." Gas Turbine World 7(5):20, May 1977 .

20. "Noise Control Economics of Siting Gas Turbine Power Plants," Gas Turbine Ilternacional 18(3):22, May - June 1977. 


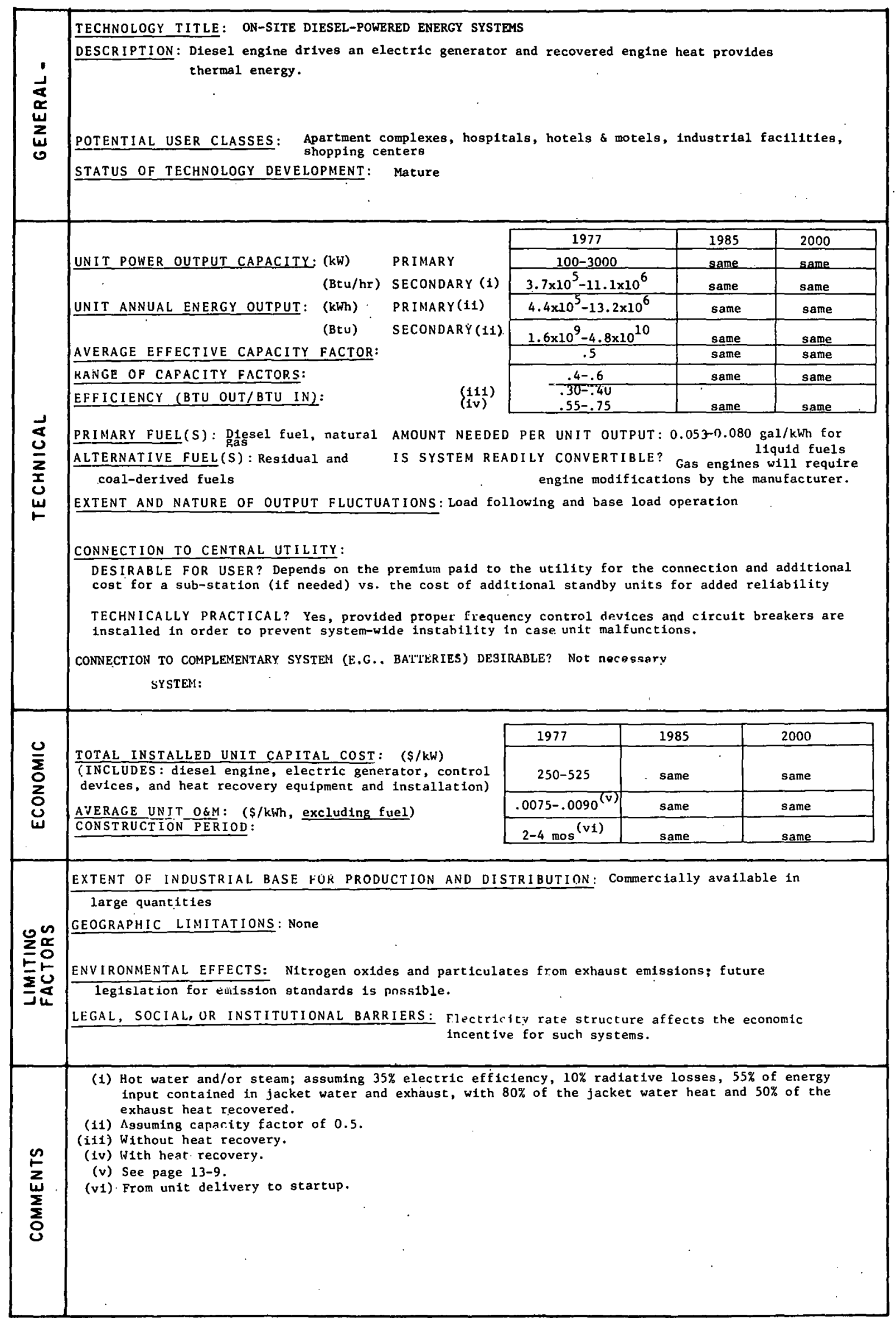


CHAPTER 13

\section{ON-SITE DIESEL-POWERED ENERGY SYSTEMS}

\section{Section 13.1: Introduction}

The diesel engine* was patented in. 1892 by Dr. Rudolph Diesel in Germany. The first successful commercial diesel engine was installed in St. Louis, Missouri, in 1898, and by 1910.the diesel engine had become a common source of shaft horsepower. Major engine design improvements were the advent of turbocharging in the mid-1940's and charge-air cooling in the 1950's. Since the 1960's, U.S. development has been limited to obtaining higher operating pressures and engine speeds. (1) European diesel development (Sulzer, Brown Boveri, MAN) resulted in lowerspeed residual fuel engines. Today diesel engine sizes vary anywhere from small portable $1.6-\mathrm{kW}$ sets to large $40,000-\mathrm{kW}$ units installed by utilities for power generation. For on-site power applications, unit sizes usually fall in the $100-\mathrm{kW}$ to $3000-\mathrm{kW}$ range.

Although the diesel engine was developed primarily for mechanical power, recovery of the engine heat from the jacket's cooling water and the exhaust gases is practical and, for on-site power generation application, is in fact desirable. In terms of mechanical power production, the efficiency of diesels varies from $30-40 \%$ (at $80 \%$ rated capacity), depending on the size and design of the engine. In addition, part-load efficiencies down to as low as one-third full power remain high. Recovery of the otherwise rejected engine heat can increase the overall energy efficiency of the engine to the range of $55-75 \%$, depending on the type and degree of sophistication of heat-recovery equipment.

\footnotetext{
${ }^{*}$ Here diesel engine refers to engines operating on liquid fuels - diesel fuel, bunker C residual fuel, etc. Diesel engines that operate by burning natural gas are referred to as gas engines and differ only in the fuel injection system.
} 
The feasibility of installing diesel engines for on-site electric power and heat generation should be based on a careful analysis of the total energy requirements, the balance between the demand for electricity (or mechanical power) and the demand for heat, the plant load factor, and the relationship of fuel cost to the cost of energy available from other sources.

\section{Section 13.2: Technical Discussion}

\section{A. Design Principles}

The diesel engine is an internal-combustion reciprocating engine. It is similar to the standard automobile engine, with the principal difference being in the way in which the fuel-air mixture is ignited. In the automobile engine, ignition is accomplished by means of an electrical spark, whereas in the diesel the compression stroke itself produces a sufficiently high pressure (hence temperature) to cause ignition. The diesel engine requires higher compression ratios than the gasoline engine (in the range of 12:1 to 20:1 for the diesel as compared to the range of $5: 1$ to $10: 1$ for a gasoline engine). (2)

The engine speed is a principal design consideration. There are three basic categories: 1ow-speed (80-300 rpm), medium-speed (300-900 rpm), and high-speed (900 rpm and up). Low-speed diesels are used primarily for marine propulsion and sometimes for power generation in large central stations. Medium-speed engines are used for marine propulsion and standby or continuous-duty power generation. High-speed engines are used almost exclusively for automotive, locomotive, and on-site power generation:

Almost all of the diesel engines manufactured tuday in the United States operate on a four-stroke cycle comprised of:

1. Intake stroke -- in which the moving piston draws in fresh air;

2. Compression stroke -- in which air is compressed by the upward moving piston and fuel is injected into the cylinder;

3. Power stroke -- in which combustion of the mixture of air and atomized fuel occurs and the expanding 
gases force the p1ston down; and

4. Exhaust stroke -- in which the products of combustion are forced out through the exhaust valve by the upward-moving piston.

The lower-speed European diesels operate on a two-stroke cycle combining intake and compression strokes in one stroke and power and exhaust strokes in another stroke.

B. Output Power Range

There are many diesel engine manufacturers in the United States and around the world, some with more than half a century of experience in the field. Diesel engines built today range from small $1.6-\mathrm{kW}$ sets (Bernard four-stroke air-cooled, manufactured by Bermotor of England) to large units of more than $40,000 \mathrm{~kW}$, e.g., the lower-speed, two-stroke cycle version built primarily by Sulzer and MAN in Europe which are mainly used for marine propulsion. In the United States, Delaval of Oakland, California, manufactures medium-speed engines of up to $10,000 \mathrm{~kW}$; these are the largest units built in this country.

On-site generating stations (for electric power or combined electric power and heat), similar to large utilities, must be able to modify their output to meet the dally and weekly load profiles. For this and for reasons of reliability, it is necessary to distribute the total load (mechanical and heat) of a facility among several generating units. Load centers suitable for diesel-powered prime movers (schools, hospitals, shopping centers; etc.) usually install several units in the range of $100-3000 \mathrm{~kW}$ each. $(3,4)$

The units must be optimized for simultaneous delivery of heat and electricity to the load. This is necessary since it is not possible to reduce the electrical energy output of the machine in order to gain more thermal energy and vice versa.

C. Units Without Heat Recovery

Diesel engines without heat recovery are used to drive electric generators, compressed air and air conditioning compressors, and deep-well 
pumps, and to pump gas in distribution lines as well as in ship propulsion systems. Units can provide either continuous or standby power. If continuous service is required, it is necessary to provide reserve capacity so that the system will still have full-load supply capability in case of a forced outage or routine maintenance of one unit. Standby units can usually be brought on-line in less than 5 seconds for units up to about $300 \mathrm{~kW}$ and in less than 30 seconds for units on the order of $1000 \mathrm{~kW}$. This applies to units on "hot" standby where the engine oil is maintained at operating temperature. Larger units of several megawatts and upward require several minutes for startup and power delivery.

An internal combustion reciprocating engine is the most efficient heat engine available today for converting the energy content of a prime fuel lutu shaft horsepower. Today the efficiencles of diese1 engines vary from $30 \%$ to approximate1y $40 \%(3,4,5)$ (corresponding to heat rates of about 11,000 to $8500 \mathrm{Btu} / \mathrm{kWh}$, respectively), depending on the size, design, manufacturer, age, and maintenance condition of the unit.

\section{Units With Heat Recovery}

In a diesel engine, as mentioned above, about $30-40 \%$ of the total available fuel energy is utilized in the form of mechanical power; the remaining energy appears in the form of heat, and if not recovered, is rejected to the environment. Of the $60-70 \%$ hear energy, about $5-10 \%$ is radiated away by the engine and is not recoverable; of the remaining $50-60 \%$, about one-half is contained in the facket cooling water and the other half in the exhaust gases from the engine. $(6,7)$ While all of the heat in the jacket water is available for recovery, only part (approximately one-half) of the heat energy of exhaust gases can be recovered. (If the temperature of the exhaust gases drops below the sulfur compounds' dewpoint temperatures, sulfur compound deposits are formed on the surfaces.)

Jacket water heat can be recovered by three methods: 
- the hot water system,

- the hot water and steam system

(with flash boiler), and

- the ebullient system.

In the hot water system, jacket water with an outlet temperature of about $180^{\circ} \mathrm{F}$ is passed through a heat exchanger (water tube type) for additional heat recovery from the exhaust gases, and then passed through a she11-and-tube heat exchanger, where the heat is transferred to a secondary circuit. It is possible to obtain higher hot water temperatures by opcrating the jacket cooling-water loop under pressure (to prevent boiling of water in the loop). Typical pressures range from 5 psig to 20 psig with outlet temperatures in the $220^{\circ} \mathrm{F}$ to $250^{\circ} \mathrm{F}$ range.

The hot water and steam system incorporates many features of the hot water system, plus a flash boiler for generating low-pressure (2 to 8 psig) steam. (7) The jacket water circuit is always maintained at higher pressures than the boiler to prevent boiling within the engine. Sceam is generated in the flash boiler and in the piping to the hoiler, becauoc of the pressure differential that exists in the system by design.

The ebullient system utilizes the heat of vaporization to remove rejected heat from the engine. Heat removal is based on natural water circulation within the engine due to inlet and outlet water density differential. Steam is not separated within the engine but is removed through the water passages, along with the high-temperature water, to a steam separator located at a higher elevation than that of the engine. Figure 13-1 shows the ebullient system and the various components of a two-unit diesel package with both jacket-water heat recovery (ebullient) and exhaust-gas heat recovery.

\section{E. Control}

The control system and switchgear for an on-site diesel installation vary in the degree of sophistication and depend on the type of facility and load served by the plant. The basic consideration is whether the plant is controlled manually or automatically. In the case of installations 


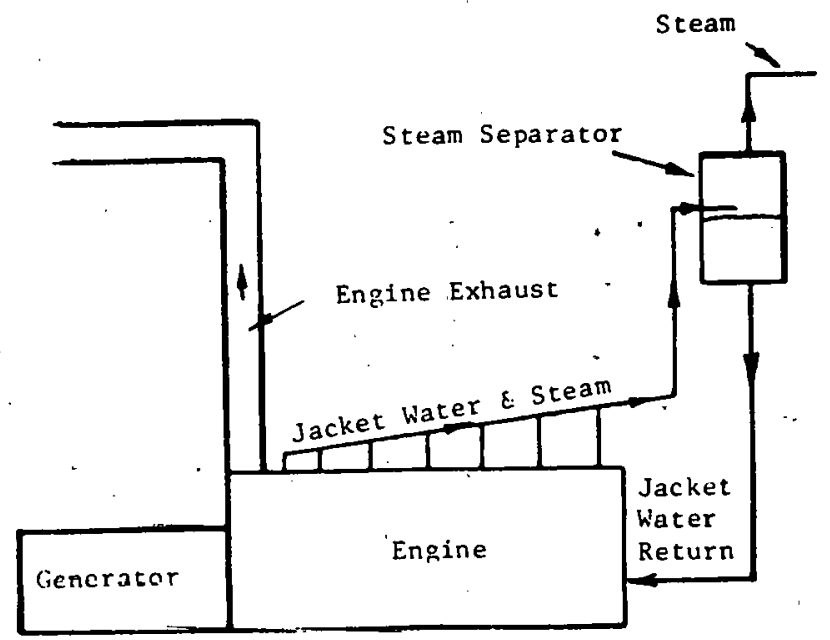

Ebullient. System

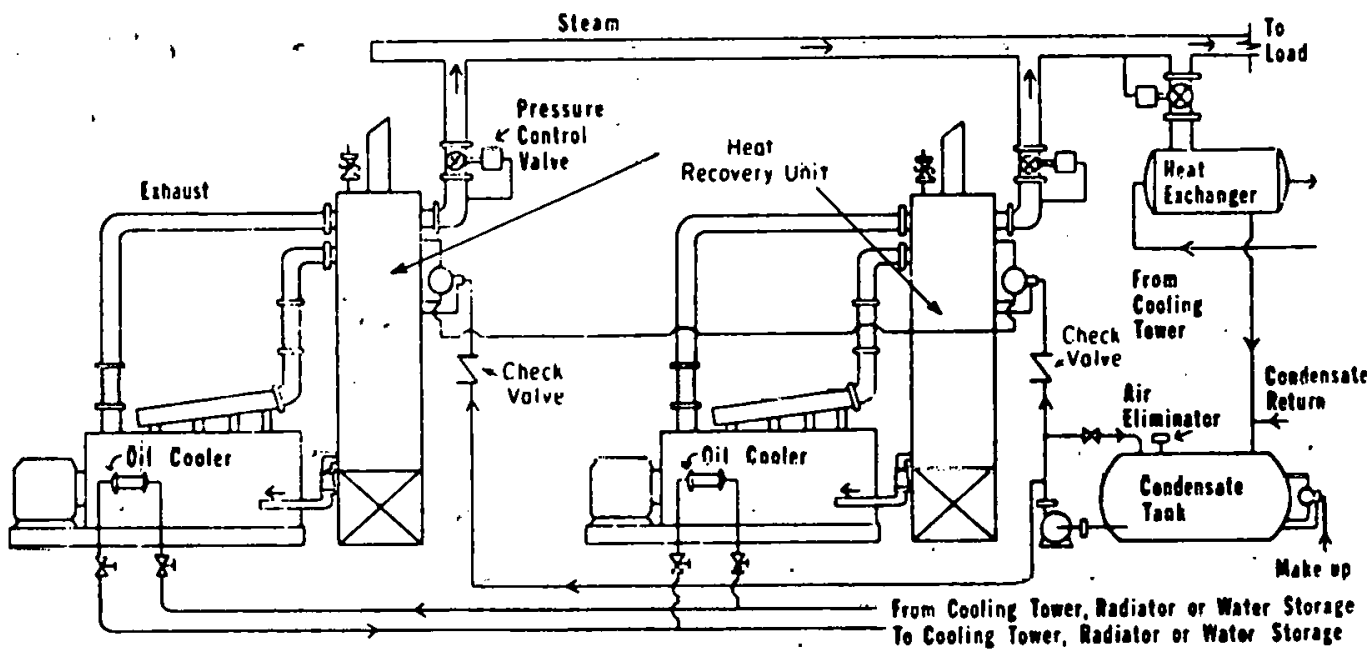

SOURCE: References 4 and 7 .

FIGURE 13-1 SCHEMATIC DIAGRAMS OF EBULLIENT HEAT RECOVERY (Top) AND A TWO-UNIT DIESEL PACKAGE WITH EBULLIENT AND EXHAUST HEAT RECOVERY (Bottom) 
operated manua11y, the plant attendant places units on or off service as demanded and load-sharing is controlled by manual adjustments.

In automatically controlled installations, units are placed on or off service by signals from an automatic load-sensing device and are paralleled by an electric governor. (3) In addition to customary safety controls (e.g., reverse current trips, low oll pressure, high oll temperature, overspeed shutdown, etc.), unattended Installations should have automatic shutdown capability for high oil temperatures, low coolant level, or excessive vibration, as well as remote read-out devices to Indicate when other than routine servicing is required.

F. Reliability

Over the years, the diesel engine has gone through many stages of design and manufacturing improvement, along with millions of hours of operating experience. It represents a fully developed and mature technology with the avallability of marine-type engines (slow-speed, two-stroke) approaching more than $90 \%$.

A recent scudy ${ }^{(1)}$ has indicated that the average rate of fallure to start is one in every 650 attempts; $80 \%$ of these failures were due to electrical faults (the starting system), and only random mechanical faults were noted. In continuous operation, world-wide failure rate is reported to be one "stoppage" in every 2500 hours, for a forced outage rate of 3.5 per year. The majority of the forced outages are assoclated with fuel system failure.

System reliability can be improved by dividing the total load into "essential" and "non-essential" parts, so that, in case of a partial outage, non-essential load can be dropped and the essential load can be served without interruption.

\section{Section 13.3: Economics Discussion}

\section{A. Market Opportunities}

The diesel-powered on-site energy system has many applications, including: 
- Apartment complexes,

- Hospitals,

- Hotels and motels,

- Industrial factlities,

- Schools,

- Office buildings, and

- Shopping centers.

Careful cost/benefit analysis is required in each case and factors affecting the outcome include:

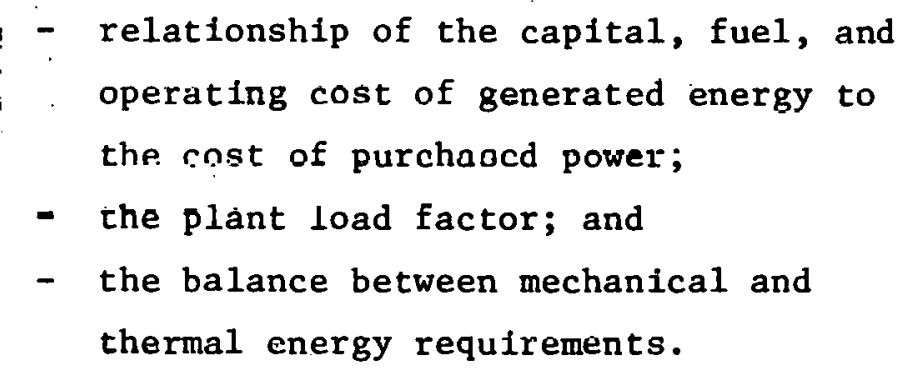

B. Costs

Costs associated with an on-site diesel installation include capital cost, fuel cost, maintenance cost, and other operating costs. Highspeed engines cost less, have a higher fuel consumption rate, and shorter IIfe than medium- and low-speed englnes. Low-speed englnes have a slightly better fuel consumption rate than medium-speed engines. Also, low-speed engines can burn heavy bunker $C$ fuels, whereas high-speed engines require cleaner diesel fuel.

Capital costs for high-to-medium-speed engines (including heat recovery boller) range from $\$ 250$ to $\$ 525$ per installed $\mathrm{kW}$, depending on the size (a few hundred to a few thousand $\mathrm{kW}$ ), engine design, speed, and control equipment furnished, $(3,4,8)$ with $\$ 375$ per installed $\mathrm{kN}$ being a typical cost within this range. The high end in this range applies to unattended medium-speed installations, and the low end applies to high-speed units. 
Fuel costs relate to the efficiency as well as to the fuel acceptability of the engine. For an efficiency range of $30-40 \%$, corresponding to heat rates of 11,000 to $8500 \mathrm{Btu} / \mathrm{kWh}$, fuel consumption is calculated below.

Assuming the heat content of diesel fuel to be 18,835 to 19,376 $\mathrm{Btu} / 1 \mathrm{~b}$ and a fuel density of 7.4 to $8.2 \mathrm{lb} / \mathrm{gal}$, a heat value of 140,000 to $160,000 \mathrm{Btu} / \mathrm{gal}$ for diesel fuel is obtained. At $8500 \mathrm{Btu} / \mathrm{kWh}$, fuel consumption will be in the $0.053-0.060 \mathrm{gal} / \mathrm{kWh}$ range; for $11,000 \mathrm{Btu} / \mathrm{kWh}$, fuel consumption increases to $0.070-0.080 \mathrm{gal} / \mathrm{kWh}$, depending on the heat value of the fuel. A reasonable rate for the bulk delivery of diesel fuel is about $\$ 0.40 /$ gal. Therefore, the fuel cost will range from a low of $\$ 0.0212 / \mathrm{kWh}$ for an engine with $40 \%$ efficiency (mechanical) and burning $160,000 \mathrm{Btu} / \mathrm{gal}$ fuel, to a high of $\$ 0.032 / \mathrm{kWh}$ for an engine with $30 \%$ efficiency (mechanical) and burning 140,000 Btu/gal fuel.

With the addition of a heat recovery boller, the overall effictency increases to the $55-70 \%$ range. The economic benefit can be estimated by calculating the cost of the fuel required to heat the water directly, taking into account the cost of the boller.

The maintenance and other operating costs of an on-site diesel installation are not so easily estimated as fuel and initial capital costs. However, maintenance and service.contracts, which are being offered at an increasing rate, can be used to estimate these costs. Maintenance contracts vary from agreements for complete service and maintenance (including engine rebullding), covering all parts and labor, to contracts for routine maintenance (oil change and check, filter change, etc.). The contracts are generally written for a definite period of time, usually for 10 years, which in fact corresponds to the average life of a diesel engine. A complete service and maintenance contract costs in the range of $\$ 0.0075-\$ 0.0090 / \mathrm{kWh} .(3,4)$. Therefore, the total fuel and operating costs (including fuel, operation, and maintenance, but excluding salaries of full-time operatiors) of an on-site diesel plant vary from approximately $\$ 0.029 / \mathrm{kWh}$ to $\$ 0.041 / \mathrm{kWh}$, with $\$ 0.034 / \mathrm{kWh}$ being typical within this range. 
Section 13.4: Limitations

Factors limiting the use of diesel engines for on-site power and heat generation include economic disincentives of decining electric rates set by utilities and regulatory agencles, as well as adverse effects of exhaust emissions on local air quality.

The declining utility block rate system is an institutional and economic issue that may discourage customers with large electric demands from generating their own electricity.

As mentioned before, diesel engines are capable of burning natural gas (In which case the engine is referred to as "gas engine") and distillate fuels, as well as heavy residual fuels. The emissions from burning of natural gas and distillate fuels generally conform with the provistons of the Clean Air Act. However, burning of residual fuels or coal-derived fuels * may have adverse effects on local air quality and hence limit the application of diesels for on-site energy systems with such fuels.

*

The Department of Energy has funded research and development projects for the production of clean burning coal-derived fuels. (9) 


\section{REFERENCES}

1. Shearer, A.B. "The Historical Development and Future Prospects of the Diesel Engine." Diesel Engineering 72(790):155, 1976.

2. Gill, P.W., et al. Fundamentals of Internal Combustion Engines. Annapolis; Maryland: The U.S. Naval Institute, 1964. p. 11.2.

3. Cummins Engine Company, Inc., 100 Allied Drive, Dedham, Massachusetts 02036. Private correspondence. March 1978.

4. Caterpillar Tractor Company, 100 N.E. Adams, Peoria, Illinois 61629. Private correspondence. March 1978.

5. Shearer, A.B. "The Historical Development and Future Prospects of the Diesel Engine." Diesel Engineering 72(790):156, 1976.

6. O'Shea, J.A. "Kalamazoo Adopts Diesel-Based Total Energy." Diesel Engineering 72(788):33, 1976.

7. Jones, R.A. Caterpillar on Total Energy. London: Diesel Engineers and Users Association, 1972. Publication 345.

8. DeLaval Turbine Inc., 550 85th Ave., Oakland, California 94621. Private correspondence. March 1978.

9. Power Systems Division of United Technologies, Inc., 1690 New Britain Ave., Farmington, Connecticut 06032. Private correspondence. February 1978. 
THIS PAGE

WAS INTENTIONALLY LEFT BLANK

$13-12$ 


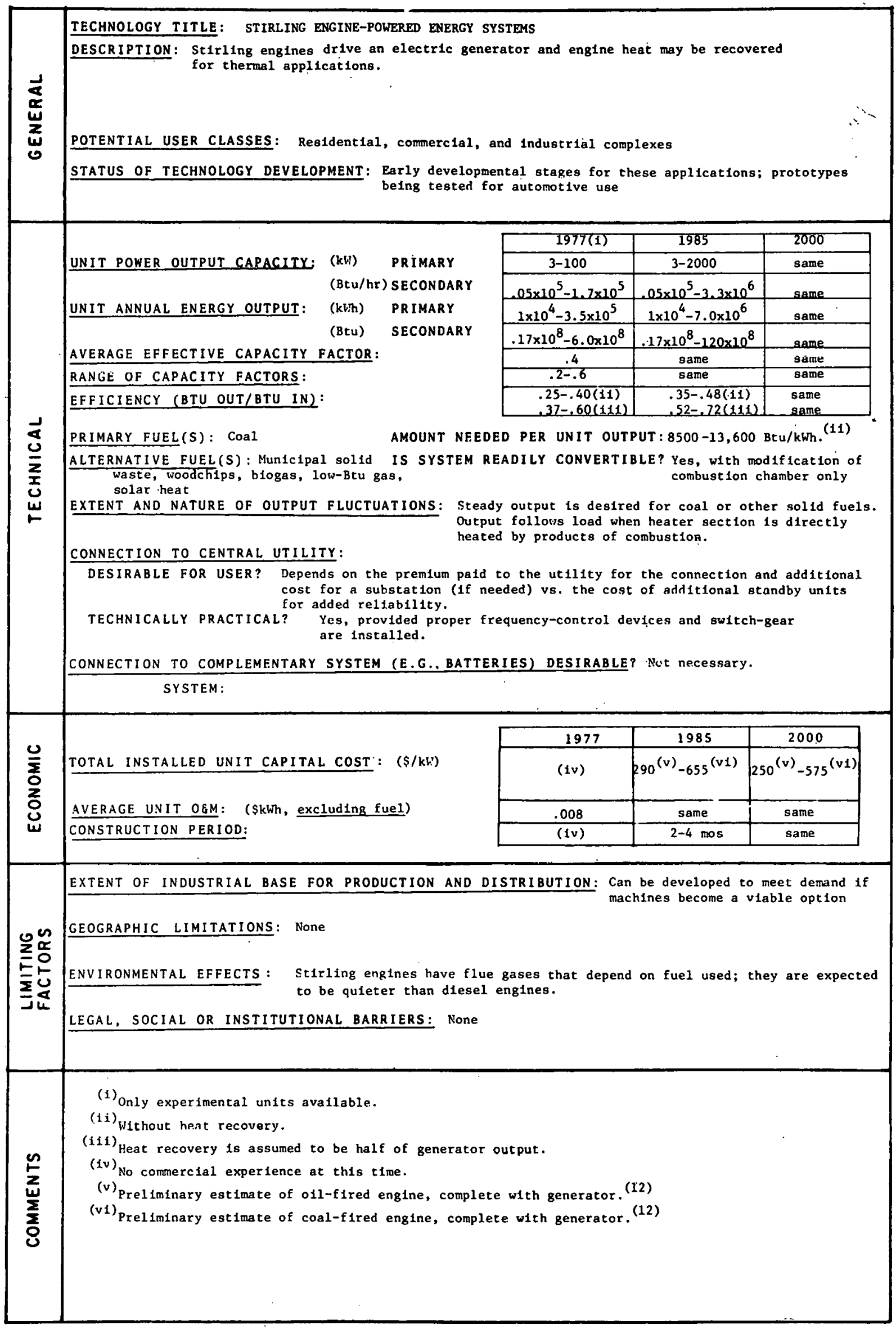


CHAPTER 14

STIRLING ENGINE-POWERED ENERGY SYSTEMS

Section 14.1: Introduction

The principles of the Stirling thermal engine were understood long ago, and operating devices based on them were introduced in 1818. Nevertheless, it required modern technology to translate the concept into practical devices that may compete favorably with more established prime movers. For this reason, the Stirling engine is not yet in commercial use and is relatively unfamiliar to the engineering community compared with Otto, Diesel, and Rankine cycle engines. Accordingly, it may be useful to review the development of the Stirling englne, clting reasons for its introduction and until recently its lack of acceptance and growth to a competitive position.

The invention of the Stirling engine was disclosed in a patent issued in 1816 to Robert Stirling, a Scottish minister. The invention record shows a hot-air engine in a configuration remarkable in that it had all the features of a modern unit. Over a period of years, attempts were made to have the engine perform satisfactorily, but the safe working temperature of the cast iron hot parts was exceeded under conditions of practical power output, and they usually failed in less than a year. Stirling's last air engine was replaced by a steam engine in 1847. From then until 1938, steam engines -- and later internal combustion engines -- completely overshadowed the concept of the Stirling engine.

In 1938, the Philips Research Laboratories in Eindhoven, the Netherlands, needed a small, quiet, reliable heat-driven source of power for radios and similar equipment used in parts of the world where batteries and electric power were scarce. In this context, Philips reviewed alternatives and chose the stirling engine. (1) 
In the following years, Philips subjected the Stirling system to detailed investigations, and prototypes of many small engines were bullt. Later, electronic developments and the more widespread availability of batteries made the air engine less attractive as a power source for small wlectronic equipment. However, the research had provided deeper insight into the potential of higher-power models. Phllips has continued research and development on a broad front. Engines demonstrating low vibration, low noise, and high efficiency have been constructed, although their performance has been inhibited by large size, heavy weight, and high cost. The reduction of these non-competitive characterfstics has been an evolutionary process, mainly involving improvements in drive mechan1sms, seals, and the materials used in the hot parts.

United Stirling, a Swedish firm, holds a license from Philips and has been actively developing a Stirling automotive engine since 1968. Two German 1icensees, MAN and MWM, have bullt heavy-duty engtnes including one demonstrated in a bus.

In 1958, Ceneral Motors became the first licensee In the United States, but terminated the contract in 1970 ( $^{(2)}$ In this period, GM constructed and tested a number of engines of different sizes, with 25,000 hours of operating experience. Part of GM's work led to the delivery and test of silent, portable motor generator sets rated at $3 \mathrm{~kW} .(3,4)$.

In about 1970, Ford Motor Company conducted an in-house review of Stirling technology, being motivated by the increasingly stringent exhaust regulations established by the Federal Government and the potentlal of the external combustion feature of the Stirling engine to accommodate these regulations. As a result of this review, Ford proceeded to negotiate agreements with Philips and with United Stirling(5) in 1972.

In a joint Ford/United Stirling program, various engineering model versions of a $40-\mathrm{kW}(54-\mathrm{hp})$ engine were tested, including some operation in a Ford Pinto and a Ford Taunus. (6) Ford/Philips have co-operated to examine and test a 170-hp Stirling engine alternative 
to Ford's 351 CID conventional gasoline automobile englne. From 1975

to 1977 , Ford worked under contract to $\mathrm{DOE}(5,7)$ on the "80-100 hp St1rling Engine Feasibility Design Study Program."

In October 1977, DOE and Ford signed a cost-shared contract for the development of a stirling passenger car engine. (8) DOE is also funding a parallel stirling engine development program with a team consisting of United Stirling, American Motors, and Mechanical Technology; Inc. (8)

Section 14.2: Technical Discusston

\section{A. Basic Operation}

The basic principle of stirling englne operation is shown in Figure 14-1. First, a cool volume of gas, entrapped by a piston, is compressed (Figure 14-1a) and then heated by an external heat source (F1gure 14-1b). As the gas heats, its pressure increases and the piston is driven downward to turn the crankshaft (1.e., to produce mechanical work). After expansion (Figure 14-1c), the gas 1s cooled by an external cooling source (Figure 14-1d). Its pressure decreases and the gas is once again compressed. Since, as indicated in Figure 14-2, the pressure during the hot expansion is much higher than during the cool compression, there is a net work output from the engine. The complete cycle takes place in one revolution of the crankshaft as opposed to two revolutions required by most conventional engines.

Since exchanging the heating and cooling sources is a cumbersome process, Robert Stirling replaced the alternating use of hot and cold sources by adding a displacer piston. This mechanism allows the heating source to be stationary at one end of the cylinder and the cooling source to be stationary at the other end (Figure 14-3).

One more element -- a regenerator -- is required in an engine which executes the thermodynamic cycle shown. In Figure $14-2$. The regenerator (Figure 14-3) is located between the fixed heating and cooling sources. It stores the heat that is otherwise wasted during the constant volume 

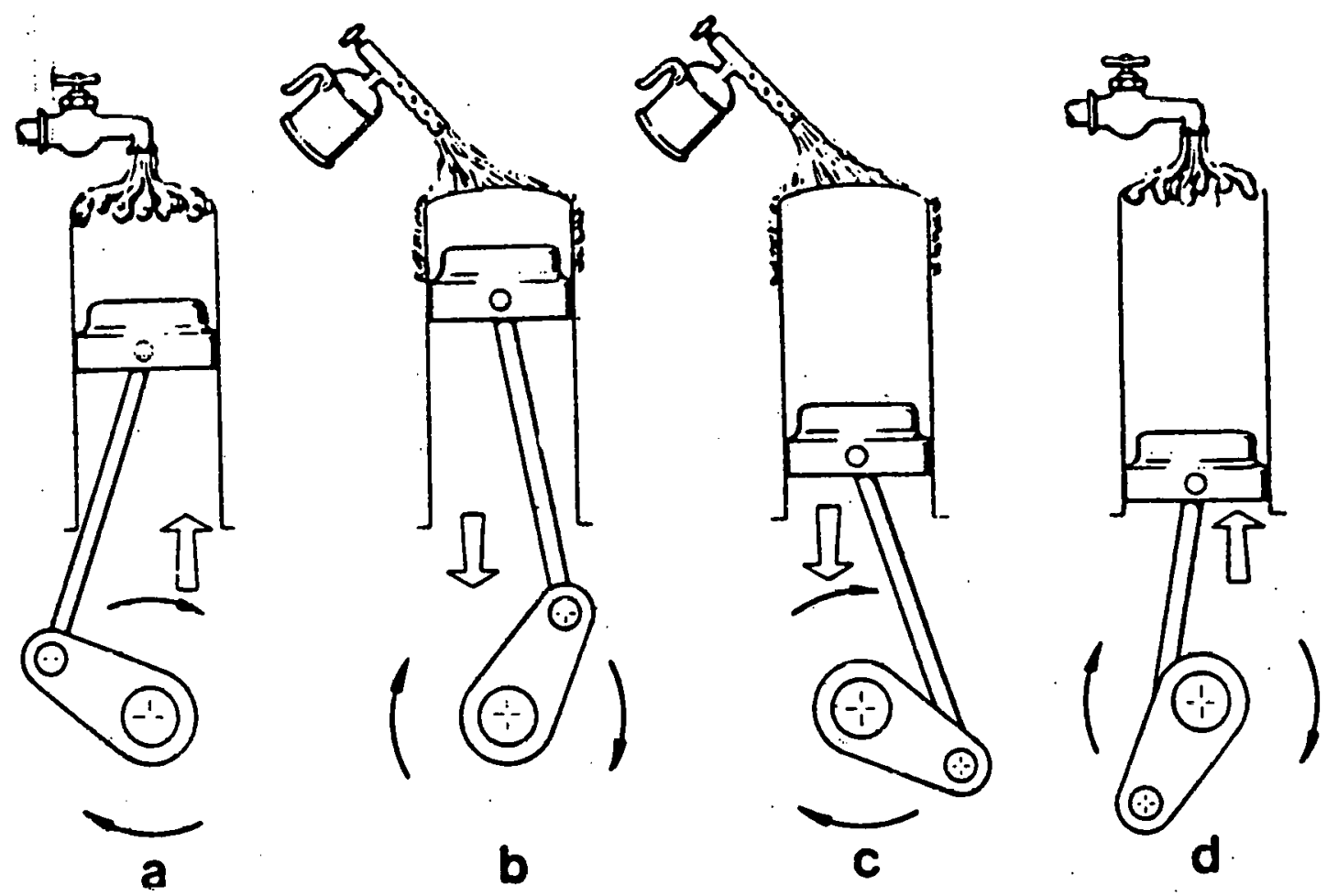

SOURCE: Reference 9.

FIGURE 14-1 SIMPLIFIED ILLUSTRAT ION OF THE STIRLING ENGINE CYCLE 


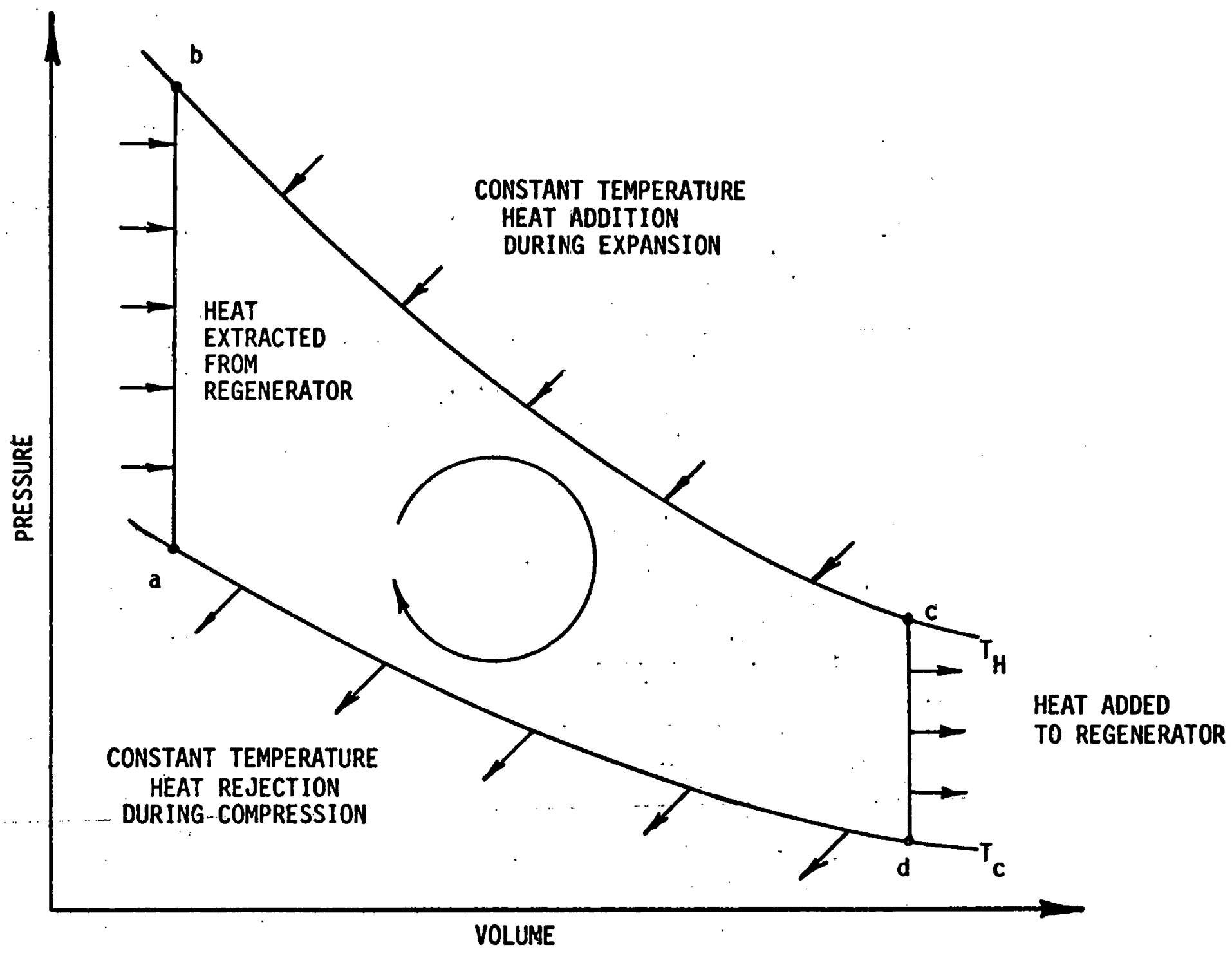

FIGURE 14-2 STIRLING ENGINE THERMODYNAMIC CYCLE 


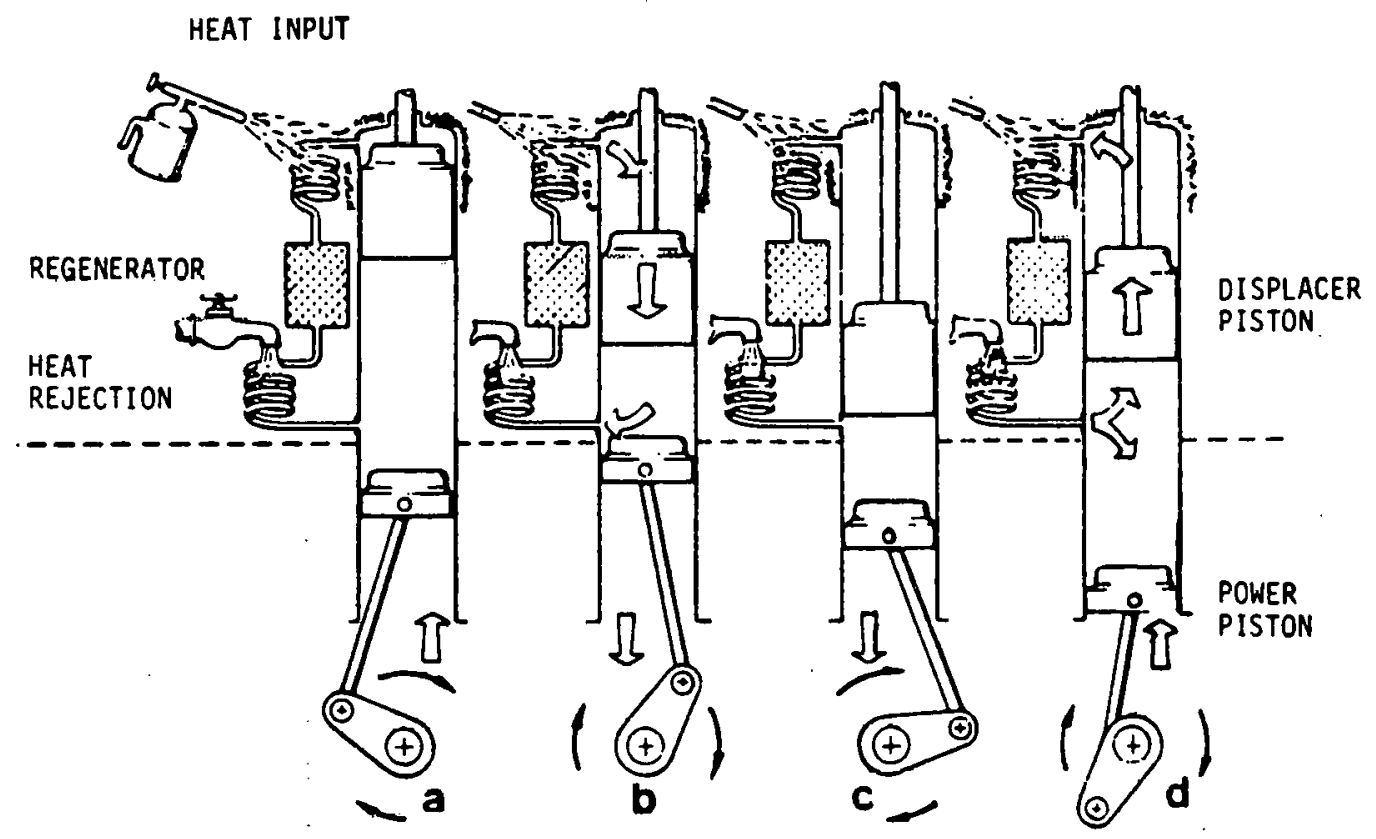

SOURCE: Reference 9.

FIGURE 14-3 ILLUSTRATION OF THE TDEAL STIRLING ENGINE CYCLE WITH DISPLACER PISTON 
cooling process and returns it to the gas during the heating: phase. Figure 14-3a shows the cooled gas being compressed by the power piston as in a conventional internal combustion engine. In Figure 14-3b, the compressed gas is being heated and its pressure increased because the displacer piston is moving a portion of the gas into the upper or hot part of the displacer section. The pressure increase is felt on the power piston. In Figure 14-3c, the hot high-pressure gas has completed its heating cycle, the displacer piston has completed its stroke, and the power piston, driven by the high-pressure gas, is descending. Figure 14-3d shows the displacer piston moving upward tu force the working gas through the regenerator where the gas pressure is reduced as its temperature is lowered. The power pistion is now ready to repeat the compression stroke, thus completing the cycle.

\section{B. Ideal Efficiency}

The 1deal stirling engine cycle shown in Figure 14-2 consists

of :

- an isothermal expansion during which heat is added to the cycle;

- a decrease in temperature and pressure at constant volume which results from moving the gas from the hot zone to the cold zone, during which heat is transferred into a regenerator matrix;

- an isothermal compression during which heat is rejected from the gas; and

- an increase in temperature and pressure at constant volume which results from moving the gas from the cold zone to the hot zone, during which heat is transferred from the regenerator matrix back into the gas. 
In an Ideal Stirling cycle the efficlency is the same as the Carnot effictency. In principle, therefore, it can achleve the highest efficlency possible for a heat engine. This efficiency is plotted in Figure 14-4 for a range of maximum and minimum cycle temperatures. As will be indicated later, most Stirling engines built to date operate at input temperatures, $\mathrm{T}_{\mathrm{H}}$, of about $1400^{\circ} \mathrm{F}$ and rejection temperatures, $\mathrm{T}_{\mathrm{C}}$, of $170^{\circ} \mathrm{F}$. These engines typically have actual efficienctes of $30-35 \%$ or only about $50-60 \%$ of that of the Ideal cycle.

\section{Loss Mechanfsms}

Several loss mechanisms significantly reduce the efficiency of practical 3lirling engines from the ideal. These include:

- mechanical losses in the plstons and the drive mechanisms,

- flow losses (pressure drops) resulting from the cyclic motion of the gas between the hot and cold spaces and, in particular, in the regenerator matrix,

- deviations from isothermal compression and expansion processes,

- conduction-heat transfers between the hot and cold ends of the cngine cylinders,

- less than $100 \%$ regeneration of heat during the constant volume processes, and

- non-ideal relative motion between the power and displacer pistons because of the use of practical drive mechanisms.

\footnotetext{
$\overline{{ }^{*}} \mathrm{~T}_{\mathrm{H}}$ and $\mathrm{T}_{\mathrm{C}}$, respectively, in Figure $14-2$.
} 


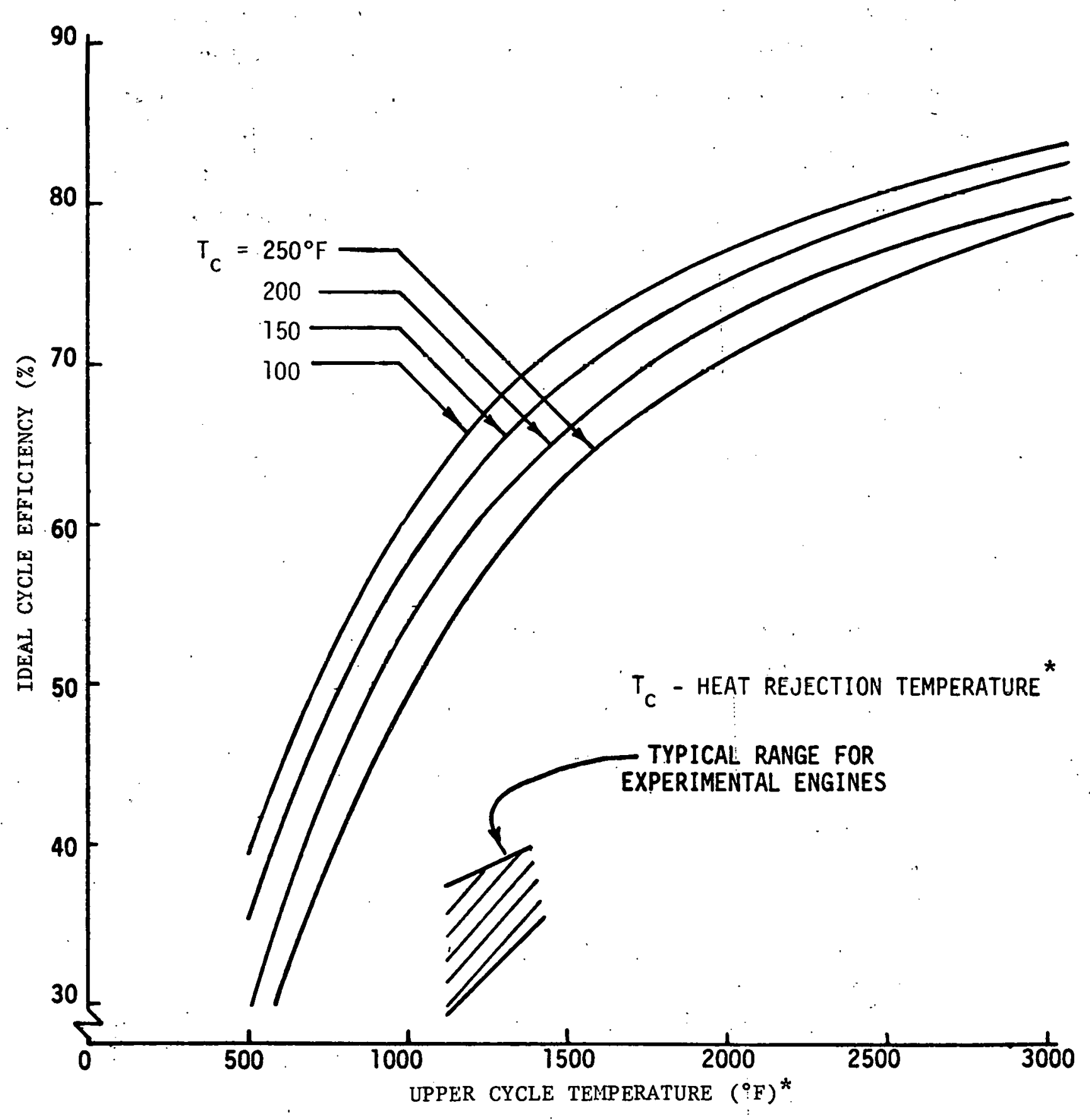

${ }^{*}$ Corresponding to $\mathrm{T}_{\mathrm{H}}$ and $\mathrm{T}_{\mathrm{C}}$ in Figure 14-2.

FIGURE_14-4 IDEAL CYCLE EFFICIENCY OF STIRLING ENGINES 


\section{Effect of Temperature Levels}

As indicated in Figure 14-4, the efficiency of a stirling engine increases with increasing heat-input temperature levels. Most Stirling engines to date have been limited to working gas temperatures of about $1400^{\circ} \mathrm{F}$ in part because of high working pressures ${ }^{*}$ (2000-3000 psi). At these temperatures engine efficiencies have typically been in the 30-35\% range. If higher-temperature alloys and/or ceramic heaters can allow operation at temperatures of $1900-2200^{\circ} \mathrm{F}$, efficiency levels of $42-48 \%$ may be obtainable, assuming that a constant percentage of Carnot efficiency is obtained (a conservative assumption).

\section{E. Practical Configurations}

In an ideal stirling cycle engine, the power piston and the displacer would move in a fixed relationship to one another $\left(90^{\circ}\right.$ out of phase) in a series of discrete movements. In practice, all engines use mechantsms which allow both the power and displacer pistons to move in a sinusoidal motion which comes close to the movement required of an ideal engine. In many of the earliest engines, this motion was develuped by using simple crankshaft arrangements that put the motion of the power and displacer pistons $90^{\circ}$ out of phase. A dlagram of one of the earliest (1938) hot-air engineo develuped by Philips is shown in Figure 14-5.. In this arrangement the power and displacer systems are contained in a common cylinder and the relative motion between the two pistons is maintained by a crankshaft/rocker arm arrangement.

The type of configuration represented by Figure 14-5 has several drawbacks, including:

- large physical volumes,

- unbalanced motion, and

- requirement for a pressurized crankcase.

\footnotetext{
${ }^{*}$ Required to achieve high power densities for automotive propulsion applications .
} 


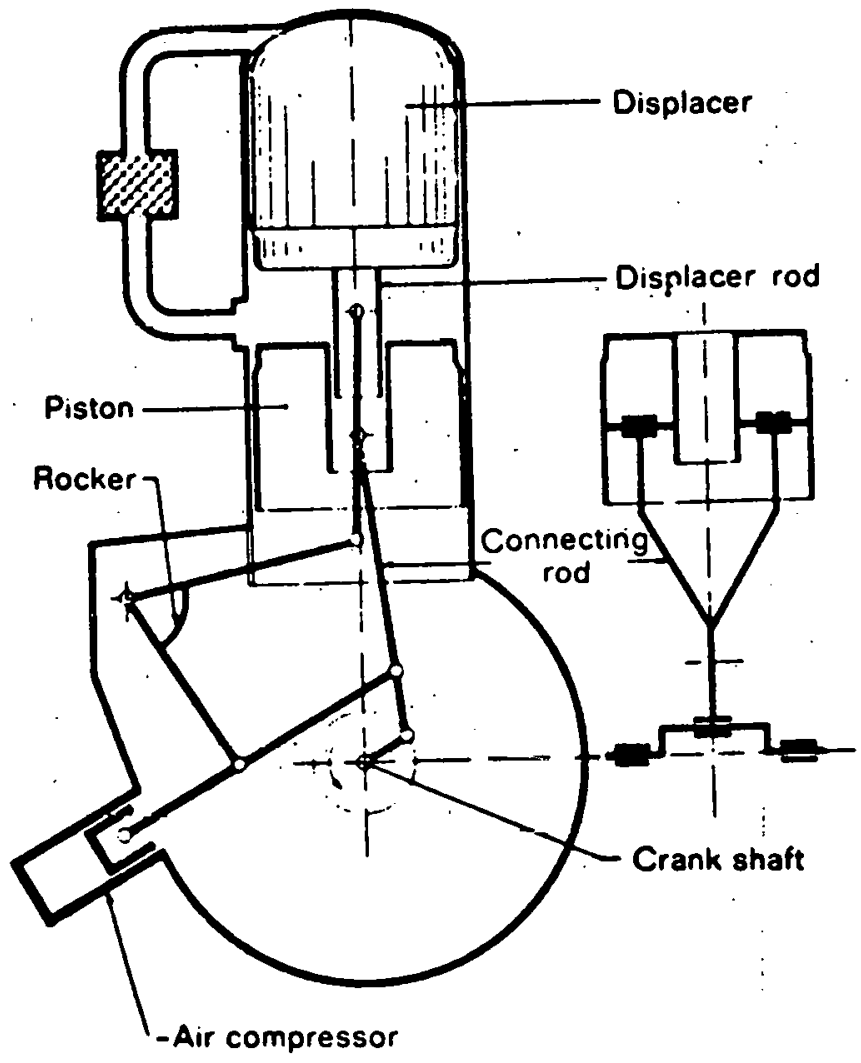

Diagram of a crank drive as previously used in small hot-air engines. The forked connecting rod of the piston is driven directly. by the crankshaft. The displacer connecting rod is actuated by means of a rocker arm, which is driven from a point on the piston connecting rod.

SOURCE: Reference 10.

FIGURE 14-5 STIRLING ENGINE WITH CRANKSHAFT/ROCKER ARM DRIVE 
These problems are particularly severe for Stirling engines in vehicular propulsion applications, which require compact physical arrangements, low-vibration operation, and light weight. The latter two problem areas were resolved by the development of the rhombic drive ${ }^{(10)}$ in 1953, which made it possible to design a displacer engine with a non-pressurized crankcase. It also permitted a single-cylinder engine to be fully balanced. The further evolution of practical configurations, however, required Innovative as well as evolutionary improvement in the seals, heater heads, and mechanical drives, as described in the following paragraphs.

\section{Seals}

The coaxial motion of the rhombic drive mechanisms allows for the use of "rollsock" seals to separate the high-pressure working space from the crankcase (Figure 14-6). This seal arrangement can, in principle, maintain the desired separation of working space. However, in practice, it has been one of the greatest sources of unreliability because of hydrogen diffusion through the seal material and mechanical fallures after extended (thousands of hours) cyclic motion.

A serlous source of concern relative to the rollsock seal is that it falls in a catastrophic mode. Failure can, In effect, disable the engine and lead to a very expensive repair operation. This is one reason for the efforts to develop alternative seal arrangements which allow some (hopefully sma11) gas leakage, but are not susceptible to catastrophic failure.

\section{Heater Heads}

Early Stirling engines used heater heads which, at best, used ribs or fins to increase heat transfer between the head and the working gas. These simple heater-head arrangements were not consistent with the high heat fluxes'required by high-power-density engines as a result of thetr use of pressurfzed hydrogen or helium as the vorking gas. In 


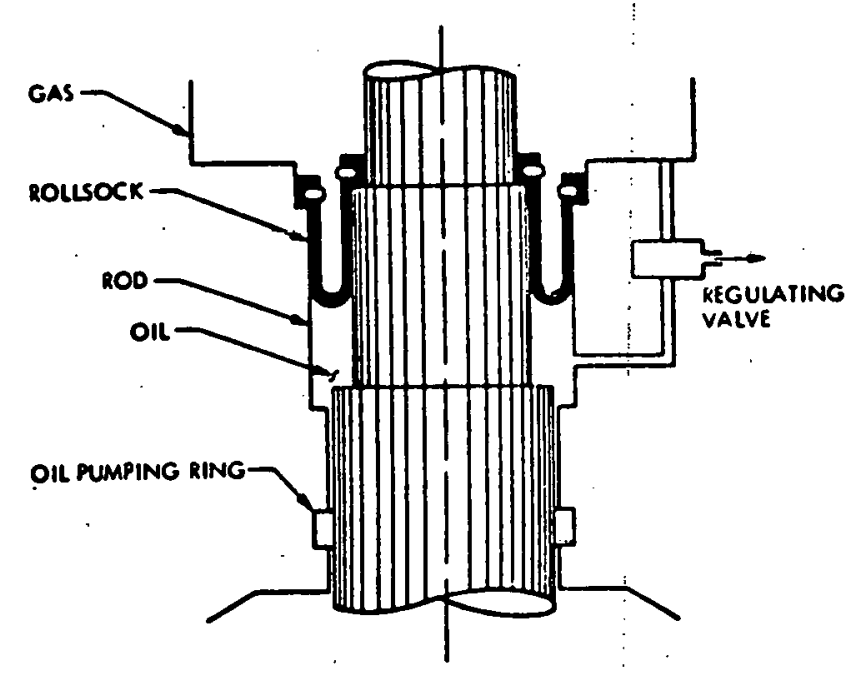

(a) Rollsock Seal Subsystem

(Philips Laboratories)

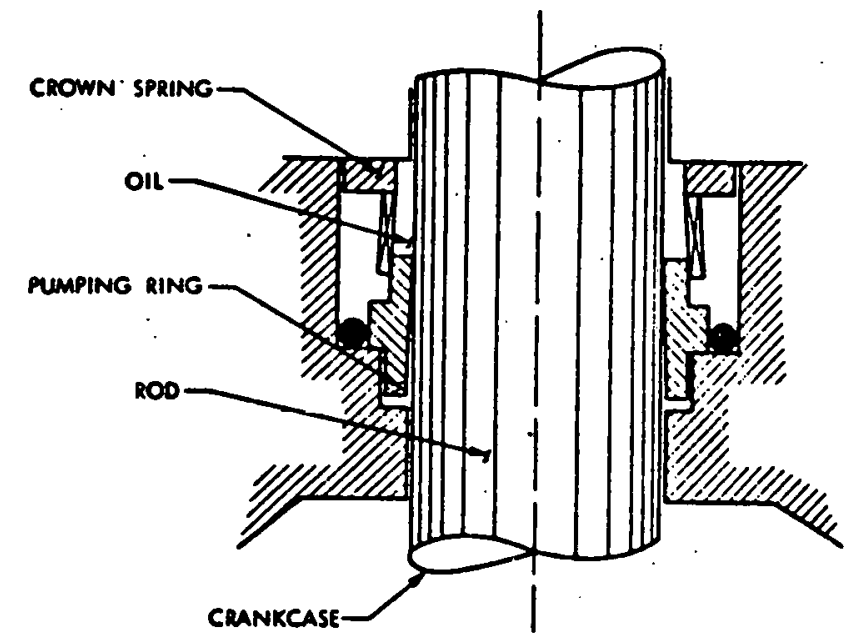

(b) Oil Pumping Ring

(Philips Laboratories)

SOURCE: Reference 10 .

FIGURE 14-6 ROLLSOCK SEAL ARRANGEMENT 
a modern Stirling engine, therefore, the heater heads are made from tubes which allow for the very high surface-area-to-volume ratios required by a high power-density engine operating with high-pressure gas.

\section{Double-Acting Designs}

While the rhombic drive engine has been the primary tool in recent Stirling engine development work, it is still excessively large and complex for use in vehfcular propulsion systems. A more recent Stirling engine development, the double-acting piston, results in an eng ine better sulted for automotive use. (9) Phllips has found it is possible to construct an engine of four spparatc intelcunnected cylinders, as shown in Figure 14-7, and to control the motion of the pistons by a device which phases them at $90^{\circ}$ intervals. With this type of construction, each piston serves as both a power piston and as a displacer for the adfacent cylinder, thus, the name "double-acting."

Arranging the four double"-acting piston configuration into a cylinder forms a compact swashplate engine in which the four separate heating sources are grouped into one common source. The four-cylinder swashplate engine is perfectly balanced and has four torque impulses per revolution similar to an eight-cylinder internal combustion engine. However, the magnitude of the impulses is much less than that of an elght-cylinder internal combustion engine.

Figure 14-8 shows a cutaway of a double-acting swashplate engine. At the front of the engine is the single burner which supplies heat to the heater tubes. A rotating preheater, concentris: with the burncr, recovers waste heat from the exhaust and transfers it to the Incoming combustion air. Regenerator and cooling tubes are located botween and slightly outboard of the cylinders. A rollsock seal on the platon rod retalns the working gas within the engine. The piscon rods are connected to the swashplate by lubricated slider bearings. 


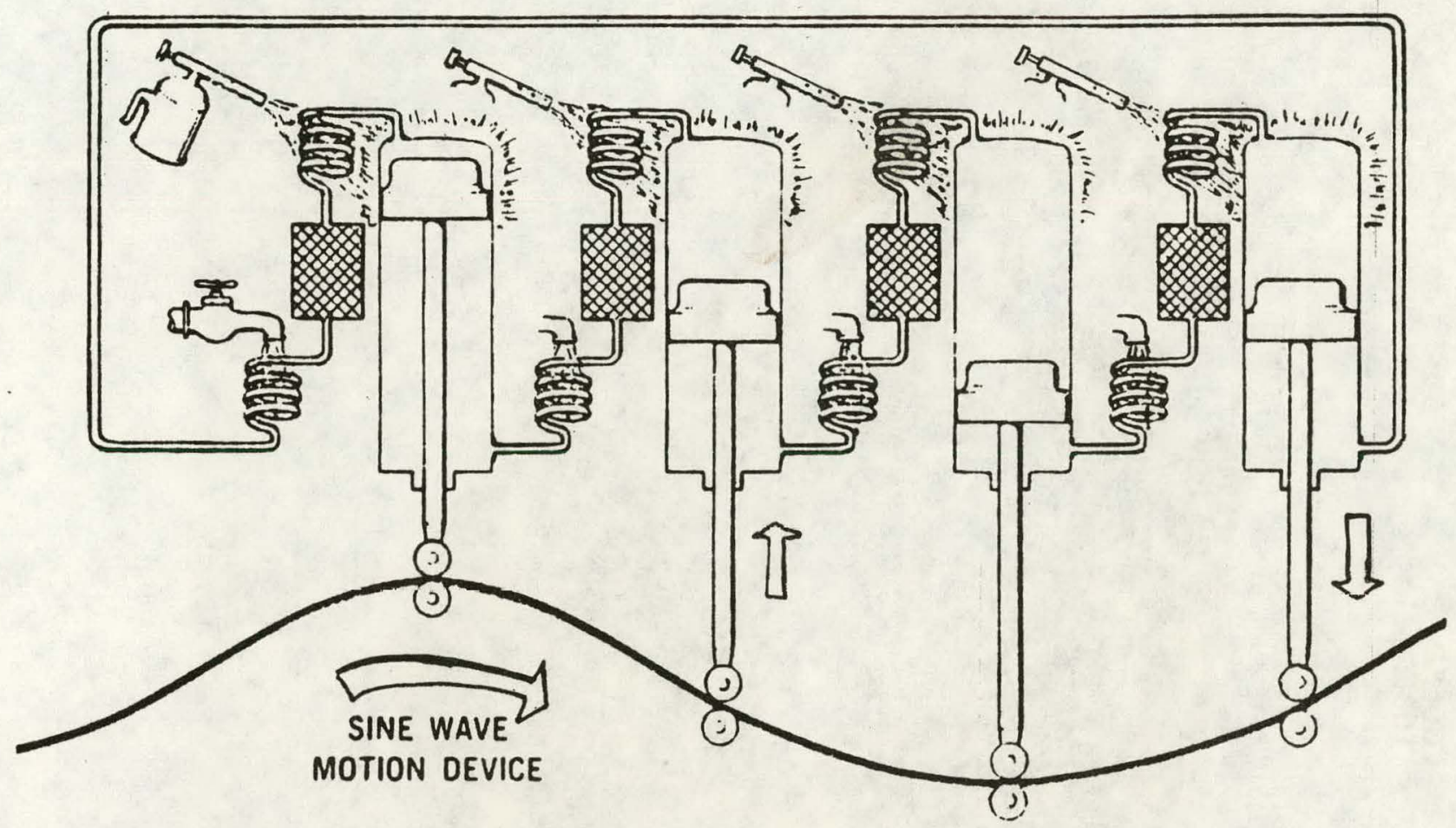

SOURCE: Reference 9.

FIGURE 14-7 ILLUSTRATION OF THE DOUBLE-ACTING STIRLING CYCLE ENGINE 


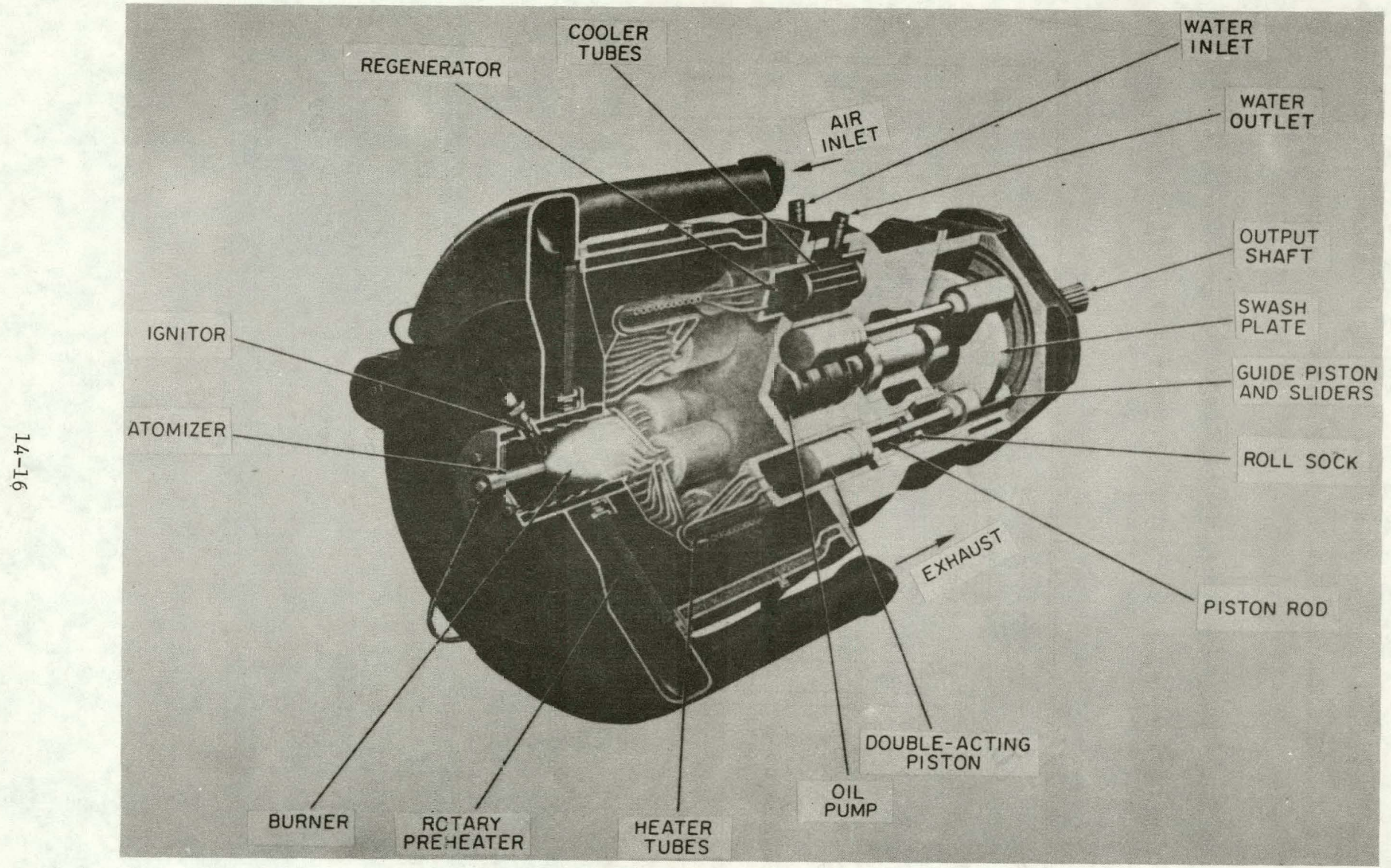

SOURCE: Reference 11.

FIGLRE 14-8 DOUBLE-ACTING SWASHPLATE ENGINE 


\section{F. Summary}

Most activity in the Stirling engine field is now directed toward further refining the double-acting engine designs similar to the one shown in Figure 14-8. (In-1ine deșigns, with crankshafts, are also being considered.) This arrangement results in a highly compact, lowweight engine consistent with the use in vehicular propulsion applications. It is not clear, however, that the design best suited to automotive use is necessarily best for stationary applications in distributed energy systems where size and weight may be less fmportant than efficiency, reliability, multi-fuel capability, maintainability, etc.

Table 14-1 summarizes the performance of many of the Stirling engines developed to date, indicating important parameters such as power leve1, pressure levels, working gas, temperature levels, and operating speeds. It should be noted that all these engines operate at the high power densities required for vehicular propulsion applications by using highpressure working gases and high operating speeds.

\section{Section 14.3: Special Attributes of Stirling Engines}

The primary potential advantages of the Stirling engine which could make its use attractive in stationary applications are simflar to those associated with automotive applications:

- high thermal efficiency,

- good part load characteristics,

- fuel flexibility,

- low emissions,

- good reliability, and

- low noise.

of these advantages, those which could be most decisive are:

- The possibility of achieving very high efficiency (in the $40-48 \%$ range), and 
TABLE 14-1

STIRLING ENGINE CHARACTERISTICS

\begin{tabular}{|c|c|c|c|c|c|c|c|c|}
\hline Manufacture & $\begin{array}{c}\text { Ph111ps } \\
4-215\end{array}$ & Philips & $\begin{array}{l}\text { United } \\
\text { Stirling }\end{array}$ & $\begin{array}{l}\text { GNRL* } \\
\text { GPU-j }\end{array}$ & $\begin{array}{l}\text { Ph111ps } \\
4-235\end{array}$ & $\begin{array}{l}\text { Philips } \\
40 \text { hp }\end{array}$ & $\begin{array}{l}\text { United } \\
\text { Stiriling }\end{array}$ & $\begin{array}{l}\text { MAN- } \\
\text { MWNI } \\
4-400\end{array}$ \\
\hline Status & $\begin{array}{l}\text { Proto * } \\
\text { (Ford) }\end{array}$ & $\begin{array}{l}\text { Analy.* } \\
\text { (opt 1- } \\
\text { mized) }\end{array}$ & Proto & Proco & Proto & Proto & $\begin{array}{l}\text { Analy. } \\
\text { Phase I }\end{array}$ & Proto \\
\hline Type & $\begin{array}{l}\text { 'l'wo } \\
\text { piston }\end{array}$ & $\begin{array}{l}\text { Piston- } \\
\text { disp }\end{array}$ & $\begin{array}{l}\text { Two } \\
\text { piston }\end{array}$ & $\begin{array}{l}\text { Piston- } \\
\text { disp }\end{array}$ & $\begin{array}{l}\text { Ptston:- } \\
\text { disp : }\end{array}$ & $\begin{array}{l}\text { Piston- } \\
\text { disp }\end{array}$ & $\begin{array}{l}\text { Troo } \\
\text { piston }\end{array}$ & $\begin{array}{l}\text { Piston- } \\
\text { disp. }\end{array}$ \\
\hline Working fluld & $\mathrm{H}_{2}$ & $\mathrm{He}$ & $\mathrm{H}_{2}$ & $\mathrm{H}_{2}$ & He & $\mathrm{H}_{2}$ & $\mathrm{H}_{2}$ & He \\
\hline $\operatorname{Max}_{\text {PaI }}$ Press. $\overline{\mathrm{P}}$ & $2850 !$ & 3200 & 2100 & 1000 & 3200 & 2058 & 2100 & 1570 \\
\hline No. of cylinders & 4 & 4 & 4 & 1 & 4 & 1 & 8 & 4 \\
\hline $\operatorname{Max}$ bhp ${ }^{\star}$ & 170 & 275 & 49 & 11 & 200 & 40 & 200 & 120 \\
\hline RPM at max power & $4000-6200$ & 1600 & 3400 & 3600 & 3000 & 1500 & 2400 & 1500 \\
\hline $\begin{array}{l}\text { Max torque, } \\
\text { ft-1bs }\end{array}$ & 300 & 1287 & 120 & 19 & 253 & 108 & 520 & 475 \\
\hline RPM at max torque & 1400 & 400 & 955 & $\begin{array}{l}1200- \\
2400\end{array}$ & 1000 & 900 & .600 & 700 \\
\hline Gas temp (hot), ${ }^{\circ} \mathrm{F}$ & 1300 & 0.1400 & 1275 & $1400^{j}$ & 1260 & 1200 & 1325 & 1170 \\
\hline $\begin{array}{l}\text { Gas temp (cold), } \\
{ }^{\circ} \mathrm{P}\end{array}$ & 175 & 160 & 160 & 180 & 108 & 60 & 160 & 105 \\
\hline $\begin{array}{l}\text { Efficlency at max } \\
\text { bhp, \% }\end{array}$ & 24 & 30 & 24 & 25 & 30 & 30 & 30 & 29 \\
\hline Max efficiency, \% & $32^{(2)}$ & $43^{(2)}$ & 30 & $26.5^{(2)}$ & 31 & 38 & 35 & 32 \\
\hline $\begin{array}{l}\text { Power at max } \\
\text { effictency, bhp }\end{array}$ & 75 & 100 & 35 & 27 & 2175 & 23 & 96 & 88 \\
\hline $\begin{array}{l}\text { RPM yL max } \\
\text { efficlency }\end{array}$ & $1100-2000$ & 600 & 2000 & 1900 & 1800 & 725 & 1200 & 1000 \\
\hline We1ght, ${ }^{(3)}$ ih & 750 & $\mathrm{~N} / \mathrm{n}^{*}$ & $\mathrm{~N} / \mathrm{D}$ & $165^{(4)}$ & 1272 & $N / D$ & 1435 & $N / D$ \\
\hline Dimensions, ${ }^{(3)} \mathrm{ft}$ & $\mathrm{N} / \mathrm{D}$ & $\begin{array}{l}4.9 \times 4.3 \\
\times 2.2\end{array}$ & $N / D$ & $\begin{array}{l}1.3 \times 1.3 \\
\times 2.4\end{array}$ & $\begin{array}{l}4.1 \times 1.7 \\
\times 3.6\end{array}$ & $N / D$ & $\begin{array}{l}3.7 \times 2.7 \\
\text { x. } 3.1\end{array}$ & $\begin{array}{l}5.0 \times 2.3 \\
\times 4.3\end{array}$ \\
\hline Applications & Auto & Bus & Auto & EPS $^{\star}$ & Bus & LRE * & $\begin{array}{l}\text { Bus, } \\
\text { truck }\end{array}$ & LRE \\
\hline
\end{tabular}

(1) Heater-tube wall temperature.

(2) Net brakè efflclency accounting for all auxlliarles including cooling fan, combustlon blower, and water pump, among others.

(3) Includes all auxillaries except cooling system with fan and transmission.

(4) Engine and auxiliarles less electrical power generator.

(5) Engine only.

*abbreviations:

Proto: operating prototype engine; LRE: Laboratory Research Engine; Analy: computer design projection;

N/D: no data; EPS: electrlc power supply; bhp: brake horse-puwer; GMRL: Ceneral Motors Research Laborator1es. 
- The ability to use a multiplicity of fuel forms

Inc uding coal, municipal wastes, and low Btu

gases (from digestor systems).

These two issues are discussed further in the'following paragraphs.

\section{A. Efficiency}

Although Stirling engines with efficlency levels approaching $40 \%$ have been built and tested as part of the Philips development programs, most Stirling engines built to date have efficiency levels of about $32-35 \%$. The ideal efficiency of these engines would be as high as 60-70\%; therefore, most present engines achieve about $50 \%$ of Carnot efficiency. The rather large divergence between obtained efficiency and the ideal is due, in part, to the restrictions placed on the engines as a result of their predominant development for automotive propulsion. This application emphasizes low first costs, high-power-to-volume (or power-to-weight) ratios, and air cooling.

Since chese features need not apply so strongly to Stirling engine design' for stationary applications, there is greater opportunity to develop a design that maximizes efficiency consistent with a low overall operating cost (capital charges + fuel charges). For Stirling. engines operating with a high-capacity factor, efficiency can be a strong economic driving force. For example, one study indicated that increasing operating efficlency for an oil-fired unit from $40 \%$ to $42 \%$ can justify $\$ 55 / \mathrm{hp}(13)$ In added initial cost when the value of future fuel savings is considered.

The realistic limit on Stirling engine efficiency is difficult to specify. However, extrapolations of existing data indicate that Stirling engine efficlencles of about $45 \%$ are a realistic goal, and even higher efficlency levels may be obtainable if ceramic heat exchangers can be developed which allow operation at higher temperatures.

These high efficlency levels are expected to be obtainable in engines covering a wide power range (a few kilowatts to thousands of kilowatts), thus making them viable for a number of distributed energy system applications. 


\section{B. Fuel Flexibility}

One of the major advantages of the Stirling engine is its ability to use a multiplicity of fuels, including coal, municipal solid wastes, and possibly blomass-derived fuels (wood chips, biogas, etc.).

Figure 14-9 shows a system demonstrated by Philfps ${ }^{(14)}$ which would allow for using such a multiplicity of fuels. In this system, the heat is transferred to the Stirling engine by a sodium heat pipe system. (See Chapter 21.) This allows for a unfform, high-flux heat Input to the Stirling engine heater without subjecting the heater tubes to the potential corrosion and fouling associated with the combustion of many solid-fuel forms. The heat input to the heat-pipe system can be via heat exchanger configurations (fins, etc.) which are easily cleaned and which have sufficient heat-transfer area to keep down gas-to-metal heat fluxes and temperature drops. It should be noted that the above arrangement is not without problems, particularly those associated with the safety of liquid metal systems and the choice of containment materials.

The fuel flexibllity of the Stirling engine in distributed energy system applications is matched only by the Rankine cycle engine alternatives. However, simple Rankine cycle engines using water or organlc working fluids would not have nearly the efficiency of the Stirling engine systems, whlch will be an increasingly important factor. in the cholce of a power system.

\section{Section 14.4: Applications}

The high efficiency and fuel flexibility of stirling engines make them well suited for stationary applications within distributed energy systems. Their use could be particularly attractive within total energy or "co-generation" systems where reject heat from the engine coolers could also be put to use. (15) 


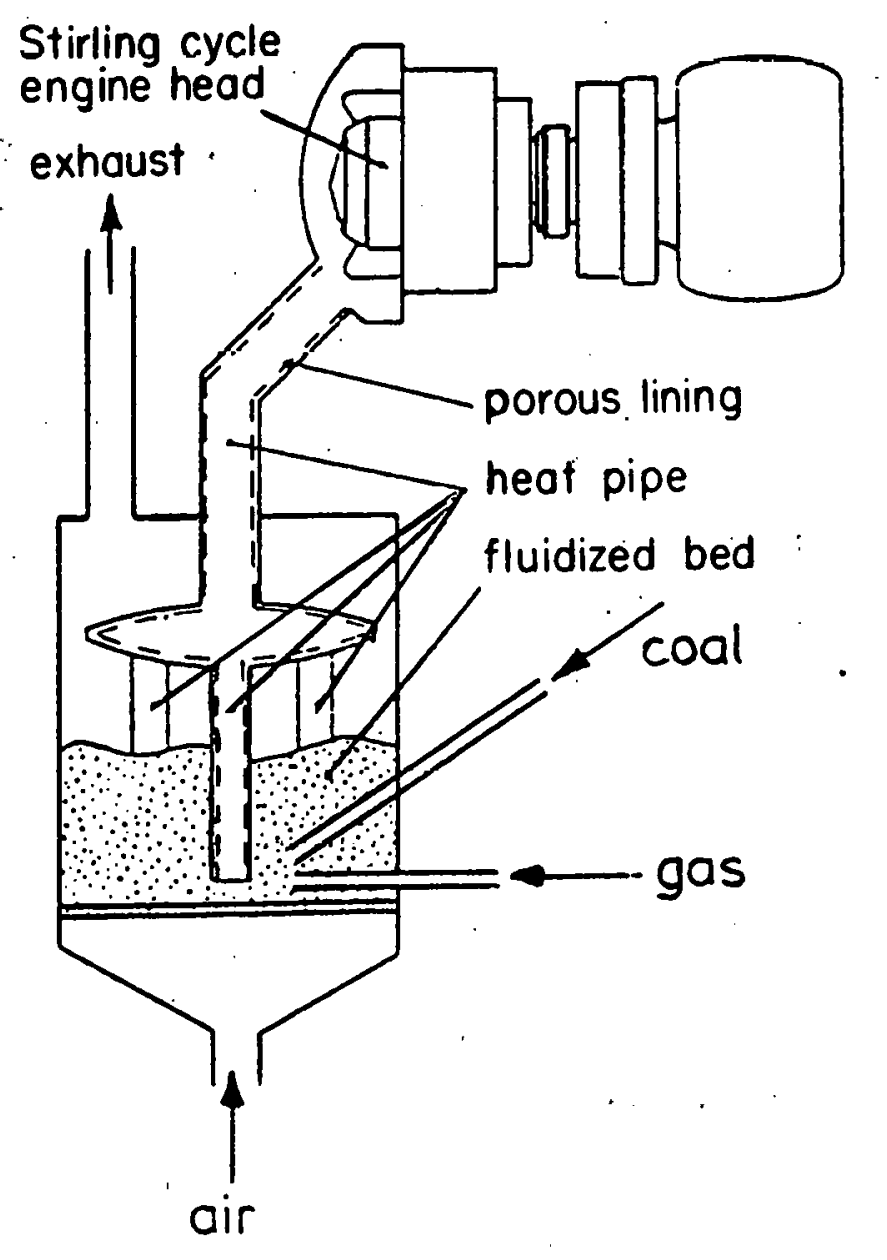

SOURCE: Reference 14 .

FIGURE 14-9 STIRLING ENGINE CONNECTED TO A FLUIDIZED BED OF COAL BY A HEAT PIPE 
Such distributed energy system arrangements (power plus heat) could be utilized over a wide range of sizes from residential units $(3 \mathrm{~kW})(16)$ to larger-scale factlities (100 kW and higher) required for industrial, commercial, and residential complexes.

As indicated in Figure 14-10, there are two sources of heat in a Stirling engine which can be used to heat water. The hot water can, in turn, be used for a variety of applications including hot water, space heating and the operation of absorption cooling systems. The two heat sources are:

- Coolers: Stirling engines require coolers where heat is rejected from the cycle during compression. These coolers should operate at as low a temperature as pussible so they are attractive sources of energy to preheat domestic or process hot water at temperatures of $90^{\circ}-140^{\circ} \mathrm{F}$.

- Exhaust gases: Even with air preheaters, the exhaust gases from the Stirling engine combustor are at temperatures in excess of $500^{\circ} \mathrm{F}$. A portion of this exhaust gas heat could be used to heat water to temperatures in excess of $300^{\circ} \mathrm{F}$, thereby increasing the range of applications for this heat snurce.

In the system 11lustrated in Figure 14-1.0, heat is stored at two temperature ranges to provide maximum system.flexibility and thermal loads.

A Stirling engine with a recovery system such as that shown in Figure 14-10 can be used within total energy systems. In such systems, both hot water and space heating needs are satisfled by preheating the water at modest temperatures with heat provided by the coolers. Higher temperature water can be provided by the burner exhaust-heat recovery system. Space heating is provided by passing warm water from the coolers through a coll placed in the air distribution system. 


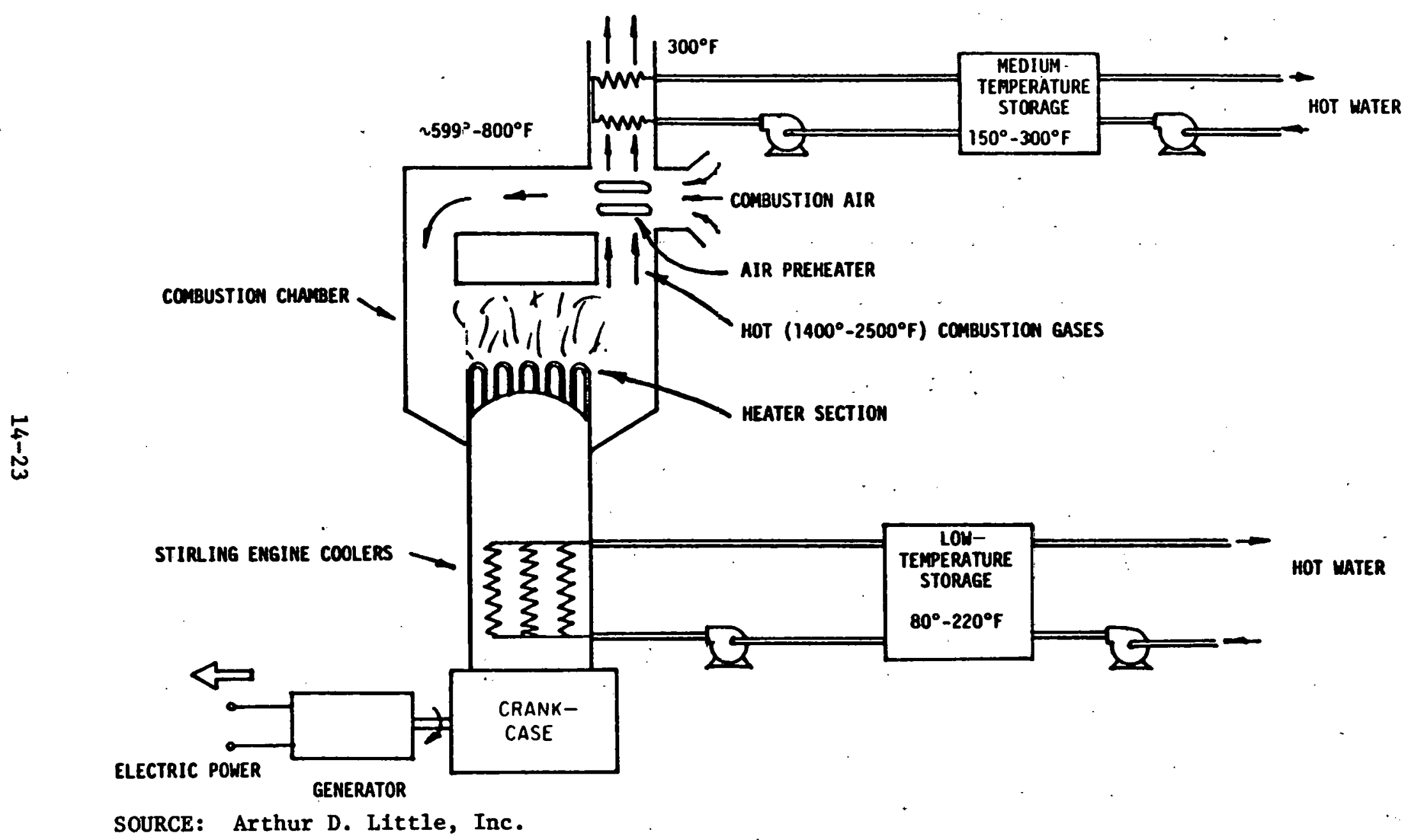

FIGURE 14-10 SCHEMATIC OF STIRLING ENGINE HEAT-RECOVERY SYSTEM 
One advantage of the Stirling engine in total energy systems 1s that the heat can be extracted from the coolers in the form of hot water at little, or no, additional cost since the coolers must be provided with water cooling, even if the only function of the engine is electric power production. This is in contrast to the situation with diesel or gas turbine engines. In these systems, much of the heat must be extracted by placing waste heat boilers in the hot exhaust-gas streams. These heat exchangers represent an additional cost factor in the overall total energy system.

The above advantage (i.e., ease of extracting heat) is, however, somewhat counterbalanced by the fact that this heat will be primarily. at lower temperature levels $\left(200^{\circ} \mathrm{F}\right)$, unless significant degradations in engine efficiency are acceptable. 'Ihis may increase the cost of the energy distribution and storage systems as compared to the diesel and gas turbine options where heat can be readily generated in the form of steam or pressurized hot water in the waste-heat boilers.

\section{Section 14.5: Limitations}

\section{A. General Considerations}

Efficient Stirling engines can be (and have been) built and operated experimentally for thousands of hours using present technology. The long-term stability of Stirling engines has, however, not been well demonstrated in the field. In particular, the seal arrangement and hydrogen permeation through hot surfaces are recognized rellability issues still requiring resolution. Also, higher-temperature heaters, regenerators, and afr preheaters will have to be developed and their reliability demonstrated before the full efficiency potential of the Stirling engine can be realized.

\section{B. Equipment Availability}

At present, there are no firms offering Stirling engines on a commercial basis. Although most present developments stress automotive applications, these engines can he adapted for stationary 
applications and have been provided on a contractual basis for test and evaluation. Based on the schedule for the automotive Stirling engine program, engines would not be avallable for that high-production application unt11 the late 1980's or early 1990's. However, St1rling engines could probably be made available for more limited applications within 5-10 years if there were an incentive to do so.

\section{Costs}

Very few cost data are available on Stirling engines, particularly those being considered for stationary application. When making an economic analysis, several investigators $(11,17)$ have assumed that the cost of Stirling engines will be about $\$ 50 / \mathrm{kW}$ higher than that for comparable diesel engines. This cost differentlal is justified by the larger number of heat exchangers required by the Stirling engines (as compared with the number required by a diese1) and the need for a sophisticated combustion system. Another study ${ }^{(12)}$ estimated capital costs of $\$ 290 / \mathrm{kW}$ for o11fired Stirling engines and $\$ 655 / \mathrm{kW}$ for coal-fired Stirling engines. It was emphasized, however, that these costs were highly tentative because of the lack of data in this field.

No maintenance cost data are available for these engines. However, for diesels driving 200- to $300-\mathrm{kW}$ generators, maintenance costs range from 7-9 mills/kWh. We shall assume, as a preliminary estimate, that Stirling-cycle, engine-maintenance costs are $8 \mathrm{mills} / \mathrm{kWh}$. Assuming a fuel cost of $\$ 0.42 / \mathrm{gal}\left(\$ 2.77 / 10^{6} \mathrm{Btu}\right)$ and an engine effictency of $46 \%$, fuel oil costs amount to $\$ 0.021 / \mathrm{kWh}$.

\section{Safety}

Most Stirling automotive engines utilize pressurized hydrogen as the working gas. For stationary applications where engine weight is not so critica:l, pressurized hellum could also be used. (If efficiencies comparable to those of hydrogen engines are to be achieved, helium must be used at higher pressures, which necessitates a heavier engine.) Clearly, there is the potential for safety problems with the use of hot, high-

pressure hydrogen, although the quantities involved are relatively small. 
In stationary applications using "dirty" fuels (coal, etc.), there is a good possibility that a liquid-metal heat pipe could be used to transfer heat between the heat source (combustion chamber) and the tubular structure of the engine heaters. These hot liquid metals, e.g., sodium, would constitute another potentlal safety hazard.

\section{E. Environmental Concerns}

It is expected that the Stirling engine would have a less adverse environmental effect compared with other engine types. This is due to 1) high efficiency resulting in less fuel consumption, and 2) external combustion processes which are more consistent with low exhaust emissions than internal combustion engines. 


\section{REFERENCES}

1. Meijer, R.J. "Philips Stirling Engine Activities." International Automotive Engineering Congress, Detro1t, Michigan, January 11-15, 1965. Warrendale, Pennsylvania: Soclety of Automotive Engineers, 1965.

2. Percival, W.H. H1storical Review of Stirling Engine Development . in the United States from 1960 to 1970. Energy Research and Deve1opment Administration and National Aeronautics and Space Administration.: July 1974. NASA Report No. NASA CR-121097.

3. Flynn, Jr., G., et al. GMR Stirling Thermal Englne: Part of the Stirling Engine Story, 1900 Chapter. Warren, Michigan: General Mntors Corporation, Research Laboratories, August 1966.

4. Heffner, F.E. H1ghlights of 6500 Hours of Stirling Engine Operation. Warren, Michigan: General Motors Corporation, Research Laboratories, 1965.

5. Ford Motor Company, Power Train Research Office. "Stirling Engine Program." Advanced Automotive Power Systems Contractors' Coordination Meeting. Dearborn, Michigan, May 8, 1975.

6. Rosenquist, N.K.G., et a1. "The Development of a $150 \mathrm{~kW}$ (200 hp) Stirling Englne for Medium Duty Automotive Application -- A Status Report." International Automotive Engineering Congress, Detroit, Michigan, February 28 - March 4, 1977. Warrendale, Pennsylvania: Society of Automotive Engineers, 1977.

7. Ford Motor Company, Power Train Research Office. "Stirling Engine Program." Advanced Automotive Power Systems Contractors'

Coordination Meeting. Dearborn, Michigan, October 19, 1976.

8. "ERDA Authorization Bill Advances." Energy Research Digest $3(2): 4$, October 10, 1977 .

9. Postma, N.D., et al. "The Stirling Finglne for Passenger Car Appl1cation." Preprint. Soclety of Automotive Engineers Meeting, June 18-22, 1973. SAE Preprint No. N 730648.

10. Meijer, K.J. The Philips Stirling Engine. Eindhoven, The Netherlands : Philips Physical Laboratories, 1966.

11. Hogland, L., et al. A Technology Evaluation of the Stirling Engine for Stationary Power Generation in the 500-2000 Horsepower Range. Report prepared by Amtech, Inc. under Contract No. EC-77-C-05-5392 for the Department of Energy, September 1978. DOE Report No. ORD/ 5-392-1. 


\section{REFERENCES (continued)}

12. Jet Propulsion Laboratory, California Institute of Technology. Should We Have a New Engine?: An Automobile Power. Systems Evaluation. Vol. II. Pasadena, California, August 1975. Jet Propulsion Laboratory Report No. .JPL-SP-43-17.

13. Steitz, P., et a1. Assessment of the Role of Advanced Technologies In Sma11 Utilities. Report prepared by Burns \& McDonnel1 Eng1neering Company for Electric Power Research Institute, May 1978: EPRI Report No. EPRI EM-696.

14. Asselman, G.A.A. Fluidized Bed Coal Combustion as a Heat Source for Stirling Engines. Eindhoven, The Netherlands: Philips Research Laboratory, 1976.

15. Lehrfeld, D. Systems Analysis Design and Proof of Concept Exper1ment of Total Energy System. Briarcliff, New York: Philips Laboratories, 1977.

16. Beale, W.T., et al. Free-P1ston Stirling Engines - A Progress Report. Warrendale, Pennsylvania: Society of Automotive Engineers, June 1973. Paper No. 730647.

17. Lehrfeld, D. "Practicability S̀tudy of Stirling Total Energy Systems." Proceedings of the Twelfth Intersociety Energy Conversion Engineering Conference, Washington D.C., August 28 - September 2, 1977. Pp. 1504 ff.

18. Davis, S.R., et al. Combustion and Emisston Formation in the Stirling Engine with Exhaust Gas Recirculation. Warrendale, Pennsylvania: Society of Automotive Engineers, June 1971. Paper No. 710824. 


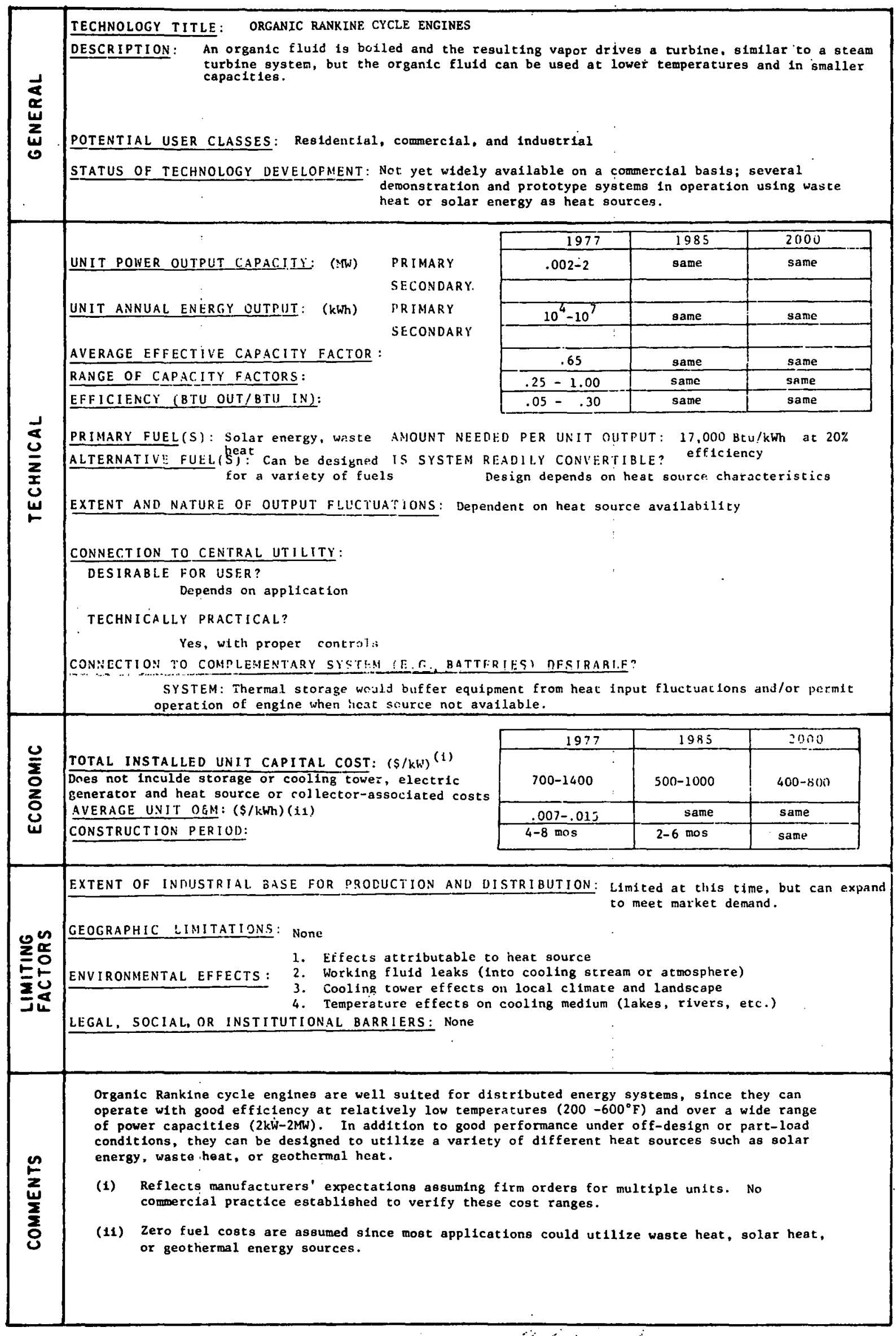


CHAPTER 15

\section{ORGANIC RAINKINE CYCLE ENGINES}

\section{Section 15.1: Introduction}

An organic Rankine cycle (ORC) engine converts heat energy into merhanical energy by alternately evaporating a working fluid at high pressure and producing shaft power from the high-pressure vapor as it expands through a turbine (or some otler suitable expansion device) to a condenser which operates at low pressure. Similar in concept to a simple steam Rankine cycle, ORC engines can use any one of a number of organic working fluids, the choice being a function of peak cycle temperature and expander type. The use of organic working fluids allows the engine to operate efficiently at lower temperatures and in emaller sizes than more conventional steam systems.

ORC engines have several characteristics which may make their use particularly appropriate for distributed energy systems. They are one of the few engines which can effectively utilize heat at relatively low temperatures in the $200-600^{\circ} \mathrm{F}$ range. This gives ORC engines great flexibility for use with a variety of heat sources such as solar energy, industrial waste heat streams, geothermal energy, and hot engine exhausts. Also, ORC engines can be designed for use over a wide range of capacity levels as indicated by present development programs which include $2-\mathrm{kW}$ systems for on-site solar applications and 2-MW systems for waste heat applications.

The advantages of $\mathrm{ORC}$ engines have resulted in programs by a number of companies to develop systems that could become commercially available in the next two to five years. ORC engines could, therefore, represent a near-term option for distributed energy system applications. 
Section 15.2: Technical Discussion

\section{A. System Configuration}

A schematic of an organic Rankine cycle engine for waste heat applications is shown in Figure 15-1. This system consists of:

- a "boller," which can transfer heat from solar collectors, engine exhausts, or a direct combustion process in order to convert the working fluld to a vapor;

- an expander (turbine or positive displacement configuration), which produces shaft power when supplied with a pressurized vapor;

- a condenser, consisting of a water-cooled heat exchanger in most applications, in which the lowpressure vapor is condensed to a liquid; and

- a feedpump (positive displacement or centrifugal).

With some working fluids, the vapor leaving the expander is superheated. To Increase cycle efficlency, a recuperator may be placed at the outlet of the expander to use the superheat energy for preheating the fluid from the feedpump before it flows into the boiler.

The efficlency of the system depends on both the Ideal thermodynamic effictency of the cycle (assuming 100\% component efficlencies and zero pressure drop in the heat exchangers) and the actual efficiencies of the major system components, such as the expander and feedpump. The results of testing by a number of firms for a range of component configurations indicate that the following efficlencles (energy out/energy in) can be obtalned using existing technology:

- Expander efficlency, 70-85\%; and

- Feedpump efficlency, 70-93\%.

The component efficiencies used to calculate the system performance curves shown in Figure 15-2 are an expander efficlency of $75 \%$, a feedpump efficiency of $75 \%$, and a recuperator effectiveness of 0.9 . As these figures Indicate, system performance tends to improve as the peak cycle temperature increases and as the condenser temperature decreases. 


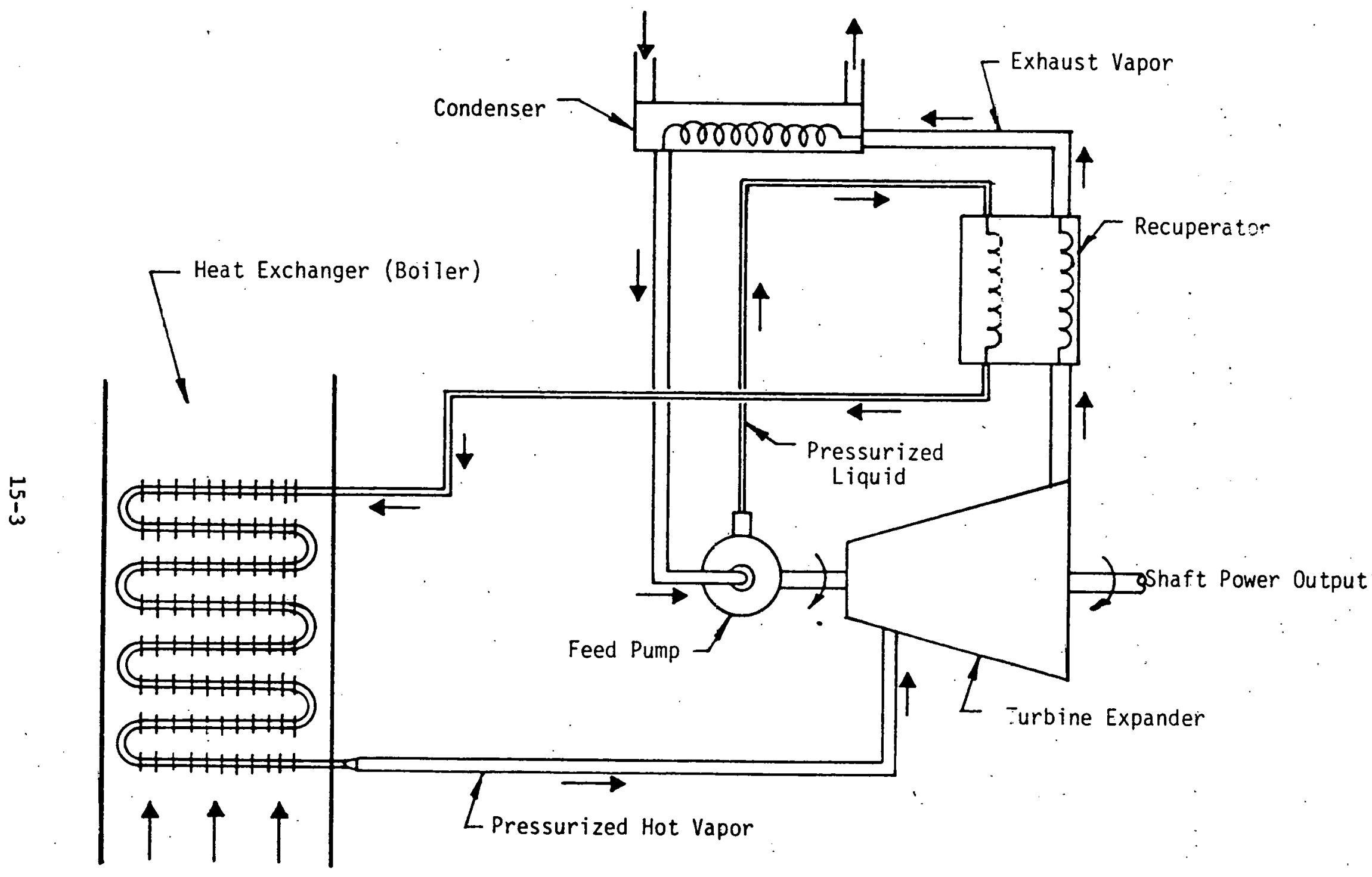

Hot Gas Stream

SOURCE: Arthur D. Little, Inc.

FIGURE 15-1 SCHEMATIC OF A WASTE-HEAT-RECOVERY ORGANIC RANKINE CYCLE ENGINE 


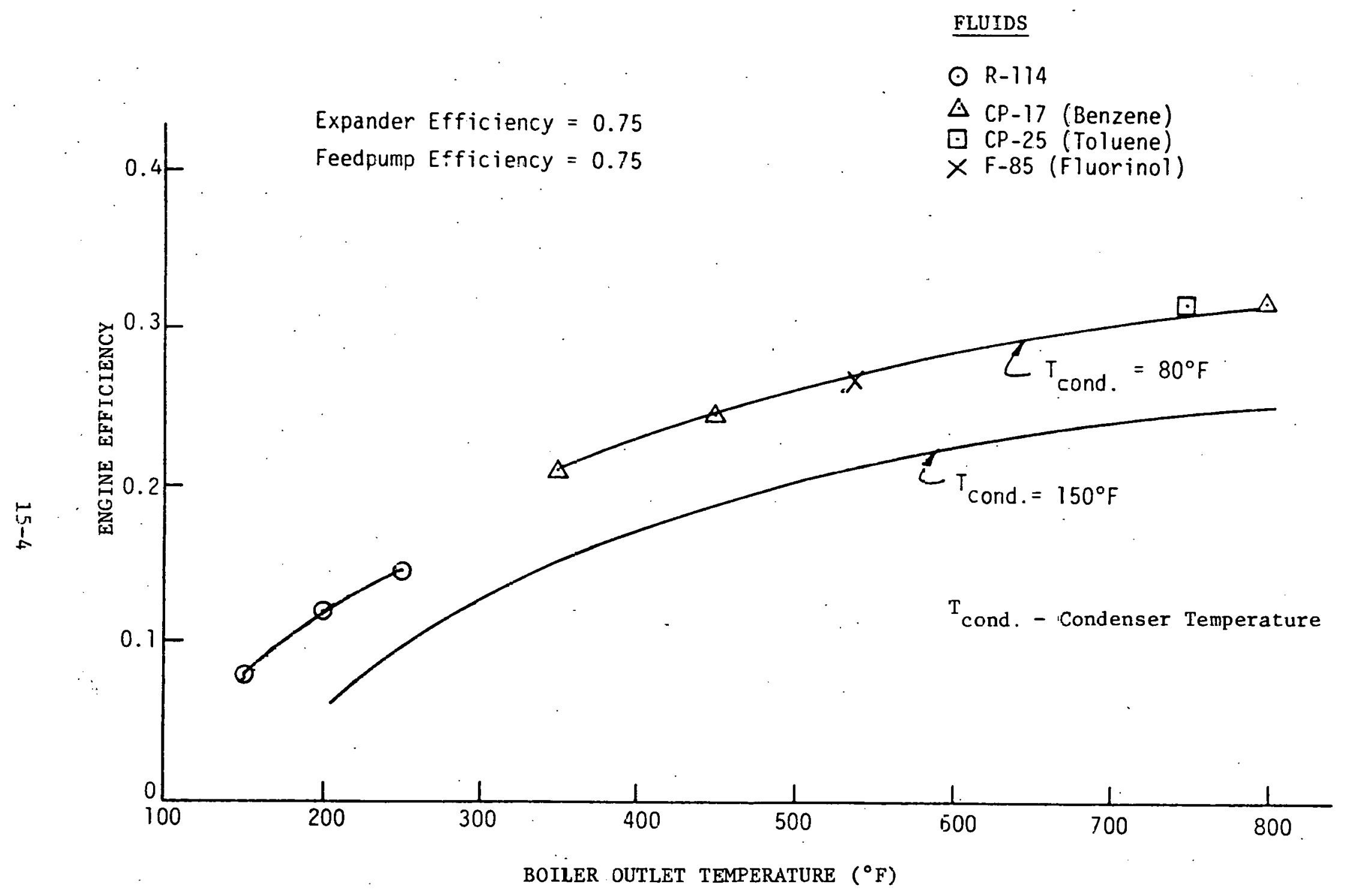

SOURCE: Arthur D. Little, Inc.

FIGURE 15-2 RANKINE CYCLE ENGINE EFFICIENCY - VARIATION NITH PEAK CYCLE TEMPERATURE 


\section{B. Component Configuration}

Most of the components of organic Rankine cycle engines would be standard commercial items. For example, the boiler and condenser could be tube-in-shell counterflow heat exchangers commonly used in the air conditioning industry. The feedpump might be a hydraulic fluld pump modified to account for the low viscosity of refrigeration fluids.

The key component within the system that is of a unique nature is the expander, used to convert high-pressure vapor into mechanical work during its expansion from boiler to condenser pressure. To a great extent, this component determines the thermal efficiency of the system. A number of expander Lypes can be used with the organic Rankine cycle including:

- reciprocating engines,

- turbines, and

- positive displacement rotary devices, such as rotating vane and screw expanders.

For relatively large systems (in excess of $100 \mathrm{~kW}$ ), turbines are generally the most appropriate cxpander type. However, for smaller units, positive displacement expanders have several advantages, $(1,2,3)$ including low operating speeds, high efficiency, and good part-load performance.

The heat exchangers acting as boller, regenerator, and condenser are by far the largest components, based on physical size. This is indicated by Figure 15-3, which shows the layout of a 2000-kW system. These heat exchangers will also tend to dominate system costs, particularly in larger production quantities.

\section{Working Fluid Considerations}

The performances of organic Rankine cycle engines using several working fluids are shown in Figure 15-2. Several common refrigeration fluids, such as R-114, are candidates for lower-temperature applications (up to $400^{\circ} \mathrm{F}$ ), while fluids with high thermal stability, such as benzene, toluene, and F-85 (Fluorinol) must be used for higher-temperature applications.

A large number of working fluids can be considered for use in addition to those indicated in Figure 15-2. The characteristics of several working fluids which are now being used in developmental engines are summarized 


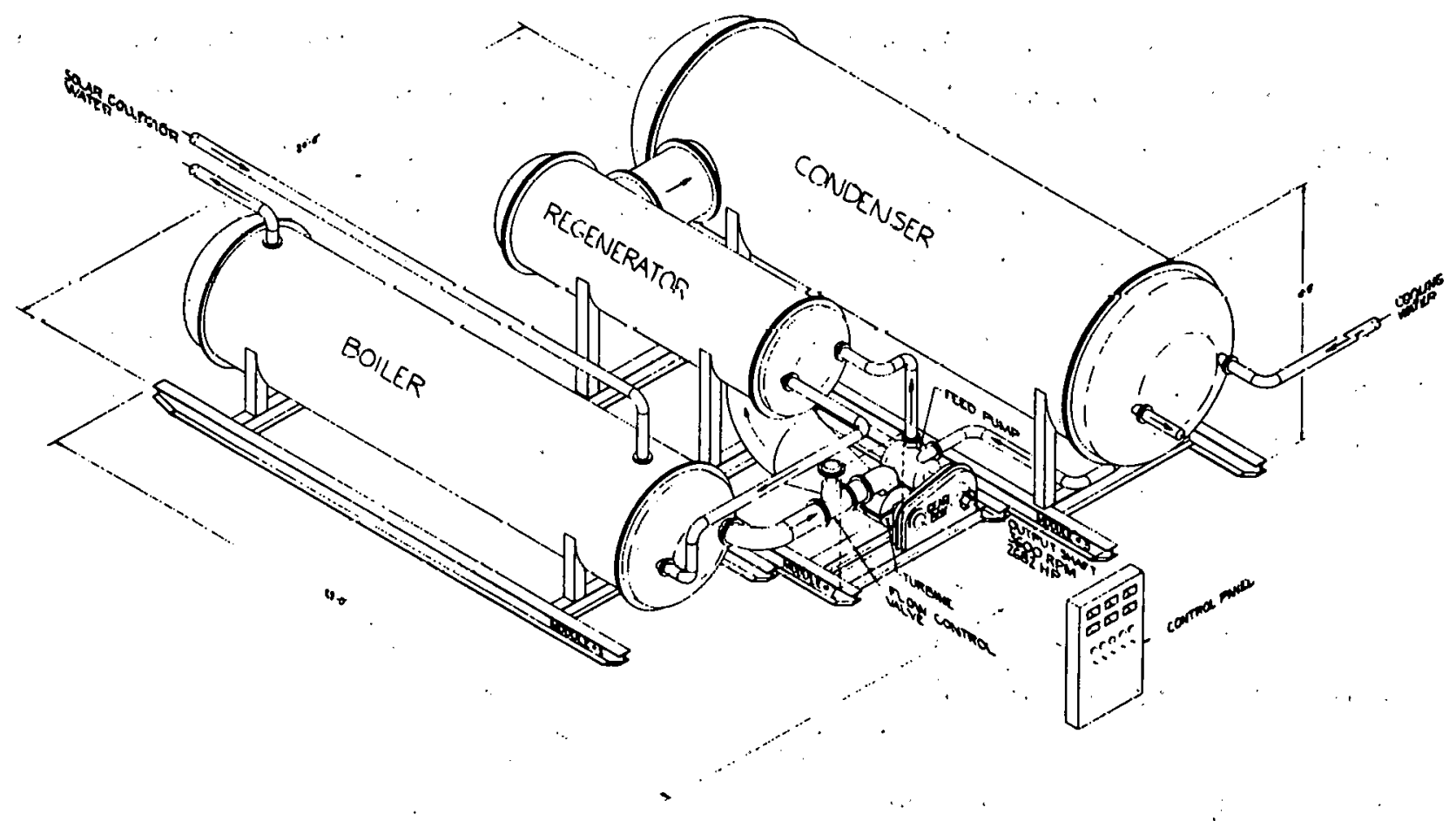

SOURCE: Reference 4.

FIGURE 15-3 LAYOUT OF A 2-MEGAWATT ORGANIC RANKINE CYCLE ENGINE (R-113 Working Fluid, $\mathrm{T}_{\mathrm{m}}=325^{\circ} \mathrm{F}$ ) 
in Table 15-1. Choice of a fluid will depend on a number of factors, including:

- peak operating and heat rejection temperatures,

- type of expander (turbine or positive displacement),

- power level, and

- toxicity and/or flammability restrictions.

As indicated in Figure 15-2, there are relatively modest variations in efficiency between working fluid options at any given temperature; and therefore, working fluid choice is usually determined by considerations such as the need for a recuperator, line size requirements, compatibility with expander type, and safety.

To date, $R-11$ and $R-113$, toluene, and $F-85$ have been the fluids most commonly used in those applications utilizing turbine equipment. Lowervolume-flow-rate-fluids (such as $\mathrm{R}-22$ and $\mathrm{R}-114$ ) might be better choices if positive displacement equipment is used.

\section{Applications}

In its intial development, the organic Rankine cycle engine was generally a flame-fired device. Areas investigated for possible use include automotive power plants, gas-fired cold generators for air conditioners, and military generators. The advantages of the organic Rankine engine in these applications include low exhaust emissions (because of the more easily controlled external combustion process) and a high degree of fuel flexibility (also attributable to external combustion).

However, the primary advantages of this engine cycle are its ability to use a variety of heat sources (solar, waste heat, geothermal, etc.) over a wide temperature range $\left(200-800^{\circ} \mathrm{F}\right)$ and the fact that system performance is not drastically affected by system size. In comparison, conventional Rankine cycle power systems using steam are generally considered only for large-scale (1-Megawatt and higher) applications with heat source temperatures in excess of $800^{\circ} \mathrm{F}$. The flexibility of the organic Rankine engine indicated above with respect to the heat source used and system output make it 1deally suited for distributed energy system use. 
TABLE $15-1$

ORGANIC POWER-CYCLE WORKING FLUIDS USED IN SYSTEM TESTING OR IN DEVELOPMENT

\begin{tabular}{|c|c|c|c|c|c|c|}
\hline Fluid & $\begin{array}{l}\text { Maximum } \\
\text { Boller Outlet } \\
\text { Temperature } \\
\left({ }^{\circ} \mathrm{F}\right) \\
\end{array}$ & $\begin{array}{l}\text { Freezing } \\
\text { Point }\left({ }^{\circ} \mathrm{F}\right) \\
\end{array}$ & $\begin{array}{c}\text { System } \\
\text { Test } \\
\text { Experlence } \\
\end{array}$ & Flammab111ty & $\begin{array}{l}\text { Current } \\
\text { Development } \\
\text { Underway }\end{array}$ & Comments \\
\hline$R-11$ & 2250 & -168 & Yes & Nonf lammable & Yes & $\begin{array}{l}\text { Favorite low temperature } \\
\text { working fluid; power and } \\
\text { comblned power/air } \\
\text { conditloning. }\end{array}$ \\
\hline$R-114$ & 7400 & -137 & I.imitred & Nonf lammahle & Nn & $\begin{array}{l}\text { Inmhined pnwar/atr } \\
\text { conditioning. }\end{array}$ \\
\hline$R-22$ & 425 & -256 & Yes & Nonf lammable & No & $\begin{array}{l}\text { Combined power/air } \\
\text { conditioning. }\end{array}$ \\
\hline Isobutane & 2500 & -217 & Yes & H1ghly flammable & Yes & 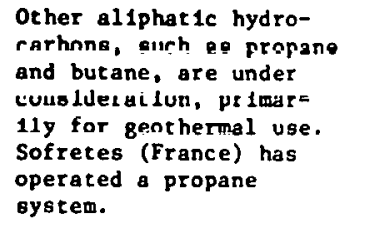 \\
\hline Thlophene & 550 & -37 & Yes & H1ghly flamable & No & Tox1c \\
\hline FC-75 & $\sim 600$ & -76 & Yes & Nonf lammab le & No & $\begin{array}{l}\text { Reyulres very high re- } \\
\text { generation, generally } \\
\text { lower efflclency than } \\
\text { other flulds at given } \\
\text { boller outlet temperature. }\end{array}$ \\
\hline Chlorobenzenes & 2600 & $\begin{array}{l}-49 \\
\text { (Mono- } \\
\text { chloro- } \\
\text { benzene) }\end{array}$ & Yes & Fire Resistant & No & $\begin{array}{l}\text { Used in Ormat (Israel) } \\
\text { system. }\end{array}$ \\
\hline $\begin{array}{l}\text { Monolsopropyl } \\
\text { Biphenyl }\end{array}$ & 2600 & -68 & Yess & Highly flammable & No & $\begin{array}{l}\text { Requires high regeneration, } \\
\text { very low condenser pressure. }\end{array}$ \\
\hline Fluorinol & $625-650$ & -82 & Yes & F1re Resistant & Yes & $\begin{array}{l}\text { Extensive experience, } \\
\text { seven years of system } \\
\text { testing. }\end{array}$ \\
\hline $\begin{array}{l}\text { Pyridinel } \\
\text { water mixture }\end{array}$ & 2700 & -75 & No & Flammable & No & Toxic \\
\hline Dowtherm-A ${ }^{\circledR}$ & $2700-750$ & +54 & Yes & Flameable & No & $\begin{array}{l}\text { Requires high regeneration, } \\
\text { very inw cnndenser pressure. }\end{array}$ \\
\hline $\begin{array}{l}\text { Toluene } \\
(C P-25)\end{array}$ & 2750 & -140 & Yes & H1ghly flammable & Yes & Extensive experience. \\
\hline $\begin{array}{l}\text { Hexafluoro- } \\
\text { benzene } \\
\text { Octufluoru- } \\
\text { benzene mixture }\end{array}$ & $2800-850$ & -40 & Yes & Nonf lamable & No & $\begin{array}{l}\text { Very expensive fluid } \\
\text { at present. }\end{array}$ \\
\hline $\begin{array}{l}\text { Hexafluoro- } \\
\text { benzene } \\
\text { Pentaf luoro- } \\
\text { benzene mixture }\end{array}$ & $2800-850$ & -40 & No & Nonf latmable & Yes & $\begin{array}{l}\text { Very expensive fluid } \\
\text { at present. }\end{array}$ \\
\hline SOURCE : & $\begin{array}{l}\text { Jndated product } \\
\text { Jaltham, Massac }\end{array}$ & $\begin{array}{r}\text { litera } \\
\text { husetts }\end{array}$ & The & Electron & Corpor & in, \\
\hline
\end{tabular}


The following is a list of promising DES applications for organic Rankine cycle engines:

- Bottoming cycles on existing generating equipment $(5,6,7)$

- diesel exhaust

- gas turbine exhaust

o Waste heat applications $(2,8,9,10)$

- furnace and flue exhausts

- boller exhaust

- hot process water

- Solar applications $(4,11,12,13)$

- Geothermal applications. $(14,15)$

- Flame-fired applications $(16,17,18)$

- using a variety of fuels (biomass, biogas, oils, gas, etc.).

The engines for each of these applications are basically the same (shown schematically in Figurc 15-1), with the exception of the vapor generator (or boiler) used for transferring heat to the working fluid.

Since the output of ORC engines is shaft power, it is possible to use any of the above applications to: 1) generate electric power ( $A C$ or $D C$ ), 2) directly drive vapor-compression refrigeration units (to chill water or provide comfort conditioning), or 3 ) to pump a liquid or gas (irrigation water, compressed air, etc.).

\section{E. Auxiliary Components}

The auxillary components required for an organic Rankine engine system depend on the application. With all systems, some type of cooling must be provided, and for locations without a nearby river or cool-water source, a cooling tower (wet or dry) will most likely be used. Similarly, all systems require a heat-input system to vaporize the heat-transfer fluid used in the engine boiler. This is generally a gas-to-liquid or liquid-to-liquid heat exchanger, depending on the heat source.

An ORC engine can be used to drive directly an electric generator, compressor, or pump as required by each specific application. When electric 
power is produced, it may be destrable to use this power in parallel with utility-supplied power. The utility interface will require switchgear and associated controls to ensure appropriate phasing of the on-site and ut1lity power sources.

For solar applications, some form of thermal storage may be desirable, so that operation during perlods of darkness or cloudiness can be maintained, and to smooth out short-term fluctuations in output due to passing clouds. This storage would probably take the form of pressurized hot water, a mixture of heat-transfer oil and crushed rock, or just heat-transfer ofl. The approach taken for energy storage would depend on factors such as the operating temperature levels and storage capacity requirements. (See Chapter 19.)

\section{Section 15.3: Economics Discussion}

The cost of organic Rankine cycle engines is difficult to estimate. These engines are not widely available on a strictly commercial basis. Furthermore, the cost depends on several variables, including:

\footnotetext{
- power output,

- temperature of heat input, and

- production levels.
}

Figure 15-4 shows estimates for the cost of organic Rankine cycle engines based on conversations from 1976 through 1978 with several potential manufacturers, Arthur D. Little, Inc., estimates, and 11terature on the subject. $(8,19,20)$ The rather wide cost range reflects, in part, the 1 imited commercial experience with these engines. These figures do not include any energy storage, generator, or cooling tower costs (estimated at $\$ 50 / \mathrm{kW}$ ). Furthermore, these figures do not include the cost of extra heat exchangers that might be required to transfer heat to a medium suitable for the Rankine engine boiler.

As indicated, at lower power levels, engine system costs per unit output decrease as the power level increases. This is due to the fact that the cost of mechanical equipment (expanders, pumps, etc.) and controls tends to increase slowly with increasing power level. For larger capacity engines, the cost of heat exchangers predominates and engine cost per unit output is not significantly affected by engine capacity. 


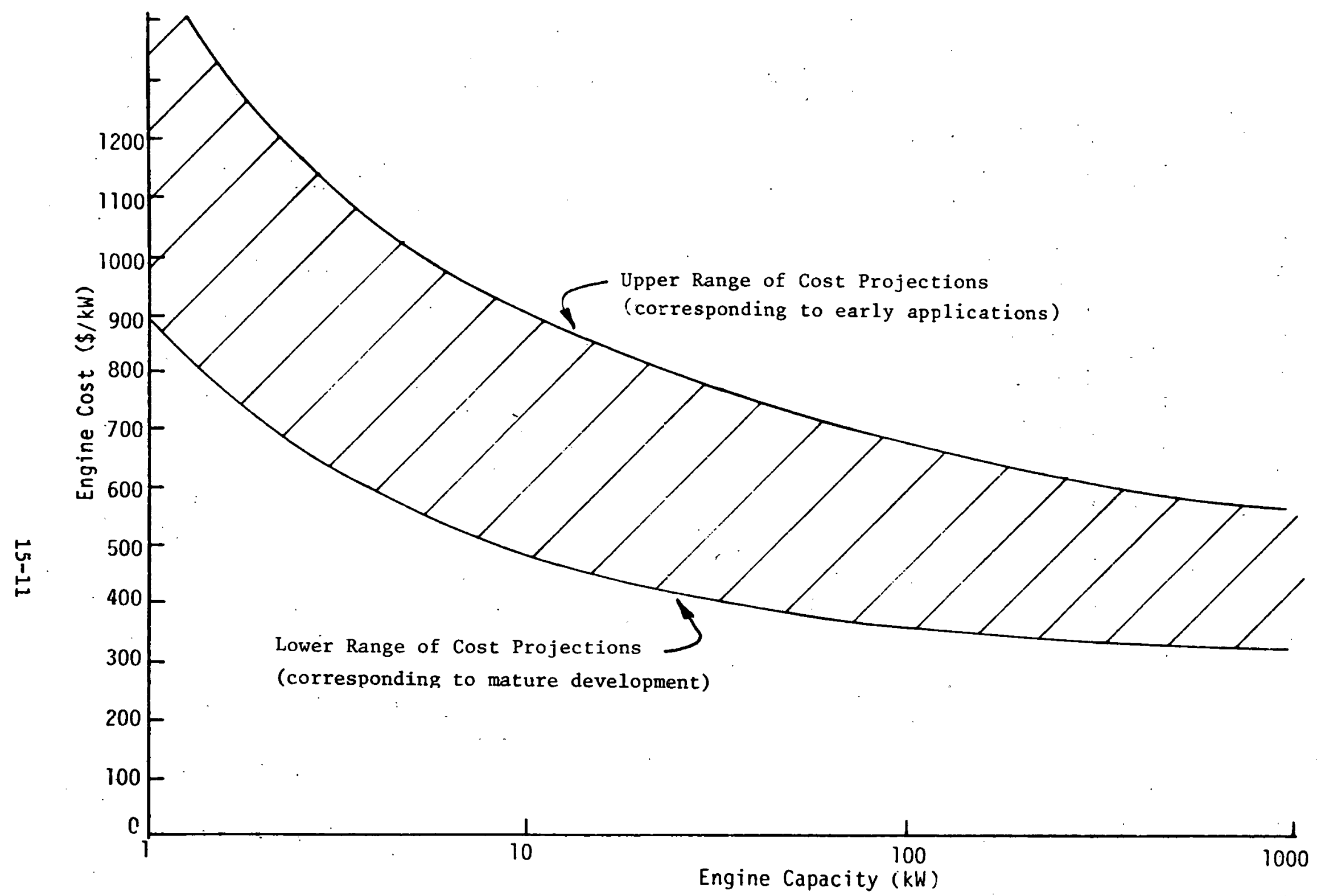

Condenser Cooling Systems not included.

SOURCE: References 8,19 , and 20 . 
In all cases, ORC englnes are expected to be highly reliable once they are fully developed because of their sealed construction (similar to vapor compression air conditioning systems) and their relatively low operating temperatures. The $0 \& M$ costs assoclated with their operation could be quite varlable, however, depending on operating temperature levels, nature of the heat source (flue gases, solar collectors, etc.), system size, and type of condenser cooling system. For purposes of this power cost analysis, $0 \& M$ costs are assumed to be $6 \%$ of the initial system cost. This number is quite tentative at this time because of the lack of long-term operating experience.

Figure 15-5 shows energy cost as a function of englne capacity, based on annual capital costs of $14 \%$ (including depreciation and interest), a $6 \%$ O\&M, and a "free" source of heat (such as would be available in a wasle heat application). The lower curve is based on a load factor of 1.0 (24-hour-a-day operation at full load, 365 days a year) and the upper curve, a load factor of 0.5 . The economics of ORC engines benefit from a high degree of engine utilization during the year. (This is espectally true with a fuel cost of zero, as assumed here for waste heat recovery applications.)

\section{Section 15.4: Limitations}

\section{A. Equipment Avallability}

A number of firms have made prototype organic Rankine cycle engines for a diversity of applications, including Industrial waste heat recovery, bottoming cycles on diesel engines, solar irrigation pumping, and solar air conditioning. A list of the most active tirms in the fleld is shown in Table 15-2. The efforts of several of these firms are sponsored by DOE as part of the solar cooling, geothermal, and energy conservation programs.

A 60-kW system using geothermal hot water as the heat source began operation in September, 1977, in E1 Centro, California. (21) This system uses isobutane as the working fluid and operates at a temperature of about $325^{\circ} \mathrm{F}$. Work is also proceeding on a 500-kW system which will operate on either. isobutane or pentane in a similar operating temperature range.

Several solar-powered demonstration ORC engine systems have been assembled in the United States, primarily as a result of government- 


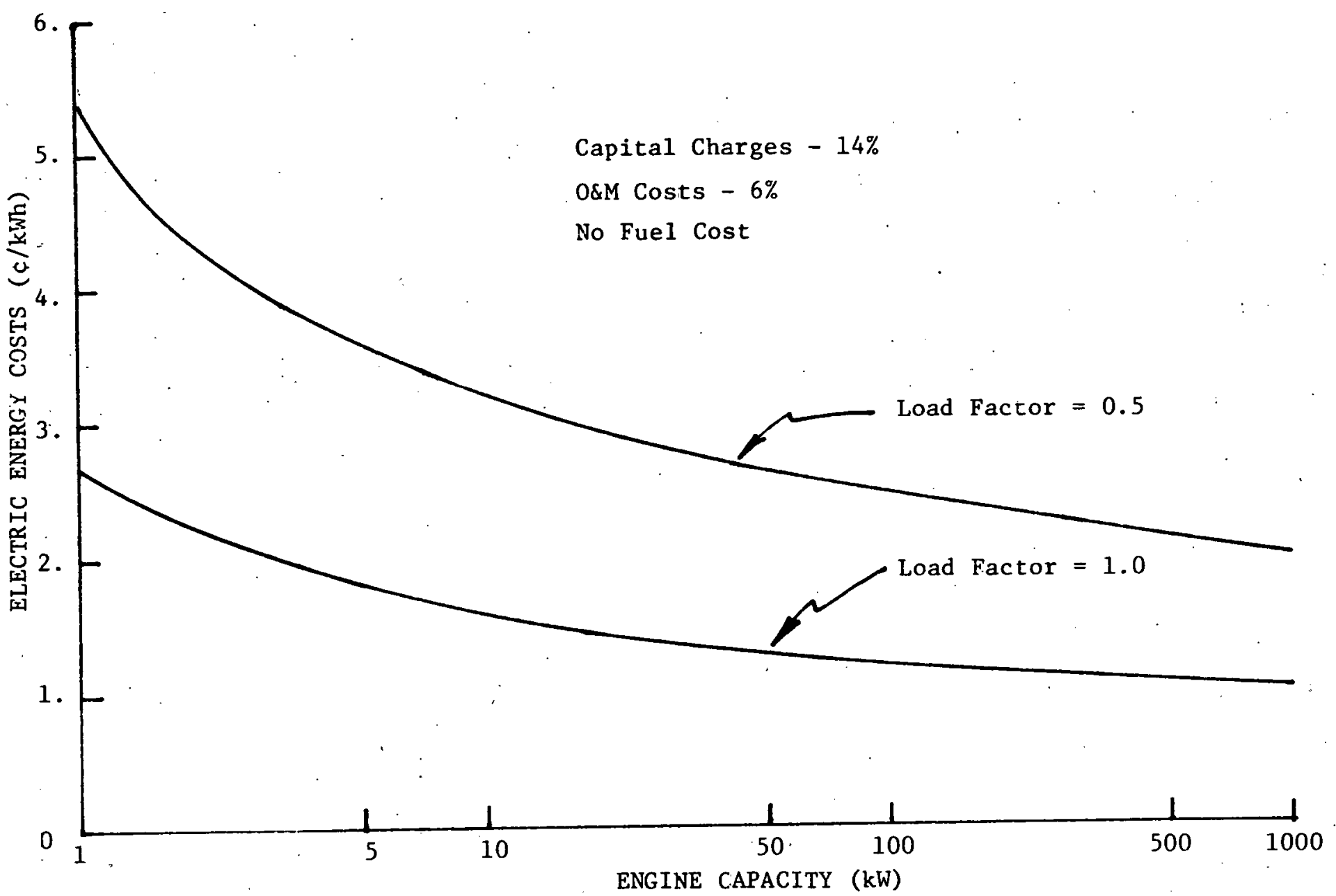

SOURCE: Arthur D. Little, Inc.

FIGURE 15-5 COST PROJECTIONS FOR ORGANIC RANKINE CYCLE ENGINES 
TABLE 15-2

DEVELOPERS AND/OR SUPPLIERS OF ORGANIC RANKINE CYCLE ENGINES

\begin{tabular}{|c|c|c|c|c|}
\hline & $\begin{array}{l}\text { Type of Mechanical } \\
\text { Equipment }\end{array}$ & $\begin{array}{l}\text { Output } \\
\text { (kW) }\end{array}$ & $\begin{array}{l}\text { Working } \\
\text { Fluid } \\
\end{array}$ & Applications \\
\hline $\begin{array}{l}\text { Thermo Electron Corporation } \\
\text { Sunstrand }\end{array}$ & $\begin{array}{l}\text { Reciprocating \& Turbine } \\
\text { Turbine }\end{array}$ & $\begin{array}{r}3-1000 \\
20-500\end{array}$ & $\begin{array}{l}\text { F-85\& Water } \\
\text { Toluene }\end{array}$ & $\begin{array}{l}\text { Automotive \& Bottoming Cycle } \\
\text { Solar Power, Waste-Heat } \\
\text { Recovery }\end{array}$ \\
\hline Barber-Nichols & Turbine & $2-100$ & $\begin{array}{l}\mathrm{R}-11, \mathrm{R}-113 \\
\mathrm{~F}-85 \text {, Iso- } \\
\text { butane }\end{array}$ & $\begin{array}{l}\text { Solar Power, Air Conditioning, } \\
\text { Waste-Heat Recovery, } \\
\text { Geothermal }\end{array}$ \\
\hline Aerojet General & Turbine & 150 & $\begin{array}{l}\text { Froprietary, } \\
\text { Pyridine- } \\
\text { Water }\end{array}$ & Automotive, Waste-Heat Recovery \\
\hline General Electric & Rotary Vane & $3-10$ & $\mathrm{R}-11$ & Solar Air Conditioning \\
\hline DuPont & Rotary Boiler \& Turbines & $10-200$ & Proprietary & Automotive \\
\hline Kinetics, Inc. & Generator, Helical Screw & $1-5000$ & $\mathrm{R}-12, \mathrm{R}-114$ & Solar \& Waste-Heat Recovery \\
\hline Ormat (Israel) & Turbine & $1-5$ & $\begin{array}{l}\text { Monochloro- } \\
\text { benzene }\end{array}$ & Remote Power System \\
\hline IHI (Japan) & Turbine & $100-500$ & $\mathrm{R}-11$ & Waste-Heat Recovery \\
\hline United Technologies & Turbine & 3 & $\mathrm{R}-11$ & Solar Air Conditioning \\
\hline Sofretes (France) & Reciprozating \& Turbine & $1-50$ & $\mathrm{R}-11$ & Solar Pumping \\
\hline $\begin{array}{l}\text { Mechanical Technologies, } \\
\text { Inc. }\end{array}$ & Turbine & i500 & $\begin{array}{l}\text { R-114 \& } \\
\text { Water }\end{array}$ & Waste-Heat Recovery \\
\hline
\end{tabular}

SOURCE: Compiled by Arthur D. Little, Inc. 
sponsored programs. These include a $2-1 / 2-h p$ solar-driven engine using $\mathrm{R}-113^{(12)}$ as the working fluld. These engines are directly coupled to the compressor of air conditloning systems.

A $32-\mathrm{kW}$ system is being used at Sandia Laboratories ${ }^{(22)}$ in their solar "total energy" test system. This system uses toluene as the working fluid at a relatively high temperature (between $500^{\circ}-600^{\circ} \mathrm{F}$ ) because of the use of focusing collectors.

One firm (Sofretes in France) ${ }^{(23)}$ is now producing a limited number of solar water pumping units using flat-plate collectors and an organic Rankine cycle engine. These systems are primarily for use in remote areas of developing countries. Ormat* has been manufacturing small (1-kW) URC engines for more than 10 years. These systems are of highly specialized, costly design which emphasizes high reliability. They are most of ten used in unattended remote areas (mountain tops, polar regions, etc.) to operate critical communications and signal equipment.**

The development of solar-driven irrigation pumping systems using ORC engines as the prime mover is also recelving a great deal of attention in the Infted States. One 25-hp system (sponsored by DOE) recently Initiated operation in the Estancia Valley of New Mexico and a 50-hp system (sponsored by Northwest Mutual Life Insurance Company) is now operating in Gila Bend, Arizona. (24) Both these systems use ORC engines with R-113 as the working fluid and operate at temperatures of $300-400^{\circ} \mathrm{F}$.

As part of the DOE energy conservation program, three firms will make demonstration engines in the 500-kW range which w111 use diesel engine exhaust heat or Industrial waste heat as the energy input. Manufacturers listed in Reference 23 report that these engines are in an advanced development stage and operation was initiated in late 1978.

No U.S. firms offer solar-driven engines on a strictly commercial basis (although prototype units are avallable by negotiation), but there are a number of major firms in the United States and elsewhere which percelve that solar-powered organic Rankine cycle englnes represent a viable

*Ormat Turbines, Ltd. of Yavne, Israel. ** In sunny regions solar cell power units are increasingly being usped for these functions. (See Chapter 2.) 
approach to on-site power generation, air conditioning, and water pumping. All indications are that the number of such firms is increasing and that ORC engine systems will be available on a commercial basis in the near term (2-5 years) over a range of system capacities from $3 \mathrm{~kW}$ for solar air conditioning applications to more than $1 \mathrm{MW}$ for waste heat and geothermal applications.

\section{B. Fuel Availability}

It is expected that most applications of organic Rankine engines will use solar, geothermal, hot engine exhausts, and industrial waste heat sources. Fossil fuel avallability will have, therefore, only an indirect effect on the economic viability or range of applications.

\section{Safety}

Because of the nature of these systems, safety considerations (other than those associated with any piece of rotating equipment) are mainly limited to working-fluid properties. None of the organic working fluids is completely free of problems associated with flammability and toxicity. Low-cost fluids such as toluene, benzene, and isobutane are all flammable, and may also be toxic and carcinogenic. Both thiophene and pyridine are quite toxic (including the inhaled vapor), which will tend to restrict their application. Fluorinol appears to be one of the safest of the high-temperature working fluids since both toxicity and flammability levels are quite low. (25)

The fluorocarbon refrigerant fluids heing constdered for organic Rankine cycle engine applications are nonflammable and have low coxicity. (26) One of the more serlous safety considerations with the refrigeration fluids could be the products of their thermal decomposition. These products can include phosgene, which is highly toxic. This consideration may be a serious one in some waste heat recovery applications, particularly if the "boiler" is in a hot flue-gas stream.

D. Environmental Concerns

Environmental concerns beyond those associated with the heat source are principally due to working fluid considerations and any 
effects associated with the condenser cooling system. With some refrigerant working fluids, atmospheric ozone layer degradation due to released. working fluid gas is of concern. If a cooling tower is used, the plume could perhaps have an effect on local climate, and the tower itself could adversely affect the view of the landscape. Care would have to be taken to avoid large temperature rises and working-fluid leaks into a local body of water, should this method of direct condenser cooling be selected. 
THIS PAGE

\section{WAS INTENTIONALLY LEFT BLANK}




\section{REFERENCES}

1. Marsters, G.F., et al. "Rotary Vane Expander Development: Some Design Considerations." 7th Intersociety Energy Conversion EngineerIng Conference, San Diego, California, September 25-29, 1972. pp. $249 \mathrm{ff}$.

2. Eckard, S.E. "Multi-Vane Expander as Prime Mover in Low Temperature Solar or Wasteheat Applications." 10th Intersociety Energy Conversion Engineering Conference, Newark, Delaware, August 17-22, 1975. pp. 1399 ff.

3. Teagan, W.P., et al. "3KW Organic Rankine Cycle Power System." Proceedings of the 25th Power Sources Symposium, Atlantic City, New Jersey, May 23-25, 1972. Sponsored by the U.S. Army Electronics Command, Fort Monmouth, New Jersey. - Available from PSC Publications Committee, P.0. Box 891, Red Bank, NJ.

4. Teagan, W.P., et al. "Solar Thermal Power Generation." COMPLES International Meeting, Petroleum and Minerals University, Dhahran, Saudi Arabia, November 1977. Sponsored by Coopération Méditerranéenne pour 1'Energie Solaire. Paper available from author c/o Arthur D. Little, Inc., Cambridge, Massachusetts.

5. Thermo Electron Corporation. Organic Rankine Bottoming Cycle for Long Haul Diese1 Trucks. Waltham, Massachusetts, November, 1975. Thermo Electron Corporation Report No. TE4193-40-76.

6. Doyle, E.F., et al. "Diese1-Organic Rankine Compound Engine Development." 12th Intersociety Energy Conversion Engineering Conference, Washington, D.C., August 28 - September 2, 1977. pp. $1073 \mathrm{ff}$.

7. Rheinhart, H., et al. "Development Status; Binary Rankine Cycle Waste Heat Recovery System." 12th Intersociety Energy Conversion Engineering Conference, Washington, D.C., August 28 - September 2, 1977. pp. $1090 \mathrm{ff}$.

8. Drexel University. Industrial Applications Study. Volume 1. Executive Summary: Industrial Waste Energy Data Base Technology Evaluation. Final Report. Prepared for Energy Research and Development Administration, December 1976. NTIS Report No. C00/2862-1.

9. Lewis, G., et a1. "Sulfuric Acid Plant Rankine Cycle Waste Heat Recovery." 11th Intersociety Energy Conversion Engineering Conference, State Line, Nevada, September 12-17, 1976. pp. $1182 \mathrm{ff}$.

10. Lacey, R.D., et a1. "600 KW Organic Rankine Cycle Waste Heat Power Conversion System." 12th Intersociety Energy Conversion Engineering Conference, Washington, D.C., August 28 - September 2, 1977. pp. $1095 \mathrm{ff}$. 


\section{REFERENCES (continued)}

11. Curran, H.M., et al. Assessment of the Rankine Cycle for Potent1al Application to Solar-Powered Cooling of Buildings. Prepared by Hittman Associates, Inc. for Natlonal Sclence Foundation, August 1974. NTIS Report No. PB 238069.

12. Prigmore, D.R., et al. "A Prototype Solar Powered, Rankine Cycle System Providing Residential Air Conditioning and Cooling." 9th Intersociety Energy Conversion Engineering Conference, San Francisco, California, August 26-30, 1974. pp. $326 \mathrm{ff}$.

13. Eckard, S. "Test Results for a Rankine Engine Powered Vapor Compression Air-Conditioner for $366 \mathrm{~K}$ Heat Source." 11th Intersociety Energy Conversion Engineering Conference, State Line, Nevada, September 12-17, 1976 . pp. $1169 \mathrm{ff}$.

14. Walter, R.A., et a1. "Economic Optimfzation of Binary Fluid Cycle Power Plants for Geothermal Systems. 11th Intersociety Energy Conversion Engineering Conference, State Line, Nevada, September 12-17, 1976. pp. 731 ff.

15. Eskesen, J.H. "Cost and Performance Comparison of Flash Binary and Steam Turbine Cycles for the Imperial Valley, California," 12th Intersociety Energy Conversion Engineering Conference. Washington, D.C., August 28 - September 2, 1977. pp. $842 \mathrm{ff}$.

16. Morgan, D., et a1. "Laboratory Test Results - Low Emission Rankine Cycle Engine with Organic Based Working Fluid and Reciprocating Expander for Automobiles." 8th Intersoclety Energy Conversion Engineering Conference, Philadelphia, Pennsylvania, August 13-17, 1973. pp. $158 \mathrm{ff}$.

17. Wigmore, D.B. Determination of the Optimum Fluid and System Vartables for .5-5 KWE Rankine Cycle Power Systems. Report prepared by Sundstrand Aviation for U.S. Army Mobility Fruif pment Research and Devclopment Center, February 1972. NTIS Report No. AD 741835.

18. Sundstrand Corporation. Organic Rankine Cycle Silent Power, 15KW, 28 VDC. Report prepared for U.S. Army Mobility Equipment Research and Development Center, February 1972.

19. Barber, R. "Solar Powe red Organic Rankine Cycle Engines - Characteristics and Costs." 11th Intersociety Energy Conversion Engineering Conference, State Line, Nevada, September 12-17, 1976 pp. $1151 \mathrm{ff}$.

20. Stern1icht, B. "The Equipment Side of Low Level Heat Recovery." Power $119(6): 71-77$, June 1975.

21. "New Heat Exchangers in Binary Cycle Process Used to Generate Electricity from Geothermal Fluids." DOE News Release, October 4, 1977. Avallable from U.S. Department of Energy, Washington, D.C. 
REFERENCES (continued)

22. Petterson, B., Jr. Solar Total Energy Test Facility Project; Semiannual Report, October 1976 - March 1977. August 1977. Prepared by Sandia Laboratories for Energy Research and Development Administration. NTIS Report No. SAND77-0738.

23. Promotional Literature from:

a) Ishikawajima-Harima Heavy Industries Co., Ltd. New Ohtemachi Bldg., 2-chome, 2-1 Ohtemachi, Chiyoda-ku, Tokyo, Japan

b) Thermo Electron Corporation 101 First Avenue Waltham, Massachusetts 02154

c) Sundstrand Corporation 4751 Harrison Avenue Rockford, Illinois 61101

d) Barber-Nichols Engineering Company 6325 W. 55th Avenue

Denver, Colorado 80221

e) Kinetics Corporation 3822 Colerain Avenue Cincinnati, Ohio 45223

f) Sofretes (Renault Moteurs Internationa1) La Boursdidiere, France.

24. U.S. Department of Energy. Solar Powered Irrigation Systems Technical Progress Report. February 28, 1978. NTIS Report No. SAN-1101/ PA2-21.

25. Hazards Research Corporation. Flammability Studies in Fluorinol 61 and Fluorinol 85. Report prepared for Halocarbon Products Corporation, 1974. Report No. 3344.

26. E.I. DuPont deNemours, 1007 Market, Wilmington, Delaware 19898. "Freon Compounds and Safety." Product Brochure, S-16. 1969. 


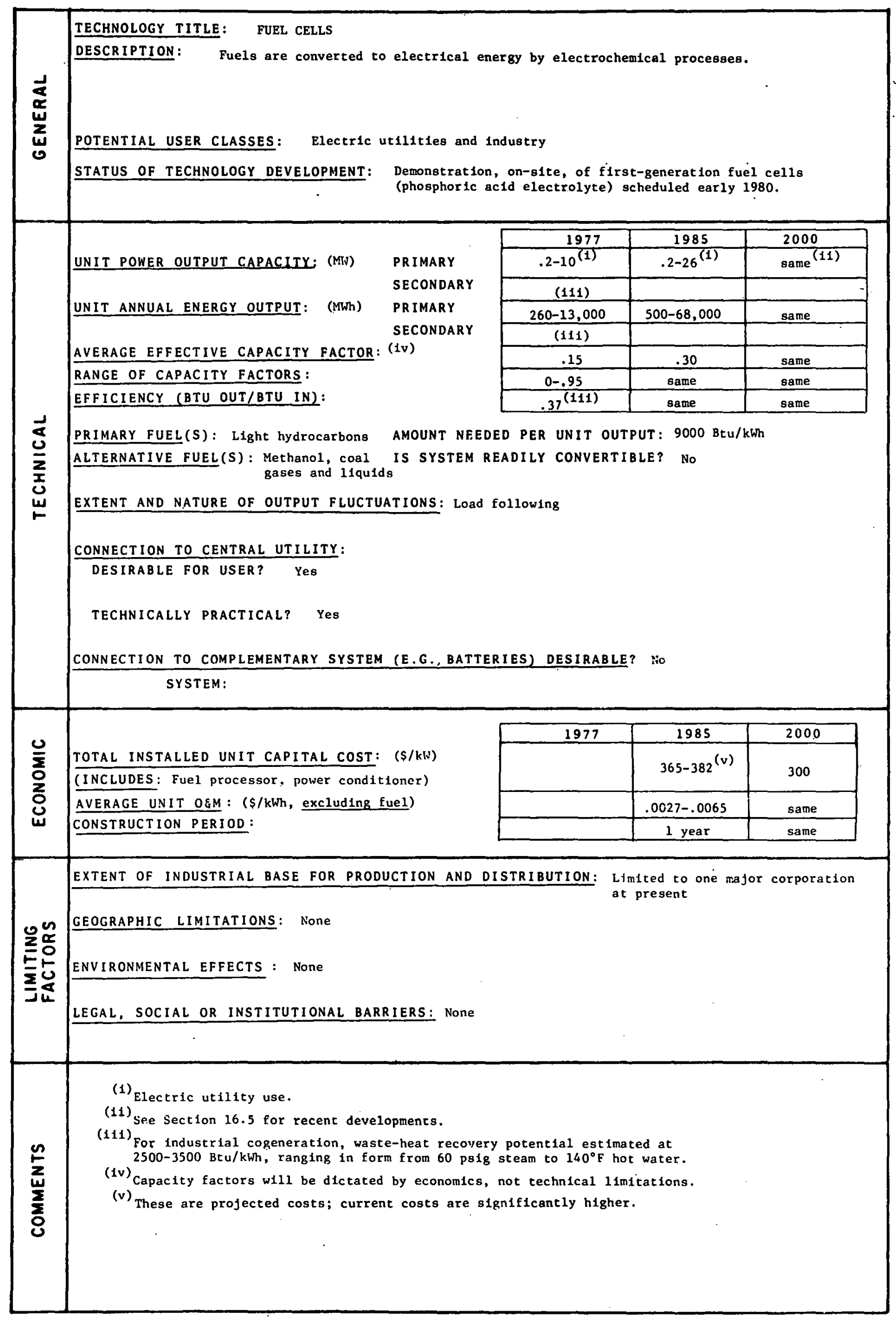


CHAPTER 16

FUEL CELLS

\section{Section 16.1: Introduction}

A fuel cell is an electrochemical device that converts the chemical energy of a fuel directly into electricity. As such, it is a primary source of electrical energy, not a storage device, that is well suited to a distributed energy system. The characteristics that make it an attractive candidate are modular construction, good load following capabilities without loss of efficlency, automatic startup and shutdown, low-pollutant emissions, and silent operation.

The major limitation in the application of existing fuel cell technology (based on a phosphoric acid electrolyte operating at $190^{\circ} \mathrm{C}$ ) is the requirement for a clean fuel that can be used to generate hydrogen, such as naphtha. Hydrogen is the only fuel that can be oxidized in the fuel cell itself at acceptable power levels. A thermally integrated steam reformer and fuel-cell stack scheduled for demonstration in early 1980 are expected to operate at a heat rate of $9300 \mathrm{Btu} / \mathrm{kWh}$. (1) A second-generation molten-carbonate-electrolyte fuel cell operating at $600^{\circ} \mathrm{C}$ and using advanced fuel conversion technology would make less stringent demands for a clean fuel. It is anticipated that if the technology can be developed, a heat rate of $7340 \mathrm{Btu} / \mathrm{kWh}^{(2)}$ would be obtained but this is not expected before the late 1980 's.

Present technical activities revolve around the on-site demonstration of a fuel cell and reformer module for $4.8 \mathrm{MW}$. (3) Though originally considered primarily for peak load operation, depending on location, fuel avallabllity and price, fuel cells could be used to meet intermediate loads. An installation of this size is particularly attractive if there is an on-site use for the waste heat from the system -- the concept of cogeneration. There also appears to be the promise of using molten-carbonate cells for baseload operation. However, baseloaded fuel cell power plants, like conventional and other advanced system concepts, would have to be quite large to match 
the use of energy obtalnable from large coal-burning plants. As such, they would not qualify as distributed energy systems and are not considered in this report.

\section{Section 16.2: Technical Discussion}

The physical form of a fuel cell is very similar to that of a battery -- two electrodes separated by an ionically conductive electrolyte. The difference between the fuel cell and a battery is that the latter stores its chemical enetgy listernally, while the firel cell requires a continuous external supply and, in turn, provides continuous electrical power. The most common fuel is hydrogen, although attempts have been made (unsuccessfully) to use propane, melhatul, and hydrazine directly.

The hydrogen fuel is fed to the anode of the fuel cel1; oxygen from air reacts at the cathode. The overall chemical reaction is the formation of water, and it is the free energy of this reaction that defines the maximum electrical energy that a fuel cell can produce. Since there is no thermomechanical work involved, the efficlency of the energy-conversion process is not limited by the Carnot cycle. However, there are voltage losses associated with internal resistance, mass-transport limitations, and kinetics of the electrode reactions. The variation of voltage with load is shown in Figure 16-1. The output is low-voltage high-current power from a single cell with a voltage of 0.65 and a current density of 250 amperes/ft ${ }^{2}$ of electrode. Present technology consists of mult1-cell stacks that are approximately $4 \mathrm{ft}^{2}$ in cross section, producing 1000 amperes at 50-300 volts, depending on the size of the stack.

The types of fuel cell are most easily classifled by temperature and the nature of the electrolyte. Currently avallable technology ${ }^{(1)}$ is based on a phosphoric acid cell operating at $190^{\circ} \mathrm{C}$. Acid systems are favored because they do not react with carbon dioxide. and thus may use air as the oxidant. Phosphoric acid is preferred because it is a system in which it is relatively easy to control water removal. The most difficult aspect of fuel cell technology is the establishment of the three-phase interface between the 


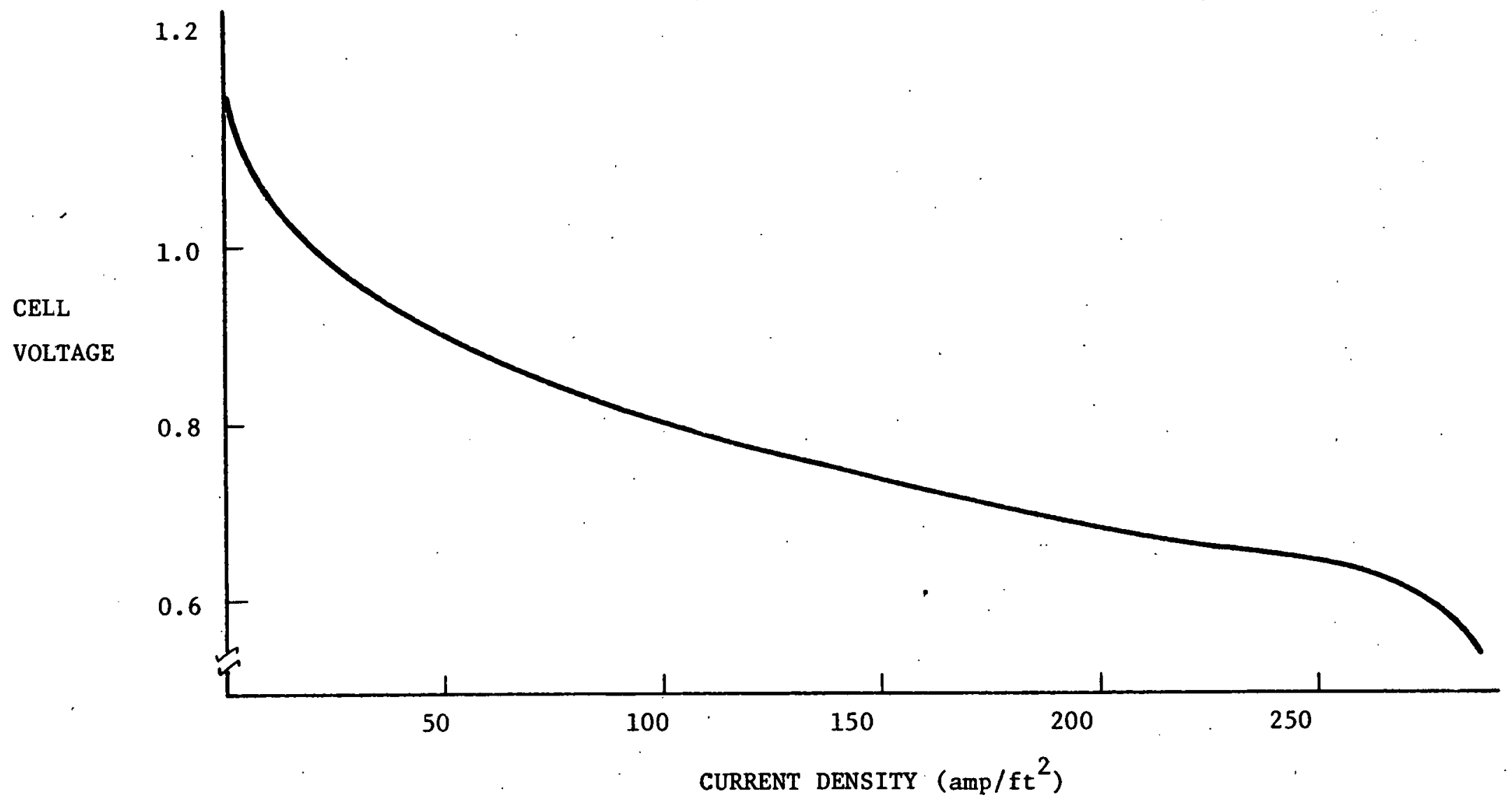

SOURCE: Reference 2.

FIGURE 16-1 TYPICAL CURRENT-VOLTAGE CURVE FOR A FUEL CELL 
reacting gases, the electrolyte, and the electrodes. In the phosphoric acid cell the electrodes are made wetproof (hydrophobic) by using a plastic binder for the platinum-on-carbon electrocatalyst. The electrolyte is contalned by capillarity in a porous separator.

Another fuel cell type under active englneering development ${ }^{(2)}$ has a molten carbonate as 1 ts electrolyte and operates at $600^{\circ} \mathrm{C}$. A mixture of potassium and lithium carbonates is contalned in a solld or sem1solid ceramic matrix. The electrochemical reaction at the cathode is. the reduction of oxygen from the air with added carbon dioxide to form carbonate ions. At the anode a fuel, such as carbon monoxide or hydrogen, is oxidized by the carbonate fons that migrate through the electrolyte to produce carbon dioxtde and water. The carbuin dioxide le racycled to the cathode. The performance characteristics are similar to those of a phosphoric acid fuel cell, the principal advantages of the molten-carbonate fuel cell being that it is tolerant to carbon monoxide and is potentially less expensive than the phosphoric acid cell.

A third type of fuel cell, still in the engineering research phase, is based on a solid-oxide electrolyte that operates at $1000^{\circ} \mathrm{C}$. The electrolyte most commonly used is doped zirconia, which has gond ionic conductivity related to the migration of oxide ions. The biggest difficulty is obtaining long life. This system is unlikely to be operational before 1990 .

A complete fuel cell generalor consisty of the cell stack, plus a fuel processor that converts a commerclal fuel to a form sultable for feeding to the cell stack. For example, in a phosphoric actd fuel cell, naphtha (after sulfur removal) is steam-reformed to produce hydrogen and carbon monoxide; then a shift reactor converts the carbon monoxide and steam to produce a fuel stream of hydrogen with low levels of carbon monoxide and hydrogen sulfide. The molten-carbonate system can utilize the hydrogen-carbon monoxide stream directly; that is, no separate shift reactor is needed, but $1 t$ is still important to remove the sulfur. The hope for baseload systems is to achieve an overall heat rate of 7500 $\mathrm{Btu} / \mathrm{kWh}$ by integrating a coal gasifier with the molten-carbonate systcm. 
As mentioned above, a fuel processor is necessary for the fuel cell to use commerclally available fuels. The key to obtaining high efficiency is the use of waste heat from the fuel cell. in fuel processing. A power condtioner converts the DC power of the fuel cell to $\mathrm{AC}$ power at a voltage level compatible with the local distribution system. A schematic of a fuel cell system is shown in Figure 16-2.

The fuel cell generator has many advantages to offer to a dispersed energy system. Modular constiuction confers flexibility In size. There is capability to follow load without loss of efficiency at low loads. (See Figure 16-3.) Note that pressurized cell operation is needed to maintain a proper water balance, and twin-flow turbocompressors are used, since it is necessary to have a low-flow unit to maintain high . efficiency at lower power output. Fuel consumption closely follows the power demand. Fuel cell systems are being designed to operate automatically and to require no supervision and a minimum of maintenance. Low pollutant levels and stlent operation allow a wide range of siting options.

Present technology is based on the phosphoric acid cell; the first unit is scheduled to be tested on-site in ear1y 1980. (1) The basic size is a single 4.8-MW module. More than 50 modules of this type are planned for installation in the future, but the extent to which this wili take place is very dependent on the success of the first demonstration. This number of systems, with approximately 10,000 cells per 4.8-MW module, represents a modest manufacturing effort that should in no way inhibit' the application of fuel cells in dispersed energy systems.

\section{Section 16.3: Economics Discussion}

Table 16-1 gives the projected costs for three fuel cell systems: steam reforming coupled with the phosphoric acid cell, steam reforming with a molten-carbonate cell, and auto-thermal reforming with a moltencarbonate cell. Total capital costs are expected to approach $\$ 400 / \mathrm{kW}$ 


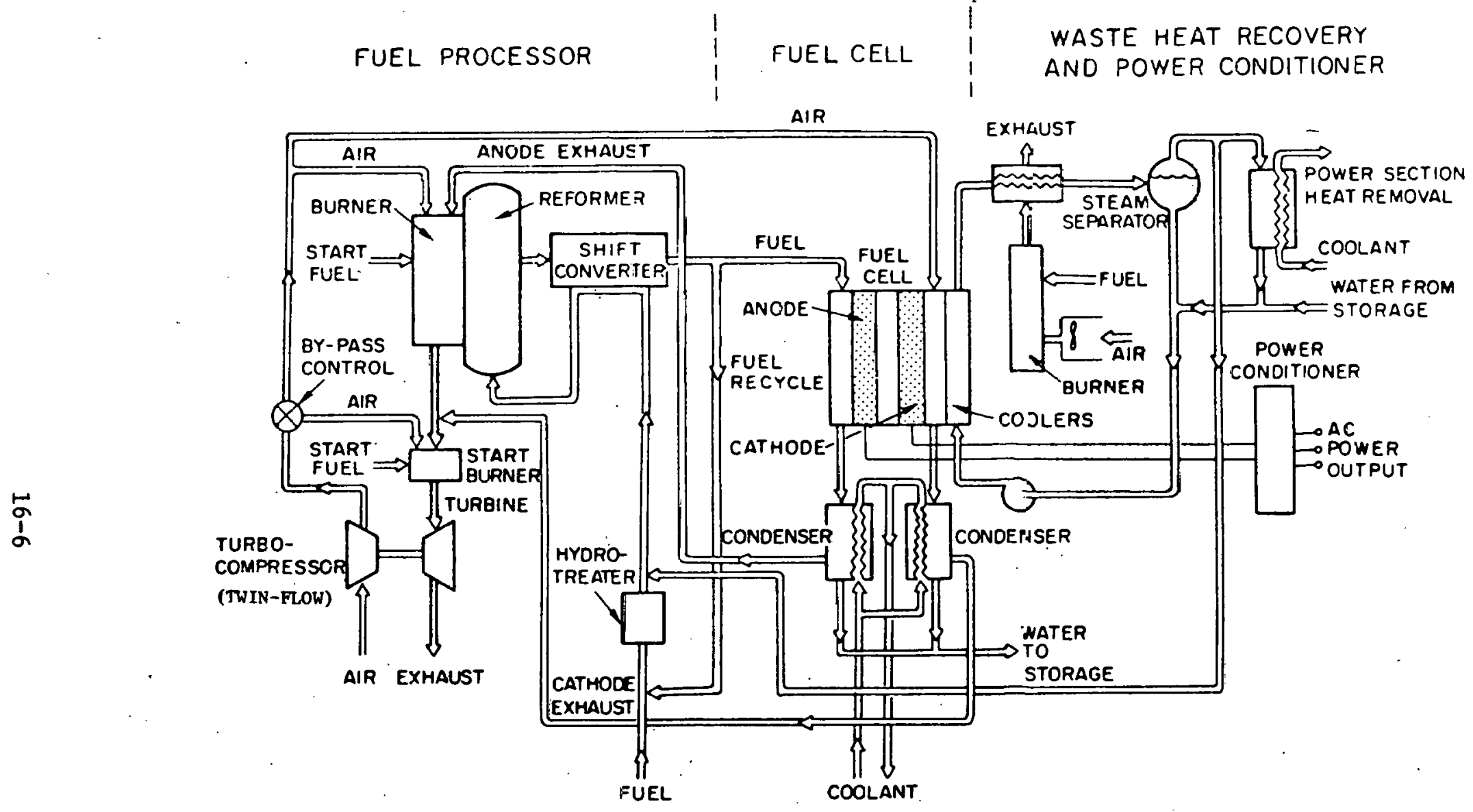

SOURCE: Reference 4.

FIGURE 16-2 SCHEMATIC DIAGRAM OF A FUEL CELL SYSTEM INCLUDING FUEL CELL, FUEL PROCESSOR (REFORMER, SHIFT CONVERTER AND AUXILIARIES), WASTE HEAT RECOVERY SYSTEM, AND POWER CONDITIONER 


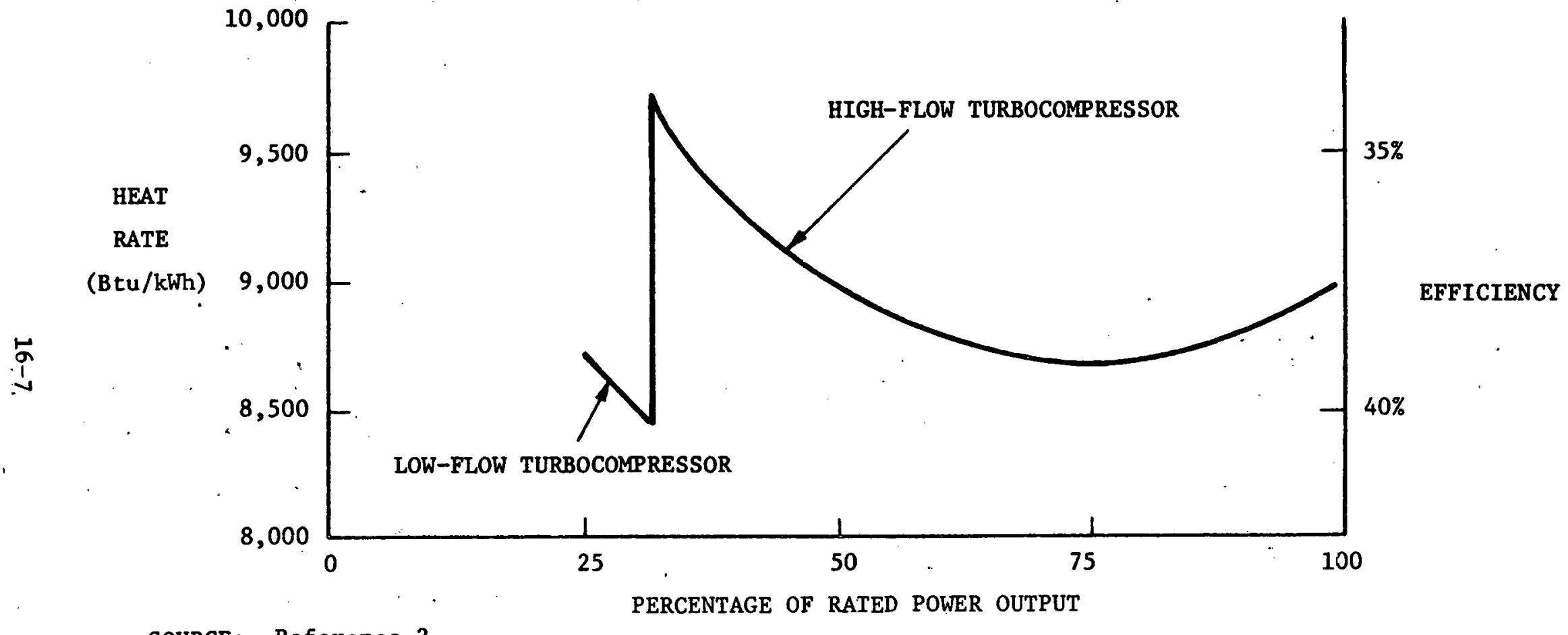

SOURCE: Reference 2.

FIGURE 16-3 FUEL CELL EFFICIENCY AS A FUNCTION OF POWER OUTPUT 
TABLE $16-1$

ESTIMATES OF 1985 CAPITAL AND ENERGY COSTS FOR FUEL CELL SYSTEMS (1977\$)

Ce11/Processor Technology

\begin{tabular}{|c|c|c|c|c|c|}
\hline \multirow[b]{3}{*}{$\begin{array}{l}\text { Heat Rate, Btu/kWh } \\
\text { Feed Sulfur Content, p?m } \\
\text { Capital Costs }(\$ / \mathrm{kW})\end{array}$} & \multicolumn{5}{|c|}{ Ce11/Processar Technology } \\
\hline & \multicolumn{2}{|c|}{$\begin{array}{ll} & \text { Acid } \\
\text { Steam } & \text { Reforming } \\
\end{array}$} & \multirow{2}{*}{$\begin{array}{c}\text { Molten-Carborate } \\
\text { Steam Reforming } \\
7,945 \\
200\end{array}$} & \multicolumn{2}{|c|}{$\begin{array}{l}\text { Molten-Carbonate Auto- } \\
\text { thermal Reforming }\end{array}$} \\
\hline & 200 & $9,00 \mathrm{C}$ & & 200 & 2,000 \\
\hline $\begin{array}{l}\text { Processor and thermal } \\
\text { Pawer cell } \\
\text { Site ancillaries }\end{array}$ & $\begin{array}{r}168 \\
146 \\
56 \\
\end{array}$ & $\begin{array}{r}163 \\
146 \\
56 \\
\end{array}$ & $\begin{array}{r}180 \\
146 \\
56 \\
\end{array}$ & $\begin{array}{r}168 \\
146 \\
56 \\
\end{array}$ & $\begin{array}{r}174 \\
146 \\
56 \\
\end{array}$ \\
\hline Total Capital Cost & 370 & 365 & 382 & 370 & 376 \\
\hline$\frac{\text { Energy Costs (mills/kWh) }}{\text { Capital Charge }}$ & 22.2 & 21.9 & 22.9 & 22.2 & 22.6 \\
\hline $\begin{array}{l}\text { O\&M Expenses }(4) \\
\text { Fuel Charge } \\
(5)\end{array}$ & $\begin{array}{r}3.2 \\
30.2 \\
\end{array}$ & 33.7 & 26.6 & $\underline{24.6}$ & 24.2 \\
\hline Total Energy Cost & 55.6 & 58.3 & 52.6 & 49.9 & 53.3 \\
\hline
\end{tabular}

(1) Includes cell stacks, inverter, and turbocompressor.

(2) ppm: parts per million.

(3) $18 \%$ of capital investment.

(4) 3,000 hours operation per year.

(5) Assumes naphtha at $\$ 3.30(2,000 \mathrm{ppm}$ sulfur), $\$ 3.35$ (200 ppm sulfur), and $\$ 3.75$ (0.5 ppm sulfur) per $10^{6}$ Btu.

SOURCE: Reference 5, updated from 1975 dollars to 1977 dollars. 
in 1985 with delivered energy costs (including fuel and capttal charges) in the range of 50 to $58 \mathrm{mills} / \mathrm{kWh}$.

Certain capital cost credits can be applied to these figures for a distributed energy system. One credit includes transmission and distribution savings of $\$ 29$ to $\$ 36 / \mathrm{kW}^{(6)}$ because the fuel cell can be located close to the load. Another credit of $\$ 4$ to $\$ 15 / \mathrm{kW}$ is due to a decrease in the need for spinning reserve, which is required by conventional power plants that operate at relatively low efficiency at low loads. (6)

It slivuld be emphasized that the power cost estimates reported in Table 16-1 are for fuel cell systems operated only 3,000 hours/year (peak to intermediate range). It would be unrealistic to attempt to compare these figures with the cost of power from baseloaded systems which write off their capital charges over many more operating hours.

On-site fuel cell cogeneration systems have been studied for a number of industrial applications. (7) In these cases the economics are improved both by higher capacity factors (since the systems are usually baseload) and by credits for waste-heat recovery in the form of steam and hot water for plant use. The economies of scale derive from the fuel processor and ancillary equipment rather than the power system itself which is modular in construction. Waste heat output from both the molten carbonate and phosphoric acid systems is generally estimated at 2500$3500 \mathrm{Btu} / \mathrm{kWh}$ at $100-130^{\circ} \mathrm{C}$.

\section{Section 16.4: Limitations}

It is perhaps premature to assess the limiting factors that might prevent acceptance of fuel cells as primary power generators. The first objective is a successful demonstration of the phosphoric acid cell in a utility application; the prime factor is a cell stack life of at least 10,000 hours at an acceptable level of performance. Also important is meeting a cost goal of $\$ 400 / \mathrm{kW}$. The next objective is to demonstrate rechnical success with molten-carbonate technology.

Without credits and other intangible factors, the phosphoric acld cell is only marginally attractlve and at best should be considered 
only in the context of transition to the more efficient molten-carbonate system. Unless it turns out that the molten-carbonate cell is not technically feasible, fuel cell systems must be considered as primary candidates for future distributed energy systems and other selected applications in which the low-grade waste heat can be used advantageously.

\section{Section 16.5: Recent Developments}

The molten carbonate fuel cell has long been considered tolerant to high-sulfur fuels, and it is true that anode performance and 11 fe are little affected. However, if the anode exhaust is recycled to the cathode as a source of carbon dioxide, then its sulfur content is absorbed almost completely in the oxidizing environment. The sulfur (as sulfate) can then migrate across the cell and attack the ulckel components of the anode. Complete surlfur removal from the fuel will add significantly to both the capital and operating cost of molten-carbonate fuel cells.

Major improvements have heen made, however, In molten-carbonate ce11 fabrication. (9) These 1mprovements increase the time for mixing of the fuel and oxidant streams to occur through the electrolyte--a major source of inefficiency and limitation on life in earlier designs. 


\section{REFERENCES}

1. Handley, L.M., et al. "4:80 Megawatt Fuel Cell Module Demonstrator." Proceedings of the Twelfth Intersociety Energy Conversion Engineering Conference, Washington D.C., August 28-September 2, 1977 . pp. $341 \mathrm{ff}$.

2. King, J.M. Advanced Technology Fuel Cell Program. Report prepared by United Technologies Corporation for Electric Power Research Institute, November 1977. EPRI Report No. EPRI-EM-576.

3. Lawrence, L.R. "The ERDA Fuel Cell Program." Energy Development IV. IEEE Power Engineering Society, 1978. pp. 199 ff. IEEE Paper No. 78TH0050-S-PWR.

4. Cusamano, J.A., et a1. Assessment of Fuel Processing Alternatives for Fuel Cell Power Generation. Report prepared by Catalytica Assoclates, Inc., for Electric Power Research Institute, October 1977. pp. 3-2 ff. EPRI Report No. EPRI-EM-570.

5. Stickles, R.P., et al. Assessment of Fuels for Power Generation by Electric Utility Fuel Cells. Vol. I. Report prepared by Arthur D. Little, Inc., for Electric Power Research Institute, March 1978. EPRI Report No. EPRI-EM-695.

6. Wood, W., et al. Economic Assessment of the Utilization of Fuel Ce1ls in Electric Utility Systems. Keport prepared by Public Service Electric and Gas Company, for Electric Power Research Institute, November 1976. EPRI Report No. EPRI-EM-336.

7. United Technologies, Power Systems Division. On-Site Fuel Cell Resources Conservation in Industrial Process Applications. Report prepared for Energy Research and Development Administration, August 1977. ERDA Report No. FCR-0439.

8. Appleby, J., ed. Proceedings of the DOE/EPRI Workshop on Molten Carbonate Fuel Cells, Oak Ridge National Laboratory, November 1978. To be published by NTIS.

9. Appleby, J., Electric Power Research Institute, Palo Alto, California. Private communication. March 1979. 


\section{SUPPLEMENTARY BIBLIOGRAPHY}

1. Bockris, J.0., et al. Fuel Cells: Their Electrochemistry. New York: McGraw-Hill, 1969.

2. Liebhafsky, H.A., et al. Fuel Cells and Fuel Batteries. New York: John Wiley \& Sons, Inc., 1968.

3. Baker, B.S., ed. Fuel Cell Systems-II. Washington, D.C.: American Chemical Society, 1969.

4. Baker, B.S., ed. Hydrocarbon Fuel Cell Technology. New York: Academic Press, 1965.

5. Young, G.J., et al., eds. Fuel Cell Systems. Washington, D.C.: American Chemical Society, 1965.

6. Mitche1l, W. Jr., ed. Fuel Cells. Vol. I.: Chemical Technology. New York: Academic Press, 1963.

7. Steitz, P., et al. An Assessment of the Fuel Cell's Role in Small Utilities. Report prepared by Burns and MacDonnell for Electric Power Research Institute, February 1978. EPRI Report No. EPRI-AF-696.

8. Houghtby, W.E., et al. Advanced Technology Fuel Cell Program. Report prepared by United Technologles, Corp. for Electric Power Research Institute, December 1.978. EPRI Report No. EPRI-EM-956.

9. Wakefield, R., et al. An Analysis of the Application of Fuel Cells in Dual Energy Use Systems. Report prepared by Mathtech, Inc. for Electric Power Research Institute, February 1979. EPRI Report No. EPRI-EM-981.

10. Simons, S.N., et al. Comparison of Fuel-Cel1 and Diesel Integrated Energy Systems and a Conventional System for a 500-Unit Apartment. National Aeronautics and Space Administration, November 1978. NASA Report No. NASA-TM-79037.

11. Stickles, R.P., et al. Assessment of Industrial Applications for Fuel Cel1 Cogeneration Systems. Report prepared by Arthur D. Little, Inc. for National Aeronautics and Space Administration, September 1978: NASA Report No. NASA-CR-135429.

12. Dynatrend, Inc. National Fuel Cell Seminar, Boston, Massachusetts, June 21, 1977. Prepared by the U.S. Department of Energy, 1977. NTIS Report No. CONF-770664.

13. Energy Research and Developmnet Administration. ERDA/EPRI Fuel Ce11 Seminar, Palo Alto, California, June 29, 1976. Sponsored jointly by the Division of Conservation Research and Technology of the Energy Research and Development. Administration and the Electric Power Research Institute, June 1976. NTIS Report No. CONF-760.6156. 


\section{SUPPLEMENTARY BIBLIOGRAPHY (continued)}

14. Cavagnaro, D. Hydrocarbon Fuel Cells (Citations from the American Petroleum Institute Data Base). Report for 1967 - Apr11 1978. National Technical Information Service, July 1978. NTIS Report No. NTIS/PS-78/0651.

15. Cavagnaro, D. Fuel Cells. Vol. 3: 1977 - June 1978. Nationa1 Technical Information Service, June 1978. NTIS Report No. NTIS/ PS-78/0633.

16. Cavagnaro, D. Fuel Cells. Vo1. 2: 1974-1976. National Technical Information Service, July 1978. NTIS Report No. NTIS/PS-78/0632.

17. Burnett, W.M. Fuel Cell Benefits: The Program Management office Viewpoint. Energy Research and Development Administration, 1976. NTIS Report No. TID-27748.

18.. Energy Research and Development Administration. Fuel Cells: A Bibliography. June 1977. NTIS Report No. TID-3359.

19. King, J.M. Energy Conversion Alternatives Study (ECAS). Integrated Coal Gasifier/Molten Carbonate Fuel Cell Powerplant Conceptual Design and Implementation $\Lambda$ ssessment. Final Report on Phase 2. Report prepared by United Technologies Corporation for National Aeronautics and Space Admintstration, 1976. NTIS Report No. PB 270016.

20. Mixon, W.R., et al. Market Assessment of Fuel Cell Total Energy Systems Summary Report. Oak Ridge National Laboratory, March 1979. NTIS Report No. ORNL/CON-36.

21. Wood, W., et al. "Economic Assessment of the Utilization of Fuel Cells in Electric Utility Systems." IEEE Trans. Power Apparatus and Systems PAS-97(5):1805, September/October 19.78 .

22. Cameron, D.S. "Fuel Cell Energy Generators; Platinum Catalysts Used in Alternative Energy Source." Platinum Met. Rev. 22(2):38, April 1978.

23. Voelker, G.E. "Department of Energy Fuel-Cell Program." Workshop on Dual Energy, Use Systems, Yarmouth, Maine, September 19, 1977. Sponsored by the Electric Power Research Institute. EPRI Report No. EPRI-EM-718-W.

24. Fickett, A.P. "DEUS Fuel Cells." Workshop on Dual Energy Use Systems, Yarmouth, Maine, September 19, 1977. Sponsored by the Electric Power Kesearch Inștitute. EPRI Report No. EPRI-EM-718-W.

25. Davis, J.C. "Fuel-Cell Trials: Ut1lities Now, CPI Next?" Chemical Engineering 85:79, August 14, 1978. 


\section{SUPPLEMENTARY BIBLIOGRAPHY (cont Inued)}

26. Fickett, A.P., ed. Conference Proceedings: Fuel Ce11 Catalys1s Workshop, Palo Alto, California, January 15-17, 1975. Prepared by Electric Power Research Institute, August 1975. NTIS Report No. PB 245 115. :

27. Blurton, K.F. "Gas Utilities and Fuel Cells." Conference on Fuel Cells and the Hydrogen Economy: A Viable Alternative Source of

$\therefore \quad$ Energy for New York State, O1d Westbury, New York, September 14 , 1978. NTIS Report No. CONF-7809101-1. 


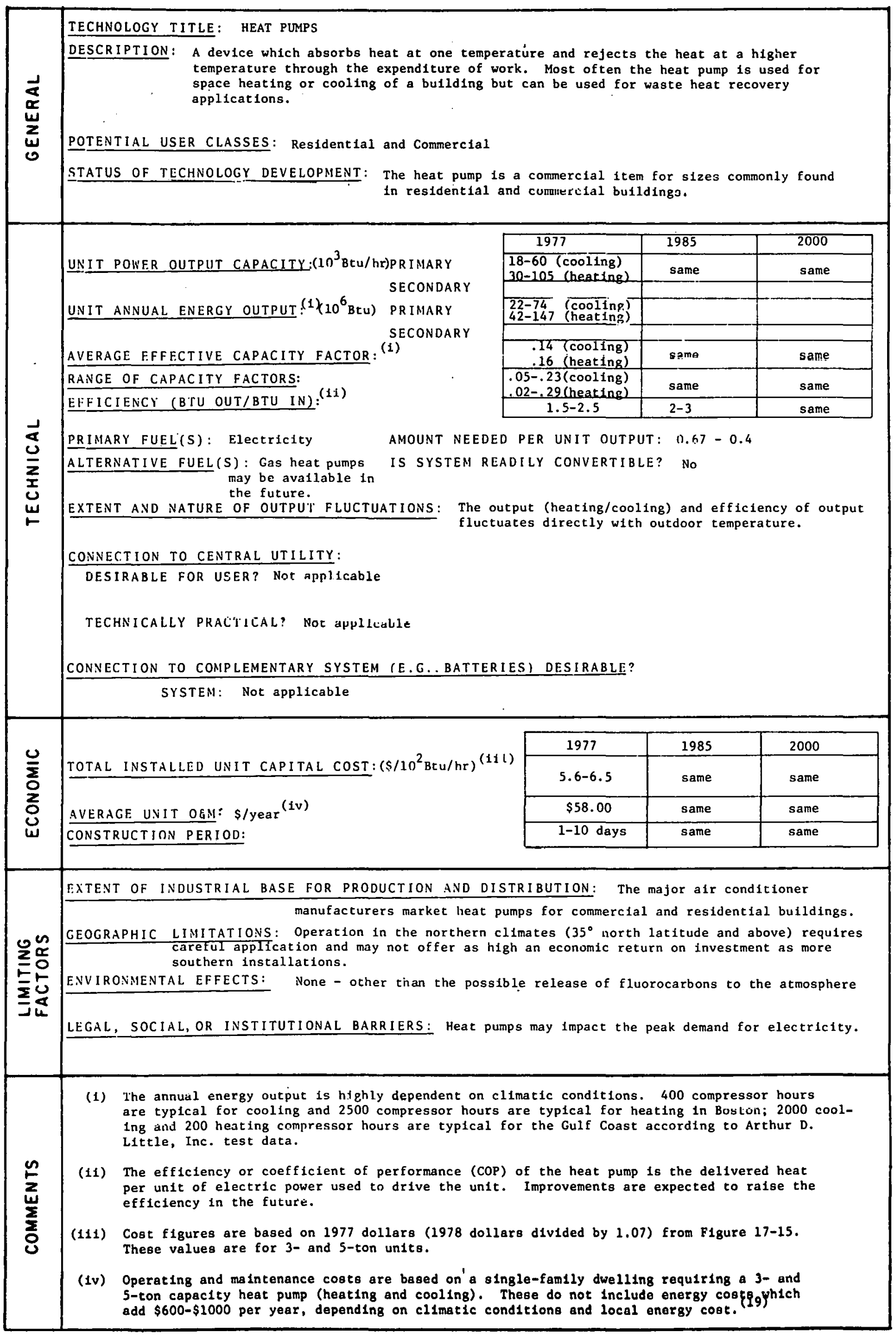




\section{HEAT PUMPS}

\section{Section 17.1: Introduction}

A. What is a Heat Pump?

A heat pump is a thermodynamic refrigeration cycle machine which moves heat from a low-temperature source to a higher-temperature sink by the addition of work. When low temperatures are desired, as in air conditioning or refrigeration, the heat pump removes unwanted heat and expels it to a higher-temperature sink (such as warm outside air or water). When high-temperature heating applications are desired, the heat pump supplies this energy by drawing it from a low-temperature source (usually cold outside air or water). Thus, there is 1ittle difference between a refrigerator and heat pump; the difference is entirely in the purpose of the process.

In many applications, including most residential and commercial uses, the same machine may at one time operatc ao an air conditioner, and at another time as a heater. In some industrial applications, the heat pump may be used for cooling at one temperature level and simultaneously for heating at another temperature. For instance, in a brewery in Florida, (1) a heat pump is being considered to remove heat (i.e., refrigerate) from the fermentation vats and "pump" this heat up to heat water to be used elsewhere in the facility. In large commercial buildings, heat pumps have been used to "pump" heat from the warm side of the building (sun load or internal heat generation) to the colder side of the building.

Figure 17-1 shows the thermodynamic system. The absolute temperature of the source is $\mathrm{T}_{\mathrm{L}}$ degrees, and the heat extracted from the source is $Q_{L}$. The energy rejected to the sink at temperature $T_{H}$ degrees is $Q_{H}$. Both effects are accompanied by the input of work, $W$. From the first law of thermodynamics:

$$
Q_{H}=Q_{L}+W ;
$$




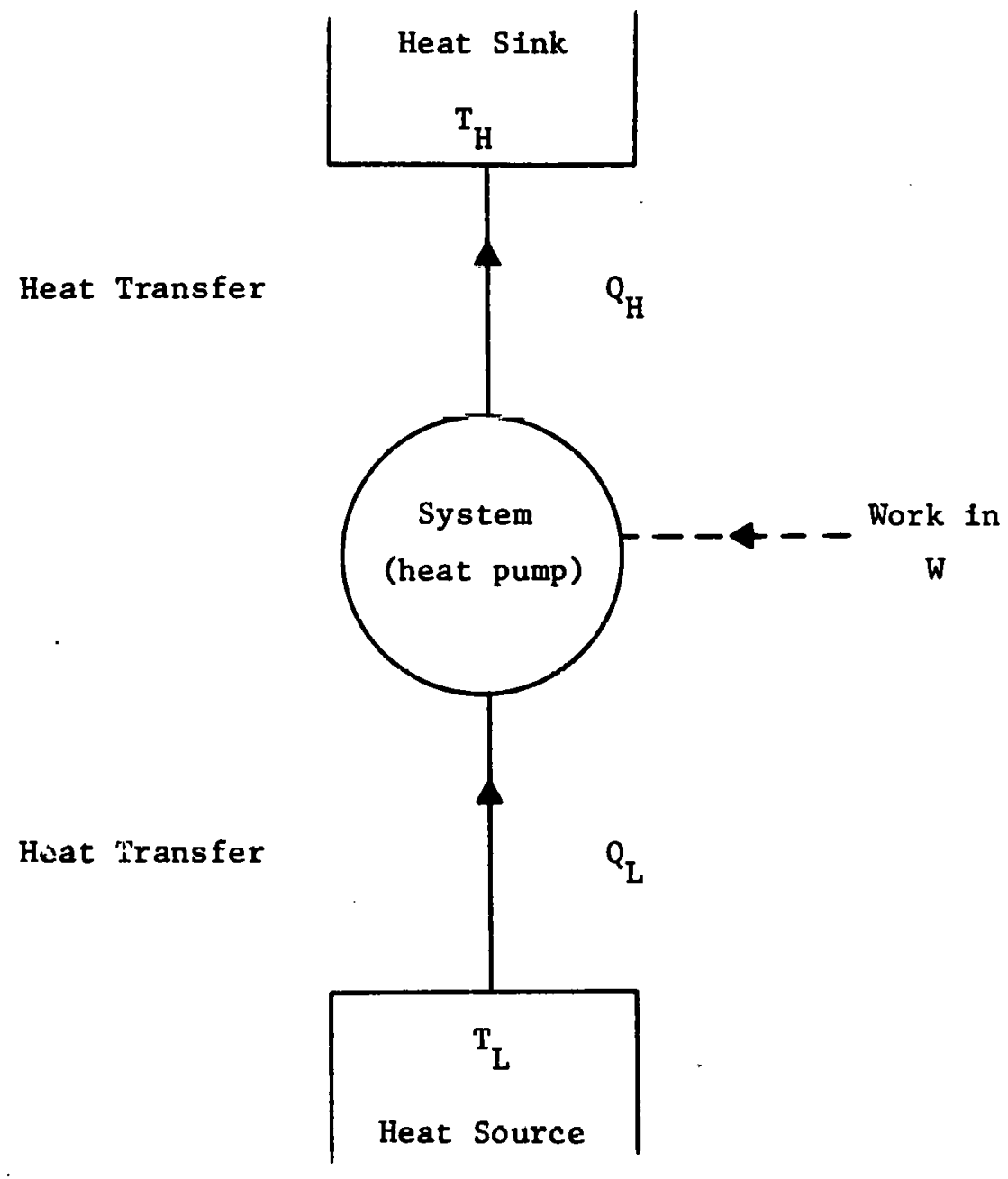

FIGURE 17-1 A THERMODYNAMIC SYSTEM ACTING AS A HEAT PUMP 
that is, the heat output, $Q_{H}$, is the sum of that heat extracted from the cold region plus the energy added to the heat pump. Therefore, the total heat output will always be greater than the energy required to run the device, and thus the coefficient of performance (COP) will always be greater than unity:

$$
{ }^{\mathrm{COP}}{ }_{\mathrm{HP}}=\mathrm{Q}_{\mathrm{H}} / \mathrm{W}>1 \text {. }
$$

It is important to note that sometimes a portion of the heat, $Q_{H}$, is not delivered to the desired space. For example, when outdoor compressor units are used, some of the energy available for space heating is lost before it can enter the house. Under these conditions, the actual COP based on delivered $Q_{H}$ can be less than 1 .

Conversely, heat removed in air conditioning or refrigeration is less than the heat rejected, and therefore the COP of a heat pump in the cooling mode is less than when it is used for heating. It can be shown that

$$
{ }_{\mathrm{COP}}^{\mathrm{CPC}}=\mathrm{Q}_{\mathrm{L}} / \mathrm{W}=\mathrm{COP}_{\mathrm{HP}}-1 \text {. }
$$

Vapor cycles utilizing mechanical compression are most common for heat pumps. The majority of heat pumps used in the United States are refrigeration cycle machines which typically use liquid-vapor refrigerant as the working fluid in a vapor-compression cycle. The primary components of a vapor-compression cycle and a typical set of fluid states during cycle operation are shown in Figure 17-2. Compressed vapor is liquefied in the condenser and subcooled to a temperature $5^{\circ}$ to $10^{\circ} \mathrm{F}$ less than the condensing temperature. The subcooled liquid is expanded through a flow restriction (a valve or capillary tube), creating a two-phase, low-pressure, cold fluid which passes through the evaporator where heat. is drawn from the environment to be cooled, evaporating the cold liquid so that gas may be returned for compression. Compressors used in residential applications are typically positive displacement devices and are capable of providing compressed gas over a wide range of pressures. 

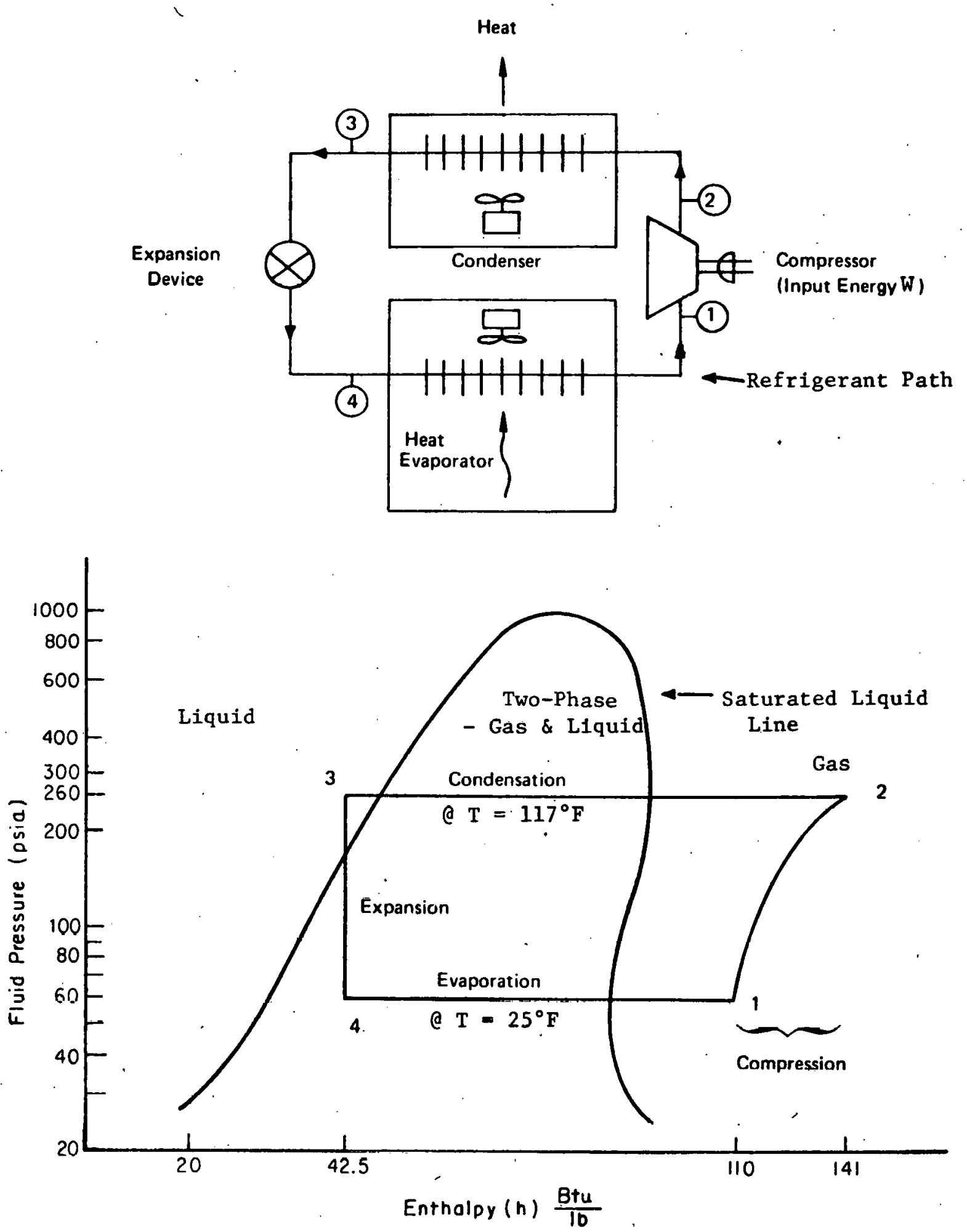

SOURCE: Arthur D. Little, Inc., estimates based on a $45^{\circ} \mathrm{F}$ outdoor temperature and a $20^{\circ} \mathrm{F}$ air-to-heat exchanger temperature difference, standard fluid properties of refrigerant 22, and an ideal gas compression process. Derived from General Electric sales literature entitled "General Performance Curves for Packaged Units,". July 1973.

FIGURE 17-2 TYPICAL FLUID STATES DURING HEAT PUMP HEATING MODE 


\section{B. Typical Applications for Heat Pumps}

The predominant use of heat pumps sold for residential and commercial purposes is for space heating in the winter and space cooling in the summer. During the winter, heat is extracted from outdoor air and "pumped up" to the desired temperature levels for heating indoor air; during the summer, the heat pump cycle is reversed and operated as a conventional air conditioner wherein heat is removed from the indoor space and rejected to higher-temperature outdoor air. Because of its ability to move heat "uphill" from a low-temperature source to a higher temperature, the heat pump can also be used as a heat recovery unit. In a 1977 study for ERDA, (2) a heat pump was incorporated into a drainwater heat-recovery system to supply heat to a hot water tank. A schematic for this system is shown in Figure 17-3.

Another use of heat pumps has been in the annual cycle energy storage (ACES) concept ${ }^{(3)}$ in which a heat pump is used to draw heat from a large contatiner of water during the winter for use in heating the house, and this large chilled container is then used for space cooling in the summer. This system is discussed in Chapter 19 (Thermal Energy Storage).

\section{Section 17.2: Technical Discussion}

\section{A. System Description}

Common heat pumps can be categorized as either air-source or water-source heat pumps, as shown in Figure 17-4. Air-source equilpment, Including air-to-air (first term refers to source, second to sink) and alr-to-water units, is dependent upon outside alr for heat exchange. Water-source equipment, including water-to-air and water-to-water units, makes use of groundwater tables, large reservolrs, and, in some commerclal applications, rivers.

Heat pumps can be either self-contained (1.e., packaged) or split-system. (See Figure 17-5.) Self-contained heat pumps typically consist of a hermetic compressor (housed in an 1solated compartment to cut the sound leve1), a condenser, evaporator, fans, defrost controls, 


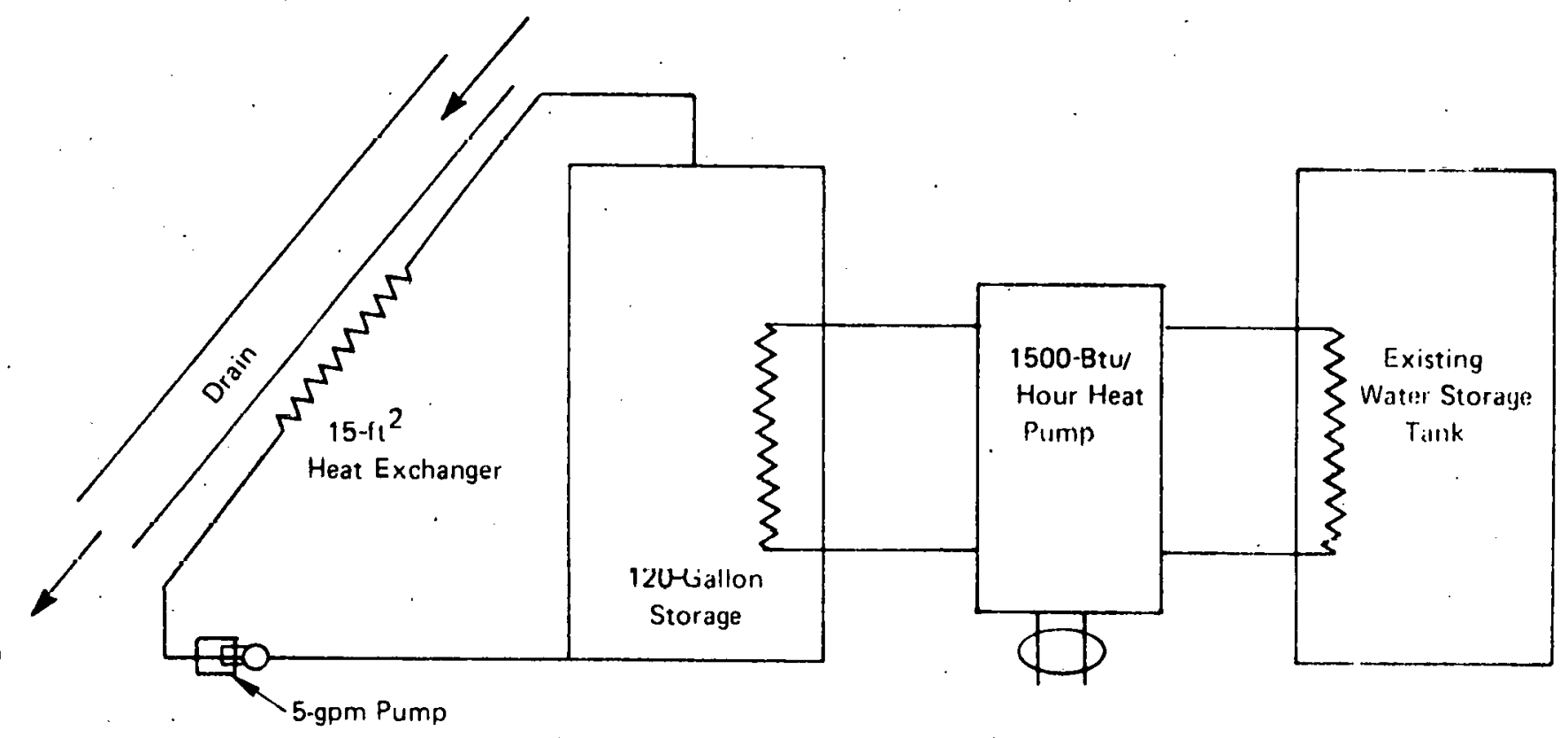

SOURCE: Reference 2.

FIGURE 17-3 SCHEMATIC OF A DRAIN-HEAT-RECOVERY SYSTEM FOR WATER PREHEAT 


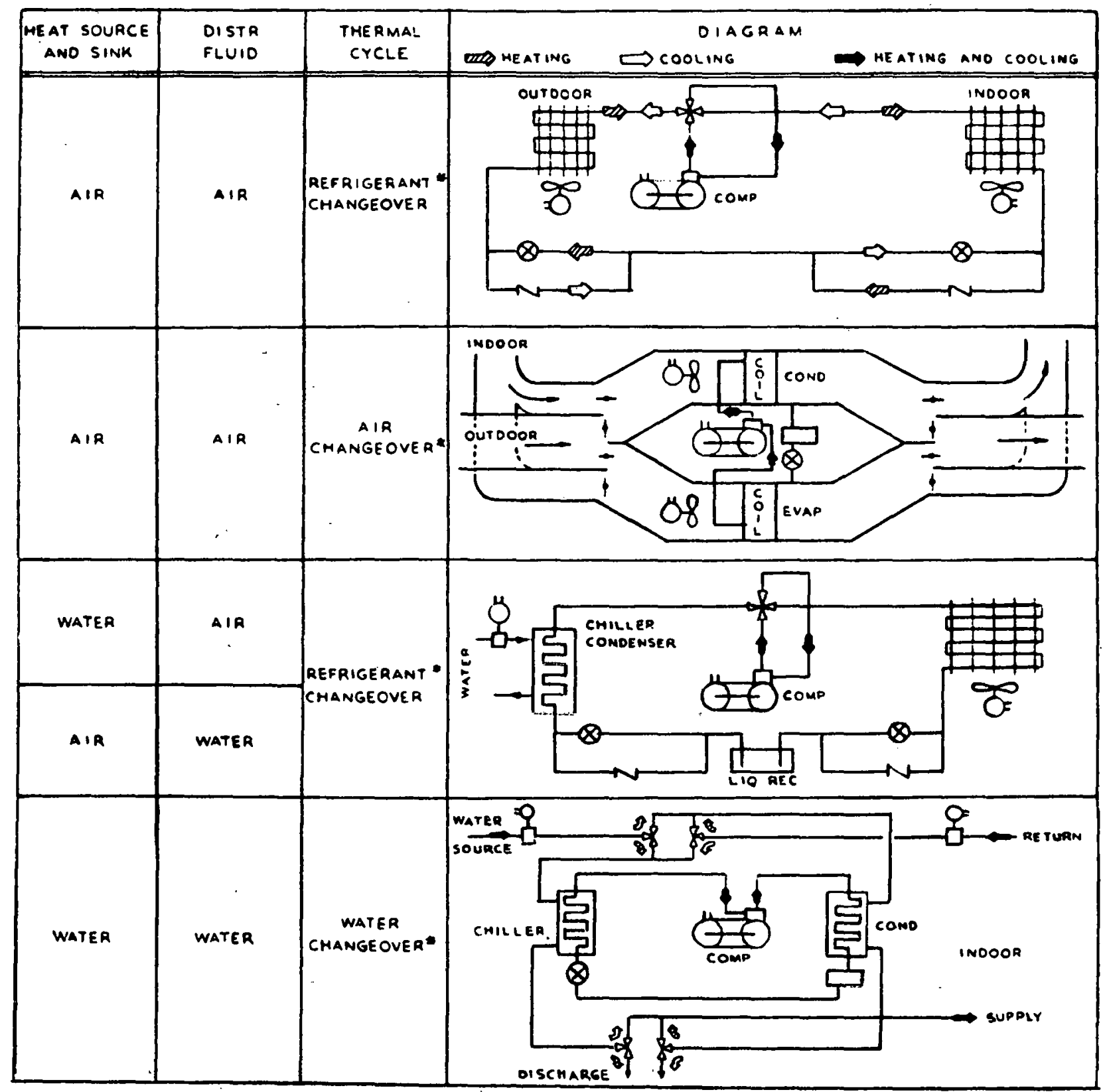

\section{*A11 single-stage compression}

SOURCE: Reference 4 .

\section{FIGURE 17-4 COMMON HEAT PUMP CATEGORIES}



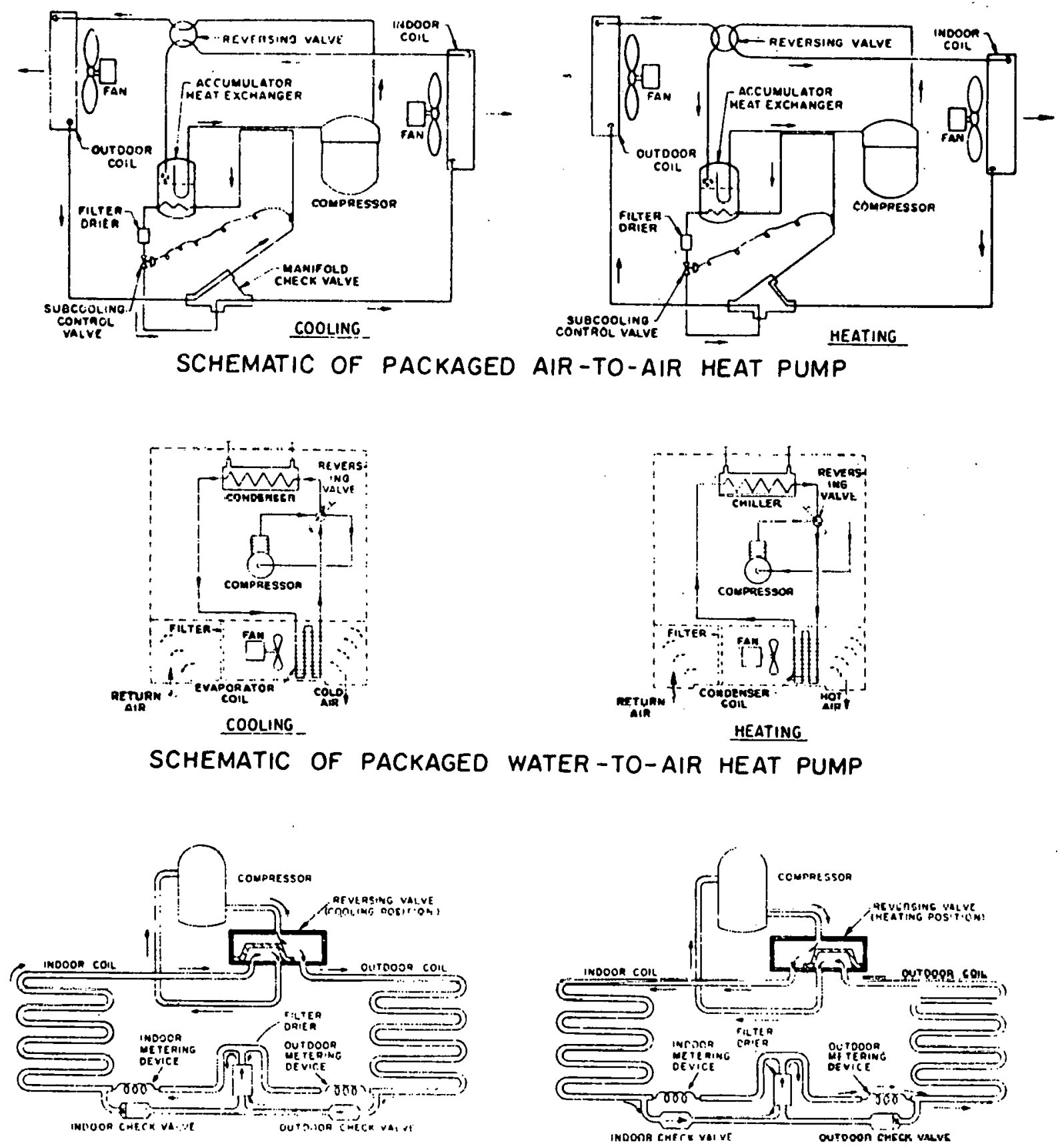

COOLING

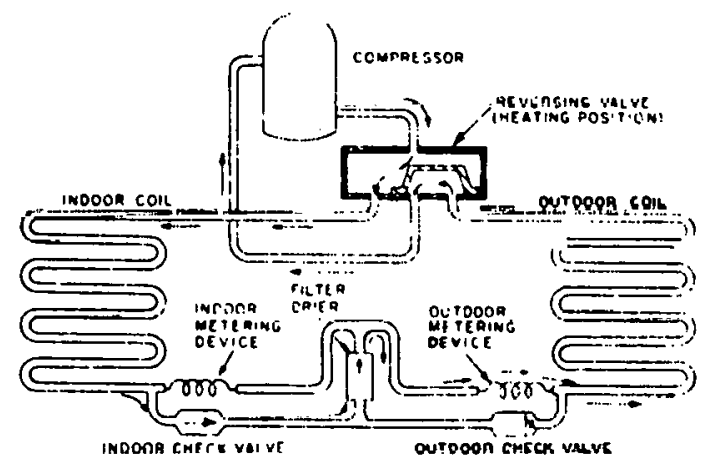

HEATINC

SCHEMATIC OF A SPLIT AIR-TO-AIR HEAT PUMP SYSTEM

SOURCE: Reference 5.

FIGURE 17-5 SAMPLE HEAT PUMP SCHEMATICS 
and an optional supplemental electric resistance heating element. In current split-system heat pumps, the air-handling unit (indoor coll, fan, and supplemental heater, if used) is remote from the main unit, which is outdoors. This configuration is similar to that of conventional residential central air conditioning installations.

A1r and water source models can be found in elther configuration, though self-contained air-to-air units are by far the most common, particularly in residential construction, where unit capacities typically range from 1.5 to 3 tons. * Large water-to-water machines are used mainly for commercial or industrial applications. Light commercial units run about 5-25 tons, while large commerclal and industrial units exceed 25 tons. (5) Water-to-water machines also come in sizes small enough for residential applications, but the costs of a water interchanger and a water-cooled condenser make such installations expensive.

Packaged air-to-air heat pumps typlcally do not exceed 15 tons of cooling capacity. Packaged water-to-air machines are available with up to 40 tons of cooling capacity, and some models go up to 200 tons. Split-system heat pumps have no upper limit on capacity, and commercial systems have been installed with centrifugal compressors and capactites exceeding 10,000 tons.

The major manufacturers of heat pumps, in order of ranking by sales volume, are: General Electric, Carrier, Lennox, Amana, and Westinghouse. (6) All are suppliers of a broad range of equipment, although only Carrier offers large equipment for commercial projects and only General Electric provides water source equipment.

Since 1975, when 158,000 units were shipped, sales of afr-toair heat pumps have risen rapidly although not as steeply as projected. For example, estimates from Reference 7 show sales of 560,000 untts in

* The common unit of refrigeration is the ton. This was originally intended to be the rate of heat transfer necessary to freeze 1 ton $(2,0001 \mathrm{~b}$ mass) of water at $32^{\circ} \mathrm{F}$ in 24 hours. If the latent heat or enthalpy of fusion of liquid water to ice is taken as $144 \mathrm{Btu} / 1 \mathrm{~b}$, the definition is obtained: 1 ton is equivalent to the removal of $288,000 \mathrm{Btu} / \mathrm{day}$, which is more convenfently applied as $12,000 \mathrm{Btu} / \mathrm{hr}$ or $200 \mathrm{Btu} / \mathrm{min}$. 
1978 and projected sales of 475,000 to 525,000 in 1979 which 1s about 500,000 less than projected sales for 1979 made a year earlier. (See Figure 17-6.)

Table 17-1 (10) shows the 1974 end-use of heat pumps by sector and type. While Reference 10 has not been updated for subsequent years, the residential market probably now holds an even greater percentage of total shipments, since the growth of heat pump sales is in large part due to new home installations.

\section{B. Operational Characteristics}

Whether the heat pump application is conventional air-to-air or water-to-air or a heat-recovery unit, the heat pump performance is highly dependent on the two temperatures between which it operates. For a typical heat pump during the heating season, the following performance variations with outdoor and Indoor temperature variations were found by Kelley:

- $+1.1 \%$ increase in COP per $1^{\circ} \mathrm{F}$ increase in outdoor temperature;

- $+1.3 \%$ increase in COP per $1^{\circ} \mathrm{F}$ decrease in return indoor afr temperature.

This dependence on temperature is common for all thermodynamic refrigeration cycles, for which an "ideal" thermodynamic efficiency can be defined. The French physicist Carnot hypothesized a perfect thermodynamic cycle using perfect machines for pumping heat between two temperature sources. For this cycle the upper limit of the coefficient of performance is found to be:

$$
\mathrm{COP}_{H P_{H}}=\frac{T_{H}}{T_{H}-T_{L}} .
$$

Absolute temperatures are used (Rankine or Kelvin) for the high temperature, $T_{H}$, and low temperature, $T_{L}$. The maximum Carnot (1dea1) effictency, assuming ideal heat exchangers, is shown in Figure 17-7, along with Kelley's data representing the actual measured efficlency of a particular heat pump presently sold for residential air-to-air application. The deviation between the Ideal and the actual is due to three real machine constraints: 


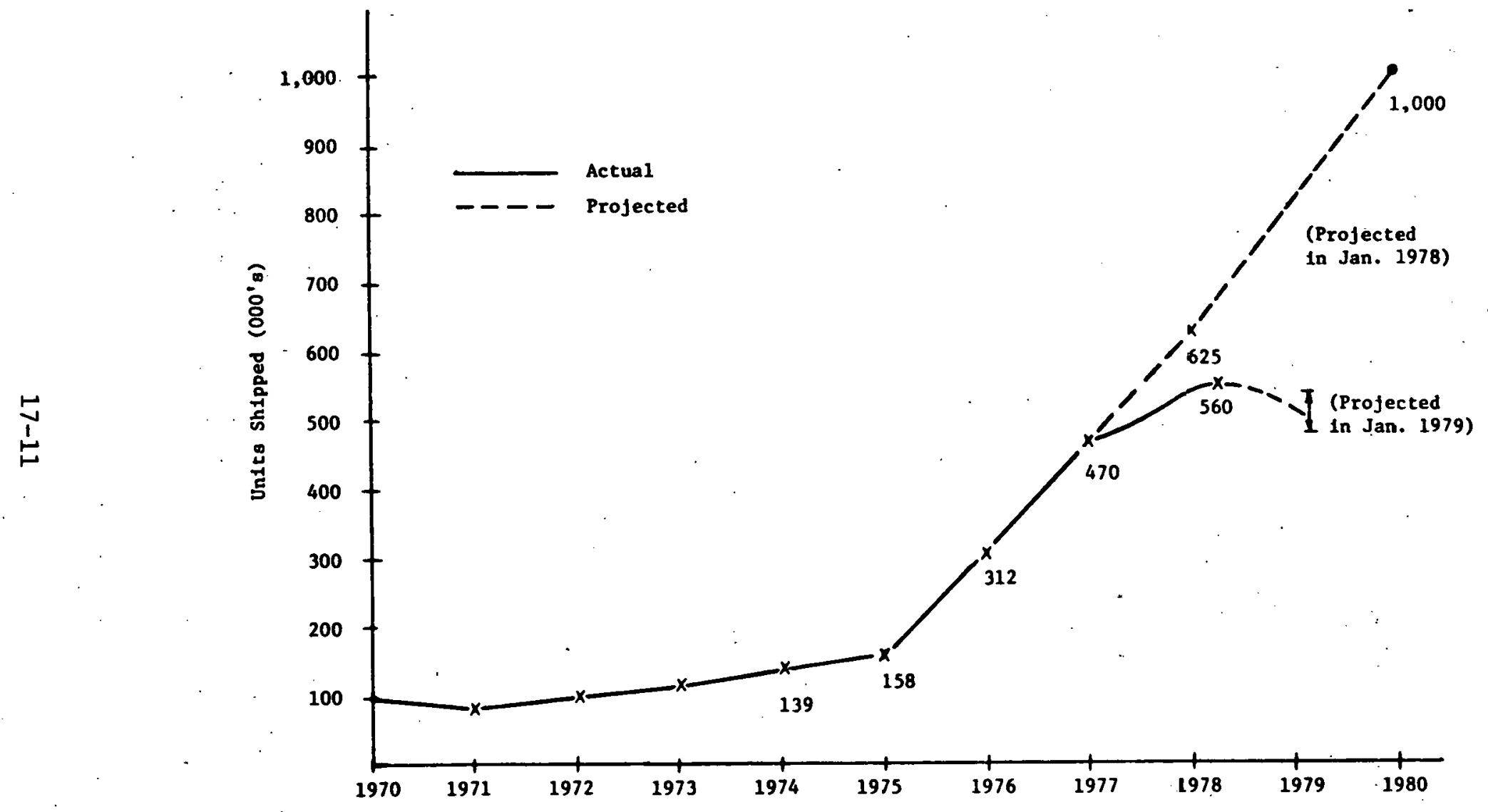

SOURCE: References 7 and 8. FIGURE 17-6 HEAT PUMP SHIPMENTS (INCLUDING EXPORTS) 
TABLE $17-1$

END-USE OF HEAT PUMPS SHIPPED TO U.S. MARKETS, 1974

(thousands of units)

Self-contained

Split System

49

7

56

127

SOURCE: (1) Reference 10.

(2) Reference 8. 


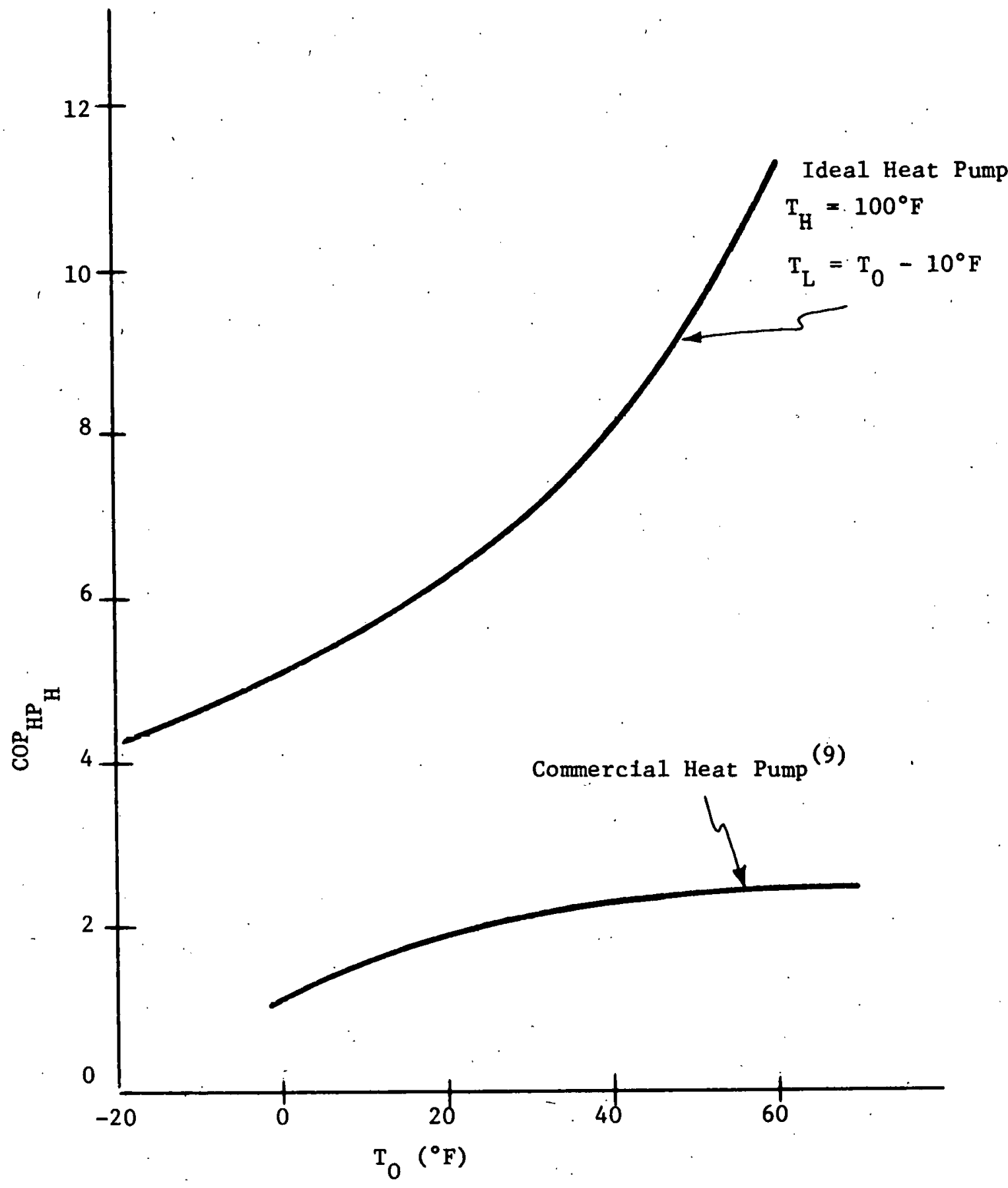

${ }^{C O P}{ }_{H P}$ denotes the coefficient of performance (COP) for a heat pump ${ }_{\mathrm{HP}} \mathrm{H}$. (HP) during the heating mode $(\mathrm{H})$.

FIGURE 17-7 COP ${ }_{\mathrm{HP}}$ VERSUS $\mathrm{T}_{\text {OUTSIDE }}\left(\mathrm{T}_{0}\right)$ 
- finite size of heat exchangers, which causes the heat pump to operate between greater temperature differences than the differential between room temperature and outdoor temperature, in order to transfer the heat pumped;

- fan power requirements which do not add to the heating capacity but add to the power requirement; and

- non-ideal compressor efficiencies (typically around $60-70 \%$ isentropic efficiency).

The cun-ldeal heat exchangers with limited size cause the refrigeration unit to reach elevated temperatures on the condensing side in order to reject the heat and depressed temperatures on the evaporator side to absorb the heat. Figure 17-8 shows the effect of the real heat exrhanger capacity on the system performance when compared to an ideal heat exchanger.*

If the non-ideal features of a compressor are added, the final cop drops to the level shown in Figure 17-9. Also shown in this figure is the range of reported COP's for air-to-air heat pumps presently sold in the United States. Our estimate of the performance of real components lies somewhat lower than that of the average heat pump sold currently in the United States because we chose to use Hiller's (11) estimate of heat exchanger and compressor efficiencies.

The characteristics of the heat pump efficiency discussed in the foregoing section were based on steady-state efficiencies of the units. Three non-steady state factors affect the actual annual Seasonal Performance Factor (SPF), defined as the total seasonal heating over the total energy consumption:

1) Supplemental electric resistance heating is required when the heat pump capacity is unable to keep up with the heating load;

\footnotetext{
*

The 1deal heat exchanger used here is one in which a constant temperature difference is maintained between the refrigerant and the air temperature: Maintaining constant temperature would in actuality require a variable-flow-rate fan that just matches the heating capacity with the airflow volume.
} 


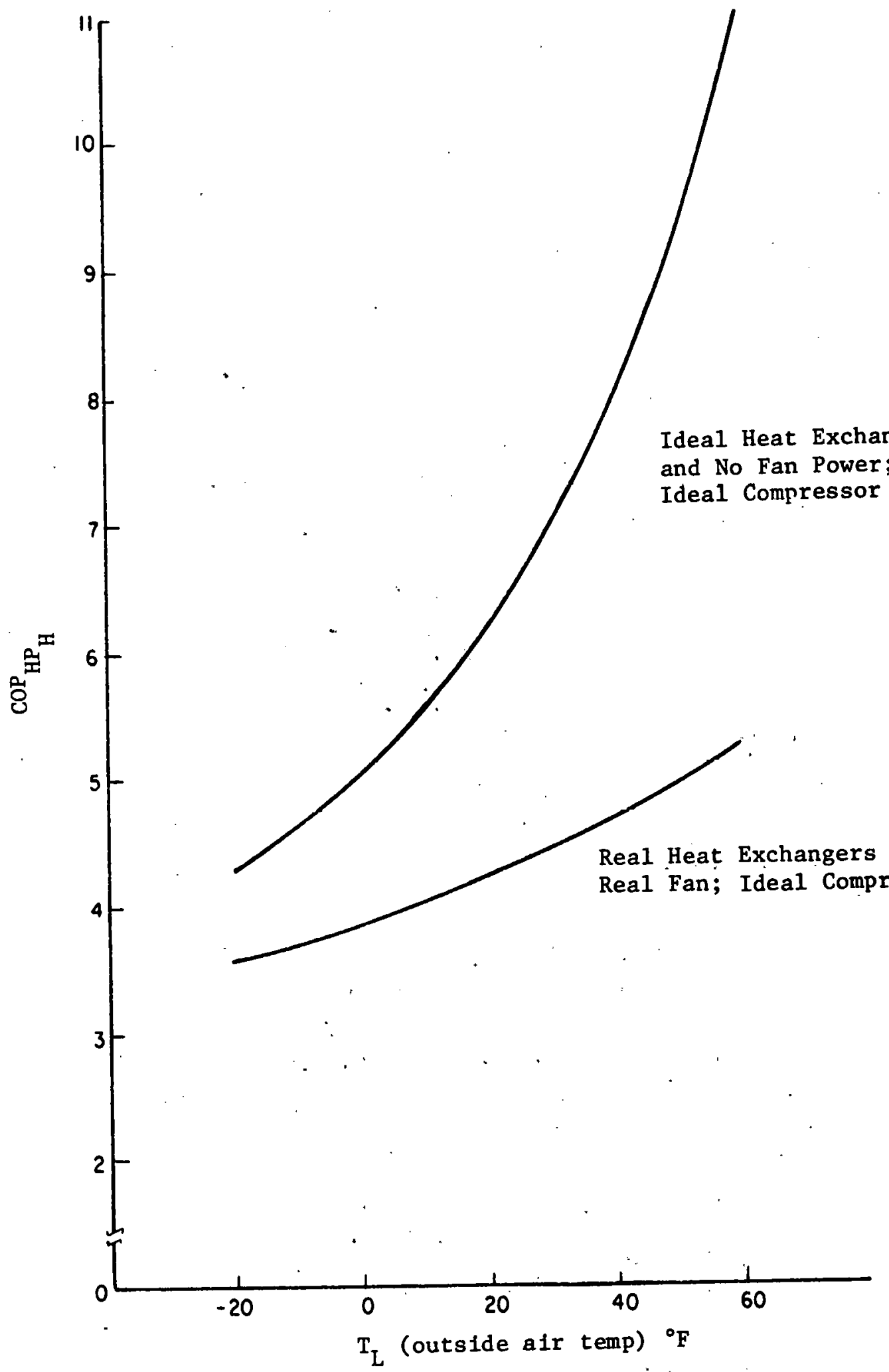

SOURCE: Arthur D. Little, Inc., calculations based on a typical unit performance.

FIGURE 17-8 EFFECT OF REAL HEAT EXCHANGERS ON HEAT PUMP COP ${ }_{\mathrm{HP}}$ [FOR $\mathrm{T}_{\mathrm{H}}=70^{\circ} \mathrm{F}$ (INDOOR TEMP)] 


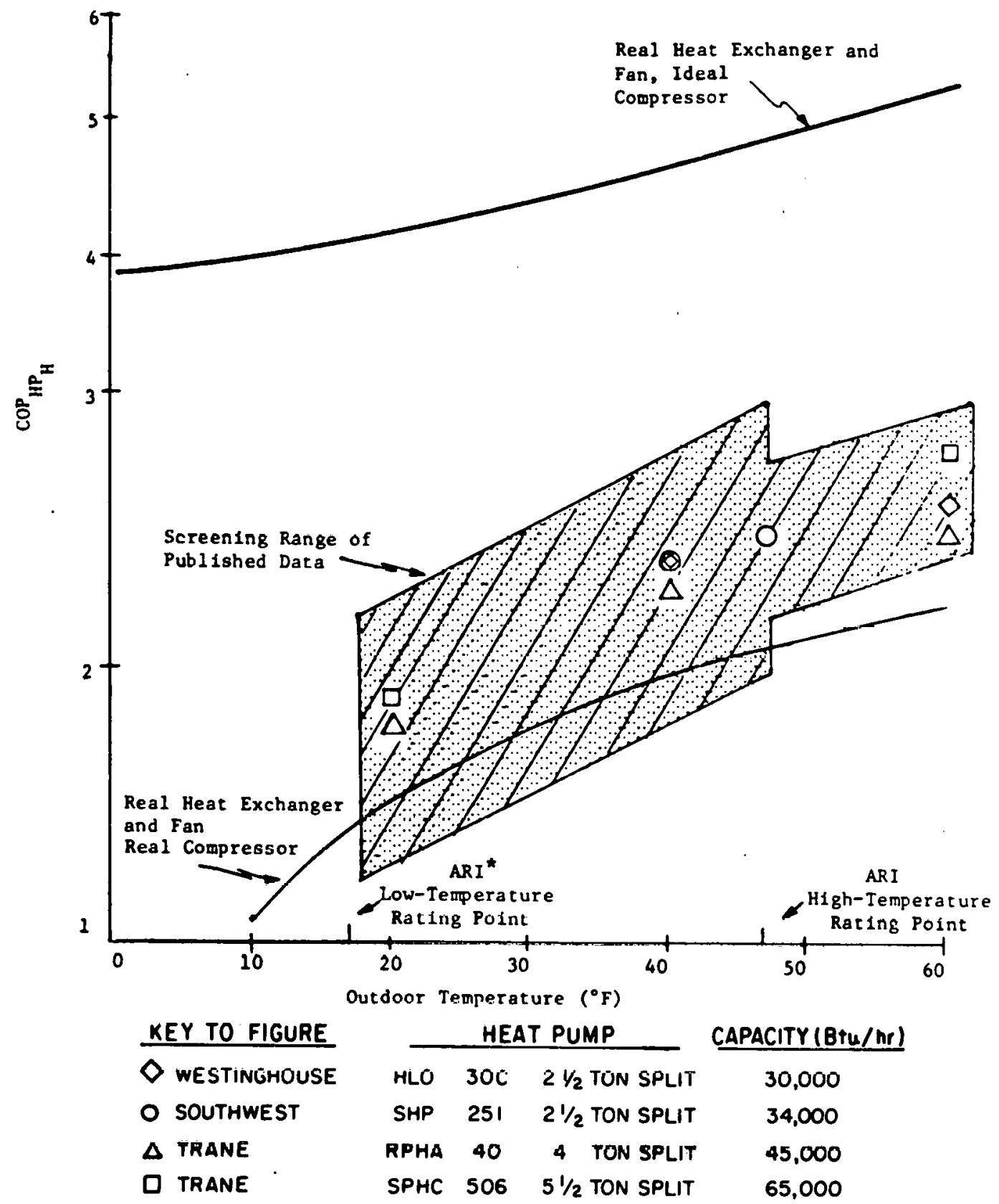

* Alr Conditioning and Refrigeration Institute.

SOURCE: Arthur D. Little, Inc., calculations and manufacturers' product literature as follows:

Westinghouse data from "An Investigation of Methods to Improve Heat Pump Performance and Reliability in a Northern Climate," Final Report, Vo1. II, App.A, prepared by Electric Power Research Institute, Report No. EPRI EM-319. Southwest data from newspaper advertisement (date unknown). Trane data from untitled 1977 product literature on models SPHC 506 and RPHA 40.

FIGURE 17-9 EFFECT OF COMPRESSOR EFFICIENCY ON HEAT PUMP PERFORMANCE 
2) During mild, humld, outdoor temperature conditions (below $45^{\circ} \mathrm{F}$ ) the outdoor coil will accumulate frost which limits heat exchange and must be removed, and this requires add1tional energy that does not contribute to the useful space heating; and

3) Cycling of the heat pump will accumulate energy losses because of the cooldown of the heating coll when it is not contributing to the space heating.

As the outdoor temperature falls, the capacity of the heat pump also falls, while the heating requirements of the building rise. This is shown in Figure 17-10. "At the cross-over point or the "balance point," the heat pump must be operated continuously in order to keep up with the heating requirement. At temperatures below this balance point, auxillary electric resistance heating is required. " At these lower temperatures, the $\mathrm{COP}_{\mathrm{HP}_{\mathrm{H}}}$ of the heat pump begins to approach that of an electrical resistance system (1.e., $\mathrm{COP}_{\mathrm{HP}} \rightarrow 1$ ).

As the outdoor temperature falls below approximately $45^{\circ} \mathrm{F}$, the outdoor coil temperature is generally below freezing and frost accumulates on the outdoor coil. Most heat pumps defrost the outdoor coil by reversing the cycle temporarily ( 2 to 10 minutes) to provide warm refrigerant to the outdoor coil to melt the frost. Depending on the outdoor temperature, reversing-cycle defrost may add between 5 and $10 \%$ to the annual energy cost of the heat pump.

The reverse cycling of the heat pump not only causes the annual energy consumption to rise but is thought to reduce the life of the unit. A sudden thermal shock to the system components occurs during the reversing operation, and after many thousands of these reversals, the performance of the compressor may deteriorate. (14)

Each start and stop of the heat pump has a loss or inefficiency associated with 1t. There are two causes of this transient loss:

${ }^{*}$ Growing attention has been given to supplementing the electric heat pump with a gas-fired backup because of the lower cost of gas per end-point Btu. Lennox sells a Fuelmaster Plus based on this principle; see Reference 12 . 


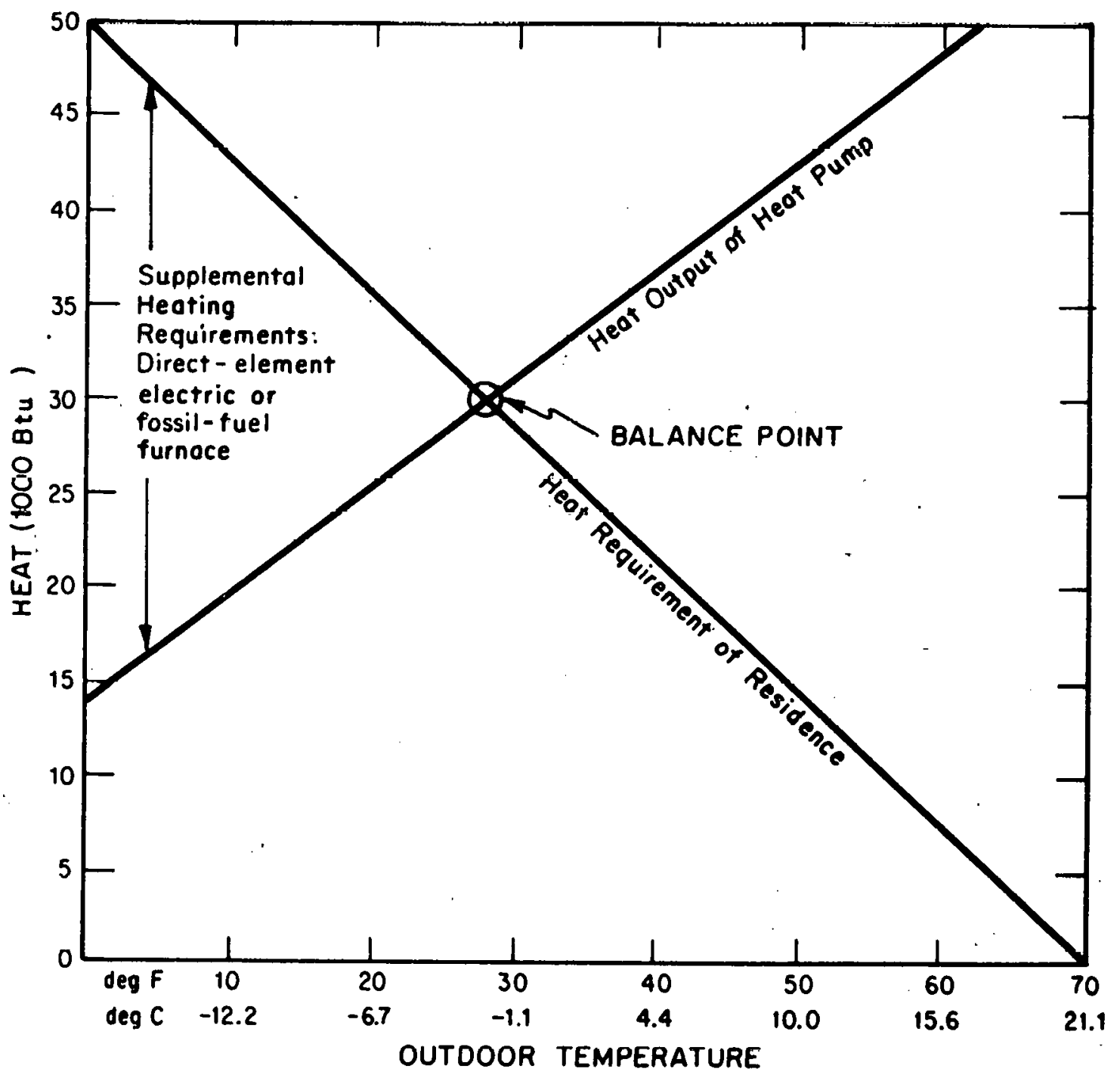

SOURCE: Reference 12.

FIGURE 17-10 COMPARISON OF HEAT PUMP OUTPUT TO THE HEATING REQUIREMENTS OF A TYPICAL RESIDENCE VS. OUTDOOR TEMPERATURE 
- Heat stored in the indoor coll is allowed to dissipate into a non-useful space, and

- Each compressor start must separate the refrigerant from the lubricating oil within the system; this requires energy, causing a small but noticeable. loss in system performance.

Kelley's data ${ }^{(9)}$ on the defrost and the start-up and stop requirements of a heat pump indicate the distinct drop in $\mathrm{COP}_{\mathrm{HP}}$ of about $20 \%$ at $38^{\circ} \mathrm{F}$. The energy cost of defrost, start and stop, and the auxiliary electric resistance heating lowers the annual SPF from an average value of 2-2.5 to $1.5-2.0$.

Most heat pumps used in the United States locate the compressor unit outdoors because of the noise associated with compressor operation. Some of the heat rejected by the heat pump is lost from the hot compressor to the cold outside air. Electrical resistance heaters are sometimes employed to keep the compressor warm to offset some of the adverse startup problems with a cold compressor; this means that additional energy is lost with the compressor located outside. Present Atr Conditioning and Refrigeration Institute (ARI) test procedures permit the incluston of the compressor heat as useful space heating if indeed this heat will be usefully provided to the indoor conditions. Some manufacturers have recognized this advantage and have begun to package compressors on the indoor units and provide sound insulation to make this application acceptable, although compressor heat rejected indoors in summer may decrease the heat-pump cooling capacity.

\section{Advanced Heat Pumps}

An improvement under development is the two-stage or two-speed compressor. In this case, a single stage of compressor capacity is used when the outdoor temperature is above the balance point, and a second stage of heat pump capacity is brought on line below the outdoor balance point. The details of this concept are discussed in References (1) and (9).

Advanced heat pumps using higher motor-compressor efficiencles, varlable speed compressors, rotary compressors, increased heat-exchanger surface areas, and Improved fans have been under study by the Department 
of Energy. (15) Figure 17-11 shows the relationship of anticipated improvements in heat-pump space-heating energy use with the estimated relative capital cost for a single-family home in Atlanta, Georgla. For purposes of comparison with these systems, the relative space-heating energy use and canital cost for domestic gas-fired heating systems is also included. Figure 17-12 gives similar data for Philadelphia where conventional gas-fired heating-system improvements can achleve a $40 \%$ savings; but beyond that level, improvements in gas-fired heating require heat pump operation.

The greatest disadvantage of the electric vapor-compression refrigeration system is the expenditure of electricity and the associated fuel consumption at a power plant. The elimination of this work (except for a relatively small liquid pumping requirement) is largely responsible for the perceived economic success of various chemical absorption and absorption-vapor refrigeration systems in commerclal use. The systems operate on the principle that certain substances attract and hold large quantities of vapor of other substances at a relatively low temperature which are driven off when the temperature is raised. When the vapor is retained on the surface, or in the capillary pores of the solid, the process is adsorption. When the two substances react, or when the vapor goes into solution, the process is absorption; and for practical combinations of refrigerant and absorbent (exothermic reactions), the chemical reaction heat must be removed along with the latent heat of the vapor. Since the refrigerant-absorbent solution is liquid, it can be pumped to condenser pressure with very little shaft work, and the vapor refrigerant is then driven from the absorbent by heating. Thus the absorption system is attractive where electricity is costly and natural gas or low-grade heat energy (such as waste steam) is plentiful.

The Department of Energy, the Gas Research Institute, and Allied Chemical Corp. are undertaking research to develop an absorption heat pump. It is expected that the machine will be similar in principle to the standard absorption refrigeration cycle shown in Figure 17-13, although specific components and the organic working fluids (absorbent and refrigerant) will be designed for a heat pump characterized by higher temperature differentials than those experienced in a refrigeration unit. (16) The expected performance of the heat pump using proprietary organic working fluids is shown in 


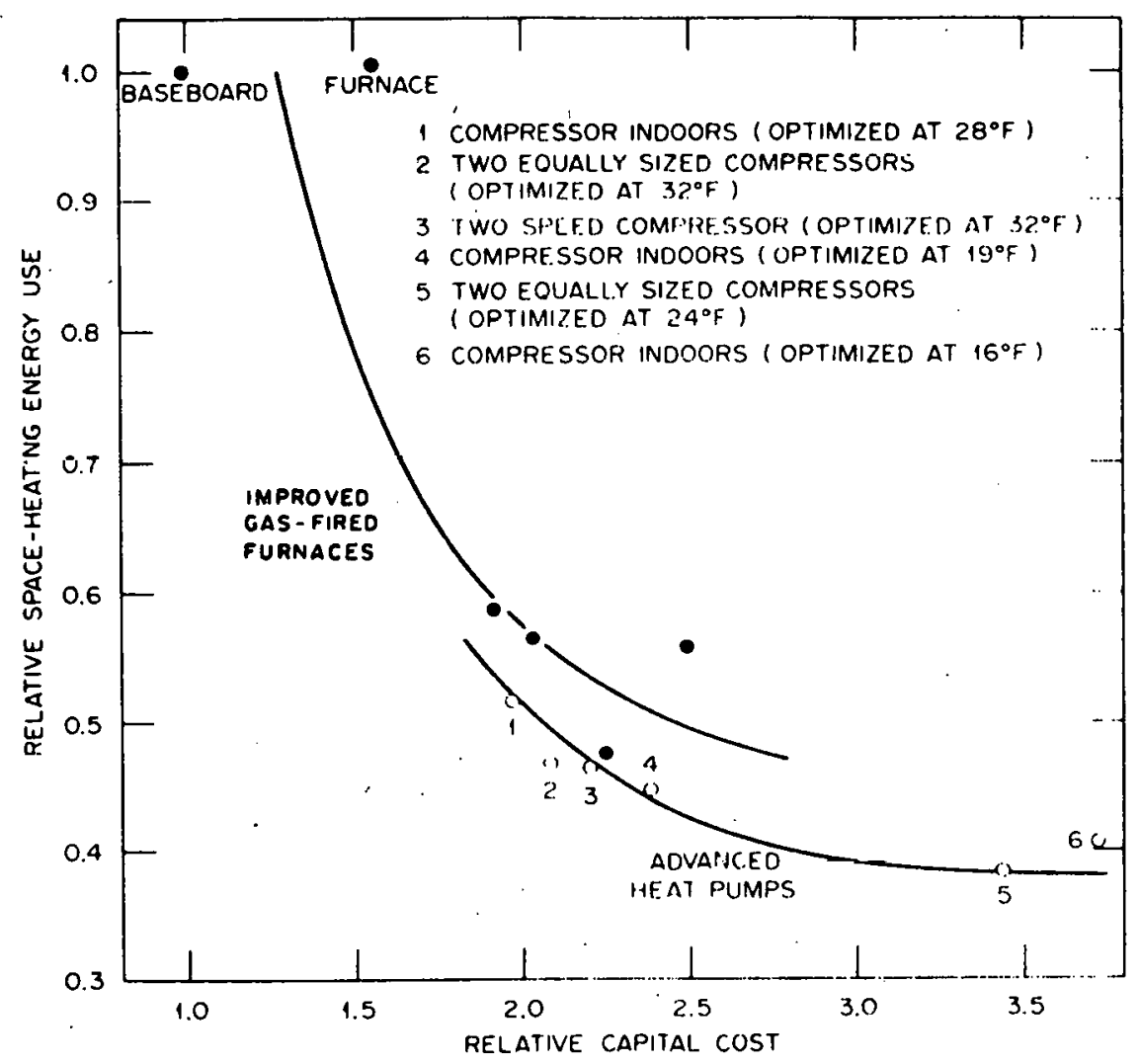

(Systems shown are for a single-family home in Atlanta, Ga. The filled in circles represent existing technologies; the open circles represent advanced technologies.)

SOURCE: Reference 15.

FIGURE 17-11 ANNUAL SPACE-HEATING ENERGY USE FOR IMPROVED GAS FURNACES AND ADVANCED HEAT PUMPS VERSUS RELATIVE CAPITAL COST 


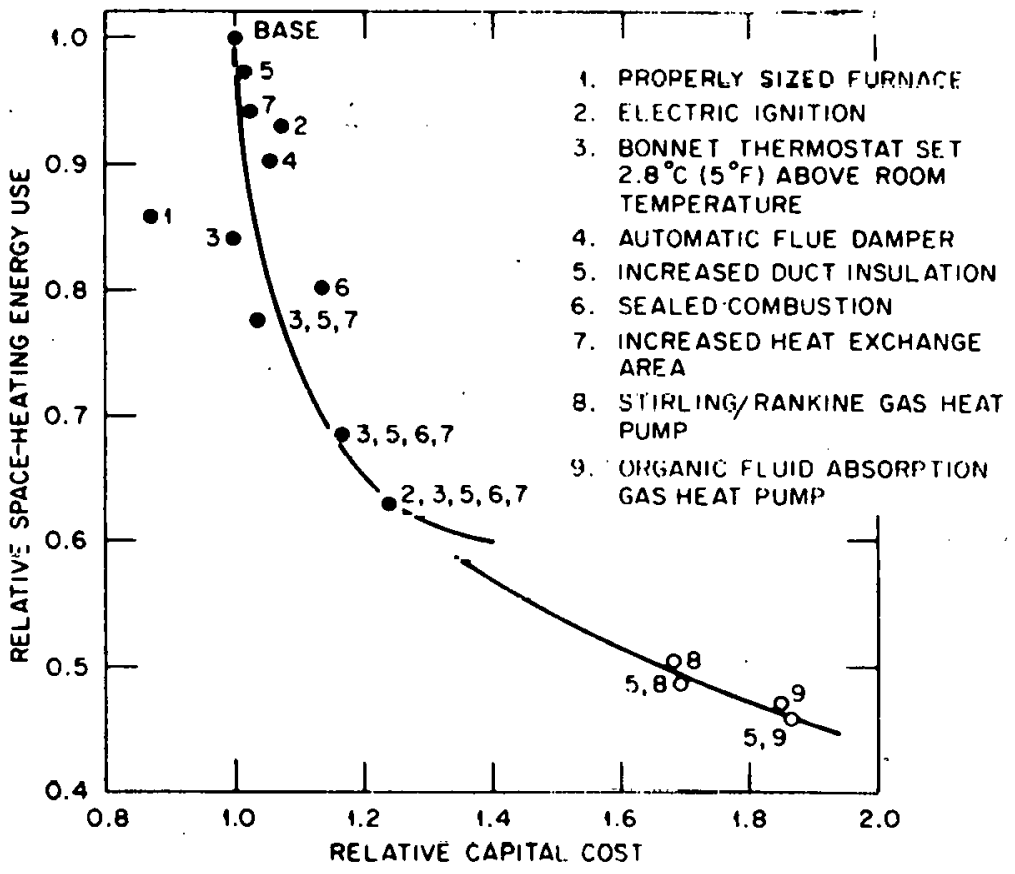

(Units and combinations of units (multiple numbers) are shown for a single-family home in Philadelphia, PA.)

SOURCE: Reference 15 .

FIGURE 17-12 ANNUAL SPACE-HEATING ENERGY USE FOR CONVENTIONAL AND ADVANCED GAS-FIRED SYSTEMS VERSUS RELATIVE CAPITAL COST 


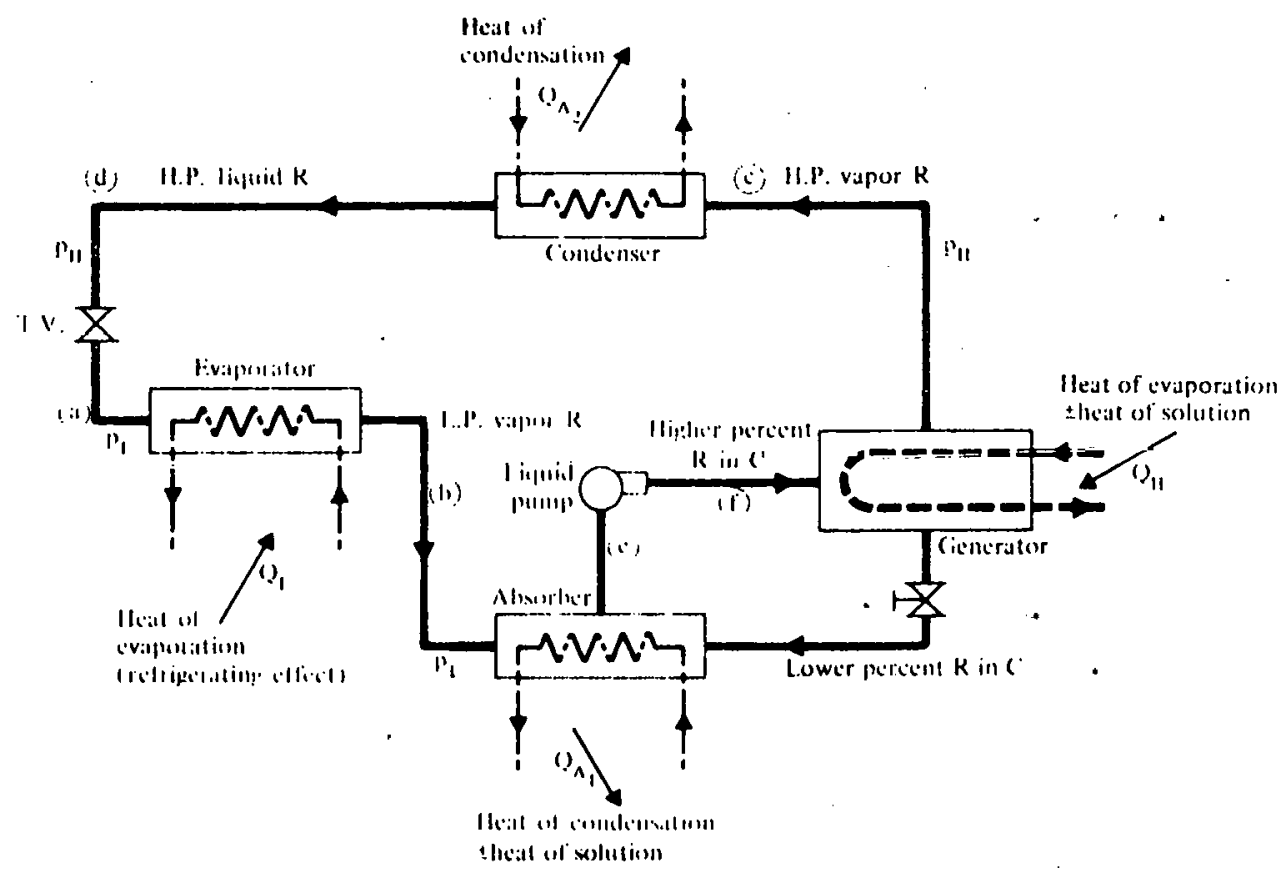

Symbol

\begin{tabular}{l|l|l}
\hline$R-$ refers to refrigerant & Ammonia & Water \\
\hline$C$ - refers to absorbent & Water & $\begin{array}{l}\text { Lithium } \\
\text { Bromide }\end{array}$
\end{tabular}

SOURCE: Reference 17. 
Figure 17-12 (point 9) in comparison with energy-conserving approaches r on a standard gas-fired furnace (points 1-7). Combinations (e.g., 3, 5, ind 7) of improvements are also shown in this figure.

In addition to the gas-fired absorption heat pump, DOE is sponsoring the development of the Stirling/Rankine gas heat pump which has a gas-fired Stirling engine that produces power for driving a conventional Rankine cycle heat pump. The relative cost and energy conservation potentlal of the Stirling/Rankine gas heat pump are shown in Figure 17-12 as data point 8 .

An alternative absorption system is based on batch chemical processes as opposed to flow processes as in the Allied Chemical absorption heat pump. This concept is presently under investigation by the Department of Energy and Sandia Laboratories. In this system, shown in Figure 17-14, heat from a solar collector or fossil fuel is used to evolve a gas, B, over to the condensing unit to form a chemical compound, $B C$, releasing heat. After this has been accomplished, the chemical, $B$, is once again driven off the compound, $B C$, but at a substantially lower temperature, which provides the refrigeration effect at the low-temperature unit. During the heating mode, low-grade energy is used to evolve the gas at the low-temperature source, $B C$, from which it is transported to the high-temperature unit. Here the gas, $B$, condenses to form chemical compound $A B$, thereby liberating thermal energy for space heating. The difficulty of using this system is that it is inherently a batch or nonflow system. This means that a duplicate system must run on alternate cycles in order to maintain a constant heat pump capacity.

Four chemical systems are presently under consideration:

- salt-methanol,

- an ammoniated salt,

- a hydrated salt, and

- sulfuric acid and water.

Section 17.3: Economics Discussion (Resident1al Applications)

The limited availability of gas to heat new housing and increasing energy prices have encouraged installation of electric heat 


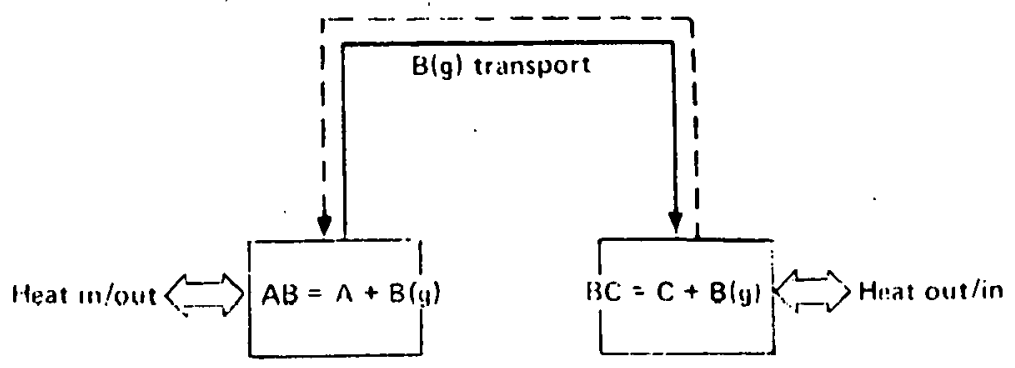

llighti teingeralure Low tempersture unit

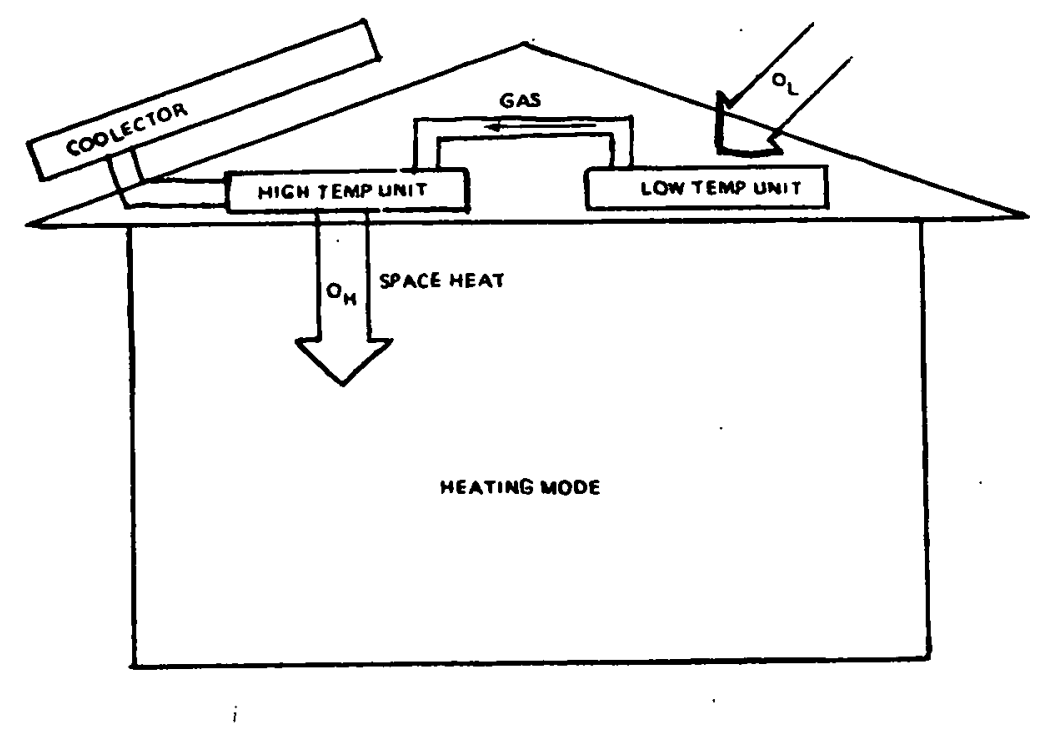

SOURCE: Reference 18.

FIGURE 17-14 PROPOSED CHEMICAL ABSORPTION HEAT PUMP 
pumps. The growing demand for central afr conditioning has also enhanced the market appeal of the heat pump, as has the Increasing cost of fuel oil in relation to electric energy for residential heating. There is also a sizable market in add-on's, where electric hot-air furnaces are being upgraded to electric heat pumps to provide air conditioning as well as heating.

A study by Gordian Associates ${ }^{(19)}$ for the Federal Energy Administration reported owning and operating costs for selected heating/air conditioning systems. (See Table 17-2.)* In this study, heating and cooling loads and equipment performance were computer-modeled for elght representative cities and calibrated by actual data from a test house in which the alternative heating/cooling systems were installed.. Equipment was sized for each city by established commercial practice and pricecorrected for the local labor rate. Annual owning and operating costs include operating and maintenance costs as well as the annual cost required to replace the equipment at the end of its service $11 \mathrm{fe}$. At current energy prices, the first cost of an electric heat pump is still too high to make it cost-competitive with the gas furnace/central air conditioning system; the heat pump is competitive only in temperate regions.

Installed cost of residential split-system heat pumps is plotted in Figure 17-15. This is a 1978 estimate made by a Boston contractor. Comparative pricing is given in Table $17-3^{*}$ for 1978 installed costs of alternative heating/air conditioning systems.

Table 17-3 also indicates that annual maintenance costs for the heat pump are comparable to those for other heating/air conditioning systems.

Section 17.4: Limitations

One of the principal 1imiting factors on the use of heat pumps Is their performance in the northern climates. As indicated in Section 17.3, heat pump capacity and efficiency fall rapldly with any decrease in

\footnotetext{
* Note: The original data in Tables $17-2$ and 17-3 were escalated to 1978 dollars (unlike the cost data in other chapters) for consistency with the 1978 data in Figure 17-15.
} 
TABLE $17-2$

ANNUAL OWNING AND OPERATING COSTS FOR ALTERNATIVE RESIDENTIAL SPACE CONDITIONING SYSTEMS

(1978 Dollars)

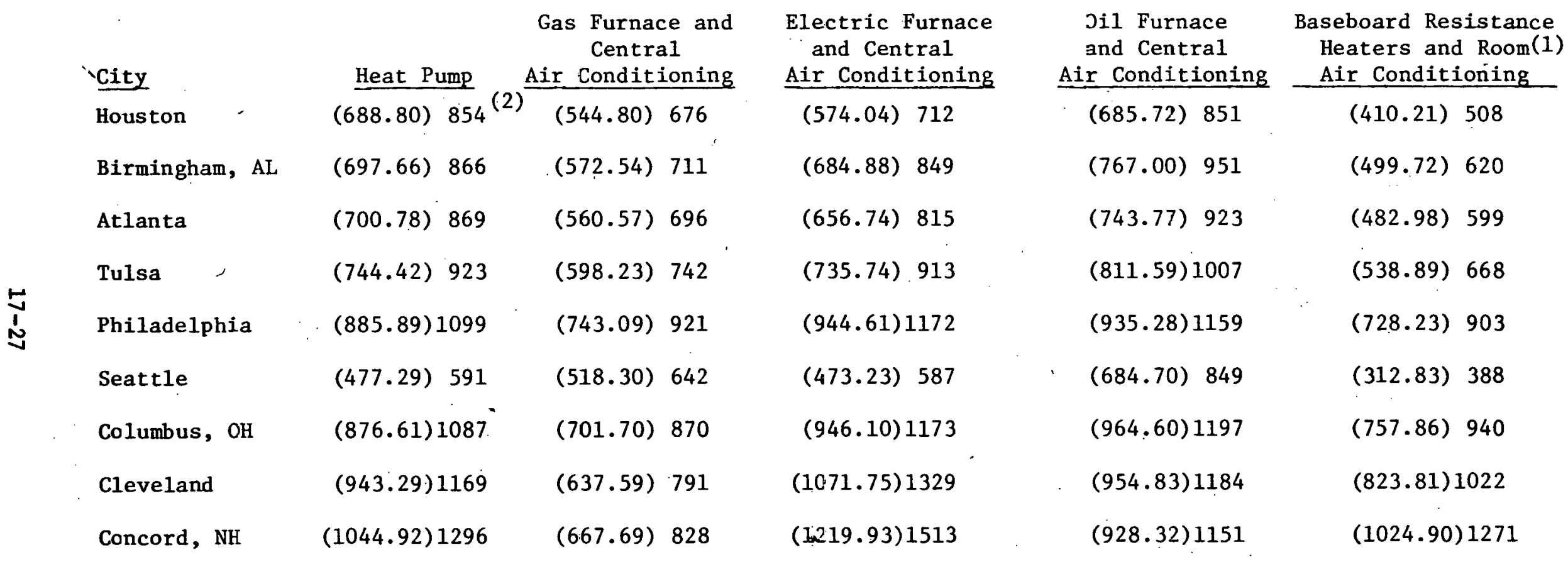

(1) Individual room cooling equivalent to $57-89 \%$ of full cooling load.

(2) Original cost estimates (19) are given in 1975 dollars in parentheses. The adjacent costs (including fuel costs) in 1978 dollars were obtained by escalating 1975 dollars b7 $24 \%$. 


$$
\text { 具 }
$$


TABLE $17-3$

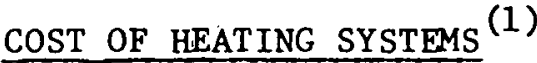

(1978 Dollars)

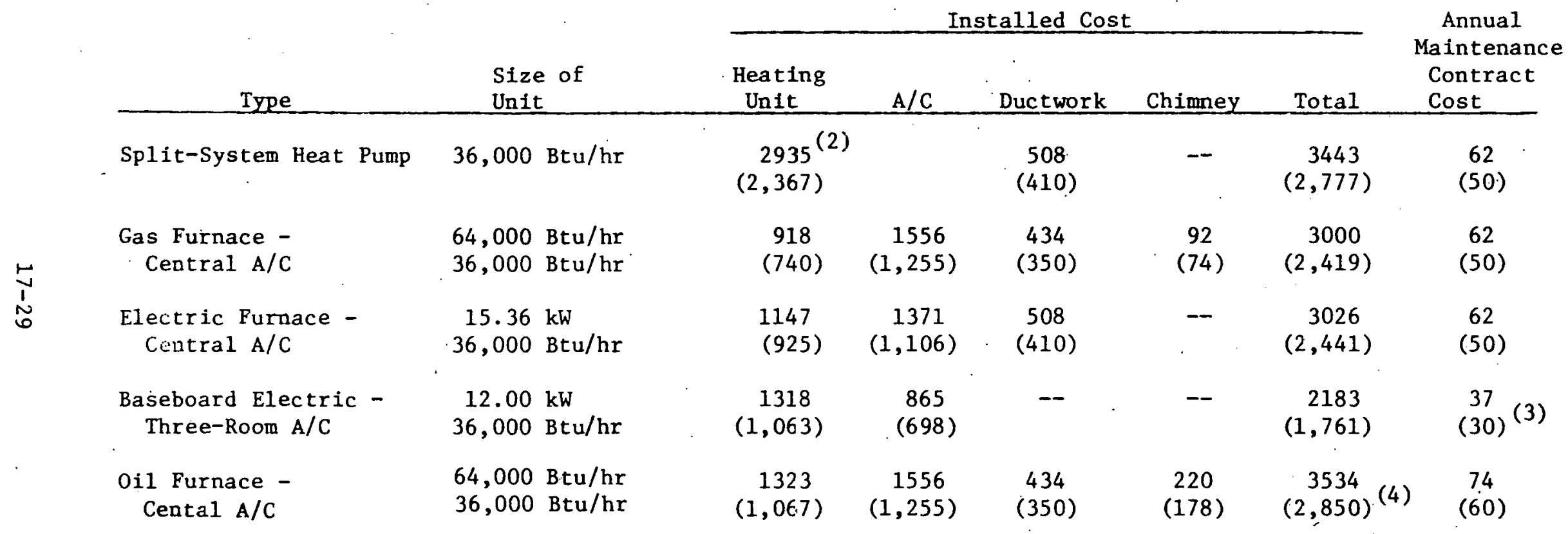

(1) Philadelphia, 1975 .

(2) Original cost estimates (19) are given in 1975 dollars in parentheses. The adjacent costs in 1978 dollars were obtained by escalating 1975 dollars by $24 \%$.

(3) Assumed equal to cost of contract for central air conditioners.

(4) Includes installed cost of ofl tank -- \$270.

SOURCE: Reference 19: Gordian Associates, Inc. equipment costs are based on catalog prices or quotations from General Electric Co. except for room air conditioner prices which were taken from Sears, Roebuck and Co. catalog. 
outdoor temperature. Improvements in the northern-climate heat pumps will permit their introduction in these areas. Defrost requirements for heat pumps are a limitation since present reverse-cycle-defrost methods reduce performance and are the single largest contributor to reduced system life. Studies. $(1,19)$ indicate that acceptable. operating 1 ife can be expected from available heat pumps but few data are ava1lable. W1th improved defrost techniques, lifetimes can clearly be extended and the attractiveness of the heat pump enhanced. Extensive data on the average life of modern heat pumps are not yet avallable; but it is probably approaching 8-10 years. 


\section{REFERENCES}

1. Looney, Q., Electric Power Research Institute, Palo Alto, California. Personal communications. April 1978.

2. Arthur D. Little, Inc. Design, Development, and Demonstration of a Promising Integrated Appliance, Phase I - Design. Prepared under Contract No. EY-76-C-03-1209 for the Energy Research and Development Administration, September 1977.

3. Moyers, J.C., et al. "The Annual Cycle Energy System Concept and Application." Proceedings of the International Conference on Energy Use Management, Tucson, Arizona, October 24-28, 1977. Vol. II. pp. $231 \mathrm{ff}$. New York: Pergamon Press, 1978.

4. American Society of Heating, Refrigerating and Air-Conditioning Engineers, Inc. ASHRAE Handbook and Product Directory: 1973 Systems. New York: American Society of Heating, Refrigerating and AirConditioning Engineers, Inc., 1973.

5. American Society of Heating, Refrigerating and Air-Conditioning Engineers, Inc. ASHRAE Handbook and Product Directory: 1975 Equipment. New York: American Society of Heating, Refrigerating, and Air-Conditioning Engineers, Inc., 1975.

6. "Manufacturers' Share of Market or Order of Ranking." Appliance Manufacturer, January 1976. pp. $81 \mathrm{ff}$.

7. Duffy, G. "Statistical Panorama XIV." Air Conditioning, Heating, and Refrigeration News 146(5):3, January 29, 1979.

8. Duffy, G. "Statistical Panorama XIII." Air Conditioning, Heating, and Refrigeration News 143(5):3, January 30, 1978 .

9. Kelley G.E., et al. Dynamic Performance of a Residential Air-toAir Heat Pump. Washington, D.C.: National Bureau of Standards, 1977.

10. U.S. Department of Commerce. "Air Conditioning and Refrigeration Equipment, 1974." Current Industrial Reports, Series MA-35M.

Table 7.

11. Hiller, C.C. et al. "Energy Savings in Vapor Compression Refrigeration and Heating Devices." Proceedings of the Technical Opportunities for Energy Conservation in Appliances, Boston, Massachusetts, May 11, 1976. Conference conducted by Arthur D. Little, Inc. for Energy Research and Development Administration, 1976. NTIS Report No. CONF-7605139.

12. Consdorf, A.P. "Stage Research for Heat Pump Boom." Appllance Manufacturer, November 1975. Pp. $43 \mathrm{ff}$. 


\section{REFERENCES (continued)}

13. Comley, J., et al. Heat Pumps; Limitations and Potential. Schenectady, New York: Corporate Research and Development, General Electric Company, 1975.

14. Groff, G., et al. "Investigation of Heat Pump Performance in the Northern Climate Through Field Yonitoring and Computer Simulation." Preprint. American Society of Heating, Refrigerating and Air-Conditioning Engineers 1978 Semiannual Meeting, Atlanta, Georgia, January 29 - February 2, 1978. To be published in ASHRAE Transactions 84 (Part 1), 1978,

15. Hirst, E. Energy and Economic Benefits of Residential Energy Conservation RD and D. Prepared by Oak Ridge National Laboratory, February, 1978.

16. Murphy, K.P., Allied Chemical Corporation, Morristown, New Jersey. Personal communications. December $1,1978$.

17. Wood, B.D. Applications of Thermodynamics. Reading, Massachusetts: Addison-liesley, 1969. (Addison-Wesley Series in Mechanics and Thermodynamics.) pp. 205 ff.

15. Miller, M. "Chemical Heat Pumps Now Seem Technically Feasible." Air Conditioning, Heating, and Refrigeration News 143(12):14, March 20, 1978.

19. Gordian Associates. Evaluation of the Air-to-Air Heat Pump for Residential Space Conditioning. Prepared for the Federal Energy Administration, April 23, 1976. NIIS Report No. PB 255652.

20. American Air Conditioning Company, Boston, Massachusetts. Personal somunications. March 1978. 


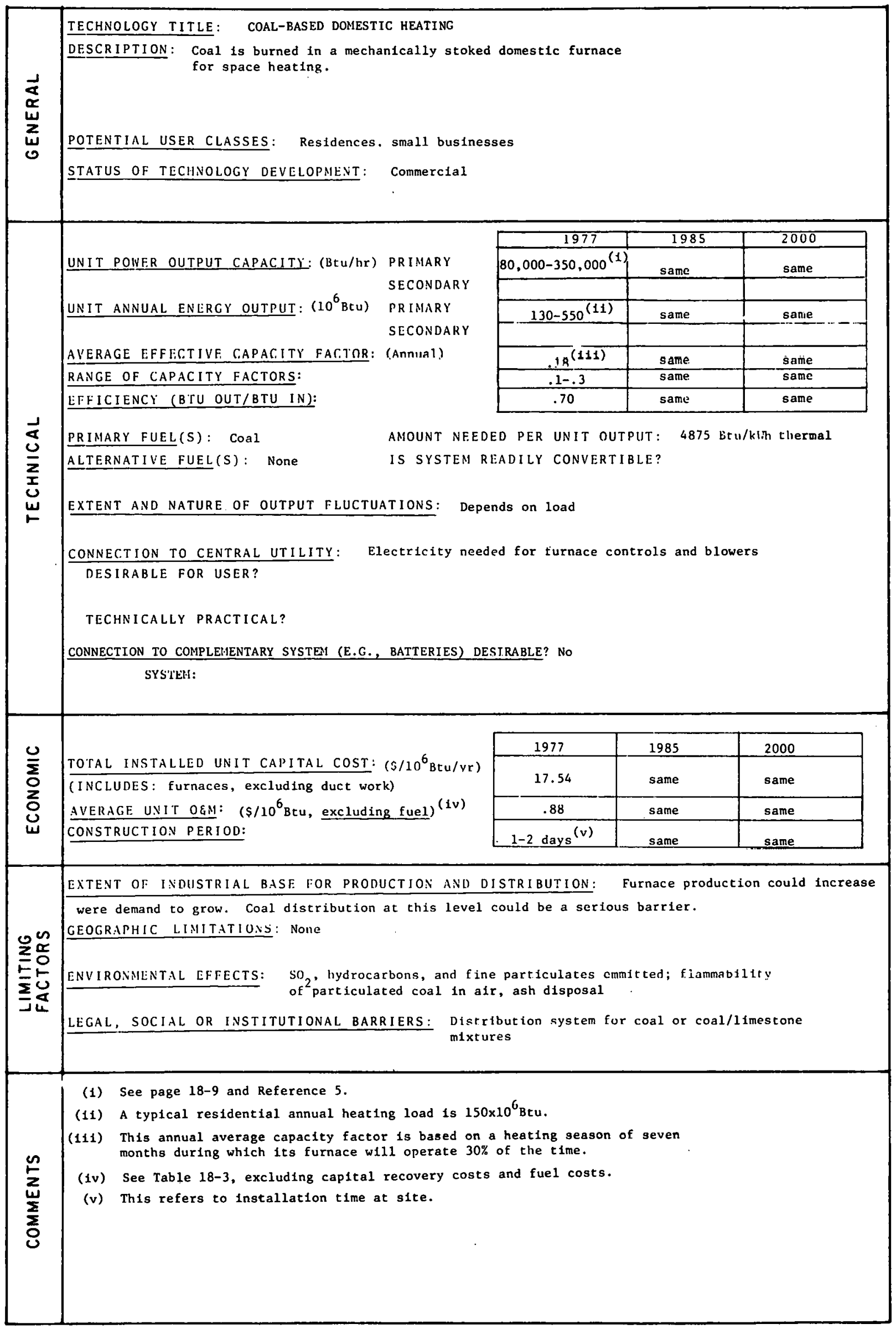


CHAPTER 18

COAL-BASED DOMESTIC HEATING

Section 18.1: Introduction

Until the widespread availability of distillate fuels, light petroleum fractions, and natural gas, the primary domestic fuels were coal, wood, and charcoal. Coal was usually burned in fireplaces or in hand-stoked domestic furnaces or boilers. Considerable labor was involved in stoking or tending the fire several times per day and in disposing of ash and clinker (fused ash particles) about once a day or slightly less frequently. The resulting smoke also noticeably reduced the air quality in heavily populated areas. In Europe, considerable work has been done to convert coal to a smokeless fuel (via. low-temperature carbonfzation) suftable for domestic use. However, the avallability, cost, and convenience of liquid or gaseous fuels effectively ended dependence on coal for domestic heating except in isolated locations.

It has recently been claimed $(1,2)$ that the technical problems in domestic coal-based fluidized-bed furnaces have been substantially solved and that such furnaces should be cheaper than and indistinguishable from an oil furnace. This chapter compares approaches that would allow the return to coal-based domestic heating. (This excludes burning coal in fireplaces or in open grates, because this approach has very high emissions and is inefficient. Such open-grate burning of coal has been banned in many citles, e.g., London, for many years for this reason.) Obviously, these methods would compete against oil- or gas-based domestic heating.

The approaches for a return to coal-based domestic heating are:

- hand-stoked or mechanically stoked-coal furnaces or bollers;

- fluldized-bed combustion; and

- coal/o11 slurries. 
of these, hand-stoked and mechanically stoked furnaces are now avallable on the market. Much of the work on the small fluldized-bed boller has been performed in the United Kingdom by Fluidfire, but it appears that the units developed there are not being sold commercially. $(1,3)$ Coal/o1l slurries are prepared by suspending fine particles of coal, about $40 \%$ by weight, in distillate or residual fuel oil. Typlcally, the slurry contains $4-6 \%$ water and $0.5 \%$ chemicals which are added to stabilize the slurry. These slurries have been burned successfully in bollers designed for gas/oll firing. In principle, this approach could be extended to domest1c heating where it would have apparent advantages in being able to use extsting tanks for distribution and storage. However, since such slurries would still contain about $55 \%$ fuel ofl, the cost saving from coal additions would probably not compensate for increased maintenance requirements, caused by ash in the coal and residual oil and particulate emission problems. Because of this, coal/oil slurries for domestic heating have not been evaluated, but the other two approaches are evaluated in deta11.

\section{Section 18.2 Technical Discussion}

A. Hand-Stoking and Mechanical Stoking

1. Hand-Stoking

Hand-stoking was the traditional method used to burn coal in small boilers. In such boilers, ideal unfform combustion cannot be maintalned because firing is intermittent. The best condition of the fuel bed is obtained when the coal is fired frequently, in small amounts, and with proper distribution; when caked masses of coal (if any) are broken up as rapidly as formed; and when ashes and clinkers are not allowed to clog the fuel bed. The hand-stoking of a boiler requires skill and technique. There are three general methods:

- Spread-firing. A small amount of fresh coal is distributed evenly over the entire surface of the fire. This is commonly done with anthracite and other low-volatile coals. 
- Alternate-firing. Fresh coal is fired on just one-half of the grate at a time. The freshly liberated volatile matter absorbs the necessary heat for combustion from the brighter parts of the fire. It is particularly suitable for non-caking coals.

- Coking-firing. Fresh coal is placed on the front edge of the fire and allowed to coke. After distillation is complete, the coke is spread over the fire. It is especially suited to caking coals. Lower rates of combustion are obtained with this method than with the other two.

We belleve that a return to these methods on a large scale is unlikely in the near-term future on any significant scale because of the labor involved (all the coal has to be shoveled and properly sprinkled on the grate), the messy/grimy nature of handstoking which would be unacceptable in most homes, and the high emissions that would result from improper hand stoking. A few manufacturers still sell boilers in this size range. $(3,4)$

\section{Mechanical Stoking}

The Prill furnace, (5) shown in Figure 18-1, is an example of a domestic, mechanically stoked hot air furnace for space heating. The Prill Manufacturing Company also sells a domestic hot water heater of similar design. Coal is stored in a bunker, withdrawn mechanicaliy by an auger, and fed to a rotating ring that serves as a grate on which the coal burns. The ring slopes slightly downward towards its outer edge so. that coal ash falls over this edge into an ash pan as new coal is pushed up through the center of the ring. The ash falling into the pan has to be removed and disposed of periodically. Thus, the furnace is an updraft forced-air furnace somewhat similar to underfeed-stokers used in larger installations. It is interesting that while the larger underfeed-stoker was designed specifically to handle bituminous caking coals, (6) the Prill furnace is advertised for use only with noncaking sub-bituminous coal or lignite. (5) The furnace has automatic 


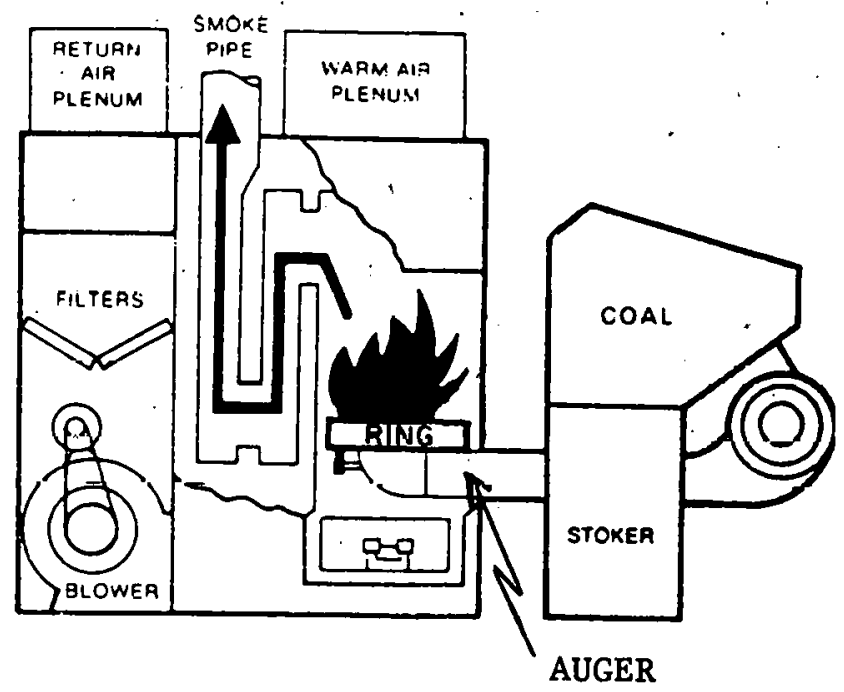

SOURCE: Undated sales Iiterature (c1rca. 1977), Prill Manufacturing Co., Sheridan, Wyoming.

FIGURE 18-1 SCHEMATIC DIAGRAM OF THE PRILL FURNACE 
controls and draft regulators. This furnace is started with "charcoal lighter fluid" or a propane torch at the beginning of the heating season and always maintains a "pilot fire" so that the start-up procedure does not have to be repeated each time the thermostat demands heat. The flue gases heat the air or water and are discharged to the atmosphere through a chimney. The environmental emissions from mechanical stokers are shown in Table 18-1, along with comparative figures for other systems, 1.e., o11, gas, and fluidized bed. Equivalent data for hand-stoking are not available, but these emissions would be comparable to those for mechanical stoking if the operator is skilled, or would be much higher if the operator is unskilled. The table shows that emissions are significantly higher for coal-based systems and might cause pollution problems in urban locations which already have problems in achieving federal ambient air quality standards.

\section{B. Fluidized-Bed Combustion}

Domestic fluidized-bed bollers have been described enthusiastically as a transitional technology by Luvins: ${ }^{(2)}$

"They are very compact: a unit producing $8.8 \mathrm{~kW}(t)$ $(30 \mathrm{kBtu} / \mathrm{hr})$ is about $25 \times 25 \times 36 \mathrm{~cm}$. From the user's point of view it should be indistinguishable from an oil furnace (except cheaper). Granular coal is delivered by hose from a tank truck to a bunker, then gravity fed to a small packaged furnace with very low emissions (NO typically a few parts in $10^{6}$ ). Ash is collected by overflow in a snap-on container akin to a vacuum cleaner bag, changed at each fuel delivery, or in a bunker that can be emptied by a coupled vacuum hose. The technical problems of such a system appear to be substantially solved, and plans for U.S. fleld testing are proceeding despite lack of federal interest outside CEQ and EPA." 
TABLE $18-1$

\section{EMISSIONS COMPARISONS}

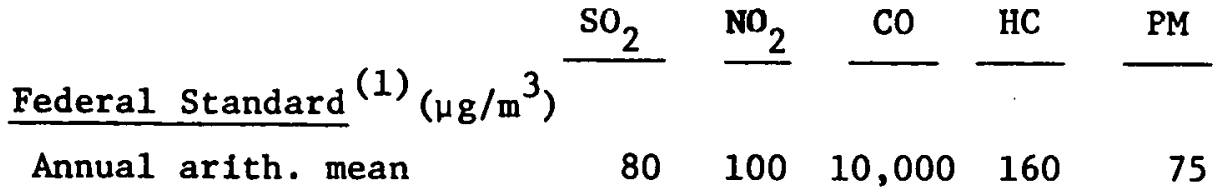

In Flue Gas $\mathrm{mg} / \mathrm{m}^{3}$

(2)

Gas

011

Coal stoker (Pri11)

Flutdized-Bed Coal

$\begin{array}{rrrrr}\text { NIL } & 100 & 25 & 12 & \text { NIL } \\ 220 & 80 & 30 & 20 & 30 \\ 1530 & 140 & 400 & 120 & 80 \\ 1470 & 610 & 860 & 28 & 75\end{array}$

(1) Federal standard is for ambient afr level.

(2) Assumes excess air of $30 \%$ for gas, $50 \%$ for o1l and coal stoker, and $30 \%$ for flujdized-bed coal.

SOURCE: Reference 3. 
This description, based on an experimental unit at the University of Aston, England, simplifies the problems involved in installing an appliance of this type for cyclic duty in a home. The potential problems are several.

The pneumatic handling of powdered coal is dangerous since coal/ air mixtures are explosive. While coal/air mixtures are handled in industrial power plants during pulverizing, this equipment is ruggedly constructed and designed for proper venting of unavoidable explosions. Venting of explosions in the domestic context could be quite hazardous.

The University of Aston unit is apparently vented to the atmosphere as shown by Squires in a drawing reproduced here as Figure 18-2. A fluidized bed operating in this mode would be expected to discharge the particulates to the atmosphere. Even with cyclones and bag filters, discharge of heavy metals in the form of fine particulates would continue. Further, in a variable environment such as a home heating furnace, it is doubtful if such bag filters would recelve proper maintenance and whether temperature excursions could always be prevented. In addition, a shallow fluidized bed, as suggested by the late Professor Elliott, ${ }^{(1)}$ is likely to have high concentrations of carbon monoxide in the flue gas. While $\mathrm{SO}_{2}$ emissions would be controlled by adding limestone or dolomite to the bed along with the coal, the efficiency of $\mathrm{SO}_{2}$ control in a shallow bed would also be low.

Another problem is one of startup and of cyclic operation. The University of Aston furnace was reportedly started with a propane burner until the bed solids had reached the operating temperature. (1) Electric heating for this purpose is a suggested alternative. (3) For cyclic operations, the bed solids would be expected to retain their heat for a few hours if the fluldized-bed were "slumped". (defluldized). However, the heat loss problem would be severe because of the low solids inventory.

Overall, many safety-related operating problems have to be overcome before the fluidized-bed heater could be considered for domestic installation. Technical solutions to these problems are unlikely to result in a furnace that is "cheaper" than an oil furnace as is claimed by Lovins. 


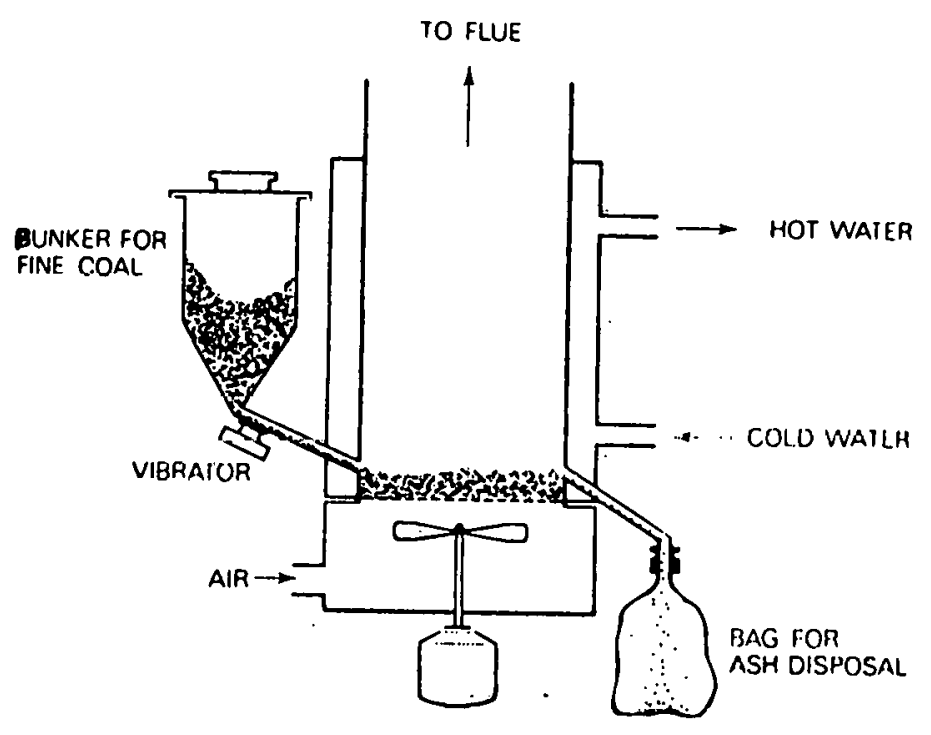

SOURCE: Reference 1.

FIGURE 18-2 THE FLIITAFIRE FURNACE OF DOUGLAS ELLIOTT, THE UNIVERSITY OF ASTON, BIRMINGHAM, ENGLAND 
Section 18.3: Economics Discussion

Any coa1-based domestic heating system requires an infrastructure for the distribution of coal (or a coal/limestone mixture). Cart et al. (3) investigated the availability and estimated the cost of such services. However, many problems have to be addressed regarding modes of delivery and storage. Table 18-2 shows the capital cost differences between the Prill furnace and oil- or gas-flred furnaces of the same capacity of about $105,000 \mathrm{Btu} / \mathrm{hr}$. As might be expected, the coal furnace is the most expensive in terms of inftial investment. A very detailed analysis by Cart ${ }^{(3)}$ reaches essentially a similar result and concludes that for a spccific location (Columbus, Ohio) direct coal utilization and coal-derived substitute natural gas would cost virtually the same in terms of annual costs to a consumer.

Given the environmental and safety problems of the domestic fluidized-bed boiler, we have not attempted to estimate its capital or operating cost. However, the solutions to all the technical problems are likely to result in a furnace that is at least as costly as the Prill furnace, which is significantly costlier than an oil furnace. It should be noted that the capital investment and maintenance costs for these systems were estimated by Cart ${ }^{(3)}$ to be approximately the same as those for the Prill furnace.

TABLE $\quad 18-2$

CAP ITAL COST COMPARISON FOR A PRILL COAL FURNACE

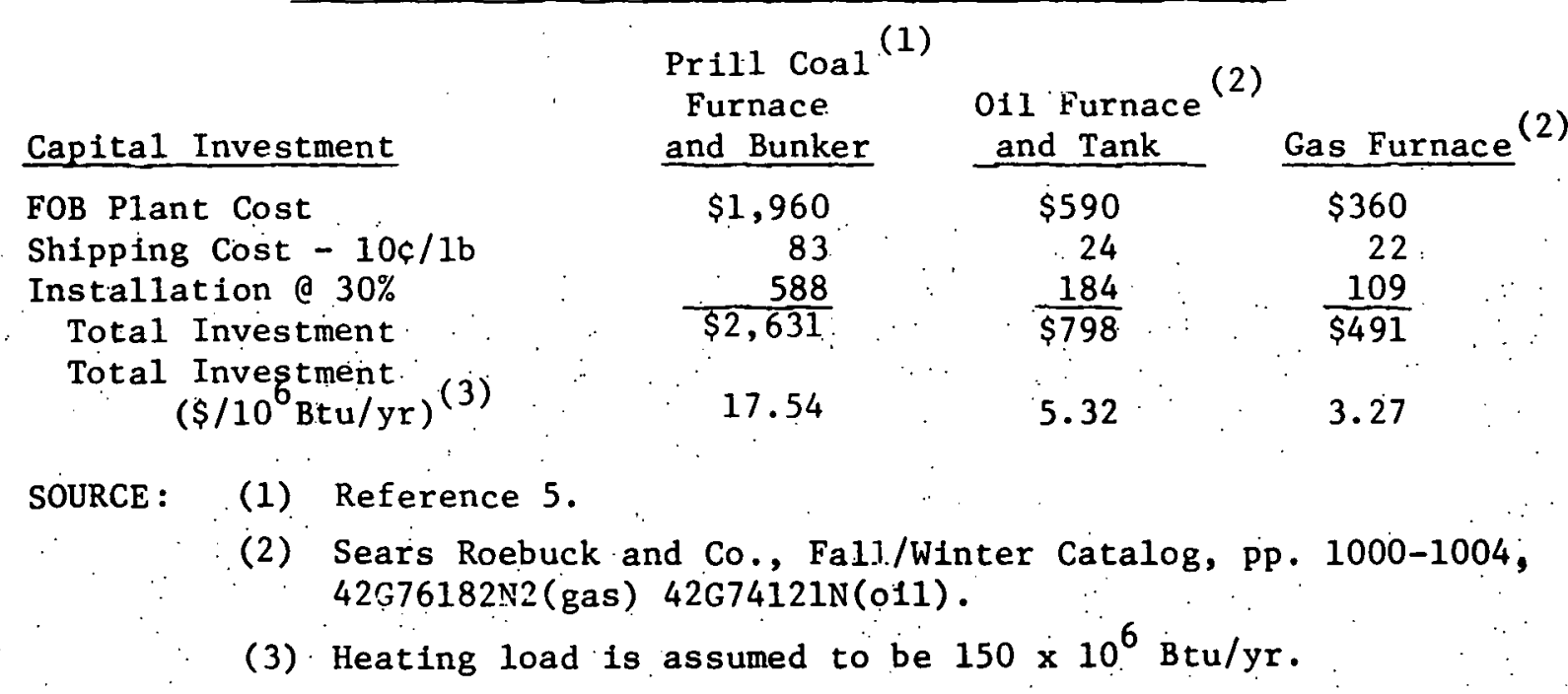

${ }^{*}$ Prill furnaces range in capacity from 80,000 to $350,000 \mathrm{Btu} / \mathrm{hr}$. 
Table 18-3 shows estimates of the operating costs for the Prill furnace, and operating costs and breakeven fuel costs for oil and gas furnaces using the economic ground rules used by Cart, ${ }^{(3)} 1 . e$. , personal discount rate, $7 \%$; mortgage interest rate, $9 \%$; inftial equity in the house, 20\%; depreciation period, 10 years; personal marginal income tax rate, 25\%; local property tax rate, 3\%; and property insurance cost, $0.4 \%$. These economic ground rules result in a capital recovery factor of 0.1695 . These numbers have been converted to a constant dollar basis by deducting an inflation rate of $6 \%$, resulting in a capital recovery factor of $11 \%$.

The units are typlcally sized so that the unit operates only $25-30 \%$ of the total time during an average winter. (3) Table 18-3 ussumes that the annual heating load w111 be $150 \times 10^{6} \mathrm{Btu} / \mathrm{yr}$. The assumed cost of coal, delfvered to the home is $\$ 2.50 / 10^{6} \mathrm{Btu}$ and the annual malntenance costs are $5 \%$ of investment, consistent with Cart. (3)

\section{TABLE $18-3$}

TOTAL OPERATING COST FOR A PRILL FURNACE AND CORRESPONDING FUEL BREAKEVEN COSTS FOR OIL AND GAS SYSTEMS

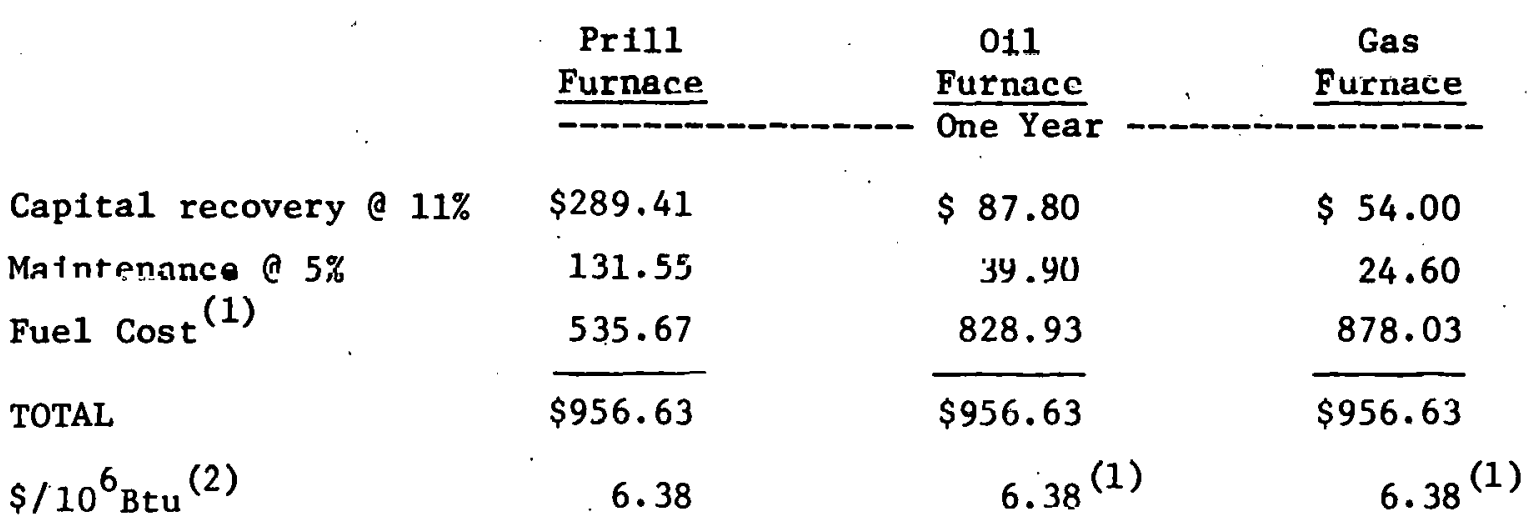

(1) Coal at $\$ 2.50 / 10^{6} \mathrm{Btu} ; 6_{011}$ and gas costs are equivalent breakeven costs at $\$ 4.42$ and $\$ 4.68 / 10^{6} \mathrm{Btu}$, respectively, to give $\$ 6.38 / 10^{6} \mathrm{Btu}$.

(2) Heating load is assumed to be $150 \times 10^{6} \mathrm{Btu} / \mathrm{yr}$. 
Section 18.4: Limitations

There are numerous barriers that would have to be overcome before the direct use of coal for domestic heating could become widespread. The safety and environmental aspects have been discussed already. Equally important is the lack of a retail distribution system for coal which would provide the automatic delivery and service currently available from fuel oil retallers. The ashes would also present a disposal problem.

The combustion of coal in urban areas will emit significant quantities of hydrocarbons to the atmosphere, as shown in Table 18-1. During the early years of this century, these emissions were reduced. in Europe by preparing a "smokeless fuel" for domestic use by low temperature carbonization of coal. These processes were never widespread in the United States. Currently, only one plant produces such briquettes ("Grilltime" briquettes by Husky) which are nationally distributed. 
THIS PAGE

WAS INTENTIONALLY LEFT BLANK

$8 \cdot 12$ 


\section{REFERENCES}

1. Squires, A.M. "Coal: A Past and Future King." Ambio 3(1): 1-14, 1974 .

2. Lovins, A.B. Soft Energy Paths: Toward a Durable Peace. Cambridge, Massachusetts: Ballinger Publishing Company, 1977.

3. Cart, E.N., Jr., et al. Evaluation of the Feasibility for Widespread Introduction of Coal into the Residential and Commercial Sectors. Vols. 1 and 2. Report prepared by Exxon Research and Engineering Company for the Council on Environmental Quality, 1977. N'IIS Repurl Nús. PB 281191 and PB 2.81. 192.

4. American Society of Heating, Refrigerating and Air-Conditioning Engineers, Inc. ASHRAE Handbook and Product Directory: 1975 Equipment. New York: American Society of Heating, Refrigerating and AirConditioning Engineers, Inc., 1975.

5. PMC Corporation, Box 6416, Sheridan, Wyoming. "Engineering Data and Specifications." Undated product literature.

6. Sallsbury, J.K. and C. Carmichael, eds, Kent's Mechanical Engineers' Handbook. 12 th ed. 2 volumes. New York: John Wiley and Sons, 1950. 


\begin{tabular}{|c|c|}
\hline & 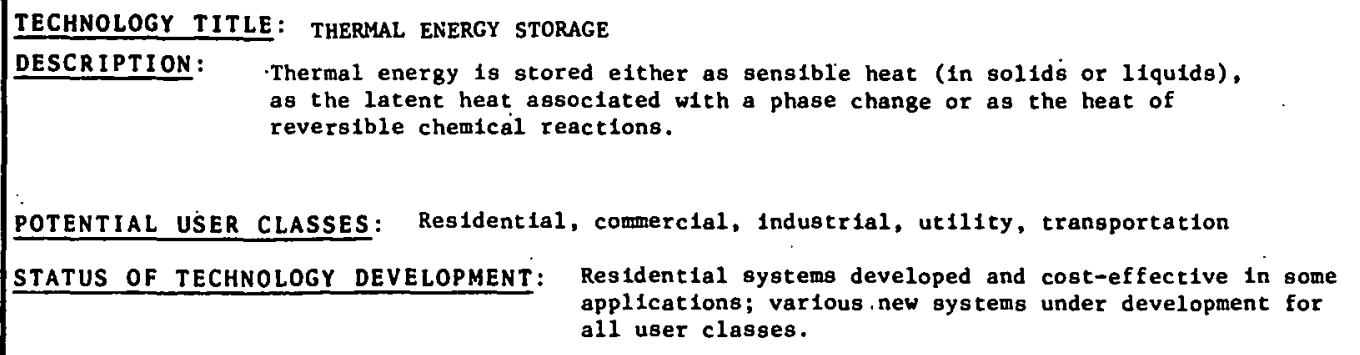 \\
\hline \multirow[b]{3}{*}{ 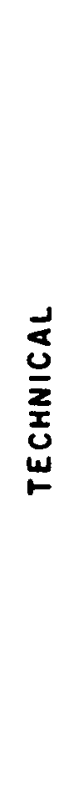 } & $\frac{\text { THERMAL STORAGE ENERCY DENSITY }\left(\mathrm{Btu}^{-\mathrm{ft}^{3}}{ }^{3}\right) \text { FOR SPACE }}{\text { HEEATING APPLICATIONS: }}$ \\
\hline & 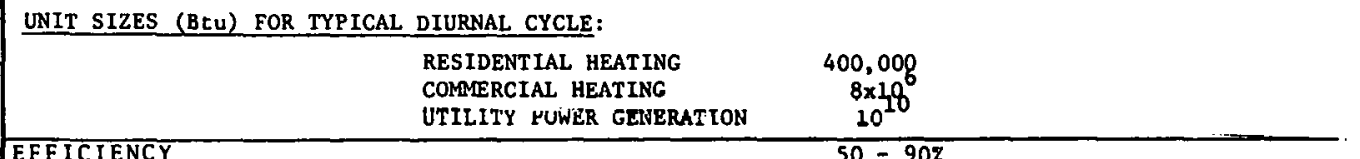 \\
\hline & 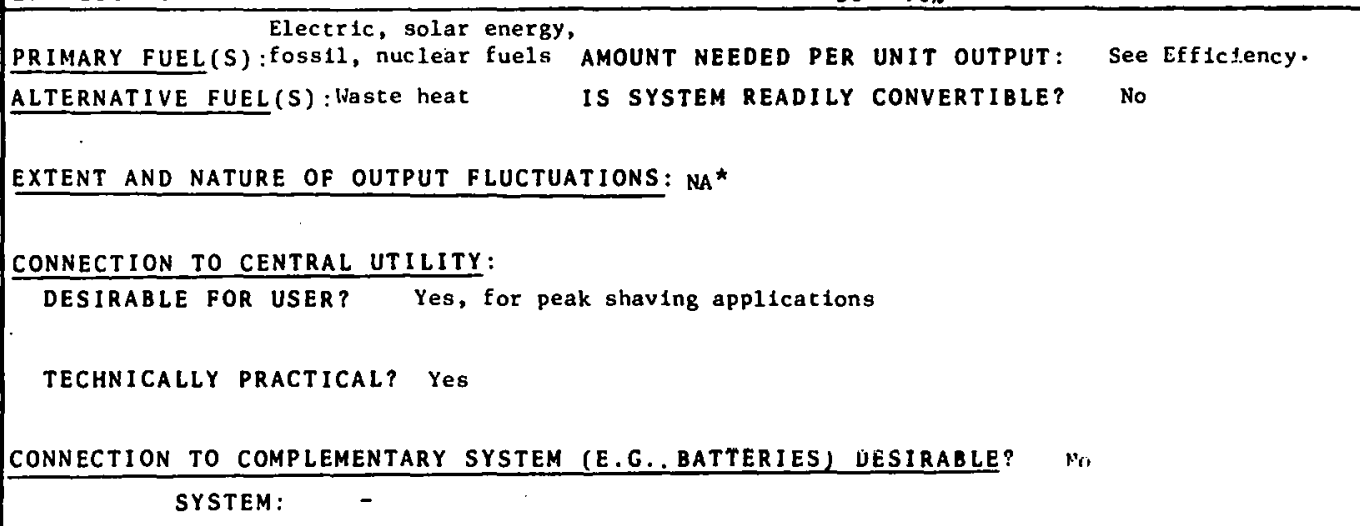 \\
\hline 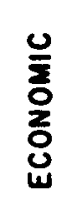 & 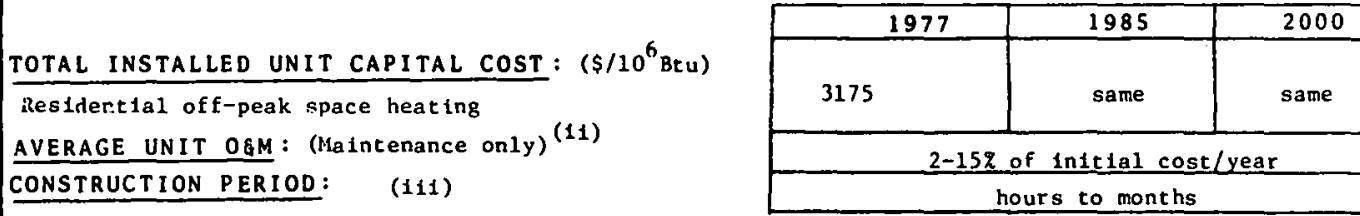 \\
\hline$\sum_{\substack{0 \\
0}}^{0}$ & $\begin{array}{l}\text { EXTENT OF INDUSTRIAL BASE FOR PRODUCTION AND DISTRIBUTION: } \begin{array}{c}\text { Snme mater lals suggested as } \\
\text { STORage media not avallable in commercial quantities. Production capability adequate. }\end{array} \\
\text { GEOGRAPHIC LIMITATIONS: None } \\
\text { ENVIRONMENTAL EFFECTS Safety of some systems questionable } \\
\text { LEGAL, SOCIAL OR INSTITUTIONAL BARRIERS: } \begin{array}{l}\text { Public utility regulations and electric } \\
\text { utility pricing policies }\end{array}\end{array}$ \\
\hline 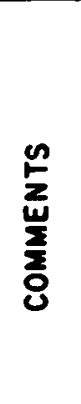 & 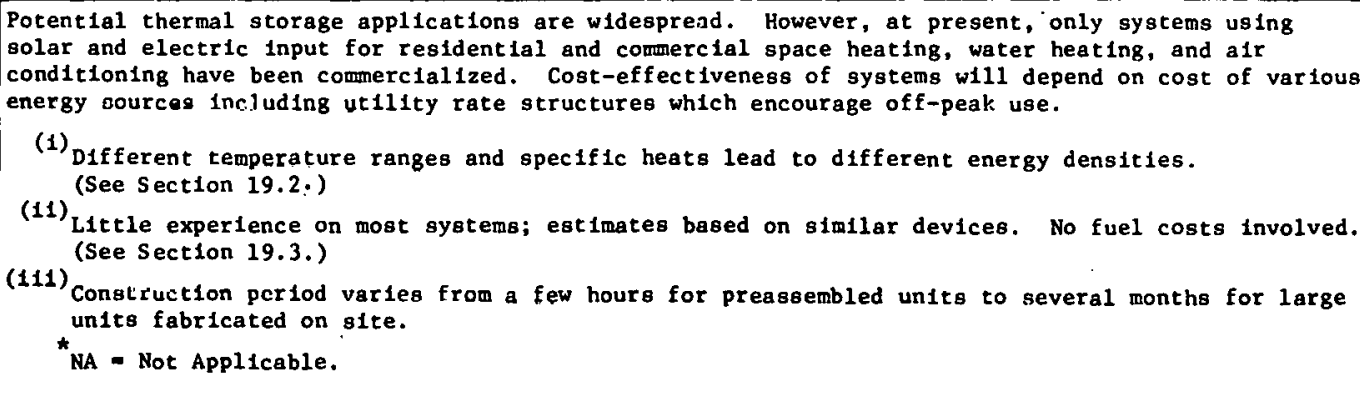 \\
\hline
\end{tabular}


CHAPTER 19

\section{THERMAL ENERGY STORAGE}

\section{Section 19.1: Introduction}

Thermal energy storage can be used for several general types of applications. The primary ones are:

- Storing thermal energy for use in reducing peak loads on utility power plants,

- Reducing energy consumption by recovering heat that' would normally be wasted and storing it until such time as it can be used either by the same process or by another process (e.g., recovering waste heat from air conditioners for water heating or industrial waste heat recovery),

- Improving the efficiency of heating or cooling devices by reducing cyclic losses, *

- Providing a better source/sink temperature match by storing energy when favorable ambient conditions exist (e.g., an air conditioner could be run at night to charge a cold storage device, or summer heat could be stored to provide space heating in the winter), and

- Making it practical to utilize renewable energy sources which are periodic (e.g., excess solar energy collected during the day can be stored for heating during the night).

For the application involving storage to. reduce utility peak loads, either thermal energy is stored at a central utility during off-peak periods to be used to generate power to meet peak demands, or it

\footnotetext{
* Losses associated with starting a device and bringing it up to its efficient operating range, or similarly with shutting such a device off.
} 
is stored at the point of use in storage appliances such as water heaters, space heaters, or air conditioners using off peak electricity. During peak demand periods, inputs to these storage devices are turned off and energy is withdrawn from storage. The utflity in this case may be a central power plant or it may be an on-site system. In elther case, thermal energy storage is important in reducing operating costs and capital equipment investment. * Reducing peak demand will result in conserving gas and 011 for peak shaving and in higher utilization of coal and nuclear baseload generation equipment.

In most industrial applications, waste heat is recovered and stored for use at a later time. $(5,6)$ This energy may be used in the industrial process itself to reduce energy consumption, ur it may be used to supply space heating or cooling either to the industrial complex or to the nearby area. The waste heat from a utility may also be used in this way.

\section{Section 19.2: Technical Discussion}

\section{A. Types of Storage Media}

1. Sensible Heat

One way to store thermal energy is as senstble heat. In this case, a mass of material is heated to raise 1 ts temperature. The temperature rise required tn store a given amount of heat depends on the specific heat of the material. This, is numerically equal to its heat capacity which in engineering units is the amount of energy (Btu's) required to ralse the temperature of 1 lb of the material $1^{\circ} \mathrm{F}$. Water has one of the highest heat capacities. Its value is $1 \mathrm{Btu} / 1 \mathrm{~b}^{\circ} \mathrm{F}$. Rock has a value of approximately $0.2 / 1 b^{\circ} \mathrm{F}$. The specific heats of most metals fall in the range

\footnotetext{
* For further information on these applications for thermal storage see References 1, 2, 3 and 4, and Chapter 3, Solar-Thermal Power Systems, and Chapter 23, Total Energy Systems, of this report.
} 
of 0.05 to 0.2 , while insulating materials typically have values ranging from 0.2 to 0.5 .

In considering a material for use as a heat storage medium, the density of the material is also important because the heat stored per unit volume depends on both the specific heat and the density. A denser material requires a smaller container, less insulation, and smaller heat exchangers. Since the major cost elements of systems are the storage medium, the container, the heat exchangers and the insulation, units with high volumetric heat capacity are likely to be less expensive.

As energy is withdrawn from a sensible heat storage system, the temperature of the material falls in direct proportion to the amount of heat taken out. Unless appropriate designs are employed, this produces a continuously decreasing exit temperature as the storage unit is discharged. To produce a constant exit temperature in European electric storage space heaters, hot air from storage is mixed with cool return air using thermostatically controlled baffles. Another approach, common in solar applications, uses geomctries which promote thermal stratification in the storage medium so that the heat-transfer medium exits from the storage unit at a temperature close to the highest storage temperature. In either case, the storage unit is discharged when the exit temperature of the heat-transfer medium drops below a useful level. This determines the effective storage capacity of a particular design. To charge a storage system, heat must be available at a temperature greater than that to which the device will be elevated due to temperature drops in heat exchangers. These considerations are important in considering how well a heat storage system utilizing a sensible heat storage material will match the application requirements.

Most commercially available thermal storage systems employ sensible heat storage. Examples include storage units for electric space heating, which use ceramic bricks or cast iron, and storage systems for solar space heating, which employ water or rock beds. The former have been used successfully in Europe to improve central utility load factors. (7) 
The latter systems have been installed in a variety of U.S. demonstration applications. Representative rock bed and water storage systems for solar applications are shown in Figures 19-1 and 19-2. Storage densities and system sizes selected to meet various residential, commercial, and industrial energy demands have been calculated and are shown in Table 19-1.

\section{Phase Change}

A second method for storing heat is to use a material which undergues a phase change at about the temperaturc at which llie energy is also to be used. When a material undergoes a phase change; it. absorbs or releases a greater amount of thermal energy than would be exchanged if the material. were simply heated or cuoled. Phase changes which may be utilized involve the process of solidification, vaporization, crystallization, or hydration. The heat of crystallization is absorbed or released (depending upon whether the process is exothermic or. endothermic) when a salt in a saturated solution crystallizes. The heat of hydration is the heat which is released or absorbed when a salt takes on or releases water molecules in going from one hydrate form to another.

A number of phase change systems are currently belng marketed for solar heating applications. Many of these use sodium sulfate decahydrate (Glauber's salt) as the heat storage medium. Among lie organizations marketing these systems are:

- OEM Products, Tampa, Florida,

- Architectural Research Corporation, Iivonia, Michigan,

- Institute of Energy Conversion, University of Delaware, Newark, Delaware, and

- Solar, Inc., Meads, Nebraska.

A calcium chloride hexahydrate system developed by Dow Chemical, Midland, Michigan, and marketed by Texxor Corp., Omaha, Nebraska, under the trade name of Thermal 81, has been recently introduced. (10) Table 19-2 gives information on these two types of systems plus others which are currently under development.

* Reference 9 presents a general discussion of chemical storage systems. 


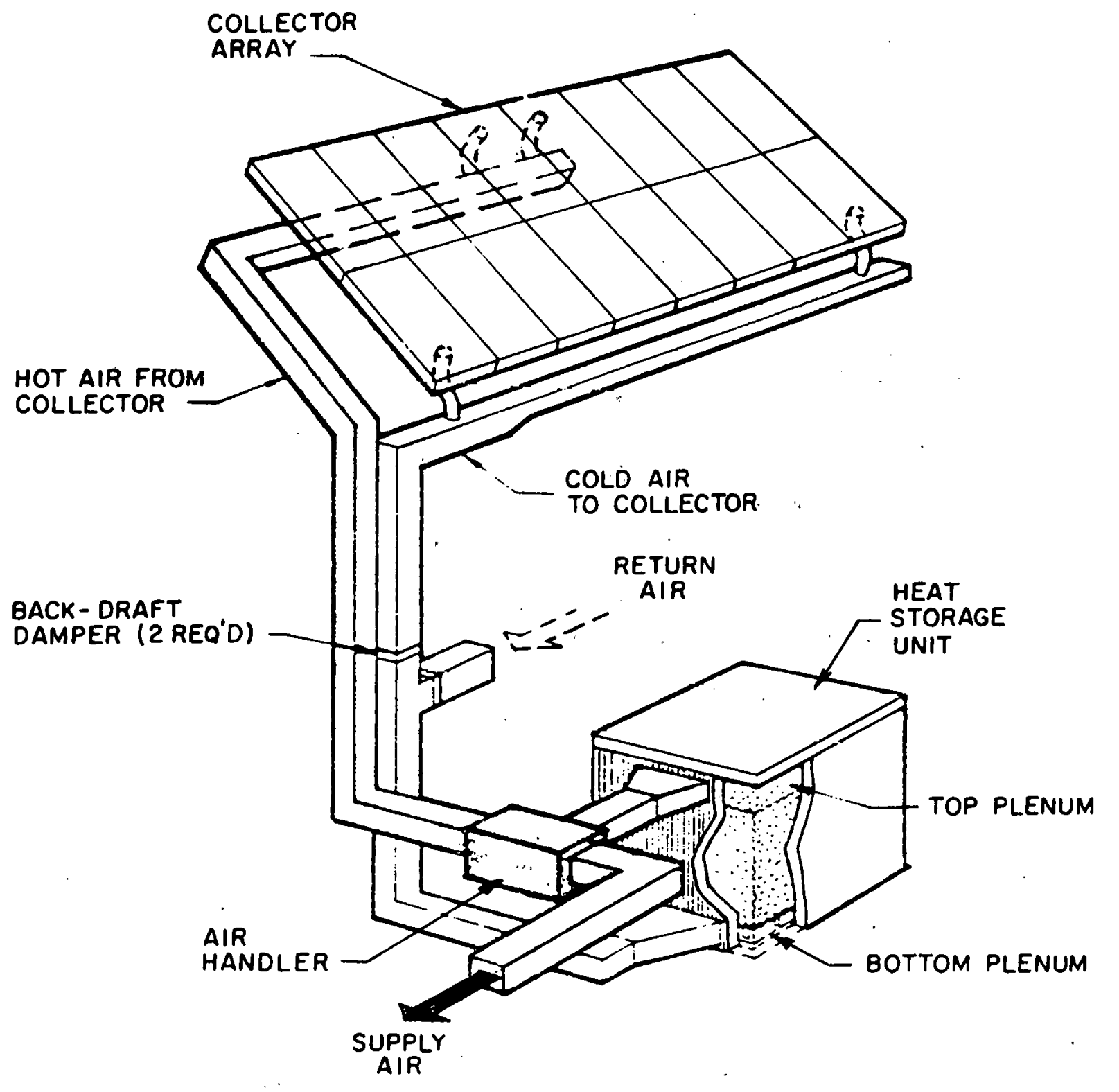

SOURCE: Solaron Corporation, Denver, Colorado, undated product 1iterature. FIGURE 19-1 ROCK BED THERMAL STORAGE SYSTEM 


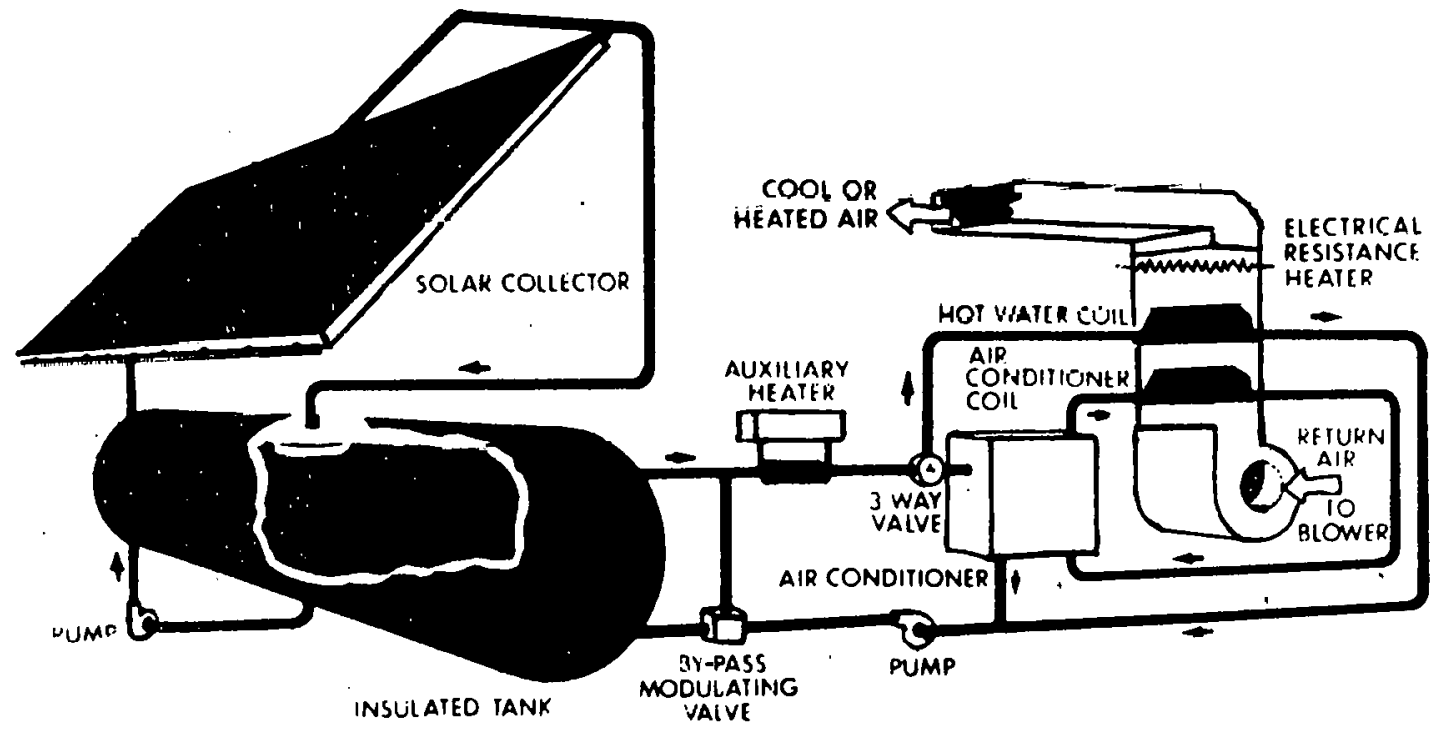

SOURCE: Reference 8.

FIGURE 19-2 WATER-BASED THERMAL STORAGE SYSTEM 
TABLE 19-1

TYPICAL CHARACTERISTICS OF POSSIBLE HEAT STORAGE SYSTEMS

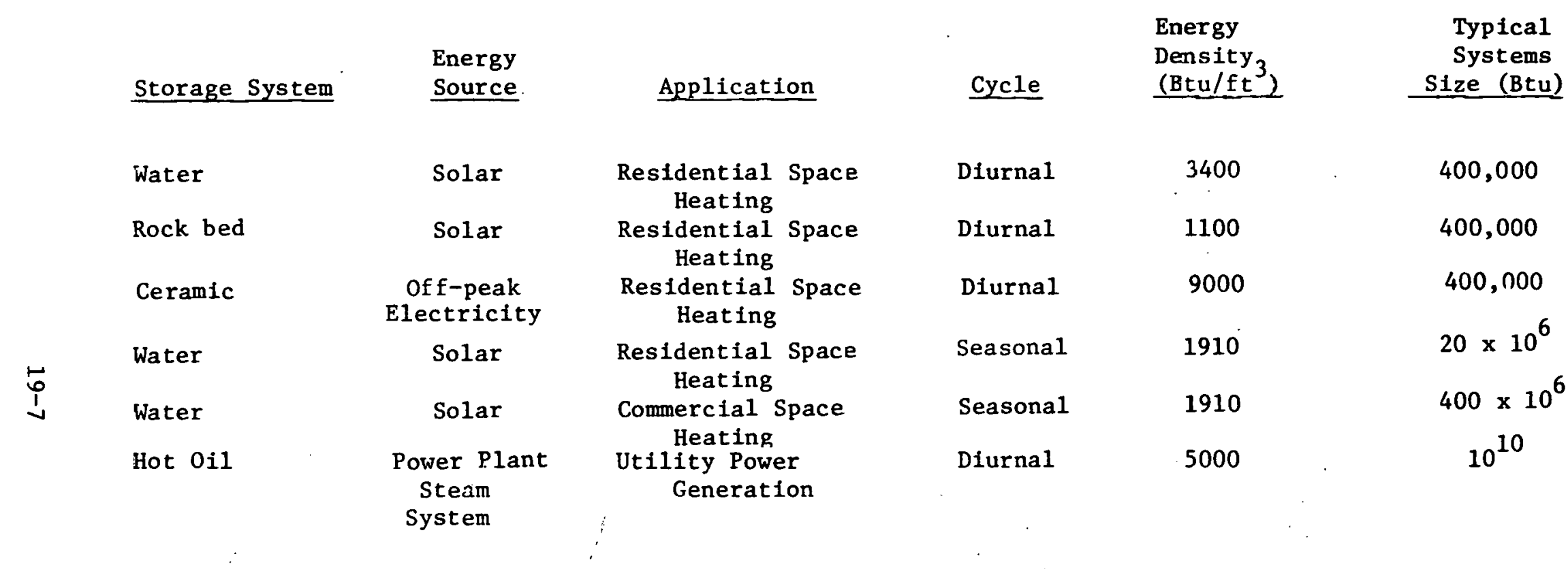

SOURCE: Arthur D. Little, Incí, estimates. 
TABLE 19-2

THERMAL ENERGY SIORAGE SYSTEMS USING PHASE CHANGE MATERIALS

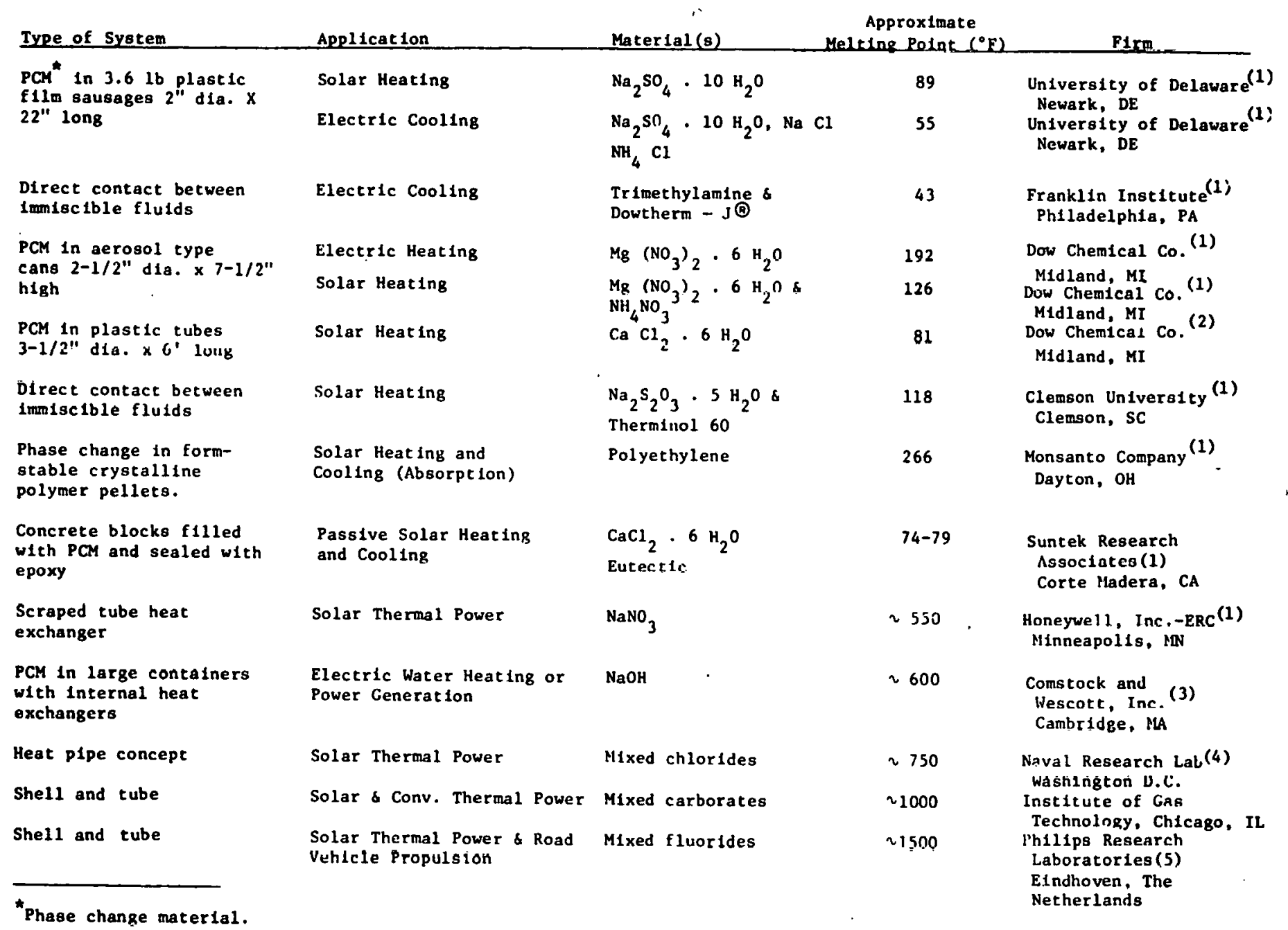

SOURCE: (1) Reference 12.

(2) Reference 10.

(3) Reference 11.

(4) Reference 13.

(5) Reference 14. 
In order to ut1lize phase change materials, a number of design problems must be solved. First, the materials are generally corrosive. Second, they may involve a state change which can limit heat transfer because of a build-up of solid material on heat exchanger surfaces. In order to provide better heat transfer, "active" heat exchangers are being developed which employ mechanical methods to remove solidified material from heat exchanger surfaces or to prevent the material from forming on the surfaces. Other research is directed toward developing immiscible fluid systems which employ direct contact heat between a heat-transfer fluld and a saturated solution of a salt to avoid the problem of crystal build-up on heat exchanger surfaces. The major problem with this approach is the selection of two fluids which are truly immiscible. In practice, although fluids may be immiscible intitally, repeated thermal cycling with agitation leads to the formation of emulsions. A third problem with the advanced phase-change systems is that they are more expensive than the systems based on sensible heat materials.

It is anticipated that these disadvantages will be offset by cconomies which result from the ability to store and remove heat at a constant temperature and thus more closely match the requirements for a particular application. For instance, when water is used as the storage medium, it is typically cycled from a low temperature of $100^{\circ} \mathrm{F}$ to a high temperature between 150 and $200^{\circ} \mathrm{F}$. In this case a collector will have to provide energy at a temperature of $175-225^{\circ} \mathrm{F}$. The use of a phasechange material for the storage medium means that a simpler, lower cost, and more efficient collector could be used. Similarly, in a cold storage application where a heat pump, air conditioner, or ice maker is used to cool a mass of material, the operating efficiency of the compressor decreases as the temperature of the storage medium drops. The use of a material which maintains a constant temperature means that the compressor can be smaller and consequently lower in cost and in energy required to operate it.

\section{Chemical Systems}

The third class of storage systems involves chemical reactions. In this case, a chemical reaction which goes in one direction or another 
direction, depending on the temperature at the two end-points, is utilized to store energy. Because the thermal energy is stored chemically, standby losses are minimized. This makes these systems particularly attractive for long-term storage applications.

In one type of chemical storage system intended for solar space heating and cooling applications, energy is put in at a high temperature $\left(250-400^{\circ} \mathrm{F}\right)$, driving a gas off a salt. This gas elther combines exothermally with another salt at a lower temperature $\left(50-100^{\circ} \mathrm{F}\right)$, or it is condenged in a low-temperature container. The reaction is reversed in order to give up heat as required by the application. This is done by adding heat to the low-temperature reservoir from ambient, while heat is removed from the higher temperature reservoir. These systems, called "chemical heat pumps," can provide both heating and cooling. The space heating coefficient of performance is greater than one if the heat rejected while charging the system is used for space heating and the unit is discharged by supplying low-temperature energy at outdoor ambient conditions. This means that less collector area will be required to meet a given heating load.

Higher temperature chemical reactions are being explored for storing energy over longer periods for solar power generation. In this case, heat at temperature levels of $500-1000^{\circ} \mathrm{F}$ from a concentrating collector or collector field is used.

A number of different chemical reactions are currently being explored for these applications. (See Table 19-3.) As with the phase change systems, none of these is presently commercially available, and there are many technical areas which muct bc considered before they can be utilized. The materials are generally corrosive. Some reactions involve combustible or hazardous gases. In addition, the processes may use gases at pressures of 10 atmospheres or more and require sophisticated instrumentation and controls. It is hoped that the costs associated with solving these areas will be balanced by the fact that the storage material is at ambient temperature and therefore can be used to store energy over a long period of time with minimum standby losses. 
TABLE 19-3

CHEMICAL REACTION-BASED THERMAL ENERGY STORAGE SYSTEMS

Chemical Reaction(s)

$\mathrm{CaCl}_{2} \cdot 2 \mathrm{CH}_{3} \mathrm{OH}$ (solid) + Heat $\rightleftharpoons \mathrm{CaCl}_{2}$ (solid) $+2 \mathrm{CH}_{3}$ OH (vapor)

$\mathrm{H}_{2} \mathrm{SO}_{4} \cdot \mathrm{H}_{2} \mathrm{O}$ (liquid) $+\mathrm{Heat} \rightleftharpoons \mathrm{H}_{2} \mathrm{SO}_{4}$ (liquid) $+\mathrm{H}_{2} \mathrm{O}$ (vapor)

$\mathrm{MgCl}_{2} .6 \mathrm{NH}_{3}$ (solid) + Heàt $\rightleftarrows \mathrm{MgCl}_{2} \cdot 2 \mathrm{NH}_{3}$ (solid) $+4 \mathrm{NH}_{3}$ (vapor)

$\mathrm{CaCl}_{2} \cdot 8 \mathrm{NH}_{3}$ (solid) $+\mathrm{Heat} \rightleftharpoons \mathrm{CaCl}_{2} \cdot 4 \mathrm{NH}_{3}$ (solid) $+4 \mathrm{NH}_{3}$ (vapor)

$\mathrm{MgCl}_{2} \cdot 4 \mathrm{H}_{2} \mathrm{O}$ (solid) + Heat $\rightleftarrows \mathrm{MgCl}_{2} \cdot 2 \mathrm{H}_{2} \mathrm{O}$ (solid) $+2 \mathrm{H}_{2} \mathrm{O}$ (vapor)

$\mathrm{SO}_{3}$ (vapor) + Heat $\rightleftarrows \mathrm{SO}_{2}$ (vapor) $+\frac{1}{2} \mathrm{O}_{2}$ (vapor)

$\mathrm{Mg}(\mathrm{OH})_{2}$ (solid) + Heat $\rightleftarrows \mathrm{MgO}$ (solid) $+\mathrm{H}_{2} \mathrm{O}$ (vapor)

$\mathrm{NH}_{4} \mathrm{HSO}_{4}$ (1iquid) + Heat

(1) Reference 12.

(2) Reference 15.

(3) Reference 16.

(4) Reference 17.

\begin{tabular}{|c|c|c|}
\hline Application & $\begin{array}{l}\text { Tempezature } \\
\text { Range }\left({ }^{\circ} \mathbf{F}\right)\end{array}$ & $\begin{array}{c}\text { Firm } \\
\text { Developing }\end{array}$ \\
\hline $\begin{array}{l}\text { Solar heating } \\
\text { and cooling }\end{array}$ & $100-250$ & $\begin{array}{l}\text { EIC Corp. } \\
\text { Newton, MA }\end{array}$ \\
\hline $\begin{array}{l}\text { Solar heating } \\
\text { and cooling }\end{array}$ & $100-380$ & $\begin{array}{l}\text { Rocket Research } \\
\text { Corp. } \\
\text { Woodinville, WA }\end{array}$ \\
\hline $\begin{array}{l}\text { Paired reactions } \\
\text { for solar heating } \\
\text { and cooling }\end{array}$ & $\begin{array}{r}200-350 \\
60-100\end{array}$ & $\begin{array}{l}\text { Martin-Marietta } \\
\text { Denver, Colorado }\end{array}$ \\
\hline $\begin{array}{l}\text { Solar heating } \\
\text { and cooling }\end{array}$ & $100-250$ & $\begin{array}{c}\text { Chemicai Energy } \\
\text { Specialists }\end{array}$ \\
\hline Power generation & $750-1600$ & $\begin{array}{l}\text { Boeing(3) } \\
\text { Seattle, WA }\end{array}$ \\
\hline $\begin{array}{l}\text { Solar heating or } \\
\text { power generation }\end{array}$ & . 700 & $\begin{array}{l}\text { Atomics } \\
\text { International } \\
\text { Canoga Park, .CA }\end{array}$ \\
\hline $\begin{array}{l}\text { Solar heating or } \\
\text { power generation }\end{array}$ & $750-1600$ & $\begin{array}{l}U_{\text {. of Hous ton }}(1) \\
\text { Houst on, Texas }\end{array}$ \\
\hline
\end{tabular}




\section{B. Storage Duration}

The length of time during which thermal energy must be stored depends on the particular application. Most systems are planned to operate on a fairly regular cycle, which may range from a day to a year. A daily cycle might be used in some solar systems, where heat collected during the day can then be used to heat through the night. To cover extended periods of low insolation, such systems might be increased to several days' capacity. Alternatively, an electrically based heating system might benefit from thermal storage, which could be charged during periods with lower cost, off-peak electricty. Seasonal storage systems, which would have'a yearly cycle, may also be practical. The Annual cycle Energy System (ACES) ${ }^{(18)}$ is one such system. In this system, a heat pump is used to make 1ce while it is heating a building in the winter. This ice is stored in a large bin and is used.as a heat sink in the summer to provide space cooling. In addition to improving seasonal heat pump performance, the ACES system can be used to reduce peak demand on utilities. Recently, several installations have been made in commcrcial buildings based solely on economic analyses of payback periods. Examples include the Reedburg Vocational School, Reedburg, Wisconsin, and the Getty Manufacturing Company, Racine, Wisconsin.

Seasonal storage is also being investigated both to utilize the seasonal temperature changes by storing energy available in one season for use in another season and for recovering waste energy which may be available throughout the year but can only be utilized at particular times during the year. ${ }^{(15)}$ In the latter case, heat rejected by a power plant could be stored in a large storage system continuously and withdrawn as needed by a group of residences in a distributed heating system. Several groups are investigating the possibility of storing this heat underground in large aquifers. (20) water heated by solar collectors, waste heat from a utility, industrial process, or from a total energy system would be pumped underground. When heat was required, the hot water would be extracted. Cold storage can function in a similar way by using cooling ponds, cooling towers, or large natural bodies of water to cool water which is pumped underground. (21) 
C. Active vs. Passive Systems

Another distinction which is made in considering storage systems is whether they are active or passive. Active systems generally involve the movement of a fluid to transfer energy from a source of some sort to the point at which energy is to be stored and/or the movement of another fluid to extract energy from storage and transfer it to the point of use. In these systems, energy can be extracted on demand. The source in this case may be a heat exchanger located in a waste stream, a solar collector, or a similar device. The transfer fluid may be water, a heat-transfer oil such as Dowtherm? a methanol solution which does not freeze, or air. A similar type of fluid plus heat exchangers may be required on the output side.

In passive systems, various building elements, such as walls, ceilings, and floors, may be used to store energy. (22) The energy may be obtained as solar heat from the outside, by a heating system such as a fuel-fired furnace on the inside of the building, or from waste heat. In passive systems, methods for controlling input and withdrawal of energy are limited to means such as shading a structure from the sun with curtains, overhangs, etc., or by opening or closing ducts to modify natural convective flow.

In an early example of this type of storage (Figure 19-3), a concrete wall was bullt directly behind a large south-facing window. Recent efforts ${ }^{(24)}$ have attempted to improve the passive systems by impregnating porous concrete blocks with phase change materials to increase their thermal capacity at a temperature suitable for space heating or cooling and thereby providing a constant temperature source or sink. A major advantage of any heat storage capacity in the walls of a building is that it tends to dampen the effect of external temperature swings. (25) Thus, during the summer, air conditioning demand is reduced by the storage in the walls of a building.

\section{Storage Efficiency}

The turn-around efficiency of a storage device depends on various 


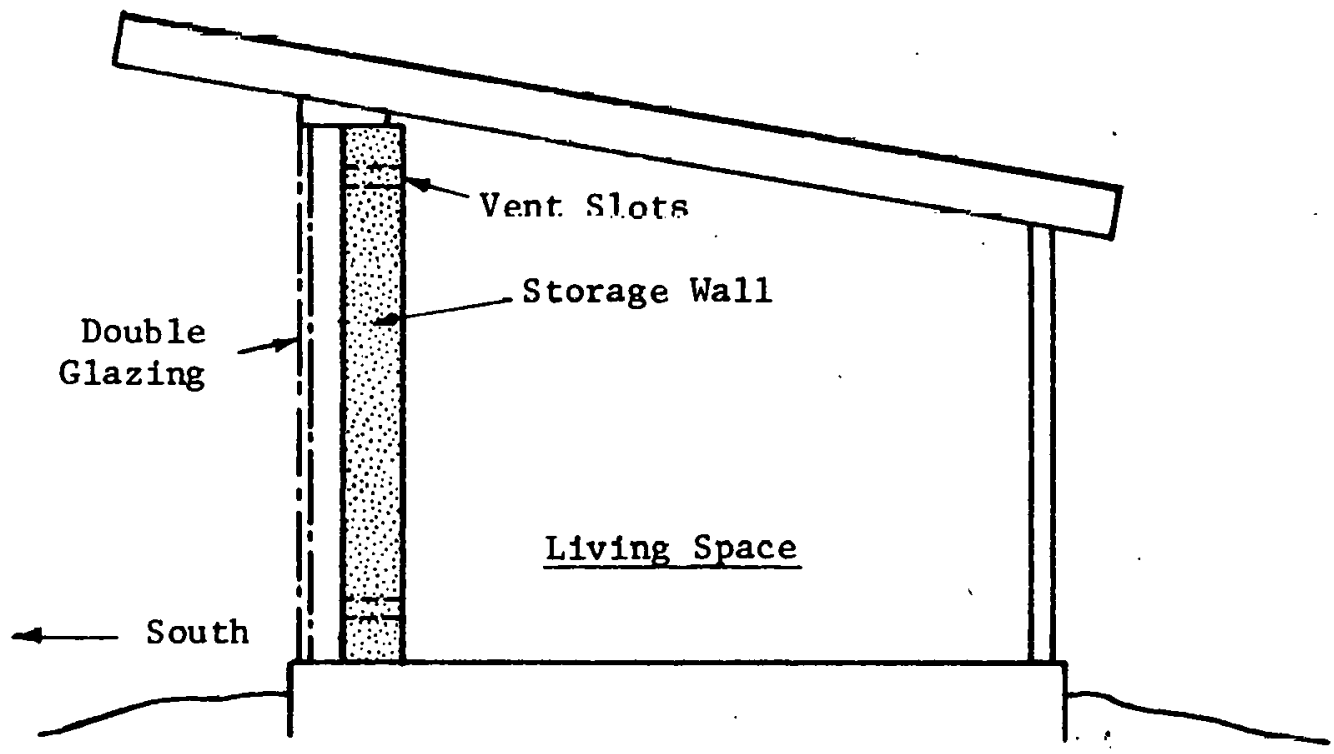

SOURCE: Reference 23.

\section{FIGURE 19-3 TROMBE WALL PASSIVE THERMAL STORAGE SYSTEM}


factors, such as its operating temperature range, surface area, insulation, storage interval, etc. Most of the systems currently available are used for space heating in residential buildings on a diurnal basis and are installed in the building. A percentage of standby "losses" contributes useful space heating. The actual percentage depends on whether the unit is located in a space which is normally heated, whether the space is overheated, air circulation paths in the building, etc. These losses are typically $10 \%$ or less. Seasonal storage systems may be installed outside and, in addition, standby losses will be higher due to the length of the storage interval. In this case, the losses may be as high as $50 \%$. Estimating efficiencies of the advanced systems is difficult because many are only conceptual designs or laboratory models; however, the efficiencies should lie between the two extremes discussed above.

Section 19.3: Economics Discussion

Costs of thermal energy storage systems in most cases are not well defined at this point. Systems for use with solar energy inputs are generally designed on a one-of-a-kind basis, and, even in the residential market, only a limited number of installations have actually been made. Water and rock are the two media generally used for these applications, with about $70 \%$ of the installed systems utilizing water. Approximate costs for these systems for a representative storage capacity are shown in Table 19-4. These are based on the same temperature differential, assuming that the supply temperature from the solar collector is the same in both cases. The cost estimates include insulation and installation of the systems.

Units for storing off-peak electric energy for space heating have been available in Europe for many years. In recent years European companies have begun to market similar units in the United States. These have been modified to meet the more demanding performance and safety requirements of American space heating systems. The system shown in Table 19-4 for this application utilizes bricks and is based on the system manufactured by Creda Corporation in Europe and currently marketed in the United States by TPI Corporation of Johnson City, Tennesee. The 
TABLE $19-4$

COSTS OF RES.IDENTIAL THERMAL ENERGY STORAGE SYSTEMS

\begin{tabular}{|c|c|c|c|c|c|c|}
\hline $\begin{array}{l}\text { Input } \\
\text { Energy }\end{array}$ & Method & $\begin{array}{c}\text { Quantity of } \\
\text { Storage }\end{array}$ & $\operatorname{Cost}^{(2)}(s)$ & Capacity (Btu) ${ }^{(3)}$ & $\begin{array}{l}\text { Temperature } \\
\text { Swing }\left({ }^{\circ} \mathrm{F}\right)\end{array}$ & $s / 10^{6} \mathrm{Btu}$ \\
\hline Solar & $\begin{array}{c}\text { Unpressurized } \\
\text { Water: }\end{array}$ & $900 \mathrm{gal}$ & 2000 & 400,000 & 55 & 5000 \\
\hline Solar & Rock & $30,0001 \mathrm{~b}$ & $1500^{(4)}$ & 400,000 & 55 & 3750 \\
\hline Electric & Bricks & $1,380 \quad 1 b$ & $1270^{(5)}$ & 400,000 & 1200 & 3175 \\
\hline Electric & Ice & $6301 \mathrm{~b}$ & 600 & 108,000 & $\begin{array}{l}\text { Melting } \\
20\end{array}$ & 5560 \\
\hline Electric & $\begin{array}{c}\text { Pressurized } \\
\text { Hot Water }\end{array}$ & 363 gal & $5000^{(6)}$ & $\angle 00,000$ & 160 & 12500 \\
\hline
\end{tabular}

(1) These are representative of systems that are commercially available or have been extensively field-tested.

(2) Cost includes installation. These are Arthur D. Little, Inc.: estimates based on manufacturers' data referenced below and, for unpressurized water storage, Reference 26. For the ice system, the cost is actually estimated as $\$ 100$ plus twice the projected production cost from Reference 27 ; these units are not commercially avallable.

(3) Residential sizes for residential applications.

(4) Based on Solaron Corporation, Denver, Colorado, designs and construction costs from 1978 (Building Construction Cost Data - 1978, Robert Snow Means Co., Inc., Duxtury, Massachusetts).

(5) TPI, Corporation, Johnson City, Tennessee, 1979 quote plus installation estimated at 2 man-days @ \$20/hr.

(6) Megatherm, Providence, Rhode Island, 1978 quote plus installation at 2 wan-days @ $\$ 20 / \mathrm{hr}$. 
price shown is a reasonably firm one. for this particular application.

Cold storage for off-peak air condtioning is a relatively new fleld. Several companies are developing and marketing such systems, but the costs are high and do not yet reflect economies of large production volumes.

The systems shown in this table represent the state-of-the-art for thermal energy storage for residential and commercial heating and cooling equipment. Costs per million Btu's are expected to be somewhat lower for larger systems. * However, while the costs assoclated with the space required are not significant for these small diurnal residential systems, they are increasingly significant for larger seasonal storage systems and commercial-size installations.

The advanced systems currently being developed have not yet reached the point where production cost estimates are avallable. As mentioned earlier, it is anticipated that the advanced systems will cost more for an equivalent capacity than the sensible heat systems, but that this cost differential will be offset by improved operational characteristics and reduced opacc requirements of as much as $50 \%$. Within the nexc year or so, more definitive comparisons of these systems should be possible.

Installation of commercially avallable, factory-built, off-peak electric space heating is similar to installation of electric furnaces and requires several hours. Larger systems are assembled on site or fabricated from materials obtained from a varlety of suppllers. The installation may include large excavation, erecting large tanks, etc., and take several months.

The annual maintenance requirements of most of these systems are not well established as most are available only as field test prototype or laboratory units. Typical malntenance requirements would include replacing electrical components, recharging spent material; replacing leaking or corroded parts, etc., in order to give an average life of 15 to 20 years which would be required in most applications. Estimates of

* Unpublished calculations suggest that unft storage costs ( $\$ / B t u$ ) may be reduced by a factor of 2 for an increase in system size by a factor of 10. These estimates are limited in their application to residential and commerclal diurnal applications. 
maintenance costs ranging from 2-15\% of inftial cost per year have been made by Arthur D. Little, Inc., in unpublished work by comparing these systems on a component-by-component basis with similar components in other applications. Salvage value of the materials is low. No fuel, costs are included in operating costs. Some systems use blowers and pumps which require electric input, typically $5 \%$ or less of total capacity.

\section{Section 19.4: Limitations}

No real barriers exist to the distribution of the commercially available residential systems other than the economics associated with their use. The economic advantages are dependent upon current energy costs and prices: At present, much attention is being given to development of electric rate structures which would encourage the use of offpeak devices. Many utilities are experimenting with storage devices in an attempt to develop guidelines for reasonable off-peak rate structures. The European experience indicates that this is a viable means of shaping utility loads, and the changing fuel price structure in the United States will undoubtedly encourage its further implementation.

Barriers to commercialization which must be considered when evaluating the advanced thermal storage systems are:

- use of space;

- availability of materials; and

- safety.

Storage systems require devoting a significant amount of space in a structure to the storage device. This is a factor which affects the cost of the building itself. In some cases the storage systems can be put underground, but the cost of this type of installation may be higher than the cost of including it within a building. The advanced systems are generally more.compact than the systems available commercially, which may offset to some extent their higher costs.

Availability of materials is an important consideration for energy storage systems because large quantities of heat storage material 
would be required. Many chemicals currently being considered as heatstorage materials are available in such limited quantities that widespread use would affect the supply and raise the price above levels which are acceptable at present.

The materials being considered for the advanced systems are in many cases corrosive or toxic. In addition, they are stored at elevated temperatures. For example, the Rocket Research System cited above employs concentrated sulfuric acid heated to temperatures of $350-400^{\circ} \mathrm{F}$. Another uses ammonia. Clearly these systems will have to be properly engineered and choroughly tested before they can be accepted for use in residential and commercial installations. This must include demonstrations of these systems to convince insurance companies, regulatory agencies, builders. and banks which will provide financing that the systems are reliable and cost-effective. 


\section{THIS PAGE \\ WAS INTENTIONALLY \\ LEFT BLANK}

$19 \cdot 20$ 
REFERENCES

1. "Energy Storage User Needs and Technology Applications." Engineering Foundation Conference, Asilomar, Pacific Grove, California, February 8-13, 1976. NTIS Report No. CONF-7602/2.

2. Public Service Electric and Gas Company. An Assessment of Energ: Storage Systems Sultable for Use by Electric Utilitles. Report prepared under Contract No. E(1101)-2501 for Energy Research and Development Administration, July 1976. NTIS Report No. EM-2 64.

3. Segaser, C.L., et al. MIUS Systems Analysis - The Effects of Thermal Energy Storage and Solid Waste Incineration OptIon on MIUS Cost and Fuel Consumption. Oak Ridge National Laboratory, July 1976. NTIS Report No. ORNL/HUD/MIUS-26.

4. Wolfer, B.M. The Potential Benefit of an Advanced Integrated Ut1lity System. National Aeronautics and Space Administration, Lyndon B. Johnson Space Center, Houston, Texas, November 1975. NASA Report No. N76-18671.

5. Cutler, R.R., et al.,"Energy Savings through Heat Recovery in the Glass Industry." Proceedings of the Twelfth Intersociety Energy Conversion Engineering Conference, Washington, D.C., August 28 September 2, 1977. pp. 505 ff.

6. Glenn, D.R. Technical and Economic Feastbility of Thermal Energy Storage. General Electric Company, Philadelphia, Pennsylvania, February 1976. NTIS Report No. COO 2558-1.

7. Asbury, J.G., et al. Electric Storage Heating: The Experience in England and Wales and in the Federal Republic of Germany. Argonne National Laboratory, May 1976. NTIS Report No. ANL/ES-50.

8. Patton, A.R. Solar Fnergy for Heating and Cooling of Buildings. Noyes Data Corporation, New Jersey, 1975. (Energy Technology Review, No. 7.)

9. Grodzka, P.G. Thermal Energy Storage. Lockheed Missiles and Space Company, Inc., Huntsville, Alabama, November 1975. NASA Report No. N76-13592.

10. "Dow Enters Solar Storage Field." Energy User News 4(19):1, May 7, 1979.

11. Cohen, B.M., et al. Development of a Phase-Change Thermal Storage System Using Modified Anhydrous Sodium Hydroxide for Solar Electric Power Generation. Comstock and Wescott, Cambridge, Massachusetts, December 1978. 


\section{REFERENCES (continued)}

12. Proceedings of the Third Annual Thermal Energy Storage Contractors' Information Exchange Meeting, U.S. Department of Energy, Springfield, Virginia, December 5-6, 1978. To be published as NTIS Report Nos. CONF-781231.

13. Maru, H.C., et al. Molten Salt Thermal Energy Storage Systems. Institute of Gas Technology, Chicago, Illinois, March 1978. NTIS Report No. COO-2888-3.

14. Asselman, G.A.A. "Design Considerations on a Thermal Energy Storage Stirling Engine Automobile." International Automotive EngIneering Congress, Society of Automotive Engineers, Detroit, Michigan, February 28 - March 4, 1977. SAE Paper No. 770080.

15. Proceedings of the Second Annual Thermal Energy Storage Contractors' Information Exchange Meeting, Energy Research and Development Administration, Gatlinburg, Tennessee, September 29, 1977. Published as NTIS Report Nos. CONF-770955.

16. Gintz, J.R. Technical and Economic Assessment of Phase Change and Thermochemical Advanced Thermal Energy Storage (TES) Systems. Report prepared by Boeing Engineering and Construction for Electric Power Research Institute, December 1976. Report No. EPRI-EM-256.

17. Ervin, G. "Solar Heat Storage Based on Inorganic Chemical Reactions." Solar Energy Storage Subsystems for the Heating and Cooling of Buildings, Workshop Proceedings, Charlottesville, Virginia, April 16-18, 1975. NTIS Report No. PB 252-449.

18. Fischer, H.C., et a1. The Annual Cyclc Energy System: Inillal Investigations. Oak Ridge National Laboratory, October 1976. NTIS Report No. ORNL/TM-5525.

19. Minturn, R., Oak Ridge National Laboratory, Oak Ridge, Tennessee. Personal communications. February 28, 1979.

20. Thermal Energy Storage in Aquifers, Workshop Proceedings, Berkeley, California, May 10-12, 1978. NTIS Report No. CONF-7805140.

21. Davison, R.R., et al. "Storing Sunlight Underground - The Solaterre System." Chemica1 Technology 5:736, December 1975.

22. Berlad, A.L., et al. Enthalpy Management in Bulldings: An Analysis and an Integrated Approach. Brookhaven National Laboratory, July 197.5. NTIS Report No. BNL 20572. 
REFERENCES (continued)

23. Duffle, J,A., et al. Solar Energy Thermal Processes. New York: John Wiley and Sons, 1974.

24. Charoudi, D. "Thermocrete and Thermotile Components with Isothermal Heat Storage." Second Annual Proceedings of Thermal Energy Storage Contractors' Information Exchange Meeting, September 1977. NTIS Report No. CONF-770955.

25. Wessling, Jr., F.G. Thermal Energy Storage in Adobe and in Stone Structures. American Society of Mechanical Engineers. 1974. ASME Paper No. 74-WA/HT-15.

26. Szego, G.C. "Hot Water Storage Systems Group Report." Solar Energy Storage Subsystems for the Heating and Cooling of Bulldings, Workshop Proceedings, Charlottesvilie, Virginia, April 16-18, 1975. NTIS Report No. PB 252449.

27. Cook, R.E., et al. "Concept and Development of a Residential Ice Storage System." ASHRAE Transanctions 83(Part 1):687, 1977. 


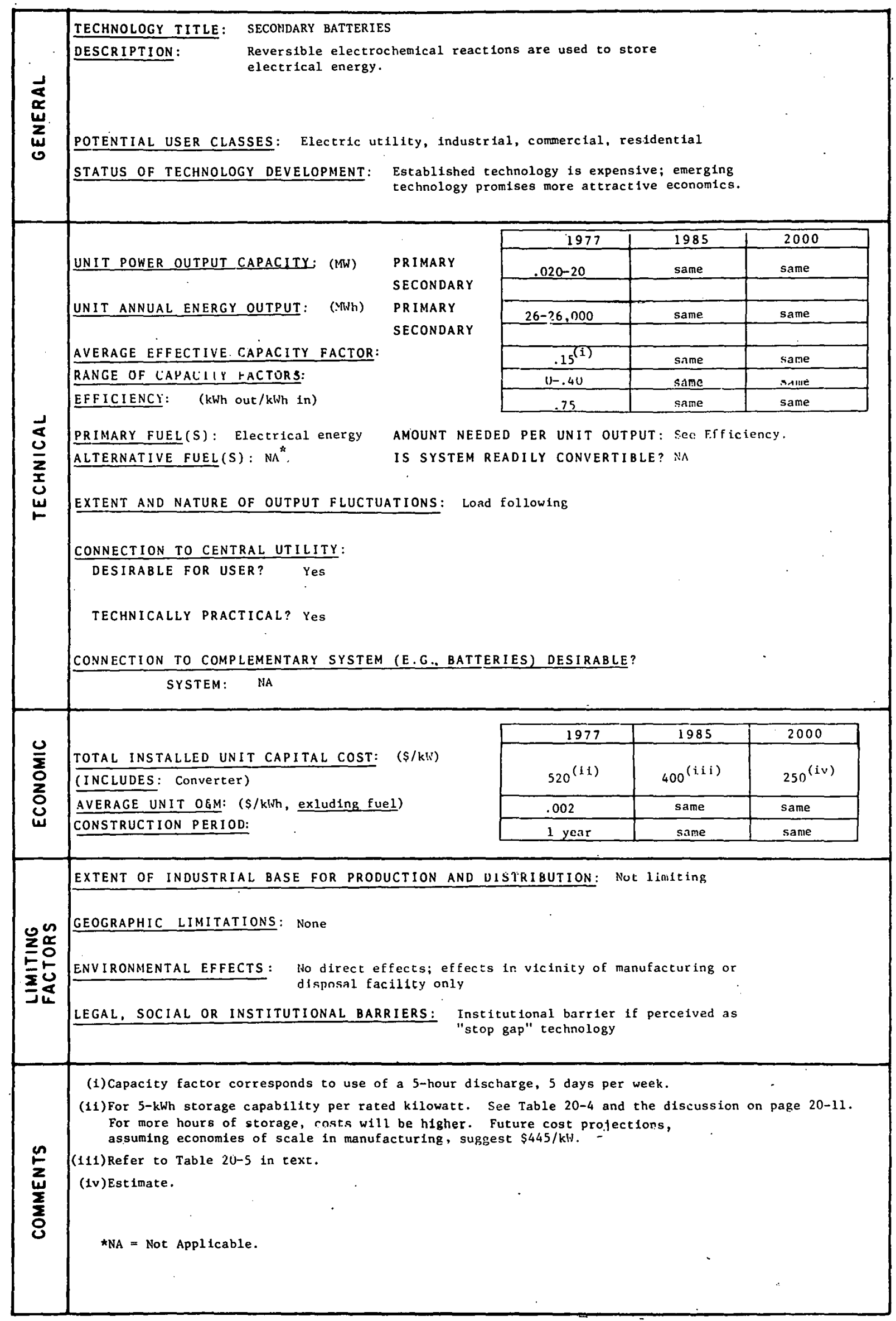


CHAPTER 20

SECONDARY BATTERIES

Section 20.1: Introduction

Batteries constitute a complementary technology in the concept of distributed energy systems (DES). They can assist in the more effective use of centrally generated electrical power by load leveling or peak shaving. Also, they are an almost essential component of distributed primary generating systems, such as photovoltaic arrays or windmills, that operate on a variable or intermittent basis. Batteries can also assist dispersed primary generators to meet peak demands above the generator's rated power capability.

The manufacture of batteries based on the lead-acid system is a long established technology that is avallable today. However, the industry has little experience in bullding the very large batteries contemplated for load leveling (that is, routine deep discharge).. Very large emergency power systems, designed for occasional deep discharge, have been very carefully designed and engineered for our telephone systems. (1) In anticipation of the need for batteries for load leveling, five major U.S. companies have developed detailed cost and design studies $(2,3,4,5,6)$ geared to the production of large lead-acid batteries. The lead time to full-scale production is estimated to be two to three years from the time of the decision to go ahead. New battery systems, described later, are also at the engineerIng stage. (A compendium of these activities and the level of effort in each has been published. (7)) The preferred systems will probably require 10 years to reach large-scale production.

Secondary batteries (that is, batteries used to store energy produced elsewhere) have no immediately discernible environmental impact in operation, but there are many safety factors that require special attention.

(8) 


\section{Section 20.2: Technica1 Discussion}

Batteries are familiar devices that can store electricity as chemical energy. In a primary battery, for example, a flashlight battery, electrical energy is derived from packaged chemicals in an irreversible discharge process. In a secondary battery, such as a car battery, the chemical reactions can be reversed after discharge by returning electrical energy to the ce11. To be a useful storage device for DES applications, the secondary battery should be capable of being charged and discharged many times. (With rare exceptions, for example, military applications, primary batteries are small and may be disregarded in any analysis of DES.) This discussion is restricted to those battery systems that can meet, or be expected to meet, certain performance and cost gnals, The numbers presented refer specifically to such systems and should not be compared to similar battery systems designed for other applications.

The, general objectives for the system are as follows:

- Low cost,

- long life (number of cycles and calendar life),

- high efficiency (ratio of Watt-hours delifuered to Watt-hours required to charge),

- high energy density (measured as $\mathrm{kWh} / \mathrm{ft}^{3}$ or $\mathrm{kWh} / \mathrm{ft}^{2}$ of floor space), and

- hign power density (the capability to deliver the stored energy at the maximum demand rate).

The goals that are generally used ${ }^{(9)}$ are for a compact system, capable of more than 2000 cycles at a five-hour discharge rate (to $20 \%$ rated capacity) and 200 cycles/year at a cost of between $\$ 20$ and $\$ 30 / \mathrm{kWh}$ of storage capacity.

The efficiency and cycle life are very much a function of the pattern of use, primarily rate of charge and discharge, depth of discharge, and the extent of routine overcharge. (This is true for all secondary batteries, regardless of application.) The definitions of energy and power densities 
of a battery designed for energy storage require spectal comment. Conventionally, batteries are compared on a specific volume basis, but because of the large floor area involved in even a moderate size energy storage system, the footprint $\left(\mathrm{kWh} / \mathrm{ft}^{2}\right)$ becomes important. One technical tradeoff is between the smaller cells (say, $5 \mathrm{kWh}$ ) that can be moved for maintenance purposes with a forklift truck, and can therefore be stacked in tiers, and the large cells that offer some economy of scale, but require an overhead crane to be moved and cannot be stacked. This factor explains the range of cell sizes, $5 \mathrm{kWh}$ to $125 \mathrm{kWh}$ for the leadacid battery system in Table 20-1.

The battery systems under Immediate consideration for energy storage are listed in Table 20-1. The engineering development work is directed at producing units with megawatt hours of storage capacity that will meet the requirements of the electric utilities in load leveling. For DES, this means a range from a typical substation capability to deliver 40 megawatts down to smaller units rated at hundreds of kilowatts.

The smallest installation compatible with present demands (such as a photovoltaic array) io approusimately $60 \mathrm{kWh}$. For special circumstances, a 20-kWh battery might suffice. From Table 20-1, it is apparent that the lead-acid battery is the on $1 y$ system that can make a contribution in the immediate future. The zinc-chlorine cell, which also operates at ambient temperature, ${ }^{*}$ is a reasonable candidate for DES. Again, there is no depth of experience in the large-scale production or operation of this system. The sodium-sulfur ${ }^{* *}$ cell depends on a conductive ceramic as the electrolyte, which limits the profected size of Individual cells to less than $0.5 \mathrm{kWh}$. However, the degree of reliability in the manufacture of the ceramic electrolyte is such that large batteries can be expected to be built, and will be avallable in the mid 1980's. The 1ithium-iron sulfide

* A summary of the physical and performance characteristics of each of the cells listed in Table 20-1 is presented later in this chapter as Table 20-3.

** Development of the sodium antimony chloride cell which also uses a Beta-alumina electrolyte has recently been abandoned. 
TABLE $20-1$

SECONDARY BATTERIES FOR DISTRIBUTED ENERGY SYSTEMS

\section{Current Status}

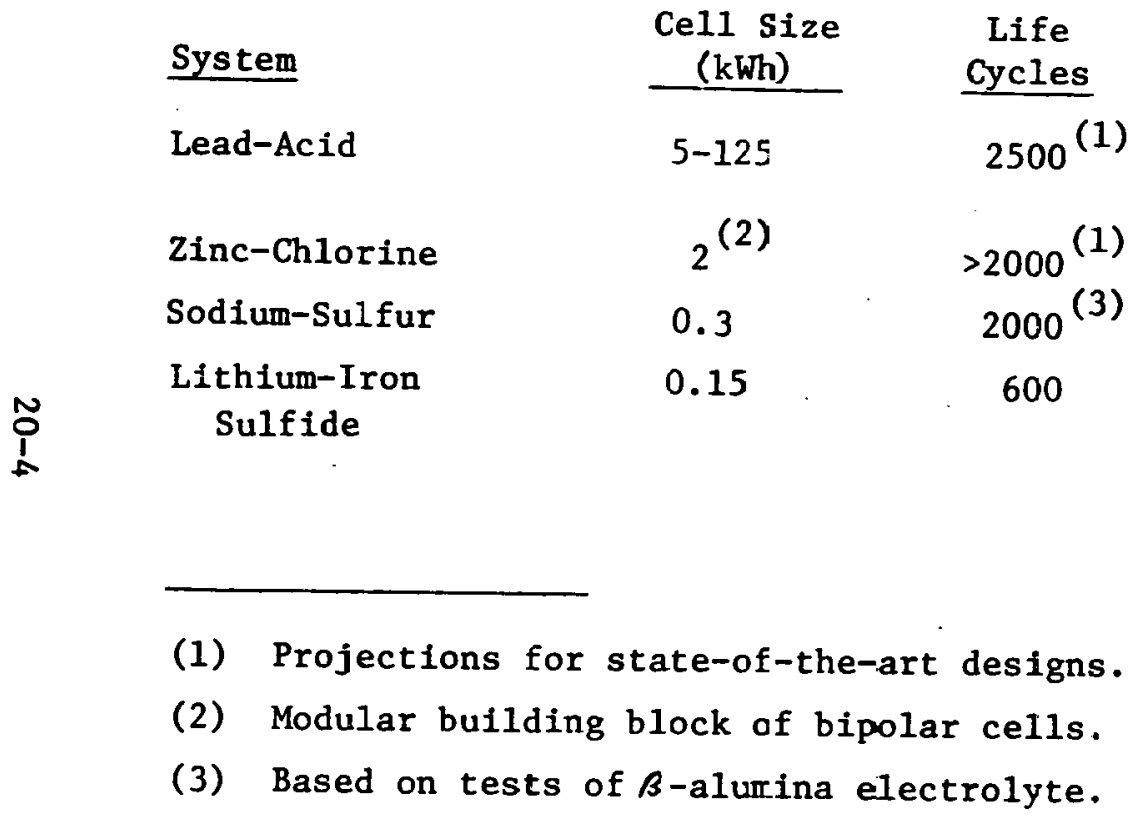

SOURCE: References 2, 3, 4, 5, 6, 7, and 8 . 
cell is being studied extensively.

The primary problems are with materials of construction, but it is anticipated that these problems will be solved and that production of large batteries will be possible by the mid-1980's. (7)

Immedlate opportunities are, therefore, limited to the lead-acid

system. Five manufacturers have carried out design (and cost) studies (2, $3,4,5,6)$ on lead-acid batteries intended specifically for the largescale storage of electrical energy. A description of each design is given in the references cited above; a comparison of the individual specifications has also been made. (8) A summary is given In Table 20-2; the principal variation 1 s in individual cell size and the influence this has on the footprint. The gravimetric energy density is low, but technically this is of minor importance from the standpoint of DES. However, since the bulk of the weight is due to the lead, the ultimate cost (discussed in the next section) is affected and is very sensitive to the price of lead.

The prime reason for developing new secondary batteries is to reduce the capital cost and to increase cycle life. A summary of the characteristics of the various candidates is presented in Table 20-3 and a discussion of their special problems follows.

The zinc-chlorine battery has an aqueous electrolyte which is recirculated through the cell at ambient temperatures. Chlorine generated during the charging process is carried by the electrolyte to a chiller, where it forms solid chlorine hydrate. The hydrate requires only slight refrigeration to provide convenient storage for the chlorine. For discharge, the hydrate is warmed to liberate chlorine. Principal problems are the control of electrolyte flow, achieving simplicity in the ancillary equipment, and the minimization of the parasitic pumping and refrigeration loads.

The sodium sulfur battery depends on a $\beta$-alumina ceramic electrolyte and operates at temperatures ranging from $400-700^{\circ} \mathrm{F}$. The ceramic is made in tubular form; it is difficult to make and there is a limit to the size -- measured in tens of inches in height. This means that tens of thousands of tubes would be needed for 
TABLE 20-2

IEAD/ACID BATTERY CELL SPECIFICATIONS (1)

\section{Specification}

Capacity (kWh at 5 - hr rate)

Gravimetric Energy Density (Wh/1b)

Footprint (kWh/ft$\left.{ }^{2}\right)$

Lead Weight $(1 \mathrm{~b} / \mathrm{Wh})$

\begin{tabular}{lcl}
\multicolumn{4}{c}{ Manufacturers } \\
\hline$\underline{C E D}^{(2)} \quad \underline{E S B}^{(2)}$ & $\underline{\text { Globe-Union }} \quad$ Gouid & Westinghouse
\end{tabular}

$\begin{array}{rrrrr}17.9 & 18.2 & 36.9 & 128.0 & 5.19 \\ 9.0 & 8.6 & 8.0 & 8.8 & 10.3 \\ 5.2 & 5.5 & 2.4 & 6.2 & 4.5 \\ 62.2 & 76.7 & 63.8 & 60.3 & 70.7\end{array}$

ڤั

(1) For electric utility storage application.

(2) The C\&D Battery Division is part of the ELTRA Company; ESB is a division of the International Nickel Company.

SOURCE: References 7,8 , and 10 . 
TABLE 20-3

CHARACTERISTICS OF BATTERIES FOR DES

Energy and Power Densittes

\begin{tabular}{|c|c|c|c|c|c|}
\hline & $\begin{array}{l}\text { Operating } \\
\text { Temperature }\left({ }^{\circ} \mathrm{F}\right) \\
\end{array}$ & $\mathrm{Wh} / \mathrm{kg}$ & $\mathbf{W} / \mathbf{k g}$ & $\mathrm{kWh} / \mathrm{ft}^{3}$ & $\begin{array}{c}\text { Efficiency } \\
(\%)\end{array}$ \\
\hline Lead-Acid & Ambient & 20 & 45 & 1.0 & 70 \\
\hline Zinc-Chlorine & Ambient & 55 & 65 & 3.4 & 65 \\
\hline Sodium-Sulfur & 660 & 88 & 100 & 4.3 & 70 \\
\hline Lithium-Iron Sulfide & 800 & 88 & 66 & 2.8 & 75 \\
\hline
\end{tabular}

SOURCE: References 7, 8, and 11. 
a multi-MW capability, a factor that puts a severe strain on the reliability of a component already acknowledged to be difficult to manufacture.

The lithium-iron sulfide cells operate at very high temperatures -$800^{\circ} \mathrm{F} \mathrm{--}$ and at these temperatures there are severe problems. in corrosion of the cell container, breakdown of the separator between the plates, and breakdown of the insulators in the terminal feed-throughs. some $(12)$

It is anticipated that all the previously described problems, and for thelr solution are derived to a large extent, from other potential applications, such as electric vehicles, but the cost savings for DES could be significant, as is discussed in the next section.

Section 20.3: Economics Discussion

As cited earlier, detailed cost analyses $(2,3,4,5,6)$ for lead-acid batteries have been carried out by five companies for current technology. Their findings are summarized in Table 20-4. Note that these costs were derived using $26 \mathrm{c} / 1 \mathrm{~b}$ as the price of lead. Since approximately $30 \%$ of the cost of a lead-acid battery can be attributed to the lead content, the future price will be quite sensitive to any change in the price of lead (at $58 \mathrm{c} / 1 \mathrm{~b}$ in 1979 ).

For the other systems, the only figures available are cost goals, derived from raw material costs and assumptions on manufacturing costs in large quantities. Both sets of figures are presented in Table 20-5. A comparison of the two sets immediately points to the hasis for solection of other than the lead-acid system. The cost of advanced state-of-theart lead-acid batteries may be reduced to approximately $\$ 40 / \mathrm{kWh}^{(13)}$ in the early 1980's, and the newer systems would have to be significantly below this figure to warrant the investment in their engineering development. (It is for economic reasons, among others, that nicke1iron and nickel-zinc systems are excluded from energy storage applications, although they are under.active consideration for electric vehicles.*)

* The welght savings of the nickel-iron and nickel-zinc systems over leadacid are important for electric vehicle use, but are less Important in load-leveling applications. 
TABLE 20-4

ECONOMIC SPECIFICATIONS FOR LEAD-ACID BATTERIES DESIGNED FOR FIVE-HOUR DISCHARGE AT RATED POWER

(1) (in 1977 dollars)

\begin{tabular}{|c|c|c|c|c|c|}
\hline Specification & $C \& D^{(2)}$ & ESB & Globe-Union & Gould & Westinghouse \\
\hline Cost $(\$ / \mathrm{kWh})(3)$ & 55 & 56 & 58 & $54^{(4)}$ & 49 \\
\hline Life (cycles @ $77^{\circ} \mathrm{F}$ ) & 2000 & 2000 & 2000 & 2000 & $1750\left(95^{\circ} \mathrm{F}\right)$ \\
\hline Capital Cost/Cycle (mill/kWh) & 27 & 28 & 29 & 27 & 28 \\
\hline Efficiency $(\%)$ & 73 & 76 & 72 & 70 & 68 \\
\hline Replacement Price $(\$ / \mathrm{kWh})$ & 40 & 32 & 38 & 25 & 34 \\
\hline Maintenance Cost (mills $/ \mathrm{kWh}$ ) & 0.28 & 0.18 & NA & NA & NA \\
\hline
\end{tabular}

(1) For utility applications.

(2) Based upon $85 \%$ depth of discharge to achieve 2000 cýcles instead of $95 \%$ depth of discharge to achieve 1250 cycles at a price of $\$ 29 / \mathrm{kWh}$.

(3) Assumes $26 c / 1 b$ lead.

(4) Installed cost.

(5) Includes inversion efficiency of $90 \%$.

*NA $=$ Not Available.

SOURCE: Reference 8. 
TABLE 20-5

GUIDE TO COSTS FOR BATTERY ENERGY STORAGE

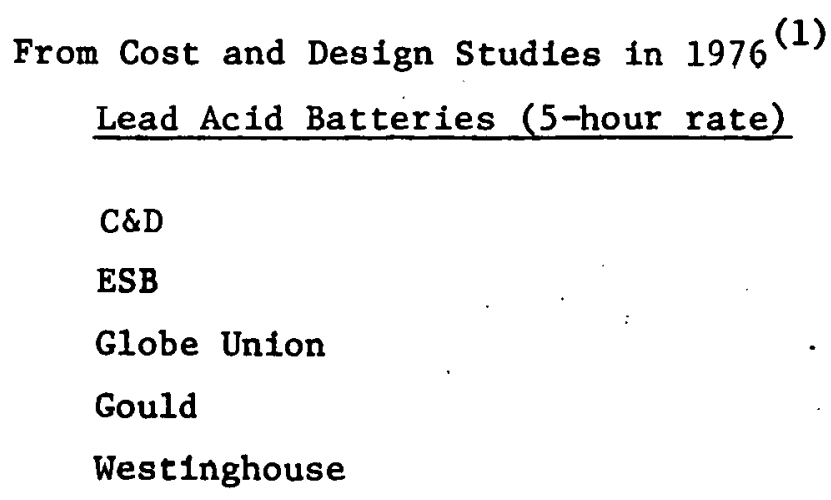

$\$ / \mathrm{kWh}$ (1977\$)

55

56

58

54

49

Cost Goals for 1985 in $1977 \$^{(2)}$
Zinc-Chlorine

EDA

$15-40$

Sodium-Sulfur

Dciw

$15-30$

Ford Motor Co.

$15-30$

General Electric

$15-30$

Lithium-Iron Sulfide

ANL

20-30

General Motors

20

SOURCE: (1) From Reference 14.

(2) From Reference 7 . 
The replacement costs, as 1 isted in Table $20-4$, could be as low as $\$ 25 / \mathrm{kWh}$ because of the intrinsic value of the lead. The situation could be quite different with the newer systems. Since they are essentially based on inexpensive and relatively abundant materials, solutions to the technical problems should lead to economically viable storage systems.

The cost of storage batteries per unit power capacity, $c(\$ / \mathrm{kW})$, is given by the expression,

$$
C=C_{s} T+C_{p}
$$

where $C_{S}$ is the cost per unit energy storage capacity $(\$ / \mathrm{kWh})$,

$T$ is the time (hrs) for which the battery can deliver rated power ( $T=5$ for a "five-hour battery"), and

$C_{p}$ is the "balance of plant" costs which include ac-dc power conversion, building, installation and site costs.

$r_{p}$ is typically about $\$ 245 / \mathrm{kW}^{(15)}$ so that if $C_{s}=\$ 55 / \mathrm{kWh}$ (Table 20-4), $c=\$ 520 / \mathrm{kW}$ for a five-hour battery.

Using these costs, one can calculate the costs of energy delivered by a storage battery discharged 5 hours per cycle, 260 cycles per year, and charged with inexpensive base load power. The results are presented in Table 20-6.

For utility-owned battery installations, several credits may be applied toward the computation of the delivered energy cost. These include:

- transmission and distribution savings (batteries located close to load center),

- reduction in spinning reserve requirements (when utility is servicing daily peak demand) and power production costs, and

- replacement capacity (capital cost of gas turbines). 
COSTS OF DELIVERED ENERGY FROM A

BATTERY STORAGE SYSTEM

(all costs in 1977 dollars)

Item

1. Capitai Cost $(\$ / \mathrm{kW})$

2. Fixed Charge Rate ${ }^{(1)}$

520.00

3. Annual Charge (no salvage) ( $\$ / \mathrm{kW})$

.2374

4. Salvage Credit ${ }^{(2)}(\$ / \mathrm{kW})$

123.00

5. Total of Annual Fixed Charges $(\$ / \mathrm{kW})$

15.00

6 . Annual Hours of Operation (3)

108.00

7. Energy Cost due to Fixed Charges $(\$ / \mathrm{kWh})$

1300

8. Maintenance ${ }^{(4)}(\$ / \mathrm{kWh})$

$.083($ ine $5 \div 1$ ine 6 )

9. Range of Basic Charging Energy Costs $(\$ / \mathrm{kWh})$

.002

.006 (nuclear)

.020 (coal)

10. Actual Charging Energy Required ${ }^{(5)}\left(\$ / \mathrm{kWh}_{\mathrm{n}}\right)$

.008 (nuclear) .027 (coa 1 )

11. Total Energy Cost ( $\$ / \mathrm{kWh})$

$.083+.002+(.008$ to .027$)$

12. Range of Delivered Energy Cost ( $\$ / \mathrm{kWh})$. .093 to .112

(1) Based on battery life of 5 years, $6 \%$ "cost of capilal" because constant ( $\$ 1977)$ dollars are used throughout.

(2) Assumes batteries represent $\$ 275 / \mathrm{kW}$ out of the $\$ 520 / \mathrm{kW}$, of which $30 \%$ is due to recoverable lead. Salvage value of $\$ 83 / \mathrm{kW}$ taken at end of 5-year life and converted to annual credit of $\$ 14.72$, or $\$ 15$.

(3) Assumes operation 5 days per week, 5 hours per day.

(4) Estinate based on Table 20-4.

(5) Because the system efficiency is $75 \%, 4 \mathrm{kWh}$ of charging energy are required. for $3 \mathrm{kh}$ h of output.

SOURCE: Arthur D. Little, Inc. calculation, based on data in text. 
Details of their significance and impact as they apply to a particular utility can be obtained from the analysis carried out by Johnson et a1. and updated by MITRE ${ }^{(15)}$ in 1978. They calculate total credits of up to $\$ 405 / \mathrm{kW}$ toward installed costs of $\$ 445 / \mathrm{kW} *$ The resulting net cost of $\$ 40 / \mathrm{kW}$ is very sensitive to the nature of the assumptions made in calculating the credits.

When battery storage is used in support of a remote primary generator, the cost and benefits of each system must be analyzed on an individual basis. For example, the option of battery storage in a photovoltaic system is discussed in Chapter 2 .

Section 20.4: Limitations

From a technical viewpoint, secondary batteries can play a role In DES in the immediate future. However, the economic penalties of. adding an energy storage system to a primary energy generator are very large. These penalties are tolerable in remote lccations and can be offset to some extent when used in an existing power distribution system. New technology, in the form of the zinc-chlorine cell and the high-temperature cells, looks as if it might reduce costs by ahout a factor of 2. Although this is significant, the battery storage system remains an expensive component. This is particularly true when it is realized that batteries continuously degrade in capacity and efficiency during their lifetimes so that overdesign is needed initially.

Further limitations might be site-specific, for example, lack of floor space, climate, accessibility for required maintenance, and lack of skilled personnel.

Some account must also be taken of possible poor acceptance of the concept of a decentralized energy installation with the additional complexity of a large storage battery. Also, because of the demands for capital, the major battery manufacturers might limit their investments to meet the premium priority needs of the electric utilities and not provide production capabilities for a more wide-reaching market.

\footnotetext{
* Based on expected future costs of $\$ 40 / \mathrm{kWh}$ as a result of 1 arge-scale manufacturing economies.
} 


\section{THIS PAGE}

\section{WAS INTENTIONALLY \\ LEFT BLANK}




\section{REFERENCES}

1. "Twelve Papers on the Development of Reserve Batterles for Bell System Use." Bell Techntcal Journal 49:1249, 1970.

2. Westinghouse Electric Corporation. Study of the Manufacturing Costs of State-of-the-Art Lead Acid Batteries for Peaking Power. Prepared under Contract No. E949-180-2114 for Energy Research and Development Administration, December 1977.

3. ESB Incorporated. Design and Cost Study for State-of-the-Art Lead Acid Load Leveling and Peaking Batteries. Prepared for Electric Power Research Institute, February 1977. EPRI Report No. EPRI EM-375.

4. Hellman, E.V. "Lead-Acid Battery Design for Electric Utility Load Leveling." Lead-Acid Batteries for Utility Application: Workshop II. March 1977. Electric Power Research Institute Special Report No. EPRI EM-399-SR. pP. $113 \mathrm{ff}$.

5. Boden, D.P. "A New Lead-Acid Battery for Utility Peaking." Lead-Acid Batteries for Utility Application: Workshop II. March 1977. Electric Power Research Institute Special Report No. EPRI EM-399-SR. Pp. $127 \mathrm{ff}$.

6. Towle, W.L. "Lead-Acid Cell of High Performance for Utility Networks." Lead-Acld Batteries for Utility Application: Workshop II. March 1977. Electric Power Research Institute Special Report No. EPRI EM-399-SR. pp. $145 \mathrm{ff}$.

7. Nelson, P.A. "Comparison of U.S. and European High Temperature Battery Program." Proceedings of the Symposium and Workshop on Advanced Battery Research and Design, Argonne, Illinois, March 22-24, 1976. NTIS Report No. ANL-76-8. pp. A99 ff.

8. B1rk, J.R. "The Lead-Acid Battery for Electric Utilities: A Review and Analysis." Lead-Acid Batteries for Utility Application: Workshop II. March 1977. Electric Power Research Institute Special Report No. EPRI EM-399-SR. pp. $163 \mathrm{ff}$.

9. Cairns, E.J., et al. "High Temperature Batteries." Proceedings of the Symposium and Workshop on Advanced Battery Research and Design, Argonne, Illinois, March 22-24, 1976. NTIS Report No. ANL-76-8. pp. A $81 \mathrm{ff}$.

10. Stolte, W.J. "An Engineering Study of a 20 MW Lead-Acid Battery Energy Storage Demonstration Plant." Lead-Acid Batteries for Utility Application: Workshop II. March 1977. Electric Power Research Institute Special Report No. EPRI EM-399-SR. pp. 329 ff. 
11. Symons, P.C. Development of High-Efficiency Cost-Effective ZincChlorine Batteries for Utility Peak-Shaving, 1976. Report prepared by Energy Development Associates for Electric Power Research Institute, March 1978. Interim Report No. EPRI-EM-711.

12. Murie, R.A. "Post Test Analysis of Lithium Iron Sulphide Compact Cells." Proceedings of the Twelfth Intersociety Fnergy Conversion Engineering Conference, Washington, D.C., August 28 - September 2, 1977. Pp. $349 \mathrm{ff}$.

13. Johnson, A.C., et al. "Economic Assessment of the Utilization of Lead-Acid Batterles in Electric Utility Systems." Lead-Acid Batteries for Utility Application: Workshop II. March 1977. Electric Power Research Institute Special Report No. EPRI-EM399-SR. PP. $4 \mathrm{ff}$.

14. Smith, J.C. "Summary Economic Comparisons." Lead-Acid Batteries for Utility Application: Workshop II, March 1977. Electric Power Research Institute Special Report No. EPRI EM-399-SR. pp. $349 \mathrm{ff}$.

15. Davis, F., et al. Lead-Acid Battery: An Evaluation of Commercialization Strategies. Report prepared under Contract No. EC-77-C-015025 by METREK Division of MITRE Corporation for U.S. Department of Energy, November 1977. 


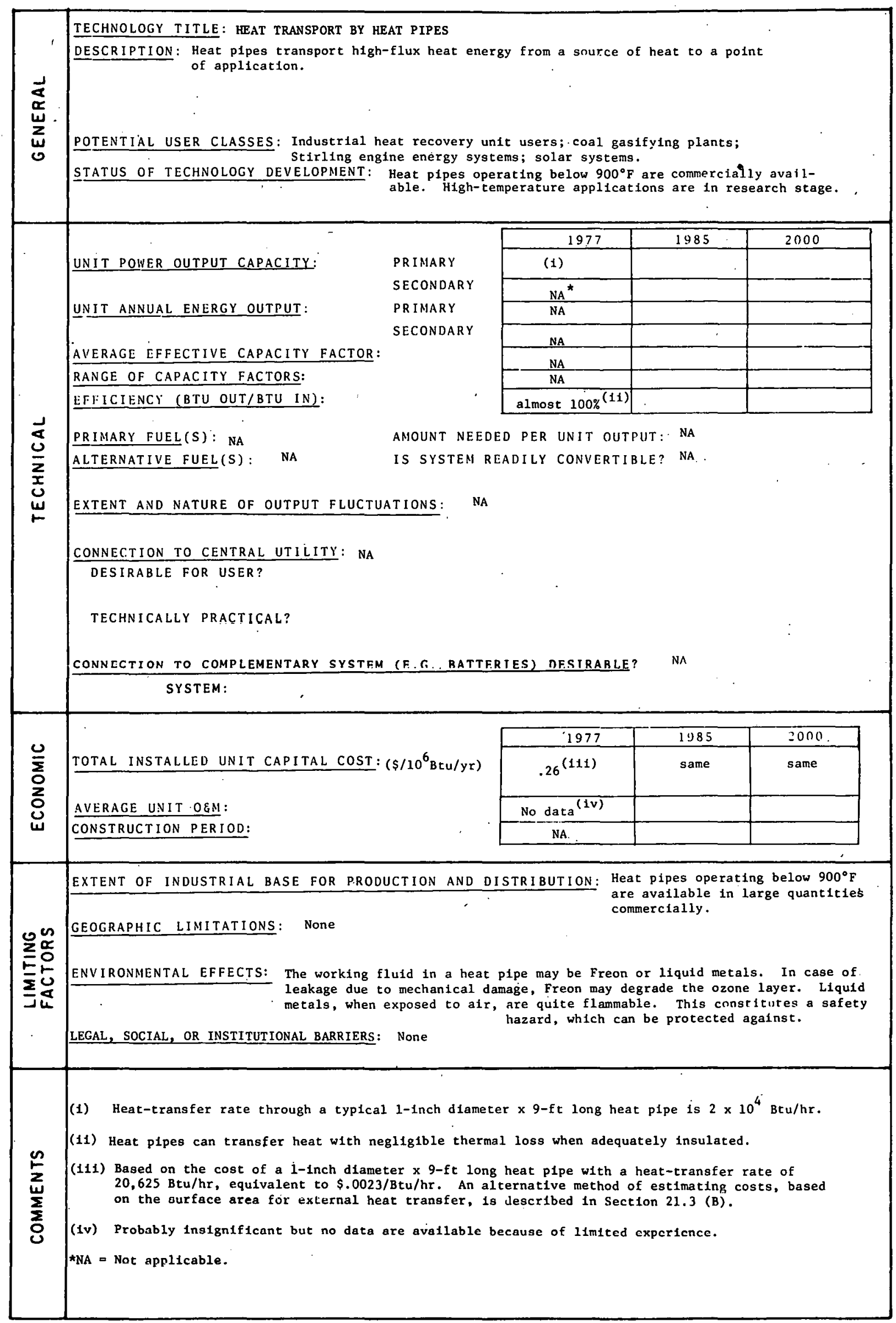


CHAPTER 21

HEAT TRANSPORT BY HEAT PIPES

\section{Section 21.1: Introduction}

A heat pipe is a device that transports heat energy from one point to another through a pipe. Heat flux through a heat pipe can be a thousand times more than that through a solid copper conductor of the same diameter, since the heat-transfer mechanism is the evaporation and condensation of a fluid with high latent heat. This very high effective thermal conductivity makes heat pipes very valuable tools in a varlety of distributed energy system applications.

The heat pipe consists of a sealed pipe with a working fluid inside (Figure 21-1) contained under its own vapor pressure. When one end of the heat pipe is exposed to a higher temperature, fluid in contact with the heated wall absorbs heat and evaporates. The vapor then flows to the cooler end, where it rejects heat and condenses. The midsection of the pipe length is usually insulated. The condensed fluid returns to the evaporator section by gravity and/or by the capillary action of grooves, wicks, etc., along the pipe wall. The operation then repeats.

In addition to the advantage of very high effective thermal conductivity, heat pipes have the unique capability to function as thermal transformers. As such, heat can be supplied to the evaporator section at relatively low flux levels and rejected at the condenser at high flux levels (and vice versa). This characteristic permits the utilization of heat pipes for the thermal coupling of high heat-flux energyconversion devices, such as Stirling engines, to thermionic converter's with relatively low heat-flux flame-fired heat sources.

Other application areas for heat pipes have been solar collectors, hot water heaters, thermal control of spacecraft, cooling of electronic parts by non-metallic tubes, coal gasification, heat recovery from 


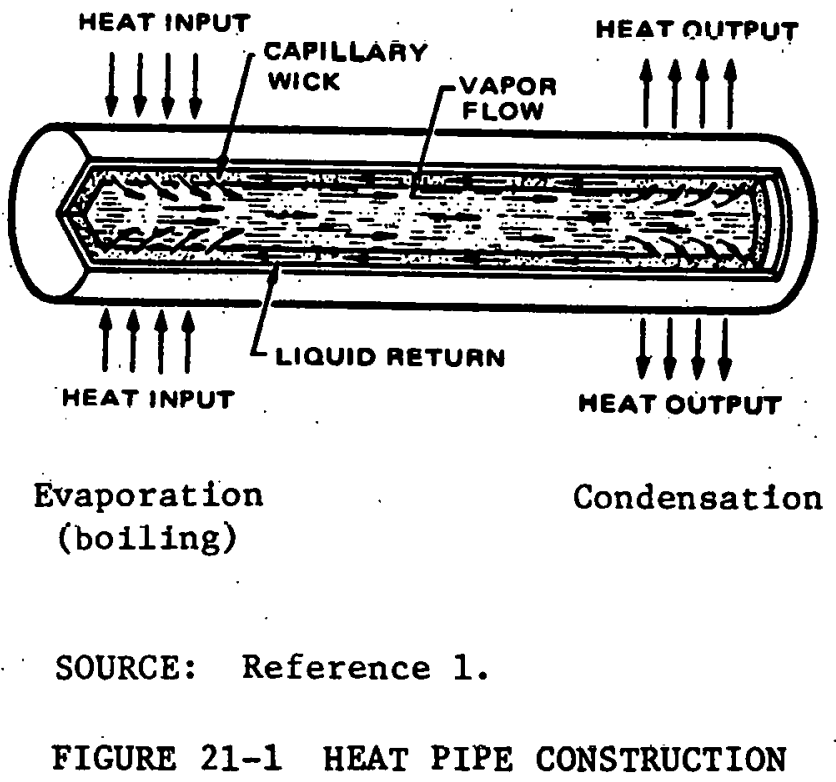


exhaust gases, and cryosurgery. $(2,3,4,5,6,7)$ The most widely publicized application $q f$ heat pipes has been in the Alaska pipeline, where they are used to keep support columns of above-ground pipelines colder than the permafrost ground so that the problems of thawing foundations and consequent weakening of support structures are eliminated. (8)

Section 21.2: Technical Discussion

\section{A. Heat Pipe Construction}

Heat pipes have three basic components: (1) the sealed tube, (2) the working fluid inside the tube, and (3) the wick structure, which helps return the working fluid from the condenser section to the evaporator section.

Selection of materials for these three parts depends on the requirements of a particular application. The main factors are:

(1) temperature of heat source, (2) temperature of heat sink, and (3) other operational requirements (exposure to flue gases, safety, heat-flux requirements, etc.).

Typical tube materials for lower-temperature applications are aluminum, copper, or steel. Special steel is used for temperatures in the vicinity of $1700^{\circ} \mathrm{F}$. Ceramic tubes are used for temperatures above $2700^{\circ} \mathrm{F} .{ }^{(9)}$ At the evaporator and condenser sections of the pipe, extended surfaces are of ten provided, as in conventional liquid-toair heat exchangers. At operating temperatures, the tube material must be compatible with the working fluid and the wick material. The tube must also be able to withstand the vapor pressure of the working fluid and not be subjected to stress-corrosion effects.

Some commonly used working fluids and their ranges of temperatures are given in Figure 21-2 and Tables 21-1 and 21-2. $(1,10)$ Working flulds should have a high latent heat, since boiling-condensation is the mechanism by which heat is transferred. They should have a low viscosity and a high surface tension, so that the condensate will return rapidly 


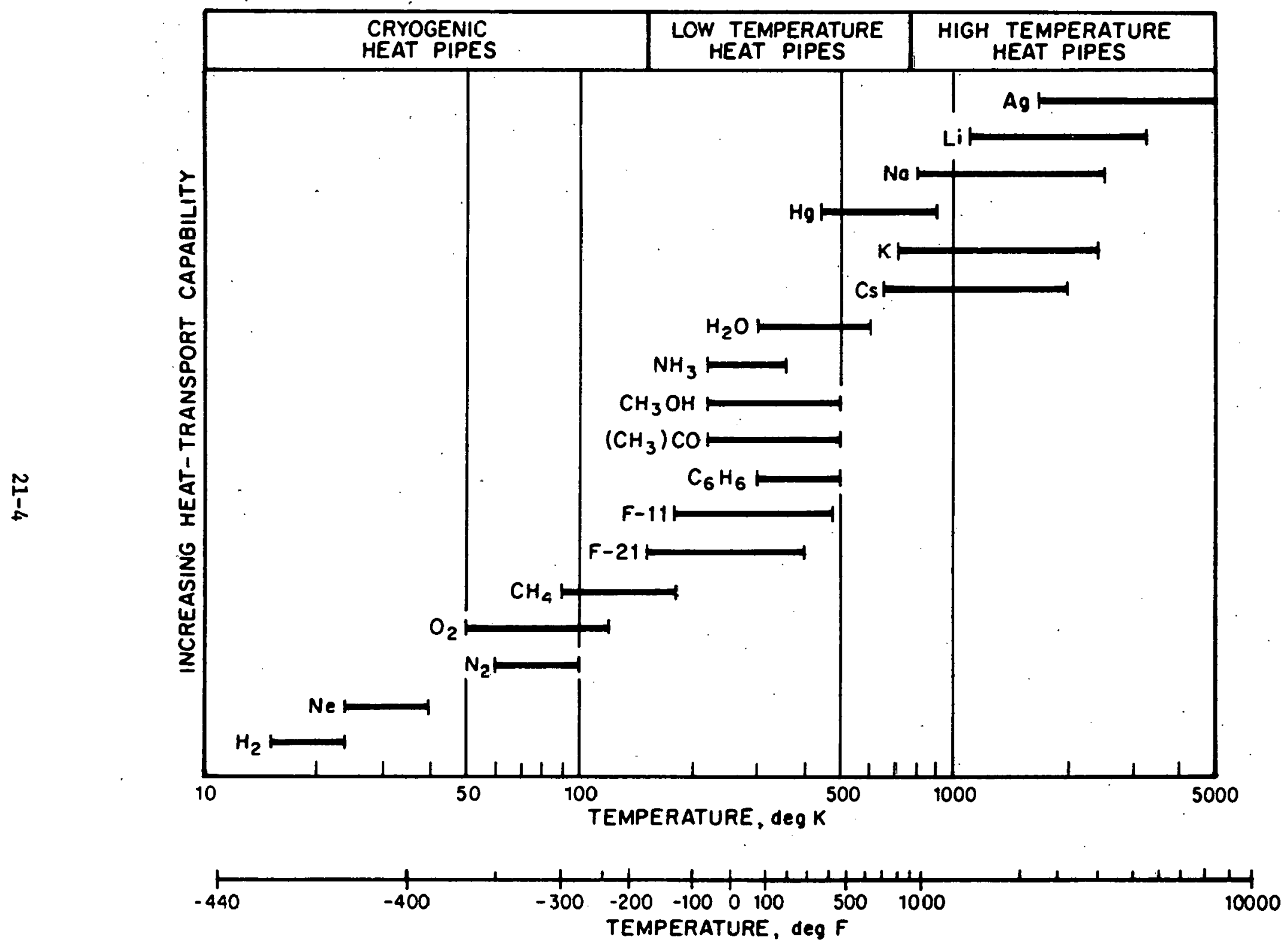

SOURCE: Reference 1.

FIGURE 21-2 TYPICAL TEMPERATURE RANGES FOR HEAT PIPE WORKING FLUIDS 
TABLE 21-1

PROPERTIES OF MOST COMMONLY USED HEAT PIPE WORKING FLUIDS

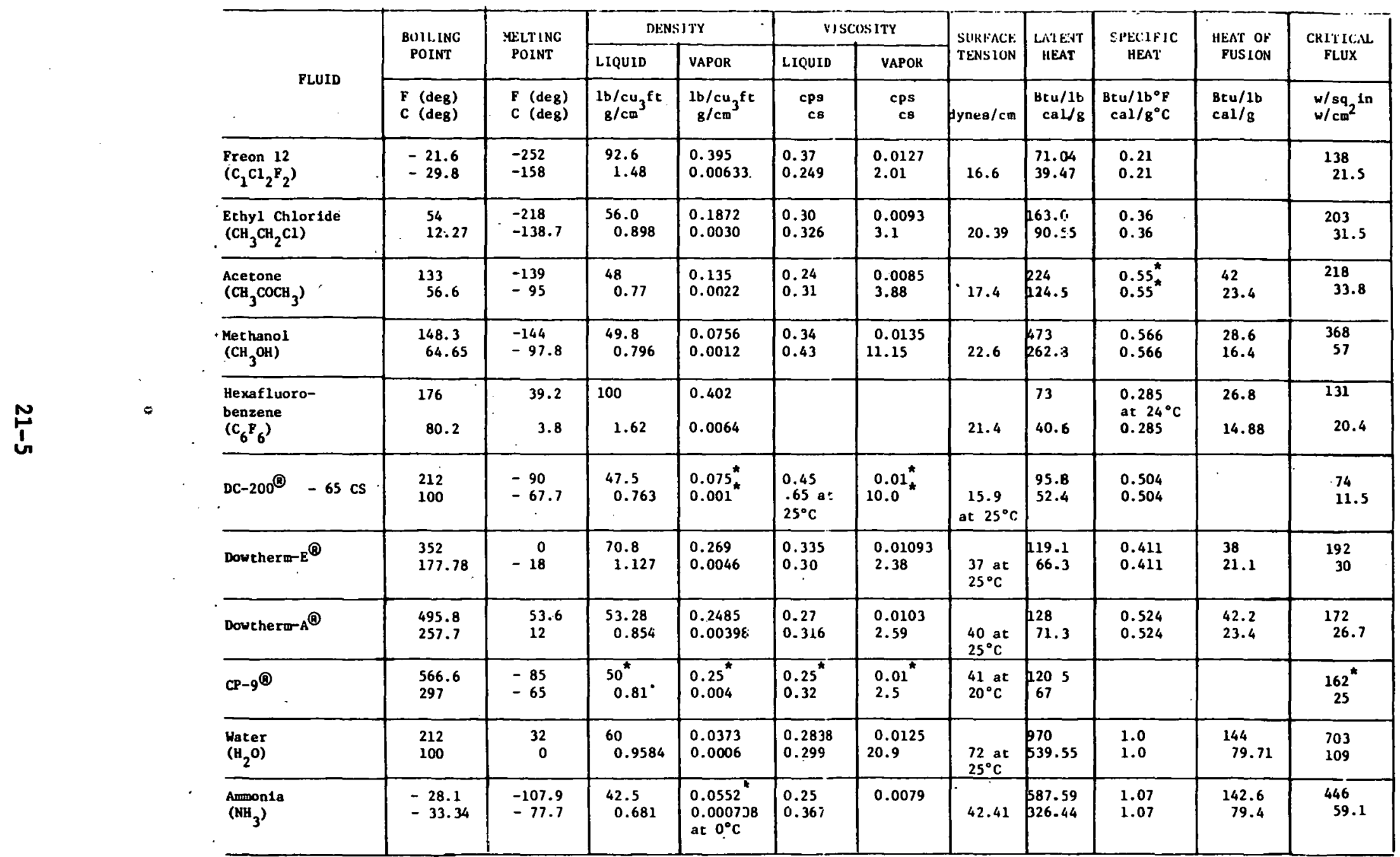

NOTES:

1. All values given at the Bolling point unless otherwise noted.

2. An asterisk indicates estimated or approximate values.

SOURCE: Reference 1 . 
TABLE 2I- 2

PROPERTIES OF LIQUID METAL WORKING FLUIDS

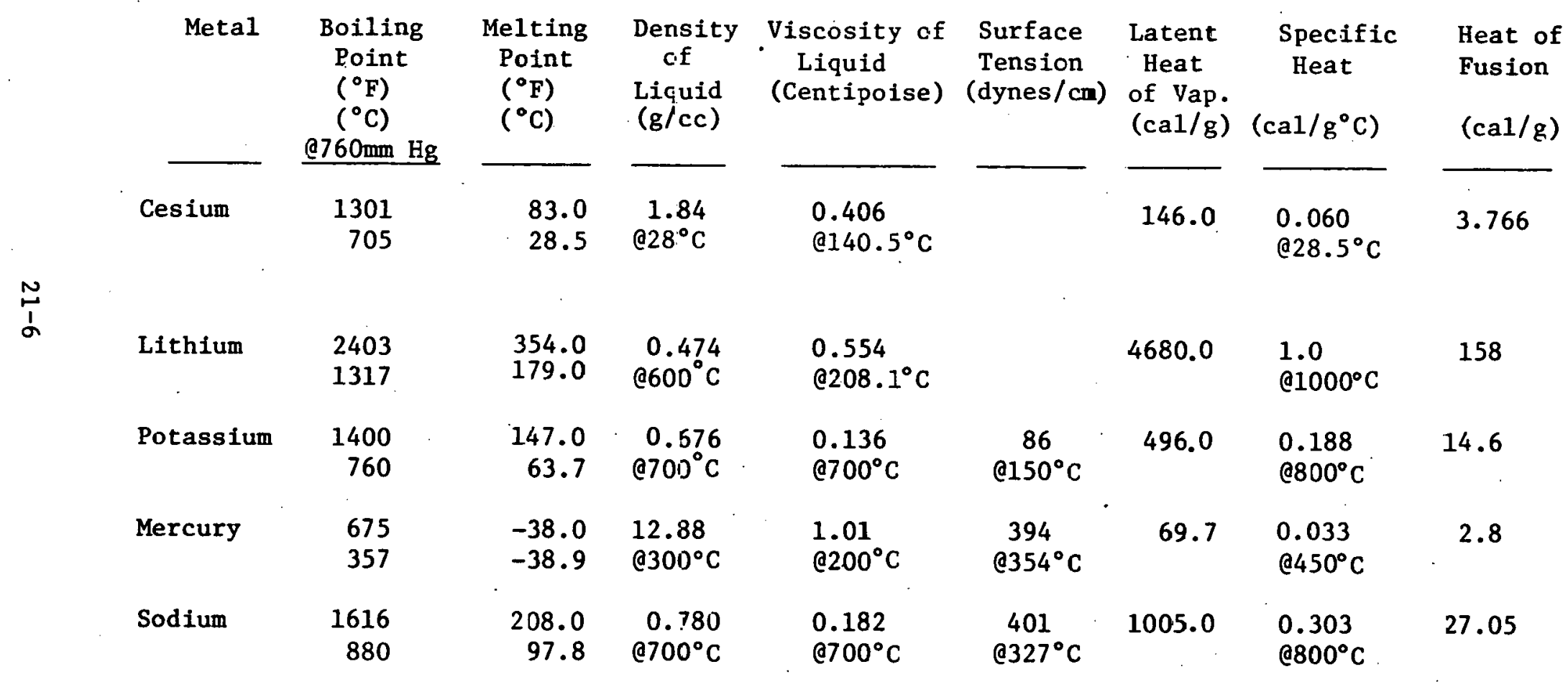

SOURCE: Reference 10. 
to the evaporation section by the capillary effect of the wick structure. In addition, the fluids must be chemically compatible with the tube and the wick materials. Finally, the fluid must be thermally stable at the operating temperature of the heat pipe.

Water is often considered as the working fluid at temperatures in the range of $150^{\circ} \mathrm{F}$ to $450^{\circ} \mathrm{F}$. (11) At lower temperatures the low vapor pressure of water leads to low heat-flux levels, while at higher temperatures the vapor pressure of water is excessive (for example, 680 psia at $500^{\circ} \mathrm{F}$ ). For temperatures in the $400-750^{\circ} \mathrm{F}$ range, various organic fluids, such as Dowtherm ${ }^{\circledR}$, can be utilized. lihe upper temperature limit for heat pipes with organic fluids results from the fact that these fluids tend to decompose at higher temperature levels. Varlous liquid metals such as sodium, potassium, and lithium can be used as the working fluids in heat pipe systems at higher temperature levels, 1.e., In excess of $1000^{\circ} \mathrm{F}$.

The temperature of the working fluid will be between that of the source and that of the sink, and is fairly uniform throughout the pipe. The "soak" temperature of a heat pipe is the maximum temperature to which it can be exposed on a continuous basis without damage to tube or fluid, when there is no heat removal at the condenser section. Usually the heat pipe design is chosen so that the source temperature is less than the "soak" temperature. However, there is often a significant temperature difference between the heat source (such as hot gas) and the wall of the heat pipe because of relatively low air-to-surface heat-transfer coefficients. Under these conditions, heat pipes can be used in heat sources above their "soak" temperatures if proper controls are used to remove the heat source should a malfunction result in an excessive temperature condition.

A wide varlety of wick configurations is avallable, including stainless-steel wire mesh, sintered metal, and grooves of various types in the tube wall (Figure 21-3). The primary requirement is that the wick return the 

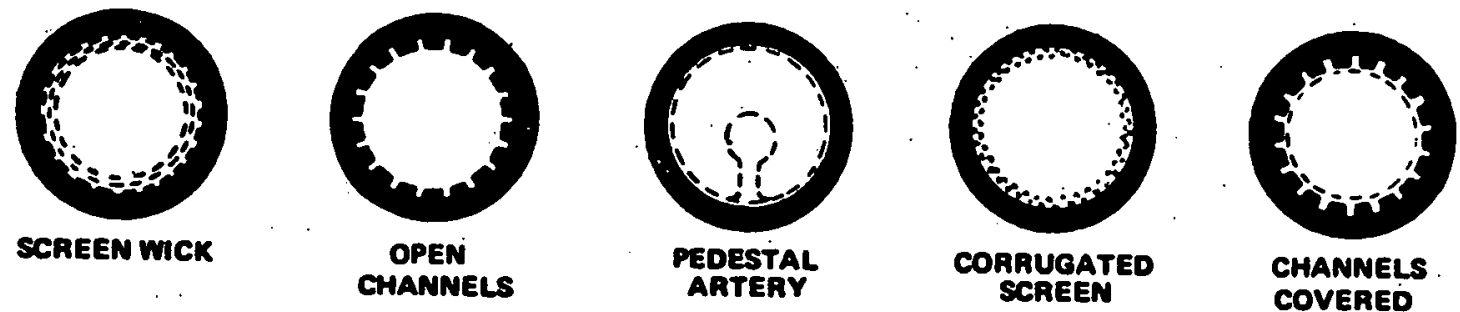

CHANNELS COVERED MTH SCREEN

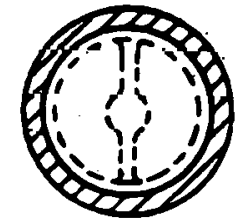

SCREW THREAD CAPILLARY MTH SCREEN ARTERY
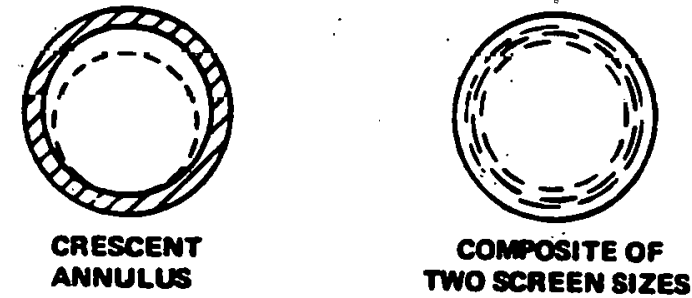

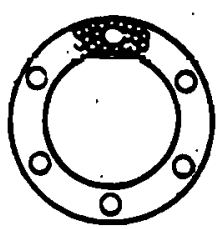

ARTERIES WITHIN SINTERED HOMOGENEOUS WICK

SOURCE: Reference 1.

FIGURE 21-3 TYPICAL HEAT PIPE WICK STRUCTURES 
condensate rapidly to the evaporator. Considerations in the selection of the wick type are compatibility with other materials, cost, and the ability to prevent entrainment of the condensate by the vapor stream moving in the opposite direction. Wicking capabilities have already been analyzed $(12)$ for various structures. This capability can be augmented further by wire cloth covers over the grooves.

Heat flux through a heat pipe depends upon the properties of the working fluid, e.g., viscosity, density, latent heat of evaporation, and pipe characteriscics such as inclination, diameter, and length, and the thermal resistance of the interface between the wick structure and heat pipe envelope. Heat flux along the heat pipe varies inversely with the effective transport length of the heat pipe. (12) A 40-ft long, 1inch diameter heat pipe with water as the working fluid can have a heat flux per unit cross-sectional area as high as $5500 \mathrm{Btu} / \mathrm{hr}-\mathrm{ft}^{2}{ }^{\circ} \mathrm{F}$ compared to $5.5 \mathrm{Btu} / \mathrm{hr}-\mathrm{ft}^{2}{ }^{\circ} \mathrm{F}$ for a $40-\mathrm{ft}$ long copper rod. ${ }^{(1)}$ Such high heat-f1ux rates are quite common in many heat pipe applications. For example, in the Alaska pipeline support structure, one 2-1nch diameter, 40-ft 1ong heat pipe transfers heat at a rate of $60,000 \mathrm{Btu} / \mathrm{hr}$ with only a few degrees temperature difference between the ends.

\section{B. Advanced Developments}

To extend the operating range of heat pipes, DOE is currently sponsoring a program at the Los Alamos Scientific Laboratory to develop a high-temperature heat pipe. ${ }^{(9)}$ The objective is to handle temperatures in excess of $2000^{\circ} \mathrm{F}$ for application in advanced high-temperature processes such as coal gasification. The design to be evaluated uses a ceramic tube lined on the inside with a thin coat of metal. The working fluid will be a liquid metal. Sodium and 11thium are two candidates for this purpose.

\section{Applications}

Heat pipes can be used in various distributed energy systems, such as the following: 


\section{Solar Collector}

Heat pipes have been considered for a variety of applications in solar collector systems where their operational simplicity and low temperature-drop heat-transfer characteristics can be used to advantage. In one such system, shown in Figure 21-4, the heat pipes are used to cransfer heat from parabolic solar collectors to the steam generators. $(11,13)$ Experiments have already been performed ${ }^{(11)}$ on such applications. Each heat pipe is made of 1-inch diameter, 17-ft long stalnless-steel tube; the evaporator section is about $13.5 \mathrm{ft}$ long and the condenocr section is $2.0 \mathrm{ft}$ long. The wick structure is made of 100-mesh, stainless-steel screen. Water is found to be a good working medium in this case. Heat pipes are also being considered to transfer heat from a flat-plate solar colliector to the circulatiug fluid in a solar heating system. (14)

\section{Stirling Englne Thermal Coupling}

Stirling engines (discussed in Chapter 14) are externally heated engines in which a gas (usually pressurized hydrogen or hellum) is used as a working medium. For high effictency, the heater head temperature of the engine is required to be quite high, typically $1200^{\circ}-1500^{\circ} \mathrm{F}$. They can, in principle, use any external heat source, e.g., coal-fired furnace, solar concentrators, combustion of lithium with sulfur hexafluoride, ${ }^{(15)}$ heat accumulators, ${ }^{(16)}$ etc. Heat pipes can be used to connect these or any non-conventional heat source to the Stirling engine. The heat pipe has particular advantages for such applications since it can recelve heat from the source at low intensity and delfver it at high intensity to the engine.

Figure 21-5 shows a schematic of one such application in which a heat pipe connects the Stirling engine to a fluidized-bed coal combustor acting às a heat source. (13) Maximum bed temperature is $1750^{\circ} \mathrm{F}$. Material for the heat pipe is stainless steel and the working fluid is sodium.

\section{Coal Gasifier}

In another high-temperature application, heat pipes can be utilized in indirect coal gasifiers, as shown in Figure 21-6, to obtain high-heat recovery efficiency along with other benefits. (6) The heat 


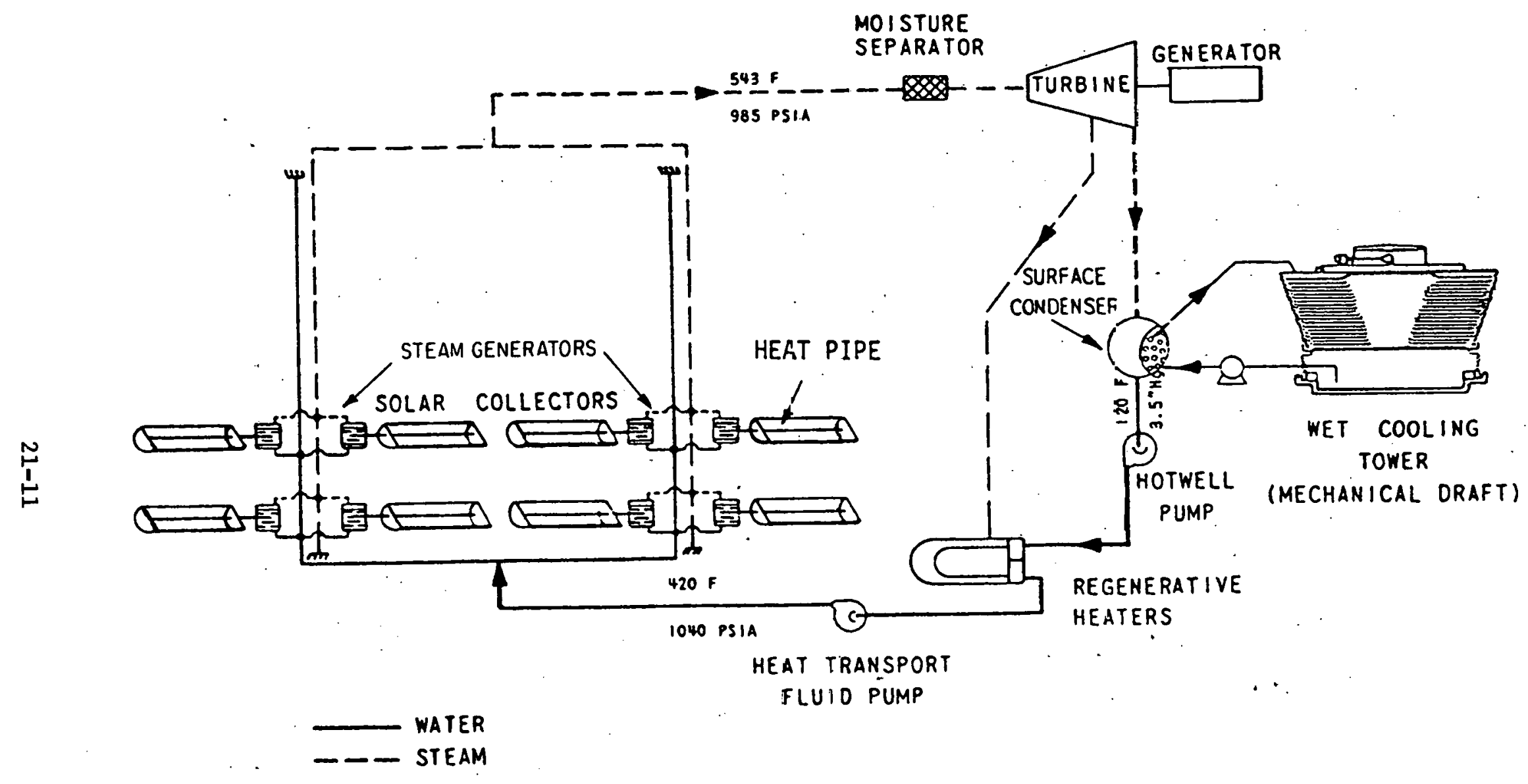

SOURCE: Reference 13.

FIGURE 21-4 HEAT PIPE IN PARABOLIC SOLAR COLLECTOR TRANSPORTS HEAT TO STEAM GENERATOR 


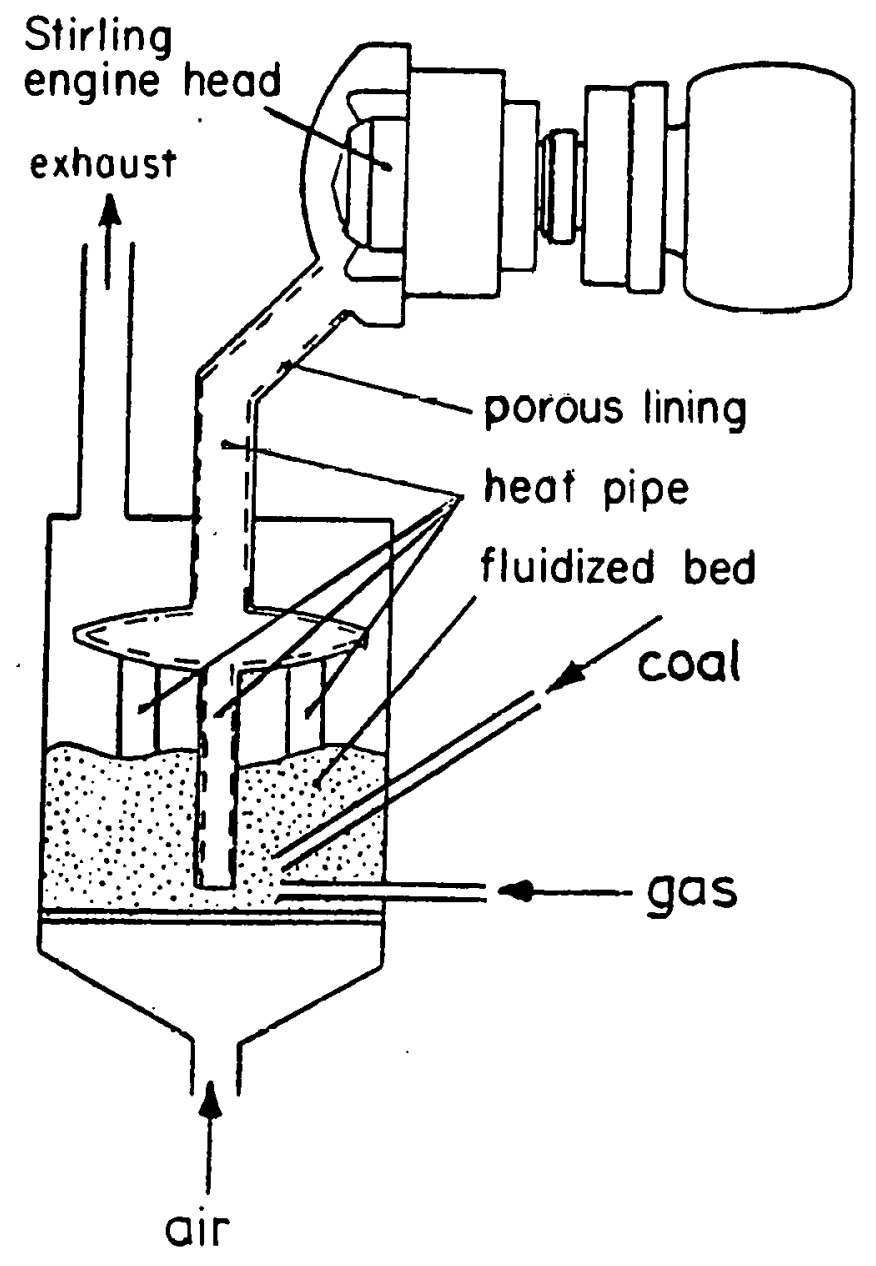

SOURCE: Reference 15.

FIGURE 21-5 A HEAT PIPE IS USED TO CONNECT A STIRLING ENGINE TO A FLUIDIZED-BED COAL COMBUSTOR 


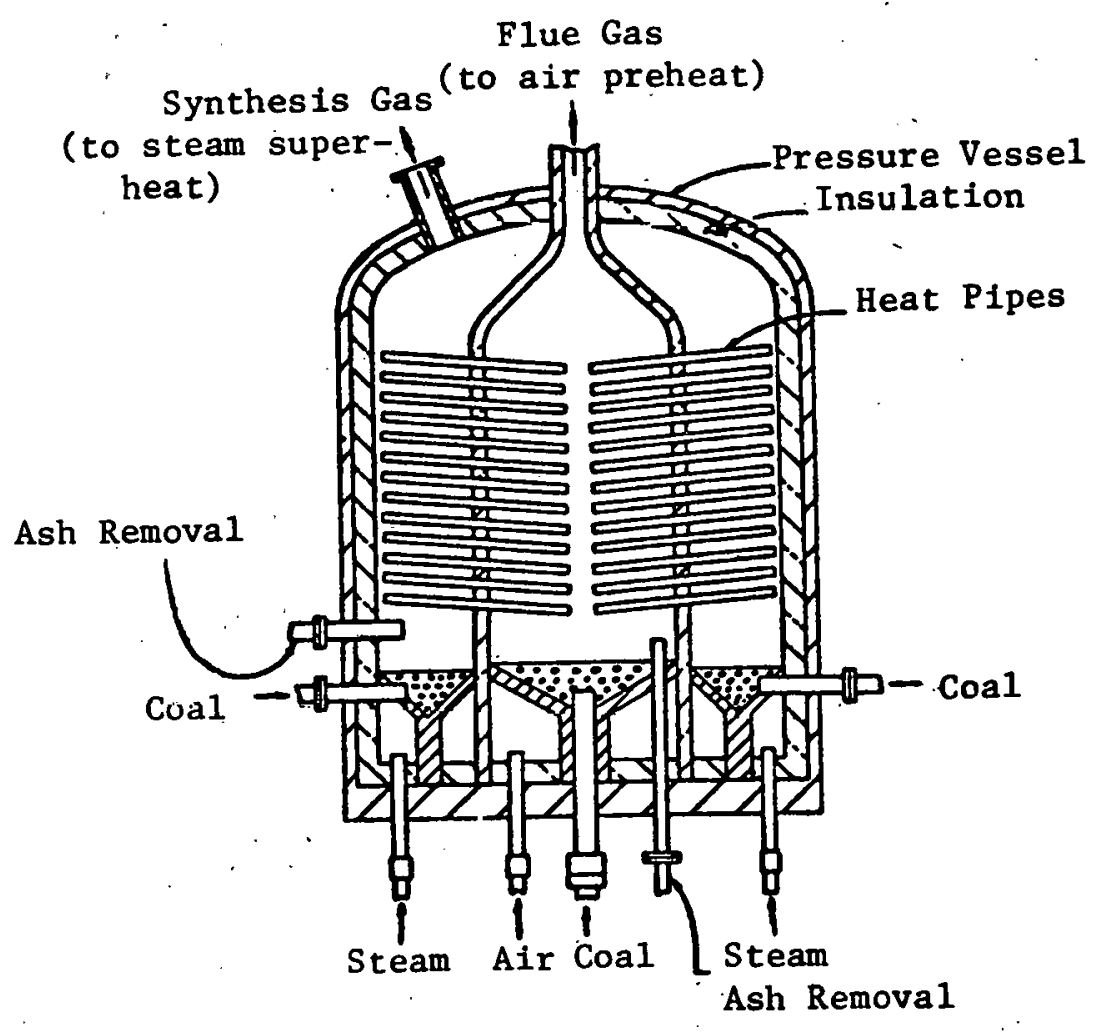

SOURCE: Reference 6 .

FIGURE 21-6 HEAT PIPES CONNECT CENTRAL COMBUSTION REGION TO CONCENTRIC HIGH-PRESSURE COAL-GASIFICATION REGION IN INDIRECT COAL GASIFIER 
plpes are shown with a slight tilt so that gravity can assist the return of condensed working fluid from the reaction vessel to the combustion vessel. The most suitable working fluid for an operating temperature of $2000^{\circ} \mathrm{F}$ is sodium. Ceramic tube is usually considered in the heat pipe for such high-temperature applications.

\section{Heat-Recovery}

Ilse of heat pipes in heat-recovery units has been commercialized in recent years and now represents the largest commercial application of heat pipes. Figure 21-7 shnws how the heal plpes are grouped together to make a thermal recovery unit. For waste-heat recovery units, metal tubes are usually used, and water and organic flulds are common working fluids up to $750^{\circ} \mathrm{F}$. The bulk. of theec applications involves preheating make-up af $x$ for ovens and dryers, for example, in textile ovens and automotive paint-drying ovens.

\section{Residential and Commercial}

Energy-saving heat pipe applications for appliances such as water heaters have been proposed. (17) other gas-fired appliances where heat pipes can be effectively used to obtain uniform temperature, fast response to temperature changes, compactness, and operating efficiency are griddles and deep fryers.

\section{Section 21.3: Limitations}

\section{A. Equipment Availahility}

Six firms in the United States manufacture heat pipe unlts, primarily for waste-heat applications. These firms, indicated in Table 21-3, are: Q-Dot, Isothermics, Hughes, Dynatherm, Gamewe11, and Heat Pipe of America Corporation.

The types of fins used, the standard number, and the method of attachment vary from manufacturer to manufacturer. A11 manufacturers use freon or water for working fluids in the lower temperature ranges. At higher temperatures, most use "proprietary" fluids. These are probably organic heat-transfer fluids similar to Dowtherm-A ${ }^{\circledR}$ (Table 21-1). 


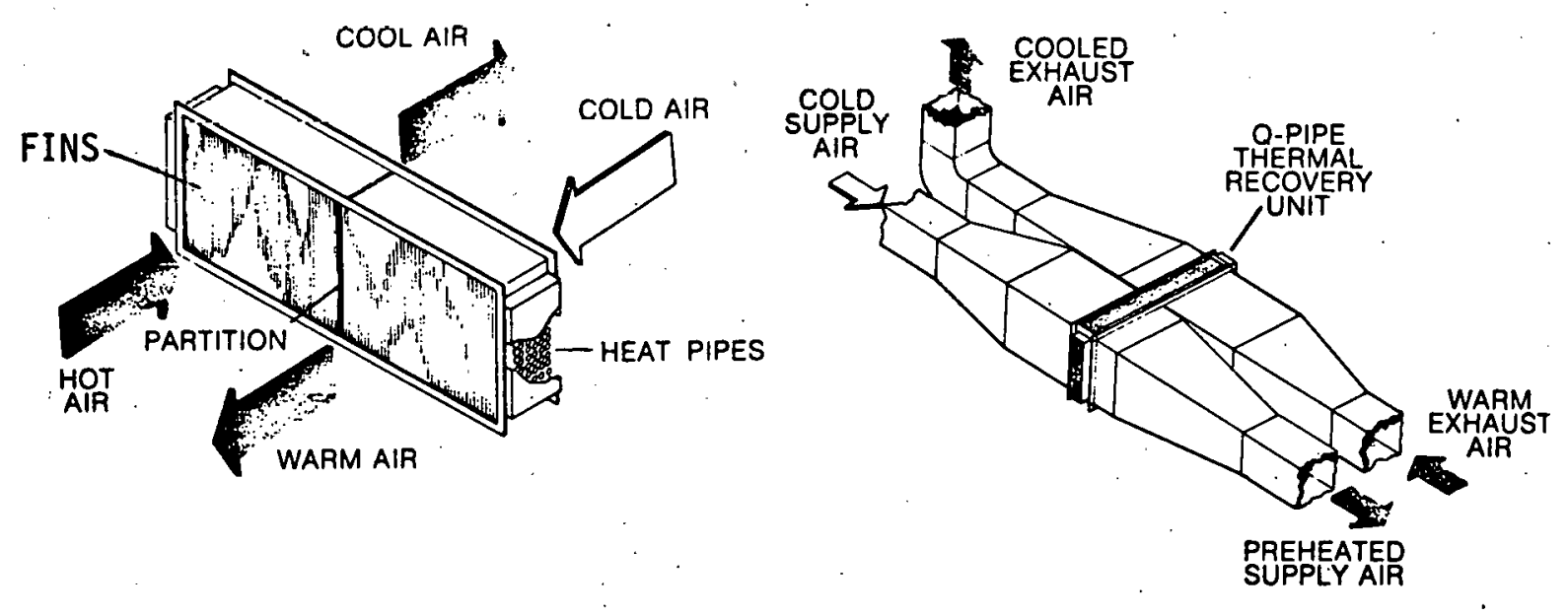

SOURCE: Reference 18.

FIGURE 21-7 TYPICAL HEAT PIPE HEAT-RECOVERY UNIT 


\section{CHARACTERISTICS OF U.S. HEAT PIPE HEAT EXCHANGERS}

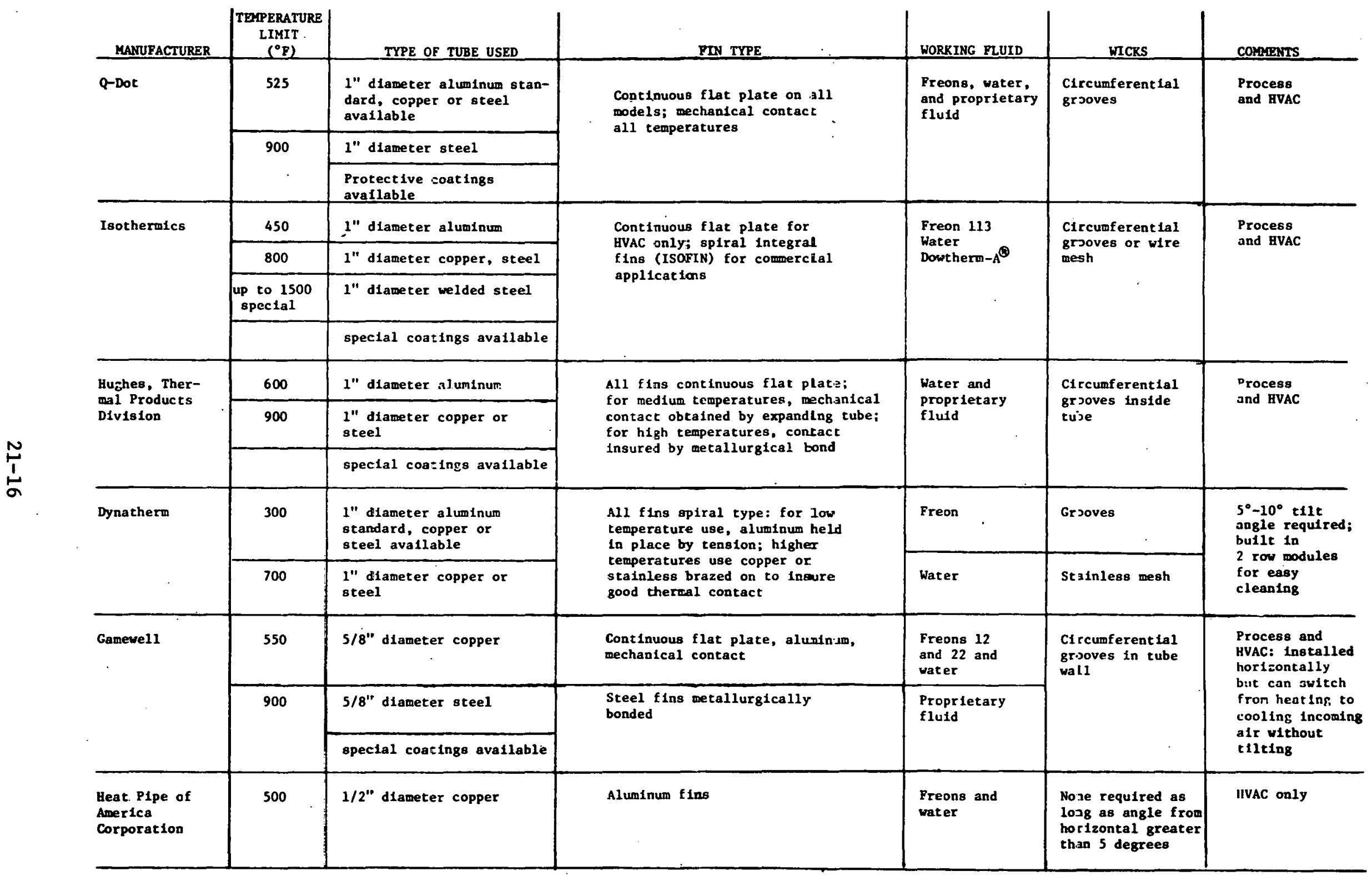

SOURCE: Compiled by Arthur D. Little, Inc. from information provided by the listed manufacturers. 
The temperature ranges quoted by various manufacturers in Table 21-3 vary greatly. The temperatures above $700^{\circ} \mathrm{F}$ are the maximum exhaust stream temperature, assuming that a suitable system of safeguards has been included to prevent the heat pipe surfaces from reaching a temperature greater than $700^{\circ} \mathrm{F}$ if removal of heat from the cooler end should be reduced.

\section{B. Costs}

It is often difficult to give prectse cost estimates or predictions for most pipes since they are normally manufactured for highly specific purposes and may be integral with other parts of the equipment. Furthermore, for most applications, except in heat-recovery heat exchangers, they are still in the experimental stage. The following example may, however, give an indication of costs. One manufacturer, Q-Dot, produces heat exchanger units consisting of sixty-four 9-ft aluminum heat pipes, 1 inch in diameter. The cost is $\$ 47.50$ per pipe, and the design heat-transfer rate is $20,625 \mathrm{Btu} / \mathrm{hr}$ (per heat pipe) equivalent to about $\$ .0023 / \mathrm{Btu} / \mathrm{hr}\left(\$ .26 / 10^{6} \mathrm{Btu} / \mathrm{yr}\right)$. More commonly, costs are estimated in somewhat different terms. Most heat pipes are provided with a finned external surface for better overall fluid-to-gas heat exchange. The heat transfer ability of this surface must match that of the heat pipe so that this area is a measure of the heat pipe's performance. Following the practice common in the heat exchanger industry, we estimate the costs of heat pipe recovery units with external heat transfer surfaces are about $\$ .90 / \mathrm{ft}^{2}$ of heat transfer surface. (19) This cost is comparable to that of more conventional heat exchangers, such as plate-type recuperators. Heat pipe recovery units have the advantage of being easier to clean and more compact than plate-type units.

\section{Environmental and Safety Considerations}

The primary environmental and safety considerations associated with heat pipes are those connected with the working fluids in the event that the fluid leaks out of the pipe because of faulty construction or 
an accident. For example, several of the Freon-type working fluids used in medium-temperature heat pipes are among those suspected of causing degradation of the ozone layer. Also, direct contact of several of these organic flufds with a flame can result in the formation of harmful phosgene-type compounds. The liquid metals which might be used in high-temperature heat pipes are of ten quite flammable when exposed to air or moisture and can, therefore, constitute a significant safety hazard.

The above environmental and safety 1ssues are somewhat mitigated by the fact that the liquid inventory present in a heat pipe system is quite smali since the principal heat-transfer mode involves evaporation and coindensation.

\section{Failure Modes and Reliability}

The effective operation of heat pipes requires that the liquid in the pipe be sealed in a vacuum so that there are no significant amounts of non-condensable gases present. If non-condensable gases are present, they will tend to be swept down to the cold end of the pipe, thereby reducing the area avallable for condensation. This effect can make the heat pipe totally inoperable. Non-condensable gases can result from leakage of air into the pipe because of faulty construction, or from chemical degradation of the working fluid following operation at excessive temperatures.

Experience with commercial heat pipe heat-recovery equipment appears to Indicate, however, that heat pipe failures, such as those discussed above, are not a major problem when the equipment is used correctly. Consequently, the guarantees of fered on such equipment are consistent with those offered on more conventional heat exchanger packages, (18) which is indicative of commercial maturity. 
1. Basiulis, A., et al. "Designers' Guide to Heat Pipes." Design News 29(6): 159, March 1974.

2. The Aerospace Corporation. Technical Summary of Distributed Solar Power Collector Concepts. Prepared for Energy Research and Development Administration under Contract No. E(04-3)1101. E1 Segundo, California, undated. Aerospace Report No. ATR-76(7523-07)-1(II).

3. Asselman, G.A.A. "Fluidized Bed Coal Combustion as a Heat Source for Stirling Engines." 11th Intersociety Energy Conversion Engineering Conference, State Line, Nevada, September 12-17, 1976. Paper No. 729132 .

4. Aronson, R.B. "Heat Pipe: Hot New Way to Save Energy." Machine. Design $48(6): 52,1976$.

5. Midwest Research Institute. Heat Pipes. Report prepared for National Aeronautics and Space Administration, 1975. NASA Report No. NASA-CR-2508.

6. Ranken, W.A. "The Potential of the Heat Pipe in Coal Gastfication Processes." 11th Intersociety Energy Conversion Engineering Conference, State Line, Nevada, September 12-17, 1976. pp. $876 \mathrm{ff}$.

7. Blenert, W.B., et al. "Application of Heat Pipes to Solar Collectors." 10th Intersociety Energy Conversion Engineering Conference, Newark, Delaware, August $17-22,1975 . \mathrm{pp}=153.3 \mathrm{ff}$.

8. Waters, E.D., et al. "The Application of Heat Pipes to the TransAlaska Pipeline." 10th Intersociety Energy Conversion Engineering Conference, Newark, Delaware, August 17-22, 1975. pp. $1496 \mathrm{ff}$.

9. Ranken, W.A. Ceramic Heat Pipe Heat Exchangers. Report prepared by Los Alamos Scientific Laboratory for Energy Research and Development Administration, October 1976. NTIS Report No. LA-6514-MS.

10. Rohsenow, W.M., et al. Handbook of Heat Transfer. New York: McGraw-Hill, 1972. pp. 2 ff.

11. The Aerospace Corporation. Highlights of the Solar Total Energy Systems, D1stributed Collector Systems, and Research and Development Projects Semiannual Review, Atlanta, Georgia, January 26-27, 1976. Sponsored by the Energy Research and Development Administration under Contract No. E(04-3)-1101. E1 Segundo, California, March 26, 1976. Aerospace Report No. ATR-76(7523-11)-5.

12. Yip, F.C. "Design Parameter for Assessing Wicking Capabilities of Heat Pipes." Journal of Spacecraft $13(4): 237,1976$.

13. Uhlemann, Ho, et al. "The Combination of a Stirling Engine in a Remotely Placed Heat Source." 9th Intersociety Energy Conversion Engineering Conference, San Francisco, California, August 26-30, 1974. pp. $620 \mathrm{ff}$. 


\section{REFERENCES (continued)}

14. Schroeder, J. "Thermal Energy Storage Using Fluorides of Alkal1 and Alkaline Earth Metals." Proceedings of the Symposium on Energy Storage, 148th Meeting of The Electrochemical Society, Dallas, Texas, October 5-9, 1975. Princeton, New Jersey: The Electrochemical Society, Inc., 1976. pp. $206 \mathrm{ff}$.

15. Jet Propulsion Laboratory, California Institute of Technology. A Preliminary Technical and Economic Assessment of Solar Power Plants Using Line Concentrators. Pasadena, Calffornia, July 1978.

16. Bienert, W.B., et al. Heat Plpes Applied to Flat-Plate Solar Collectors. Cambridge, Massachusetts: Dynatherm Corporation, 1976.

17. Lazaros, J.S. Energy Saving Heat Pipe Applications for Reyldencial and Commercial Appliances. Waltham, Massachusette: Thermo Electron Corporation, 1974.

18. Q-Dot Corporation, Dallas, Texas. Product 1iterature. 1978.

19. Arthur D. Little, Inc., Cambridge, Massachusetts. Data based on personal communications with selected manufacturers. January 1978. 


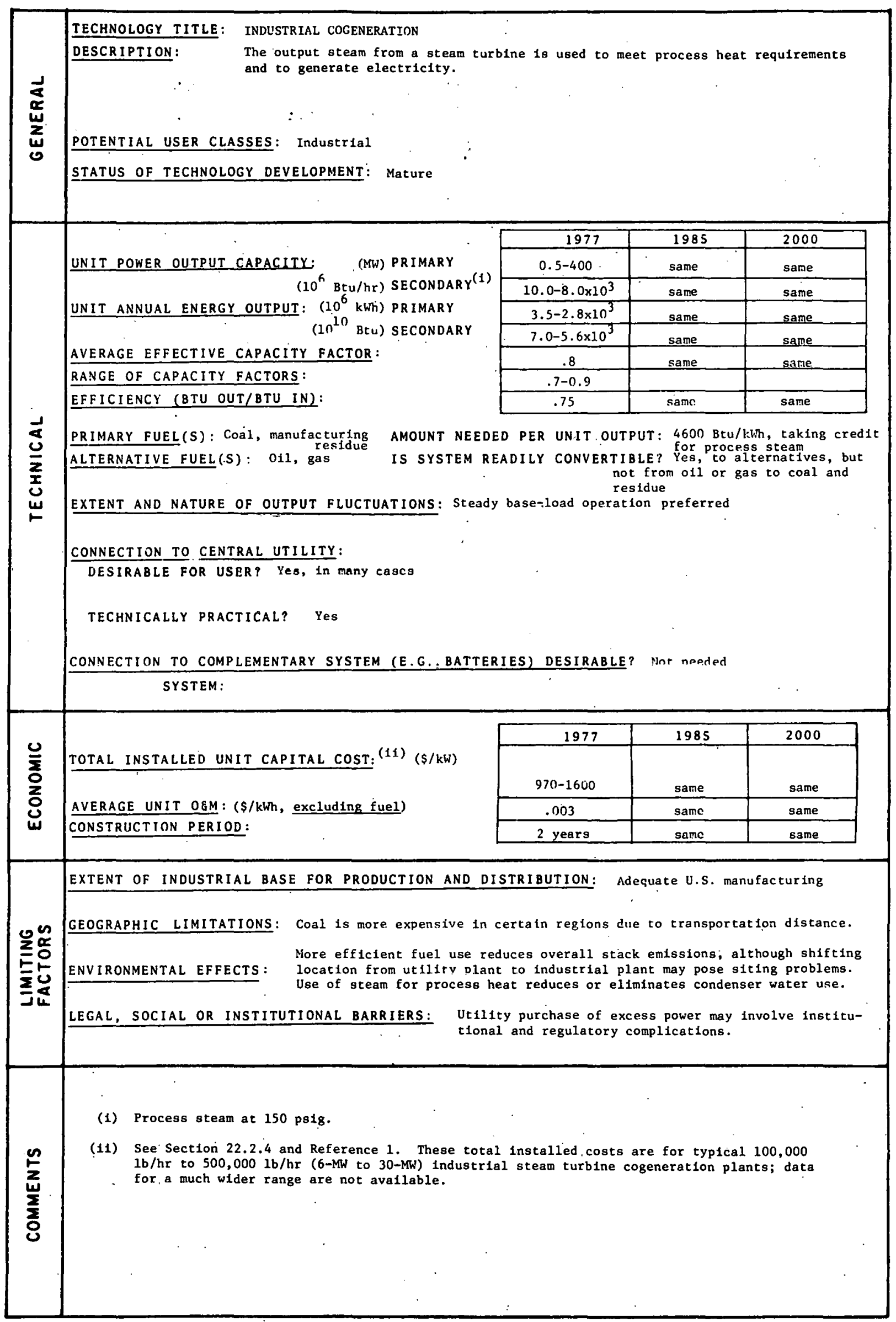


CHAPTER 22

INDUSTRIAL COGENERATION

Section 22.1: Introduction

A heat engine is a device that converts thermal energy at a high temperature to useful work, e.g., driving machinery, and rejects a smaller amount of thermal energy at a lower temperature. According, to the principle of conservation of energy, the thermal energy provided by the fuel equals the sum of the work performed and the heat rejected provided all these quantities are expressed in the same units. The Second Law of Thermodynamics postulates that in an "Ideal" engine the ratio of the heat input to the heat rejected is the ratio of the absolute temperature* at which the heat is absorbed, $\mathrm{T}_{\mathrm{u}}$, to the lower absolute temperature, $T_{L}$, at which heat is rejected. It follows that the ratio of the work performed to the heat input is equal to $\left(T_{u}-T_{L}\right) / T_{u}$. This "ideal" measure of performance is the Carnot efficlency, $\varepsilon_{c}$, and can be used to predict the maximum work output that can be obtained, in principle, from any heat engine. Two aspects are important: (a) heat is always rejected in any real engine so that the energy absorbed from the fuel is never completely converted to useful work, and (b) the actual work output of a real engine is always less than that predicted by $\varepsilon_{c}$ because of heat losses, friction, non-ideal thermodynamic behavior of the thermal fluid, and unavoldable temperature differences in heat exchangers. For example, a steam engine with an input temperature of $1000^{\circ} \mathrm{F}$ which rejects heat to ambient $\left(80^{\circ} \mathrm{F}\right)$ has an 1deal efficiency of $63 \%$, corresponding to a heat rate of $5400 \mathrm{Btu} / \mathrm{kWh}$, whereas the most effictent coal fired steam turbine generators have an efficiency of approximately $40 \%$, 1.e., a heat rate of $8500 \mathrm{Btu} / \mathrm{kWh}$. Figure. 22-1 11lustrates the work output versus heat rejected from an Ideal heat engine with input temperature of $900^{\circ} \mathrm{F}$ as $1 \mathrm{t}$ operates to different lower (1.e., heat refection) temperatures, $T_{L}$.

${ }^{\star}$ The absolute temperature, expressed $1 n{ }^{9} R$, equals $\left({ }^{\circ} F+460\right)$. 


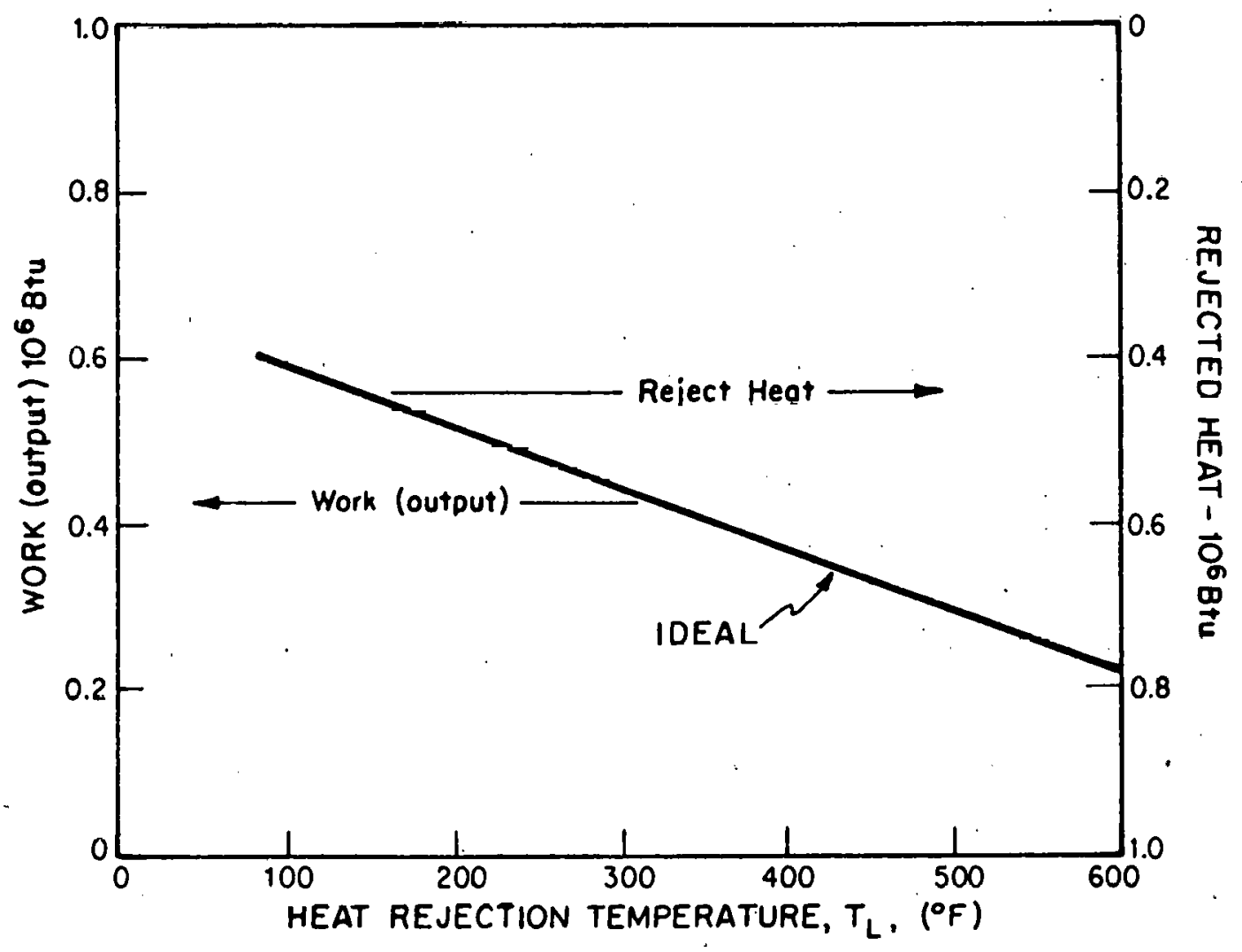

FIGURE 22-1 WORK OUTPUT AND HEAT REJECTED FROM AN IDEAL HEAT ENGINE WITH AN INPUT OF $10^{6}$ BTU AT A TEMPERATURE; $T_{u}$, OF $900^{\circ} \mathrm{F}$ VS. HEAT REJECTION TEMPERATURES, $T_{L}$, BETWEEN $100^{\circ} \mathrm{F}$ AND $600^{\circ} \mathrm{F}$ 
When heat rejection occurs at or close to ambient temperatures the temperature of the "waste" heat is so low that it is of 11ttle use. If, however, the machine is modifled so that the exhaust heat is delivered at, for example, $150^{\circ} \mathrm{F}$, the heat can be used for space heating; or if it is made available at still higher temperatures, for example, $300-400^{\circ} \mathrm{F}$ (50 psig ${ }^{*}$ to $230 \mathrm{psig}$ when the working fluid is saturated steam) the heat could be used for industrial processes (process heat).

The simultaneous production of work (usually converted into electricity) and usable (process) heat from a heat engine is "cogeneration." It is a technique widely used in industry to make available, from the same fuel source, power and usable heat at the cost of a reduction in the real efficlency of power generation but providing, overall, more efficient use of the thermal. energy input. (From Figure 22-1 it is clear that, as the extraction or delfvery temperature, $i_{\text {.e., }} T_{L}$, rises above amblent, less of the fuel's energy is converted into work and more becomes available as process heat.) To put this statement in perspective, consider a heat engine operating between $T_{u}-900^{\circ} \mathrm{F}$ and either $T_{L}=100^{\circ} \mathrm{F}$ or $T_{L}=365^{\circ} \mathrm{F}$ (150 peig). The resu1.ts, ** for a postulated electricity output of $1 \mathrm{kWh}$ (3413 Btu), are presented in Table 22-1.

Several different power generation technologles are avallable and have been used in industrlal cogeneration; other more advanced technologies have been proposed for use in the future. The systems in use today are steam turbine, combustion ${ }^{\star \star *}$ turbine and diesel-powered electricity generation. The steam turbine cycle will be examined in detail in Section 22.2.1. Combustion turbine and diesel generation systems are discussed in Chapters 12 and 13, respectively, so that their description here will be limited to those features of particular importance in cogeneration. In Section 22.2 .3 we shall present a comparison of those features ${ }^{\star}$ psig $=1 b s / i^{2}$ (gauge) or pressure above atmospheric pressure, 1.e., approximately $15 \mathrm{lbs} / \mathrm{in}^{2}$ less than the absolute pressure (psia). A fixed relationship between steam temperature and pressure exists only for saturated non-superheated steam. This situation may be assumed for process steam; both parameters are needed to define the input steam conditions.

$\star \star$

The detalls of the analysis will be given in Section 22.2. Commonly known as "gas" turbines. 
TABLE 22-1

THERMAL ANALYSIS OF IDEAL AND REAL HEAT ENGINES ${ }^{(1)}$

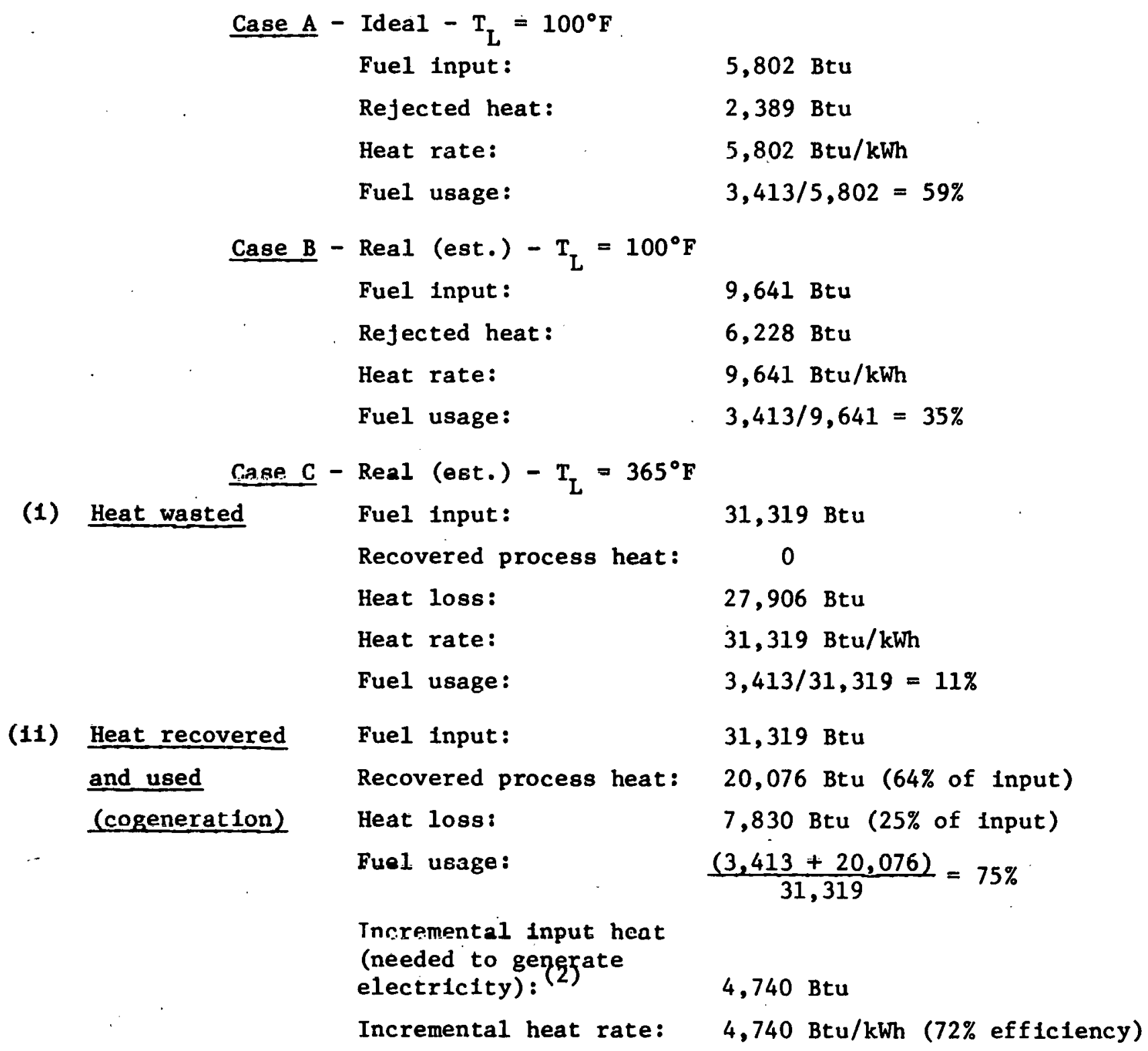

(1) This analysis is based on delivering $1 \mathrm{kWh}(3,413 \mathrm{Btu})$ of work from an input at $900^{\circ} \mathrm{F}$ and with exhaust temperatures of $100^{\circ} \mathrm{F}$ and $365^{\circ} \mathrm{F}$ (w1th and without heat recovery). The "real" cases are representative of a typical modern steam turbine cogenerator. See Section 22.2 for detalls.

(2) That is to say, if the steam turbine could be bypassed in a lossless manner, then only $26,579 \mathrm{Btu}$ of input heat would be needed to provide $20,076 \mathrm{Btu}$ of process heat $(26,579=31,319-4,740)$.

SOURCE: Arthur D. Little, Inc. calculations. 
that play a role in their selection for industrial cogeneration.

Advanced technologies proposed for use in cogeneration in the future are Stirling cycle, and organic Rankine cycle engines and fuel cell.

systems. None of these is presently in commercial use for power generation; since they have been discussed extensively in Chapters 14, 15 and 16, their reviews in Section 22.2 .5 will be brief.

Cogeneration systems fall into two general categorles - "topping" and "bottoming" cycles. If process heat is required for industrial use at temperatures between ambient and, for example, $400^{\circ} \mathrm{F}$, it might be economically attractive to construct a boller capable of delivering steam at $900^{\circ} \mathrm{F}$ and to use the energy avallable between $900^{\circ} \mathrm{F}$ and $400^{\circ} \mathrm{F}$ for electricity generation. This is a steam "topping" cycle. If, however, process heat is required at still higher temperatures, then it might be worthwhile to deliver the process heat directly from the boiler at an appropriate selected temperature. After use, the process heat could be recovered at some still useful temperature, e.g., $300^{\circ} \mathrm{F}$, for electricity generation in a "bottoming" cycle provided, for example, by an organic Rankine cycle engine.

The balance of this chapter consists of the following: Section 22.2 -- a review of cogeneration technologies; Section 22.3 -- a discussion of the factors affecting the use of industrial cogeneration; and Section 22.4 -- a review of future prospects for cogeneration.

\section{Section 22.2: Technical Discussion}

\section{Introduction}

The practical cogeneration of electricity and heat places fairly stringent requirements on the systems used: they must be mechanically reliable and maintainable, reasonably cost-effective, environmentally acceptable, avallable in a size appropriate to the job at hand, and give promise of long-term fuel availability. Traditionally, a number of configurations have survived the trade-offs between these requirements; however, 
changing conditions may permit new technologies to gain acceptance in the future.

The application of cogeneration is discussed in detail in Section 22.4. Here we summarize to explain our cholce for sample calculations.

Potential applications of cogeneration range from small units supplying a single building complex such as a shopping center or business park with electricity and space heat to large centralized electric power stations which also supply steam for district heating and industrial process heat. Potential intermediate size applications of several to tens of megawatts can be found in larger industrial plants.

At present, cogeneration finds its widest application in six Industries (food, textiles, pulp and paper, chemicals, petroleum refining and steel). The technical, economic and institutional factors which induce these Industries to cogeneration also appear to indicate that their potential for further technically feasible cogeneration exceeds that of all other industries combined. * For example, the pulp and paper Industry provides a nearly Ideal basis for cogeneration because plant sizes are large enough to support economical units utilizing proven technology; the need for electrictty and process steam is well balanced; organic waste for fuel supplementation is available; and siting is often sufficiently remote that utility-supplied power is more expensive and less reliable than locally cogenerated electricity.

Because cogeneration in the intermediate multi-megawatt range typlcal of these six industries is most likely to contribute to the nation's energy pool, the example case used below for comparison of alternat ive technologies is sized to their needs. More specifically, we consider a process steam plant typical of that found in the pulp and paper industry $^{(1)}$ which has been modifled for cogeneration. Table 22-2 1ista the major parameters which define this specimen plant.

\footnotetext{
${ }^{\star}$ See Table 22-8 for data.
} 
TABLE 22-2

\section{PARAMETERS DEFINING THE "TYPICAL" STEAM COGENERATION PLANT USED IN THIS CHAPTER}

Size:

Cycle:

Generator Inlet Conditions:

Generator Exhaust Conditions:

Process Steam Input Conditions:

Recycled Boller Water Conditions:
500,000 pounds of steam per hour (Electricity output depends on alternatives considered.)

Topping

1,250 psig, $900^{\circ} \mathrm{F}$

150 psig, $350^{\circ} \mathrm{F}$ (saturated)

150 psig, $350^{\circ} \mathrm{F}$ (saturated)

$75 \%$ recycled at $180^{\circ} \mathrm{F}$

$25 \%$ makeup at $70^{\circ} \mathrm{F}$

Notes: 1. Parameters dependent on system choice are given in the text or in Table 22-3.

2. Of the total number of new bollers installed by the pulp and paper industry in the period 1965-1975, 20\% operated at 850 psig or greater pressure. These represent $44 \%$ of the steam capacity installed during that period with mean unit steam generation (at $80 \%$ capacity factor) of $460,000 \mathrm{lbs} /$ hour. Botlers in this pressure range represented $31 \%$ of total installed steam capacity in 1975 and more than half of total cogeneration capacity.(1) Thus the chosen system is indeed typical of new capacity.

3. Because the specific heat of superheated steam is so much smaller than the latent heat, process steam will nearly always be saturated. Similarly, it is uneconomic for the turbine exhaust to be more than slightly superheated. 
Each potential application of cogeneration technology presents its own system requirements. It is therefore perhaps fortunate that the three widely used cogeneration technologies differ significantly in major system parameters: size range, capital and operating costs, division of output power between steam and electricity, efficlency, fuel, etc. These technology-dependent characteristics are summarlzed later, after each is discussed. In order to be relatively complete, we include below both efficiency equations and system parameter graphs to permit the reader to perform similar calculations for applications other than our sample case.

As mentioned in Section 22.1, topping cycles are cycles in which the highest "quality," i.e., highest temperature and pressurc, working fluid (steam.or combustion product) is used to generate electricity with the lower temperature exhaust used for heating purposes. Bottoming cycles utilize the high quality heat stream for heating and the cooleddown steam for electricity generation. In either case, unused heat is either wasted or returned to the heat source for reheating.

As a general rule, topping cycles are more desirable than bottoming cycles. It is more difficult effictently to extract an equal amount of electrical energy from a low-temperature stream than from a high-temperature stream. The lower pressure requires larger, more expensive machinery. Also, although much of the stream into a bottoming generator can be used, a bottoming generator operating on a low quality heat stream and small temperature differences is thermodynamically less efficient than its topping cycle counterpart. Lower overall system efficiency is inevitable. . Why then consider bottoming cycles at all? In certain cases, a large high quality heat stream is needed and the exhaust may well contain large amounts of extractable energy, providing practical and economic bottoming cycles can be developed.

\section{Section 22.2.1: Steam Turbine Topping Cycle}

of the cycles mentioned in Section 22.1, the steam turbine topping cycle has found the widest acceptance in relatively large-scale. applications such as those which occur in the pulp and paper industry. 
The cycle produces electrical power by means of a back-pressure (noncondensing) steam turbine and generator. The exhaust steam from the turbine provides process heat for the industrial plant. Figure 22-2 shows this cycle in schematic form (stack gas heat recovery economizers and space heating applications are not shown). An efficient, modern steam generator which provides generator inlet steam conditions of 1,250 psig and $900^{\circ} \mathrm{F}$ is assumed. The exhaust conditions are design parameters; 150 psig was chosen as a normative value.

A major advantage of the steam turbine topping cycle 1 les in its very high fuel utilization efficiency.-- approaching $75 \%$. ${ }^{*}$ Assuming a wel1-balanced operating system in which steam and electricity requirements are compatible, the major loss is in heat lost through the boiler smoke stack; generator and turbine losses are smaller contributors. Essentially all the heat carried off by the low temperature outlet steam stream can be recovered as process heat or can be recycled to the boiler as hot condensate. (In a conventional steam turbine generator most of the wasted energy is rejected through the condenser at relatively low temperatures.) The numerical examples following assume that $75 \%$ of the process steam is condensed and returned to the boller as $180^{\circ} \mathrm{F}$ water. In order to run in a steady-state, the $25 \% 1$ lost is made up as $70^{\circ} \mathrm{F}$ water. To be more specific, the heat energy, $Q_{\text {tot, }}$ available from burning a unit of fuel can be expended in three ways: as useful process or recycled heat, $E_{H}$, as electrical energy, $E_{E}$, or as wasted energy, $E_{10 s s}$,

$$
Q_{\text {tot }}=E_{E}+E_{H}+E_{\text {loss }} \text {. }
$$

The overall system or fuel utilization efficiency, ${ } \mathrm{FU}$, is

$$
\eta_{F U}=\frac{E_{E}+E_{H}}{Q_{\text {tot }}}=\frac{E_{E}}{Q_{\text {tot }}}+\frac{E_{H}}{Q_{\text {tot }}} .
$$

The advantage of cogeneration is that its fuel utilization efficlency can be much larger than the thermodynamically 1imited effictency

*In the overall cogeneration process. 

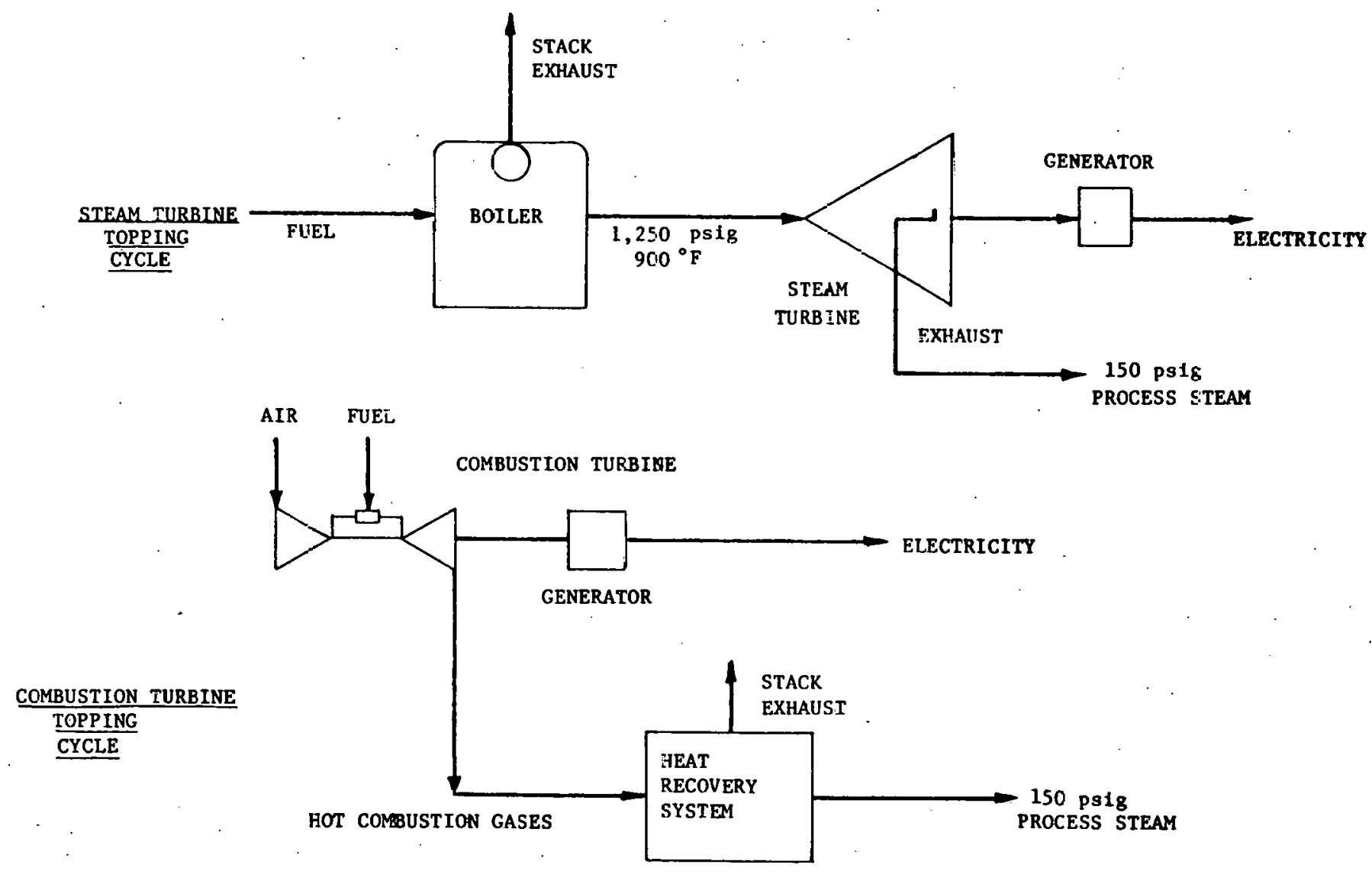

SOURCE: Arthur D. Little, Inc.

FIGURE 22-2 ALTERNATIVE COGENERATION SYSTEMS - SIMPLIFIED SCHEMATICS 
of electric generation without waste heat recovery. The overa11 fuel utilization efficiency, $n_{\mathrm{FU}}$, of the sample steam turbine topping cycle is typically $75 \%$. (1) A simflar plant optimized for electric generation alone would be about $35 \%$ efficient ( $E_{H} \sim 0$, Equation 22-2). It is worth stressing that the cogeneration of electricity is an incremental process; a little more steam energy is generated than needed for process heat and most of this "extra" energy is extracted as electrical energy. A small fraction of the "extra" energy is lost up the boiler smoke stack and smaller fractions to friction and other heat sinks, but the large fraction which would otherwise be wasted as exhaust enters the process heat stream. Thus the effective ${ }^{*}$ effictency for conversion of the incremental heat input to electrical energy is high.

To be more specific, for the sample case described here and in Reference 1, process steam alone can be generated at an efficiency somewhat greater than $75 \%$; the effective (or marginal) efficiency, $\dot{\eta}_{E}^{\prime}$, for electricity generation is about $72 \%$ when a steam turbine topping cycle is added to the process steam boiler. That is to say, $72 \%$ of the incremental heat energy input, $\Delta Q$, required for the output of one unit of electrical energy, $E_{E}$, appears as electricity. Thus, the incremental. heat energy required for this form of electrical cogeneration is roughly half of that required by a central power station. The positive implications for the nation's fuel utilization and the institutional constraints on the implementation of large-scale industrial cogeneration are discussed elsewhere ${ }^{(1,2)}$ and in Sections 22.3 and 22.4 .

The division of the useful output energy between electricity and heat depends on the purpose and design of the entire system; this will be discussed in detall later. For the sample case with steam turbine topping cycle cogeneration, the ratio of electrical energy output to process heat output, $\alpha$, is small (about 1/6). (1) If the input heat energy utilized for process steam generation, $Q_{P},\left(Q_{P}=Q_{\text {tot }}-\Delta Q\right)$ is ut1lized with efficiency, ${ }_{\mathrm{H}}$, we can summarize as follows:

\footnotetext{
*The phrase "marginal efficiency" is generally used to describe the effective efficiency of electricity cogeneration; the phrase "incremental efficiency" is also appropriate. The point to be taken is that the increment in heat input is used efficiently to generate electrical energy and process steam energy - not that the second law of thermodynamics can be abrogated to permit greater than $70 \%$ efficient generation of electricity alone. 


$$
\begin{gathered}
\eta_{F U} Q_{t o t}=\eta_{F U}\left(Q_{P}+\Delta Q\right)=E_{H}+E_{E} ; \\
\bar{E}_{E}=\alpha E_{H} \\
\eta_{E}^{\prime} \Delta Q=E_{E} \\
\eta_{H} Q_{P}=E_{H}
\end{gathered}
$$

where $n_{F U}=0.75, n_{E}^{\prime}=0.72$, and $\alpha=0.17$. The efficiency of process heat generation, $\eta_{H}$, is not particularly meaningful because an entirely different boiler system is used for process steam generation without cogeneration. Nonetheless, it is useful in comparing cogenerating and non-cogenerating steam supply systems. In this case, the set of Equations 22-3 can be solved to give $\eta_{H} \sim 75.5 \%$.

Conventionally, heat rate, rather than its inverse, efficiency, is used as a system design parameter. In this case, the major concern is with the marginal heat rate, $\rho_{E}^{\prime}$; the overall heat rate, $\rho_{F U}$, is also used in the literature

$$
\begin{array}{r}
\rho_{E}^{\prime}=\frac{1}{\eta_{E}^{\prime}}=\frac{\Delta Q}{E_{E}} \text {; and } \\
\rho_{F U}=\frac{1}{n_{F U}}=\frac{Q_{\text {tot }}}{E_{H}+E_{E}} .
\end{array}
$$

Note that because energy is used in more than one way in cogeneration, more than one efficiency (or heat rate) can bc defined.

Also, conventionally, heat energy is measured in British thermal units (Btu) and electrical energy in kilowatt-hours (kWh). Because one $\mathrm{kWh}$ is equivalent to $3,413 \mathrm{Btu}$, a heat rate of $3,413 \mathrm{Btu} / \mathrm{kWh}$ is equivalent 
to $100 \%$ efficlency. That is to say, the sample $75 \%$ efficient cogeneration system would have an overall heat rate of approximately $4,550 \mathrm{Btu} / \mathrm{kWh}$ $(4,550=3,413 / 0.75)$; a fuel input of $4,550 \mathrm{Btu}$ would give $1 \mathrm{kWh}$ of useful energy divided between electrical power and heat for process applications. The corresponding marginal heat rate for electrical generation is 4,740 Btu/kWh $(4,740=3,413 / 0.72)$.

Figure 22-3, adapted from Figure 3-1 of Reference 1, is a plot illustrating the preceding discussion. The horizontal line at 3,413 Btu/ $\mathrm{kWh}$ represents $100 \%$ efficiency in fuel use; the horizontal line at about $4,740 \mathrm{Btu} / \mathrm{kWh}$ illustrates that steam turbine cogeneration efficiency is nearly independent of outlet steam quality. Also shown are curves for combustion turbine and diesel cogeneration which will be discussed later. Note, however, that both are less efficient electricity producers (more Btu's of fuel required per $\mathrm{kWh}$ of useful output) and grow progressively less efficient as process steam quality requirements increase. Note that Figure 22-3 assumes the given boiler, recycle and makeup conditions, and that no heat is extracted for supplementary, higher quality steam.

The division between heat energy available for process utilization and the amount generated as electricity remalns to be discussed. If it is assumed that the generator exhaust is not significantly superheated,* a single parameter, taken to be process steam pressure, is adequate to describe this division. Figure 22-4 gives the ratio of the electrical energy generated to process heat energy $\left(E_{E} / E_{H}\right)$ as a function of process steam pressure for the three topping cycles. The left hand vertical axis is labeled in terms of available power both in kilowatts of electrical power available per million $\mathrm{Btu} /$ hour of heat power and nondimensionally as $\alpha$ (in a common set of units). The right hand vertical axis gives the percentage of the total usable energy available as electricity. At 150 psig steam pressure, $14.5 \%$ of the avallable energy appears as electricity and $\alpha=0.17$. The steam turbine topping cycle is a notably efficient producer of high quality process steam and, therefore, produces less electrictty per unit of process heat than its competitors. As steam quality is reduced, e.g., for district heating, the steam turbine topping cycle produces relatively more electricity. In any case, it is

* See footnote 3 to Table 22-2. 


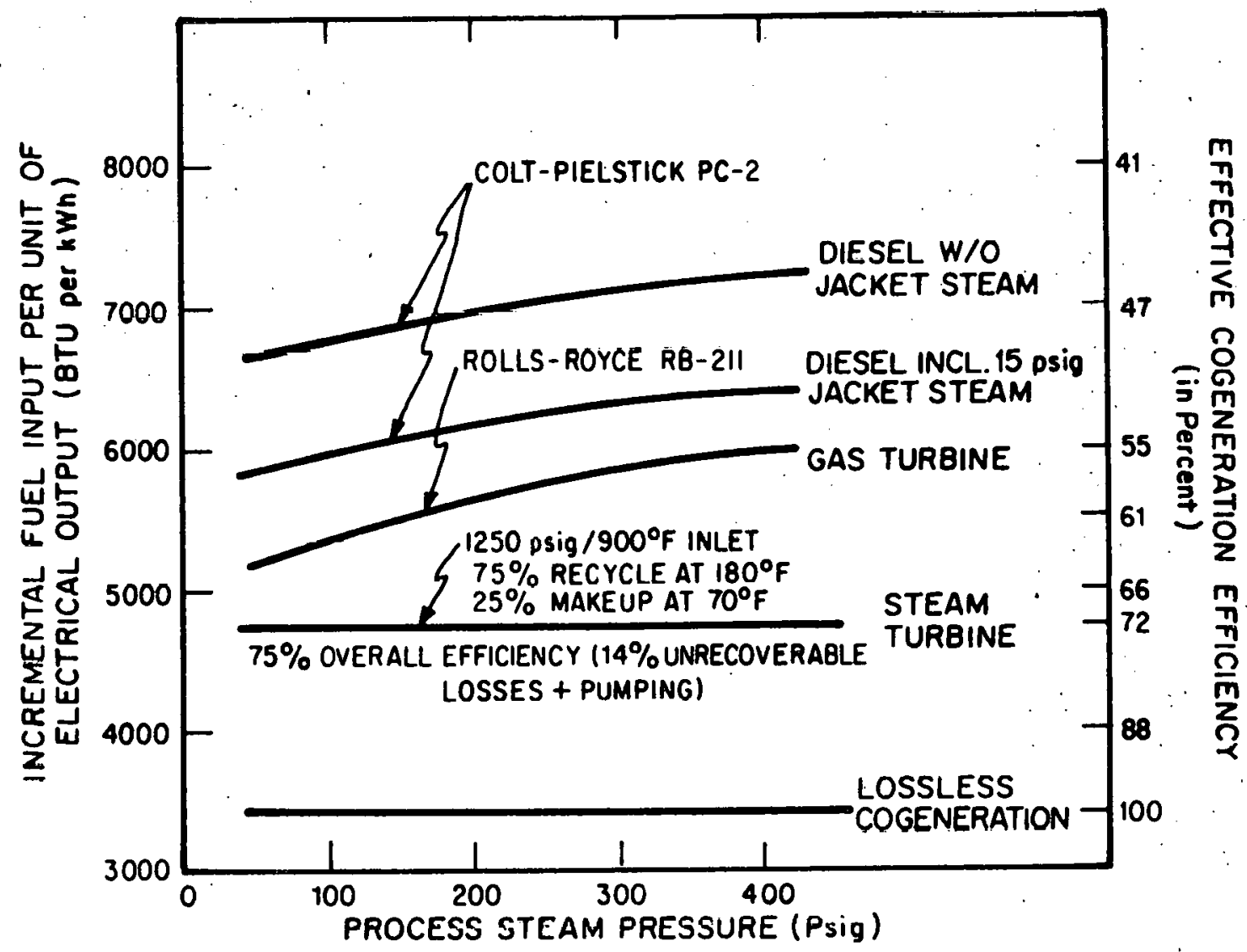

SOURCE: Reference 1.

FIGURE 22-3 INPUT HEAT REQUIREMENTS FOR ELECTRICAL COGENERATION AS A FUNCTION OF PROCESS STEAM PRESSURE 


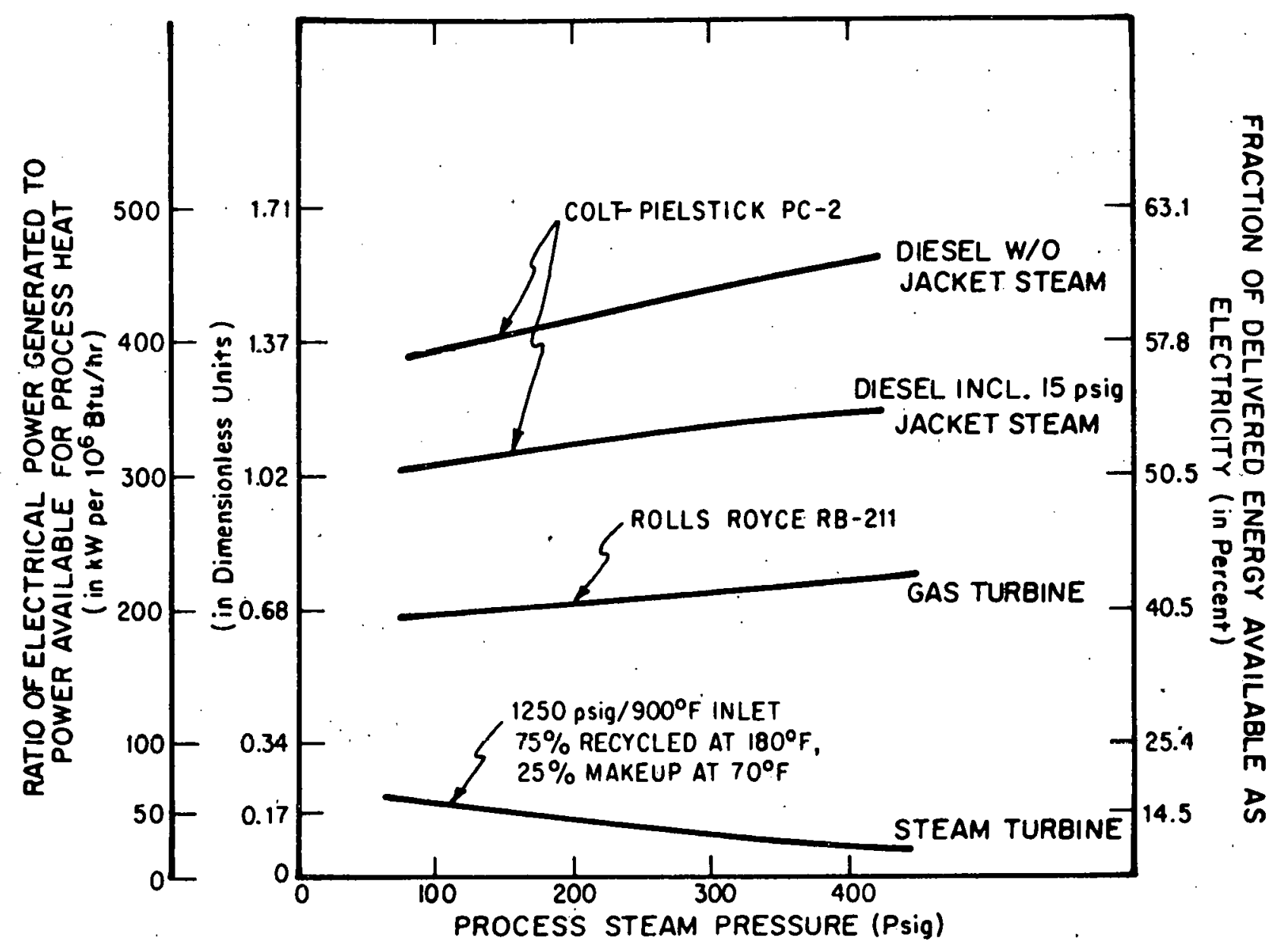

SOURCE: Reference 1.

FIGURE 22-4 ELECTRIC POWER GENERATION CAPABILITIES PER UNIT OF PROCESS STEAM USING DIFFERENT COGENERATION TOPPING TECHNIQUES 
overall the most fuel efficlent of the three systems.

Backpressure turbines, in which all of the exhaust stream is delivered as process heat and steam, are the most commonly used type of turbine in steam turbine cogeneration. Typically, exhaust pressures range from 100 to 300 psig. Specific applications, however, may require a larger ratio of electricity to process heat. This can be achieved by the use of extraction turbines in which part of the steam supply is extracted from the turbine at an appropriate pressure and temperature for process use, while the diminished steam continues to produce power In the lower pressure expansion stages of the turbine. Since the final output pressure and temperature may be too low for process application, the system may be less energy efficient than the backpressure turbine although it provides more electricity. Steam turbine topping cycles are Lherefore quice flexible in design but very inflexible in economic use.*

Steam turbine generators are available in unit sizes from a few kilowatts to over 1,000 megawatts. The range of sizes applicable to the pulp and paper industry cover the range from below $100 \mathrm{~kW}$ to more than $5 \mathrm{MW}$ of electrical output with most applications in the high end of the range.

Steam turbine generators consistently operate up to several years without a major inspection and ten years between overhauls. Service life is very long; many units presently in operation are over 40 years old. The steam turbine generator cogeneration configuration has demonstrated reliability higher than either diesel or combustion turbine cycles. It is a mature product, and further development can be expected only in the form of minor improvements. Installation of a steam turbine generator takes about two years from commitment to startup.

Fuels which can be used for steam turbine cogeneration are. principally coal, o1l, gas, wood wastes and manufacturing residue. It Is significant that otherwise unusable residue can he used and supplemented with coal, essentially replacing purchased oil and gas while substantially reducing the problems of waste disposal. In the wood pulp industry, wood wastes may be able to meet all fuel requirements. Gas or

*Because steam turbines can be operated efficiently and safely only within a narrow range of operating parameters. Excess electricity might be sold to a public utility; excess heat will be wasted. 
oil requirements can be reduced to that required only for startup and flame stabilization.

Siting of a power plant of this type is easier than siting a major generation plant. With the exception of the pulp and paper industry, plants are frequently located in an already industrialized area and are much smaller than electric utility installations. The cooling problem is less severe, because exhaust steam is delivered to the process rather than to a water-cooled condenser or cooling tower. With increasing burning of coal, emission control will be an expensive requirement. Low sulfur western coal is not readily available to eastern plants, and scrubhers may be necessary even with low sulfur coal.

Section 22.2.2: Other Current Cogeneration Technologies

In addition to steam turbine cogeneration, combustion turbines and diesel engine plants are used for cogeneration. They are reviewed only briefly in the following paragraphs since they have been discussed at length in Chapters 12 and 13.

\section{A. Combustion Turbine Congeneration}

In this syslell, a combustion (gas) turbine (see Chapter 12) is used to generate electricity and the high temperature exhaust is passed through a heat recovery steam generator to provide steam for industrial process heat at temperatures up to approximately $400^{\circ} \mathrm{F}$ (200 psig). Because the temperature of hot gas in the combustion turbine is much higher (up to $1,500^{\circ} \mathrm{F}$ ) than that of the steam from the boiler $\left(900^{\circ} \mathrm{F}\right.$ in the preceding discussion), it contains more thermal energy that can be used to generate electricity before the residual heat is used to generate process steam. As a result, the ratio of electrical power to process steam heat is higher for a combustion turbine than for a steam turbine cogeneration plant. This is illustrated in Figure 22-4 which indicates that, at the same process steam temperature, the available electrical power output of a combustion turbine system. (called there a gas turbine) may be 3 to 5 times that of a steam turbine cogeneration plant. ${ }^{*}$ This is not

*For the nominal case, the combustion turbine topping cycle achieves an overall $65 \%$ efficiency $\left(n_{\text {FU }}=0.65\right)$, with $62.5 \%$ marginal electrical generation efficlency $\left(n^{-}=0.625\right)$. The corresponding marginal heat rate is $5,460 \mathrm{Btu} / \mathrm{kWh}$. Without cogeneration, combustion turbine electricity generators operate at about $23 \%$ efficiency. 
to be interpreted as a statement that the combustion turbine is a good producer of electricity but rather that it is a poor producer of steam because of the relatively poor heat transfer from the exhaust gas to the heat recovery boller. Operating flexibllity in the ratio of steam produced per unit of electricity can be obtained by providing supplemental heating in the steam generator, usually with gas or oil, or by by-passing part of the turbine exhaust.

Combustion turbine generators are commercially avallable in sizes from below $300 \mathrm{~kW}$ to $100 \mathrm{MW}$. The attractive features of combustion turbines are that they are quickly started and brought on line, do not require a cooling system, and are easily installed because of their simplirity and light weight. Lead time is one to two years from decision to startup. The installed cost per $\mathrm{kW}$ is less than that for a steam turbine, but operation and maintenance costs are higher. A hot-section inspection (approximately one day of downtime) is required every six months, and major overhauls in the range of 20,000-30,000 hours of operation. Service 11 fe of 15 to 20 years can be expected.

Combustion turbines have been in use for many years for electricity generation; recent developments in materials and design have improved operating life and cycle efficiency. This equipment is now quite mature In its development cycle, and only improvements of an evolutionary nature are expected.

Combuation turbines require liquid or gaseous hydrocarbon fuels. Many are operating on crude ofl. While experimental work has been done on the use of pulverized coal, these efforts have been discontinued because of the apparently insurmountable difficulties of extensive turbine blade erosion. (1) This implies that the combustion turbine topping cycle is one that cannot be directly based on coal (in the near future at least) and requires oil, gas, or coal-derived fuels.

Combined cycles have been proposed in which the process steam developed in the combustion turbine exhaust heat recovery boiler is used to generate additional electricity. The residual stream is then lowpressure process steam. Clearly, as the second stage of power generation 
exhausts to lower and lower temperatures, the heat recoverable as process steam continues to diminish and the overall process approaches utility power generation. This complex system thus loses its attractiveness as a conservation measure and is only of interest in specialized applications where the demand for process steam is small and variable.

\section{B. Diese1 Engine Cogeneration}

As discussed in Chapter 13 and also in Chapter 23 (Total Energy Systems) waste heat can be recovered from the cooling system and from the exhaust of the diesel engine. Since the diesel engine uses fuel relatively efficiently, much of the waste heat is at relatively low temperatures. The ratio of work (that is, electricity) to recoverable process heat is high (Figure 22-4). Hence, the diesel engine is used in cogeneration systems where the demand for electricity determines the size of the plant and waste heat becomes a useful but not size-determining consideration. In addition, since the power output is determined by fuel supply to the engine and the efficiency of fuel use varies only slightly with power output, the ratio of electrical and thermal output does not vary greatly (Figure 22-4). In consequence, the split betwcen electricity and process steam is relatively inflexible. Electric incremental heat rates are in the 6,000 to $7,000 \mathrm{Btu} / \mathrm{kWh}$ range corresponding to $57 \%$ to $49 \%$ overall energy use efficiency.

Typical diesel engine sizes in cogeneration use are in the 1 to $3 \mathrm{MW}$ range. A major drawback to substantial increase in the use of diesel generation, which applies also to gas turbines, is their need for the use of petroleum based fuels. Some of the larger diesels, however, can burn residual fuels and combustion turbines can use natural gas.

Industry is showing substantial interest in the purchase of small prepackaged diesel cogeneration plants for use where electriclty costs are high. $(3,4)$. The long-term effects of the resulting increased consumption of diesel fuel have not been considered (at least publicly) although the effect upon the local utility load is causing concern. (3) Nelther have the environmental effects recelved wide attention although 
these units are frequently installed in non-industrial urban locations. Unit size for small prepackaged diesel cogeneration systems ranges from $200 \mathrm{~kW}$ to $4 \mathrm{MW}$, which has made them attractive to small industries and large buildings.*

Section 22.2.3: Summary of Cogeneration Characteristics

Table 22-3, entitled Characteristics of Important Cogeneration Systems, provides a generalized comparison of the steam turbine, combustion turbine and diesel topping cycles. Some of the data presented, e.g., concerning diesel generation, is discussed in detall elsewhere in this report. Nonetheless, it is appropriate to summarize in capsule form at this point. Justification and amplification for the simplified summary statements can be found in the text, extracted from the lables and graphs, or is directly referenced.

Meaningful cost comparisons are especially difficult to make because of the very different characteristics of the three systems; for any given application, no more than two approaches are competitive. As an illustrative rough comparison, the two turbine cycles are costed for the example process requiring 500,000 pounds of steam per hour. A diesel based system which generates one half million pounds of 150 psig steam per hour would also generate about 200 megawatts of electricity. Because diesel cogeneration of that much elertricity lo highly luprobable,** we list the cost of $a$ diesel cycle generating about the same amount of electricity as the steam turbine cycle. This system could produce only about 100,000 pounds of steam per hour. Therefore, the diesel cycle cost should be further incremented by the additional cost of providing 400,000 pounds of steam per hour, an additional $\$ 12 \times 10^{6(1)}$, thus demonstrating

* Diesel cogeneration is characterized by a relatively low-quality heat stream. It is best sulted for small installations providing electricity and space heating. This is borne out by the fact that about 600 such installations are in the field in the form of partial or complete "total energy" packages. (4)

Very few industrial applications would be capable of utilizing half the electricity generated by a 190-megawatt system. In that case, it is questionable if this distiflate oll-powered system would qualify for the cogeneration exemption to the Power Plant and Industrial Fuel Use Act of 1978 . 
TABLE 22-3

\section{CHARACTERISTICS OF IMPORTANT COGENERATION SYSTEMS}

\section{Reliab1lity}

overall (comparative) typlcal inspection/overhaul typlcal service life periods

Costs $^{(1)}$ (1bs stean/hr/elec. gen.)

Initlal (incremental) per kW generating capacity of electricity.generated

Fuel Reoulrements

Fuel Utilization Efficiency (nominal)

output mix - electricity

$$
\text { - heat }
$$

Flexibility in Design

overall (comparative)

size range

electricity/heat ratio ${ }^{(4)}$

steam quality

Flexibility in Operation

(In heat to electric1ty ratio)

Slting Problems

Emissions

Technological Status

Installation Time

\section{Steam Turbine \\ Topping Cycle}

highest

3-5 yrs/10 yro

$30-50$ yrs

$500, n 00 / 30 \times 10^{6} \mathrm{w}$

$\$ 15 \times 10^{6}$

$\$ 500$

$2.0 \mathrm{c} / \mathrm{kWh}^{\text {(3) }}$

flexible, can use coal or waste products

$75 \%$

$14 \%$

$86 \%$
Combustion

Turbine Topping

few

depends on fuel, can

be a major problem

2 years Cycle

high

$6 \mathrm{mos} / 2-4$ yrs

15-20 yrs

$500.0 \mathrm{~m} / 120 \times 10^{6} \mathrm{~W}$

$\$ 20 \times 10^{\mathrm{h}}$

$\$ 170$

$2.4 \mathrm{c} / \mathrm{kWh}$

residual ofl or gas, dist1llate

$65 \%$

$40 \%$

$60 \%$

highest

$300 \mathrm{~kW}-100 \times 10^{6} \mathrm{k}$

$\pm 5 \%$

moderate

high, efficiency

penalty

least

Diese1

Topping

Cycle

lowest $600 \mathrm{hrs}^{(4) /}$

$1-3$ yrs

20-25 yrs

$100,000^{(2)} / 40 \times 10^{6} \mathrm{~W}$

$\$ 10 \times 10^{6}$

$\$ 280$

$2.8 \mathrm{c} / \mathrm{kl} \mathrm{hh}$

$70 \%$

$52 \%$

$48 \%$

11 itied

$100 \mathrm{~kW}^{\mathrm{w}}-4 \times 10^{6} \mathrm{~W}$

$\pm 6 \%$

infted

lovest, but good part

load electrical

performance

noise

none to low

low

mature

$1-2$ years

21 year

(1) Costs are In 1977 dollars; for more detalls see Section 22.2 .4 and Reference 1 .

(2) Multiple unit system; additional 400,000 lbs steam generation would increase cost by about $\$ 1 \times 10^{7}$. Larger units, to 40 megawatts, are avallable for utility service.

(3) Fuel assumed is coal with no use of waste byproducts.

(4) without extraction or supplementary heating.

SOURCE: Reference 1 and Arthur D. Little, Inc., calculations. 
that diesel cogeneration is not cost-effective when large amounts of process steam are required. All costs are in 1977 dollars and based on information in Reference 1; in Section 22.2.4 the costing assumptions are given. The 1 isted costs are the incremental costs required for electrical generation over and above steam production.

\section{Section 22.2.4: Cost Estimates}

The busbar cost for electricity produced by cogeneration is estimated in Table 22-4. The costs listed there are based on the costs of complete cogeneration systems designed to produce both steam and electricity less the cost of 150 psig steam generating equipment. This approach permits calculation of electrical energy cost due solely to the electrical part of a cogeneration system. There 1s wide installation-specific variation in cogencration sysiem costs because more diverse dcmands are placed on cugeneration systems than on single-purpose electrical generation or steam plants. (6) Thus the costs given here are for comparison purposes only; nonetheless, they fall centrally within the inflation adjusted range of costs recently estimated for twenty-nine selected sites in New York State. (6) Similarly, In the base line year (1977), oil costs were very varlable depending on a number of factors, which cannot be all addressed in a simplified, industry-wide, cost estimate. For this reason, we have used a single cost for combustion turbine and diesel fuel.*

Finally, for completeness, Table 22-5 alsn inoludes tulal costs fur entire cogeneration systems.

\section{Seclion 22.2.5: Proposed Cogeneration Technologies}

Several energy conversion technologies now in an advanced stage of development have been proposed for use in future cogeneration systems. These are: Stirling engines, fuel cells, and organic Rankine cycles. None of these systems is currently avallable in commerclal sizes likely to be of industrial interest. Nevertheless, their potential usefulness warrants their receiving attention for possible use in cogeneration systems when and if they reach commercial and technical maturity. Stirling cycle englines (Chapter 14) are attractive for their high thermal

\footnotetext{
* See Chapter 1 for a discussion of fuel costs.
} 
TABLE 22-4

INCREMENTAL ${ }^{(1)}$ BUSBAR COST OF ELECTRICAL ENERGY FROM COGENERATION

(1977 dollars)

\begin{tabular}{|c|c|c|c|}
\hline$\frac{\text { Steam Flow }}{(1 \mathrm{bs} / \mathrm{hr})}$ & $\begin{array}{l}\text { Coal-fired } \\
\frac{\text { Steam Turbine }}{(\$ / \mathrm{kWh})}\end{array}$ & $\begin{array}{c}\text { Oil-fired } \\
\text { Combustion Turbine }\end{array}$ & $\frac{\text { Diesel }}{(\$ / k W h)}$ \\
\hline 100,000 & 0.027 & 0.025 & 0.028 \\
\hline 300,000 & 0.022 & 0.024 & 0.028 \\
\hline 500,000 & 0.020 & 0.024 & 0.028 \\
\hline
\end{tabular}

\section{ASSUMPTIONS}

1. $15 \%$ charge rate based on $10 \%$ cost of capital, 25 year operating 1ife, miscellaneous fixed charges of $4 \%$.

2. Capital costs from Reference 1 with inflation multiplier of 1.134 (1975-1977).

3. $80 \%$ capacity factor.

4. Coal-fired steam turbine cogeneration e $\$ 1.20 / 10^{6}$ Btu -- use of waste byproducts, as is possible in the pulp and paper industry, can significantly lower fuel costs. 011-fired combustion and diesel cogeneration @ $\$ 2.90 / 10^{6} \mathrm{Btu}$.

5. Process steam credit at following marginal efficiencies: Steam turbine -- $72 \%$, combustion turbine -- $62.5 \%$, diesel engine - $56 \%$.

6. O\&M costs (excluding fuel): Steam turbine -- $\$ 0.003 / \mathrm{kWh}$, combustion turbine and diesel -- $\$ 0.004 / \mathrm{kWh}$.

7. For capital costs see Table 22-5. The busbar costs above are based on incremental cost of electricity generation.

(1) These include incremental capital costs. (See Table 22-5.) O\&M costs (excluding fuel) are allocated entirely to electricity generation because with cogeneration these costs are much greater than those for low-pressure process steam bollers.

SOURCE: Reference 1 and Arthur D. Little, Inc., calculations. 
TABLE 22-5

COGENERATION SYSTEMS TOTAL CAPITAL AND ELECTRICAL INCREMENTAL COSTS

(1977 dollars)

\begin{tabular}{|c|c|c|c|c|c|c|}
\hline \multirow[t]{2}{*}{$\begin{array}{c}\text { Steam Flow } \\
(1 \mathrm{bs} / \mathrm{hr}) \\
\end{array}$} & \multicolumn{2}{|c|}{ 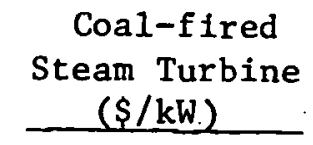 } & \multicolumn{2}{|c|}{$\begin{array}{c}\text { 011-fired } \\
\text { Combustion Turbine } \\
(\$ / \mathrm{kW})\end{array}$} & \multicolumn{2}{|c|}{$\begin{array}{r}\text { Diesel } \\
(\mathbf{S} / \mathrm{kW})\end{array}$} \\
\hline & Total & Increm. & Total & Increm. & Tota1 & Increm. \\
\hline 100,000 & 1600 & 830 & 350 & 240 & 360 & 280 \\
\hline 300,000 & 1100 & 590 & 280 & 170 & 360 & 290 \\
\hline 500,000 & 970 & 500 & 270 & 170 & 350 & 290 \\
\hline
\end{tabular}

\section{ASSUMPTIUNS}

1. Costs from Reference 1 with 1.134 inflation factor (1975 - 1977).

2. Steam turbine totals include fuel and ash handling equipment and pollution control equipment. Incremental costs exclude fuel handifing, ash handling and pollution control equipment as these would be required for process steam generation.

3. Combustion turbine and diesel incremental costs are based on differential between complete system and alternative oll-fired process heat boller system with the requisite fuel handling and pollution control systems. Coal-fired process heat boller cost differentials are about $\$ 27 / \mathrm{kW}$ and $\$ 34 / \mathrm{kW}$ less for diesel and combustion turbines, respectively.

SOURCE: Reference 1. 
efficlency and their ability to use many different types of fuel. Since the waste heat can be extracted relatively easily (as in the case of a diesel engine) their application to cogeneration systems is unlikely to present major difficulties.

Fuel cells (Chapter 16) are not yet available in large commercial sizes and the temperature at which waste heat can be made available by existing cells is 1 imited to $260^{\circ} \mathrm{F}$. Nevertheless, the relative simplicity by which heat can be extracted may make fuel cells attractive in situations where the electricity demand establishes system size and where there is a need for quantitles of heat at modest temperatures.

The technical and financtal issues associated with the use of utility-owned, grid-connected, dispersed fuel cells operating as dual energy use systems (DEUS) have been assessed in an investigation supported by. the Electric Power Research Institute. (7) The study examined the role of fuel cells to provide economic intermediate or peaking duty for the electric utility system, and to satisfy thermal loads in the residential, commerclal, industrial and utility sectors. The results indicated that both phosphoric acld and molten carbonate fuel cells were economicaliy attractive and technically viable for DEUS applications. The most attractive applications were building systems such as universities and hospitals; paper and pulp mills in industry; and air preheating for utility power plants.

Organic Rankine cycle machines (Chapter 15) may be of use where the residual stream at the low temperature end of the process steam cycle is present in sufficient quantity and quality to justify the addition of a bottoming cycle the capital costs of which tend to be high. The technology is available to construct organic Rankine cycle machines of commercially attractive sizes, but this new and operationally unproven technique has not yet attracted open market interest. Clearly, such bottoming cycles are only of interest where there is a need for process steam at high temperatures and an absence of attractively priced electricity. 
Section 22.3: Factors Affecting the Use of Industrial Cogeneration

It has been recognized for some time that the fraction of electricity demand that industry has met by cogeneration has decreased substantially between the 1950's and the early 1970's. The pattern of electricity generation and use for the $81 x$ major power consuming industries-food, textiles, pulp and paper, chemicals, . petroleum refining and steel--for the years 1947 and 197618 presented In Table 22-6. It Indicates that although total electricity generated by these Industries Increased by $91 \%$ and total electricity consumption by $382 \%$, the fraction cogenerated decreased from $31.6 \%$ to $12.5 \%$ of the total consumption. ${ }^{(8)}$

During this period the electric generating capacity of the U.S. Increased by a factor of 8.7 and was assoclated with a drop in the real price of electricity for all classes of customers. As a result it became harder for an Industry, planning to construct process steam producing bollers, to justify the incremental cost of the electric generating plant.

The cost of electrictity from the local utility is not the only factor to be considered although it may be a major one. Other considerations are technical and institutional. Technical considerations Include, for example, the constancy, or lack thereof, of a plant's demand for electriclicy and the ability of the local utflity to handle a demand which may vary seasonally. For example, sugar cane processing is seasonal and for much of the year the demand on the uility is low. On the other hand, agricultural waste products provide an inexpensive fuel supply so that cogeneration can become attractive. The ratio of electricity to process steam and its constancy determine the type of cogeneration plant that is desirable and consequently the costs of cogenerated energy.

In a 1975 report to the National Sclence Foundation by the Dow Chemical Company ${ }^{(9)}$ the following factors were suggested as causes of the decline in industrial cogeneration:

a. corporate income tax rates that encourage the 
TABLE 22-6

PATTERN OF ELECTRCITY GENERATION AND USE FOR SIX MAJOR U.S. INDUSTRIES

\begin{tabular}{|c|c|c|c|c|}
\hline \multirow[b]{3}{*}{ Industry } & \multicolumn{4}{|c|}{$\begin{array}{c}\text { Electricity Generated by Industry and Used by } \\
\text { Generating Company }\end{array}$} \\
\hline & \multicolumn{2}{|c|}{$10^{6} \mathrm{kWh}$} & \multirow{2}{*}{$\begin{array}{l}\% \text { of Industry } \\
1947\end{array}$} & \multirow{2}{*}{$\begin{array}{l}\text { Consumptior } \\
\underline{1976}\end{array}$} \\
\hline & 1947 & $\underline{1976}$ & & \\
\hline Food & 1753 & 2584 & 17.2 & 6.2 \\
\hline Textiles & 1753 & 484 & 17.5 & 1.7 \\
\hline Pulp and Paper & 9211 & 25487 & 59.9 & 37.0 \\
\hline Chemicals & 7647 & 14954 & 39.0 & 9.3 \\
\hline Petroleum Refining & 2745 & 4499 & 42.2 & 14.0 \\
\hline Steel & 9217 & 13698 & $\underline{22.7}$ & 8.5 \\
\hline Total & 32326 & 61706 & 31.6 & 12.5 \\
\hline
\end{tabular}

SOURCE: Reference 8 . 
substitution of expenses for capital investments, and generally tend to foster shorter term thinking;

b. decreasing prices for electricity from central power stations that encourage substituting electric power for steam in some situations, thereby eroding the industrial steam base over time;

c. changes in the labor situation that make it difficult for industry to find and keep people able to handle the problems of coal-fired bollers;

d. avallability of gas- and o11-fired low-pressure packaged bollers that replace hlgher pressure coal-fired bollers sultable for cogeneration;

e. the shortened work week in many industries that increases operating problems and lowers the utilization of capital equipment;

f. the continual widening of a difference in average size of central power stations vs. industrial power generators, thus tilting economies of scale in favor of central power stations:

g. an attitude on the part of industrial management either to say, In effect, "we're not in the power business" or to Impose on power operations those policies relating to operation, maintenance, spare parts, etc., which apply to the major portion of the business;

\footnotetext{
* For example, power plant maintenance usually comes in infrequent but expensive doses. In his desire to keep up production levels, the uninitiated manager may attempt arbitrary economies, which may appear successful because a power plant normally has substantial built-in reserves. Continuation of this practice, based upon its apparent success, can bring the manager to a point at which he suddenly finds himself without a functioning power plant. Industrial plants have abruptly connected to the utility following the above scenario, and the process has seldom been reversed. (9)
} 
h. long-standing policles on the part of most privately owned electric utilities, such as declining rate schedules and heavy electrical demand charges that have discouraged the generation of electricity by other types of organization.

In addition to the technical complexities of matching the utility to the industrial plant's demand, the above considerations inevitably play a role in a company's deciston to undertake the construction of a cogeneration facility: The decision, in each case, will reflect the objectives and perspectives of the individual company and the power supply and financial conditions in which it finds itself. The effect of institutional constraints to be faced in the implementation of cogeneration is well summarized in the following quotation from Reference 6: "Of vital concern to industrial plant managers is security of supply and flexibility of operation; cogeneration systems will not be implemented, irrespective of the extent by which they reduce purchased power costs, if product manufacture or essential services are put at risk."

\section{Section 22.4: Future Prospects for Cogeneration}

The discussion of the preceding paragraphs has made two points clear: (1) much more complete use can be made of the energy in fuels when electricity and process steam or heat are cogenerated than when they are produced separately, and (2) technologies are avallable and others are being developed for efficient and economic cogeneration for a wide variety of industrial applications. Since it is widely recognized that energy conservation is the most cost-effective way of reducing the nation's demand for fuels of all types, cogeneration is likely to play an important role. The question then arises -- What national benefits can be achieved by the widespread use of cogeneration, and what must be done to realize them?

Two studies $(1,10)$ have examined in detail the economics and techniques of cogeneration; (a) "A Study of Inplant Power Generation in the Chemical, Petroleum Refining, and Paper and Pulp Industries," by Thermo Electron Corporation for the Federal Energy Administration, (1) 
and (b) "The Potential for Cogeneration Development in S1x Major Industries by 1985," by Resource Planning Assoclates, Inc. (RPA) for the Department of Energy. (10) The RPA report studied the factors that industry considers in deciding whether or not to install a cogeneration plant. It then provided an estimate of the potential for growth in cogeneration if economic and regulatory conditions remained unchanged (no Government action) and if the U.S. Government were to act to reduce the perceived barriers to the widespread installation of cogeneration. Table 22-7 summarizes their finding if there were no Government action.

With U.S. Covernment action, the predicted 1985 cogenerated steam total of $1.7 \times 10^{15}$ Btu can, according to RPA, be increased to a possible maximum of $2.6 \times 10^{15} \mathrm{Btu}$, an increase of $0.9 \times 10^{15} \mathrm{Btu}$. (See Table 22-8.) The corresponding increase in power generating capacity will be between 2000 and $6000 \mathrm{MW}$. (For comparison, the total installed generating capacity of the U.S. electric industry in 1978 was 557 GW.) These very substantial increases in cogeneration plant capactty could result from the following government actions:

- a $30 \%$ investment tax sredit;

- a 12 year depreciation option;

- government loan guarantees;

- exemption from FERC and PUC juriadictions of industrial cogeneration plants operating in parallel with, but not selling to, a utility;

- equitable prices for purchases of power by utilities from cogeneration plants;

- establishment of industrial electric power flat rate structures;

- exemption from ofl and gas use taxes;

- relaxation of sulfur dioxide emission standards; and

- preferential treatment on oll and gas allocations.

The first two actions are expected to induce the greatest development of cogeneration and thus result in the largest energy savings, but the remainder are generally more cost-effective. The reader is referred to the original report for a more detailed discussion and for estimates of the contributions to more cogeneration that each action would stimulate. 
TABLE 22-7

COMPARISON OF COGENERATED PROCESS STEAM PRODUCTION IN 1976 AND 1985 (EST.) IN SIX MAJOR INDUSTRIES (NO GOVERNMENT ACTION)

Cogenerated Process Steam $\left(10^{15}\right.$ Btu)

\begin{tabular}{lll} 
Industry & $\underline{1976}$ & $\underline{1985}$ \\
\hline Food & 0.027 & 0.049 \\
Textiles & 0.015 & 0.013 \\
Pulp and Paper & 0.236 & 0.891 \\
Chemicals & 0.190 & 0.408 \\
Petroleum Refining & 0.015 & 0.107 \\
Steel & $\underline{0.101}$ & $\underline{0.247}$ \\
& $\underline{0.584}$ & $\underline{1.715}$ \\
Corresponding Electrical Capacity & $4,000 \mathrm{MW}$ & $10,000 \mathrm{MW}$ \\
SouRCE: & &
\end{tabular}


TABLE 22-8

PROCESS STEAM COGENERATION AND COGENERATION POTENTIAL

$$
\text { (In units of } 10^{12} \text { Btu) }
$$

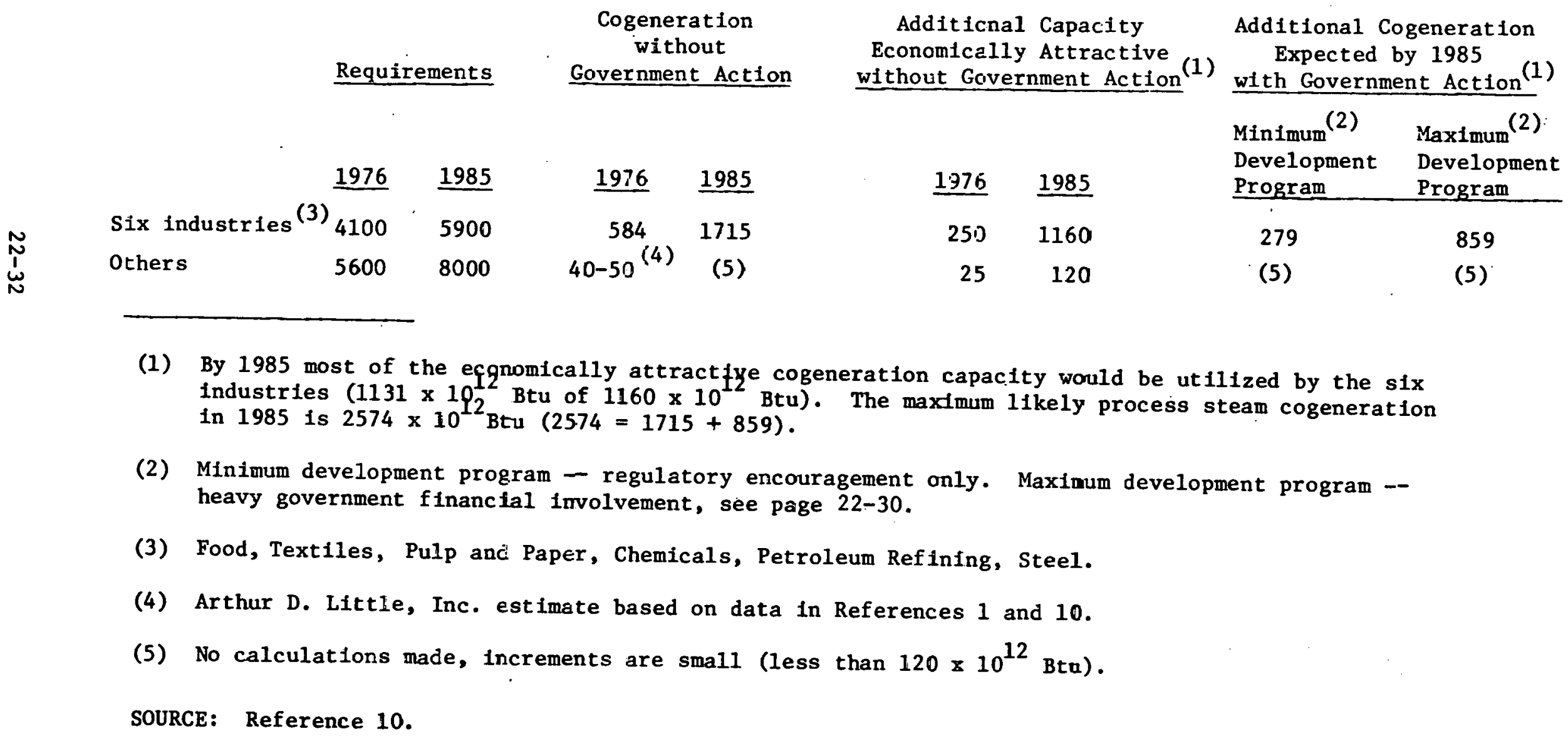




\section{REFERENCES}

1. Thermo Electron Corporation. A Study of Inplant Electric Power Generation in the Chemical, Petroleum Refining, and Paper and Pulp Industries. Prepared for Federal Energy Administration, June 1976. NTIS Report No. PB255 659 .

2. Arthur D. Little, Inc. Energy Penalties Associated with Environmental Regulations in the Pulp and Paper Industry. Vol. II, Analytical Results. Washington, D.C.: Environmental Protection Agency, Office of Planning and Management, June 1977.

3. Alexander, T. "The Little Engine that Scares Con Ed." Fortune 98 (13) : 80. December 31, 1978 .

4. Cummins Cogeneration Co., Inc., Empire State Building, 350 Fifth Avenue, New York, New York. Personal communication. September 1979.

5. Economic Regulatory Administration, U.S. Department of Energy. "Powerplant and Industrial Fuel Use Criteria for Petition for Exemption from Prohibitions." (Interim Rule). Federal Register 44 (97): 28949. May 17, 1979.

6. Acres American, Inc. Survey of Cogeneration Potential of Selected New York State Industries. Albany, New York: New York State Energy Office, June 1979.

7. Mathtec, Inc. An Analysis of the Applicalion of Fuel Celis in Dual Energy Use Systems. Vo1. 2. Report prepared for Electric Power Research Institute, February 1979. EPRI Report No. EM-981.

8. $0^{\prime} \mathrm{Ne} 111$, J. $\dot{\mathrm{K}}$. et a1. "Cogeneration in the Chemical Process Industries." Unpublished paper. Cambridge, Massachusetts: Arthur D. Little, Inc., [1979].

9. Dow Chemical Company. Energy Industrial Center Study, Report prepared for National Science Foundation, June 1975. NTIS Report No. PB 243 823.

10. Resource Planning Associates, Inc. The Potential for Cogeneration Development in Six Major Industries by 1985. Report prepared for U.S. Department of Energy, December 1977. NTIS Report No. HCP/ M60172-01/2. 


\section{SUPPLEMENTARY BIBLIOGRAPHY}

1. Bos, P.G. et al. "Cogeneration's Future in the CPI." Chemical Engineering 86(5):104. February 26, 1979.

2. Troop, P.A. "Cogeneration in a Changing Regulatory. Environment." Chemical Engineering 86(5):111. February 26, 1979.

3. Javetski, J. "Cogeneration: Washington Fiddles While Industry Burns." Power 122(4):35. April 1978.

4. Hallman, D.W. "Save Energy by Cogeneration." Hydrocarbon Processing $57(5): 151$. May 1978.

5. Hilsen, N.B. et al. "Env1ronmental, Economic and Conservation Aspects of Integrated Energy Systems." Proceedings of the 12th Intersociety Energy Conversion Engineering Conference, Washington, D.C., August 28 - September 2, 1977. pp. $621 \mathrm{ff}$. 
CHAPTER 23

TECHNOLOGY SUMMARY SHEET

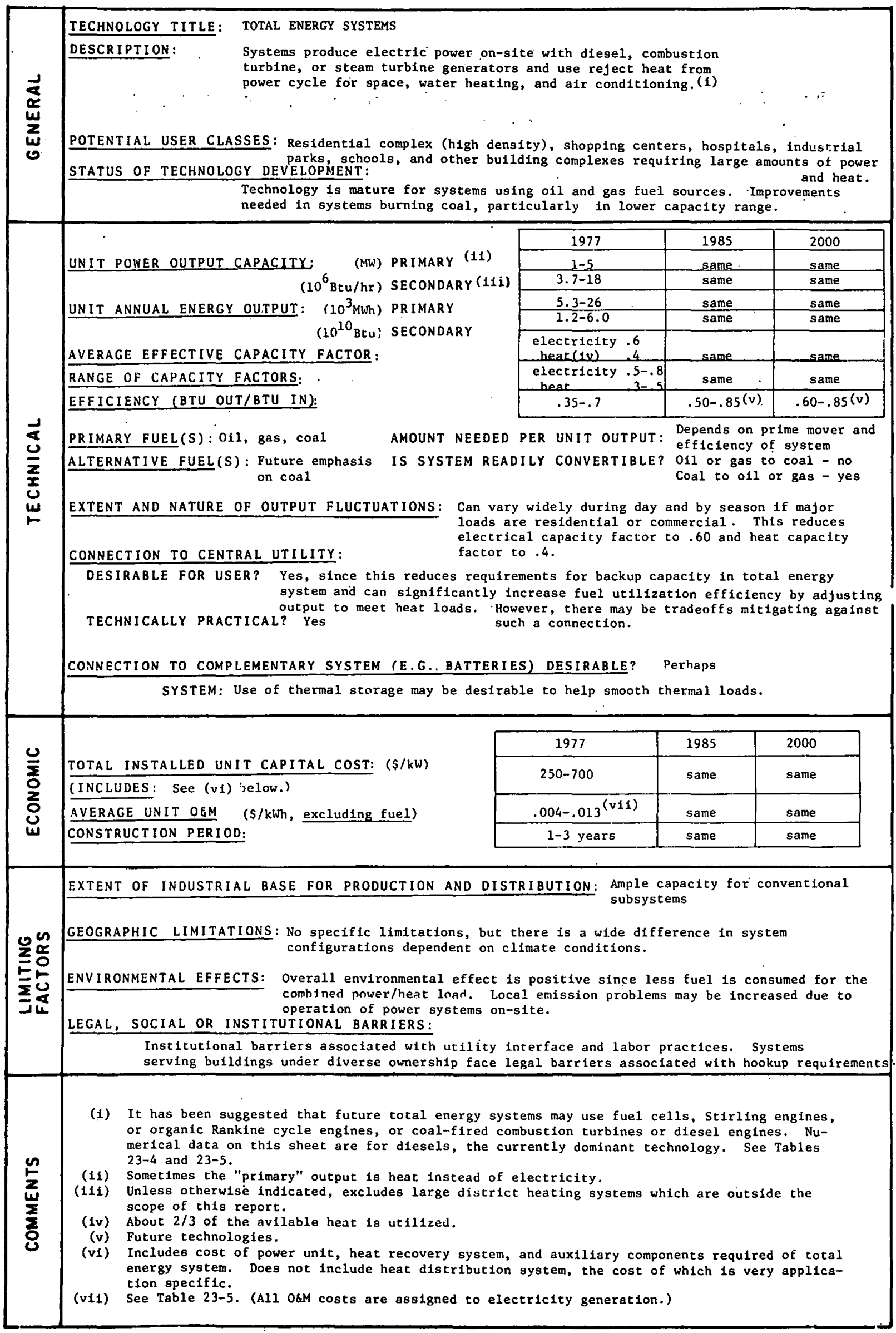


CHAPTER 23

TOTAL ENERGY SYSTEMS

Section 23.1: Introduction

Central power generating systems (steam plants, combustion turbines, diesels) convert $20-40 \%$ of the energy content of the fuel into power. The remaining $60-80 \%$ of the energy is rejected in the condenser and/or exhaust gas streams. A portion of this rejected heat can, in principle, be recaptured and used for a range of space heating. and water heating applications. Systems which perform such a dual function (power generation and heating) have been utilized for years under a variety of descriptive names, such as total energy, district heating, and cogeneration. "Total energy" usually refers to the production, on site, of electrical power for large residential, commercial, or institutional building complexes (hospitals, hotels, etc.) by diesel engines or combustion turbines, with the rejected heat being used for space and water heating applications.

In more than 40 cities in the United States, heavily populated downtown areas are serviced by a district heating system where the heat is supplied by a central utility. (1) In some cases, the steam is supplied by back pressure or extraction turbines in central steam power plants operated by the electric utility. Cogeneration ${ }^{*}$ usually refers to the combined generation of power and process heat in large industrial plants, such as paper mills.

Despite the high energy efficlency of total energy systems (as compared to those that generate electric power only), their use has been quite limited and, in fact, has tended to diminish over the last decade. One reason for this has been the increasing efficiency of large central generators which has resulted, until recently, in steadily declining electric power rates. This factor, combined with the high costs of operating and maintaining sophisticated on-site power generating equipment, has tended to put total energy systems at an economic disadvantage.

* Discussed in more deta11 in Chapter 22. 
Furthermore, there are additional economic penalties associated with part load performance of isolated total energy systems. For total energy systems where the primary concern is electric power, the pena1ties of part load performance can be substantial, especially in the cases of combustion turbines and steam turbines. The part load performance degradation is basically due to the drop in efficiency and hence the increase in fuel consumption per kllowatt hour of electricity generated. Diesel engines have somewhat better part load performance and have often been the cholce for applications where cyclic demand variations are expected.

If, on the other hand, the primary purpose of a total energy system is providing heat energy, then the effects of part load performance may not be significant because one way or the other the fuel heat energy is effectively utilized.

The recent rapid increases in the cost of energy delivered by central utility systems have significantly altered the competitive position of total energy systems. As a consequence of the emphasis being placed on conserving energy supplies, the government now supports several programs intended to improve the technology options avallable for total energy systems and to encourage their extended use.

The Modular Integrated Utility System (MIUS) program, $(2,3)$ which was started by the Department of Housing and Urban Development (HUD) in 1972, has as its major thrust the development of total energy systems for use in residential/commercial communities. They are based on standard components and a standard modular construction to allow for easy expansion and reduced engineering and design costs. The MIUS programs also include integration of other utility services required by a community (waste disposal, potable water, etc.) into the overall system concept.

The Integrated Community Energy Systems (ICES) program $(4,5)$ is sponsored by the U.S. Department of Energy (DOE). The goal of this program is to develop total energy systems for communities to support energy conservation and the use of coal as the primary fuel. The ICES program also uses total energy systems in conjuction with the utility 
power network to: (a) reduce the need for redundant or excess capacity in the total energy package, (b) provide for a sales outlet for excess electric power produced by the total energy system, and (c) provide the utility with relatively inexpensive distributed power sources which can be used, if needed on an emergency basis.

The combination of changing energy economics, increased R\&D in more efficient and reliable equipment, and government participation in demonstration projects, is expected to increase the future use of total energy systems so that they may become a significant factor in the overali energy picture.

Section 23.2: Technical Discussion

A. System Description

The prime mover options most of ten used to generate electrical power in total energy systems are: steam turbines (Rankine cycle engines), dtesel engines, and combustion turbines. (Brayton cycle engines). In addition to these conventional prime movers, total energy systems using advanced technologies, such as Stirling engines and fuel cells, are also being developed. The systems using these advanced technologies are not yet commercially available, however. The choice of engine generator systems is influenced by many factors including system size, temperature requirements of heating loads, fuel flexibility requirements, ratio of electrical to thermal demands, initial costs, and operation and maintenance costs.

Schematics of simplified total energy arrangements using the three conventional prime mover options are shown in Figures 23-1, 23-2, and 23-3. In steam turbine systems, hot, high-pressure steam is produced in a boiler and passed through a turbine to produce power. The partially expanded and cooled steam can then be extracted and used for space heating or water heating functions. The heat from this steam can also be transferred in a condenser to a pressurized hot water loop. Usually the steam is used at temperatures in the $212-350^{\circ} \mathrm{F}$ range to 1 imit pressure levels and to reduce efficiency penalties in the operation of the steam turb1ne system. 


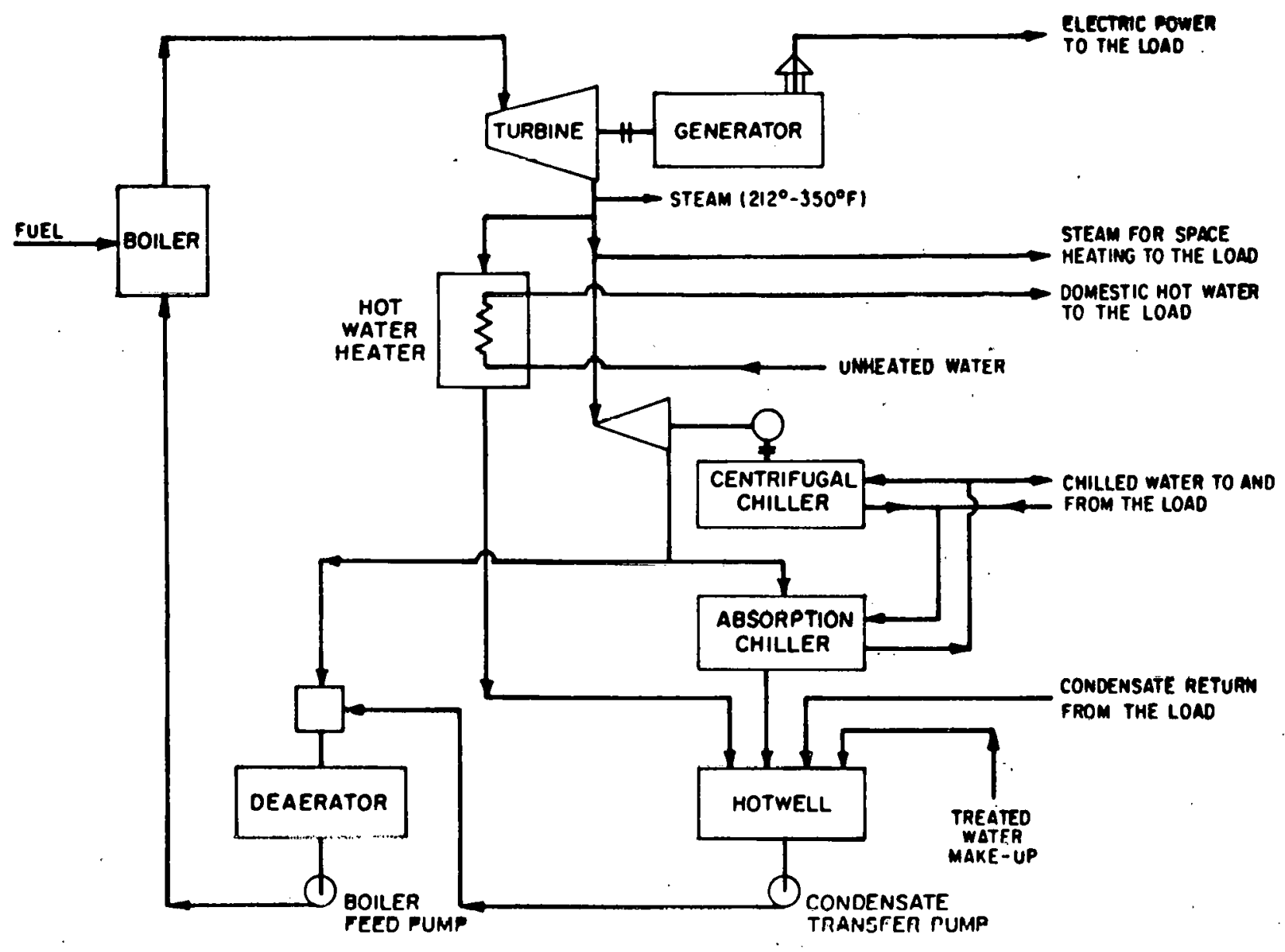

SOURCE: Reference 6.

FIGURE 23-1 TOTAL ENERGY SYSTEM SCHEMATIC USING STEAM TURBINE 


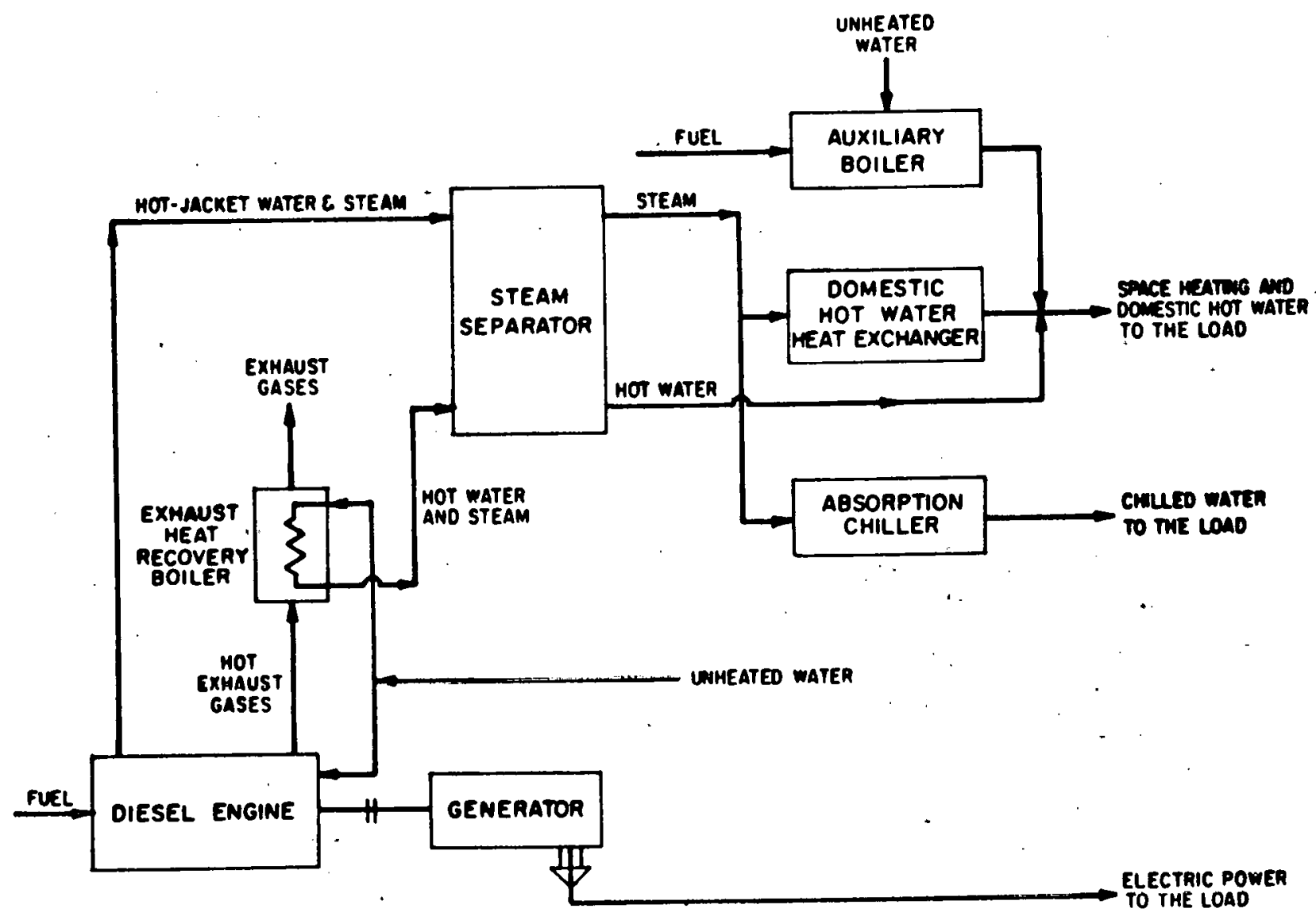

SOURCE: Reference 6 .

FIGURE 23-2 TOTAL ENERGY SYSTEM SCHEMATIC USING DIESEL ENGINE 


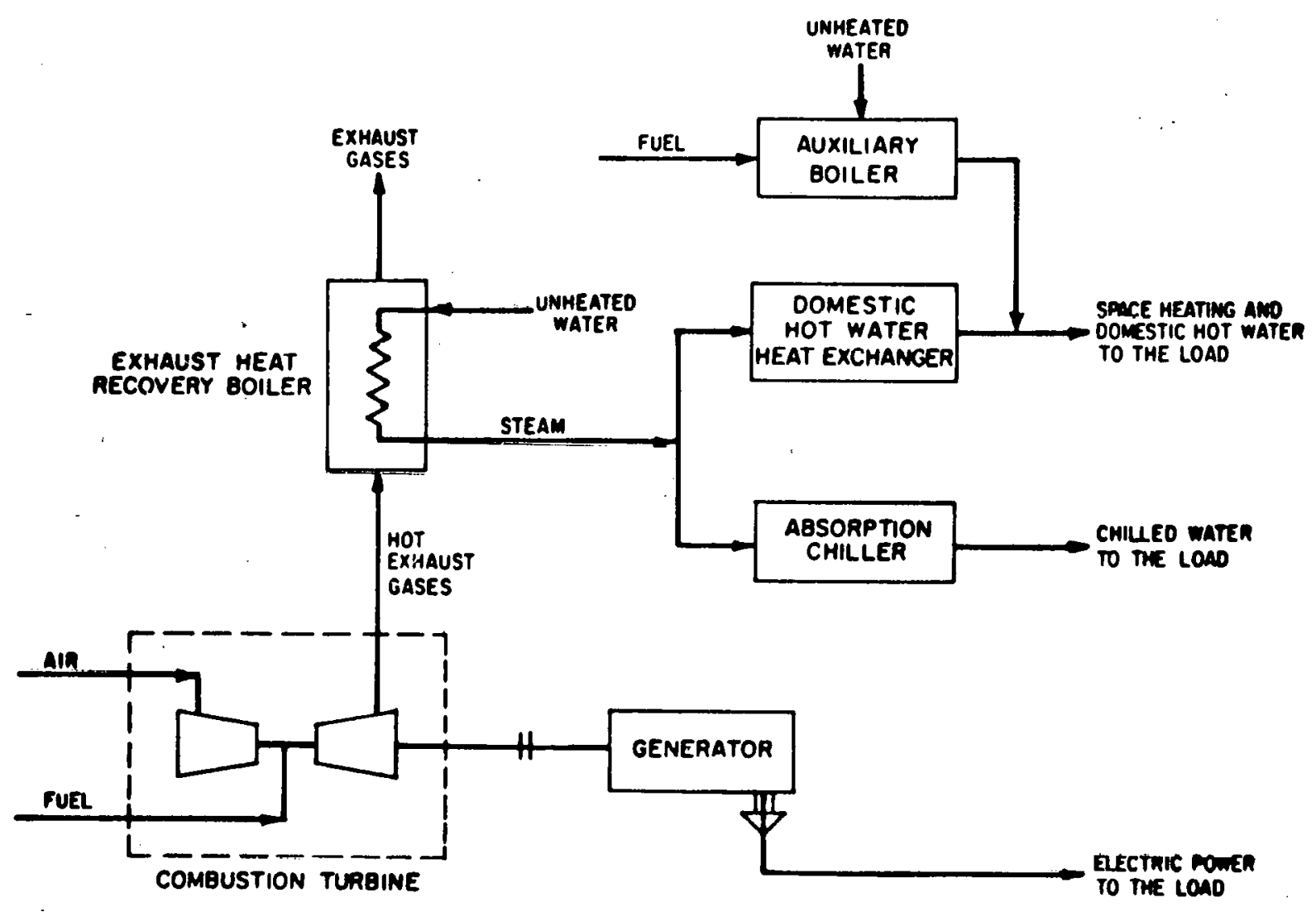

SOURCE: Reference 6

FIGURE 23-3 TOTAL ENERGY SYSTEM SCHEMATIC USING COMBUSTION TURBINE 
In systems using diesel engines as the prime mover, most ( $65 \%$ ) of the heat is generated in waste heat bollers placed in the hot (600$1000^{\circ} \mathrm{F}$ ) engine exhaust stream. Hot water at lower temperatures can be generated from the engine jacket water cooling systems. With combus-. tion systems, all the heat is generated in heat recovery bollers placed in the engine exhaust.

These options have different. efficiency levels for converting thermal energy into power and, therefore, different power-to-heat ratios. These are indicated in Figure 23-4 for a number of systems used or being considered for use in total energy systems. If all of the rejected heat available in a total energy system arrangement based on any of the above technology options could be recovered and utilized, the overall efficiency of energy utilization would be in the 75-85\% range. However, such an efficiency level could require a consistent match between the electrical power and thermal energy loads. Where the system output is dictated by the demand for electrical power, this match is usually not the case all year if a major share of the thermal loads is determined by climatic conditions, e.g., space heating and air conditioning. Typical steam load curves for a residential/ commercial community are shown in Figure 23-5. The thermal loads vary considerably by season, while the electrical demand remains fairly constant during the year.

One common subsystem in all the total energy systems indicated in Figures 23-1, 23-2, and 23-3 is a heat-actuated cooling machine (typically 1ithium bromide absorption chillers). The use of absorption cooling helps to even out the thermal load during the year when a major portion of the thermal output of the total energy systems is for space conditioning.

For most community applications there is also a wide daily variation in electrical and thermal loads (as per Figure 23-6). Those daily load variations can lead to additional mismatches between electrical output requirements and thermal needs. Such mismatches which occur on a daily cycle can, however, be somewhat smoothed out by use of thermal storage (elther hot water for heating or chilled water for air conditioning). 


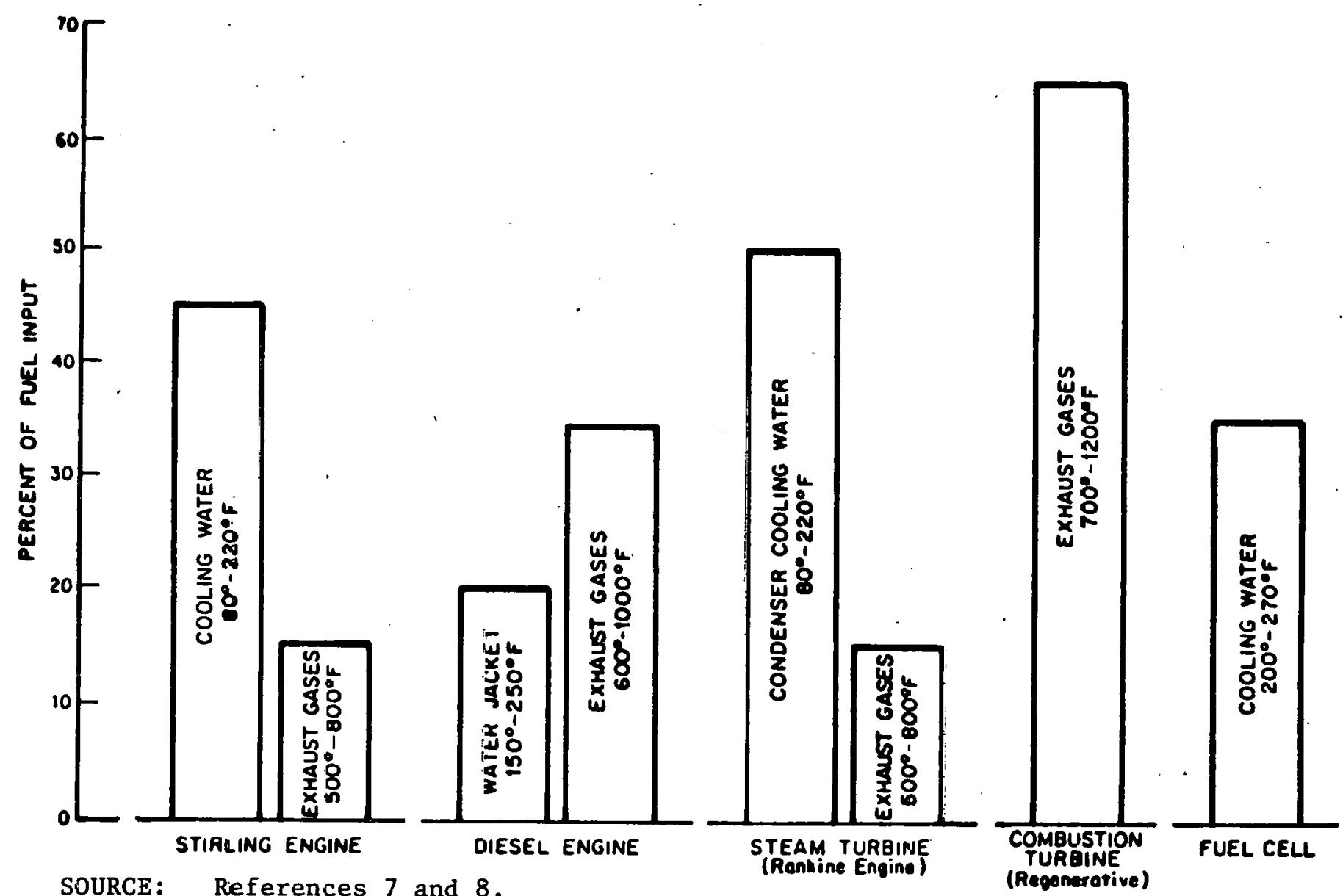

FIGURE 23-4 WASTE HEAT AVAILABLE FROM TOTAL ENERGY SYSTEM PRIME MOVERS 


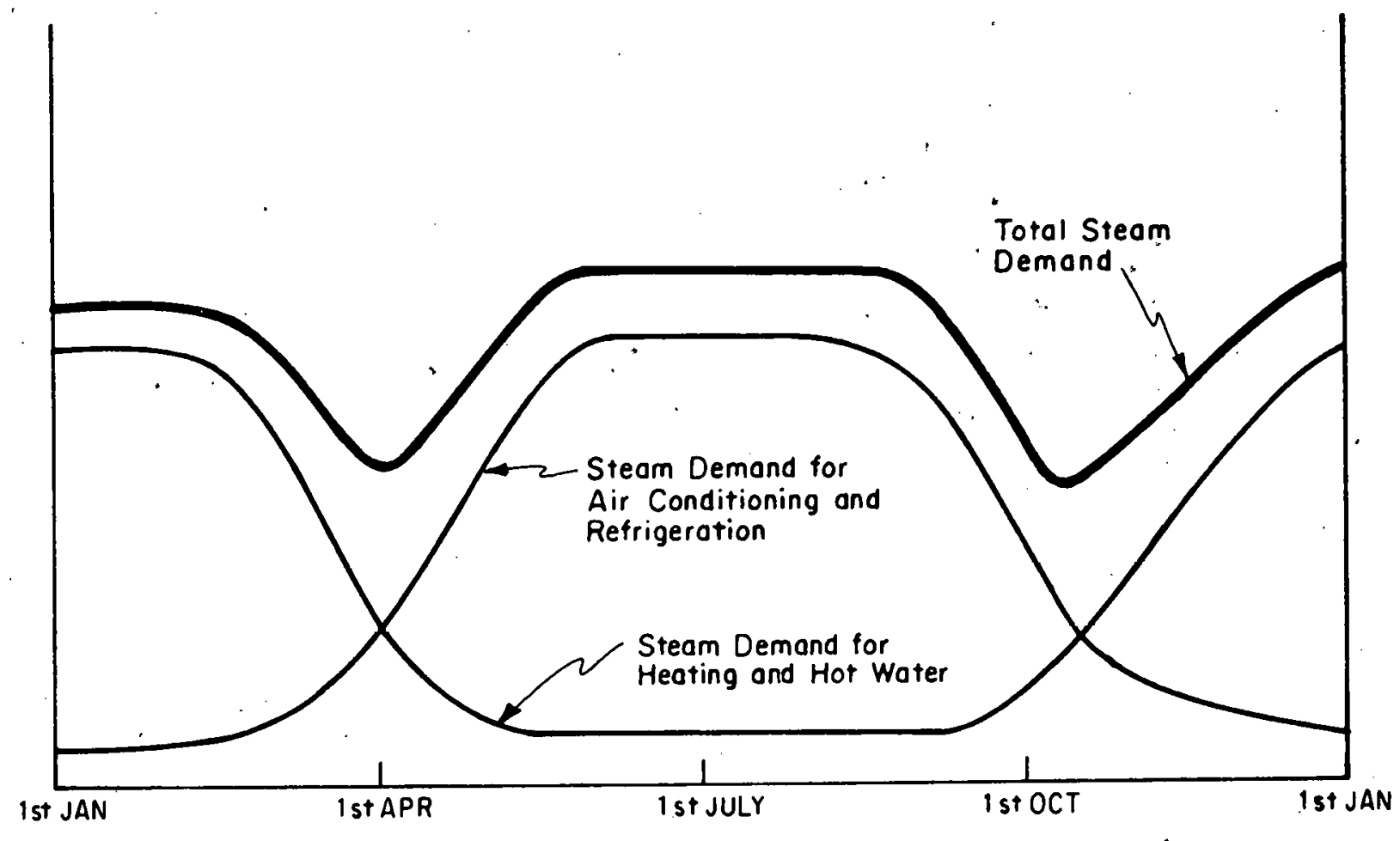

SOURCE: Reference 9 .

FIGURE 23-5 VARIATION IN STEAM DEMAND DURING THE YEAR FOR A TYPICAL COMMUNITY 


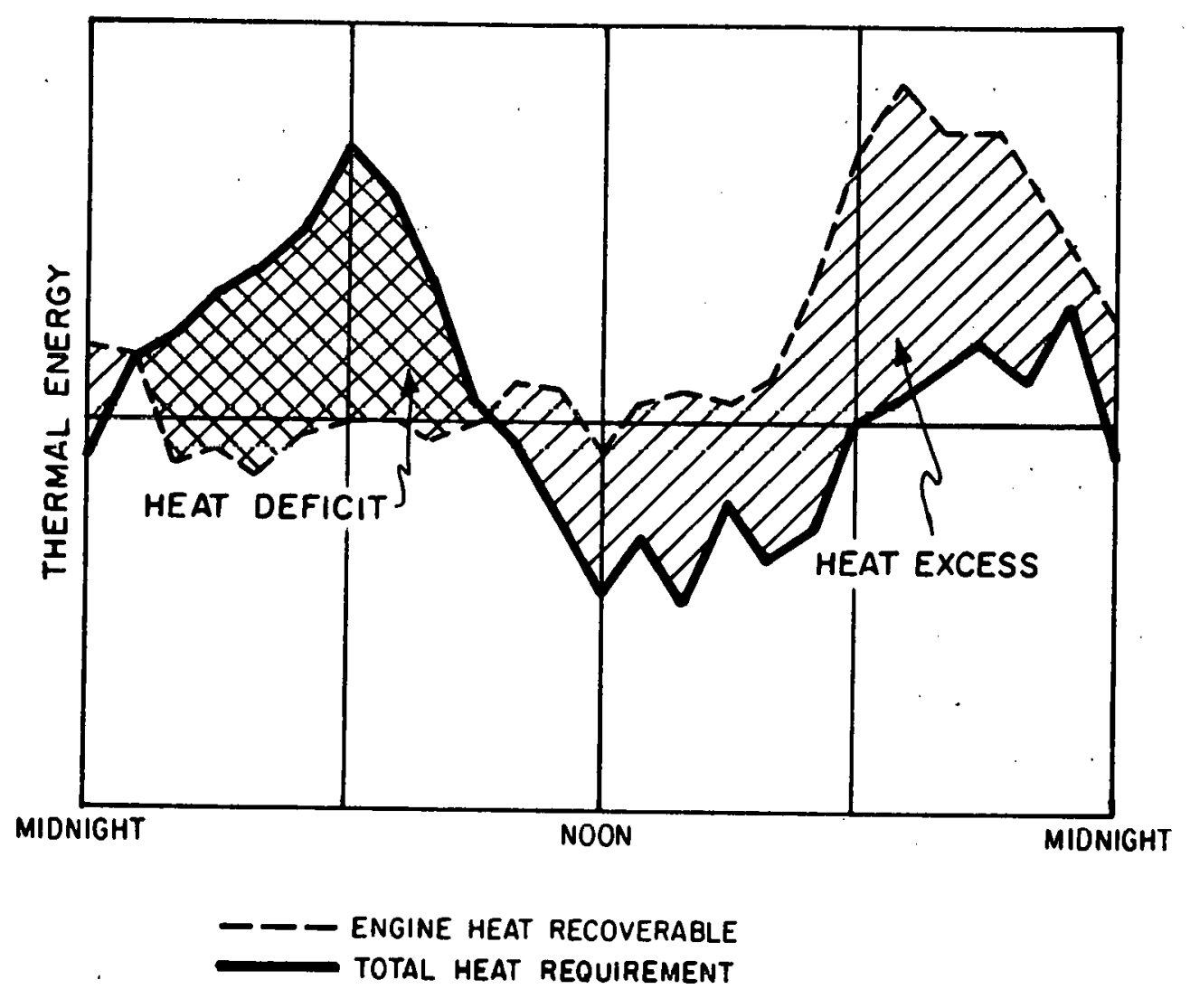

SOURCE: Reference 9.

FIGURE 23-6 TYPICAL THERMAL MISMATCH BETWEEN HEAT REQUIRED AND RECOVERABLE HEAT FOR A TOTAL ENERGY PLANT OF A RESIDENTIAL COMPLEX IN NORTHERN LATITUDES 
As a result of the above considerations, most total energy systems must dissipate excess thermal energy during the course of the year, with the result that net system fuel utilization is usually in the $50-70 \%$ range, which is still much better than that of electrical power production alone. One of the goals of the ICES program is to operate the system according to thermal demand and to sell excess electric power produced back to the utilities. A system so designed has the advantage that it can attain very high annual efficiency levels since no thermal energy is ever dissipated. It does, however, require an agreement with the local electric utility to accept excess power from the total energy system, which may not. be practical in many cases.

Operational flexibility of these systems is fairly limited. For the conventional installation operated to meet electrical demand, flexibility can be achieved by wasting heat or firing auxiliary boilers. The first option reduces fuel utilization efficiency, the second increases capital costs. These systems have typically been diesel powered partly because dlesels exhibit good part load performance, thus permitting some electrical flexibility. Multiple-unit diesel systems are, of course, more flexible than single-unit systems because additional units can be brought on line as needed. For units operated to meet thermal demand, flexibility will be provided by the connection to public utility grids. Equitable allocation of the costs of these widely varying loads is not simple, although the interconnection of many total energy systems will tend to average the load fluctuations somewhat.

B. Advanced Systems

The areas of advanced development for total energy systems include solar-based and coal-fired energy sources, and fuel cells.

\section{- Solar-based Total Energy Systems}

The concept of total energy utilization is being extended to combined solar power/heating/cooling systems, such as is indicated in Figure 23-7. These systems are under development at Sandia Laboratories 


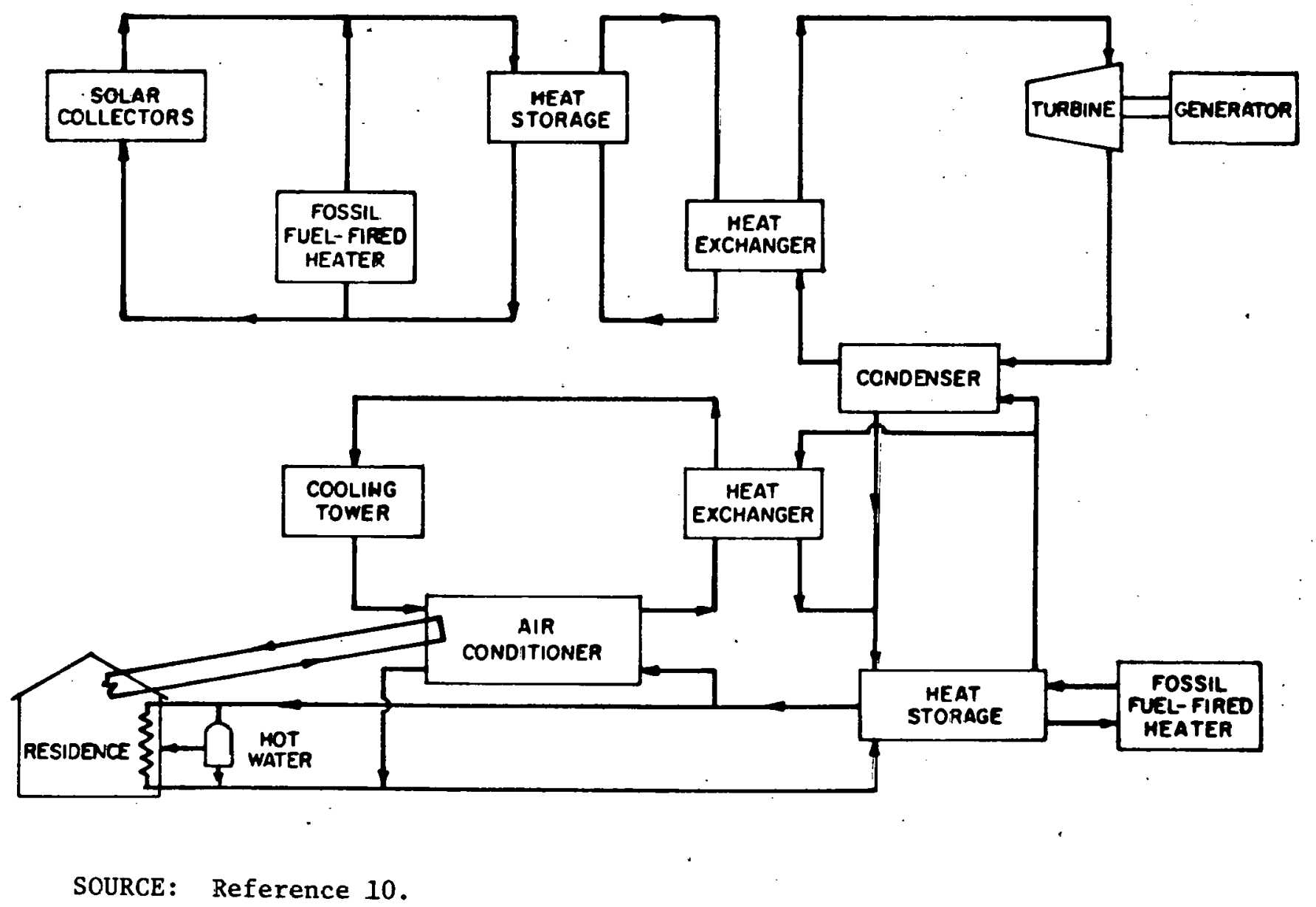

FIGURE 23-7 SCHEMATIC DIAGRAM OF A SOLAR TOTAL ENERGY SYSTEM 
as part of the DOE solar program. (10) Generally, solar total energy systems use concentrating solar collectors to allow for the operation of heat engine driven generators (usually Rankine cycles). The rejected heat from the heat engine systems is then used for space and water heating functions as with conventional total energy system arrangements. A variation of this approach (Figure 23-8) uses solar energy in conjunction with diesel generators within a total energy arrangement. (11) Such a system may have synergistic effects since the heat engine and thermal storage unit can make use of two heat sources (solar and engine exhaust).

\section{- Coa1-Fired Total Energy Systems}

The decreasing avallability of oll and gas provides a strong Incentive to develop total energy systems which can use coal as the basic energy source. Of course, coal can be, and is, used to fire large total energy systems using boller/steam turbine configurations. Present coal-fired systems in smaller sizes typical of total energy systems are, however, of ten quite inefficient, costly to maintain, and difficult to operate consistent with environmental regulations. Consequently, there is now a signiflcant effort to develop advanced coal-fired systems. One major activity in this field is work at Oak Ridge National Laboratories in support of the MIUS program. (12) One system under particular consideration as a result of this effort is the use of fluidized-bed reactors providing heat to closed Brayton cycle engines. This system is projected to convert about $30 \%$ of the energy into electricity and about $50 \%$ into heat which can be used for space and water heating. A primary incentive behind the use of the fluidized-bed combustion is its ability to use a wide variety of coals with little environmental impact. (See Chapter 11.) Argonne National Laboratory has recently started to evaluate the use of Stirling engines in total energy systems, again with particular emphasis on coal-fired systems. (13) The potential advantages of stirling engines include potentially very high electric efficiency (35\%), low nolse levels, good part load performance, and a ready adaptability for using the waste heat dissipated. (See Chapter 14 for a further discussion of the Stirling Engine.) 


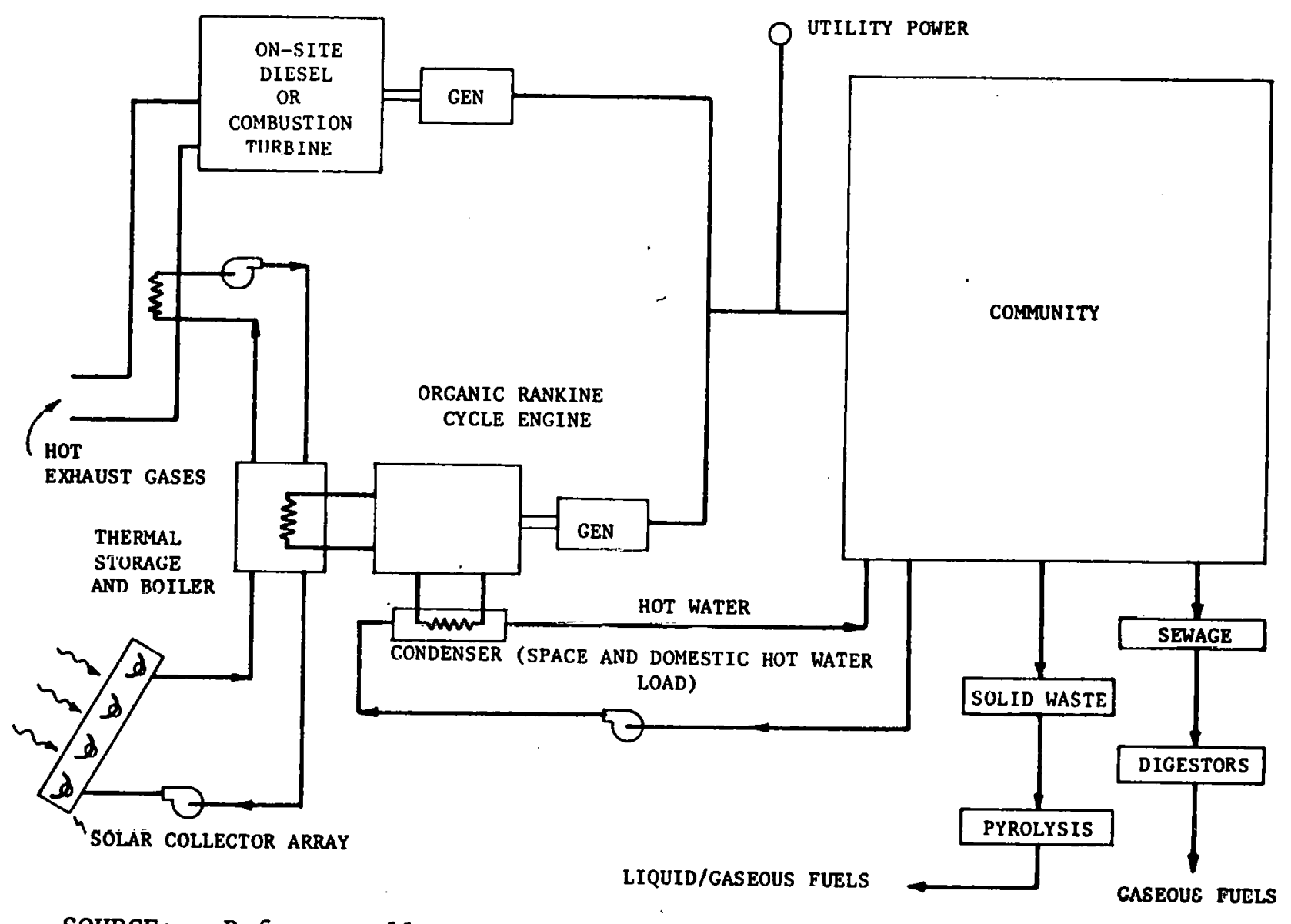

SOURCE: Reference 11.

FIGURE 23-8 SCHEMATIC OF A COMBINED SOLAR/CONVENTIONAL TOTAL ENERGY SYSTEM 
- Fuel Cel1s

In recent years, fuel cells have been greatly improved and are under development in sizes up to several megawatts (see Chapter 16) and large enough to be able to make useful contributions to the nation's electricity supply. (8)

The application of fuel cells to total energy systems also results from 1ts efficiency which is not limited by the Carnot cycle effictency as in the case for heat engines. A recent study (14) shows that fuel cells operating as a source of both heat and electricity can have overall efficiencies in excess of $80 \%$. Furthermore, a fuel cell has nearly constant efficlency from 25 to $100 \%$ of its rated power output and hence has an excellent load-following characteristic. (See Chapter 16.)

A major project concerned with the total energy application of fuel cells is presently at the planning stage. It is an extension of the TARGET project (Team to Advance Research for Gas Energy Transformation). The TARGET project was initiated in 1967 by the United Technologles Corporation and a consortium of gas and gas-electric utilities for the development of on-site residential and commercial phosphoric acid fuel cell power plants, utilizing gas (natural or synthetic) as fuel. In 1972 and 1973, more than 60 power plants of 12.5-kW capacity were. tested, and in 1975 a 40-kW plant was developed. (15) Now an extension of the TARGET project supported by the Department of Energy and the Gas Research Institute has the objective of testing 50 plants of $40-\mathrm{kW}$ capacity between 1979 and 1981 and a fully commercialized technology by 1982 .

\section{Applications}

To date, the primary applications of total energy systems have been within large bulldings or clusters of bulldings under the control of a single owner. Typical applications have been in large school buildings, hospitals, apartment complexes, shopping centers, office buildings, and institutional complexes.

In addition, there are more than 40 district heating systems 
in the United States serving downtown areas of large cities. These systems, usually operated by the electric utility, often* use backpressure or extraction steam from a turbine system (Figure 23-1). A1though they can be classified as a type of total energy system, largescale district heating systems are not normally so considered.

Table 23-1 indicates the specifications for several typical total energy systems in the United States and Canada; Table 23-2 1ists the location and capacity of the major district heating systems in the United States. As indicated, almost half of all the installed capacity is located in New York City (operated by Consolidated Edison Company).

It should be noted that the present government-sponsored total energy programs (MIUS and ICES) are intended to serve complete communities, or significant portions of complete communities. As such, these systems will often require the laying of pipes for hot water or steam distribution In public streets as is the case with district heating systems (with their assoclated institutional and cost problems as discussed 1ater). Table 23-3 indicates the specifications for four ICES systems to be connected to the public power network which are now in the design phase.

Section 23.3: Economics Discussion

The energy conseryation incentives behind total energy systems have been well known for a long time. Nevertheless, total energy in all its forms has had a very uneven developmental history. This is primarily because, in many situations, the overall costs associated with total energy systems have been higher than the costs for purchasing electricity from the utility and operating conventional fuel-fired heating systems. Several economic factors now tend to favor the introduction of total energy systems. They include the following:

*However, in some cities most of the steam is produced in separate
central boilers without any associated electrical power generation. 
TABLE 23-1

REPRESENTATIVE TOTAL ENERGY SYSTEMS IN THE UNITED STATES AND CANADA

System Location

1. Brooklyn Union Gas Co. Rochdale Village, New York

2. Regency Square Jacksonville, Florida

3. Park P1aza Little Rock, Arkansas

4. Gulf of Mexico

5. Hillcrest, Edmonton, Alberta, Canada

6. Burns Brick Co. Macon, Georgia

\section{Application}

Apartment building and shopping center

Shopping center

Shopping center

Oil drilling rigs

Junior high school

Industrial building w/machines, cranes, hoist

7. Engineered Plastics Ltd. Production plant Edmonton, Alberta, Canada

8. Cattle Marketeers, Inc. St. Cloud, Florida

9. Ohio State University Columbus, Ohio

\section{Power Source}

Total Capacity (MW)

2 Steam turbines

15.0

9 Natural gas engines ${ }^{(1)}$

1 Combustion turbine

2 Natural gas engines $(1)$

1.2

Combustion turbines

0.3

2 natural gas engines (1)

0.6

Natural gas-fired

1.2

combustion turbine $(1)$

2 Natural gas engines ${ }^{(1)}$

0.5

Combustion turbine

0.33

4 Natural gas engines (1) 
TABLE 23-1 (Continued)

\begin{tabular}{lll} 
10. & System Location & \multicolumn{1}{c}{ Application } \\
11. Peoria, Illinois & High school \\
12. & Wendover, Nevada & Motel \\
13. Anoka, Minnesota & Mill \\
14. Chenoa, Illinois & Manufacturing \\
15. Sheldon, Illinois & Manufac:uring \\
16. Galesburg, Illinois & School \\
$\underset{\omega}{\omega}$ & 17. Lake Forest, Illinois & Service station \\
18. & Chicago, Illinois & Service center \\
19. New Haven, Missouri & Bottling .
\end{tabular}

\section{Power Source}

Natural gas engines $(1)$

Diesel engines

Diesel engizes

Diesel engizes

Diese1 engines

Diesel engines

Diesel engines

Diesel engines

Diesel engines

Diesel engines
Total Capacity (MW)

1.4

0.57

0.5

0.15

0.28

0.11

0.25

0.17

0.53

0.25

(1) Modified diesel engines.

SOURCE: References 9 and 16. 
DISTRICT HEATING SYSTEMS IN THE UNITED STATES

rotal Steam

City

New York, NY

Philadelphia, PA

Detroit, MI

Boston, MA

Indianapolis, IN

Rochester, NY

Cleveland, $\mathrm{OH}$

Milwaukee, WI

Baltimore, $\mathrm{MD}$

st. Louis, MO

Dayton, $\mathrm{OH}$

Cambridge, MA

Denver, $C O$

Pittsburgh, PA

Seattle, WA

Harrisburg, PA

San Francisco, CA Lansing, MI

Grand Rajids, MI

Minneapolis, Mr

Eugene, OR

Akron, $\mathrm{OH}$

Spokane, WA

Erie, PA

Birmingham, AL

St. Paul, MN

Toledo, $\mathrm{OH}$

Youngstown, $\mathrm{OH}$

Scranton, PA

Hartford, CT

Rochester, MN

Nashville, TN

Salt Lake, UT

Concord, NH

Bronxville, NY

Piqua, $\mathrm{OH}$

Springfield, $\mathrm{OH}$

Southfield, MI

Rice Lake, WI

San Antonio, TX
Company Name

Consolidated Edison Co. of N.Y.

Philadelphia Electric Co.

Detroit Edison Co.

Boston Edison Co.

Indianapolis Power \& Light Co.

Rochester Gas \& Electric Corp.

Cleveland Elec. Illuminating Co.

Wisconsin Electric Power Company

Baltimore Gas \& Electric Co.

Union Electric Co.

Dayton Power \& Light Co.

Cambridge Steam Corp.

Public Service Co. of Colorado

Allegheny County Steam Htg. Co.

Seattle Steam Corp.

Pennsylvania Power \& Light Co.

Pacific Gas \& Electric Co.

Board of Water \& Light

Consumers Power Co.

Central Heating Co.

Eugene Water \& Electric Board

Ohio Edison Co.

Washington Water Power Co.

Pennsylvania Electric Co.

Alabama Power Co.

Northern States Power Co.

The Toledo Edison Co.

Ohio Edison Co.

Community Central Energy Corp.

Hartford Steam Service Co.

Rochester Public Utilities

Nashville Thermal Transfer Corp.

Utah Power \& Light Co.

Concord Steam Corp.

Lawrence Park Heat, Light \& Power Co

Municipal Power System

Ohio Edison Co.

Dayton Hudson Properties

Rice Lake Steam Corp.

City Water Board
Delivered

(10 1b)

41,886

8,461

6,573

6,543

4,864

3,732

2,540

2,499

2,496

1,929

1,836

1,644

1,459

1,678

1,400

1,121

987

923

819

692

629

727

622

613

565

532

467

494

455

371

287

207

221

155

194

142

128

87

66

72

SOURCE: Reference 1 (1975 data). 
TABLE 23-3

\section{PROPOSED ICES DEMONSTRATION PROJECTS}

Community

Clark Ủniversity

Worcester, MA

\section{City of Trenton}

Trenton, NJ

$\stackrel{N}{\sim}$

Health Education Authority of Louisiana (HEAL)

New Orleans, LA

University of Minnesota Minneapolis, MN

\section{Type}

Small Campus

- Education and Residential Buildings

Downtown Redevelopment

- Commercial, Institutional, Residential Buildings

Medieal Complex

- Hospitals and Health Educational Buildings

Large University Campus and Adjacent Hospitals

\section{Size}

1 million $\mathrm{ft}^{2}$

$1.5 \mathrm{MWe}$

$20,000 \mathrm{lb} / \mathrm{hr}$ steam

2 million $\mathrm{ft}^{2}$

$10 \mathrm{MWe}$

$120,0 j 0 \mathrm{lb} / \mathrm{hr}$ steam

3 million $\mathrm{ft}^{2}$ present

7.5 milition $\mathrm{ft}^{2}$ ultimate

11.7 MWe

$157,0001 \mathrm{~b} / \mathrm{hr}$ steam

14 million $\mathrm{ft}^{2}$

7.5 to $12.5 \mathrm{MWe}$

$300,000 \mathrm{lb} / \mathrm{hr}$ steam
On-Site

Power Source

Diese1

Engines

Combustion

Turbines

Coal

Boilers

Coal Boilers and Solid-Waste Gasifier

SOURCE: Reference 4 . 
- Electric utility rates are generally increasing faster than inflation as fuel costs and the costs of new plant construction increase dramatically. This is in contrast to the period from 1950-1965 when utility rates were declining;

- The costs of all fossil fuels are increasing rapidy and their availability (gas and oil) is becoming more questionable. This provides an additional incentive to improve the efficiency of fuel utilization and consider systems with some degree of fuel flexibility;

- The equipment required for total energy systems is improving, partly as a result of government programs;

- A number of government financial incentives (tax credits) reduce the effective cost of total energy systems to their tax-paying owners;

- Electric utilities are showing more flexibility about integrating total energy systems into the electric power network and thereby redueing the need for cxpcnsive otandby power systems. This is indicated, for example, by the willingness of several major utilities to buy back power from the ICES systems listed in Tab1e 23-3. (4)

Several of the major cost factors associated with the installation and operation of total energy systems are:

- Direct costs of power-generating equipment, heat recovery units, sophisticated electrical switching systems, relatively complex controls, as well as the costs of satisfying environmental regulations;

- Cost of providing the considerable space required for a total energy system (which requires, at least, twice the space of a simple heating unit);

- Costs assoclated with the skilled manpower needed to keep the equipment functioning under normal operation and to repair equipment as needed; and

- Increased taxes and insurance costs assoctated with having expensive equipment in-house. 
Table 23-4 1ists the approximate costs on an installed basis of conventional power units which might be appropriate for use in total energy arrangements. The lowest cost systems are seen to be gas turbines. Counteracting this inftial cost advantage is the low thermal efficiency of gas turbines and their present restriction to burn only high priced (and increasingly scarce) fuel forms (natural gas, refined ofl products). All costs are for complete engine-generator systems with all controls and switchgear.

For total energy systems serving a single, large building complex, the cost of distributing heat to the loads is generally not significantly different from a conventional system. However, for those systems serving a complete community (or section thereof), such as district heating, there are large additional costs associated with the steam or hot water piping system required to distribute heat from a central location to all the buildings being served. In present district heating arrangements in urban areas, the formidable cost associated with the distribution system is a major impediment to system expansion.

There are many factors affecting the choice of hot water or steam heat distribution systems. The principal advantage of a steam distribution system is that, since return piping is not required* (as opposed to a hot water system where return piping is necessary), the cost of the distribution system is substantially lower. A steam distribution system is more appropriate for applications where a high temperature $\left(\sim 250^{\circ} \mathrm{F}\right)$ heat source is needed. For long distance heat transport, the hot water system is generally used due to pressure losses associated with steam distribution and because hot water systems can carry more power per unit cross sectional area. European practice, which frequently involves long distance heat transport, tends to hot water distribution; U.S. practice tends to steam distribution. In

*The mass flow rate in low-pressure steam systems tends to be low enough to encourage dumping used condensate into the local sewer system. This practice has encouraged utilities to move to separate boilers for district heating when they replace old cogenerating steam turbine systems; the cost of conditioning make-up water for modern high-temperature turbines is high and wasting the exhaust steam becomes uneconomical. 
TABLE 23-4

COST AND PERFORMANCE OF ENGINE/GENERATOR SYSTEMS

(1)

(in 1977 dollars)

$\begin{array}{llc} & \begin{array}{l}\text { Unit Cost } \\ (1977 \$ / \mathrm{kW})\end{array} & \begin{array}{l}\text { Efficiency for } \\ \text { Electricity }(\%)\end{array} \\ \begin{array}{l}\text { Diese1 } \\ \text { Combustion Turbine } \\ (1-20 \mathrm{MW})\end{array} & 300-625 & 30-40 \\ \text { Steam Turbines }(5) & 250-450 & 20-33 \\ 10 \mathrm{MW} & & \\ 50 \mathrm{MW} & 400-700 & 17-24 \\ & 300-500 & 22-30\end{array}$

(1) Installed costs including site preparation, switchgear, etc: The cost of a coal-fired boiler is included for steam turbine stations.

(2) Includes heat recovery apparatus, but not heat distribution system.

(3) Derated for continuous operation, and hence cost in $\$ / \mathrm{kW}$ is slightly higher than that given in Chapter 13. (Turbine system costs are also derated for continuously operating systems.) In this size range, the heat(17) recovery system is approximately $10-15 \%$ of the total system cost.

(4) Typical fuel utilization for a diesel total energy plant is as follows: electricity generation - 35\% of input energy, avallable heat - $37 \%$, wasted heat $-28 \%$ ( $10 \%$ radiative losses, $18 \%$ minimum stack losses to prevent exhaust condensation). As discussed previously, annual average fuel utilization is typically about $60 \%$ because of mismatch of the electrical and thermal loads and other inevitable heat losses. If $25 \%$ of the input energy is utilized in the heat load, the effective annual heating capacity factor is $25 / 37$ of the elctrical capacity factor.

(5) Simple cycle.

SOURCE: References 9 and 18. References 19, 20, 21, 22, and 23 corroborate these values for a variety of cases including several specific applications. 
many cases, familiarity and past practice will be the determining factors in a close trade-off. Distribution losses can range from as little as $5-10 \%$ for a compact, well designed and maintained system to $50 \%$ in an old, leaky and underutilized district heating system.

The thermal/electrical characteristics associated with total energy systems vary widely, depending on application. Further complicating the economic evaluation of total energy is the sensitivity of the analysis to a wide variety of parameters including:

- interest rates,

- taxes,

- fuel costs (present and projeçted).

- utility rate structures and ulilily polloles,

- environmental regulations, and

- local codes and labor regulations.

The potential economics of total energy systems is indicated by considering a simplified example where:

- there are no incremental costs associated with the heat distribution system (such as might be the case in a single, large building);

- thermal mismatch is relatively small so that the effective operating efficiency is relatively high;

- power is generated by a diese1-generator system and building thermal needs are provided by a waste heat recovery boller on the engine exhaust and a water preheater on the cooling jacket;

- space is already available for system installation at no direct additional cost;

- the fuel input required by the heating loads is unaffected; and

- the cost of heating equipment (waste heat boilers, etc.) is approximately the same as conventional equipment to perform the same function. 
The above situation is quite beneficial for a total energy installation and, therefore, should indicate the potential economic benefits of total energy in well selected applications.

The economic performance of systems with the basic characteristics indicated above is indicated in Table 23-5 for two capacities, $1 \mathrm{MW}$ and $5 \mathrm{MW}$. As indicated, the larger system provides power at a cost of about $3.5 \mathrm{c} / \mathrm{kWh}$, while power from the smaller system costs about $4.7 \mathrm{c} / \mathrm{kWh}$. This power cost range is competitive with utility-supplied power in many parts of the country. The costs of Table 23-5 illustrate a common characteristic of total energy systems, namely, that small systems tend to be less economical than larger ones. One reason for this is the relatively high cost of operating personnel, which becomes an increasingly high percentage of overall $0 \& M$ costs as size decreases.

Although the costs of Table 23-5 are for illustrative purposes only, they also indicate the importance of economic parameters and capacity factor on system economics. In particular, the cost of power from the system is reduced if the capacity factor is increased (making better use of high cost capital equipment) or if annual capital charges can be reduced as a result of reduced interest rates, tax credits, or the use of longer life equipment.

\section{Section 23.4: Limitations}

\section{A. Equipment and Fuel Availability}

Conventional total energy systems can be implemented using: powergenerating and heat-transfer equipment of standard design. The only available equipment, however, which can use coal or solid wastes as fuel is based on the boiler-steam turbine system. These systems are readily adaptable only in larger power levels (20 MWt) and are not very efficient within the relatively limited output range of total energy systems (as compared to central utilities). Also, the economical burning of coal in small power plants consistent with environmental regulations can represent a problem. $(4,5,24)$

As indicated earlier, advanced systems for burning coal (fluidized beds) and for efficiently and reliably converting heat into power (closed 
SIMPLIFIED ESTIMATE OF TOTAL ENERGY SYSTEMS ECONOMICS (in 1977 do1lars)

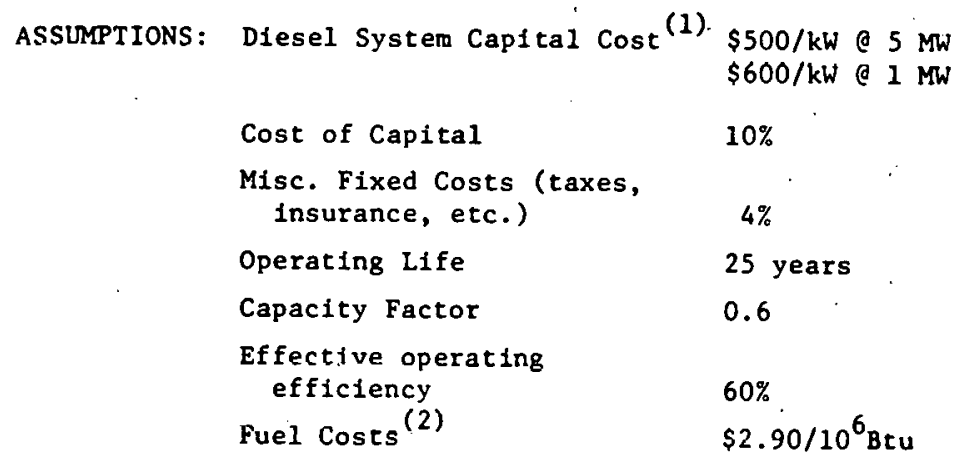

ANNUJAL COSTS

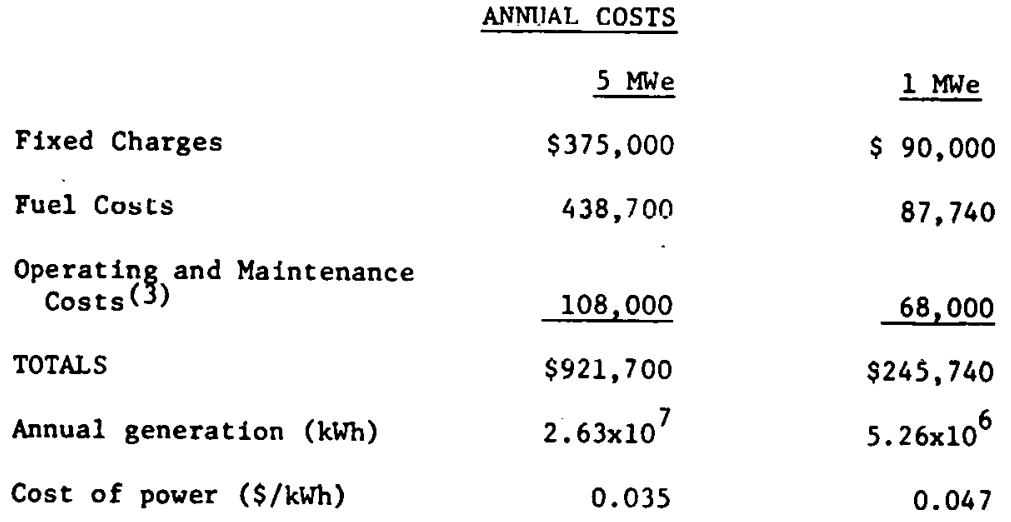

(1) These represent typical costs for Installations of these olgos, and correspond to the upper range of capital costs given in Table 23-4.

(2) See Chapter 1.

(3) Including labor and materials but excluding fuel. Because electricity generation dominates these $08 M$ costs, they have been allucated entirely to electricity. Parts and lubricants contribute about $\$ 0.0005 / \mathrm{kWh}$ to O\&M costs. Labor costs, therefore, dominate O\&M costs, but these are very varlable. Smaller units, up to about $1 \mathrm{MW}$, are heavily automated; larger units economfically employ a supporting crew including a qualifled technician/shift supervisor. Outside service and maintenance contracts for the smaller unit typically cost about $\$ 0.008 / \mathrm{kWh}$ (See Chapter 13). Some total energy projects have found it necessary to mafntain a full two-man crew for three shifts; In this case, the O\&M costs for the 1 MWe plant would be considerably higher (a two-man crew at $\$ 12 / \mathrm{hr}$. total pay would cost $\$ 105,000 /$ year).

SOURCE: References 9 and 17 . 
Brayton cycle engines, Stirling engines) are in various stages of development. However, most of these more advanced systems are not expected to be commercially avallable for 10 years or more.

\section{B. Environmental Issues}

There are several environmental issues associated with total energy systems. Two of the most important are noise and emissions.

- Noise

The operation of all power plants involves some degree of noise generation. This problem is of particular concern for diesel engines. In general, the noise resulting from the on-site power generators can be kept within acceptable limits by proper muffiling of engine exhausts and the use of sound-insulated enclosures.

\section{- Emissions}

The control of exhaust emissions from total energy systems can often be somewhat more difficult than from conventional boilers if engine generators (diesel engines, gas turbines) are the prime movers. Also the large-scale implementation of total energy systems may require increasing use of coal-fired systems which are more difficult to operate within acceptable environmental limits than ofl- or gas-fired systems. In addition, these systems will be located on site, and so emissions will be of concern to the users and the surrounding population. Ambient air quality regulations may affect the nature and operation of the system. In many cases, total energy systems must, therefore, be provided with appropriate emission control equipment, which can add significantly to initial and operational costs.

\section{c. Institutional Issues}

Several Institutional issues have affected the implementation of total energy systems in the past and still remain serious issues when considering specific applications. These particularly important issues are local codes which often affect labor requirements, the nature of the utility interface, and how power delivery can be guaranteed in a community system. 
- Codes and Regulations

Labor can be a major cost factor in the operation of total energy systems. In some cases, the cost of labor is increased by local and state codes and regulations beyond that which may, in fact, be sufficient for reliable operation. For example, the operation of coal-fired steam bollex/generator systems in some locations may require the continuous supervision of skilled labor with a 2nd class fireman's 1icense. (25) Similar rules governing the supervision of other forms of on-site generating equipment can significantly increase operational costs.

Some of these codes and regulations may now be unnecessary in the light of improved equipment rellability and automatic safety controls. To the extent that unnecessary codes remain in force, they could impede the implementation of a total energy system.

- Utility Interface

In the past, most electric utilities have opposed total energy systems* lest they would decrease electric energy sales and increase ut1lity load factor problems (in the case of total energy system malfunction). (23) The concerns of some utilities have beer: manifested in a reluctance to allow total energy systems to connect into the network and, in the case of connection, in levying a very high charge for such a connection. In very few cases have utilities allowed total energy systems to sell electricity back to the utility. These utility interface barriers are being reduced, but still are very important when evaluating total energy system operations. (23)

\section{- Load Guarantee}

If a total energy system services a single bullding or building complex, the owner of the total energy system controls the load (and therefore guarantees demand). The situation is quite different for community energy systems where the electrical and thermal loads are associated with a multiplicity of buildings under private (and diverse) ownership.

*Except utility-operated district heating systems. 
The high costs associated with heat (steam or hot water) piping systems usually require that a high percentage of the potential loads do, In fact, connect into the heat distribution grid. . One example of the effect of market penetration in an urban area on delivered cost of heat is indicated in Figure 23-9. How a high market penetration can be ensured within the existing social framework is a serious problem. This problem is not a new one and has troubled district heating systems in the United States and Europe in the past. 


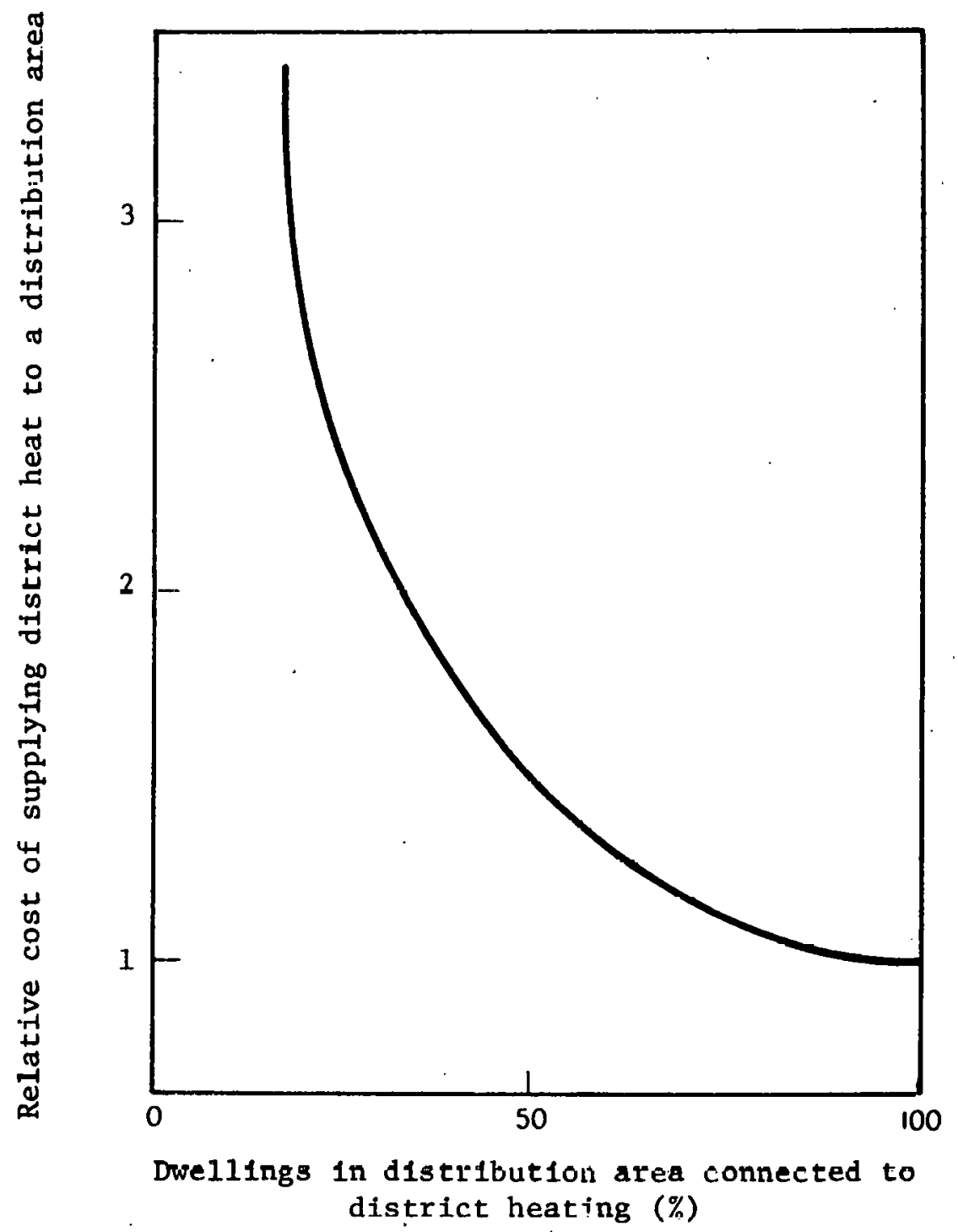

SOURCE: Reference 9.

FIGURE 23-9 TYPICAL RELATIONSHIP BETWEEN DISTRIBUTED HEAT COST AND PERCENTAGE OF AREA MARKET PENETRATION 


\section{REFERENCES}

1. Energy and Environmental Sciences Division, Argonne National Laboratory. Potential for Scarce-Fuel Savings in the Residential/ Commercial Sector through the Application of District Heating Systems. Draft. Prepared for Energy Research and Development Administration, Undated.

2. Leighton, G.S. "The Modular Integrated Utility System - A New Approach to the Supply of Utility Services." Proceedings of the Eighth Intersociety Energy Conversion Engineering Conference, Philadelphia, Pennsylvania, August 13-16, 1973. pp. $648 \mathrm{ff}$.

3. Office of Research and Technology, U.S. Department of Housing and Urban Development. Modular Integrated Ut1lity Systems Program Description. Washington, D.C., December 1972 .

4. Davis, S.A. "An Overview of Grid-Connected Integrated Community Energy Systems (ICES) Demonstration Projects." Preprint prepared for presentation at the Third ERDA Energy Management Symposium, Knoxville, Tennessee, September 19-21, 1977.

5. Kennedy, A.S., et al. Integrated Community Energy System (ICES) Commercialization Case Studies. Vo1. 1. Argonne National Laboratory, 1978. NTIS Report No. ANL/ICES-TM-4.

6. Kurtz, N.D. "Total Energy Keynote Address." Proceedings of the Solar Total Energy Symposium, Albuquerque, New Mexico, January 25, 1977. NTIS Report No. SAND77-0029.

7. Arthur D. Little, Inc. Assessments and Recommendations of the Potential for Stirling Engines in Integrated Community Energy Systems Applications. Report prepared for Argonne National Laboratory under Contract No. 89-8421, December 1977.

8. Shields, V.Y., et al. "Application of Fuel Cells with Heat Recovery for Integrated Utility Systems." Proceedings of the Tenth Intersociety Energy Conversion Engineering Conference, Newark, Delaware, August 17-22, 1975. pp. $278 \mathrm{ff}$.

9. Diamant, R.M.E. Total Energy. Oxford, England: Pergamon Press, 1970 (International Series in Heating, Ventilation and Refrigeration, Vol. 6.)

10. Patterson, B. Solar Total Energy Test Facility Project-Semiannual Report, October 1976-March 1977. Sandia Laboratories, August 1977. NTIS Report No. SAND77-0738

11. Arthur D. Little, Inc. Solar Assessment Study in Support of the International Ekistics Program, Phase I Report. Report prepared for Argonne National Laboratory, July 1977. NTIS Report No. ANL/ICES-TM-12. 
12. Fraas, A.P. "Small Coal Burning Gas Turbine for Modular Integrated Utility Systems." Proceedings of the Ninth Intersociety Energy Conversion Engineering Conference. San Francisco, California, August 26-30, 1974, pp. 499 ff.

13. Lehrfeld, D., System Analysis Design and Proof-of-Concept Experiment of a Total Energy System. Quarterly Progress Report, August 16,1976 - November 15,1976 . Report prepared by Philips Laboratories for Energy Research and Development Administration, December 1976. NTIS Report No. COO-2947-2.

14. Mathtec, Inc. An Analysis of the Application of Fuel Cells in Dual Energy Use Systems, Vo1. 2. Report prepared for Electric Power Research Institute, February 1979. EPRI Report No. EM-981.

15. United Technologies Corporation. Venture Analysis Case Study for On-Sile Fuel Cell Energy Systems. Volume 1. Final Report, FCR-078.3. Prepared for U.S. Department of Energy, July 31, 1978.

16. O11 Total Energy. Washington: National Oil Fuel Institute, 1966.

17. Cummins North Atlantic, Inc., Dedham, Massachusetts. Persona1 communication. September 1979.

18. Independence, Missouri. Grid Connected Integrated Cummunlly Energy System. Final Report. Vol. 1 Executive Summary. Report prepared for Energy Research and Development Administration, July 1977. NTIS Report No. COO/4213-1/1.

19. Clark University. A Preliminary Feasibility Study of a Grid-Connected Integrated Community Energy System at Clark University. Vol. I Executive Summary. Report prepared for Energy Research and Development Administration, July 1977. NTIS Report No. $\mathrm{COO}-4211-1 / 1$.

20. Department of Planning and Development, Trenton, New Jersey. Trention ICES, Vo1. 1, Phase 1, Final Report. Report prepared for Energy Research and Development Administration, July 14, 1977, NTIS Report No. COO/4212-1/1

21. DeLaureal Engineers, Inc. Grid-Connected ICES Preliminary Feasibility Analysis and Evaluation. Final Report. Vol. 1, Executive Summary. Report prepared for Energy Research and Development Administration, June 1977. NTIS Report No. $\mathrm{COO} / 2414-1 / 1$.

22. Minnesota University. Grid-Connected Integrated Community Energy System. Executive Summary. Fina1 Report. Phase 1, February 1, 1977-May 31, 1977. Report prepared for Energy Research and Development Administration, June 1977. NTIS Report No. COO/4210-1. 
23. Weber, E.R. "On-Site Solar Systems, A Utility Point of View." Proceedings of the Solar Total Energy Symposium, Albuquerque, New Mexico, January 25, 1977. Sandia Laboratories, 1977. NTIS Report No. SAND77-0029.

24. District Heating Working Party of the Combined Heat and Power Group, U.K. Department of Energy. District Heating Combined with Electricity Generation in the United Kingdom. London: H.M. Stationery office, 1977.

25. Uniform Boiler and Pressure Vesse1 Laws Society. Synopsis of Boiler and Pressure Vesse1s, Laws, Rules and Regulations. Hartford, Connecticut: The Society, September 1978. 